Marco Penske

Finanzierung

der Gesetzlichen

Krankenversicherung

- Probleme und

Reformoptionen 


\section{Finanzierung der Gesetzlichen Krankenversicherung - Probleme und Reformoptionen}

Die Reform der Gesetzlichen Krankenversicherung ist eine der wichtigsten Strukturreformen. Nach der systematischen Darstellung der Finanzierung der GKV und den damit verbundenen Problemen wird der Einfluss der demographischen Entwicklung auf Einnahmen und Ausgaben analysiert. Daraus werden Ziele für eine nachhaltige Finanzreform abgeleitet. Daran bewertet werden zunächst Reformen im Umlagesystem: Steuerfinanzierung, Bürgerversicherung, Kopfpauschalen und Kompromissmodelle. Wie Kapital innerhalb und außerhalb der GKV gebildet werden kann, wird mit den jeweiligen Vor- und Nachteilen diskutiert. Als Referenzsystem wird die Private Krankenversicherung analysiert und gezeigt, wie Alterungsrückstellungen bei einem Versicherungswechsel theoretisch übertragen werden können. Zahlreiche Berechnungen untermauern die Ausführungen.

Marco Penske, geboren 1976 in Darmstadt, studierte von 1996 bis 2001 Volkswirtschaftslehre an der Universität Mainz. Von 2001 bis 2006 war er Wissenschaftlicher Mitarbeiter am Institut für Finanzwissenschaft der Universität Mainz, Lehrstuhl Volkswirtschaftslehre, insbesondere Finanzwissenschaft. Das Promotionsverfahren wurde 2006 abgeschlossen. 
Finanzierung der Gesetzlichen Krankenversicherung - Probleme und Reformoptionen 


\section{FINANZWISSENSCHAFTLICHE SCHRIFTEN}

Herausgegeben von den Professoren

Konrad, Krause-Junk, Littmann, Oberhauser, Pohmer, Schmidt

Band 115

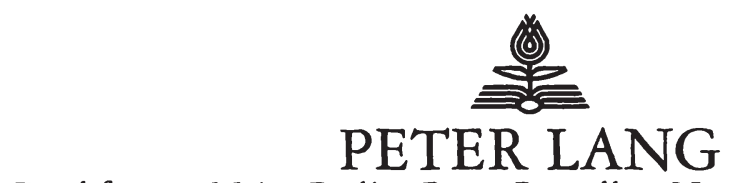

Frankfurt am Main · Berlin - Bern · Bruxelles · New York · Oxford - Wien

Marco Penske - 978-3-631-75223-4

Downloaded from PubFactory at 01/11/2019 06:54:52AM

via free access 


\title{
Marco Penske
}

\author{
Finanzierung \\ der Gesetzlichen \\ Krankenversicherung - \\ Probleme \\ und Reformoptionen
}

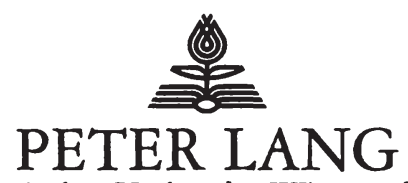

Europäischer Verlag der Wissenschaften 


\title{
Bibliografische Information Der Deutschen Bibliothek
}

Die Deutsche Bibliothek verzeichnet diese Publikation in der Deutschen Nationalbibliografie; detaillierte bibliografische Daten sind im Internet uber <http://dnb.ddb.de $>$ abrufbar.

Open Access: The online version of this publication is published on www.peterlang.com and www.econstor.eu under the international Creative Commons License CC-BY 4.0. Learn more on how you can use and share this work: http://creativecommons. org/licenses/by/4.0.

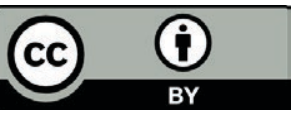

This book is available Open Access thanks to the kind support of ZBW - Leibniz-Informationszentrum Wirtschaft.

Zugl.: Mainz, Univ., Diss., 2006

Gedruckt auf alterungsbeständigem, säurefreiem Papier.

\author{
D77 \\ ISSN 0170-8252 \\ ISBN3-631-55569-5 \\ ISBN 978-3-631-75223-4 (eBook) \\ C) Peter Lang GmbH \\ Europäischer Verlag der Wissenschaften \\ Frankfurt am Main 2006 \\ Alle Rechte vorbehalten.
}

Das Werk einschließlich aller seiner Teile ist urheberrechtlich geschützt. Jede Verwertung außerhalb der engen Grenzen des Urheberrechtsgesetzes ist ohne Zustimmung des Verlages unzulässig und strafbar. Das gilt insbesondere fur Vervielfăltigungen, Übersetzungen, Mikroverfilmungen und die Einspeicherung und Verarbeitung in elektronischen Systemen.

Printed in Germany 123457 


\section{Vorwort}

Die vorliegende Arbeit entstand während meiner Tätigkeit als wissenschaftlicher Mitarbeiter am Institut für Finanzwissenschaft der Johannes Gutenberg-Universität Mainz und wurde im Wintersemester 2005/2006 vom Fachbereich Rechts- und Wirtschaftswissenschaften der Johannes Gutenberg-Universität Mainz als Dissertation angenommen. Die mündliche Prüfung war am 3. April 2006. Während der Erstellung der Arbeit wurden Möglichkeiten einer Finanzreform der Gesetzlichen Krankenversicherung breit diskutiert. Abgeschlossen wurde die Arbeit im November 2005, wesentliche Entwicklungen in der Gesundheitspolitik wurden bis zur Drucklegung berücksichtigt.

Mein ganz besonderer Dank gilt meinem Doktorvater, Herrn Univ.-Prof. Dr. Rolf Peffekoven, der mir wertvolle Anregungen für die Dissertation gegeben und meine Sicht volkswirtschaftlicher Zusammenhänge nachhaltig geprägt hat. Herrn Univ.-Prof. Dr. Georg Tillmann $(t)$ habe ich für die Übernahme des Zweitreferats gedankt.

Für die mühevolle und kritische Durchsicht des Manuskripts danke ich meinem Kollegen Herrn Dr. Markus Euler und Herrn Dipl.-Volkswirt Heiko Hannappel. Für die freundschaftliche und kollegiale Zusammenarbeit am Institut bedanke ich mich bei Herrn Dr. Frank Roland, Frau Dipl.-Volkswirtin Kristin Sänger, Frau Dr. Sibylle Wagener und Herrn Dipl.-Volkswirt Frank Zipfel. Ebenso danke ich Frau Dipl.Volkswirtin Yvonne Lange vom Institut für Statistik und Ökonometrie für ihre Unterstützung. Dank gebührt auch der Sekretärin des Lehrstuhls, Frau Edeltraud Egger, und den wissenschaftlichen Hilfskräften.

Zu guter Letzt danke ich meinen Eltern, die mir eine akademische Ausbildung ermöglicht und mich stets unterstützt haben.

Mainz, im April 2006

Marco Penske 
Marco Penske - 978-3-631-75223-4

Downloaded from PubFactory at 01/11/2019 06:54:52AM

via free access 


\section{Inhaltsverzeichnis}

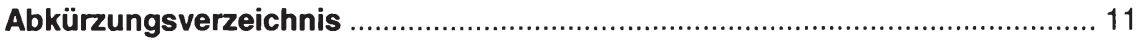

Tabellenverzeichnis ................................................................................... 13

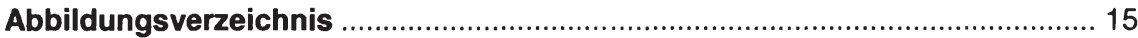

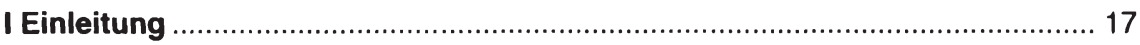

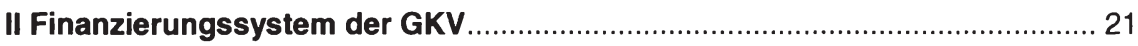

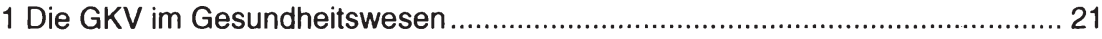

2 Vom Äquivalenzprinzip zum Leistungsfähigkeitsprinzip ................................ 24

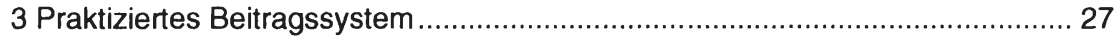

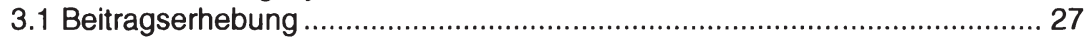

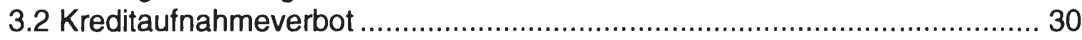

3.3 Wichtige Determinanten für den Beitragssatz .......................................... 31

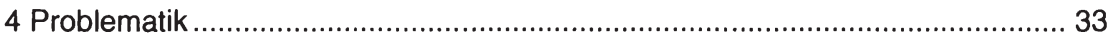

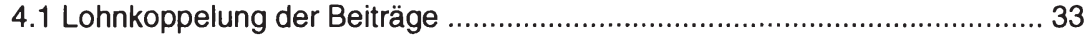

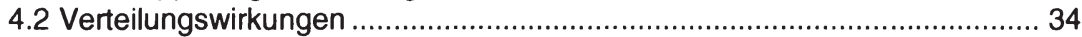

4.2.1 Ex post und ex ante Verteilungswirkungen ......................................... 34

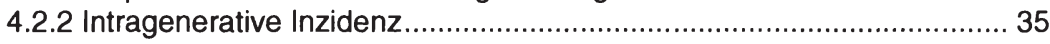

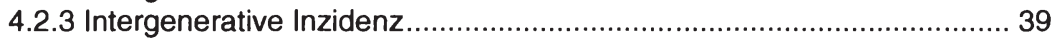

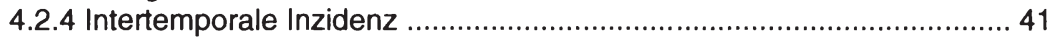

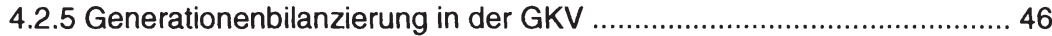

4.3 Strukturelle Schwächen ......................................................................... 50

4.3.1 Zum Ziel der Beitragssatzstabilität .................................................... 50

4.3.2 Abhängigkeit von der Versichertenstruktur ...................................... 55

4.3.3 Abhängigkeit vom Arbeitsmarkt ...................................................... 58

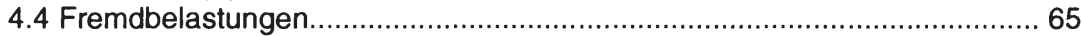

4.4.1 Reformen in den Systemen der sozialen Sicherung ............................. 65

4.4.2 Folgen der Deutschen Einheit........................................................ 71

4.5 Kostenexplosion oder Erosion der Bemessungsgrundlage ....................... 72

4.5.1 Beitragssatzanstieg................................................................... 72

4.5.2 Ausgabenseitiger Beitragssatzeffekt ................................................ 73

4.5.3 Einnahmenseitiger Beitragssatzeffekt ............................................ 76

4.5.4 Fazit: Einnahmenbedingter Beitragssatzanstieg ............................... 78

III Zukünftige Entwicklung der GKV-Finanzen ............................................ 83

1 Demographische Entwicklung und GKV-Finanzen ....................................... 83

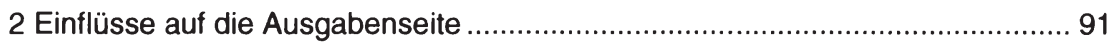

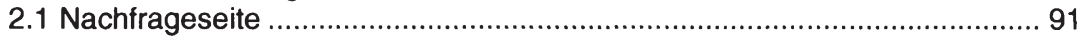

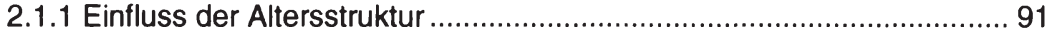

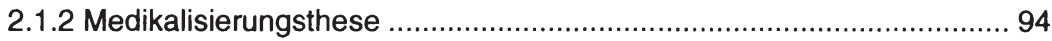

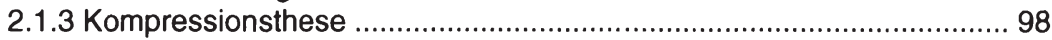

2.1.4 Bi-modales Konzept als Synthese ............................................. 104

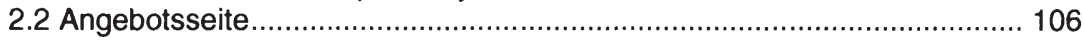


2.2.1 Medizinisch-technischer Fortschritt................................................... 106

2.2.2 Rückwirkungen über die demographische Entwicklung ....................... 109

3 Einflüsse auf die Einnahmenseite ................................................................ 110

3.1 Differenzierung der beitragspflichtigen Einnahmen .................................... 110

3.2 Bruttolohn- und Gehaltssumme ......................................................... 111

3.2.1 Arbeitskräfteangebot: Erwerbspersonenpotential GKV-Versicherter .. 111

3.2.2 Arbeitsmarktnachfrage: Wirtschaftswachstum .................................. 113

3.2.3 GKV-versicherte Erwerbstätige und Lohneinkommen ....................... 116

3.3 Renten als beitragspflichtige Einnahmen ................................................ 119

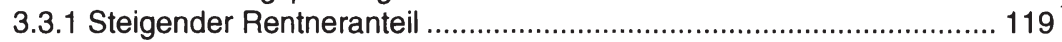

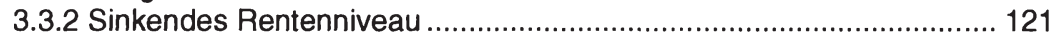

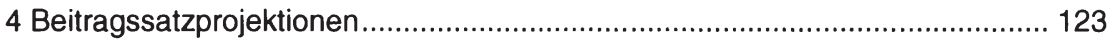

4.1 Beitragssatzprojektion mit der Bilanzgleichung ...................................... 123

4.2 Ausgewählte Beitragssatzprojektionen ..................................................... 128

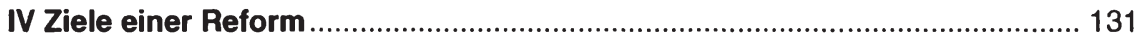

1 GKV-Modernisierungsgesetz nicht hinreichend ......................................... 131

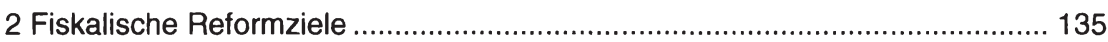

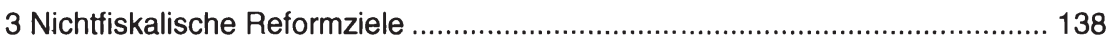

V Reformen unter Beibehaltung des Umlageverfahrens................................. 145

1 Finanzierungsformen und Reformvorschläge im Überblick .............................. 145

2 Maßnahmen zur Kompensation des demographischen Wandels ................... 147

2.1 Verlängerung der Arbeitszeit ................................................................. 147

2.2 Steigerung der Erwerbsbeteiligung..................................................... 149

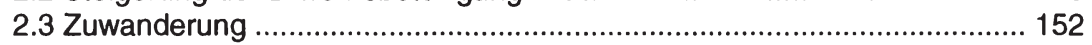

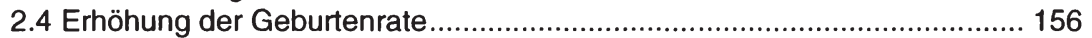

2.5 Fazit: Demographischer Wandel kaum kompensierbar ............................ 157

3 Alternative Finanzierungssysteme im Umlageverfahren .............................. 159

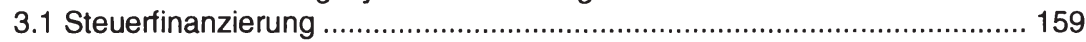

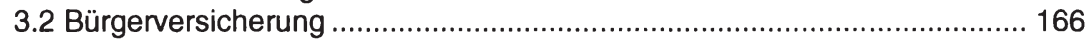

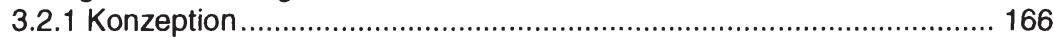

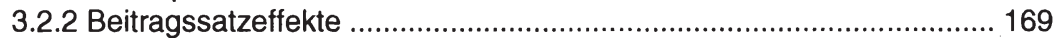

3.2.3 Auswirkungen auf die öffentlichen Haushalte ................................... 171

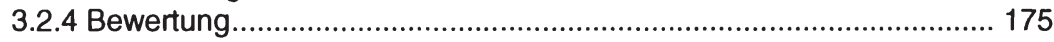

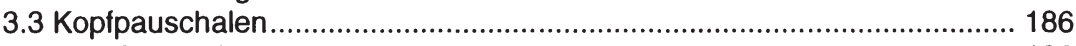

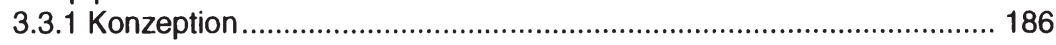

3.3.2 Finanzierung des sozialen Ausgleichs ......................................... 188

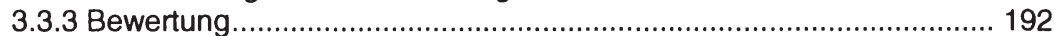

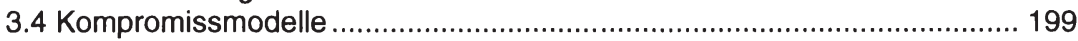

VI Einführung von Kapitaldeckung in der GKV........................................... 209

1 Umlageverfahren versus Kapitaldeckungsverfahren...................................... 209

2 Kapitaldeckungsverfahren am Beispiel der PKV ........................................... 214

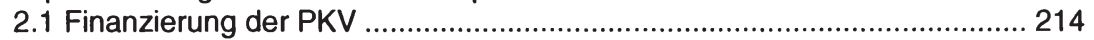

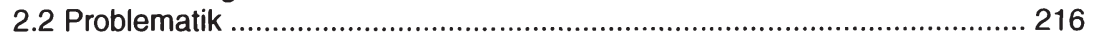




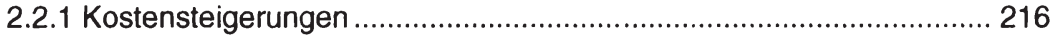

2.2.2 Demographische Abhängigkeit ................................................... 217

2.2.3 Übertragbarkeit von Alterungsrückstellungen .................................. 219

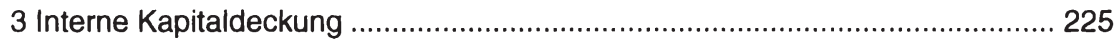

3.1 Teilweise kapitalgedeckte Finanzierungssysteme .................................. 225

3.1.1 Systemkonforme Ergänzung: Demographiereserve .......................... 225

3.1.2 Systemumstellung: Teilkapitalgedeckte Kopfpauschalen ................... 227

3.2 Vollständig kapitalgedeckte Systeme: Risikoäquivalente Prämien ............. 229

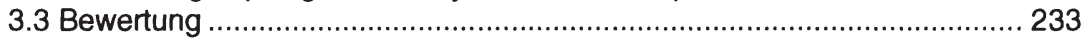

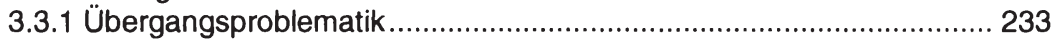

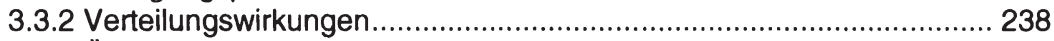

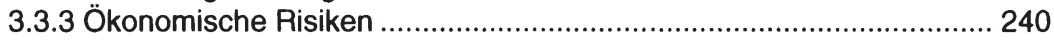

3.3.4 Ordnungspolitische Eignung .......................................................... 243

4 Externe Kapitalbildung mit Gesundheitssparkonten.................................... 244

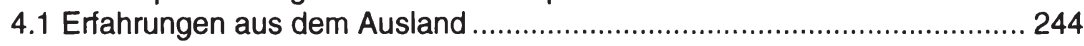

4.2 Einführung von Gesundheitssparkonten................................................ 248

VII Zusammenfassung und Schlussfolgerungen .......................................... 255

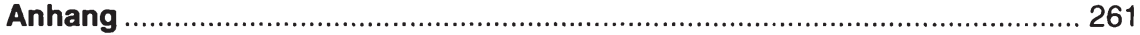

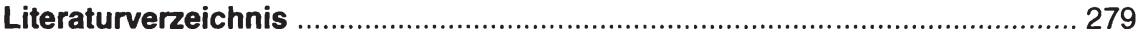


Marco Penske - 978-3-631-75223-4

Downloaded from PubFactory at 01/11/2019 06:54:52AM

via free access 


\section{Abkürzungsverzeichnis}

$\begin{array}{ll}\text { AKV } & \text { Allgemeine Krankenversicherung } \\ \text { BBG } & \text { Beitragsbemessungsgrenze } \\ \text { BIP } & \text { Bruttoinlandsprodukt }\end{array}$

BMGS Bundesministerium für Gesundheit und Soziale Sicherung

DIW Deutsches Institut für Wirtschaftsforschung

EStG Einkommensteuergesetz

EU Europäische Union

GKV Gesetzliche Krankenversicherung

GMG GKV-Modernisierungsgesetz

GRV Gesetzliche Rentenversicherung

IAB Institut für Arbeitsmarkt- und Berufsforschung der Bundesanstalt für Arbeit

KVdR Krankenversicherung der Rentner

PKV Private Krankenversicherung

RSA Risikostrukturausgleich

RVO Reichsversicherungsordnung

SGB Sozialgesetzbuch

SVR Sachverständigenrat zur Begutachtung der gesamtwirtschaftlichen Entwicklung

SVR KAiG Sachverständigenrat für die Konzertierte Aktion im Gesundheitswesen

UN United Nations [Vereinte Nationen]

VAG Versicherungsaufsichtsgesetz

VDR Verband Deutscher Rentenversicherungsträger

VPG Versicherungspflichtgrenze 
Marco Penske - 978-3-631-75223-4

Downloaded from PubFactory at 01/11/2019 06:54:52AM

via free access 


\section{Tabellenverzeichnis}

Tabelle 1: Internationaler Vergleich von Gesundheitsausgaben im Jahr 2003 ......... 22

Tabelle 2: Einkommensverteilung und Beitragsbelastung ....................................... 39

Tabelle 3: Beiträge und Ausgaben für Mitglieder und Rentner 1992-2004 ............... 40

Tabelle 4: Durchschnittlicher Lebensnettotransfer pro Mitglied .............................. 46

Tabelle 5: Beschäftigungseffekte einer Beitragssatzerhöhung in der GKV um einen

Prozentpunkt im früheren Bundesgebiet ........................................................ 54

Tabelle 6: Versicherte nach Art des Versicherungsschutzes im Jahr 2004 ............. 57

Tabelle 7: Einnahmenausfälle der GKV infolge von registrierter Arbeitslosigkeit .... 64

Tabelle 8: Belastung der GKV durch Reformen in der Sozialversicherung ............. 70

Tabelle 9: RSA-Transfers zugunsten der GKV-Ost 1999-2005 .............................. 72

Tabelle 10: Entwicklung der Bevölkerung Deutschlands bis zum Jahr 2050 ............ 88

Tabelle 11: Entwicklung der GKV-Versichertenstruktur bis zum Jahr 2050............. 90

Tabelle 12: Enwerbspersonenpotential GKV-Versicherter bis zum Jahr 2050 ........ 112

Tabelle 13: Beitragssatzprojektionen anhand der Bilanzgleichung........................ 125

Tabelle 14: Auswahl an Beitragssatzprojektionen bis zum Jahr 2050 .................. 128

Tabelle 15: Kombinationen aus Versichertenkreis und Beitragsbemessung .......... 147

Tabelle 16: Erwerbsquoten im EU-Vergleich im Jahr 2003 ................................. 150

Tabelle 17: Versicherungsfremde Leistungen i.e.S. im Jahr 2004 ........................ 160

Tabelle 18: Entlastungseffekte bei unterschiedlichen Ausgestaltungen einer

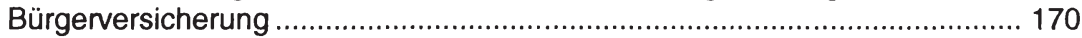

Tabelle 19: Beschäftigungseffekte der Bürgerversicherung …............................ 177

Tabelle 20: Transferbedarf für den sozialen Ausgleich....................................... 189

Tabelle 21: Beschäftigungseffekte des Kopfpauschalen-Modells......................... 194

Tabelle 22: Vergleich von Status quo, Bürgerversicherung und Kopfpauschale .... 200

Tabelle 23: Bürgerpauschale bei Bildung eines individuellen Kapitalstocks........... 228

Tabelle 24: GKV: Einnahmen, Ausgaben, Mitglieder im Jahr 2003 ..................... 261

Tabelle 25: Beiträge und Leistungen der GKV nach Alter im Jahr 2003................ 262

Tabelle 26: Entwicklung von Beitragssatz und Beitragsbemessungsgrenze 1970-

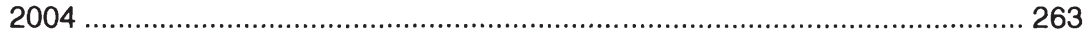

Tabelle 27: Entwicklung von GKV-Ausgaben und BIP 1970-2004 _..................... 264

Tabelle 28: Einfluss der Ausgabenseite auf den Beitragssatz im Jahr 2004 (Früheres Bundesgebiet) 
Tabelle 29: Einfluss der Ausgabenseite auf den Beitragssatz im Jahr 2004 (Neue Bundesländer) 266

Tabelle 30: Einfluss der Ausgabenseite auf den Beitragssatz im Jahr 2003 (Früheres Bundesgebiet) 267

Tabelle 31: Einfluss der Ausgabenseite auf den Beitragssatz im Jahr 2003 (Neue Bundesländer) 268

Tabelle 32: Einfluss der Einnahmenseite auf den Beitragssatz im Jahr 2004 (Früheres Bundesgebiet) 269

Tabelle 33: Einfluss der Einnahmenseite auf den Beitragssatz im Jahr 2004 (Neue Bundesländer) 270

Tabelle 34: Entwicklung von beitragspflichtigen Einnahmen und BIP 1970-2004 (Früheres Bundesgebiet)..... 271

Tabelle 35: Entwicklung von beitragspflichtigen Einnahmen und BIP 1991-2004 (Neue Bundesländer) ………................................................................ 272

Tabelle 36: GKV-Mitgliederstruktur 1991-2004................................................ 273

Tabelle 37: Einfluss der demographischen Entwicklung auf den Beitragssatz im Jahr 2003 (Bundesgebiet)

Tabelle 38: Versicherte, Mitglieder, Ausgaben und Beiträge in den Jahren 2003, 2030 und 2050 276

Tabelle 39: Anteil der GKV-Versicherten an der Bevölkerung nach Altersklassen 1992-2003 


\section{Abbildungsverzeichnis}

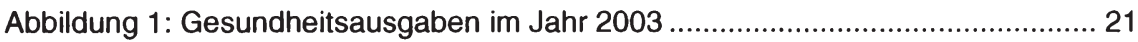

Abbildung 2: Wichtige Determinanten für den Beitragssatz...................................... 32

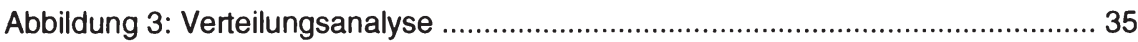

Abbildung 4: Durchschnittliche Beitragsbelastung in der GKV im Jahr 2004 ........... 37

Abbildung 5: Einkommensverteilung und Beitragszahlung ................................... 38

Abbildung 6: Beiträge und Leistungen in der GKV nach Alter im Jahr 2003............ 43

Abbildung 7: Nettobeitrag an die GKV nach Alter im Jahr 2003 ............................. 44

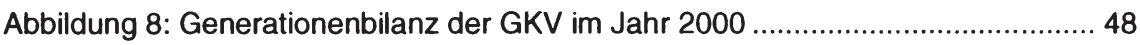

Abbildung 9: GKV-Mitgliederstruktur 1991-2004 …............................................. 56

Abbildung 10: Norm- und Nicht-Normarbeitsverhältnisse 1970-1995

(Früheres Bundesgebiet) ............................................................................. 59

Abbildung 11: Beitragssatz und Beitragsbemessungsgrenze in der GKV 1970-2004

(Früheres Bundesgebiet) ......................................................................... 73

Abbildung 12: Veränderungsraten von GKV-Ausgaben und BIP 1970-2004 ........... 74

Abbildung 13: Einfluss der Einnahmen- und Ausgabenseite auf den Beitragssatz im Jahr 2004 (Früheres Bundesgebiet) ............................................................... 78

Abbildung 14: Jährliche Wachstumsraten von beitragspflichtigen Einnahmen und BIP

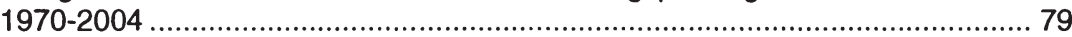

Abbildung 15: Entwicklung von beitragspflichtigen Einnahmen und BIP 1970-2004 zum Basisjahr 1975 (Früheres Bundesgebiet) .............................................. 80

Abbildung 16: Einfluss der demographischen Entwicklung auf den Beitragssatz im

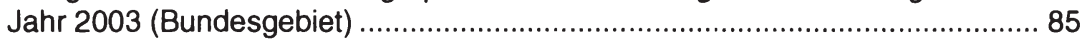

Abbildung 17: Altersaufbau der Bevölkerung nach der 10. koordinierten Bevölkerungsvorausberechnung (mittlere Variante)......................................... 87

Abbildung 18: Entwicklung der GKV-Leistungsausgaben bis zum Jahr 2050 .......... 91

Abbildung 19: GKV-Versicherte und Ausgaben in den Jahren 2003 und 2050 ........ 92

Abbildung 20: Altersausgabenprofil nach der Medikalisierungsthese ....................... 95

Abbildung 21: GKV-Ausgabenprofil in den Jahren 1995 und 2003......................... 97

Abbildung 22: Altersausgabenprofil nach der Kompressionsthese ......................... 99

Abbildung 23: Ausgaben für Versterbende und Überlebende .............................. 102

Abbildung 24: Durchschnittlicher Anstieg der altersspezifischen Pro-Kopf-Ausgaben

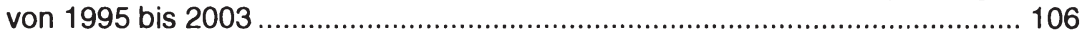

Abbildung 25: GKV-versicherte Erwerbstätige bis zum Jahr 2050 ...................... 117

Abbildung 26: Entwicklung der GKV-Beitragseinnahmen bis zum Jahr 2050......... 119 
Abbildung 27: GKV-Mitglieder und Beiträge in den Jahren 2003 und 2050............ 120 Abbildung 28: Verteilungseffekte der Bürgerversicherung.................................. 178 Abbildung 29: Grenzbelastungen der Arbeitnehmerentgelte bei einer Kopfpauschale im Vergleich zum Status quo ...................................................................... 193

Abbildung 30: Verteilungseffekte der Kopfpauschale .......................................... 197

Abbildung 31: Finanzströme der „Solidarischen Gesundheitsprämie“.................... 204 Abbildung 32: Systematisierung von Reformvorschlägen nach dem Anteil an

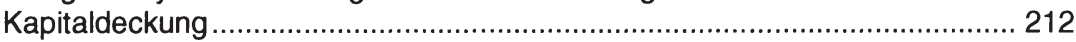

Abbildung 33: Prämienkalkulation in der PKV ................................................... 215 Abbildung 34: Auswirkungen einer steigenden Lebenserwartung auf die Prämie .. 218 Abbildung 35: Beitragssatzentwicklung mit und ohne Demographiereserve .......... 225 Abbildung 36: Entwicklung der Bürgerpauschale ............................................. 227 


\section{Einleitung}

Die Beiträge zur Gesetzlichen Krankenversicherung (GKV) sind trotz zahlreicher Eingriffe des Gesetzgebers auf der Ausgabenseite kontinuierlich gestiegen. Um dem gegenzusteuern galt das Hauptaugenmerk der Politik in erster Linie der Kostendämpfung. Aber auch die jüngste Reform - das Gesetz zur Modernisierung der gesetzlichen Krankenversicherung (GKV-Modernisierungsgesetz, GMG) ${ }^{1}$ aus dem Jahr 2003 - hat auf der Ausgabenseite keine entscheidenden Strukturreformen gebracht. Qualität und Wirtschaftlichkeit und damit eine bedarfsgerechte und kostengünstige Versorgung mit Gesundheitsleistungen setzen mehr Wettbewerb zwischen den Kassen und zwischen den Leistungserbringern voraus. Die Kassen müssen dazu weitere Möglichkeiten erhalten, Wahlleistungen und Selbstbehalte anzubieten und Verträge mit einzelnen Leistungsanbietern abzuschließen. Bei den Leistungserbringern ist eine stärkere Integration von ambulanter und stationärer Versorgung notwendig. Denkbar ist auch eine Trennung des GKV-Leistungskatalogs in Grundund Wahlleistungen. ${ }^{2}$ Vorschläge zu Reformen auf der Ausgabenseite liegen seit langem vor und sind in der Wissenschaft weitgehend unstrittig. ${ }^{3}$

Die Einnahmenseite ist in der Vergangenheit - wie der Sachverständigenrat für die konzertierte Aktion im Gesundheitswesen (SVR KAiG) ${ }^{4}$ schreibt - „mehr als stiefmütterlich“5 behandelt worden, obwohl die derzeitige Finanzierung der GKV wachstumsund beschäftigungsfeindlich ist und zu intransparenten, teilweise auch unerwünschten Umverteilungen führt. Die jetzt schon bestehenden Finanzierungsprobleme u.a. aufgrund von Arbeitslosigkeit und dem Rückgang sozialversicherungspflichtiger Beschäftigung werden in Zukunft noch durch den demographischen Wandel und den medizinisch-technischen Fortschritt verstärkt. Auch ein stärkerer Wettbewerb wird den dadurch verursachten Beitragssatzanstieg nicht verhindern können, zumal Reformen auf der Ausgabenseite kein Ersatz für eine Reform der Finanzierung der GKV sind und die Art der Beitragsbemessung mitentscheidend für die Intensität des Wettbewerbs zwischen den Kassen ist. Den erwarteten Beitragssatzanstieg können ausgabenseitige Reformen - wie die Vergangenheit gezeigt hat - ohnehin nur temporär bremsen. Auch noch vorhandene Wirtschaftlichkeitsreserven im Gesundheitswesen sind nicht geeignet, die Finanzierung der GKV langfristig sicherzustellen. Die Arbeit konzentriert sich deshalb weitgehend auf die Einnahmenseite. Soweit es notwendig ist, wird dabei auch die Entwicklung der zu finanzierenden Ausgaben betrachtet.

Mit dem Bericht der nach ihrem Vorsitzenden benannten Rürup-Kommission (Kommission für die Nachhaltigkeit in der Finanzierung der sozialen Sicherungssysteme) ${ }^{6}$

\footnotetext{
${ }^{1}$ Siehe BGBI. 2003, Teil I, Nr. 55, S. 2229.

${ }^{2}$ Vgl. SVR KAiG (1994), Ziff. 417ff. Einen Überblick über die Vorschläge gibt Wille, E. (2001), S. 66ff. Zu den Problemen der Beitragskalkulation in einem Wahlleistungssystem mit einkommensabhängiger Beitragsbemessung siehe Rürup-Kommission (2003), S. 166.

${ }^{3}$ Siehe stellvertretend SVR (2002), Ziff. 483ff.; Enquete-Kommission Demographischer Wandel (2002), S. 209ff.; SVR KAiG (1995), Ziff. 370ff.

${ }^{4}$ Mit Inkrafttreten des GKV-Modernisierungsgesetzes und der damit verbundenen Abschaffung der Konzertierten Aktion wurde der SVR KAiG zum 01.01.2004 in "Sachverständigenrat zur Begutachtung der Entwicklung im Gesundheitswesen "umbenannt.
}

${ }^{5}$ SVR KAiG (2003), Ziff. 52.

${ }^{6}$ Siehe Rürup-Kommission (2003), S. 143ff. 
ist im Jahr 2003 die öffentliche Debatte um eine Reform der Finanzierung der GKV entbrannt. Die Konzeption einer Bürgerversicherung und die einer Gesundheitsprämie bestimmen seitdem weitgehend die Diskussion. Die Wirkungen des demographischen Wandels und des medizinisch-technischen Fortschritts auf die Finanzlage der GKV spielen bei diesen Reformüberlegungen bislang kaum eine Rolle. Auch der zwischen CDU, CSU und SPD beschlossene Koalitionsvertrag ${ }^{7}$ verspricht lediglich eine Reform der Einnahmenseite für das Jahr 2006. Ziel der vorliegenden Arbeit ist es daher, die GKV insbesondere unter dem Aspekt der langfristigen Finanzierbarkeit systematisch zu analysieren, daraus den Handlungsbedarf abzuleiten und darauf aufbauend Reformvorschläge zu diskutieren. Dabei wird auch untersucht, ob und wie kapitalgedeckte Elemente in der GKV implementiert werden können, um die GKV nachhaltig, d.h. dauerhaft und generationengerecht zu finanzieren. Die Arbeit wurde im November 2005 abgeschlossen. Wesentliche Entwicklungen in der Gesundheitspolitik wurden bis zur Drucklegung berücksichtigt.

In Kapitel II wird zunächst das Finanzierungssystem der GKV dargestellt. Dabei stehen die mit der Lohnkoppelung verbundenen allokativen und distributiven Probleme, aber auch die strukturell bedingte Einnahmenschwäche im Vordergrund. Das Kapitel schließt mit einer Analyse der Frage, ob der zu beobachtende Beitragssatzanstieg seine Ursache eher auf der Einnahmen- oder Ausgabenseite hat.

Die Wirkungen von demographischer Entwicklung und medizinisch-technischem Fortschritt auf die künftige Finanzierbarkeit der GKV stehen im Mittelpunkt von Kapitel III. Auf der Ausgabenseite beeinflusst der demographische Wandel die Nachfrage. Entscheidend ist dabei, ob die Ausgaben im Wesentlichen vom Alter abhängen (Medikalisierungsthese) oder von der Entfernung zum Tod (Kompressionsthese). Beide Thesen werden auch anhand empirischer Studien untersucht. Eine Synthese aus den beiden kontroversen Thesen stellt das bi-modale Konzept dar. Auf der Angebotsseite beeinflusst der medizinisch-technische Fortschritt die Ausgaben und kann zudem die ohnehin zunehmende Alterung der Bevölkerung zusätzlich fördern. Der demographische Wandel hat aber auch - bislang in der Literatur weitgehend vernachlässigt - Einfluss auf die Einnahmenseite. Beitragssatzprojektionen am Ende des Kapitels quantifizieren die verschiedenen Einflüsse und machen den Handlungsbedart deutlich.

In Kapitel IV werden die wesentlichen Änderungen durch das GMG auf der Einnahmenseite kritisch dargestellt. Dabei wird auch auf die im Jahr 2004 beschlossene Modifikation bei der Neuregelung des Zahnersatzes eingegangen. Auf Basis der Problemanalyse in den Kapiteln II und III werden fiskalische und nichtfiskalische Reformziele formuliert.

Reformvorschläge unter Beibehaltung des Umlageverfahrens stehen im Mittelpunkt von Kapitel V. Zunächst wird untersucht, ob der demographische Wandel selbst mit Maßnahmen außerhalb der GKV verhindert werden kann. Anschließend werden Maßnahmen zur nachhaltigen Finanzierung der GKV diskutiert: Eine stärkere Steuerfinanzierung von Gesundheitsleistungen über die sogenannten versicherungsfremden Leistungen hinaus wird verworfen. Sodann werden die - am Leistungsfähig-

\footnotetext{
${ }^{7}$ Siehe Christlich Demokratische Union Deutschlands; Christlich-Soziale Union in Bayern; Sozialdemokratische Partei Deutschlands (Hrsg.) (2005), S.|24ar 87.Penske - 978-3-631-75223-4
} 
keitsprinzip orientierte - Bürgerversicherung und die - dem Äquivalenzprinzip folgende - Kopfpauschale anhand ihrer allokativen und distributiven Wirkungen sowie unter verfassungsrechtlichen Gesichtspunkten gewürdigt. Bei der Bürgerversicherung wird auch die bislang kaum beachtete Wirkung auf die öffentlichen Haushalte dargestellt, bei den Kopfpauschalen wird der soziale Ausgleich, insbesondere dessen Finanzierung, thematisiert. Schließlich werden mit der Bürgerprämie, der solidarischen Gesundheitsprämie und weiteren Kompromissmodellen Möglichkeiten einer Synthese aus Bürgerversicherung und pauschalen Beiträgen kritisch diskutiert.

In Kapitel VI geht es um Möglichkeiten, kapitalgedeckte Elemente in der GKV zu implementieren. Dazu wird zunächst auf die wesentlichen Unterschiede zwischen Umlageverfahren und Kapitaldeckungsverfahren eingegangen. Als Referenzsystem für eine kapitalgedeckte Krankenversicherung dient die Private Krankenversicherung (PKV), deren Finanzierung und die damit verbundenen Problemen sind deshalb im Einzelnen darzustellen. Dabei muss insbesondere auf die Übertragbarkeit von Alterungsrückstellungen eingegangen werden. Kapital kann innerhalb der GKV oder außerhalb angespart werden. Im ersten Fall kann das Umlageverfahren um kapitalgedeckte Elemente ergänzt oder vollständig durch Kapitaldeckung ersetzt werden. Die einzelnen Möglichkeiten individueller und kollektiver Kapitaldeckung werden hinsichtlich ihrer Verteilungswirkungen, ordnungspolitischen Eignung und der mit dem Übergang verbundenen Belastungen verglichen. Augenmerk wird dabei auch auf die ökonomischen Risiken, insbesondere den Einfluss der demographischen Entwicklung auf die Kapitalrenditen, gerichtet. Für den zweiten Fall werden Erfahrungen aus dem Ausland vorgestellt und die Einführung von individuellen Gesundheitskonten in Deutschland diskutiert.

In Kapitel VII werden die wesentlichen Ergebnisse zusammengefasst und daraus Reformempfehlungen abgeleitet. 
Marco Penske - 978-3-631-75223-4

Downloaded from PubFactory at 01/11/2019 06:54:52AM

via free access 


\section{Finanzierungssystem der GKV}

\section{Die GKV im Gesundheitswesen}

Nach der Gesundheitsausgabenrechnung des Statistischen Bundesamtes wurden im Jahr 2003 in Deutschland insgesamt 239,7 Mrd. Euro für Gesundheitsleistungen ausgegeben. Das entsprach 11,3\% des Bruttoinlandsprodukts (BIP) oder 2.900 Euro je Einwohner. Mit 136,0 Mrd. Euro finanzierte die GKV 56,7\% der gesamten Ausgaben. Damit ist die GKV der größte Ausgabenträger zur Finanzierung der Leistungen im Gesundheitswesen. Mit deutlichem Abstand folgten die privaten Haushalte und private Organisationen ohne Erwerbszweck ${ }^{8}$ mit 29,4 Mrd. Euro bzw. 12,3\% sowie die Private Krankenversicherung (20,6 Mrd. Euro bzw. 8,6\%) und die öffentlichen Haushalte (18,8 Mrd. Euro bzw. 7,8\%). Auf die Pflegeversicherung entfielen 16,5 Mrd. Euro (6,9\%) und auf die Arbeitgeber 9,9 Mrd. Euro (4,1\%). Gesetzliche Rentenversicherung (GRV) und Gesetzliche Unfallversicherung trugen zusammen $8,4 \mathrm{Mrd}$. Euro $(3,5 \%)$ der Gesundheitsausgaben. ${ }^{9}$

\section{Abbildung 1: Gesundheitsausgaben im Jahr 2003 (in Mrd. Euro)}

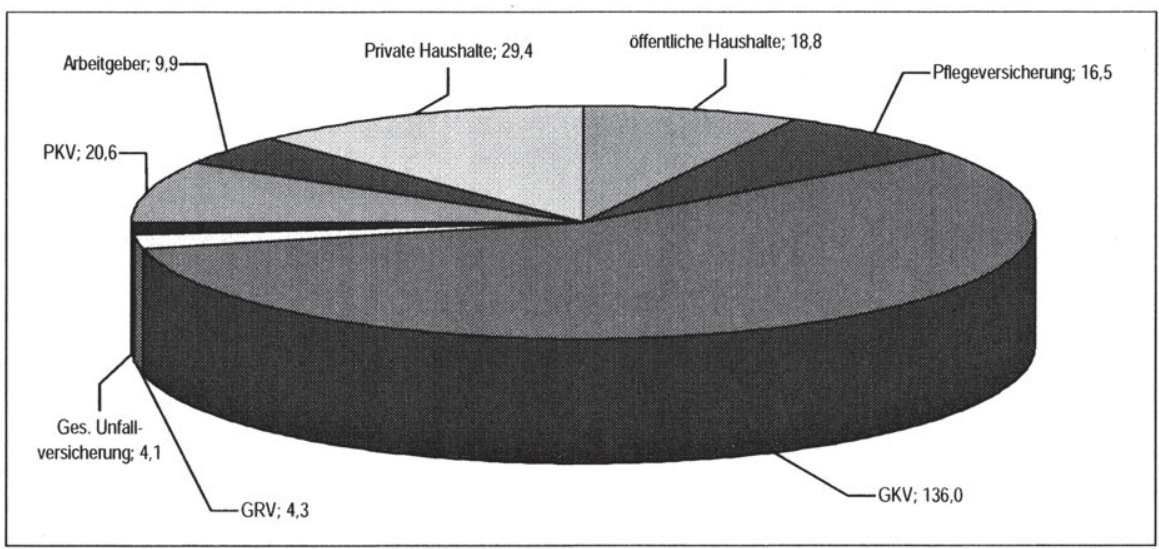

Daten: Gesundheitsberichterstattung des Bundes.

Einkommensleistungen (Krankengeld, Übergangsgeld, Entgeltfortzahlung bei Krankheit, Mutterschaftsgeld etc.) stellen im System der Gesundheitsausgabenrechnung eine Erweiterung der Gesundheitsausgaben dar; denn sie sind zwar aus Sicht des Trägers eine gesundheitsbezogene Maßnahme, nicht jedoch im volkswirtschaftlichen Sinne. Der Empfänger nutzt sie im Allgemeinen nicht für einen gesundheitlichen Zweck. Bei Einkommensleistungen handelt es sich vielmehr um Lohnersatzleistungen. Im Jahr 2003 betrugen die Einkommensleistungen 65,3 Mrd. Euro und wurden zu 11,7\% (7,6 Mrd. Euro) von der GKV getragen. Die privaten Arbeitgeber brachten mit $30,1 \mathrm{Mrd}$. Euro $(46,1 \%)$ den größten Anteil auf, gefolgt von der GRV mit

\footnotetext{
${ }^{8}$ Z.B. Deutsches Rotes Kreuz, Wohlfahrtsverbände.
}

${ }^{9}$ Daten: Gesundheitsberichterstattung des Bundes. Marco Penske - 978-3-631-75223-4 
16,9 Mrd. Euro (25,8 \%). Der Rest wurde von öffentlichen Haushalten, Gesetzlicher Unfallversicherung, Privater Krankenversicherung und Pflegeversicherung finanziert. $^{10}$

Von den Gesamtausgaben der GKV entfielen im Jahr 2004 47,6 Mrd. Euro (34,0\%) auf die Krankenhausbehandlung. Im ambulanten Bereich wurden 21,4 Mrd. Euro $(15,3 \%)$ für ärztliche und $11,3 \mathrm{Mrd}$. Euro $(8,1 \%)$ für zahnärztliche Behandlung inklusive Zahnersatz ausgegeben. Arznei-, Heil- und Hilfsmittel kosteten die Kassen $30,0 \mathrm{Mrd}$. Euro (21,4 \%). 6,4 Mrd. Euro (4,5 \%) wurden für Krankengeld ausgegeben. Weitere Ausgaben entfielen im Wesentlichen auf Fahrkosten, Kuren, Mutterschaft, Krankenpflege und Leistungen im Ausland. Hinzu kamen 8,1 Mrd. Euro Verwaltungskosten, so dass die Ausgaben der GKV im Jahr 2004 140,2 Mrd. Euro betrugen. ${ }^{11}$ Während die Ausgabenstruktur der PKV der der GKV ähnlich ist, sind die übrigen Ausgabenträger durch andere Leistungsarten gekennzeichnet. Bei den privaten Haushalten handelt es sich größtenteils um Zuzahlungen und um direkt bezahlte Gesundheitsleistungen wie z.B. Behandlungen außerhalb des GKV-Leistungskatalogs oder Arznei-, Heil- und Hilfsmittel. Die öffentlichen Haushalte (Bund, Länder und Gemeinden) sind für Krankenhausinvestitionen, aber auch für die Erstattung von Leistungen z.B. an Asylbewerber zuständig. Die Pflegeversicherung zahlt Leistungen der häuslichen und stationären Pflege, während insbesondere Krankheitsfolgekosten (z.B. Rehabilitationsleistungen, stationäre Kurbehandlung) von der Renten- und Unfallversicherung finanziert werden. Die Ausgaben der Arbeitgeber sind für Fürsorgeleistungen und den betrieblichen Gesundheitsdienst. Überwiegend zahlen die Arbeitgeber aber mit der Entgeltfortzahlung im Krankheitsfall eine Einkommensleistung an ihre Beschäftigten.

Tabelle 1: Internationaler Vergleich von Gesundheitsausgaben im Jahr 2003

\begin{tabular}{|l|c|c|c|c|}
\hline \multirow{2}{*}{ Land } & \multicolumn{2}{|c|}{ Gesamte Gesundheitsausgaben } & \multicolumn{2}{c|}{$\begin{array}{c}\text { Staatlich finanzierte } \\
\text { Gesundheitsausgaben }\end{array}$} \\
\cline { 2 - 5 } & $\begin{array}{c}\text { in Prozent } \\
\text { des BIP }\end{array}$ & $\begin{array}{c}\text { pro Kopf in US- } \\
\text { Dollar nach } \\
\text { Kaufkraftparitäten }\end{array}$ & $\begin{array}{c}\text { in Prozent } \\
\text { des BIP }\end{array}$ & $\begin{array}{c}\text { in Prozent der } \\
\text { Gesamtausgaben }\end{array}$ \\
\hline Deutschland & 11,1 & 2.996 & 8,7 & 78,2 \\
\hline Frankreich & 10,1 & 2.903 & 7,7 & 76,3 \\
\hline Italien & 8,4 & 2.258 & 6,3 & 75,1 \\
\hline Japan & 7,9 & 2.139 & 6,4 & 81,5 \\
\hline Niederlande & 9,8 & 2.976 & 6,1 & 62,4 \\
\hline Norwegen & 10,3 & 3.807 & 8,6 & 83,7 \\
\hline Schweiz & 11,5 & 3.781 & 6,7 & 58,5 \\
\hline Großbritannien & 7,7 & 2.231 & 6,4 & 83,4 \\
\hline Vereinigte Staaten & 15,0 & 5.635 & 6,7 & 44,4 \\
\hline
\end{tabular}

1) Angaben aus dem Jahr 2002.

Daten: OECD Health Data 2005.

Für einen internationalen Vergleich der Ausgaben für Gesundheitsleistungen eignen sich insbesondere zwei Indikatoren: Der Anteil der Gesundheitsausgaben am BIP

${ }^{10}$ Daten: Gesundheitsberichterstattung des Bundes.

${ }^{11}$ Vgl. BMGS (Hrsg.) (2005a), S. 1; eigene Berechnungen:co Penske - 978-3-631-75223-4 
und die Gesundheitsausgaben pro Kopf umgerechnet in US-Dollar mit Hilfe von Kaufkraftparitäten. ${ }^{12}$ In Tabelle 1 werden die entsprechenden Daten für ausgewählte OECD-Länder dargestellt. Beim Anteil der Gesundheitsausgaben am BIP lagen die Vereinigten Staaten im Jahr 2003 mit 15,0\% an erster Stelle, gefolgt von der Schweiz (11,5\%). Den dritten Rang belegte Deutschland, wo $11,1 \%$ des BIP für Gesundheitsleistungen ausgegeben wurden. Auch beim Vergleich der Gesundheitsausgaben pro Kopf belegten die Vereinigten Staaten mit 5.635 US-Dollar den Spitzenplatz im Jahr 2003. Platz zwei nahm Norwegen mit 3.807 US-Dollar vor der Schweiz (3.781 US-Dollar) ein. Deutschland folgte mit 2.996 US-Dollar pro Kopf auf Platz vier. Vergleicht man den über staatliche Systeme finanzierten Anteil der Gesundheitsausgaben an den gesamten Gesundheitsausgaben, liegt Deutschland mit einem Anteil von 78,2 \% im Mittelfeld der in Tabelle 1 ausgewählten Länder. Den geringsten Anteil verzeichnen die Vereinigten Staaten mit 44,4\%, den größten Norwegen mit 83,7\%. Betrachtet man hingegen den Anteil der staatlich finanzierten Ausgaben für Gesundheitsleistungen am BIP, belegt Deutschland mit einem Anteil von $8,7 \%$ die Spitzenposition vor Norwegen $(8,6 \%)$ und Frankreich $(7,7 \%)$.

Zur Finanzierung von Maßnahmen zur Vorbeugung und Heilung von Krankheiten sowie zur Absicherung der Risiken, die im Krankheitsfall durch Behandlungskosten und Einkommensausfall auftreten, bestehen in Deutschland im Wesentlichen zwei Systeme: Die Gesetzliche Krankenversicherung und die Private Krankenversicherung. ${ }^{13}$ Versicherungspflichtig in der GKV sind nach $§ 5$ SGB V in erster Linie Arbeiter und Angestellte, deren regelmäßiges jährliches Arbeitsentgelt eine bestimmte Höhe nicht überschreitet. Diese Versicherungspflichtgrenze (VPG) wird jährlich neu festgelegt und beträgt im Jahr 200546.800 Euro. $^{14}$ Arbeitnehmer, deren jährliches Arbeitsentgelt oberhalb der Versicherungspflichtgrenze liegt, sind gemäß $§ 6$ SGB V versicherungsfrei und können zwischen einer Mitgliedschaft in der GKV und der PKV wählen. Versicherungspflichtig in der GKV sind auch Rentner, wenn bestimmte Vorversicherungszeiten erfüllt sind, Bezieher von Arbeitslosengeld oder Arbeitslosengeld II, Letztere sofern sie nicht familienversichert sind ( 5 Abs. $1 \mathrm{Nr}$. 2a SGB V).

Prägendes Gestaltungsprinzip der GKV ist das Solidarprinzip, d.h. der Leistungsanspruch hängt nicht von der Höhe des Beitrags ab. ${ }^{15}$ In der GKV hat jeder Versicherte unbeschränkten Zugang zu notwendigen und qualitativ hochwertigen Gesundheitsleistungen (Bedarfsprinzip), während die Beiträge einkommensabhängig erhoben werden (Leistungsfähigkeitsprinzip). Im Gegensatz hierzu wird die PKV nach dem Äquivalenzprinzip finanziert. Der Beitrag wird so bemessen, dass bei Vertragsbeginn die erwartete Summe der künftigen Einnahmen der der künftigen Ausgaben entspricht. Der Beitrag des Versicherten ist eine äquivalente Abgabe für die Versicherungsleistung. In diesem Zusammenhang wird auch von einer Prämie gesprochen.

\footnotetext{
${ }^{12}$ Vgl. Statistisches Bundesamt (Hrsg.) (2002), S. 31 .

${ }^{13}$ Auf besondere Sicherungsformen (z.B. Freie Heilfürsorge von Polizei und Bundeswehr, Beihilfe für Beamte) wird im Folgenden wegen ihrer geringen Bedeutung nicht weiter eingegangen. Die Gesamtausgaben für Beihilfe beziffern Sehlen, S. u.a. (2004), S. 54f., auf 7,3 Mrd. Euro (2001). Zu den anderen Sicherungsformen liegen keine Angaben vor.

${ }^{14}$ Bereits zum 31.12.2002 in der PKV Versicherte bleiben versicherungsfrei, wenn ihr Einkommen 42.300 Euro im Jahr 2005 übersteigt; vgl. § 6 Abs. 7 SGB V.

${ }^{15}$ Einzige Ausnahme ist die Zahlung von Krankengeld/arco Penske - 978-3-631-75223-4
} 
Während in der PKV das Prinzip der Individualäquivalenz erfüllt ist, ist in der GKV nur das Prinzip der Kollektiväquivalenz in dem Sinne realisiert, dass die Summe der erhobenen Beiträge und sonstigen Einnahmen den Ausgaben entsprechen und eine Zweckbindung der Beiträge für Gesundheitsleistungen besteht.

Auch hinsichtlich des Finanzierungsverfahrens unterscheiden sich die beiden Systeme grundlegend. In der PKV wird aus den Beiträgen ein Kapitalstock gebildet, der zuzüglich der Zinserträge spätere Versicherungsansprüche mitfinanzieren soll (Anwartschaftsdeckungsverfahren). Bei diesem Verfahren besteht der Beitrag neben einem periodenbezogenen Risikobeitrag aus einer Rückstellung für mit steigendem Alter wachsende Gesundheitskosten. Damit ist die PKV in geringerem Umfang von der demographischen Alterung betroffen. Auf die Finanzierung der PKV wird in Kapitel VI.2 Kapitaldeckungsverfahren am Beispiel der PKV (S. 214) näher eingegangen. Demgegenüber wird die GKV im Umlageverfahren finanziert. D.h. die Beiträge werden nicht angespart, sondern in jeder Periode so kalkuliert, dass sie ausreichen, die Ausgaben in der laufenden Periode zu decken. Die Beitragszahlungen werden ohne zeitliche Verzögerung zur Finanzierung der Ausgaben verwendet. ${ }^{16}$ Wie im Folgenden noch gezeigt wird, ist die GKV damit in hohem Maße von der demographischen Entwicklung der Bevölkerung abhängig, was zu erheblichen Finanzierungsproblemen in der Zukunft führt und nach neuen Finanzierungswegen verlangt.

\section{Vom Äquivalenzprinzip zum Leistungsfähigkeitsprinzip}

Die GKV ist konstitutiver Bestandteil des in mehr als 100 Jahren gewachsenen Systems der sozialen Sicherung in Deutschland. Eingeführt wurde die GKV als erster Zweig der Sozialversicherung durch das "Gesetz betreffend die Krankenversicherung der Arbeiter" vom 15.06.1883, das 1911 in erweiterter Form in die Reichsversicherungsordnung (RVO) übernommen wurde. ${ }^{17}$ Seitdem haben sich Aufgabenstellung und Struktur der GKV allerdings erheblich verändert. In den Anfangsjahren war mit der Zahlung von Krankengeld im Krankheitsfall noch der Lohnersatz die zentrale Leistung der GKV. 1885 betrug der Anteil der Ausgaben für Krankengeld an den Gesamtausgaben $50,3 \%{ }^{18}$ Seit 1930 sind die Arbeitgeber bei den Angestellten und seit 1970 bei den Arbeitern verpflichtet, das Arbeitsentgelt in den ersten sechs Wochen der Arbeitsunfähigkeit weiterzuzahlen. Für diesen Zeitraum musste die Krankenkasse fortan das Arbeitsentgelt nicht mehr ersetzen. Damit nahm auch die Bedeutung der Ausgaben der gesetzlichen Kassen für Lohnersatzleistungen ab. ${ }^{19}$ Gleichzeitig kam es 1970 mit dem Krankenversicherungs-Weiterentwicklungsgesetz und dem Leistungsverbesserungsgesetz von 1973 zu einer Leistungsausweitung. Als neue Leistungen wurden z.B. Vorsorgeuntersuchungen zur Früherkennung von Krankheiten und der Anspruch auf Krankengeld und Freistellung von der Arbeit bei

\footnotetext{
${ }^{16}$ Vgl. Boetius, J.; Wiesemann, H.-O. (1998), S. 22ff.; Lampert, H.; Althammer, J. (2004), S. $241 f$.

${ }^{17} \mathrm{Vgl}$. Jessen, J. (1982), S. 51; Schulenburg, J.-M. Graf von der (1987), S. 1; Verband der privaten Krankenversicherung e.V. (Hrsg.) (1997), S. 19f. Zur historischen Entwicklung der GKV siehe Lamping, W.; Tamm, I. (1994), S. 117ff.
}

${ }^{18}$ Vgl. Frerich, J.; Frey, M. (1996), S. 102.

${ }^{19}$ Vgl. Lampert, H.; Althammer, J. (2004), S. 251. Marco Penske - 978-3-631-75223-4 
der Pflege eines erkrankten Kindes eingeführt, die Begrenzung der stationären Versorgung auf ein halbes Jahr aufgehoben und infolge der Rechtsprechung die gesamten Kosten bei kieferorthopädischen Behandlungen ab 1973 übernommen. ${ }^{20}$

Nachdem die Ausgaben von 1970 bis 1975 von 25,6 Mrd. DM auf über 60 Mrd. DM sprunghaft gestiegen waren, begann 1975 die Phase der Kostendämpfung über verschiedene Kostendämpfungsgesetze, die im Wesentlichen Selbstbeteiligungen und Leistungsbegrenzungen vorsahen. ${ }^{21} \mathrm{Da}$ das Ausgabenwachstum jeweils nur kurzfristig begrenzt werden konnte, erließ der Gesetzgeber vor allem mit dem Krankenversicherungs-Kostendämpfungsgesetz (1977), Kostendämpfungs-Ergänzungsgesetz (1981), Gesundheitsreformgesetz (1988), Gesundheitsstrukturgesetz (1992), Beitragsentlastungsgesetz (1996), 2. GKV-Neuordnungsgesetz (1997), GKV-Gesundheitsreformgesetz 2000 (1998), Arzneimittelausgaben-Begrenzungsgesetz (2002), Beitragssatzsicherungsgesetz (2002) und dem SGB V-Änderungsgesetz (2002) eine Reihe von Gesetzen zur Kostendämpfung. ${ }^{22}$ Im Rahmen des Gesundheitsreformgesetzes von 1988 wurde auch die Reichsversicherungsordnung aus dem Jahr 1911 weitgehend durch das "Fünfte Buch des Sozialgesetzbuches" (SGB V) abgelöst, das heute die gesetzliche Grundlage der GKV bildet. ${ }^{23}$

Finanziert wird die Krankenversicherung von Beginn an durch Beiträge, die bis 1949 zu zwei Dritteln von den Arbeitnehmern und zu einem Drittel vom Arbeitgeber aufgebracht wurden. Bemessungsgrundlage der Beiträge zur GKV ist seit ihrer Gründung das Arbeitsentgelt. ${ }^{24} \mathrm{Da}$ die Hauptleistung der GKV in der Zahlung von Krankengeld bestand, war durch diese Anbindung an das Arbeitsentgelt das Äquivalenzprinzip tendenziell erfüllt. Wegen der geschilderten Veränderung des Leistungskatalogs hat sich das der GKV zugrunde liegende Versicherungsprinzip aber fundamental gewandelt. Zwar berechnet sich das Krankengeld noch nach dem Arbeitsentgelt und damit nach den Beiträgen, doch fällt mittlerweile der weitaus größte Teil der Ausgaben der GKV für Gesundheitsleistungen an. Diese Leistungen werden aber nach dem Bedarf gewährt und sind unabhängig vom gezahlten Beitrag. ${ }^{25}$ Der Anteil der Ausgaben für Krankengeld an den Gesamtausgaben lag hingegen nur bei 4,5\% im Jahr 2004; nur etwa $44 \%$ der Versicherten hatten gemäß § 44 SGB V Anspruch auf Krankengeld, da Z.B. Rentner ( $28 \%$ der Versicherten) und Familienversicherte $(24 \%)$ nicht anspruchsberechtigt sind. ${ }^{26}$ Die einkommensabhängigen Beiträge auf der Einnahmenseite und die größtenteils beitragsunabhängigen Leistungen auf der Ausgabenseite führen in der GKV dazu, dass keine individuelle Äquivalenz von

${ }^{20}$ Vgl. Steffen, A. (1997), S. 25.

${ }^{21}$ Vgl. Lamping, W. (1994), S. 267f. Siehe hierzu ausführlich Kostorz, P. (1998), S. 85ff.; Oberender, P.; Hebborn, A.; Zerth, J. (2002), S. $65 \mathrm{ft}$.

${ }^{22}$ Vgl. Kostorz, P. (1998), S. 88ff.; Oberender, P.; Hebborn, A.; Zerth, J. (2002), S. 65f. Für eine Übersicht siehe Deutsche Bundesbank (Hrsg.) (2004a), S. $24 f$.

${ }^{23}$ Vgl. Link, F.J. (2000), S. 1.

${ }^{24}$ Vgl. Frerich, J.; Frey, M. (1996), S. 98f.; Lamping, W.; Tamm, I. (1994), S. 119; Bogs, W. u.a. (1966), S. 203.

${ }^{25}$ Vgl. Wille, E. (1998), S. 22; Kostorz, P. (1998), S. 116.

${ }^{26}$ Eigene Berechnungen; vgl. BMGS (Hrsg.) (2005a), S. 1; BMGS (Hrsg.) (2005b), S. 43f. Siehe auch Jacobs, K.; Schellschmidt, H. (2002), S. 16. 
Beitrag und erwarteten Ausgaben je Versicherten erreicht werden kann. ${ }^{27}$ Das Äquivalenzprinzip hat deshalb heute in der GKV weitgehend an Bedeutung verloren. Neben dem Krankengeld ist nur noch die Beitragsbemessungsgrenze (BBG), bis zu der Beiträge erhoben werden, ein Relikt der individuellen Äquivalenz. ${ }^{28}$

Soll die Beitragsgestaltung nicht politischer Willkür unterliegen, erfordert die mangelnde Verwirklichung des Äquivalenzprinzips in der GKV eine Orientierung an dem anderen Fundamentalprinzip der Abgabenerhebung: dem Leistungsfähigkeitsprinzip. ${ }^{29}$ Diesem zufolge ist die Fähigkeit des Versicherten, einen Finanzierungsbeitrag zur GKV zu leisten, entscheidend für die Verteilung der Beitragslast. Als Indikator für Leistungsfähigkeit dient nach weithin akzeptierter Auffassung das (Gesamt-)Einkommen. Da die meisten Versicherten bei Gründung der GKV kaum über andere Einkunftsarten verfügten, spiegelte das Arbeitsentgelt weitgehend die finanzielle Leistungsfähigkeit wider. Im Zeitverlauf aber haben andere Einkunftsarten (insbesondere Einkünfte aus Kapitalvermögen) stark an Bedeutung gewonnen, weshalb heute die Einengung der Bemessungsgrundlage auf das Arbeitsentgelt unter dem Aspekt der Leistungsfähigkeit problematisch ist. ${ }^{30}$ Laut Berechnungen für das Deutsche Institut für Wirtschaftsforschung (DIW) ${ }^{31}$ stiegen im Durchschnitt aller Haushalte in Westdeutschland allein von 1990 bis 1998 die jährlichen Kapitaleinkünfte von 5.671 DM auf 7.305 DM, womit der Anteil der Kapitaleinkünfte an den Markteinkommen in diesem Zeitraum von 13,1 \% auf 16,5\% zunahm. Noch deutlicher fällt der Anstieg in Ostdeutschland aus: Hier stiegen die Kapitaleinkünfte durchschnittlich von 327 DM im Jahr 1991 auf 3.339 DM (1998) und damit deren Anteil an den Markteinkommen von $1,2 \%$ auf 10,8 \%. Auch das Bundesverfassungsgericht ${ }^{32}$ geht in seiner Entscheidung vom 15.03.2000 über die Regelung des Zugangs zur Krankenversicherung der Rentner (KVdR) von einem sinkenden Anteil des Arbeitsentgelts am Gesamteinkommen der Versicherten aus. Wenn aber die Annahme, dass das Einkommen der Versicherten fast ausschließlich aus Arbeitsentgelt besteht, heute nicht mehr zutrifft, dann verstößt nach Auffassung des Bundesverfassungsgerichts die Beschränkung der Beitragsbemessung auf das Arbeitsentgelt gegen das Leistungsfähigkeitsprinzip.

In quantitativer Hinsicht hat die GKV durch gesetzliche Maßnahmen zur Ausweitung des Versichertenkreises seit ihrer Einführung als Versicherung für Arbeiter kontinuierlich an Bedeutung gewonnen: Im Jahr 1885 waren lediglich 8,8 \% der Bevölkerung in der GKV versichert. ${ }^{33}$ Seit 1941 sind aufgrund der Verordnung des Reichsarbeitsministers über die Krankenversicherung der Rentner vom 04.11.1941 Rentner

${ }^{27}$ Vgl. Hofmann, J.; Hühne, P. (1988), S. 238; Cassel, D.; Janßen, J. (1999), S. 15.

${ }^{28}$ Vgl. SVR KAiG (1994), Ziff. 469f.; SVR KAiG (2003), Ziff. $36 f$.

${ }^{29}$ Vgl. SVR KAiG (1994), Ziff. 470. Zu den beiden Fundamentalprinzipien siehe auch Haller, $\mathrm{H}$. (1964), S. $12 \mathrm{ff}$.

${ }^{30}$ Vgl. Kronberger Kreis (2002), S. 18f.; SVR KAiG (1994), Ziff. 467, 480; Düttmann, R. (1978), S. $90 f$. Zu weiteren Verstößen gegen das Leistungsfähigkeitsprinzip siehe Abschnitt 4.2.2 Intragenerative Inzidenz, S. 35.

${ }^{31}$ Siehe Grabka, M.M.; Otto, B. (2001), S. 53 f.

${ }^{32}$ Siehe Entscheidung des Bundesverfassungsgerichts vom 15.03.2000, Az 1 BvL 16/96, S. 93f., und die zugehörige Pressemitteilung Nr. 101 vom 27.07.2000, Regelung über Zugang zur Krankenversicherung der Rentner verfassungswidrig, S. 3.

${ }^{33}$ Vgl. SVR KAiG (1987), Tabelle A116. 
in der KVdR versichert. ${ }^{34}$ Seitdem besteht das GKV-System aus der Krankenversicherung der Rentner und der Allgemeinen Krankenversicherung, der Erwerbspersonen und ihre Familienversicherten angehören. Im Jahr 2003 zählte die GKV 72,5 Mio. Versicherte (87,8 \% der Bevölkerung), in der PKV waren 8,1 Mio. Personen vollversichert. Hinzu kamen rund 1,8 Mio. Versicherte in besonderen Versicherungsformen (z.B. Freie Heilfürsorge von Polizei und Bundeswehr). Etwa 200.000 Personen waren nicht krankenversichert. Hierbei handelt es sich in erster Linie um Selbständige und um ausschließlich geringfügig Beschäftigte, die nicht pflichtversichert sind, keinen Anspruch auf Familienversicherung haben und sich keine Krankenversicherung leisten können oder wollen. ${ }^{35}$

\section{Praktiziertes Beitragssystem}

\subsection{Beitragserhebung}

Die GKV finanziert sich fast ausschließlich über Beiträge, die nach den Vorschriften der §§ 220ff. SGB V von den einzelnen Kassen erhoben werden. Im Einzelnen setzen sich die Beitragseinnahmen der GKV aus folgenden Komponenten zusammen:

- Beiträge der Pflichtversicherten (Arbeitnehmer- und Arbeitgeberbeiträge)

- Beiträge der Rentner und der Gesetzlichen Rentenversicherung

- Beiträge der Bundesagentur für Arbeit für Empfänger von Arbeitslosengeld

- Beiträge des Bundes für Empfänger von Arbeitslosengeld II

- Eigenbeiträge der Empfänger von Sozialleistungen

- Beiträge von freiwillig Versicherten

Von den gesamten Einnahmen der GKV in Höhe von 144,3 Mrd. Euro im Jahr 2004 stammten 140,1 Mrd. Euro (97,1\%) aus Beiträgen, sonstige Einnahmen betrugen lediglich 4,2 Mrd. Euro ${ }^{36}$ Zwar tragen z.B. die Länder die Investitionskosten von Krankenhäusern und die Sozialhilfeträger erstatten mitunter den Kassen die Behandlungskosten für Sozialhilfeempfänger, dennoch haben Zahlungen des Staats zur Finanzierung von Gesundheitsausgaben nur geringe Bedeutung. ${ }^{37}$ Direkte staatliche Zuschüsse an die GKV wurden durch das Gesetz zur Modernisierung der gesetzlichen Krankenversicherung (GKV-Modernisierungsgesetz) vom 14.11.2003 $3^{38}$ ab dem Jahr 2004 für versicherungsfremde Leistungen eingeführt. Gemäß § 221 SGB V erhält die GKV im Jahr 20041 Mrd. Euro, 2005 2,5 Mrd. Euro und ab 2006 4,2 Mrd. Euro aus dem Bundeshaushalt. ${ }^{39}$ Die Steuerfinanzierung spielt aber trotz dieser Neuregelung nur eine untergeordnete Rolle. Die sonstigen Einnahmen, zu denen

\footnotetext{
${ }^{34}$ Vgl. ausführlich Bogs, W. u.a. (1966), S. $241 \mathrm{ff}$.

${ }^{35}$ Daten: BMGS, Verband der privaten Krankenversicherung e.V. Zu Ursachen, Ausmaß und Folgen von Nichtversicherung siehe ausführlich Greß, S.; Walendzik, A.; Wasem, J. (2005), S. $11 \mathrm{ff}$.

${ }^{36}$ Siehe BMGS (Hrsg.) (2005a), S. 1.

${ }^{37}$ Vgl. Rosenbrock, R.; Gerlinger, T. (2004), S. 93.

${ }^{38}$ Siehe BGBI. 2003, Teil I, Nr. 55, S. 2229.

${ }^{39}$ Siehe hierzu auch Kapitel V.3.1 Steuerfinanzierung:/S.r.159Penske - 978-3-631-75223-4
} 
auch staatliche Zuschüsse zählen, machten im Jahr 2004 weniger als $3 \%$ der Einnahmen der GKV aus. Der im Jahr 2004 eingeführte Bundeszuschuss soll nach der Koalitionsvereinbarung ${ }^{40}$ zwischen CDU, CSU und SPD sogar schrittweise wieder abgebaut werden. Im Folgenden wird von den restlichen Einnahmen ${ }^{41}$ der GKV, die sich größtenteils aus Vermögenserträgen, Erstattungen aus öffentlichen Mitteln und Ersatzansprüchen zusammensetzen, abgesehen.

Die Beiträge werden gemäß $\S 223$ Abs. 2 SGB V nach den beitragspflichtigen Einnahmen $^{42}$ der Mitglieder ${ }^{43}$ bemessen. Nach $\S 226$ Abs. 1 Nr. 1 SGB V unterliegt in erster Linie das Bruttoarbeitsentgelt ${ }^{44}$ aus einer versicherungspflichtigen Beschäftigung der Beitragspflicht zur Krankenversicherung. Bei Rentnern sind gemäß § 226 Abs. $1 \mathrm{Nr}$. 2ff. und $\S 237$ SGB V die Rentenzahlung der GRV sowie ggf. Einnahmen aus Versorgungsbezügen und Arbeitseinkommen maßgeblich.

Der Beitrag eines Mitglieds ergibt sich aus der Multiplikation des Beitragssatzes der jeweiligen Kasse mit den beitragspflichtigen Einnahmen des Mitglieds bis zur Beitragsbemessungsgrenze und wird gemäß § 249 Abs. 1 SGB V im Allgemeinen paritätisch ${ }^{45}$ von Arbeitnehmer und Arbeitgeber finanziert. Die die BBG übersteigenden Einnahmen bleiben nach $\S 223$ Abs. 3 SGB V beitragsfrei. Die BBG liegt im Jahr 2005 bei 42.300 Euro p.a.

$\S 240$ Abs. 4 Satz 1 SGB V sieht eine Mindestbeitragsbemessungsgrundlage für freiwillig Versicherte vor. Diese beträgt pro Kalendertag mindestens den neunzigsten Teil der monatlichen Bezugsgröße ${ }^{46}$, was 805 Euro p.m. im Jahr 2005 entspricht. Bei Selbständigen, die freiwillig in der GKV versichert sind, werden beitragspflichtige Einnahmen in Höhe der monatlichen Bezugsgröße (2.415 Euro) unterstellt. Beim Nachweis eines geringeren Einkommens wird je Kalendertag mindestens der vierzigste Teil der monatlichen Bezugsgröße zugrunde gelegt (1.811 Euro), bei Anspruch auf einen Existenzgründerzuschuss die Hälfte der monatlichen Bezugsgröße (1.208 Euro). Familienangehörige, deren Einkommen ein Siebtel der monatlichen Bezugsgröße (345 Euro) nicht überschreitet, sind nach § 10 Abs. 1 SGB V beitragsfrei mitversichert.

${ }^{40}$ Siehe Christlich Demokratische Union Deutschlands; Christlich-Soziale Union in Bayern; Sozialdemokratische Partei Deutschlands (Hrsg.) (2005), S. 68.

${ }^{41}$ Siehe Prognos (Hrsg.) (1998), S. 88.

${ }^{42}$ Bis 1998 (Gesundheitsreformgesetz) wurden die beitragspflichtigen Einnahmen als Grundlohnsumme bezeichnet; vgl. Bress, D. u.a. (2003), S. 215.

${ }^{43}$ Als Mitglieder werden die Personen bezeichnet, die Beiträge an die GKV entrichten. Die Versicherten setzen sich aus den Mitgliedern und den beitragsfrei Familienversicherten zusammen.

${ }^{44}$ Aus $\S 14$ Abs. 2 SGB IV ergibt sich, dass als beitragspflichtige Einnahme immer das Bruttoarbeitsentgelt anzusetzen ist; vgl. Bress, D. u.a. (2003), S. 223.

${ }^{45}$ Zu Abweichungen hiervon siehe Ott, G. (1981), S. 52ff. Offen bleibt, wer die ökonomische Last letztlich trägt, d.h. ob und inwieweit es dem Arbeitgeber gelingt, seinen Beitragsanteil auf den Arbeitnehmer oder über höhere Marktpreise auf die Konsumenten zu überwälzen; vgl. Wille, E. (2001), S. 13.

${ }^{46}$ Die Bezugsgröße bemisst sich gemäß $\S 18$ SGB IV nach dem durchschnittlichen Bruttojahresarbeitsentgelt des vorvergangenen Jahres, aufgerundet auf den nächst höheren durch 420 teilbaren Betrag. Im Jahr 2004 betrug die für die GKV bundeseinheitliche Bezugsgröße 28.980 Euro p.a. Aufgrund der geringen Lohnsteigerung im Jahr 2003 liegt sie im Jahr 2005 bei dem gleichen Wert. Für das Jahr 2006 ist sie auf 29.400 Euro p.a. festgesetz/larco Penske - 978-3-631-75223-4 
Beitragssatzabstufungen aufgrund eines höheren voraussichtlichen Leistungsbedarfs sind nach einem Urteil des Bundessozialgerichts ${ }^{47}$ nicht zulässig, da dies dem Solidarprinzip entgegenstünde. In der GKV wird der Beitragssatz gemäß $\S \S 241 \mathrm{ff}$. SBG V neben Sonderregelungen z.B. für geringfügig Beschäftigte, Studenten und Wehrdienstleistende nach dem Anspruch auf Krankengeld differenziert. Der allgemeine Beitragssatz gilt für Mitglieder mit Anspruch auf Krankengeld nach sechs Wochen Entgeltfortzahlung durch den Arbeitgeber, der erhöhte Beitragssatz für Mitglieder mit Anspruch auf Krankengeld vor der siebten Woche Arbeitsunfähigkeit und der ermäßigte Beitragssatz für Mitglieder ohne Krankengeldanspruch. ${ }^{48}$

Seit 01.04.2003 ist infolge des „Zweiten Gesetzes für moderne Dienstleistungen am Arbeitsmarkt ${ }^{449}$ und der damit verbundenen Neuregelungen für Arbeitnehmer ein geringfügiges Beschäftigungsverhältnis (Mini-Job) mit einem monatlichen Entgelt von bis zu 400 Euro aus arbeitsmarktspolitischen Gründen sozialversicherungsfrei. Bis zu diesem Betrag zahlt nach § 249b SGB V lediglich der Arbeitgeber einen Krankenversicherungsbeitrag in Höhe von $11 \%$ des Bruttolohns, bei Beschättigungen in Privathaushalten $5 \%$. An diese Grundzone schließt sich nach § 226 Abs. 4 SGB V eine Gleitzone für Arbeitsentgelte zwischen 401 Euro und 800 Euro (Midi-Jobs) an, in der durch die Ermittlung der beitragspflichtigen Einnahmen die Beitragsbelastung bis auf den normalen Beitragssatz ansteigt. Ab einem beitragspflichtigen Einkommen von 801 Euro im Monat gilt die reguläre Beitragserhebung.

Algebraisch lässt sich für das Jahr 2005 bei einem Arbeitsentgelt des Versicherten in Höhe von $Y$ die monatliche Beitragszahlung $B$ bei der Beitragsbemessungsgrenze von 3.525 Euro für einen unterstellten Beitragssatz von $14,2 \%$ wie folgt darstellen:

$$
B= \begin{cases}0,11 \cdot Y & \text { falls } Y \leq 400 \\ 0,142 \cdot\{F \cdot 400+(2-F) \cdot(Y-400)\} & \text { falls } 400<Y \leq 800 \\ 0,142 \cdot Y & \text { falls } 800<Y \leq 3.525 \\ 500,55 & \text { falls } Y>3.525\end{cases}
$$

Der Faktor F ergibt sich, indem der Wert $25 \%$ durch den durchschnittlichen Gesamtsozialversicherungsbeitragssatz des Jahres (2005: 42,0 \%) dividiert wird. Für 2005 beträgt der Faktor F 0,5952.

In der Gleitzone beträgt der vom Arbeitgeber zu zahlende Beitragsanteil gemäß $\S 249$ Abs. 4 SGB V die Hälfte des Beitrags, der sich aus der Anwendung des Beitragssatzes auf das gezahlte Arbeitsentgelt ergibt. Der Arbeitnehmer zahlt die Differenz aus dem nach obiger Gleichung ermittelten Gesamtbeitrag und dem Arbeitgeberbeitrag.

\footnotetext{
${ }^{47}$ Vgl. Entscheidung des Bundessozialgerichts vom 15.05.1984, Az 12 RK 59/81, S. 260 f.

${ }^{48}$ Obwohl Rentner keinen Anspruch auf Krankengeld haben, richtet sich ihr Krankenversicherungsbeitrag nicht - wie man erwarten dürtte - nach dem ermäßigten, sondern nach dem allgemeinen Beitragssatz ihrer Kasse. Lediglich auf Zins- oder Mieteinkünfte von freiwillig versicherten Rentnern wird der ermäßigte Beitragssatz erhoben. Siehe BMGS (Hrsg.) (2004b), S. 31.

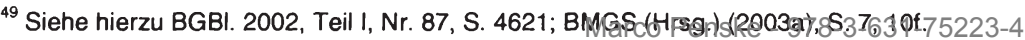




\title{
3.2 Kreditaufnahmeverbot
}

Jede Krankenkasse ist nach $\S 220$ SGB V verpflichtet, den Beitragssatz so zu bemessen, dass für das jeweilige Haushaltsjahr die voraussichtlichen Einnahmen die enwarteten Ausgaben decken und - soweit erforderlich - die Rücklage auffüllen. Die Rücklage einer Kasse muss nach $\S 261$ Abs. 2 SGB V mindestens $25 \%$ und darf höchstens $100 \%$ einer Monatsausgabe betragen. Aus $\S 220$ Abs. 2 SGB V

\begin{abstract}
„Ergibt sich während des Haushaltsjahres, daß die Betriebsmittel der Krankenkasse einschließlich der Zuführung aus der Rücklage und der Inanspruchnahme eines Darlehens aus der Gesamtrücklage zur Deckung der Ausgaben nicht ausreichen, sind die Beiträge zu erhöhen."
\end{abstract}

ist das Verbot von Kreditaufnahmen abzuleiten. In den neuen Ländern durften Kassen jedoch bis zum 31.12.1998 nach § 222 Abs. 4 SGB V Darlehen aufnehmen. Um unterjährige Schwankungen der Einnahmen und Ausgaben auszugleichen, sind kurzfristige Kassenverstärkungskredite zugelassen.$^{50}$ Dennoch kam es in der GKV infolge nicht rechtzeitig vorgenommener Beitragssatzerhöhungen rechtswidrig zu Kreditaufnahmen ${ }^{51}$ Damit hat die GKV, deren Defizit nach dem Europäischen System Volkswirtschaftlicher Gesamtrechnungen in das gesamtstaatliche Defizit eingeht, in den Jahren 2002 und 2003 mit dazu beigetragen, dass Deutschland die durch den Stabilitäts- und Wachstumspakt vorgegebene Defizitquote von $3 \%$ des BIP überschritten hat. Der Schuldenstand der GKV belief sich am 31.12.2003 auf 8,3 Mrd. Euro. $^{52}$ Dem standen Vermögenswerte von 2,3 Mrd. Euro und Rücklagen von rund 1,2 Mrd. Euro gegenüber. ${ }^{53}$ Die Rücklagen müssten allerdings mindestens 3,0 Mrd. Euro betragen haben. ${ }^{54}$ Auf die Verschuldung der Kassen hat der Gesetzgeber im

${ }^{50}$ Siehe hierzu Bundesversicherungsamt (Hrsg.) (2003), S. 3. Nicht ausgeglichene Kassenverstärkungskredite sind am Jahresende als Kredite zu verbuchen; vgl. Bundestags-Drucksache 15/3435 vom 29.06.2004, S. 3.

${ }^{51}$ Auf die Frage, wie es trotz gesetzlichen Verbots zu einer Verschuldung kommen konnte, antwortete die Bundesregierung: „Der Bundesregierung ist nicht bekannt, wie sämtliche Aufsichtsbehörden auf die Problematik reagierten. [...] Die finanzielle Entwicklung der gesetzlichen Krankenversicherung ist seit 2001 als Folge einer schwierigen konjunkturellen Situation insbes. durch eine schwache Einnahmeentwicklung bei gleichzeitig überproportionaler Ausgabenentwicklung in einigen Bereichen ärztlich verordneter Leistungen [...] geprägt"; Bundestags-Drucksache 15/3435 vom 29.06.2004, S. 10. Verantwortlich scheint indes die uneinheitliche Aufsicht über die Kassen zu sein: Für bundesweit tätige Kassen ist das Bundesversicherungsamt zuständig, für Länder-Kassen das jeweilige Sozialministerium, das schon aus arbeitsmarktpolitischen Gründen aber an niedrigen Beitragssätzen interessiert ist. Eine einheitliche Aufsicht, etwa durch den Bundesrechnungshof, könnte abhelfen.

${ }^{52}$ Vgl. Bundestags-Drucksache 15/3436 vom 29.06.2004, S. 3; eigene Berechnung. Das BMGS bezifferte die Verschuldung indes auf 5,996 Mrd. Euro; vgl. Bundestags-Drucksache 15/3435 vom 29.06.2004, S. 2, 17; Bundestags-Drucksache 15/3436 vom 29.06.2004, S. 2. Diesen Betrag erhält man durch Saldieren des Schuldenstands mit dem Vermögen der GKV. Diese Art der Verrechnung ist jedoch unüblich. Weder in den öffentlichen Haushalten noch bei privaten Unternehmen wird dies praktiziert, zumal Vermögensbestände schwer zu bewerten sind. Das BMGS weist dementsprechend selbst auf die mangelnde Aussagekraft hin: „Dem stehen jedoch teilweise Vermögenswerte gegenüber, so dass die Kredithöhen nicht den tatsächlichen Schuldenstand wiedergeben können“; Bundestags-Drucksache 15/3435 vom 29.06.2004, S. 2. In Bundestags-Drucksache 15/5484 vom 11.05.2005, S. 3, wird auch die Brutto-Verschuldung für die Jahre 1998 bis 2003 ausgewiesen.

${ }^{53} \mathrm{Vgl}$. Bundestags-Drucksache 15/3436 vom 29.06.2004, S. 2f.; eigene Berechnung.

${ }^{54}$ Bei einem Ausgabenvolumen von rund 145 Mrd. Euro im Jahr 2003 lagen die monatlichen Ausgaben bei 12,1 Mrd. Euro, wovon mindestens $25 \%$ als |Rëreklagezzis kalteg Find-631-75223-4 
GKV-Modernisierungsgesetz ${ }^{55}$ reagiert und $\S 222$ Abs. 5 SGB V neu angefügt und das Kreditaufnahmeverbot explizit ergänzt. Zudem müssen die Kassen ihre Verschuldung jährlich um mindestens $25 \%$ und bis zum 31.12.2007 vollständig abbauen. ${ }^{56}$ Dazu dient auch der Überschuss der GKV von rund 4 Mrd. Euro im Jahr 2004. ${ }^{57}$

Traditionelle Rechtfertigungen für Staatsverschuldung greifen in der GKV nicht. Weder aus dem objektbezogenen (Rentabilität, Pay-as-you-use und Intergenerationequity) noch aus dem situationsbezogenen Ansatz lässt sich ökonomisch ein Verschuldungsrecht für die GKV ableiten. Ausgaben der GKV sind keine Investitionen im eigentlichen Sinn und erwirtschaften deshalb keine Rendite für spätere Generationen. Auch entstehen keine Nutzen, deren Finanzierungslast sich nach dem Pay-asyou-use-Prinzip mittels Kreditfinanzierung auf mehrere Perioden verteilen lässt. Außergewöhnliche Sonderbelastungen liegen gleichfalls nicht vor, Kredite können demnach nicht zur gerechteren Verteilung von Lasten zwischen Generationen beitragen. Zudem hat die GKV keine stabilisierungspolitische Aufgabe, so dass auch der situationsorientierte Ansatz die Kreditfinanzierung nicht rechtfertigen kann.

Auf der Ebene der GKV ist mit Ausnahme unterjähriger Kassenverstärkungskredite die Kreditaufnahme verboten. Die einzelnen Kassen haben lediglich in Ausnahmesituationen drei Möglichkeiten zur einzelwirtschaftlichen Kreditaufnahme innerhalb des GKV-Systems:

1. Nach § 262 Abs. 4 SGB V können die Kassen unter bestimmten Bedingungen ein Darlehen aus der Gesamtrücklage des Landesverbandes erhalten.

2. „Die Satzungen der Landesverbände und der Verbände der Ersatzkassen können eine Umlage der Verbandsmitglieder vorsehen, um die Kosten für aufwendige Leistungsfälle und für andere aufwendige Belastungen ganz oder teilweise zu decken. Die Hilfen können auch als Darlehen gewährt werden“ (§ 265 SGB V).

3. Nach § 265a SGB V können „die Satzungen der Spitzenverbände [...] finanzielle Hilfen in besonderen Notlagen einer Krankenkasse ihrer Kassenart oder zur Erhaltung deren Wettbewerbsfähigkeit vorsehen. Die Hilfen können auch als Darlehen gewährt werden."

\subsection{Wichtige Determinanten für den Beitragssatz}

Die Finanzierung der GKV hat zur Folge, dass die GKV-Einnahmen zum einen aufgrund der Einkommensabhängigkeit eng an die gesamtwirtschaftliche Entwicklung gekoppelt sind und zum anderen von der demographischen Entwicklung abhängen. Abbildung 2 gibt einen Überblick, von welchen Relationen der Beitragssatz der GKV im Wesentlichen bestimmt wird. Dabei sind insbesondere die Determinanten auf der rechten Seite von der demographischen Entwicklung abhängig.

\footnotetext{
${ }^{55}$ Siehe BGBI. 2003, Teil I, Nr. 55, S. 2229.

${ }^{56}$ Der Abbau der Verschuldung der GKV hat positive Auswirkungen auf die Defizitquote, da Überschüsse in den Sozialversicherungen das gesamtstaatliche Defizit senken.

${ }^{57}$ Vgl. Bundestags-Drucksache 15/5484 vom 11.05.2pperiç. 3enske - 978-3-631-75223-4
} 
Abbildung 2: Wichtige Determinanten für den Beitragssatz

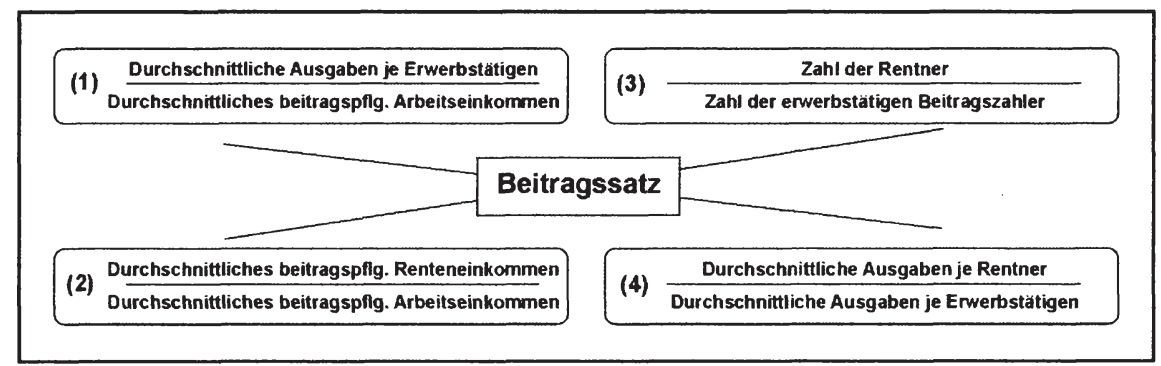

Quelle: In Anlehnung an Burger, S.; Funk, L.; Jobelius, H.-J. (1994), S. 152.

Der Beitragssatz wird vor allem von den vier in Abbildung 2 dargestellten Relationen determiniert:

(1) Wachsen die GKV-Ausgaben für erwerbstätige Beitragszahler schneller als deren beitragspflichtige Einkommen, dann steigt der Beitragssatz, weil ein größerer Anteil der Bruttoeinkommen zur Finanzierung der GKV herangezogen werden muss. Beeinflusst wird diese Relation u.a. auf der Ausgabenseite vom technischen Fortschritt im Gesundheitswesen und auf der Einnahmenseite vom Wirtschaftswachstum.

(2) Von einem indirekten demographischen Effekt auf der Einnahmenseite wird gesprochen, wenn die Durchschnittsrenten z.B. infolge der Auswirkungen des demographischen Wandels auf die Rentenversicherung im Vergleich zu den beitragspflichtigen Einkommen der Erwerbstätigen sinken ${ }^{58}$ Auch dann steigt der Beitragssatz. Daran lässt sich erkennen, dass Änderungen im Rentenrecht, die das Rentenniveau beeinflussen, über die Beiträge der Rentner ebenfalls Auswirkungen auf die Finanzierung der GKV haben. ${ }^{59}$

(3) Ein direkter demographischer Effekt liegt vor, wenn das Verhältnis von Rentnern zu erwerbstätigen Beitragszahlern, also der Rentnerquotient, zunimmt. ${ }^{60}$ Der Beitragssatz steigt dann unter der Voraussetzung, dass die durchschnittlichen Ausgaben für Rentner größer als die für Erwerbstätige und die durchschnittlichen Beiträge der Rentner geringer als die der Erwerbstätigen sind. Beide Bedingungen sind bislang erfüllt, wovon auch für die Zukunft auszugehen ist. ${ }^{61}$ Der Beitragssatz und damit auch die Belastung der Erwerbstätigen steigen somit, wenn der Rentnerquotient in der GKV zunimmt. ${ }^{62}$

(4) Auch ein Anstieg des Quotienten aus durchschnittlichen Ausgaben für Rentner und für Erwerbstätige führt zu einem Beitragssatzanstieg. Nehmen die Ausgaben je Rentner stärker zu als die Ausgaben für erwerbstätige Beitrags-

\footnotetext{
${ }^{58}$ Vgl. Enquete-Kommission Demographischer Wandel (1998), S. 233.

${ }^{59}$ Vgl. Schmähl, W. (1983a), S. 118f.; Schmähl, W. (1986), S. 220.

${ }^{60}$ Vgl. Kopetsch, T. (1997), S. 13; Ulrich, V. (1995), S. 47.

${ }^{61}$ Vgl. Schmähl, W. (1983a), S. 115; Schmähl, W. (1986), S. 220; Schmähl, W. (1989), S. 306.

${ }^{62}$ Vgl. Knappe, E. (1995), S. 24; Kopetsch, T. (2001), SVlz? co Penske - 978-3-631-75223-4 
zahler spricht man auch von einem indirekten demographischen Effekt auf der Ausgabenseite. Je größer die Pro-Kopf-Ausgabenrelation Rentner/Erwerbstätige ist, desto stärker wirkt ein Anstieg des Rentnerquotienten beitragssatzsteigernd. Das Ausmaß des Beitragssatzeffekts hängt davon ab, ob die längere Lebenserwartung zu einer Ausgabenerhöhung oder nur zu einer zeitlichen Verschiebung von Ausgaben führt. ${ }^{63}$

\section{Problematik}

\subsection{Lohnkoppelung der Beiträge}

Die Bemessungsgrundlage für den GKV-Beitrag bilden im Wesentlichen Lohneinkommen. Hieraus abgeleitet bemessen sich die Beiträge für nicht erwerbstätige Mitglieder an vergleichbaren Einkommen, z.B. Renten- oder Transferzahlungen. Diese Beitragsbemessungsgrundlagen sind in vielerlei Hinsicht problematisch. Zu nennen sind zunächst diffuse Verteilungswirkungen. Diese werden im folgenden Abschnitt 4.2 Verteilungswirkungen (S. 34) kritisch analysiert.

Zudem stellen die Beiträge zur GKV aufgrund der paritätischen Finanzierung von Arbeitgeber und Arbeitnehmer Lohnnebenkosten dar und führen zu allokativen Verzerrungen am Arbeitsmarkt, da Produzenten- und Konsumentenlohn auseinander fallen. Für die Arbeitgeber steigen die Kosten für den Faktor Arbeit, womit die Arbeitsnachfrage tendenziell sinkt. Auf das Arbeitsangebot wirken zwei gegenläufige Effekte: Der Substitutionseffekt zwischen Arbeit und Freizeit führt bei steigenden Sozialversicherungsbeiträgen zu einem Rückgang des legalen Arbeitsangebots. Dem steht aufgrund des gesunkenen Nettolohns ein Einkommenseffekt gegenüber, der zu einem Rückgang der Nachfrage nach dem Gut Freizeit und damit einer Zunahme des Arbeitsangebots führt. Theoretisch ist der Gesamteffekt auf das Arbeitsangebot offen, realistisch ist jedoch, dass in Deutschland der Substitutionseffekt den Einkommenseffekt dominiert. Insgesamt ist die Finanzierung der GKV beschäftigungsfeindlich. Deshalb wird Beitragssatzstabilität oder zumindest eine Begrenzung des Beitragssatzanstiegs gefordert, auch wenn die Gesundheitsausgaben aus gesundheitspolitischen Gründen - nicht zuletzt um Wachstum im Gesundheitswesen zu fördern steigen sollten. Dieser Zielkonflikt wird in Abschnitt 4.3.1 Zum Ziel der Beitragssatzstabilität (S. 50) aufgegriffen.

Die Lohnkoppelung macht auch die Einnahmen der GKV von der gesamtwirtschaftlichen Entwicklung abhängig, während die Gesundheitsleistungen aus medizinischer Sicht unabhängig vom Konjunkturverlauf sind. Geringe Wachstumsraten des Bruttosozialprodukts in Verbindung mit niedrigen Lohnzuwachsraten oder ein Rückgang der Zahl der Beschäftigten - z.B. demographisch bedingt oder aufgrund von Arbeitslosigkeit - wirken sich negativ auf die Bemessungsgrundlage aus und führen selbst bei moderat steigenden Leistungsausgaben zu einem Beitragssatzanstieg. Diese Zusammenhänge werden in den Abschnitten 4.3.2 Abhängigkeit von der Versichertenstruktur (S. 55) und 4.3.3 Abhängigkeit vom Arbeitsmarkt (S. 58) näher untersucht.

\footnotetext{
${ }^{63}$ Vgl. Burger, S.; Funk, L.; Jobelius, H.-J. (1994), S. 151. Siehe auch Kapitel III.2 Einflüsse auf die Ausgabenseite, S. 91. 
Durch die Koppelung der Beiträge an das Arbeitseinkommen oder ein dies ersetzendes Einkommen (Sozialtransfers oder Rentenzahlungen) beeinträchtigen zudem Reformen in anderen Zweigen der Systeme zur sozialen Sicherung die Einnahmen der GKV. In Abschnitt 4.4 Fremdbelastungen (S. 65) wird deshalb insbesondere auf die Auswirkungen der sogenannten Hartz-Gesetze und Änderungen in der GRV eingegangen. Außerdem werden die Folgen der Deutschen Einheit für die Finanzen der GKV betrachtet.

Der Frage, ob die Ursache für den zu beobachtenden Beitragssatzanstieg in der GKV auf der Einnahmen- oder Ausgabenseite liegt, wird in Abschnitt 4.5 Kostenexplosion oder Erosion der Bemessungsgrundlage (S. 72) nachgegangen.

\subsection{Verteilungswirkungen}

\subsubsection{Ex post und ex ante Verteilungswirkungen}

$\mathrm{Da}$ in der GKV kein Zusammenhang zwischen dem Beitrag des Versicherten und der von inm in Anspruch genommenen Versicherungsleistung besteht, kommt es zu vielfältigen Verteilungswirkungen. Wie in jedem Versicherungssystem findet auch in der GKV ex post eine Umverteilung von schadensfrei gebliebenen zu geschädigten Versicherten statt. Diese versicherungsimmanente Umverteilung entsteht, weil auch bei gleicher Krankheitswahrscheinlichkeit individuell unterschiedlich hohe Krankheitskosten anfallen. ${ }^{64}$ Die Personen, die hohe Behandlungskosten haben, sind Umverteilungsgewinner; Gesunde hingegen tendenziell Verteilungsverlierer. Ex post Verteilungswirkungen liegen im Wesen einer Versicherung und sind keine Besonderheit der GKV.

Anders sieht dies bei einer ex ante Betrachtung aus: ${ }^{65}$ Beim Vergleich von erwarteten Kosten und erwarteten Beiträgen ergeben sich aus ökonomischer Sicht Verteilungseffekte in der GKV, die weit über die versicherungsimmanenten hinausgehen. Diese Umverteilungseffekte werden in der Literatur vorwiegend mit Hilfe von risikoäquivalenten Prämien quantifiziert. ${ }^{66} \mathrm{Im}$ Folgenden werden drei Verteilungswirkungen unterschieden. Das sind zum einen intragenerative (innerhalb einer Generation) und intergenerative (zwischen verschiedenen Generationen) Verteilungswirkungen im Rahmen einer zeitpunktbezogenen Querschnittsanalyse. Zum anderen werden die intertemporalen Effekte untersucht, indem über einen Zeitraum die Verteilungswirkungen im Lebenszyklus einer Alterskohorte betrachtet werden (Längsschnittsanalyse) ${ }^{67}$ Anschließend werden die Ergebnisse dieser Längsschnittsanalyse mit der Querschnittsbetrachtung verknüpft und Umverteilungseffekte zwischen Alterskohorten im Zeitverlauf durch Generationenkonten quantifiziert.

${ }^{64}$ Vgl. Dudey, S. (1996), S. 53.

${ }^{65}$ Zur Problematik der Trennung von ex ante und ex post Umverteilungen siehe Andel, N. (1975), S. $42 f$.

${ }^{66}$ Vgl. Brümmerhoff, D. (1991), S. 189f. Der SVR (2005), Ziff. 495, Kasten 13, sieht den Ausgleich zwischen niedrigen und hohen Gesundheitsrisiken als sozialversicherungstypisch an und nimmt daher als Vergleichsmaßstab ein System mit pauschalen Beiträgen.

${ }^{67}$ In Anlehnung an Schulenburg, J.-M. Graf von der (1989a), S. 358f.; Schulenburg, J.-M. Graf von der (1987), S. 122f. Zur Querschnitts- und Längsschnittsanalyse siehe Schmähl, W. (1989), S. 317f.; Schmähl, W. (1983b), S. $7 f f$. 
Abbildung 3: Verteilungsanalyse

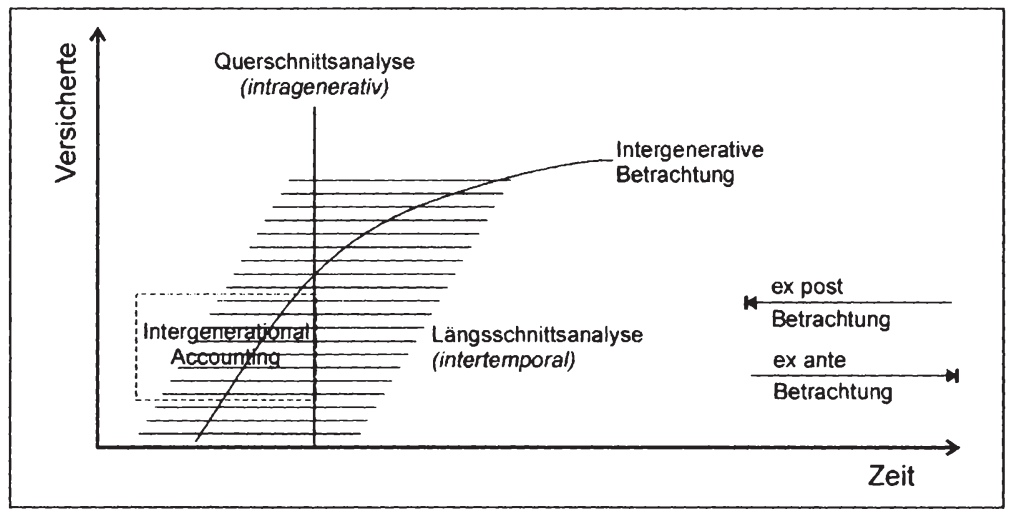

Quelle: In Anlehnung an Schulenburg, J.-M. Graf von der (1988), S. 208.

Abbildung 3 gibt einen Überblick über diese im Folgenden angewandten Verteilungsanalysen. Dabei steht ein horizontaler Strich für die Betrachtung der Lebensspanne eines Individuums, der senkrechte Strich zeigt, dass verschiedene Individuen zu einem Zeitpunkt verglichen werden. Der gestrichelte Kasten visualisiert die Kombination aus Querschnitts- und Längsschnittsbetrachtung in Generationenkonten.

\subsubsection{Intragenerative Inzidenz}

Die Einkommensbezogenheit der Beiträge führt zu intragenerativen Verteilungswirkungen innerhalb einer Generation in Form eines Risiko- und Einkommensausgleichs. Dieser Ausgleich bleibt allerdings beschränkt auf die in der GKV Versicherten. Bezieher von Einkommen oberhalb der Versicherungspflichtgrenze und damit besonders Einkommensstarke bzw. Leistungsfähige können sich der Umverteilung in der GKV durch die Wahl einer privaten Krankenversicherung entziehen. Damit wird der Versicherungsmarkt ökonomisch kaum begründbar getrennt und adverse Selektion gefördert: Ein Versicherter, der die Möglichkeit zum Wechsel in die PKV hat, wird sich aus rationalen Gründen nur für den Verbleib in der GKV entscheiden, wenn er daraus einen individuellen Vorteil erwartet. Deshalb ist davon auszugehen, dass freiwillig in der GKV Versicherte - also Bezieher hoher Einkommen - i.d.R. zu den Umverteilungsgewinnern in der GKV zählen. Dies gilt z.B. für Personen mit hohem Krankheitsrisiko, die in der PKV auch bei gleicher Versicherungsleistung eine höhere Prämie zu zahlen hätten, oder für Versicherte mit Familienangehörigen, die in der GKV beitragsfrei mitversichert sind, für die in der PKV aber Versicherungsprämien zu zahlen wären. ${ }^{68}$ Diese Subventionierungsthese, nach der die Pflichtversicherten die freiwillig Versicherten subventionieren, wird jedoch kontrovers diskutiert und ist bislang empirisch nicht eindeutig belegt. ${ }^{69}$

\footnotetext{
${ }^{68}$ Vgl. Wigger, B.U. (2004), S. $201 \mathrm{f}$.

${ }^{69}$ Vgl. Hagist, C.; Raffelhüschen, B. (2004), S. 195ff.Marco Penske - 978-3-631-75223-4 
Im Jahr 2004 sind 297.700 GKV-Mitglieder in die PKV und 130.600 Mitglieder aus der PKV in die GKV gewechselt. ${ }^{70}$ Aus einfachen Kostenvergleichen, nach denen die PKV rund 1.444 Euro p.a. pro Versicherten ausgibt, die GKV aber 1.860 Euro p.a. ${ }^{71}$, lässt sich indes keine schlechtere Risikostruktur der GKV-Versicherten ableiten. Berücksichtigt ist bei diesem Vergleich der Pro-Kopf-Ausgaben zwar, dass beide Versicherungssysteme auf unterschiedlichen Leistungskatalogen aufbauen - die gesamten Pro-Kopf-Ausgaben der in der PKV Vollversicherten betrugen im Jahr 2003 sogar 2.544 Euro. ${ }^{72}$ Die Leistungen in der PKV werden aber größtenteils mit dem 2,3fachen des Gebührensatzes (Regelhöchstsatz) abgerechnet. ${ }^{33}$ Nach einer Schätzung $^{74}$ anhand von Daten des Sozioökonomischen Panels entfallen im Durchschnitt $60 \%$ der Ausgaben der PKV auf einen der GKV vergleichbaren Leistungskatalog, $15 \%$ sind auf Wahlleistungen und $25 \%$ auf die höhere Vergütung im ambulanten Bereich zurückzuführen. Zudem ist rund die Hälfte der PKV-Versicherten beihilfeberechtigt, so dass der Staat einen Teil der Behandlungskosten übernimmt. Empirische Untersuchungen zeigen jedoch, dass PKV-Versicherte im Durchschnitt ein niedrigeres Krankheitsrisiko und eine geringere Leistungsinanspruchnahme aufweisen als Versicherte in der GKV. PKV-Versicherte in einem Alter zwischen 30 und 40 Jahren - die Altersgruppe, in der die meisten Wechsel in die PKV stattfinden, verursachen um rund ein Drittel niedrigere Ausgaben als Versicherte der gleichen Altersgruppe in der GKV. ${ }^{75}$ Das bestätigt die Vermutung, vor allem gute Risiken würden sich in der PKV versichern. Jüngere erzielen i.d.R. kein beitragspflichtiges Einkommen oberhalb der Versicherungspflichtgrenze und für Ältere und Personen mit schlechtem Gesundheitszustand ist die Prämie i.d.R. unattraktiv. Hinzu kommen überdurchschnittlich hohe Einkommen der Versicherten in der PKV. Die gegenwärtige Regelung führt also tendenziell zu einer Risikoentmischung zulasten der GKV. Da Leistungserbringer die gleiche Leistung bei einem Privatkassenpatienten zu einem höheren Preis abrechnen können als bei einem GKV-Patienten, steht dem jedoch eine indirekte Quersubventionierung von der PKV zur GKV gegenüber. Nach Angaben der PKV beläuft sich diese Quersubventionierung auf jährlich 5 bis 6 Mrd. Euro. $^{76}$

Innerhalb der GKV existiert ein ex ante Ausgleich der Risiken von Versicherten mit hohen erwarteten Gesundheitsausgaben und Versicherten mit niedrigerem Risiko, da der GKV-Beitrag unabhängig vom individuellen Erkrankungsrisiko ist. Hinzu kommen Einkommensumverteilungen: Bis zur Beitragsbemessungsgrenze findet ein vertikaler Ausgleich zwischen Versicherten mit hohem Einkommen zu Versicherten mit niedri-

\footnotetext{
${ }^{70}$ Siehe Verband der privaten Krankenversicherung e.V. (Hrsg.) (2005), S. 14.

${ }^{71}$ Vgl. o.V. (2004a), S. 7.

${ }^{72}$ Siehe Niehaus, F.; Weber, C. (2005), S. 35.

${ }^{73} \mathrm{Vgl}$. ausführlich Verband der privaten Krankenversicherung e.V. (Hrsg.) (2005), S. $66 f$.

${ }^{74}$ Siehe Schräder, W.F.; Sehlen, S.; Hofmann, J. (2004), S. 9.

${ }^{75} \mathrm{Vgl}$. Lüngen, M. u.a. (2005), S. 25ff.; Lauterbach, K.W. U.a. (2005), S. 73; Rürup-Kommission (2003), S. 151ff.

${ }^{76}$ Vgl. Schulte, R. (2004), S. 10; Zipperer, M. (2003a), S. 17. Siehe hierzu auch SVR (2002), Ziff. 513. Jüngste Berechnungen von Niehaus, F.; Weber, C. (2005), S. 20ff., 46, für die PKV ermitteln eine Quersubventionierung von 8,5 Mrd. Euro im Jahr 2003. Allerdings sind hierin auch höhere Zahlungen der PKV für aufwendigere Behandlungen von privat Versicherten und für Leistungen der PKV, die der GKV-Leistungskatalog nicht abdeckt, enthaltelarco Penske - 978-3-631-75223-4
} 
gerem Einkommen statt. Außerdem werden nicht erwerbstätige Familienangehörige beitragsfrei mitversichert und somit Familien zulasten Lediger und Kinderloser in der GKV subventioniert (Familienlastenausgleich). ${ }^{77}$ Insgesamt werden durch die Familienversicherung und den Einkommensbezug der Beiträge in der GKV rund $40 \mathrm{Mrd}$. Euro jährlich umverteilt. ${ }^{78}$ Damit nimmt die GKV neben ihrer eigentlichen Versicherungsfunktion (Allokation) auch eine Umverteilungsaufgabe (Distribution) wahr, deren Verteilungsströme allerdings kaum noch messbar und nicht zielgenau sind: $\mathrm{Da}$ die GKV einen Risiko- und Einkommensausgleich vornimmt, subventioniert z.B. ein gesundes Individuum, das nur über ein relativ niedriges Einkommen verfügt, einen Wohlhabenderen, der unter gesundheitlichen Beeinträchtigungen leidet. ${ }^{79}$

\section{Abbildung 4: Durchschnittliche Beitragsbelastung in der GKV im Jahr 2004}

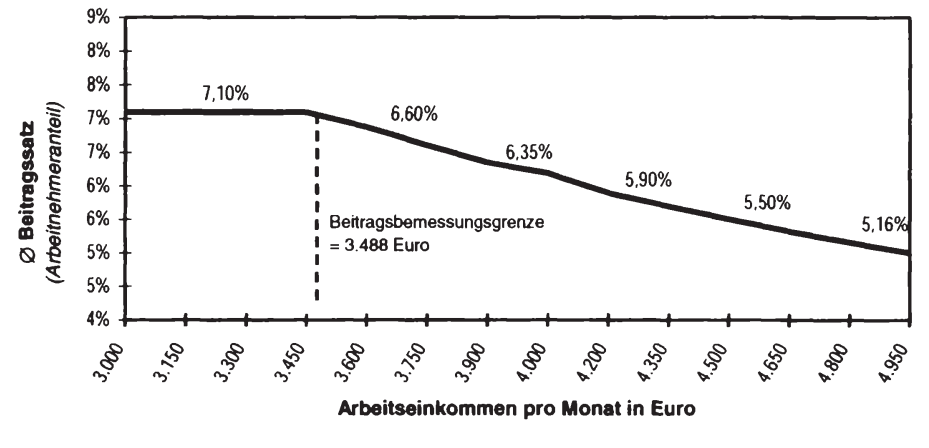

Quelle: Eigene Darstellung und eigene Berechnungen mit einem Beitragssatz von 14,2 \% (paritätisch finanziert) und der Beitragsbemessungsgrenze von 3.488 Euro im Jahr 2004.

Auch der Einkommensausgleich führt zu ungewünschten Ergebnissen. Um die Belastung für die Versicherten mit hohem Einkommen zu begrenzen und den Steuercharakter zu schwächen, werden die Beiträge nur bis zur Höhe der Beitragsbemessungsgrenze erhoben; der Grenzabgabensatz beträgt ab hier Null. Für Versicherte, deren Einkommen über dieser Grenze liegt, führt dies dazu, dass die durchschnittliche Belastung bei wachsendem Gesamteinkommen sinkt, so dass ab der Beitragsbemessungsgrenze die Beitragszahlung regressiv wirkt, wie Abbildung 4 zeigt. $^{80}$

Nimmt man die Werte für 2004, dann beträgt die durchschnittliche Beitragsbelastung bis zu einem Arbeitseinkommen von 3.488 Euro pro Monat $14,2 \%$. Bei einem abhängig Beschäftigten zahlt der Arbeitgeber die Hälfte, für den Versicherten wird sein beitragspflichtiges Einkommen bis zur Beitragsbemessungsgrenze mit 7,1\%

\footnotetext{
${ }^{7}$ Siehe hierzu SVR KAiG (1998), Ziff. 562ff.; SVR KAiG (1987), Ziff. 162; Beske, F.; Zalewski, T. (1984), S. 62ff.

${ }^{78}$ Vgl. Henke, K.-D. (2001), S. 10ff.; Schneider, W. (2003), S. 45; SVR (2005), Tabelle 39. Zu den Umverteilungsströmen zwischen einzelnen Versichertengruppen siehe SVR (2005), Ziff. 487ff.

${ }^{79}$ Vgl. Zweifel, P.; Breuer, M. (2002), S. 45.

${ }^{80}$ Vgl. Brümmerhoff, D. (1991), S. 193; Andel, N. (1975) S. 73:
} 
belastet. Oberhalb der Beitragsbemessungsgrenze sinkt die Durchschnittsbelastung z.B. bei einem Einkommen von 4.000 Euro auf $6,20 \%$. Da die Leistungsfähigkeit mit zunehmendem Einkommen steigt, beide Versicherte aber trotz ihres unterschiedlichen Einkommens den gleichen Arbeitnehmeranteil von 247,65 Euro zahlen, wird gegen den Grundsatz der vertikalen Gerechtigkeit und das Leistungsfähigkeitsprinzip verstoßen. ${ }^{81}$ Dieses verlangt, dass Individuen mit gleicher Leistungsfähigkeit gleich hohe Beiträge (horizontale Gerechtigkeit), Individuen mit unterschiedlicher Leistungsfähigkeit unterschiedlich hohe Beiträge zahlen (vertikale Gerechtigkeit).

Abbildung 5: Einkommensverteilung und Beitragszahlung

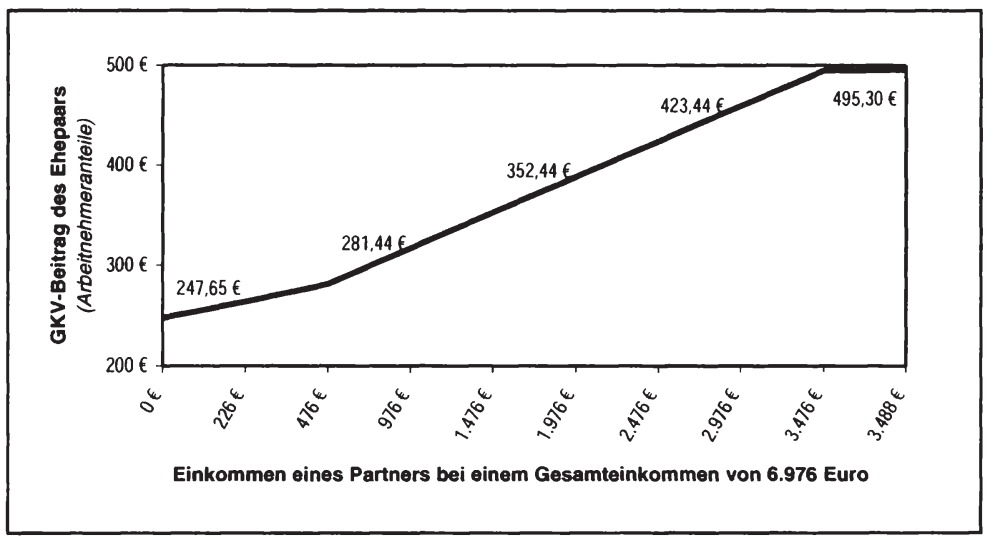

Quelle: Eigene Darstellung und eigene Berechnungen mit einem Beitragssatz von 14,2\% (paritätisch finanziert) und der Beitragsbemessungsgrenze von 3.488 Euro im Jahr 2004.

Die beitragsfreie Mitversicherung eines nicht erwerbstätigen Ehepartners und die Beitragsbemessungsgrenze können zudem zu unterschiedlichen Beitragsbelastungen bei gleich hohen Familieneinkommen und damit zu einem Verstoß gegen den Grundsatz der horizontalen Gerechtigkeit führen. Denn wenn das Einkommen eines Ehepartners oberhalb der Beitragsbemessungsgrenze liegt, hängt der von den Versicherten zu zahlende Beitrag, wie das Beispiel in Abbildung 5 zeigt, von der Verteilung der Einkommen zwischen den Ehepartnern ab.

Begünstigt werden grundsätzlich Ehepaare, bei denen das Arbeitseinkommen eines Partners oberhalb der Beitragsbemessungsgrenze liegt. Im Extremfall zahlt, wie Tabelle 2 zeigt, ein Ehepaar, bei dem beide Partner ein individuelles Arbeitsentgelt in Höhe der Beitragsbemessungsgrenze erzielen, einen doppelt so hohen Beitrag wie ein Alleinverdiener-Ehepaar mit gleichem Gesamteinkommen ${ }^{82}$ Im Jahr 2004 beträgt diese monatliche Beitragsdifferenz 247,65 Euro, mit Arbeitgeberanteil das Doppelte. Auch die Beschränkung der Beitragserhebung auf das Arbeitsentgelt widerspricht dem Leistungsfähigkeitsprinzip, da dieses stets auf das Gesamteinkommen und nicht

${ }^{81}$ Vgl. SVR KAiG (1994), Ziff. 482 .

${ }^{82}$ Vgl. Andel, N. (1975), S. 75; SVR KAiG (1994), Ziff. 475f. Siehe auch Institut der deutschen Wirtschaft (Hrsg.) (2002), S. 5. 
auf eine einzige Einkunftsart abstellt. Je mehr die nicht sozialversicherungspflichtigen Einkünfte (vor allem Kapitaleinkünfte) an Bedeutung gewinnen, desto stärker subventionieren Mitglieder mit niedrigerer Leistungsfähigkeit diejenigen mit höherer. ${ }^{83}$

Tabelle 2: Einkommensverteilung und Beitragsbelastung

\begin{tabular}{|l|r|r|r|}
\hline & Partner A & Partner B & \multicolumn{1}{c|}{ Haushalt } \\
\hline Arbeitsentgelt & $6.976,00 €$ & - & $6.976,00 €$ \\
Arbeitnehmerbeitrag GKV & $247,65 €$ & - & $247,65 €$ \\
\hline Arbeitsentgelt & $3.488,00 €$ & $3.488,00 €$ & $6.976,00 €$ \\
Arbeitnehmerbeitrag GKV & $247,65 €$ & $247,65 €$ & $495,30 €$ \\
\hline Arbeitsentgelt & $5.000,00 €$ & - & $5.000,00 €$ \\
Arbeitnehmerbeitrag GKV & $247,65 €$ & - & $247,65 €$ \\
\hline Arbeitsentgelt & $3.488,00 €$ & $1.512,00 €$ & $5.000,00 €$ \\
Arbeitnehmerbeitrag GKV & $247,65 €$ & $107,35 €$ & $355,00 €$ \\
\hline
\end{tabular}

Quelle: Eigene Berechnungen mit einem unterstellten Beitragssatz von 14,2\% (paritätisch finanziert) und einer Beitragsbemessungsgrenze von 3.488 Euro im Jahr 2004.

Der allgemein akzeptierten Annahme, dass der Unterhalt von Kindern die Leistungsfähigkeit einer Familie mindert, entspricht die beitragsfreie Mitversicherung von Kindern. Dennoch kann die Familienversicherung durch die oben beschriebene Beitragsbemessung zu unerwünschten Verteilungsergebnissen führen; z.B. dann, wenn ein Spitzenverdiener mit nicht erwerbstätiger Ehefrau und zwei Kindern einen geringeren Beitrag zahlt als ein berufstätiges Ehepaar mit ebenfalls zwei Kindern, aber mit Arbeitseinkommen jeweils in Nähe der Beitragsbemessungsgrenze. ${ }^{84}$ Infolge des demographischen Wandels sinkt die Anzahl der Kinder, womit gleichzeitig der Anteil an Kinderlosen steigt, die aber gerade wegen dieser Umverteilung in der GKV schlechter gestellt sind als im Referenzsystem PKV. Die Zahl der Umverteilungsgewinner in der GKV und damit auch die Akzeptanz des ganzen Systems könnten sinken. ${ }^{85}$ Hinzu kommt, dass auch Familien - die eigentlichen Umverteilungsgewinner - durch steigende Beitragssätze für das jeweils enwerbstätige Familienmitglied zunehmend zur Mitfinanzierung der Krankenversicherung der Rentner herangezogen werden. ${ }^{86} \mathrm{Um}$ diese Zusammenhänge zu verdeutlichen, werden im Folgenden die intergenerativen Umverteilungseffekte zwischen verschiedenen Generationen betrachtet.

\subsubsection{Intergenerative Inzidenz}

Die in der GKV praktizierte Umlagefinanzierung führt zu einer intergenerativen Umverteilung von Erwerbstätigen zu Rentnern; denn trotz ihrer im Durchschnitt höheren

${ }^{83}$ Vgl. Kruse, U.; Kruse, S. (2001), S. 92. Auf die Verteilungseffekte zwischen PKV und GKV-Versicherten wird in diesem Zusammenhang nicht weiter eingegangen; siehe hierzu Wenzel, D. (1999), S. 41ff.; Dudey, S. (1996), S. 58.

${ }^{84}$ Vgl. Braun, B.; Kühn, H.; Reiners, H. (1998), S. 104f.; Greisler, P. (2002), S. 15; Wille, E. (2002a), S. 263

${ }^{85}$ Vgl. Berthold, N. (1991), S. 166. Zu dem mit dem demographischen Wandel verbundenen politökonomischen Aspekt siehe Breyer, F.; Schulenburg, J.-M. Graf von der (1987a), S. 66ff.; Breyer, F.; Schulenburg, J.-M. Graf von der (1987b), S. 532ff.

${ }^{86}$ Vgl. Schulenburg, J.-M. Graf von der (1989a), S. 369arco Penske - 978-3-631-75223-4 
Behandlungskosten zahlen ältere Versicherte keine entsprechend höheren Beiträge. Die durchschnittliche Rente wegen Alters für einen Mann in Westdeutschland betrug im Jahr 2003 monatlich 879 Euro $^{87}$, während der durchschnittliche monatliche Bruttolohn bei 2.415 Euro $^{88} \mathrm{lag}$. Rentner zahlen daher einen deutlich geringeren durchschnittlichen Beitrag als Erwerbstätige. Diese intergenerative ${ }^{89}$ Umverteilung folgt dem gedanklichen Konstrukt des Generationenausgleichs, nach dem die erwerbstätige, junge Generation durch ihre Beiträge teilweise die Kosten der nicht mehr erwerbstätigen, älteren Versicherten mitträgt. ${ }^{90}$

Tabelle 3: Beiträge und Ausgaben für Mitglieder und Rentner 1992-2004

\begin{tabular}{|c|c|c|c|c|c|c|c|c|c|}
\hline (in Euro) & 1992 & 1994 & 1996 & 1998 & 2000 & 2001 & 2002 & 2003 & 2004 \\
\hline \multicolumn{10}{|l|}{ AKV } \\
\hline Beitrag p & 269 & 619 & 742 & 2.833 & 2.950 & 2.995 & 3.118 & 184 & 3.18 \\
\hline Ausgaben pro Kopf ${ }^{1 /}$ & 1.632 & 1.768 & 1.938 & 1.895 & 1.944 & 2.017 & 2.041 & 2.058 & 1.96 \\
\hline Saldo & 637 & 851 & 804 & 938 & 1.006 & 978 & 1.077 & 126 & 1.2 \\
\hline Beiträge i & 82,9 & 94,1 & 98,1 & 100,4 & 105,4 & 106,9 & 108,4 & 108,5 & 107 \\
\hline Ausgaben in Mrd. & 59,6 & 63,5 & 69,3 & 67,2 & 69,5 & 72,0 & 70,9 & 70,1 & 66 \\
\hline Saldo in & 23,3 & 30,6 & 28,8 & 33,2 & 35,9 & 34,9 & 37,4 & 38,4 & \\
\hline Deckungsquote & $39,0 \%$ & $148,2 \%$ & $141,5 \%$ & $149,5 \%$ & $151,7 \%$ & $148,5 \%$ & $152,8 \%$ & $154,8 \%$ & 162,5 \\
\hline \multicolumn{10}{|l|}{ KVdR } \\
\hline Beitrag pro & 1.137 & 395 & 1.456 & 1.553 & 1.609 & 1.633 & 1.717 & 792 & 1.92 \\
\hline Ausgaben pro Kopf ${ }^{1)}$ & 2.946 & 3.217 & 3.386 & 3.451 & 3.690 & 3.832 & 3.907 & .963 & 3.85 \\
\hline Saldo & -1.809 & -1.822 & -1.931 & -1.898 & -2.080 & -2.199 & -2.190 & -2.171 & -1.93 \\
\hline Beiträg & 16,3 & 20,5 & 21,9 & 23,6 & 24,6 & 25,0 & 27,9 & 29,9 & \\
\hline Ausgaben & 42,1 & 47,2 & 51,0 & 52,5 & 56,5 & 58,7 & 63,4 & 66,1 & 64 \\
\hline Saldo in Mrd. & $-25,9$ & $-26,7$ & $-29,1$ & $-28,9$ & $-31,8$ & $-33,7$ & $-35,6$ & $-36,2$ & -32 \\
\hline Deckungsquote & $38,6 \%$ & $43,4 \%$ & $43,0 \%$ & $45,0 \%$ & $43,6 \%$ & $42,6 \%$ & $43,9 \%$ & $45,2 \%$ & $49,8^{\circ}$ \\
\hline
\end{tabular}

1) Ohne Verwaltungskosten; inklusive Ausgaben für beitragsfrei mitversicherte Familienangehörige.

Quelle: Eigene Berechnungen; vgl. BMGS (Hrsg.) (2005a), S. $1 f$.

Die Deckungsquote gibt das Verhältnis von Beiträgen zu Ausgaben einzelner Versichertengruppen an. Auch wenn im gesamten Bundesgebiet die Deckungsquote in der KVdR von 38,6\% im Jahr 1992 auf 49,8\% im Jahr 2004 gestiegen ist, ist über einen längeren Zeitraum betrachtet die Quote deutlich gesunken. Im Jahr 1950 lag die Deckungsquote in Westdeutschland noch bei $112,7 \%$, sank dann aber bis auf 44,5\% im Jahr 2003 ab. Entsprechend umgekehrt ist der Verlauf der Deckungsquote für die allgemeine Krankenversicherung (AKV). In Westdeutschland stieg die Deckungsquote von $114,8 \%$ im Jahr 1950 kontinuierlich auf 154,8 \% im Jahr 2003 an. ${ }^{91}$ Für das gesamte Bundesgebiet lag sie im Jahr 2004 bei 162,5\%. Wie die absoluten

\footnotetext{
${ }^{87}$ Vgl. Verband Deutscher Rentenversicherungsträger (Hrsg.) (2004a), S. 46.

${ }^{88}$ Vgl. Verband Deutscher Rentenversicherungsträger (Hrsg.) (2004a), S. 29; eigene Berechnung.

${ }^{89}$ Die Begriffe intergenerativ und intergenerational werden synonym verwendet.

${ }^{90}$ Vgl. Berthold, N. (1991), S. 164; Schulenburg, J.-M. Graf von der (1989a), S. 347; Schulenburg, J.M. Graf von der; Kleindorfer, P.R. (1986), S. 413. Genau genommen handelt es sich um einen Dreigenerationenvertrag, da auch Kinder beitragsfrei mitversichert sind; vgl. Schulenburg, J.-M. Graf von der (1989b), S. 284.
}

${ }^{91}$ Vgl. Berié, H.; Fink, U. (2003), S. 57f.; eigene Berec/nungep.enske - 978-3-631-75223-4 
Beträge in Tabelle 3 zeigen, zahlte ein Rentner im Jahr 2004 im Durchschnitt einen Beitrag von 1.921 Euro p.a., verursachte allerdings inklusive der Ausgaben für beitragsfrei mitversicherte Familienangehörige Leistungsausgaben in Höhe von 3.854 Euro. Die Differenz wurde von den Mitgliedern in der AKV aufgebracht. Diese zahlten im Jahr 2004 durchschnittlich einen Beitrag von 3.189 Euro, während sie und inre Familienangehörigen Leistungen in Höhe von 1.963 Euro in Anspruch nahmen. Insgesamt überstieg die Beitragszahlung der AKV-Mitglieder deren Ausgaben im Jahr 2004 um 41,5 Mrd. Euro, während die KVdR mit 32,5 Mrd. Euro subventioniert wurde.

Bei diesem Vergleich muss allerdings berücksichtigt werden, dass es auch innerhalb der Generation der inrem Alter nach Erwerbstätigen Rentner gibt, die statistisch in der KVdR geführt werden. Ausgaben für junge Rentner, die ihrem Alter nach der Gruppe der Erwerbstätigen zuzuordnen wären, werden also der Gruppe der Rentner zugerechnet. Folglich wird der Transfer in Tabelle 3, den die junge Generation an die ältere zahlt, tendenziell zu hoch ausgewiesen.$^{92}$ Zudem werden bei dieser Betrachtungsweise außerhalb der GKV stattfindende Transfers ausgeblendet. Untersuchungen zeigen, dass monetäre Leistungen z.B. in Form von Schenkungen und Erbschaften im Wesentlichen von den Älteren zu den Jüngeren fließen. Z.B. leisten $24,2 \%$ der 70- bis 85 jährigen monetäre Transfers an ihre Kinder, aber nur 2,9\% erhalten Geld- oder Sachgeschenke von ihren Kindern. ${ }^{93}$

Im derzeitigen Finanzierungssystem werden die Erwerbstätigen in Zukunft wegen der Alterung der Bevölkerung noch stärker die Rentnerbeiträge subventionieren. Die intergenerationale Umverteilung in der GKV wird steigen.$^{94}$ Verstärkt wird diese Umverteilung zusätzlich, weil Rentner nur den halben Beitragssatz zahlen. Die andere Hälfte - vergleichbar dem Arbeitgeberanteil bei abhängig Beschäftigten - wird nach $\S 249 a$ SGB V von der GRV übernommen, deren Ausgaben wiederum im Umlageverfahren von den Erwerbstätigen und somit größtenteils von der jungen Generation finanziert werden. Der demographisch bedingte Beitragssatzanstieg belastet die erwerbstätige Bevölkerung daher im Vergleich zu den Rentnern überproportional. ${ }^{95}$

\subsubsection{Intertemporale Inzidenz}

Die bisherige Betrachtung intergenerativer Verteilungsvorgänge zu einem Zeitpunkt (Querschnittsanalyse) berücksichtigt nicht, dass die Versicherten im Laufe ihres Lebens verschiedene Phasen durchlaufen. Über den Lebenszyklus gesehen (Längsschnittsanalyse) folgen auf Phasen mit unterdurchschnittlichen Ausgaben aber überdurchschnittlichen Beiträgen, solche mit überdurchschnittlichen Ausgaben und unterdurchschnittlichen Finanzierungsbeiträgen. ${ }^{96}$ Über ihre gesamte Lebenszeit gesehen zahlen Versicherte im mittleren Lebensabschnitt tendenziell höhere Beiträge als sie

\footnotetext{
${ }^{92}$ Siehe hierzu die Aussagen von Raible in Schulenburg, J.-M. Graf von der (1989a), S. 375.

${ }^{93}$ Vgl. Kohli, M. u.a. (2000a), S. 194f.; Kohli, M. u.a. (2000b), S. 53ff.; Friske, C.; Friske, H.-J. (2003), S. 3ff.

${ }^{94}$ Vgl. Fetzer, S.; Raffelhüschen, B. (2002), S. 6f.; Schulenburg, J.-M. Graf von der (1989a), S. 348; SVR KAiG (1987), Ziff. 145, 163.

${ }^{95}$ Vgl. Dudey, S. (1996), S. 28; Erbsland, M. (1995), S. 24f.; Erbsland, M.; Wille, E. (1995), S. 679.

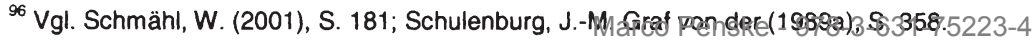


Leistungen in Anspruch nehmen, dafür liegen die im Kindes- und Rentenalter durch sie verursachten Ausgaben über den Beiträgen. ${ }^{97}$ Ökonomisch betrachtet zahlt ein junger Versicherter mehr ein als es seinem altersäquivalenten Risiko entspricht und enwirbt auf diese Weise (fiktive) Forderungen gegenüber der nächsten Generation. Diese Forderungen werden im Alter eingelöst, wenn der Versicherte mehr Leistungen in Anspruch nimmt und dafür einen nicht altersäquivalenten Beitrag entrichtet. ${ }^{98}$

Weil keine versichertenbezogenen Längsschnittsdaten über Beiträge und Leistungsausgaben der Versicherten in der GKV vorliegen, werden anhand eigener Berechnungen aus Querschnittsdaten "Quasi-Längsschnittsdaten“ zur Betrachtung des Lebenszyklus abgeleitet. ${ }^{99}$ Die Beiträge sind in der GKV aber nicht differenziert nach Altersjahrgängen erfasst, sondern nur nach zwei Altersklassen - erwerbstätigen Mitgliedern und Rentnern. Deshalb werden die durchschnittlichen Beiträge nach Einzelalter aus den für die GRV vorliegenden Daten ermittelt. Aus den beitragspflichtigen Jahresentgelten von versicherungspflichtig Beschäftigten nach der VDR Statistik Versicherte ${ }^{100}$ und aus den Rentenzahlungen nach der VDR Statistik Rentenbestand ${ }^{101}$ werden die durchschnittlichen beitragspflichtigen Einnahmen für die einzelnen Jahrgänge berechnet und mit dem durchschnittlichen Beitragssatz (2003: $14,3 \%)$ multipliziert. Auf der Einnahmenseite wird mit dieser Vorgehensweise das erzielte beitragspflichtige Jahresentgelt aus einer versicherungspflichtigen Beschäftigung, Vorruhestandsgeldbezug, Leistungsbezug nach SGB III (z.B. Arbeitslosengeld und Arbeitslosenhilfe) und sonstiger Leistungsbezug (Entgeltersatzleistungen wie z.B. Krankengeld, Verletztengeld und Übergangsgeld) berücksichtigt. Dabei werden für Leistungsbezieher nach SGB III und für sonstige Leistungsbezieher gemäß $\S 232 a$ SGB V $80 \%$ des der Leistung zugrunde liegenden Arbeitsentgelts angesetzt. Daneben fließen Renten wegen Alters, wegen verminderter Erwerbsfähigkeit und wegen Todes in die Berechnung der beitragspflichtigen Einnahmen mit ein. Betriebsrenten werden nicht berücksichtigt, da hierzu keine Daten gestaffelt nach Einzelalter vorliegen. Dies beeinflusst die Ergebnisse aber kaum; denn im Durchschnitt bestehen die Alterseinkommen zu $85 \%$ aus Zahlungen der GRV, $10 \%$ entfallen auf die private Altersvorsorge und lediglich $5 \%$ auf die betriebliche Altersvorsorge. ${ }^{102}$

Auf der Ausgabenseite werden die durchschnittlichen Leistungsausgaben für ärztliche Leistungen, zahnärztliche Behandlung, Arzneimittel, Krankenhausleistungen, sonstige Sachleistungen und Krankengeldleistungen ohne Verwaltungskosten aus vom Bundesversicherungsamt ${ }^{103}$ zur Verfügung gestellten Daten zum Risikostrukturausgleich (RSA) ermittelt. Zur Berechnung eines Durchschnitts über alle Versichertengruppen werden für jede Altersgruppe die RSA-Daten der sechs verschiedenen Versichertengruppen mit den entsprechenden Versichertentagen gewichtet. Da seit 2002 gemäß § 269 SGB V $60 \%$ aller Leistungsausgaben über 20.450 Euro p.a. für

\footnotetext{
${ }^{97}$ Vgl. Schulenburg, J.-M. Graf von der (1987), S. 122.

${ }^{98}$ Vgl. SVR KAiG (1998), Ziff. 564; SVR KAiG (1995), Ziff. 562.

${ }^{99}$ In Anlehnung an Fetzer, S.; Raffelhüschen, B. (2002), S. 4ff. Siehe hierzu auch Schmähl, W. (1983b), S. 14. Zu den datentechnischen Problemen siehe Simon, S. (2001), S. $255 \mathrm{f}$.

${ }^{100}$ Siehe Verband Deutscher Rentenversicherungsträger (Hrsg.) (2004b).

101 Siehe Verband Deutscher Rentenversicherungsträger (Hrsg.) (2004c).

102 Siehe Matthes, J.; Römer, C. (2005), S. 297.

${ }^{103}$ Siehe Bundesversicherungsamt (Hrsg.) (2004). Marco Penske - 978-3-631-75223-4
} 
einen Versicherten von einem gemeinsamen Risikopool aller Kassen finanziert werden, sind diese Ausgaben in den Ausgabenprofilen zunächst nicht enthalten. Um diese Kosten ebenfalls zu berücksichtigen, werden die Ausgabenprofile um die auch nach Alter erfassten Poolausgaben jeweils erhöht.

Abbildung 6: Beiträge und Leistungen in der GKV nach Alter im Jahr 2003

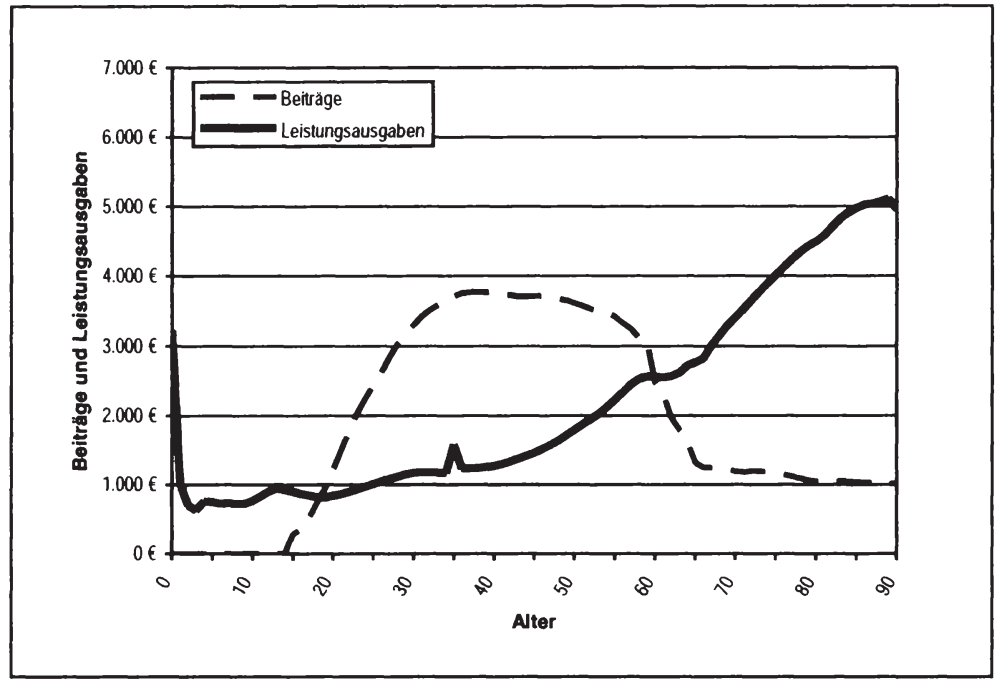

Quelle: Eigene Berechnungen in Anlehnung an Fetzer, S.; Raffelhüschen, B. (2002), S. 5ff.; siehe Tabelle 25: Beiträge und Leistungen der GKV nach Alter im Jahr 2003, im Anhang, S. 262.

Abbildung 6 stellt die altersspezifischen durchschnittlichen Zahlungsströme der Mitglieder in der GKV im Jahr 2003 dar. Der Ausschlag in der Ausgabenkurve beim 35. Lebensjahr ist darauf zurückzuführen, dass Versicherte mit einer Rente wegen Berufs- oder Erwerbsunfähigkeit, die jünger als 35 Jahre sind, statistisch als 35jährige im RSA erfasst werden. Da diese Versicherten besonders kostenintensiv sind, steigen statistisch die durchschnittlichen Kosten im RSA mit dem 35. Lebensjahr stark an und sinken mit dem 36. Lebensjahr wieder. Ähnliches gilt für die über 90jährigen Versicherten. Diese werden statistisch im RSA als 90jährige erfasst.

Wie Abbildung 6 zeigt, steigt die Summe der jährlichen Beitragszahlungen von Arbeitgeber oder Rentenversicherungsträger und GKV-Mitglied zwischen 15 und 35 Jahren von 300 Euro auf 3.700 Euro an und bleibt dann bis zu einem Alter von 50 Jahren annähernd auf einem Niveau von 3.600 Euro. Bis zum 56. Lebensjahr sinken die Beiträge auf 3.300 Euro. Beim statistischen Renteneintrittsalter von 60 Jahren betragen die Beiträge noch durchschnittlich 2.500 Euro und fallen bis zum 65. Lebensjahr auf 1.300 Euro stark ab. Bei einem Alter von 90 Jahren liegt der Jahresbeitrag noch bei knapp 1.000 Euro.

Ganz anders entwickelt sich die durchschnittliche Inanspruchnahme von Leistungen: Im ersten Lebensjahr liegen die durchschnittlichen Ausgaben in Höhe von 3.200 Euro noch relativ hoch, sinken auf 700 Euro im zweiten Lebensjahr und steigen allmäh-

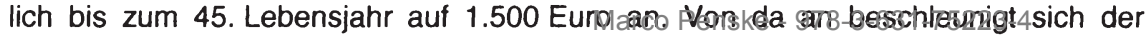


Ausgabenanstieg auf 2.600 Euro für einen 60jährigen, 3.400 Euro für einen 70jährigen und 4.500 Euro für einen 80jährigen Versicherten. Bis zu einem Alter von 90 Jahren steigen die durchschnittlichen Leistungsausgaben auf 5.000 Euro weiter an. Da für die über 90jährigen keine statistischen Datenerhebungen vorliegen, endet die Betrachtung mit dem 90. Lebensjahr.

Abbildung 7: Nettobeitrag an die GKV nach Alter im Jahr 2003

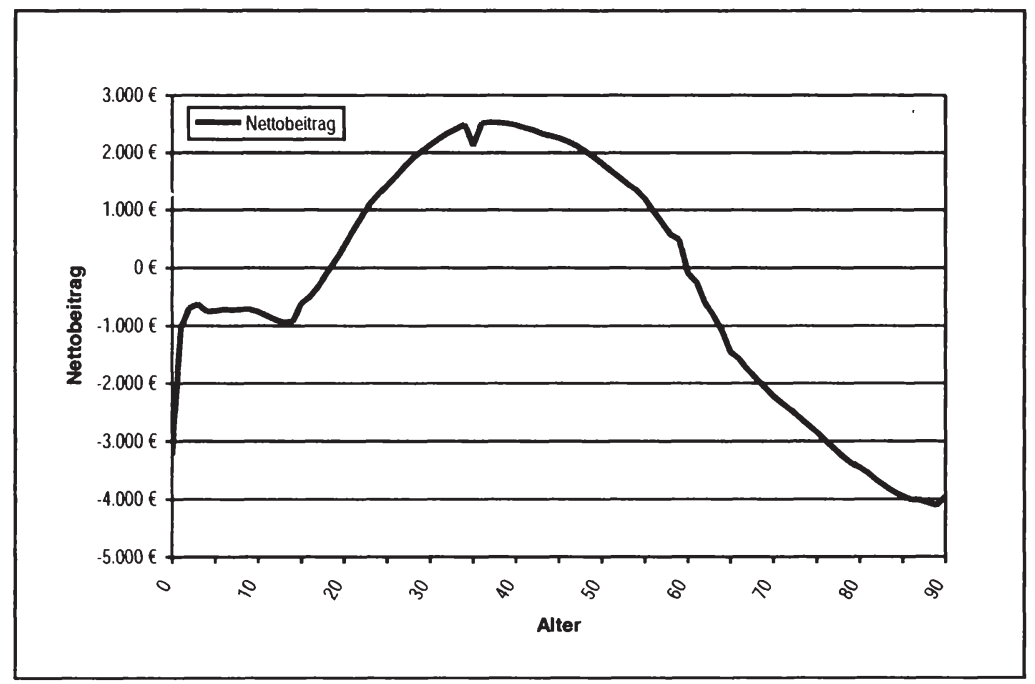

Quelle: Eigene Darstellung und eigene Berechnungen; siehe Tabelle 25: Beiträge und Leistungen der GKV nach Alter im Jahr 2003, im Anhang, S. 262.

Abbildung 7 fasst die Entwicklung der Beiträge und Leistungsausgaben in einer Darstellung der jährlichen Nettobeiträge (durchschnittliche Beiträge minus durchschnittliche Leistungsinanspruchnahme) aller GKV-Mitglieder in Abhängigkeit vom Alter zusammen. Während die 19- bis 59jährigen positive Nettobeiträge entrichten, liegt bei den anderen Jahrgängen die Leistungsinanspruchnahme über den Beiträgen. Im Maximum zahlt ein 37jähriger durchschnittlich einen jährlichen Nettobeitrag in Höhe von 2.529 Euro. Nach dem 60. Lebensjahr werden die Versicherten dann im Durchschnitt in zunehmendem Maße zu Nettoleistungsempfängern. Dieser Zusammenhang verdeutlicht auch die Abhängigkeit des Beitragssatzes von dem Verhältnis von Rentnern zu Erwerbstätigen.

Zur Beurteilung der intergenerationalen Inzidenz müssen aber auch die Auswirkungen der beitragsfreien Familienversicherung berücksichtigt werden. Die bisherige Betrachtung vergleicht die Beiträge eines Mitglieds mit seinen durchschnittlichen Ausgaben. Bei Berücksichtigung der Familienversicherung dürtten die Nettobeitragszahlungen der erwerbstätigen Bevölkerung geringer ausfallen; denn gerade in dieser Altersgruppe ist von einer höheren Zahl familienversicherter Kinder auszugehen, die keine Beiträge entrichten, aber vollen Leistungsanspruch haben. Für ein beitragszahlendes Mitglied kann dann je nach Anzahl der beitragsfrei Mitversicherten und deren Ausgaben der Status vom NettobeitragszahlenzumpNettodeistumgsemprängen wech- 
seln. Anhand der vorliegenden Daten können allerdings über die Auswirkungen der Familienversicherung nur diese Tendenzaussagen getroffen werden.

In der intertemporalen Betrachtungsweise können sich die Umverteilungen im Lebensverlauf unter bestimmten Bedingungen wieder ausgleichen. Das wäre der Fall, wenn u.a. kein Wirtschaftswachstum vorläge, im Zeitablauf sowohl die Anzahl der Versicherten in den verschiedenen Altersklassen als auch die durchschnittliche Lebenserwartung konstant wären, alle Versicherten identische Lebensläufe hätten und die Behandlungskosten in jedem Lebenszyklus konstant blieben. In dieser steady-state-Ökonomie würde es in der Längsschnittbetrachtung, wenn der Versicherte sein gesamtes Leben in der GKV versichert ist, über den ganzen Lebenszyklus gesehen zu keiner Umverteilung zwischen den Generationen kommen. Über den Lebenszyklus würden sich dann für jeden Geburtenjahrgang die Salden der während des ganzen Lebens gezahlten Beiträge und der empfangenen Leistungen ausgleichen. ${ }^{104}$ Übertragen in Abbildung 6 (S. 43) bedeutet dies, dass die Fläche zwischen Abszisse und Ausgabenkurve der Fläche zwischen Abszisse und Beitragskurve entsprechen müsste bzw. in Abbildung 7 (S. 44) das Integral der Funktion "Nettobeitrag" in den Grenzen von 0 bis 90 Null wäre.

Schon die oben aufgezählten Annahmen sind aber unrealistisch: Zum einen unterscheiden sich die Lebensläufe der Versicherten, zum anderen nehmen die Behandlungskosten im Zeitablauf zu. Insbesondere die demographische Alterung der Bevölkerung und die mit dem Alter tendenziell steigenden Gesundheitsausgaben sowie sinkende Beiträge führen $\mathrm{zu}$ wachsenden intergenerationalen Umverteilungen. ${ }^{105}$ Diese Belastung der jeweils Jungen nimmt im Laufe der Zeit zu. In ihren jungen Jahren muss eine Generation für die ältere Generation weniger aufbringen, als sie später als alte Generation von der dann jungen Generation an Leistungen erhält. ${ }^{106}$ Raffelhüschen schreibt, „dass praktisch jeder ab heute Geborene im Laufe seines Lebens wesentlich mehr aus der GKV herausbekommt als er je einzahlt“. ${ }^{107} \mathrm{Zu}$ diesem Ergebnis kommt man auch, wenn man die Nettobeiträge aus Abbildung 7 (S. 44) als Nettobeiträge eines im Jahr 2003 Geborenen im Laufe seines Lebens interpretiert und über alle Altersstufen aufsummiert. ${ }^{108}$ Für diesen im Jahr $2003 \mathrm{Ge}$ borenen ergibt sich dann selbst unter der Annahme, dass Leistungsausgaben und Beiträge sich zwar mit dem Alter ändern, aber ihre jeweilige Differenz im Zeitablauf konstant ist, bei einem Zinssatz von Null ein Lebensnettotransfer von 26.493 Euro, d.h. die Leistungsinanspruchnahme übertrifft die Beitragszahlungen um diesen Betrag. Mit anderen Worten: Ein im Jahr 2003 Geborener hinterlässt den nachkommenden Generationen eine Finanzierungslücke in Höhe von 26.493 Euro. Bei dieser Betrachtungsweise wird die Querschnittsanalyse mit der Längsschnittsanalyse kombiniert; es werden Querschnittsdaten im Zeitverlauf fortgeschrieben. Ähnliche Ansätze zur Quantifizierung der Ungleichbehandlung ganzer Generationen bieten das

\footnotetext{
${ }^{104}$ Vgl. Hauser, R. (2001), S. 39; Pimpertz, J. (2001), S. 173; Schulenburg, J.-M. Graf von der (1988), S. 209.

${ }^{105}$ Vgl. Schulenburg, J.-M. Graf von der (1988), S. 209f.; Fetzer, S.; Raffelhüschen, B. (2002), S. 7.

${ }^{106}$ Vgl. Breyer, F.; Zweifel, P.; Kifmann, M. (2005), S. 521f.; Buchner, F.; Wasem, J. (2000), S. 31.

${ }^{107}$ Zitiert nach Beise, M.; Hoffmann, A. (2002), S. 19.

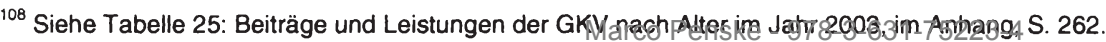


Konzept des Lebensnettotransfers und der Generationenbilanzierung (Generational Accounting).

\subsubsection{Generationenbilanzierung in der GKV}

Mit dem Konzept des Lebensnettotransfers entwickelten Schulenburg und Kleindorfer $^{109} 1986$ einen ersten Ansatz, um die Umverteilungswirkungen zwischen verschiedenen Altersjahrgängen zu ermitteln. Der erwartete Lebensnettotransfer entspricht in Abbildung 6 (S. 43) für einen im Basisjahr (2003) geborenen Versicherten dem Barwert der Fläche zwischen Ausgabenkurve und Beitragskurve. ${ }^{110}$

Tabelle 4: Durchschnittlicher Lebensnettotransfer pro Mitglied

\begin{tabular}{|c|r|r|}
\hline Jahrgang & $\begin{array}{c}\text { Variante 1 } \\
\text { (Rein demographischer } \\
\text { Effekt) }\end{array}$ & $\begin{array}{c}\text { Variante 2 } \\
\text { (Demographischer Effekt } \\
\text { und Kostensteigerung) }\end{array}$ \\
\hline $1900-1909$ & $-5.447 €$ & $110 €$ \\
\hline $1910-1919$ & $-6.482 €$ & $-152 €$ \\
\hline $1920-1929$ & $-5.564 €$ & $-654 €$ \\
\hline $1930-1939$ & $-6.162 €$ & $-1.511 €$ \\
\hline $1940-1949$ & $-2.942 €$ & $-1.354 €$ \\
\hline $1950-1959$ & $-2.069 €$ & $-650 €$ \\
\hline $1960-1969$ & $-2.036 €$ & $185 €$ \\
\hline $1970-1979$ & $-2.394 €$ & $-973 €$ \\
\hline $1980-1989$ & $7.485 €$ & $7.479 €$ \\
\hline $1990-1999$ & $5.727 €$ & $8.592 €$ \\
\hline $2000-2009$ & $7.728 €$ & $17.451 €$ \\
\hline $2010-2019$ & $9.386 €$ & $31.784 €$ \\
\hline $2020-2029$ & $9.877 €$ & $50.159 €$ \\
\hline $2030-2039$ & $8.918 €$ & $67.953 €$ \\
\hline $2040-2049$ & $6.777 €$ & $77.515 €$ \\
\hline $2050-2059$ & $4.947 €$ & $84.957 €$ \\
\hline $2060-2069$ & $2.744 €$ & $70.938 €$ \\
\hline $2070-2079$ & $1.033 €$ & $40.627 €$ \\
\hline $2080-2089$ & $277 €$ & $17.316 €$ \\
\hline $2090-2099$ & $15 €$ & $717 €$ \\
\hline
\end{tabular}

Anmerkungen: Variante 1 unterstellt konstante Gesundheitskosten und einen Zinssatz von Null. In Variante 2 wird angenommen, dass die Gesundheitsausgaben bis 1960 um $1 \%$ p.a., von 1960 bis 1990 um $10 \%$ p.a. und ab 1990 um $5 \%$ p.a. steigen. Der angenommene Zinssatz beträgt bis 1959 $1,8 \%$ p.a. und ab $19604,1 \%$ p.a.

Quelle: In Anlehnung an Schulenburg, J.-M. Graf von der; Kleindorfer, P.R. (1986), S. $426 f$.

Wie die Ergebnisse der Modellrechnungen in Tabelle 4 zeigen, ist für alle bis 1979 geborenen Versicherten über ihren ganzen Lebenszyklus gesehen der Beitrag geringer als die Leistungsinanspruchnahme. Sie erhalten über ihren Lebenszyklus

${ }^{109}$ Siehe Schulenburg, J.-M. Graf von der; Kleindorfer, P.R. (1986), S. $415 \mathrm{ff}$. Darauf aufbauend berechnet Behrens, C.S. (1991), S. 77ff. familienspezifische Verteilungswirkungen, allerdings nur für die Geburtenjahrgänge 1910 bis 1970.

${ }^{110}$ Vgl. Schulenburg, J.-M. Graf von der (1988), S. 209.Marco Penske - 978-3-631-75223-4 
einen Nettotransfer, während die danach geborenen Versicherten einen Nettobeitrag leisten müssen. Die Ergebnisse in Variante 1 machen deutlich, dass allein die Altersverschiebung zu einer Benachteiligung nachfolgender Generationen führt. Dieser intergenerationale Verteilungseffekt wird noch stärker, wenn ein Anstieg der Gesundheitskosten im Zeitverlauf unterstellt wird (Variante 2). Im Maximum zahlen die zwischen 2050 und 2059 Geborenen den Berechnungen zufolge dann einen um 84.957 Euro höheren Beitrag als sie Leistungen empfangen.

Neuere Berechnungen wenden das Konzept der Generationenbilanzierung auf die GKV an. Anfang der neunziger Jahre wurde die Generationenbilanzierung von den amerikanischen Ökonomen Auerbach, Gokhale und Kotlikoff zur Beurteilung der Nachhaltigkeit der Fiskalpolitik entwickelt. Mit diesem Konzept soll insbesondere die Belastung künftiger Generationen bei einer Fortsetzung der bisherigen Finanzpolitik ermittelt werden. ${ }^{111}$

Dieser Ansatz wird auf den Bereich der GKV übertragen, um die aus dem demographischen Wandel und der sich ändernden Kostenstruktur resultierenden Auswirkungen auf die intergenerative Umverteilung anhand von Generationenkonten für jede Altersklasse zu quantifizieren. Hierzu werden zunächst alle Beiträge und Leistungen summiert, die ein Versicherter eines Jahrgangs während seines Lebenszyklus in der GKV leisten bzw. empfangen wird. Ein Generationenkonto berechnet sich dann aus dem Kapitalwert dieser Nettozahlungen. Damit spiegelt es die empfangenen Nettotransfers oder die geleisteten Nettobeiträge eines repräsentativen Individuums eines bestimmten Jahrgangs wider. Werden alle Konten der lebenden Generation gewichtet mit der jeweiligen Jahrgangsstärke der entsprechenden Kohorte - addiert, dann stellt ein positiver Betrag die Nachhaltigkeitslücke dar. Diese Nachhaltigkeitslücke quantifiziert die Mehrbelastung künftiger Generationen. Deshalb kann sie auch als implizite Verschuldung der GKV angesehen werden. ${ }^{112}$

Fetzer und Raffelhüschen ${ }^{113}$ quantifizieren in Modellrechnungen anhand von Daten aus der Einkommens- und Verbrauchsstichprobe des Statistischen Bundesamtes aus dem Jahr 1998 und der VDR-Statistik 2000 auf der Einnahmenseite sowie der RSA-Profile des Jahres 2000 auf der Ausgabenseite die intergenerationalen Umverteilungen. Da die aus diesen Daten ermittelten Nettobeiträge nur unwesentlich von den Ergebnissen eigener Berechnungen ${ }^{114}$ auf Grundlage anderer und aktuellerer Daten abweichen, wird im Folgenden auf die Berechnungen von Fetzer und Raffelhüschen zurückgegriffen.

${ }^{111}$ Siehe Auerbach A.J.; Gokhale, J.; Kotlikoff, L.J. (1991), S. 59ff.; Auerbach A.J.; Gokhale, J.; Kotlikoff, L.J. (1992), S. 305ff.; Auerbach A.J.; Gokhale, J.; Kotlikoff, L.J. (1994), S. 75ff. Ein ähnliches Konzept entwarf Blanchard im Auftrag der OECD; siehe Blanchard, O. (1993), S. 307ff. Für einen Vergleich beider Konzepte siehe Wissenschaftlicher Beirat beim Bundesministerium der Finanzen (2001), S. 49ff.; Raffelhüschen, B. (2002b), S. $73 \mathrm{ff}$.

${ }^{112}$ Vgl. Raffelhüschen, B. (2002a), S. 150; Fetzer, S.; Moog, S.; Raffelhüschen, B. (2001), S. 12f.

${ }^{113}$ Siehe Fetzer, S.; Raffelhüschen, B. (2002), S. 9ff. Zu ähnlichen Ergebnissen kommt auch eine ältere Untersuchung; siehe Fetzer, S.; Moog, S.; Raffelhüschen, B. (2001), S. $12 f$.

114 Siehe Abschnitt 4.2.4 Intertemporale Inzidenz, S. 4/arco Penske - 978-3-631-75223-4 
Die Nettobeiträge ${ }^{115}$ der im Basisjahr 2000 lebenden Jahrgänge werden für jeden Jahrgang mit einer unterstellten Produktivitätswachstumsrate $(\mathrm{g})$ in die Zukunft fortgeschrieben, d.h. ein 25jähriger zahlt im Jahr 2005 einen $(1+g)^{5}$ höheren Nettobeitrag als ein Gleichaltriger im Basisjahr. Über diesen Faktor g gehen implizit Annahmen über Wachstum der beitragspflichtigen Einnahmen und Wachstum der Ausgaben in die Berechnungen ein. Zur Ermittlung der Generationenkonten für jeden lebenden Jahrgang werden die so ermittelten jährlichen Nettobeitragszahlungen eines Individuums über dessen ganzen Lebenszyklus mit dem Realzins ( $r$ ) diskontiert und aufsummiert. Die Nachhaltigkeitslücke ergibt sich dann aus der Summe der nach Jahrgangsstärken gewichteten Generationenkonten. Die Jahrgangsstärke entnehmen die Autoren der zweiten Variante der 9. koordinierten Bevölkerungsvorausberechnung des Statistischen Bundesamtes.

\section{Abbildung 8: Generationenbilanz der GKV im Jahr 2000}

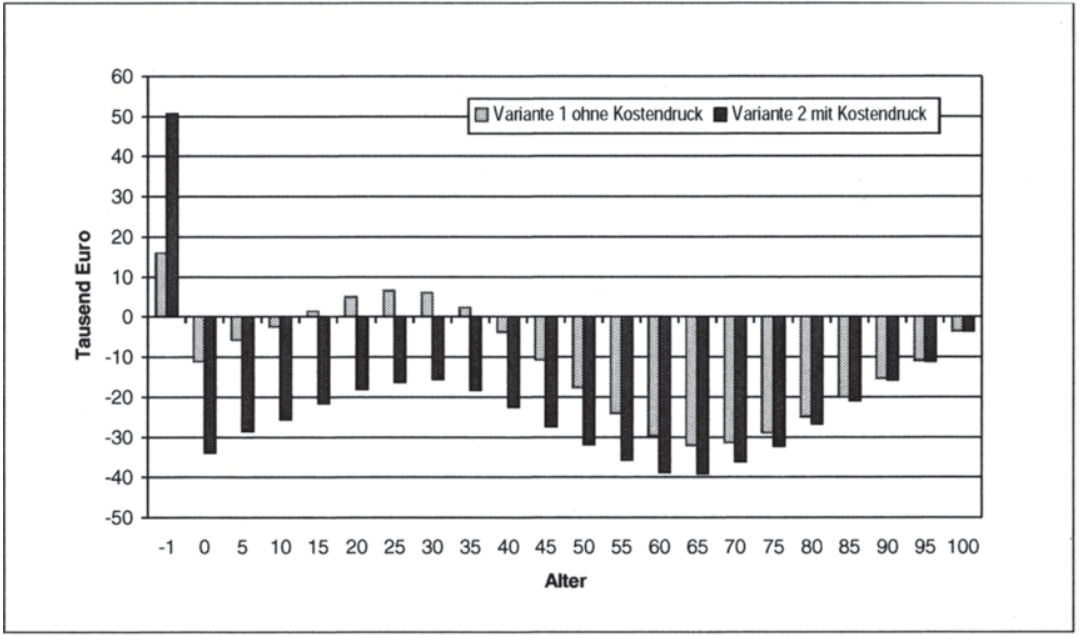

Quelle: Fetzer, S.; Raffelhüschen, B. (2002), S. 10.

Unter der Annahme, dass Beitragseinnahmen und Leistungsausgaben parallel mit $g=1,5 \%$ wachsen und ein Zinssatz von $r=3 \%$ vorliegt, weisen die Generationenkonten aller lebenden Generationen in Variante 1 nur die 14- bis 37jährigen als Nettobeitragszahler aus. Wie Abbildung 8 zeigt, sind alle anderen Jahrgänge Nettoempfänger. Im Maximum zahlt ein 27jähriger über seinen Lebenszyklus 6.900 Euro netto in die GKV ein, demgegenüber erhält ein 67jähriger über seine verbleibende Lebenszeit einen Transfer in Höhe von 32.300 Euro. ${ }^{116}$ Diese Ergebnisse bestätigen den in Abschnitt 4.2.4 Intertemporale Inzidenz (S. 41) dargestellten Verlauf von Beiträgen und Ausgaben im Lebenszyklus, lassen allerdings noch keine Rückschlüsse auf intergenerative Verteilungswirkungen im Zeitverlauf zu. Aussagen über die Gene-

\footnotetext{
${ }^{115}$ Siehe hierzu die eigenen Berechnungen in Tabelle 25: Beiträge und Leistungen der GKV nach Alter im Jahr 2003, im Anhang, S. 262.
}

${ }^{116}$ Vgl. Fetzer, S.; Raffelhüschen, B. (2002), S. 10. Marco Penske - 978-3-631-75223-4 
rationengerechtigkeit lassen sich erst dann treffen, wenn die noch nicht geborenen Generationen berücksichtigt werden. ${ }^{117}$ Müssen allein zukünftige Generationen durch Nettobeitragszahlungen die Nachhaltigkeitslücke schließen und werden alle Versicherten gleich belastet, dann kann aus dem Vergleich des Generationenkontos eines „-1jährigen“ mit dem eines im Basisjahr Geborenen die Mehrbelastung künftiger Generationen ermittelt werden. Diese Mehrbelastung ergibt sich dann aus der betragsmäßigen Differenz der beiden Generationenkonten und liegt nach diesen Berechnungen bei 27.100 Euro pro Versicherten (15.900 Euro plus 11.200 Euro). Insgesamt beträgt die Nachhaltigkeitslücke in der GKV dann 1,3 Billionen Euro oder $65,3 \%$ des BIP 2000. ${ }^{118}$

Wie wenig nachhaltig das Finanzierungssystem der GKV ist, zeigt sich noch deutlicher in der realistischeren zweiten Variante, in der unterstellt wird, dass bei gleichem Zinssatz von $r=3 \%$ die Leistungsausgaben mit einer um einen Prozentpunkt höheren Wachstumsrate $(2,5 \%)$ als die Einnahmen wachsen. Unter diesen Annahmen werden sogar alle lebenden Generationen zu Nettoleistungsempfängern. Die Nettobeitragszahlung eines -1jährigen steigt von 15.900 Euro (Variante 1) auf 50.700 Euro. Entsprechend steigt auch die Belastung zukünftiger Generationen auf $203,8 \%$ des BIP 2000 (4,1 Billionen Euro) oder 84.600 Euro pro Kopf. ${ }^{119}$ Wird diesen Berechnungen statt der 9. die 10. koordinierte Bevölkerungsvorausberechnung zugrunde gelegt, beträgt die Nachhaltigkeitslücke in der GKV sogar 236,2 \% des BIP im Jahr 2000 oder 95.900 Euro pro Kopf. ${ }^{120}$

Die berechneten Nachhaltigkeitslücken sind aber nur fiktiv, weil unterstellt wird, dass Defizite akkumuliert werden können. Da die GKV im Umlageverfahren finanziert wird, müssen in jeder Periode die Ausgaben durch die Einnahmen gedeckt sein. ${ }^{121}$ Demzufolge werden die durch den demographischen Alterungsprozess ausgelösten Finanzierungsdefizite im derzeit praktizierten System durch Beitragssatzanhebungen, die zwar insbesondere jüngere Generationen belasten, gedeckt. Von dem Beitragssatzanstieg sind aber auch die älteren Generationen betroffen. Der Vergleichsmaßstab - die gegenwärtigen Generationen könnten sich den Anpassungen entziehen - ist somit nicht haltbar. ${ }^{122}$ Zudem verändern sich die medizinischen Möglichkeiten infolge des Fortschritts, so dass die Generationenkonten über längere Zeiträume kaum vergleichbar sind. ${ }^{123}$

\footnotetext{
${ }^{117}$ Vgl. Raffelhüschen, B. (2001), S. 57.

${ }^{118} \mathrm{Vgl}$. Fetzer, S.; Raffelhüschen, B. (2002), S. 9ff.

${ }^{119} \mathrm{Vgl}$. ebenda, S. 11.

${ }^{120}$ Siehe Hagist, C.; Raffelhüschen, B. (2003), S. 5.

${ }^{121}$ Vgl. Raffelhüschen, B. (2002a), S. 150; Fetzer, S.; Raffelhüschen, B. (2002), S. 11. Als Begründung führen die Autoren allerdings die einnahmenorientierte Ausgabenpolitik in der GKV an. Ursächlich ist aber das Umlageverfahren; vgl. Wissenschaftlicher Beirat beim Bundesministerium der Finanzen (2001), S. 47; Schulenburg, J.-M. Graf von der (1989b), S. 287. Nach der einnahmenorientierten Ausgabenpolitik sollen die Leistungsausgaben nach der Entwicklung der Einnahmen gesteuert werden; vgl. Henke, K.-D. (1991), S. 146f. Hier geht es aber darum, die Einnahmen entsprechend der demographisch bedingten Ausgabensteigerungen zu erhöhen.

${ }^{122}$ In Anlehnung an Wissenschaftlicher Beirat beim Bundesministerium der Finanzen (2001), S. 39.

${ }^{123}$ Vgl. Rürup, B. (2003), S. 5. 
Neben dieser zu beachtenden Besonderheit der Finanzierung der GKV können die in der Wissenschaft vorgebrachten Kritikpunkte an der Generationenbilanzierung zur Beurteilung der Nachhaltigkeit der Finanzpolitik auch gegen eine Generationenbilanzierung in der GKV vorgebracht werden. Die durch Generationenkonten ermittelten Umverteilungswirkungen beruhen auf zahlreichen Annahmen, die aufgrund des langen Zeithorizonts unsicher sind. Das gilt zunächst für die zugrunde gelegte Bevölkerungsentwicklung. Zudem ist die Wahl des Zinssatzes zur Diskontierung von Einnahmen und Ausgaben problematisch. ${ }^{124}$ Ebenso können sich die unterstellten Wachstumsraten von Ausgaben und beitragspflichtigen Einnahmen als unzutreffend erweisen. Neben diesen Unsicherheiten über die geschätzten Größen beeinflusst die Wahl des Basisjahres die Ergebnisse erheblich. Sondereinflüsse im Basisjahr werden in die Zukunft fortgeschrieben, während eventuelle Änderungen im Finanzierungssystem der GKV oder im Verhalten der Versicherten und Leistungserbringer nicht berücksichtigt werden. ${ }^{125}$

Neben diesen Schwierigkeiten, die ,richtigen“ Annahmen zu treffen, ist die Interpretation der Ergebnisse problematisch: Zur Berechnung eines vollständigen Generationenkontos für einen Jahrgang muss der ganze Lebenshorizont betrachtet werden. Da die Analyse aber nur in die Zukunft gerichtet ist, werden alle im Basisjahr bereits existierenden Jahrgänge nicht vollständig erfasst, sondern nur über ihre Restlebenszeit. Diese Generationenkonten sind deshalb weder untereinander noch mit denen der im Basisjahr oder in den Folgejahren Geborenen vergleichbar. Aus den Generationenbilanzen kann deshalb nicht ohne weiteres abgeleitet werden, die älteren $\mathrm{Ge}$ nerationen lebten auf Kosten der jüngeren, weil die Beiträge der älteren Generation während deren Erwerbsphase nicht erfasst sind. Die Konten der in Folgejahren Geborenen sind zwar grundsätzlich untereinander vergleichbar, weil deren Beiträge und Leistungsausgaben vollständig erfasst werden. Diese unterliegen aber auch der oben genannten unzutreffenden Annahme, dass nur künftige Generationen die Nachhaltigkeitslücke schließen müssten. ${ }^{126}$

Die Ergebnisse der dargestellten Berechnungen können aus diesen Gründen nur Anhaltspunkte über das Ausmaß der intergenerativen Umverteilung in einer alternden Gesellschaft liefern. Sie sind aber ein Indiz für die Abhängigkeit der GKV von der demographischen Entwicklung und die damit verbundenen Belastungen für künftige Generationen.

\subsection{Strukturelle Schwächen}

\subsubsection{Zum Ziel der Beitragssatzstabilität}

Beitragssatzsteigerungen in der GKV wirken wie Steuererhöhungen, da - anders als in der GRV - die gegenüber stehende Leistung gleich bleibt. ${ }^{127}$ Sie senken damit die Arbeitsanreize für Arbeitnehmer. Für den Arbeitgeber führen steigende Beiträge zur

\footnotetext{
${ }^{124}$ Siehe hierzu Feist, K.; Raffelhüschen, B. (2000), S. 447; Wälde, K. (1998), S. 327.

${ }^{125}$ In Anlehnung an SVR (1998), Kasten 8, S. 226.

${ }^{126}$ In Anlehnung an Wissenschaftlicher Beirat teim Bundesministerium der Finanzen (2001), S. 38f.; Rothschild, K.W. (1998), S. 323; Boll, S. (1994), S. 58.

${ }^{127} \mathrm{Vgl}$. SVR (2001), Ziff. 386.

Marco Penske - 978-3-631-75223-4
} 
GKV zu höheren Lohnkosten, was vor allem aus drei Gründen für die Beschäftigung problematisch ist: Erstens sind aufgrund der Zunahme des internationalen Wettbewerbs der Überwälzung höherer Lohnkosten auf die Preise enge Grenzen gesetzt. Auf den heimischen Märkten werden inländische Produkte bei einer Verteuerung durch preiswertere Importe ersetzt und deutsche Exporteure müssen den Weltmarktpreis für ihr Produkt als gegeben betrachten, um auf den Märkten zu bestehen. Die internationale Wettbewerbsfähigkeit der heimischen Wirtschaft wird maßgeblich von den Herstellungskosten beeinflusst und durch steigende Lohnnebenkosten zunehmend eingeschränkt. ${ }^{128}$ Zweitens sinken mit zunehmenden Kosten die Gewinne, was zur Folge hat, dass die Unternehmen weniger in neue Arbeitsplätze investieren. ${ }^{129}$ Drittens geht mit einem Preisanstieg für den Faktor Arbeit ceteris paribus die Nachfrage nach Arbeit zurück und wird Arbeit zunehmend durch den Faktor Kapital substituiert. Damit verstärken steigende Beiträge zur GKV das Problem der Arbeitslosigkeit, was wiederum zu Beitragsausfällen in der GKV und zu weiteren Beitragssatzsteigerungen führt. Auf diese Weise entsteht ein Circulus vitiosus. Weitere Einnahmenverluste entstehen auch für die GKV, wenn die Wirtschaftssubjekte in die Schattenwirtschaft ausweichen. ${ }^{130}$

Der Grundsatz der Beitragssatzstabilität ist deshalb seit 1993 in § 71 SGB V verankert. Danach sind Krankenkassen und Leistungserbringer dazu verpflichtet, ihre Vereinbarungen über die Leistungsvergütung so zu gestalten, dass Beitragssatzerhöhungen vermieden werden; „es sei denn, die notwendige medizinische Versorgung ist auch nach Ausschöpfung von Wirtschaftlichkeitsreserven ohne Beitragssatzerhöhungen nicht zu gewährleisten“. Die Beitragssatzstabilität ist Ausdruck der einnahmenorientierten Ausgabenpolitik, die in der GKV seit dem KrankenversicherungsKostendämpfungsgesetz von 1977 verfolgt wird. Da die Leistungsausgaben der GKV durch Sozialversicherungsbeiträge finanziert werden, sollen die Ausgaben mit einer einnahmenorientierten Ausgabenpolitik der Entwicklung der beitragspflichtigen Einnahmen folgen. Damit wird zum einen versucht, den Leistungsumfang und das Ausgabenvolumen der GKV so zu steuern, dass Wirtschaftlichkeitsreserven mobilisiert werden. Zum anderen soll die relative Abgabenlast für Arbeitgeber und Arbeitnehmer konstant gehalten werden. ${ }^{131}$ Nach einer Faustformel führt ein Anstieg der Sozialversicherungsbeiträge um einen Beitragssatzpunkt zu einem Verlust von 100.000 Arbeitsplätzen. ${ }^{132}$

Auch mit einem konstanten Beitragssatz werden die Ausgaben nicht starr begrenzt. In dem praktizierten Finanzierungssystem über Beiträge steigen auch bei Beitragssatzstabilität die Einnahmen der GKV, da die Bemessungsgrundlage abhängig von der konjunkturellen Lage und dem Wirtschaftswachstum steigt und die Beitragsbemessungsgrenze vom Gesetzgeber erhöht werden kann. Soll ein konstanter Beitragssatz verwirklicht werden, dürfen die Leistungsausgaben der GKV jedoch nicht

\footnotetext{
${ }^{128} \mathrm{Vgl}$. stellvertretend SVR KAiG (1996), Ziff. 362ff.

${ }^{129}$ Vgl. Hajen, L.; Paetow, H.; Schumacher, H. (2000), S. 99.

${ }^{130} \mathrm{Vgl.} \mathrm{Schmähl,} \mathrm{W.} \mathrm{(2002a),} \mathrm{S.} \mathrm{114;} \mathrm{Wille,} \mathrm{E.} \mathrm{(1999),} \mathrm{S.} \mathrm{9.} \mathrm{Entgegen} \mathrm{der} \mathrm{herrschenden} \mathrm{Meinung}$ sehen Breyer, F. u.a. (2001), S. 41ff., steigende Lohnnebenkosten nicht als Ursache für die Arbeitslosigkeit in Deutschland.

${ }^{131}$ Vgl. Ulrich, V. (1998), S. 10f.; Wille, E.; Ulrich, V. (1991), S. 10 f.

${ }^{132} \mathrm{Vgl}$. Hansen, V. (2003), S. 10. 
schneller wachsen als die beitragspflichtigen Einnahmen. ${ }^{133}$ Aus dem damit vorgegebenen Ausgabenniveau resultient zwar ein medizinisches Versorgungsniveau, das einen konstanten Beitragssatz sicherstellt. Dieser zufällige Beitragssatz kann aber nicht als optimal angesehen werden. ${ }^{134}$ Aus ökonomischer Sicht sollte das Niveau der Gesundheitsausgaben den Präferenzen der Versicherten entsprechen und nicht durch einen politisch festgelegten Beitragssatz bestimmt werden. Ein Beitragssatzanstieg ist insbesondere dann zuzulassen, wenn er auf eine gestiegene Nachfrage der Versicherten z.B. aufgrund der Bevölkerungsalterung oder auf einen Kostenanstieg bei effizienter Produktionsstruktur zurückzuführen ist. ${ }^{.35}$

Selbst konstante GKV-Einnahmen bedeuten bei gesamtwirtschaftlicher Betrachtung nicht, dass der Anstieg der gesamten Ausgaben für Gesundheitsleistungen tatsächlich begrenzt wird. Auf die GKV entfallen rund $57 \%$ der Gesundheitsausgaben. Der Rest verteilt sich auf private und öffentliche Haushalte sowie Arbeitgeber und private Krankenkassen. Beitragssatzstabilität kann deshalb mit einer Verlagerung der Ausgaben auf andere Träger einhergehen. Diese Belastungsverschiebung findet seit dem Kostendämpfungsgesetz 1977 statt. Nach der Gesundheitsausgabenrechnung des Statistischen Bundesamtes ${ }^{136}$ sind die Ausgabenanteile der privaten Krankenversicherung und der privaten Haushalte von 1980 bis 1994 in Westdeutschland von $7,4 \%$ auf $8,6 \%$ bzw. von $8,1 \%$ auf $10,4 \%$ gestiegen, während im gleichen Zeitraum der Anteil der GKV von $61,2 \%$ auf $58,6 \%$ gesunken ist. Die Daten für das gesamte Bundesgebiet im Jahr 2004 bestätigen diese Kostenverlagerung. Auch bei einem stabilen Beitragssatz kann die Belastung von Arbeitgebern und Arbeitnehmern demzufolge also steigen. ${ }^{137}$

Im Jahr 2001 waren nach Angaben des Instituts für Arbeitsmarkt- und Berufsforschung der Bundesanstalt für Arbeit $(\mathrm{IAB})^{138} 4,5$ Mio. Personen im Gesundheitswesen beschäftigt, was einem Anteil von mehr als $13 \%$ an der Gesamtbeschäftigung entsprach. ${ }^{139}$ Aufgrund der demographischen Entwicklung wird die Zahl der Beschäftigten im Gesundheitswesen weiter steigen. ${ }^{140}$ Wachstum im Gesundheitswesen trägt zu einem höheren Beschäftigungsstand bei, zumal im Gesundheitswesen Arbeit nur begrenzt durch Kapital substituiert werden kann. Bei einer restriktiven Ausgabenbegrenzung infolge der angestrebten Beitragssatzstabilität gehen der

\footnotetext{
${ }^{133}$ Vgl. Henke, K.-D. (1993a), S. 58; SVR KAiG (1995), Ziff. 517.

${ }^{134}$ Vgl. Henke, K.-D. (1991), S. 147; SVR KAiG (1995), Ziff. 522.

${ }^{135}$ Vgl. Rürup, B. (2002), S. 16; Oberdieck, V. (1998), S. 150ff.; SVR (2000), Ziff. 469.

${ }^{136}$ Siehe Statistisches Bundesamt (Hrsg.) (1998), S. 475; Statistisches Bundesamt (Hrsg.) (2002), S. 10.

${ }^{137}$ Vgl. Henke, K.-D. (1991), S. 147f.; Henke, K.-D. (1993a), S. 59; Oberdieck, V. (1998), S. $149 f . ;$ Braun, B.; Kühn, H.; Reiners, H. (1998), S. 10.

${ }^{138}$ Siehe Institut für Arbeitsmarkt- und Berufsforschung der Bundesanstalt für Arbeit (Hrsg.) (2002), S. 1 .

${ }^{139}$ Die Zahl der Beschäftigten im Gesundheitswesen variiert in den verschiedenen Quellen; vgl. Henke, K.-D. (2002), S. 13ff.; Henke, K.-D. (1999), S. 8ff.; Göpffarth, D.; Milbrandt, B. (1997), S. 12f.; Wallau, D. (2004), S. 91f. Hier wurde auf Daten des IAB-Betriebspanels zurückgegriffen. Auf Basis der Gesundheitsausgabenrechnung ermittelte das Statistische Bundesamt für das Jahr 2002 4,2 Mio. Beschäftigte im Gesundheitswesen; vgl. Weinmann, J.; Zifonun, N. (2004), S. 455.

${ }^{140} \mathrm{Vgl}$. stellvertretend Institut für Arbeitsmarkt- und Berufsforschung der Bundesanstalt für Arbeit (Hrsg.) (2002), S. 2. 
Volkswirtschaft diese Beschäftigungsmöglichkeiten und damit der GKV wiederum potentielle Einnahmen verloren. Zudem können Wachstumschancen der gesamten Volkswirtschaft geschmälert werden, wenn das Gesundheitswesen nicht über ausreichende Mittel verfügt, um arbeitsunfähige Personen wieder ins Erwerbsleben zu integrieren. Das Gesundheitswesen kann die Leistungsfähigkeit des Humankapitals sogar verbessern und damit zu einem Produktivitätsanstieg beitragen, gerade weil Humankapital ein entscheidender Produktionsfaktor ist. ${ }^{141}$

Bei der Betrachtung der Beschäftigungseffekte muss neben den kontraktiven Wirkungen einer Beitragssatzerhöhung also auch die Mittelverwendung im Gesundheitswesen berücksichtigt werden. Diese löst expansive Effekte auf die Beschäftigung im Gesundheitswesen aus. Da es sich hierbei um eine Wachstumsbranche im überwiegend arbeitsintensiven Dienstleistungssektor handelt, haben Beitragssatzerhöhungen nicht die gleichen beschäftigungsfeindlichen Folgen wie z.B. eine Erhöhung des Beitragssatzes zur rein transferorientierten GRV. ${ }^{142}$ Dennoch kann eine Ausweitung des Gesundheitswesens gegen die Präferenzen der Versicherten verstoßen, da Krankenversicherungsbeiträge Zwangsabgaben sind, auf die der einzelne Versicherte nur geringen Einfluss hat. ${ }^{143} \mathrm{Ob}$ gesamtwirtschaftlich die kontraktiven oder die expansiven Effekte überwiegen, lässt sich nicht theoretisch, sondern nur anhand gesamtwirtschaftlicher Modelle beantworten. ${ }^{144}$

In einem Gutachten hat der Sachverständigenrat für die Konzertierte Aktion im Gesundheitswesen in Zusammenarbeit mit dem DIW ${ }^{145}$ die Auswirkungen einer Beitragssatzänderung auf die Gesamtbeschäftigung in Westdeutschland untersucht. Den Ergebnissen zufolge könnte eine Beitragssatzerhöhung um einen Prozentpunkt in den alten Bundesländern bei gleichzeitiger Verausgabung der zusätzlichen GKVEinnahmen mittelfristig 35.000 neue Arbeitsplätze schaffen. Zwar führt der Beitragssatzanstieg zu einem Rückgang des privaten Verbrauchs infolge höherer Beitragssätze und - wenn die Überwälzung des Arbeitgeberbeitrags auf die Preise gelingt infolge gestiegener Preise. Dieser kontraktive Effekt wird jedoch durch steigende Gesundheitsausgaben der GKV mehr als kompensiert. Der Beschäftigungsgewinn wird allerdings kleiner ausfallen, wenn man unterstellt, dass ein Preisanstieg zu höheren Tariflöhnen und zu einer sinkenden Wettbewerbsfähigkeit inländischer Unternehmen führt. ${ }^{146}$ Mit dem gleichen Konjunkturmodell lassen sich für Westdeutschland die Auswirkungen einer Erhöhung des Beitragssatzes zur GKV auf die Beschäftigung in Abhängigkeit von der Verwendung der zusätzlichen Mittel berechnen. Je nachdem, ob mit der Beitragssatzerhöhung Sachausgaben (z.B. Behandlungen), zusätzliche Finanztransfers (z.B. Krankengeldzahlungen) oder öffentliche Investitionen (z.B. im Krankenhausbereich) finanziert werden, ergeben sich andere Beschäftigungseffekte. ${ }^{147}$

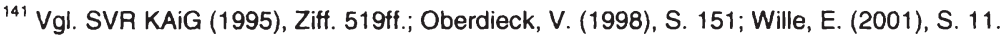

${ }^{142}$ Vgl. Rürup, B. (2002), S. 16; Oberdieck, V. (1998), S. 151. Siehe auch SVR KAiG (1996), Ziff. 383.

${ }^{143}$ Vgl. Göpffarth, D.; Milbrandt, B. (1997), S. 17.

${ }^{144}$ Vgl. SVR KAiG (1996), Ziff. 377; Henke, K.-D. (1999), S. 21.

${ }^{145}$ Siehe SVR KAiG (1996), Ziff. 341ff.

${ }^{146} \mathrm{Vgl}$. ebenda, Ziff. $378 f$.

${ }^{147}$ Vgl. SVR KAiG (1998), Ziff. 36ff.; Henke, K.-D. (1999);ç. p.9ffske - 978-3-631-75223-4 
Wie Tabelle 5 zeigt, ist bei einer Erhöhung des Beitragssatzes zur Krankenversicherung um einen Prozentpunkt zur Finanzierung zusätzlicher Sachausgaben nach fünf Jahren mit einem positiven Beschäftigungseffekt von 40.000 Arbeitsplätzen in Westdeutschland zu rechnen. Größer wird der Effekt, wenn nur die Arbeitnehmerbeiträge zur GKV um einen Prozentpunkt erhöht werden und die Belastung der Arbeitgeber konstant bleibt. Dann steigt die Beschäftigung nach drei Jahren um 30.000 und nach fünf Jahren um 50.000 Personen. Unterstellt wird dabei allerdings, dass die Gewerkschaften die Aufgabe der paritätischen Finanzierung ohne Lohnkompensation akzeptieren, was unwahrscheinlich erscheint. Werden die zusätzlichen Mittel für Finanztransfers verwendet, nimmt die Beschäftigung ab, weil die Mehrausgaben der GKV die kontraktiven Wirkungen einer Beitragssatzsteigerung auf Export und privaten Verbrauch nicht kompensieren. Dieses Szenario wird auch dann erwartet, wenn zusätzliche Ausgaben der GKV einer Verbesserung der Einkommenssituation von Ärzten oder anderen im Gesundheitswesen Tätigen dienen. Mit höheren öffentlichen Investitionen können hingegen deutlich positive Beschäftigungswirkungen erzielt werden: Nach fünf Jahren steigt die Beschäftigung in der Modellrechnung um 150.000 Personen an. Damit wird die These bestätigt, dass direkte Gesundheitsausgaben die Nachfrage stärker stimulieren als Transferzahlungen. Problematisch an diesem Szenario ist allerdings, dass die Krankenversicherungen derzeit kaum öffentliche Investitionen tätigen. Der Krankenhausbau wird z.B. überwiegend von den Bundesländern finanziert. Die Berechnungen unterstellen daher einen Anstieg der Investitionen und nicht die Änderung der Finanzierungsstruktur bei gegebenem Investitionsniveau.

Tabelle 5: Beschäftigungseffekte einer Beitragssatzerhöhung in der GKV um einen Prozentpunkt im früheren Bundesgebiet

\begin{tabular}{|l|r|r|r|r|r|}
\hline Mittelverwendung & 1. Jahr & 2. Jahr & 3. Jahr & 4. Jahr & 5. Jahr \\
\hline Sachausgaben $^{11}$ & -10.000 & -30.000 & 0 & 20.000 & 40.000 \\
\hline Sachausgaben $^{2}$ & 0 & 10.000 & 30.000 & 50.000 & 50.060 \\
\hline Finanztransfers & 0 & 0 & 0 & -30.000 & -40.000 \\
\hline Investitionen & 60.000 & 170.000 & 230.000 & 180.000 & 150.000 \\
\hline
\end{tabular}

1) Arbeitnehmer- und Arbeitgeberbeitrag steigen um insgesamt einen Prozentpunkt.

2) Nur die Arbeitnehmerbeiträge werden um einen Prozentpunkt erhöht, die Sozialversicherungsbeiträge der Arbeitgeber bleiben konstant.

Quelle: In Anlehnung an Henke, K.-D. (1999), S. 38ff.

Solange die zusätzlichen GKV-Ausgaben nicht für Transferzahlungen verwendet werden, gehen von Beitragssatzerhöhungen in der GKV deutlich geringere negative Wirkungen auf Wachstum und Beschäftigung aus als von Beitragssatzerhöhungen in der GRV. ${ }^{148}$ Einem Beschäftigungsrückgang im Nicht-Gesundheitsbereich steht dann eine Zunahme im beschäftigungsintensiven Gesundheitswesen gegenüber.

Neben den ökonomischen Argumenten ${ }^{149}$ sprechen zunehmend auch politische Gründe gegen das Ziel Beitragssatzstabilität. In der Janssen-Cilag Bevölkerungsbe-

\footnotetext{
${ }^{148} \mathrm{Vgl}$. SVR KAiG (1998), Ziff. 52.

${ }^{149}$ Einen Überblick über Argumente für und gegen Beitragssatzstabilität gibt Henke, K.-D. (1993b), S. 110 f. 
fragung $2002^{150}$ sprach sich eine Mehrheit der Befragten gegen eine einseitig an Beitragssatzstabilität orientierte Gesundheitspolitik aus. Nur $20 \%$ der Befragten antworteten auf die Frage, was im Zentrum der Gesundheitspolitik stehen solle, mit Beitragssatzstabilität, $36 \%$ votierten hingegen für mehr medizinische Leistungen und $44 \%$ für das Verfolgen beider Ziele gleichzeitig. Auch der Sachverständigenrat für die Konzertierte Aktion im Gesundheitswesen ${ }^{151}$ weist darauf hin, dass die Versicherten eher höhere Beitragssätze akzeptierten als Abstriche beim Leistungskatalog. Hinzu kommt, dass sich aufgrund der demographischen Bevölkerungsentwicklung und des medizinisch-technischen Fortschritts bei einer Fortführung des derzeitigen Finanzierungssystems ein weiterer Beitragssatzanstieg nicht vermeiden lassen wird. Will man jedoch am Ziel der Beitragssatzstabilität festhalten, wird man nicht umhinkommen, eine staatliche Mengenrationierung (z.B. Altersobergrenzen für bestimmte Behandlungen) oder eine marktwirtschaftliche Preisrationierung (z.B. über Selbstbeteiligungen) in der GKV einzuführen. Beides würde die Gesundheitsversorgung beeinträchtigen und dürtte derzeit politisch kaum durchsetzbar sein.

Die Politik der Beitragssatzstabilisierung begrenzt zwar aus arbeitsmarktpolitischen Gründen den Anstieg der GKV-Ausgaben, verstößt damit aber gleichzeitig gegen Versichertenpräferenzen und reduziert mögliches Wachstum im Gesundheitswesen. Die Koppelung der Beiträge an das Erwerbseinkommen führt zu einem Zielkonflikt zwischen Gesundheits- und Arbeitsmarktpolitik und gehört schon aus diesem Grund aufgehoben.

\subsubsection{Abhängigkeit von der Versichertenstruktur}

Aufgrund der Koppelung der Beiträge an Rente bzw. Arbeitsentgelt beeinflusst auch die Mitgliederstruktur die Einnahmen der GKV. Dies trifft insbesondere für die Versichertengruppen $\mathrm{zu}$, die über vergleichsweise geringe oder hohe beitragspflichtige Einnahmen verfügen wie beitragsfrei Versicherte, Rentner und freiwillig Versicherte. ${ }^{152}$ Deshalb wird im Folgenden die Mitgliederstruktur näher betrachtet, zumal die Gesamtzahl der Mitglieder weitgehend konstant geblieben ist. ${ }^{153}$

Negativen Einfluss auf die Beitragseinnahmen hat der Anteil der beitragsfrei Versicherten. Ein Anstieg des Anteils dieser Versichertengruppe an allen Versicherten kann für die GKV seit 1991 allerdings nicht festgestellt werden. Die Anzahl der Personen, die ein Beitragszahler durchschnittlich mittinanziert, ist nahezu konstant geblieben. Der Quotient aus der Zahl aller GKV-Versicherten und der Zahl der Mitglieder ist von 1991 bis 2004 von 1,41 auf 1,39 sogar leicht zurückgegangen.

Rentner zahlen im Durchschnitt niedrigere Beiträge als erwerbstätige Mitglieder. Ein Anstieg des Anteils der Rentner an den Mitgliedern schwächt somit die Finanzierungsbasis der GKV. Abbildung 9 zeigt, dass die Zahl der Rentner in der GKV seit 1991 schneller gewachsen ist als die Mitgliederzahl insgesamt. Der Anteil der Rent-

\footnotetext{
${ }^{150}$ Siehe Nolting, H.-D.; Wasem, J. (2002), S. 6f., 35.

${ }^{151}$ Siehe SVR KAiG (2003), Ziff. 47.

${ }^{152}$ Vgl. Wille, E. (2001), S. 21; SVR KAiG (2003), Ziff. 61.

${ }^{153}$ Der SVR (2004), Ziff. 344, sieht indes einen Grund für die Wachstumsschwäche der beitragspflichtigen Einnahmen im Rückgang der Zahl der Mitglieder. Dies gilt aber erst ab dem Jahr 2003 und nur in geringem Maße; siehe Tabelle 36: GKV-Mitgliederstrektur A991/20046 in-Akbang/S. 273.
} 
ner an allen Mitgliedern nahm von 27,97\% (1991) auf 33,33\% im Jahr $2004 \mathrm{zu}^{154}$, wodurch das Wachstum der Beiträge zur GKV geschwächt wird.

Einen positiven Einfluss auf die Entwicklung der beitragspflichtigen Einnahmen hat das in Abbildung 9 gezeigte starke Wachstum der Zahl der freiwillig versicherten Mitglieder bis zum Jahr 2001. Aufgrund der Erhöhung der Versicherungspflichtgrenze hat die Zunahme der Zahl der freiwillig Versicherten merklich nachgelassen. Im Jahr 2002 ist sogar ein deutlicher Einbruch zu verzeichnen, nachdem die Versicherungspflichtgrenze von 40.500 Euro (2002) auf 45.900 Euro (2003) angehoben wurde. Da bei den meisten ${ }^{155}$ freiwilligen Mitgliedern Einnahmen in Höhe der Beitragsbemessungsgrenze der Beitragspflicht unterliegen und diese damit den Höchstbeitrag zur GKV leisten, geht von dieser Versichertengruppe zumindest ein positiver Einfluss auf die Einnahmen der GKV aus. ${ }^{156}$

Abbildung 9: GKV-Mitgliederstruktur 1991-2004

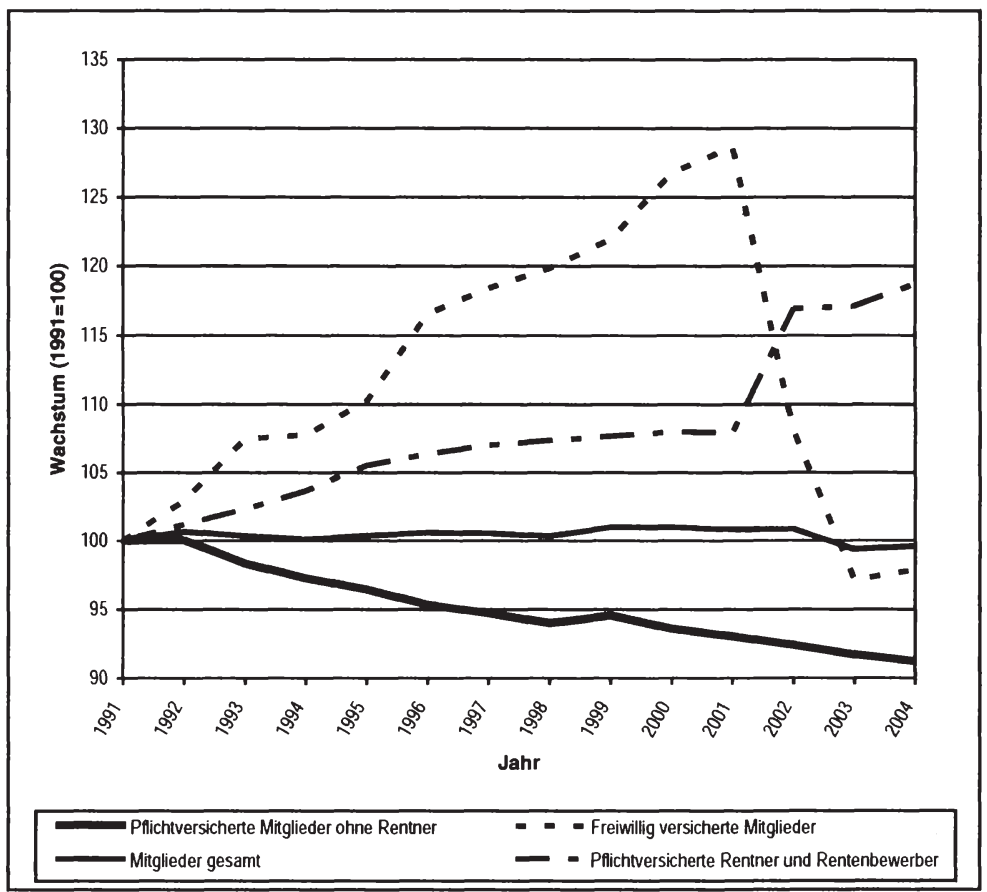

Quelle: Eigene Darstellung und eigene Berechnungen; siehe Tabelle 36: GKV-Mitgliederstruktur 19912004, im Anhang, S. 273.

${ }^{154}$ Eigene Berechnung; siehe Tabelle 36: GKV-Mitgliederstruktur 1991-2004, im Anhang, S. 273.

${ }^{155}$ Bei freiwillig Versicherten, die selbständig tätig sind, können gemäß § 240 Abs. 4 Satz 2 SGB V auf Nachweis geringere Einnahmen der Beitragspflicht unterliegen.

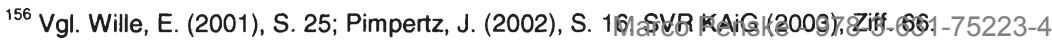


Bei Berücksichtigung der Ausgabenseite zeigt sich jedoch, dass freiwillig Versicherte aufgrund der großen Zahl an Mitversicherten per saldo keinen positiven Einfluss auf die GKV-Finanzen haben müssen (Subventionierungsthese). Tabelle 6 zeigt, dass bei einem freiwillig in der GKV versicherten Mitglied durchschnittlich 0,85 Familienmitglieder beitragsfrei mitversichert sind. Bei den Pflichtmitgliedern sind es durchschnittlich nur 0,49 Familienversicherte.

Tabelle 6: Versicherte nach Art des Versicherungsschutzes im Jahr 2004

\begin{tabular}{|l|c|c|c|c|}
\hline (in Tausend) & Pflichtmitglieder & Freiwillige Mitglieder & Rentner & Summe \\
\hline Mitglieder & 28.591 & 5.069 & 16.831 & 50.491 \\
\hline Familienversicherte & 14.046 & 4.290 & 1.453 & 19.789 \\
\hline Gesamt & 42.637 & 9.359 & 18.284 & 70.280 \\
\hline Anteil Familienvers. & $32,94 \%$ & $45,84 \%$ & $7,95 \%$ & $28,16 \%$ \\
\hline Mitversichertenquote & $49,13 \%$ & $84,63 \%$ & $8,63 \%$ & $39,19 \%$ \\
\hline
\end{tabular}

Daten: BMGS, Mitgliederstatistik KM 6.

Auch die Lohnstruktur der Versicherten beeinflusst aufgrund der Beitragsbemessungsgrenze die Höhe der beitragspflichtigen Einnahmen: Je weiter der Anstieg der Löhne von Pflichtversicherten hinter dem Wachstum der Löhne von freiwillig Versicherten zurückbleibt, desto geringer ist die Zunahme der beitragspflichtigen Einnahmen der GKV im Vergleich zur Bruttolohn- und Gehaltssumme. Durch die Globalisierung dürtte dieser Einfluss noch an Bedeutung gewinnen. Da infolge der EUOsterweiterung das Angebot an Arbeitskräften stärker zunehmen wird als das an Kapital, werden sich die Knappheitsverhältnisse und damit auch die relativen Preise zuungunsten des Faktors Arbeit verschieben. Insbesondere der Druck auf mittlere und untere Lohngruppen wird dadurch steigen und die Einnahmenbasis der GKV schwächen. ${ }^{157}$

Der GKV entstehen auch durch besondere Beitragsregelungen z.B. für Studierende und Praktikanten, für Personen in Einrichtungen der Jugendhilfe oder für Teilnehmer an berufsfördemden Maßnahmen Einnahmenausfälle. ${ }^{158}$ Deren Quantifizierung ist aufgrund der unzureichenden Datenlage und methodischer Probleme außerordentlich schwierig, weil dafür der "normale“ Beitrag bekannt sein müsste. Dieser beinhaltet aber ebenfalls distributive Elemente, die sich nicht eindeutig von Fremdleistungen abgrenzen lassen. Die beitragsfreie Mitversicherung des nicht berufstätigen Ehepartners eines Mitglieds, dessen beitragspflichtige Einnahmen unterhalb der Beitragsbemessungsgrenze liegen, kann z.B. als Normalbeitrag oder als familienpolitische Fremdleistung aufgefasst werden. ${ }^{159}$

Insbesondere die beitragsfreie Mitversicherung von nicht erwerbstätigen Familienangehörigen nach $\S 10$ SGB V führt zu Einnahmenausfällen in der GKV. Tabelle 6 zeigt, dass rund $28 \%$ der Versicherten im Jahr 2004 in der GKV familienversichert waren und demzufolge auch keine eigenen Beiträge entrichtet haben. Beim Vergleich des Anteils der Familienversicherten zwischen der Generation der Erwerbstäti-

\footnotetext{
${ }^{157}$ Vgl. SVR KAiG (1994), Ziff. 196; Wille, E. (1999), S. 14; Wille, E. (2002b), S. 8f.; SVR KAiG (2003), Ziff. 68 .

${ }^{158}$ Vgl. Beske, F. (2001), S. 108f.; Beske, F.; Kern, A.O. (2000), S. 12, 31 .

${ }^{159} \mathrm{Vgl}$. SVR KAiG (2003), Ziff. 120. 
gen (Pflichtmitglieder und freiwillige Mitglieder) und der Rentner zeigt sich ein weiterer intergenerativer Umverteilungseffekt durch die beitragsfreie Familienversicherung. Von dieser profitiert insbesondere die Generation der Erwerbstätigen, da deren Familienversichertenquote höher liegt als die der Rentner. D.h. auf der Einnahmenseite findet durch die beitragsfreie Familienversicherung tendenziell eine Umverteilung zugunsten der Gruppe der Erwerbstätigen statt. Die Ausgaben der GKV für beitragsfrei Familienversicherte schwanken je nach Schätzung zwischen 8 Mrd. Euro $(1999)^{160}$ und 30 Mrd. Euro (1997) ${ }^{161}$. Der Sachverständigenrat für die Konzertierte Aktion im Gesundheitswesen ${ }^{162}$ und Henke ${ }^{163}$ beziffern auf Basis von RSA-Profilen die finanzielle Belastung der GKV durch die beitragsfreie Familienversicherung im Jahr 2002 auf etwa 20,3 Mrd. Euro, wovon 11,0 Mrd. Euro auf die beitragsfreie Mitversicherung von Kindern und Jugendlichen unter 20 Jahren entfallen. ${ }^{164}$

Sieht man diese Leistungen als Teil des Familienleistungsausgleichs und als Aufgabe der gesamten Gesellschaft an, lässt sich daraus die Forderung ableiten, die Familienversicherung als versicherungsfremde Leistung nicht von den GKV-Mitgliedern, sondern aus dem allgemeinen Steueraufkommen zu finanzieren. Diese Auffassung folgt der impliziten Annahme, die Finanzierung der GKV beruhe auf dem Äquivalenzprinzip. Die Finanzierung der GKV folgt aber weitgehend ${ }^{165}$ dem Prinzip der Leistungsfähigkeit, wonach bei fehlendem Einkommen keine Beiträge erhoben werden. ${ }^{166}$ Die Familienversicherung und die damit einhergehenden Einnahmenausfälle können dann als eine Folge der Verteilungsaufgabe der GKV gesehen werden.

\subsubsection{Abhängigkeit vom Arbeitsmarkt}

Neben der Versichertenstruktur hängt die Finanzierungsbasis der GKV durch die Lohnkoppelung der Beiträge auch von der generellen Entwicklung auf dem Arbeitsmarkt ab. Aufgrund des Rückgangs von Vollzeitarbeit und der gleichzeitigen Zunahme von Teilzeitbeschäftigung, geringfügiger Beschäftigung, befristeter Arbeitsverhältnisse oder Scheinselbständigkeit gewinnen nicht beitragspflichtige Einkommen zunehmend an Bedeutung. ${ }^{167}$ Nach einer Zusammenstellung der Kommission für Zukunftsfragen der Freistaaten Bayern und Sachsen ${ }^{168}$ wurde das Normarbeitsverhältnis von 1970 bis 1995 zunehmend durch Nicht-Normarbeitsverhältnisse abgelöst. Auch die Deutsche Bundesbank ${ }^{169}$ stellt für den Zeitraum von 1991 bis 2004 einen

\footnotetext{
${ }^{160}$ Siehe Ruland, F. (2001), S. 1678.

${ }^{161}$ Siehe SVR (2000), Ziff. 484; Beske, F. (2001), S. 110; Schneider, W. (2003), S. 45.

${ }^{162}$ Siehe SVR KAiG (2003), Ziff. 121.

${ }^{163}$ Siehe Henke, K.-D. (2005), S. $106 f$.

${ }^{164}$ Einen Überblick über Schätzungen gibt Rosenschon, A. (2001), S. 11.

${ }^{165} \mathrm{Zu}$ den Verstößen siehe insbes. Abschnitt 4.2.2 Intragenerative Inzidenz, S. 35.

${ }^{166}$ Vgl. SVR (2000), Ziff. 484; Braun, B.; Kühn, H.; Reiners, H. (1998), S. 104f.; Kruse, U.; Kruse, S. (2001), S. 94.

${ }^{167}$ Vgl. stellvertretend Wille, E. (1999), S. 14; Wille, E. (2001), S. 27f.; Amelung, V.; Glied, S.; Topan, A. (2001), S. 284; SVR KAiG (2003), Ziff. 69. Kontrovers hierzu Baumann, E.; Weidmann, J. (2003), S. $178 \mathrm{ff}$.

${ }^{168}$ Siehe Kommission für Zukunftsfragen der Freistaaten Bayern und Sachsen (1996), S. 62ff.

${ }^{169}$ Siehe Deutsche Bundesbank (Hrsg.) (2005a), S. 15ff. Vgl. auch Greß, S.; Walendzik, A.; Wasem, J. (2005), S. $11 \mathrm{ff}$. 
Anstieg der atypischen ${ }^{170}$ Beschäftigungsverhältnisse fest, während gleichzeitig das Normalarbeitsverhältnis an Bedeutung verliert.

Abbildung 10: Norm- und Nicht-Normarbeitsverhältnisse 1970-1995 (Früheres Bundesgebiet)

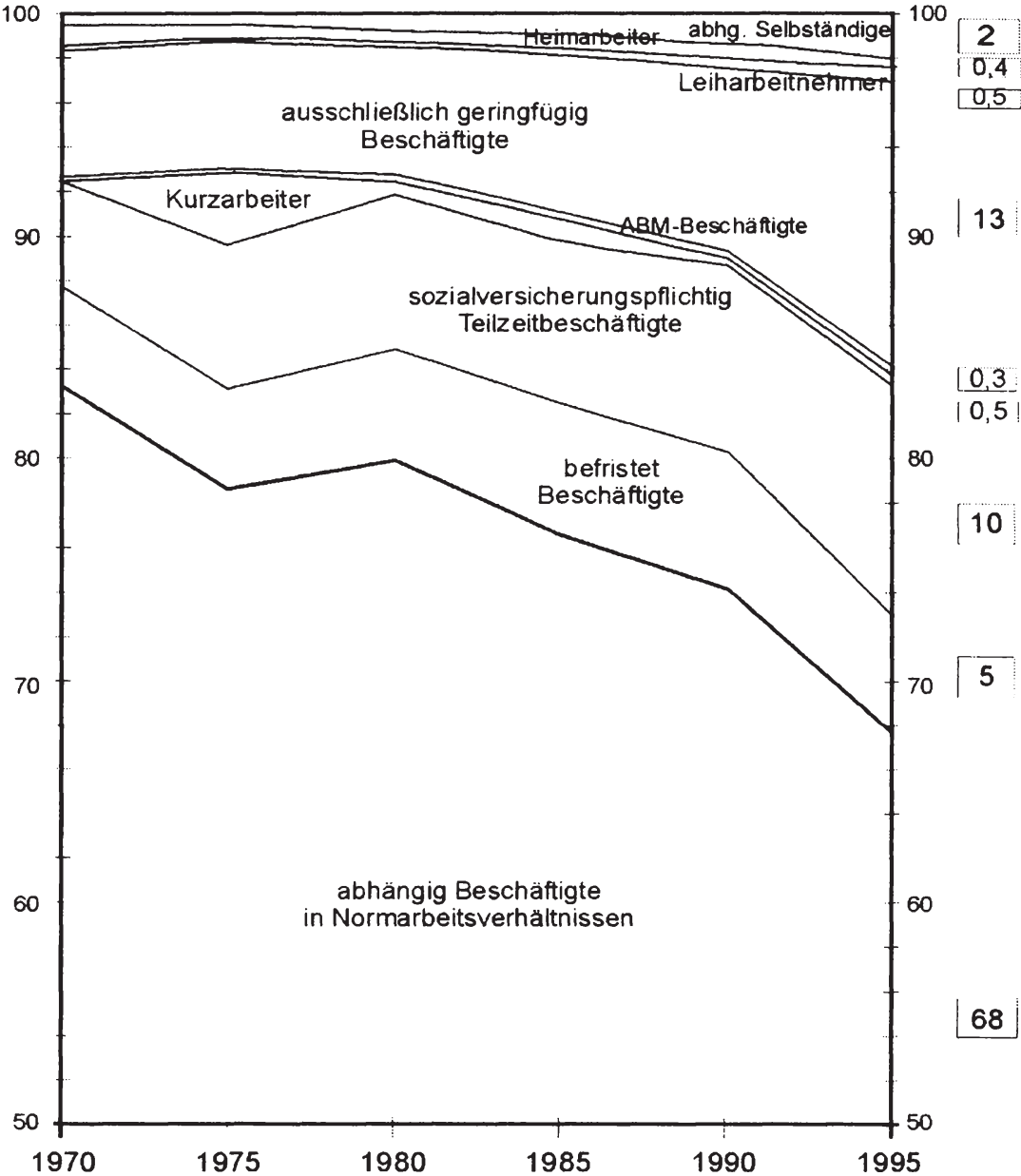

Anmerkung: In Prozent der abhängig Beschäftigten und abhängig Selbständigen.

Quelle: Kommission für Zukunftsfragen der Freistaaten Bayern und Sachsen (Hrsg.) (1996), S. 64.

Wie Abbildung 10 zeigt, ist der Anteil der abhängig Beschäftigten in Normarbeitsverhältnissen an allen Beschäftigten von 1970 bis 1995 im früheren Bundesgebiet von

${ }^{170}$ Unter atypischen Beschäftigungsverhältnissen werden Beschäftigungsformen verstanden, die nicht auf Dauer oder nicht auf Vollzeit angelegt sind. Marco Penske - 978-3-631-75223-4 
über $80 \%$ auf rund $68 \%$ gesunken. ${ }^{171}$ Diese Entwicklung muss für die Einnahmenseite der GKV nicht nachteilig sein, wenn durch einen Anstieg von z.B. TeilzeitBeschäftigungen oder befristeten Beschäftigungsverhältnissen neue Arbeitsplätze entstehen oder vormals nicht berufstätige beitragsfrei Familienversicherte einer Beschäftigung nachgehen ${ }^{172}$, und damit die beitragspflichtigen Einkommen steigen. Problematisch ist diese Entwicklung dagegen, wenn Normarbeitsverhältnisse durch Nicht-Normarbeitsverhältnisse ersetzt werden. Dafür gibt es in Deutschland Hinweise. Im früheren Bundesgebiet sind die Anteile atypischer Beschäftigungsverhältnisse gestiegen, während der Anteil der Erwerbstätigen an der Bevölkerung eher gesunken ist. ${ }^{173}$ Allerdings ist der Wandel branchenabhängig. Die Vollzeitstellen wurden größtenteils in der Industrie und im Baubereich abgebaut, während im Dienstleistungsbereich Teilzeitstellen geschaffen wurden. ${ }^{174}$

Die Gründe für den Strukturwandel der Erwerbsarbeit liegen zum einen in der steigenden Bedeutung des Dienstleistungsbereichs, in dem flexible Beschäftigungsformen notwendig sind, und in der zunehmenden Erwerbsbeteiligung westdeutscher Frauen, die überwiegend Teilzeitarbeitsplätze anstreben. Zum anderen fördern die institutionellen Rahmenbedingungen den Substitutionsprozess. Aufgrund des steigenden Abgabenkeils zwischen Produzenten- und Konsumentenlohn weichen die Unternehmen zunehmend auf Beschäftigungsformen mit geringeren Sozialversicherungsbeiträgen aus, die auch für die Arbeitnehmer attraktiver sind. Hinzu kommt, dass die mit einer Vollzeitbeschäftigung verbundenen Vorschriften zum Kündigungsschutz restriktiv gefasst sind, während die Möglichkeiten anderer Beschäftigungsformen vom Gesetzgeber erweitert und die Regelungen flexibilisiert wurden. ${ }^{175}$ Inwieweit jüngste Regelungen des Gesetzgebers - insbesondere die Hartz-Reformen den Substitutionsprozess gefördert haben, wird im folgenden Abschnitt 4.4.1 Reformen in den Systemen der sozialen Sicherung (S. 65) noch näher zu betrachten sein.

Der Anteil der Teilzeitbeschäftigten an allen Beschäftigten hat sich nach Abbildung 10 von $4 \%$ auf $10 \%$ mehr als verdoppelt. Eine Substitution von Normarbeitsverhältnissen durch Teilzeitbeschäftigungen zeigen auch Angaben des $I A B^{176}$, wonach in Deutschland von 1991 bis 2004 ein Anstieg der Zahl der Teilzeitbeschäftigten um 5,4 Mio. mit einem Rückgang von 5,9 Mio. Vollzeitbeschäftigten einherging. Im Jahr 2004 waren 10,9 Mio. Erwerbstätige teilzeitbeschäftigt. Dies entspricht einem Anteil von $31,6 \%$ an allen Beschäftigten. 4,3 Mio. Personen in Teilzeitarbeit waren im Jahr 2004 sozialversicherungspflichtig beschäftigt. ${ }^{177}$

Für konstante GKV-Einnahmen hätte die Zahl der Teilzeitbeschäftigten deutlich stärker zunehmen müssen, als die der Vollzeitbeschäftigten abgenommen hat. Selbst

\footnotetext{
${ }^{171}$ Zur Problematik der Bestimmung der Anzahl der einzelnen Nicht-Normarbeitsverhältnisse siehe Kommission für Zukunftsfragen der Freistaaten Bayern und Sachsen (1996), S. 143ff.

${ }^{172}$ Vgl. Baumann, E.; Weidmann, J. (2003), S. 181.

${ }^{173} \mathrm{Vgl}$. Kommission für Zukunftsfragen der Freistaaten Bayern und Sachsen (1996), S. 62ff.

${ }^{174} \mathrm{Vgl}$. Deutsche Bundesbank (Hrsg.) (2005a), S. 20f.; Deutsche Bundesbank (Hrsg.) (2005b), S. $40 \mathrm{f}$.

${ }^{175} \mathrm{Vgl}$. Deutsche Bundesbank (Hrsg.) (2005a), S. 23f. Für eine Übersicht über wichtige Änderungen für Beschäftigungsverhältnisse siehe ebenda, S. 25; Mayer-Ahuja, N. (2003), S. 47ff.

${ }^{176}$ Siehe Institut für Arbeitsmarkt- und Berufsforschung der Bundesanstalt für Arbeit (Hrsg.) (2005a).

${ }^{177}$ Vgl. Deutsche Bundesbank (Hrsg.) (2005a), S. 16. Marco Penske - 978-3-631-75223-4
} 
wenn man unterstellt, dass Teilzeitbeschäftigte die halbe Arbeitszeit eines Vollzeitbeschäftigten (mit einem Einkommen unterhalb der Beitragsbemessungsgrenze) arbeiten und über das halbe beitragspflichtige Einkommen verfügen würden, hätten doppelt so viele Teilzeitstellen entstehen müssen wie Vollzeitarbeitsplätze weggefallen sind. Untersuchungen ${ }^{178}$ zeigen zudem, dass der durchschnittliche Stundenlohn eines Teilzeitbeschäftigten nur $91 \%$ des Lohns eines Vollzeitbeschäftigten beträgt. Die Umwandlung von Vollzeit- in Teilzeitarbeitsplätze hat die beitragspflichtigen Einnahmen somit reduziert.

Auch der Anteil der geringfügig Beschäftigten ist im früheren Bundesgebiet von 1970 bis 1995 - wie Abbildung 10 (S. 59) zeigt - von $6 \%$ auf $13 \%$ aller Beschäftigten gestiegen. Im Jahr 2004 waren bundesweit 4,8 Mio. Personen ausschließlich geringfügig beschäftigt, weitere 1,7 Mio. übten ihre geringfügige Tätigkeit als Nebentätigkeit aus. Im Jahr 1991 waren noch knapp 2,5 Mio. Personen geringfügig beschäftigt. ${ }^{179}$ Mit dem starken Anstieg der geringfügigen Beschäftigungsverhältnisse sind für die GKV Beitragsausfälle verbunden, zumal bei geringfügig Beschäftigten ein unter dem normalen Satz liegender Beitragssatz gilt. ${ }^{180}$

Außerdem beeinflusst der Anstieg des Anteils der befristet Beschäftigten die Einnahmen der GKV negativ, weil das durchschnittliche Einkommen eines befristet Beschäftigten lediglich rund $86 \%$ des eines Normalbeschäftigten beträgt. ${ }^{181} \mathrm{Im}$ Jahr 2004 hatten rund 2,5 Mio. Beschäftigte (ohne Auszubildende) einen befristeten Arbeitsvertrag. Dies entsprach einem Anteil von $8,0 \%$ an allen abhängig beschäftigten Erwerbstätigen; im Jahr 1991 lag diese Quote noch bei 7,5\%. ${ }^{182}$

"Scheinselbständige sind Erwerbstätige, die formal als Selbständige tätig sind, aus einer rechtlichen Perspektive jedoch als abhängig Beschäftigte zu bewerten sind. ${ }^{183}$ Trotz zahlreicher Abhängigkeiten gegenüber dem Auftraggeber werden von diesem keine Sozialversicherungsbeiträge gezahlt. Dem Scheinselbständigen steht es frei, als freiwilliges Mitglied in eine gesetzliche Kasse einzutreten. Eine Zunahme der Scheinselbständigkeit zulasten von sozialversicherungspflichtiger Beschäftigung

\footnotetext{
${ }^{178}$ Siehe Schäfer, H. (2001), S. $28 f$.

${ }^{179}$ Vgl. Deutsche Bundesbank (Hrsg.) (2005a), S. 18f. Siehe auch SVR (2004), Ziff. 349. Die Bundesanstalt für Arbeit führt seit 1999 eine Statistik über die geringfügig Beschäftigten; vgl. Rudolph, H. (2003), S. 4.
}

${ }^{180}$ Vgl. BMGS (Hrsg.) (2003a), S. 7, 10 f.

${ }^{181}$ Vgl. Schäfer, H. (2001), S. $28 f$.

${ }^{182}$ Vgl. Statistisches Bundesamt (Hrsg.) (2001); Deutsche Bundesbank (Hrsg.) (2005a), S. 21.

${ }^{183}$ Dietrich, H. (2001), S. 137. Zu unterschiedlichen Abgrenzungen von Scheinselbständigkeit siehe Dietrich, H. (1999), S. 95ff.; Gerber, S. (2003), S. 39ff. Der Gesetzgeber hat in dem „Gesetz zu Korrekturen in der Sozialversicherung und zur Sicherung der Arbeitnehmerrechte" vom 19.12.1998 anstelle der Definition des Begriffs der Scheinselbständigkeit vier Vermutungsmerkmale in $\S 7$ Abs. 4 SGB IV festgelegt. Waren mindestens zwei dieser Kriterien erfüllt, mussten der Beschäftigte und sein Auftraggeber nachweisen, dass es sich um eine selbständige Tätigkeit handelte; vgl. BGBI. 1998, Teil I, Nr. 85, S. 3846; Gutzeit, M.; Goger, K. (2001), S. 654f.; Dieterich, T. (1999), S. 316ff. Mit dem "Gesetz zur Förderung der Selbständigkeit“ wurden die Kriterien am 20.12.1999 rückwirkend für das Jahr 1999 auf fünf erweitert, von denen mindestens drei erfüllt sein mussten; vgl. BGBI. 2000, Teil I, Nr. 1, S. 2. Diese Regelungen wurden mit dem „Zweiten Gesetz für moderne Dienstleistungen am Arbeitsmarkt" vom 23.12.2002 wieder aufgehoben; vgl. BGBI. 2002, Teil I, Nr. 87, S. 4623. 
senkt die Einnahmen der GKV, zumal der Anreiz zur Scheinselbständigkeit gerade darin besteht, Sozialversicherungsbeiträge zu umgehen. Problematisch sind Abgrenzung und Schätzung der Anzahl der Scheinselbständigen. Obergrenze ist die Zahl der Selbständigen ohne Mitarbeiter. Nach einer Scheinselbständigenstudie des $\mid A B^{184}$ sind davon je nach Abgrenzung $49 \%$ bis $68 \%$ scheinselbständig. Demzufolge können im Jahr 2001 mit 770.000 Personen etwa 440.000 Personen mehr als im Jahr 1983 als scheinselbständig bezeichnet werden. ${ }^{185}$

Im Zeitraum von 1992 bis 2004 ist die Zahl der sozialversicherungspflichtig Beschäftigten von 29,3 Mio. auf 26,6 Mio. Personen zurückgegangen. ${ }^{186}$ Allein für die Jahre 2000 bis 2003 wird der Einnahmenausfall aufgrund des Rückgangs der Zahl der sozialversicherungspflichtig Beschäftigten um 850.000 Personen vom Sachverständigenrat zur Begutachtung der gesamtwirtschaftlichen Entwicklung (SVR) ${ }^{187}$ für die GKV auf bis zu 2,8 Mrd. Euro p.a. geschätzt. Diesem Bruttoeffekt müssen jedoch bei Arbeitslosigkeit oder Rentenbezug die entsprechenden Beiträge gegenübergestellt werden.

Die GKV erhält zwar neben den Beiträgen von abhängig Beschäftigten, Selbständigen, anderen freiwillig Versicherten und Rentnern auch Beiträge von Empfängern von Transferzahlungen. Dabei wird i.d.R. aber eine andere (niedrigere) Bemessungsgrundlage unterstellt, so dass es zu Mindereinnahmen für die GKV kommt. ${ }^{188}$

Bei den 2,8 Mio. Sozialhilfeempfängern (2003) ist zunächst zu unterschieden zwischen Sozialhilfebeziehern, die seit 2004 nach § 264 SGB V einer gesetzlichen Kasse zugewiesen werden und für die der Sozialhilfeträger die Aufwendungen zuzüglich der Verwaltungskosten erstattet ${ }^{189}$, und denjenigen Empfängern, die als freiwillige Mitglieder in der GKV versichert sind. ${ }^{190}$ Ersteres traf im Jahr 2004 auf rund 650.000 Personen zu. ${ }^{191}$ Diese sind für die Finanzen der GKV - abgesehen von etwaigen bei den Kassen verbleibenden Verwaltungskosten - ohne Belang. Bei den in der GKV versicherten Sozialhilfeempfängern bemessen sich die Beiträge gemäß $\S 240$ Abs. 1 Satz 2 SGB V nach ihrer gesamten wirtschaftlichen Leistungsfähigkeit. Damit bilden Sozialhilfeleistungen nach dem Bundessozialhilfegesetz und ggf. weitere Einkünfte des Sozialhilfeempfängers die Bemessungsgrundlage für die Berechnung des Beitrags, sofern sie über der in $\S 240$ Abs. 4 Satz 1 SGB V geregelten Mindestbeitragsbemessungsgrundlage liegen, die im Jahr 2005805 Euro p.m.

\footnotetext{
${ }^{184}$ Siehe hierzu ausführlich Dietrich, H. (1999), S. 85ff., insbes. S. $94 \mathrm{ff}$.

${ }^{185}$ Vgl. Baumann, E.; Weidmann, J. (2003), S. 182.

${ }^{186}$ Siehe BMGS (Hrsg.) (2004d), S. 2.6; Arbeitsgemeinschaft deutscher wirtschaftswissenschaftlicher Forschungsinstitute e.V. (Hrsg.) (2005b), S. 39.

${ }^{187}$ Siehe SVR (2004), Ziff. 346.

${ }^{188} \mathrm{Vgl}$. Wille, E. (1998), S. 16. Siehe hierzu auch ein Modell von Wiesemann, H.-O. (2001), S. 114 f.

${ }^{189}$ Mit dieser Neuregelung im Zuge des GMG werden Sozialhilfeempfänger, die zuvor nicht krankenversichert waren, mit in der GKV Versicherten gleichgestellt. Erstattet wird die von der jeweiligen Kasse an die Kassenärztliche Vereinigung gezahlte Kopfpauschale zuzüglich weiterer, damit nicht abgegoltener Leistungen. Ab 2006 sollen die tatsächlichen Ausgaben erstattet werden; vgl. Bundestags-Drucksache 15/1525 vom 08.09.2003, S. 140 f.

${ }^{190}$ Vgl. Beske, F. u.a. (2002), S. $88 \mathrm{ff}$.

${ }^{191}$ Siehe BMGS (Hrsg.) (2005c), S. 39ff. 
beträgt. ${ }^{192}$ Der Beitrag wird vom Sozialhilfeträger gezahlt. Insgesamt wirkt sich die Versicherung von Sozialhilfeempfängern negativ auf die Finanzen der GKV aus, da die durchschnittlichen Beiträge dieser Versichertengruppe unter ihren durchschnittlichen Ausgaben liegen. ${ }^{193}$

Gleichfalls erhält die GKV von Mitgliedern, die Arbeitslosengeld oder Arbeitslosengeld II (bis 2004 Arbeitslosenhilfe) beziehen, geringere Beiträge als bei Erwerbstätigkeit. Bei Beziehern von Arbeitslosengeld unterliegen nach § 232a Abs. 1 Satz 1 Nr. 1 SGB V $80 \%$ des zuletzt bezogenen Bruttoarbeitsentgelts der Beitragszahlung durch die Bundesagentur für Arbeit ( $\$ 251$ Abs. 4a SGB V). Für Empfänger von Arbeitslosengeld II gilt nach § 232a Abs. 1 Satz 1 Nr. 2 SGB V 36,2\% der monatlichen Bezugsgröße als beitragspflichtige Einnahme, was bei einem ermäßigten Beitragssatz von $13,2 \%$ zu einem pauschalen monatlichen Beitrag von rund 115 Euro ${ }^{194}$ führt, der vom Bund gezahlt wird (§251 Abs. 4 SGB V). Liegen weitere beitragspflichtige Einnahmen vor, werden diese zusammen mit dem Arbeitslosengeld II verbeitragt, sofern der Beitrag dann über der Pauschale liegt. Als Beitragssatz gilt für Empfänger von Arbeitslosengeld II gemäß § 246 SGB V der durchschnittliche ermäßigte Beitragssatz zur GKV, für Bezieher von Arbeitslosengeld - wegen ihres Anspruchs auf Krankengeld - der allgemeine Beitragssatz.

Bei der Beurteilung des Einflusses von Arbeitslosigkeit auf die Beitragsgrundlage der GKV sind zwei Fälle zu unterscheiden: Handelt es sich bei den Arbeitslosen um bisher Erwerbstätige, führt ein Anstieg der Arbeitslosigkeit infolge der verminderten Bemessungsgrundlage zu geringeren Einnahmen der GKV. Entscheiden sich jedoch ehemals beitragsfrei Familienversicherte dazu, eine Erwerbstätigkeit aufzunehmen, finden jedoch keine Arbeitsstelle und werden als arbeitslos registriert, steigen die Einnahmen der GKV sogar an, weil für diese Versicherten, die zuvor keine Beiträge zur GKV entrichtet haben, bei Arbeitslosigkeit Beiträge gezahlt werden. ${ }^{195}$

Trifft Letzteres zu, dann müsste mit einer steigenden Arbeitslosenquote auch der Anteil der Pflichtversicherten in der GKV wachsen, da im Gegensatz zu den Familienversicherten Arbeitslose zum Kreis der pflichtversicherten Mitglieder zählen. ${ }^{196}$ Abbildung 9 (S. 56) zeigt aber, dass die Zahl der pflichtversicherten Mitglieder ohne Rentner in Deutschland seit 1991 nicht stärker zunimmt als die der Mitglieder insgesamt. Die Anzahl ist sogar deutlich gesunken, wohingegen bei freiwillig Versicherten und pflichtversicherten Rentnern Zuwächse zu verzeichnen sind. Diese Entwicklung widerspricht der These, die steigende Arbeitslosigkeit habe durch eine Status-Änderung von beitragsfrei Versicherten zu Pflichtversicherten zu einer Zunahme an Beitragszahlern und damit zu einem Wachstum der beitragspflichtigen Einnahmen geführt. ${ }^{197}$

\footnotetext{
${ }^{192}$ Ein Drittel der monatlichen Bezugsgröße, also 28.980 Euro/12/3=805 Euro. Die Bezugsgröße beträgt nach § 18 SGB IV im Jahr 200528.980 Euro p.a.; siehe auch Fußnote 46 (S. 28).

${ }^{193}$ Siehe auch SVR KAiG (1994), Ziff. 197.

${ }^{194} 28.980$ Euro/12*0,3620*0,132=115,40 Euro; siehe auch Fußnote 46 (S. 28).

${ }^{195} \mathrm{Vgl}$. Boetius, J.; Wiesemann, H.-O. (1998), S. $26 f$.

${ }^{196}$ Vgl. SVR KAiG (2003), Ziff. $65 f$.

${ }^{197}$ Vgl. ebenda, Ziff. 65; kontrovers hierzu Boetius, J.MWiesemangk
} 
Das IAB berechnet die durch Arbeitslosigkeit verursachten Mindereinnahmen der GKV als Differenz aus den bei Arbeitslosigkeit gezahlten Beiträgen und den Beitragszahlungen, die der Versicherte bei Erwerbstätigkeit durchschnittlich geleistet hätte. ${ }^{198}$ Ausgegangen wird von einem durchschnittlichen gruppenspezifischen Arbeitseinkommen, das der Arbeitslose in einem Beschäftigungsverhältnis erzielt hätte. Dazu wird das der Lohnersatzleistung zugrunde liegende Bemessungsentgelt erhöht um Einkommensbestandteile, die zwar normalerweise bei einem Arbeitsverhältnis anfallen, bei der Leistungsbemessung aber außer Betracht bleiben (z.B. Überstundenvergütung, Urlaubsgeld). Bei Arbeitslosen ohne Leistungsbezug wird das potentielle Einkommen anhand soziodemographischer Merkmale geschätzt. Tabelle 7 gibt die Ergebnisse wieder. Danach hatte die GKV im Jahr 2004 aufgrund von Arbeitslosigkeit Mindereinnahmen in Höhe von 7,1 Mrd. Euro. 1992 betrugen die Beitragsausfälle noch 2,1 Mrd. Euro. ${ }^{199}$

Tabelle 7: Einnahmenausfälle der GKV infolge von registrierter Arbeitslosigkeit

\begin{tabular}{|l|r|r|r|r|r|r|r|r|r|r|r|r|r|}
\hline (in Mrd. Euro) & 1992 & $\mathbf{1 9 9 3}$ & $\mathbf{1 9 9 4}$ & $\mathbf{1 9 9 5}$ & $\mathbf{1 9 9 6}$ & $\mathbf{1 9 9 7}$ & $\mathbf{1 9 9 8}$ & $\mathbf{1 9 9 9}$ & $\mathbf{2 0 0 0}$ & $\mathbf{2 0 0 1}$ & $\mathbf{2 0 0 2}$ & $\mathbf{2 0 0 3}$ & $\mathbf{2 0 0 4}$ \\
\hline Früheres Bundesgebiet & 1,7 & 2,2 & 2,6 & 3,8 & 4,3 & 4,3 & 3,8 & 3,8 & 3,5 & 3,6 & 3,9 & 4,5 & 4,7 \\
\hline Neue Länder & 0,4 & 0,5 & 0,6 & 0,9 & 1,2 & 1,3 & 1,3 & 1,4 & 1,4 & 1,5 & 1,7 & 2,4 & 2,4 \\
\hline Deutschland $^{1)}$ & 2,1 & 2,7 & 3,1 & 4,7 & 5,5 & 5,6 & 5,1 & 5,2 & 4,9 & 5,1 & 5,6 & 6,9 & 7,1 \\
\hline
\end{tabular}

1) Abweichung durch Rundung.

Daten: Institut für Arbeitsmarkt- und Berufsforschung der Bundesanstalt für Arbeit (Hrsg.) (2005b).

Tabelle 7 gibt allerdings nur die Beitragsausfälle durch registrierte Arbeitslosigkeit wieder. Hinzu kommen noch die geringeren Beiträge von Personen, die zwar faktisch arbeitslos sind, aber gemäß $\S \S 428,125$ und 126 SGB III nicht als Arbeitslose gezählt werden. Dies trifft z.B. für ältere arbeitslose Versicherte zu, die zwar Leistungen beziehen, aber dem Arbeitsmarkt nicht mehr zur Verfügung stehen müssen und deshalb nicht mehr in der Statistik geführt werden. Die Ausgaben für Arbeitslosengeld, Arbeitslosenhilfe und Sozialhilfe sowie die Mindereinnahmen an Steuern und Sozialversicherungsbeiträgen werden für diese Leistungsempfänger-Gruppen auf 10,6 Mrd. Euro für das Jahr 2004 geschätzt. Unterstellt man, dass davon etwa der gleiche Anteil in Höhe von 8,3\% auf die GKV entfällt wie bei den gesamtfiskalischen Kosten der offiziellen Arbeitslosigkeit (85,7 Mrd. Euro), dann hatte die GKV wegen nicht registrierter Arbeitslosigkeit weitere Einnahmenausfälle in Höhe von rund 885 Mio. Euro im Jahr 2004 zu verkraften. ${ }^{200}$

\footnotetext{
${ }^{198}$ Zur Berechnungsmethodik siehe Bach, H.-U.; Spitznagel, E. (2003), S. 3ff.

${ }^{199}$ Neben diesen Mindereinnahmen beeinträchtigt Langzeitarbeitslosigkeit den Gesundheitszustand insbes. durch Krankheiten des Muskel-Skelett-Systems und des Bindegewebes sowie psychische Erkrankungen. Zwar gibt es auch Selektionsprozesse auf dem Arbeitsmarkt zulasten gesundheitlich beeinträchtigter Personen, deren Größe wird aber als gering eingeschätzt; vgl. Hollederer, A. (2003), S. 2, und die dort angegebenen Studien. Damit beeinflusst Arbeitslosigkeit auch die Ausgabenseite der GKV negativ.

${ }^{200}$ Eigene Berechnungen; vgl. Institut für Arbeitsmarkt- und Berufsforschung der Bundesanstalt für Arbeit (Hrsg.) (2005b). 
Insgesamt fielen im Jahr 2004 für die GKV Beiträge von rund 8,0 Mrd. Euro infolge von Arbeitslosigkeit aus. Damit sind umgerechnet 0,8 Prozentpunkte des Beitragssatzes im Jahr 2004 auf Arbeitslosigkeit zurückzuführen, da einem Beitragssatzpunkt GKV-Einnahmen in Höhe von etwa 9,6 Mrd. Euro ${ }^{201}$ entsprechen.

\subsection{Fremdbelastungen}

\subsubsection{Reformen in den Systemen der sozialen Sicherung}

Auch Reformen in anderen Zweigen der sozialen Sicherung - insbesondere in der GRV und der Absicherung bei Arbeitslosigkeit - belasten die Einnahmen der GKV. Die Folgen der negativen Entwicklung des Arbeitsmarktes auf die GKV wurden dadurch in vielen Fällen noch verstärkt. Wird mit der Gesetzgebung das Ziel verfolgt, andere Zweige der Sozialversicherung oder die Haushalte der Gebietskörperschaften zu entlasten, wird auch von „Verschiebebahnhöfen“ gesprochen. Je nach Berechnungsmethodik und Annahmen kumulierte sich die Gesamtbelastung für die GKV durch die Gesetzgebung von 1995 bis zum Jahr 2002 auf Beträge zwischen 12,1 Mrd. Euro und 29,8 Mrd. Euro. ${ }^{202} \mathrm{Zu}$ berücksichtigen ist dabei jedoch, dass bei vielen Maßnahmen nicht im Vordergrund stand, die Belastung zu verschieben, sondern die Finanzierbarkeit des jeweils reformierten Systems sicherzustellen. ${ }^{203}$

Jüngste Einnahmenausfälle für die GKV sind mit den vier Gesetzen für moderne Dienstleistungen am Arbeitsmarkt ${ }^{204}$ (Hartz-Reformen) und dem „Gesetz zu Reformen am Arbeitsmarkt “205 verbunden:

Nach 1997 wurden 2001 die Beiträge von Arbeitslosenhilfe-Empfängern zum zweiten Mal gesenkt. Infolge des Einmalzahlungs-Neuregelungsgesetzes werden nur noch $58 \%$ des Bruttoarbeitsentgelts zur Beitragszahlung herangezogen. ${ }^{206}$ Mit dem

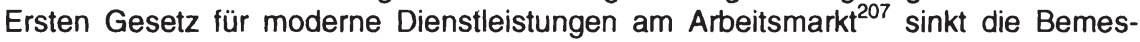
sungsgrundlage auf die Höhe der tatsächlich gezahlten Arbeitslosenhilfe weiter. Die daraus resultierenden Mindereinnahmen der GKV werden auf jährlich 700 Mio. Euro geschätzt. ${ }^{208}$ Weitere Einnahmenverluste entstehen aufgrund einer Senkung der Arbeitslosenhilfe durch eine stärkere Berücksichtigung von Vermögen und der Möglichkeit, das Bemessungsentgelt für Arbeitslosenhilfe unter bestimmten Umständen nach $\S 200$ Abs. 3 SGB III jährlich um $3 \%$ zu kürzen. Die Mindereinnahmen werden ab 2003 auf jährlich 200 Mio. Euro beziffert. ${ }^{209}$ Nach der Zusammenlegung von Arbeitslosen- und Sozialhilfe im SGB II durch Hartz IV ${ }^{210}$ werden seit 2005 für

\footnotetext{
201 Siehe BMGS (Hrsg.) (2005a), S. 2.

${ }^{202}$ Vgl. SVR (2002), Ziff. 250; Beske, F.; Drabinski, T.; Michel, C. (2002), S. 63; Beske, F.; Drabinski, T. (2004a), S. 25

${ }^{203} \mathrm{Vgl.} \mathrm{SVR} \mathrm{(2002),} \mathrm{Ziff.} 249$.

${ }^{204}$ Siehe BGBI. 2002, Teil I, Nr. 87, S. 4607, 4621; BGBI. 2003, Teil I, Nr. 65, S. 2848; BGBI. 2003, Teil I, Nr. 66, S. 2954

205 Siehe BGBI. 2003, Teil I, Nr. 67, S. 3002.

${ }^{206}$ Vgl. SVR (2002), Ziff. 247; SVR KAiG (2003), Ziff. 64; SVR KAiG (1994), Ziff. 198.

207 Siehe BGBI. 2002, Teil I, Nr. 87, S. 4607.

${ }^{208}$ Vgl. Beske, F.; Drabinski, T. (2004a), S. 35; Dräther, H.; Jacobs, K. (2003), S. 105.

${ }^{209} \mathrm{Vgl}$. Beske, F.; Drabinski, T. (2004a), S. 36.

${ }^{210}$ Siehe BGBI. 2003, Teil I, Nr. 66, S. 2954. 
Empfänger von Arbeitslosengeld II $36,2 \%$ der monatlichen Bezugsgröße als beitragspflichtige Einnahme angesetzt ( $\$ 232$ a SGB V). Damit sollte die Umstellung mit einem monatlichen Beitrag von rund 125 Euro $^{211}$ für die GKV kostenneutral sein. ${ }^{212}$ Tatsächlich beträgt die Pauschale aber etwa 115 Euro, weil nach § 246 SGB V für Bezieher von Arbeitslosengeld II der ermäßigte und nicht wie in Hartz IV ursprünglich vorgesehen der allgemeine Beitragssatz gilt. ${ }^{213}$ Wegen der Einführung des Arbeitslosengeld II können ab 2005 bis zu 1,2 Mio. Personen als Empfänger von Arbeitslosengeld II versicherungspflichtig werden; zuvor waren sie als Sozialhilfeempfänger nicht in der GKV versichert. Hierbei handelt es sich um 900.000 arbeitslos gemeldete Sozialhilfeempfänger und 300.000 enwerbsfähige Sozialhilfeempfänger, die sich neu als arbeitslos registrieren lassen, um Anspruch auf Arbeitslosengeld II zu erhalten. ${ }^{214}$ Werden deren Beiträge mit den durchschnittlichen Beiträgen der GKV-Mitglieder ohne Rentner in Höhe von gut 250 Euro $^{215}$ verglichen, ergibt sich eine Mindereinnahme für die GKV von bis zu 1,95 Mrd. Euro. ${ }^{216}$

Zu einer Ausweitung der Versicherungspflicht in diesem Ausmaß wird es jedoch nicht kommen, da nicht davon auszugehen ist, dass dieser Personenkreis vollständig neu versicherungspflichtig wird. Genaue Daten liegen bisher nicht vor, da in der amtlichen Sozialstatistik der Versicherungsstatus von Sozialhilfeempfängern nicht erfasst wird. Statistisch erfasst werden lediglich die nach § 264 SGB V von den Sozialhilfeträgern betreuten Sozialhilfeempfänger. Dies waren rund 650.000 Personen im Jahr 2004. ${ }^{217} 300.000$ Sozialhilfeempfänger waren im Jahr 2004 nach groben Schätzungen in der GKV versichert. Über den Versicherungsstatus der verbleibenden fast 2 Mio. Sozialhilfeempfänger liegen keine Informationen vor. Zudem wird ein Teil der bisherigen Empfänger von Arbeitslosenhilfe aufgrund verschärfter Einkommens- und Vermögensanrechnungen kein Arbeitslosengeld II erhalten. Dadurch können - sofern es sich nicht um Familienversicherte handelt - bis zu 300.000 Versicherte versicherungsfrei werden. ${ }^{218}$ Letztendlich müssen zur Bewertung der Folgen der Einführung von Arbeitslosengeld II für die GKV einer Belastung mögliche Mehreinnahmen gegenübergestellt werden, wenn wegen der Neuregelung sozialversicherungspflichtige Arbeitsplätze entstehen. Die Gesamtbelastung der GKV ergibt sich ohnehin aus dem Vergleich von Einnahmen und Ausgaben für den neu zu versichernden Personenkreis. Die durchschnittlichen Ausgaben dürtten aufgrund des schlechteren Gesundheitsrisikos ${ }^{219}$ zwar über den durchschnittlichen Ausgaben für

\footnotetext{
${ }^{211} 28.980$ Euro $/ 12^{*} 0,3620^{*} 0,143=125,01$ Euro; siehe auch Fußnote 46 (S. 28).

${ }^{212} \mathrm{Vgl}$. Bundestags-Drucksache 15/1516 vom 05.09.2003, S. 72.

${ }^{213}$ Durch das Verwaltungsvereinfachungsgesetz vom 21.03.2005 wurde der Beitragssatz geändert; siehe BGBI. 2005, Teil I, Nr. 18, S. 818.

${ }^{214}$ Siehe Deutsche Bundesbank (Hrsg.) (2004b), S. 43.

${ }^{215}$ Siehe auch Tabelle 3: Beiträge und Ausgaben für Mitglieder und Rentner 1992-2004, S. 40.

${ }^{216}(250-115)^{\star} 12^{\star} 1.200 .000=1.944 .000 .000$ [Euro]. Siehe hierzu auch Beske, F.; Drabinski, T. (2004a), S. 42f., die allerdings erwerbsfähige Sozialhilfeempfänger, die sich neu arbeitslos melden, nicht berücksichtigen.

${ }^{217}$ Siehe BMGS (Hrsg.) (2005c), S. 39ff.

${ }^{218} \mathrm{Vgl}$. Greß, S.; Walendzik, A.; Wasem, J. (2005), S. $36 f$.

${ }^{219}$ Siehe Fußnote 199 (S. 64).

Marco Penske - 978-3-631-75223-4
} 
GKV-Mitglieder von monatlich 170 Euro liegen, wie weit sie über dem Mindestbeitrag von 115 Euro liegen, ist aber bislang kaum abzuschätzen.

Nach Hartz I werden Arbeitslosengeld, Arbeitslosenhilfe und Unterhaltsgeld ab 2003 nicht mehr an die allgemeine Lohnentwicklung angepasst. Die dadurch entstehenden Mindereinnahmen für die GKV werden mit jährlich 20 Mio. Euro beziffert. ${ }^{220}$ Auf mindestens 100 Mio. Euro werden die jährlichen Einnahmenausfälle durch die Entgeltsicherung nach $\S 421 \mathrm{j}$ SGB III für ältere Arbeitnehmer geschätzt, da auf die Zuschüsse keine GKV-Beiträge anfallen. ${ }^{221}$ Wegen des verkürzten Anspruchs auf Arbeitslosengeld (18 Monate statt 32 ) erhalten die Betroffenen früher das geringere Arbeitslosengeld II. Damit sinken auch die Beiträge zur GKV. Aufgrund von Übergangsregelungen werden die jährlichen Einnahmenverluste ab 2006 auf jährlich 600 Mio. Euro geschätzt. ${ }^{222}$

Gemäß Hartz $\|^{223}$ wurde die in $\S 8$ SGB IV geregelte monatliche Entgeltgeringfügigkeitsgrenze zum 01.04.2003 von 325 Euro auf 400 Euro angehoben. ${ }^{24}$ Nach $§ 249 \mathrm{~b}$ SGB V wird bei diesen Mini-Jobs nur ein vom Arbeitgeber zu zahlender Beitragssatz von $11 \%$, bei einer Beschäftigung in Privathaushalten von $5 \%$, auf das Arbeitsentgelt fällig. Entstünde hierdurch zusätzliche Beschäftigung ohne Verdrängungseffekte, könnten die Einnahmen der GKV sogar steigen, maximal um 1,8 Mrd. Euro im Jahr 2004 - den tatsächlichen Beiträgen aus Mini-Jobs. ${ }^{225}$ Würden hingegen im anderen Extremfall alle Mini-Jobs aus der Umwandlung sozialversicherungspflichtiger Beschäftigungsverhältnisse resultieren, wären damit für die GKV im Jahr 2004 Einnahmenausfälle von bis zu 541 Mio. Euro verbunden. ${ }^{226}$

Nach ersten Schätzungen werden durch diese Neuregelung im Zuge von Hartz II 741.000 vormals versicherungspflichtige Beschäftigungsverhältnisse sozialversicherungsfrei, vor allem weil neben einer sozialversicherungspflichtigen Hauptbeschäftigung eine geringfügige Beschäftigung sozialversicherungsfrei ausgeübt werden kann. ${ }^{227}$ Die Einnahmenausfälle werden ab 2004 mit jährlich 180 Mio. Euro beziffert. ${ }^{228}$ Außerdem entstehen durch Hartz II rund 1,12 Mio. Midi-Jobs im Niedriglohnbereich von monatlich 400 Euro bis 800 Euro (Gleitzone) mit niedrigeren Kassenbeiträgen. Der Anstieg beruht allerdings überwiegend auf der Umwandlung bestehender regulärer Beschäftigungsverhältnisse. ${ }^{229} \mathrm{Da}$ nach $\S 226$ Abs. 4 SGB V das Arbeitsentgelt bei Midi-Jobs in der Gleitzone nur anteilig beitragspflichtig ist, werden die Einnahmenausfälle für die GKV ab 2004 auf jährlich 340 Mio. Euro geschätzt. ${ }^{230}$

\footnotetext{
${ }^{220}$ Vgl. Beske, F.; Drabinski, T. (2004a), S. $36 f$.

${ }^{221} \mathrm{Vgl}$. ebenda, S. 37 .

${ }^{222} \mathrm{Vgl}$. ebenda, S. $43 \mathrm{f}$.

${ }^{223}$ Siehe BGBI. 2002, Teil I, Nr. 87, S. 4621.

${ }^{224}$ Zur Neuregelung siehe auch Abschnitt 3.1 Beitragserhebung, S. 27.

${ }^{225}$ Siehe Schätzerkreis der Gesetzlichen Krankenversicherung (2005), S. 3.

${ }^{226} \mathrm{Vgl}$. SVR (2004), Ziff. 349, Tabelle 58.

${ }^{227}$ Vgl. Rudolph, H. (2003), S. 5.

${ }^{228} \mathrm{Vgl}$. Beske, F.; Drabinski, T. (2004a), S. 39. Die Bundesregierung geht indes von Einnahmenausfällen von jährlich 100 Mio. Euro aus; vgl. o.V. (2003), S. 6.

${ }^{229}$ Vgl. Rudolph, H. (2003), S. 1.

${ }^{230}$ Vgl. Beske, F.; Drabinski, T. (2004a), S. 39f. $\quad$ Marco Penske - 978-3-631-75223-4
} 
Ob zusätzliche Einnahmen aufgrund neuer Beschäftigungsverhältnisse die Beitragsausfälle kompensieren, ist umstritten, zumal die Zahl der sozialversicherungspflichtig Beschäftigten sinkt, was darauf hinweist, dass sozialversicherungspflichtige Tätigkeiten verdrängt werden. Steiner und Wrohlich ${ }^{231}$ ermitteln anhand eines Mikrosimulationsmodells nur geringe Beschäftigungseffekte, womit sich Beitragsausfälle für die GKV in Höhe von 392 Mio. Euro ergeben. ${ }^{232}$ Die Deutsche Bundesbank ${ }^{233}$ kommt hingegen zu dem Ergebnis, dass es sich bei den geringfügigen Beschäftigungsverhältnissen größtenteils um zusätzliche Arbeitsverhältnisse handelt. Ein differenziertes Bild zeigen Untersuchungen der Bundesagentur für Arbeit ${ }^{234}$. Danach gibt es Branchen, in denen die Zahl der sozialversicherungspflichtig Beschäftigten sinkt und gleichzeitig die Zahl der Mini-Jobs stark zunimmt (z.B. Gastgewerbe, Verkehr). Es gibt aber auch Bereiche, in denen beide Beschäftigungsarten zunehmen (z.B. Beratungsunternehmen, Sozialwesen). Empirisch lässt sich bislang keine eindeutige Wirkung auf die Beschäftigung nachweisen. ${ }^{235}$

Im Zuge von Hartz II wurde auch die sogenannte Ich-AG eingeführt; bezeichnet wird hiermit die Beschäftigung vormals Arbeitsloser, die nach § 421 SGB III einen Existenzgründerzuschuss erhalten. Da für sie gemäß $§ 240$ Abs. 4 SGB V der Mindestbeitrag weiter abgesenkt wurde, entstehen der GKV zunächst Mindereinnahmen im Vergleich zu den Beiträgen, die diese als Empfänger von Arbeitslosengeld oder Arbeitslosengeld II geleistet hätten. Nach Angaben der Spitzenverbände der Krankenkassen betragen die jährlichen Mindereinnahmen je Person in einer Ich-AG rund 1.000 Euro. Im Jahr 2004 erhielten im Jahresdurchschnitt 80.000 Personen einen Existenzgründerzuschuss. Die jährlichen Mindereinnahmen für die GKV beliefen sich damit auf 80 Mio. Euro. ${ }^{236}$

Nicht genau beziffert werden können weitere finanzielle Belastungen durch Hartz II, die Z.B. durch ein späteres Eintreten der Versicherungspflicht nach $\S 8$ Abs. 2 SGB IV bei mehreren geringfügigen Beschäftigungsverhältnissen auftreten. Kaum abschätzbar sind auch die finanziellen Belastungen durch den Umbau der Bundesagentur für Arbeit nach Hartz $\|^{237} \cdot{ }^{238}$ Zusammen mit den Neuregelungen am Arbeitsmarkt betragen die Mindereinnahmen der GKV durch die „Hartz-Gesetze“ im Jahr 2005 voraussichtlich nahezu 3 Mrd. Euro.

Hinzu kommen rentenrechtliche Neuregelungen:

Die Beitragsfreistellung eines Teils des Einkommens für den Aufbau einer privaten Altersvorsorge („Riester-Rente“) belastet die Einnahmen der GKV. Die Einnahmen-

\footnotetext{
${ }^{231}$ Siehe Steiner, V.; Wrohlich, K. (2005), S. $141 \mathrm{ff}$.

${ }^{232}$ Eigene Berechnung; vgl. Steiner, V.; Wrohlich, K. (2005), S. 145. Unterstellt wird, dass ein Drittel bei einem Gesamtsozialversicherungsbeitragssatz von $42 \%$ entfallen rund $14 \%$ auf die GKV der Ausfälle an Sozialversicherungsbeiträgen die GKV betrifft.

${ }^{233}$ Siehe Deutsche Bundesbank (Hrsg.) (2005b), S. 8, $40 f$.

${ }^{234}$ Siehe Bundesagentur für Arbeit (Hrsg.) (2004), S. $11 \mathrm{ff}$.

${ }^{235} \mathrm{Vgl}$. Bundesagentur für Arbeit (Hrsg.) (2004), S. 3, 12; Arbeitsgemeinschaft deutscher wirtschaftswissenschaftlicher Forschungsinstitute e.V. (Hrsg.) (2005a), S. $94 f$.

${ }^{236}$ Vgl. Beske, F.; Drabinski, T. (2004a), S. 40 f.

${ }^{237}$ Siehe BGBI. 2003, Teil I, Nr. 65, S. 2848.

${ }^{238} \mathrm{Vgl}$. Beske, F.; Drabinski, T. (2004a), S. 41 f. 
ausfälle für die Kassen werden im Jahr 2002 auf 360 Mio. Euro geschätzt. Aufgrund des steigenden Anteils der abzugsfähigen Beträge können die Einnahmenauställe bis zum Jahr 2008 auf bis zu 2,8 Mio. Euro p.a. ansteigen. ${ }^{239}$ Weitere Beitragsausfälle entstehen durch beitragsfreie Entgeltumwandlungen: Im Zuge der Neuregelung der privaten Altersvorsorge hat der Arbeitnehmer die Möglichkeit, einen Teil seines Arbeitsentgelts durch Entgeltumwandlung bis zum Jahr 2008 sozialabgabenfrei in eine betriebliche Altersvorsorge zu investieren. Der GKV entstanden dadurch je nach Berechnungsmethodik und Annahmen über den Umfang der Nutzung Beitragsausfälle zwischen 164 Mio. Euro und 3,0 Mrd. Euro im Jahr 2002. ${ }^{240}$ Neuere Schätzungen gehen ab 2004 von jährlichen Einnahmenausfällen von 280 Mio. Euro aus. ${ }^{241}$

Die Aussetzung der Rentenanpassung nach dem Zweiten Gesetz zur Änderung des Sechsten Buches Sozialgesetzbuch und anderer Gesetze ${ }^{242}$ zum 01.07.2004 hat für die GKV Einnahmenausfälle in den Jahren 2004 und 2005 von je 140 Mio. Euro zur Folge gehabt. Das gleiche Gesetz ${ }^{243}$ belastet die GKV ab 2006 mit jährlich 100 Mio. Euro durch die Verschiebung des Auszahlungstermins der Rente für Neurentner an das Monatsende. ${ }^{244}$

Infolge des RV-Nachhaltigkeitsgesetzes ${ }^{245}$ wird die jährliche Rentenanpassung insbesondere durch einen Nachhaltigkeitsfaktor in § 68 SGB VI verändert. Dadurch werden das Rentenniveau und damit die Beiträge der Rentner im Vergleich zu denen der erwerbstätigen Mitglieder in Zukunft weiter sinken. Die Schätzungen der Einnahmenverluste, die sich daraus ergeben, sind aufgrund fortdauernder Diskussionen um Reformen in der GRV mit großer Unsicherheit behaftet. Die Spitzenverbände der Krankenkassen rechnen mit Beitragsausfällen von jährlich 100 Mio. Euro. ${ }^{246} \mathrm{Die}$ Bundesregierung beziffert die Belastung hingegen mit 50 Mio. Euro 2005, 170 Mio. Euro 2006 und 310 Mio. Euro im Jahr 2007. ${ }^{247}$

Tabelle 8 gibt in chronologischer Reihenfolge einen Überblick über quantifizierbare Maßnahmen seit 1989, die die GKV-Finanzen jährlich belasten. Demnach wird die GKV im Jahr 2005 allein durch die Maßnahmen, deren Wirkung geschätzt werden kann, mit mindestens $10 \mathrm{Mrd}$. Euro negativ beeinflusst. Hinzu kommen die nicht oder noch nicht quantifizierbaren Neuregelungen, so dass auch in den kommenden Jahren keine geringere Belastung zu enwarten ist.

\footnotetext{
${ }^{239}$ Vgl. Schwarz, W. (2002), S. 53 f.

${ }^{240}$ Vgl. Beske, F.; Drabinski, T.; Michel, C. (2002), S. 50ff. Siehe hierzu auch Schmähl, W. (2002b), S. 664ff.; Rosenbrock, R.; Gerlinger, T. (2004), Tabelle 22; SVR (2004), Ziff. 348.

${ }^{241}$ Vgl. Beske, F.; Drabinski, T. (2004a), S. 25.

${ }^{242}$ Siehe BGBI. 2003, Teil I, Nr. 67, S. 3013.

${ }^{243}$ Siehe ebenda, S. 3019.

${ }^{244} \mathrm{Vgl}$. Beske, F.; Drabinski, T. (2004a), S. $45 f$.

${ }^{245}$ Siehe BGBI. 2004, Teil I, Nr. 38, S. 1791.

${ }^{246} \mathrm{Vgl}$. Beske, F.; Drabinski, T. (2004a), S. 46.

${ }^{247} \mathrm{Vgl}$. Bundestags-Drucksache 15/2149 vom 09.12. RPQ3
} 
Tabelle 8: Belastung der GKV durch Reformen in der Sozialversicherung

\begin{tabular}{|c|c|c|}
\hline Maßnahme & Gesetzesgrundlage & $\begin{array}{l}\text { Belastung im } \\
\text { Jahr } 2005 \\
\text { (in Mrd. Euro) }\end{array}$ \\
\hline $\begin{array}{l}\text { Senkung der beitragspflichtigen Einnahmen } \\
\text { für Leistungsbezieher nach dem } \\
\text { Arbeitsförderungsgesetz }\end{array}$ & $\begin{array}{l}\text { Rentenreformgesetz } 1992 \text { vom } \\
\text { 18.12.1989 }\end{array}$ & 1,89 \\
\hline $\begin{array}{l}\text { Senkung der beitragspflichtigen Einnahmen } \\
\text { für Bezieher von Übergangsgeld }\end{array}$ & $\begin{array}{l}\text { Rentenreformgesetz } 1992 \text { vom } \\
18.12 .1989\end{array}$ & 0,20 \\
\hline Erhöhung der Beiträge aus Krankengeld & $\begin{array}{l}\text { Rentenreformgesetz } 1992 \text { vom } \\
18.12 .1989\end{array}$ & 0,47 \\
\hline $\begin{array}{l}\text { Senkung der Entgeltfortzahlung im } \\
\text { Krankheitsfall1) }\end{array}$ & $\begin{array}{l}\text { Arbeitsrechtliches Beschäftigungs- } \\
\text { förderungsgesetz vom 25.09.1996 }\end{array}$ & \\
\hline $\begin{array}{l}\text { Senkung der Beitragsbemessungsgrundlage } \\
\text { für Bezieher von Arbeitslosenhilfe }\end{array}$ & $\begin{array}{l}\text { Wachstums- und Beschäftigungs- } \\
\text { förderungsgesetz vom 25.09.1996 }\end{array}$ & 0,12 \\
\hline $\begin{array}{l}\text { Neuregelung der Beitragsbemessung für } \\
\text { freiwillig in der GKV versicherte } \\
\text { Sozialhilfeempfänger }\end{array}$ & $\begin{array}{l}\text { Urteile des Bundessozialgerichts vom } \\
19.12 .2000\end{array}$ & 0,19 \\
\hline $\begin{array}{l}\text { Neuregelung der Renten wegen } \\
\text { Erwerbsminderung }\end{array}$ & $\begin{array}{l}\text { Gesetz zur Reform der Renten wegen } \\
\text { verminderter Erwerbsfähigkeit vom } \\
\text { 20.12.2000 }\end{array}$ & 0,72 \\
\hline $\begin{array}{l}\text { Senkung der beitragspflichtigen Einnahmen } \\
\text { für Bezieher von Arbeitslosenhilfe }\end{array}$ & $\begin{array}{l}\text { Einmalzahlungs-Neuregelungsgesetz } \\
\text { vom 21.12.2000 }\end{array}$ & 0,61 \\
\hline Einführung der „Riester-Rente“ & $\begin{array}{l}\text { Altersvermögensgesetz vom } \\
26.06 .2001\end{array}$ & $0,36-2,8$ \\
\hline Beitragsausfälle durch Entgeltumwandlung & $\begin{array}{l}\text { Altersvermögensgesetz vom } \\
\text { 26.06.2001 }\end{array}$ & $0,28^{2}$ \\
\hline Übernahme von Leistungen & $\begin{array}{l}\text { Pflegeleistungsergänzungsgesetz } \\
\text { vom 14.12.2001 }\end{array}$ & 1,50 \\
\hline $\begin{array}{l}\text { Neuregelung der Krankenversicherung der } \\
\text { Rentner }\end{array}$ & $\begin{array}{l}\text { 10. SGB V-Änderungsgesetz vom } \\
\text { 23.03.2002 }\end{array}$ & 0,15 \\
\hline $\begin{array}{l}\text { Minderung der Bemessungsgrundlage für } \\
\text { Bezieher von Arbeitslosenhilfe auf die Höhe } \\
\text { der tatsächlich gezahlten Arbeitslosenhilfe }\end{array}$ & $\begin{array}{l}\text { Erstes Gesetz für moderne } \\
\text { Dienstleistungen am Arbeitsmarkt } \\
\text { vom 23.12.2002 }\end{array}$ & 0,7 \\
\hline $\begin{array}{l}\text { Minderung der ausgezahlten Arbeitslosen- } \\
\text { hilfe }\end{array}$ & $\begin{array}{l}\text { Erstes Gesetz für moderne } \\
\text { Dienstleistungen am Arbeitsmarkt } \\
\text { vom 23.12.2002 }\end{array}$ & 0,2 \\
\hline $\begin{array}{l}\text { Wegfall der Dynamisierung des Bemes- } \\
\text { sungsentgelts für Entgeltersatzleistungen }\end{array}$ & $\begin{array}{l}\text { Erstes Gesetz für moderne } \\
\text { Dienstleistungen am Arbeitsmarkt } \\
\text { vom 23.12.2002 }\end{array}$ & 0,02 \\
\hline Entgeltsicherung für ältere Arbeitnehmer & $\begin{array}{l}\text { Erstes Gesetz für moderne } \\
\text { Dienstleistungen am Arbeitsmarkt } \\
\text { vom 23.12.2002 }\end{array}$ & 0,1 \\
\hline $\begin{array}{l}\text { Erhöhung der Entgeltgeringfügigkeitsgrenze } \\
\text { von } 325 \text { Euro auf } 400 \text { Euro }\end{array}$ & $\begin{array}{l}\text { Zweites Gesetz für moderne } \\
\text { Dienstleistungen am Arbeitsmarkt } \\
\text { vom 23.12.2002 }\end{array}$ & 0,18 \\
\hline $\begin{array}{l}\text { Einführung einer Gleitzone für } \\
\text { Arbeitsentgelte zwischen } 400 \text { und } 800 \text { Euro }\end{array}$ & $\begin{array}{l}\text { Zweites Gesetz für moderne } \\
\text { Dienstleistungen am Arbeitsmarkt } \\
\text { vom 23.12.2002 }\end{array}$ & 0,34 \\
\hline $\begin{array}{l}\text { Beitragsbemessung für Selbständige in der } \\
\text { "Ich-AG“ }\end{array}$ & $\begin{array}{l}\text { Zweites Gesetz für moderne } \\
\text { Dienstleistungen am Arbeitsmarkt } \\
\text { vom 23.12.2002 }\end{array}$ & 0,08 \\
\hline $\begin{array}{l}\text { Reduzierung der Anspruchsdauer auf } \\
\text { Arbeitslosengeld }\end{array}$ & $\begin{array}{l}\text { Gesetz zu Reformen am Arbeitsmarkt } \\
\text { vom 24.12.2003 }\end{array}$ & $\left(0,6^{3}\right)$ \\
\hline $\begin{array}{l}\text { Neuregelung der Beitragsbemessung für } \\
\text { Empfänger von Arbeitslosengeld II und } \\
\text { Ausweitung der Versicherungspflicht }\end{array}$ & $\begin{array}{l}\text { Viertes Gesetz für moderne } \\
\text { Dienstleistungen am Arbeitsmarkt } \\
\text { vom 24.12.2003 }\end{array}$ & 1,35 \\
\hline
\end{tabular}




\begin{tabular}{|l|l|l|}
\hline Aussetzung der Rentenanpassung 2004 & $\begin{array}{l}\text { Zweites Gesetz zur Änderung des } \\
\text { Sechsten Buches Sozialgesetzbuch } \\
\text { und anderer Gesetze vom 27.12.2003 }\end{array}$ & $0,14^{4}$ \\
\hline $\begin{array}{l}\text { Verschiebung des Auszahlungstermins der } \\
\text { Rente für Neurentner }\end{array}$ & $\begin{array}{l}\text { Drittes Gesetz zur Ánderung des } \\
\text { Sechsten Buches Sozialgesetzbuch } \\
\text { und anderer Gesetze vom 27.12.2003 }\end{array}$ & 0,1 \\
\hline $\begin{array}{l}\text { Modifikation der jährlichen Rentenanpas- } \\
\text { sung }\end{array}$ & $\begin{array}{l}\text { RV-Nachhaltigkeitsgesetz vom } \\
21.07 .2004\end{array}$ & $0,05-0,1^{5}$ \\
\hline Summe & & $\mathbf{9 , 8 - 1 2 , 2}$ \\
\hline
\end{tabular}

1) Diese Regelung galt bis zum 30.06.1999; siehe BGBI. 1998, Teil I, Nr. 85, S. $3849 f$.

2) Diese Regelung ist beschränkt bis zum 31.12.2008.

3) Ab 2006.

4) In den Jahren 2004 und 2005.

5) 2006: 0,17 Mrd. Euro; 2007: 0,31 Mrd. Euro.

Quelle: Eigene Zusammenstellung in Anlehnung an Beske, F.; Drabinski, T. (2004a), S. 25.

Außerdem sind Einnahmenausfälle von bislang geschätzt 300 Mio. Euro auf den erleichterten Zugang von Rentnern zur Krankenversicherung der Rentner infolge eines Urteils des Bundesverfassungsgerichts ${ }^{248}$ zurückzuführen. ${ }^{249}$ Die meisten der bislang freiwillig versicherten Rentner wurden durch den auf das Urteil folgenden Beschluss des Gesetzgebers ab 01.04.2002 zu pflichtversicherten Rentnern. Dies führt für die GKV zu Mindereinnahmen, weil die betroffenen Rentner keine Beiträge mehr auf Zinseinkünfte sowie auf Einkünfte aus Vermietung und Verpachtung zahlen müssen. ${ }^{250}$ Die Mindereinnahmen werden ab 2005 auf jährlich 150 Mio. Euro beziffert. ${ }^{251}$

Weitere Belastungen drohen der GKV durch eine Entscheidung des Bundessozialgerichts ${ }^{252}$ aus dem Jahr 2003, das den beitragsfreien Zugang zur Familienversicherung erleichtert. Bislang sind Familienangehörige in der GKV kostenlos mitversichert, wenn gemäß $\S 10$ Abs. 1 Nr. 5 SGB V ihr monatliches Einkommen unter 345 Euro (2005) liegt. Nach dem Urteil soll in Zukunft als Einkommen das Einkommen im Sinne des Einkommensteuerrechts gelten. Dies bedeutet, dass auch steuerliche Freibeträge und Werbungskosten geltend gemacht werden können.

\subsubsection{Folgen der Deutschen Einheit}

Neben den Reformen in anderen Zweigen der sozialen Sicherung belasten auch die wirtschaftlichen Folgen der Wiedervereinigung die Einnahmen der GKV. Drabinski und Beske ${ }^{253}$ zeigen, dass die Wiedervereinigung die Wachstumsraten der beitragspflichtigen Einnahmen negativ beeinflusst hat. Ohne die Wiedervereinigung hätte demnach der Beitragssatz in den alten Ländern im Jahr 2003 demnach bei 12,4 \% anstelle von $14,3 \%$ gelegen.

\footnotetext{
${ }^{248}$ Siehe Entscheidung des Bundesverfassungsgerichts vom 15.03.2000, Az 1 BvL 16/96, S. 68ff., und die zugehörige Pressemitteilung Nr. 101 vom 27.07.2000, Regelung über Zugang zur Krankenversicherung der Rentner verfassungswidrig, S. $1 \mathrm{ff}$.

${ }^{249}$ Vgl. Schwarz, W. (2002), S. 50.

${ }^{250}$ Vgl. Presse- und Informationsamt der Bundesregierung (Hrsg.) (2002), S. 13 f.

${ }^{251} \mathrm{Vgl}$. Beske, F.; Drabinski, T. (2004a), S. 25.

${ }^{252}$ Siehe hierzu Entscheidung des Bundessozialgerichts vom 22.05.2003, Az B 12 KR 13/02 R, S. $2 \mathrm{ff}$.

${ }^{253}$ Siehe Drabinski, T.; Beske, F. (2003), S. 9ff., 29. Marco Penske - 978-3-631-75223-4
} 
Der Beitragssatz zur GKV in den neuen Bundesländern wurde im Jahr 1991 einheitlich auf $12,8 \%$ festgelegt. Seit 1992 kalkulieren die Kassen ihre Beitragssätze selbständig. Von 1992 bis 1995 blieb das Beitragssatzniveau in den neuen Ländern unterhalb des Niveaus in Westdeutschland. Trotz höherer durchschnittlicher Beitragssätze ab 1996 wies die GKV-Ost von 1995 bis 1998 indes Defizite auf, die sich im Jahr 1998 auf insgesamt 0,87 Mrd. Euro summierten. Daraufhin wurden mit dem GKV-Finanzstärkungsgesetz und dem Gesetz zur Rechtsangleichung in der GKV ab 1999 über den RSA Transfers von den alten in die neuen Bundesländern eingeführt. Damit wird versucht, die aufgrund der negativen Arbeitsmarktentwicklung ungünstigere Einnahmensituation der Kassen in den neuen Bundesländern auszugleichen. ${ }^{254}$

Tabelle 9: RSA-Transfers zugunsten der GKV-Ost 1999-2005

\begin{tabular}{|l|c|c|c|c|c|c|c|}
\hline Jahr & 1999 & 2000 & 2001 & 2002 & 2003 & 2004 & 2005 \\
\hline $\begin{array}{l}\text { West-Ost-Transfers } \\
\text { (in Mrd. Euro) }\end{array}$ & 0,5 & 1,7 & 2,1 & 2,4 & 2,8 & $3,1^{1}$ & $3,4^{1}$ \\
\hline
\end{tabular}

${ }^{1}$ Geschätzter Wert.

Daten: BMGS (Hrsg.) (2004c), S. 72; Bundesversicherungsamt.

Wie Tabelle 9 zeigt, steigen die Transferzahlungen seit Einführung an und betragen im Jahr 2005 voraussichtlich 3,4 Mrd. Euro. Ohne die Deutsche Einheit und den "West-Ost-Transfer" hätte der Beitragssatz in Westdeutschland im Jahr 2003 sogar bei $12,2 \%$ gelegen. ${ }^{255}$ Der durchschnittliche Beitragssatz in den neuen Ländern hätte ohne die Übertragungen durch den RSA im Jahr 2004 bei $16,1 \%$ statt bei $14,0 \%$ gelegen. ${ }^{256}$

\subsection{Kostenexplosion oder Erosion der Bemessungsgrundlage}

\subsubsection{Beitragssatzanstieg}

Wie Abbildung 11 zeigt, wurde das Ziel der Beitragssatzstabilität in der Vergangenheit verfehlt. Der Beitragsatz stieg im früheren Bundesgebiet von 8,2 \% im Jahr 1970 auf $14,3 \%$ im Jahr 2004, obwohl im gleichen Zeitraum die Beitragsbemessungsgrenze von 614 Euro auf 3.488 Euro mehr als verfünffacht wurde. Ob die Ursache für den beobachteten Beitragssatzanstieg auf einen übermäßigen Anstieg der Leistungsausgaben oder eine Wachstumsschwäche der beitragspflichtigen Einnahmen zurückzuführen ist, wird im Folgenden näher untersucht. Dabei werden aggregierte Größen verwendet ${ }^{257}$, da für den Beitragssatz die Höhe der gesamten GKV-Aus-

\footnotetext{
${ }^{254}$ Vgl. BMGS (Hrsg.) (2004c), S. $71 \mathrm{ff}$.

${ }^{255}$ Vgl. Drabinski, T.; Beske, F. (2003), S. $9 f f$.

${ }^{256}$ Eigene Berechnung. Ein Beitragssatzpunkt in der GKV-Ost entspricht Beitragseinnahmen von 1,5 Mrd. Euro; siehe BMGS (Hrsg.) (2005a), S. 6.

${ }^{257}$ Der SVR (2002), Ziff. 244ff., verwendet in seinen Berechnungen ebenfalls aggregierte Größen. Der SVR KAiG (2003), Ziff. 54f., vergleicht hingegen auf der Einnahmenseite die beitragspflichtigen Einnahmen je Mitglied und das BIP je Erwerbstätigen. Pimpertz, J. (2003), S. 7f., plädiert für die Verwendung von beitragspflichtigen Einnahmen je Versicherten und Volkseinkommen je Einwohner. 
gaben und der gesamten beitragspflichtigen Einnahmen entscheidend sind und nicht die Entwicklung von Pro-Kopf-Größen. Außerdem bleibt damit die Konsistenz bei der Betrachtung von Einnahmen- und Ausgabenseite gewahrt.

\section{Abbildung 11: Beitragssatz und Beitragsbemessungsgrenze in der GKV 1970- 2004 (Früheres Bundesgebiet)}

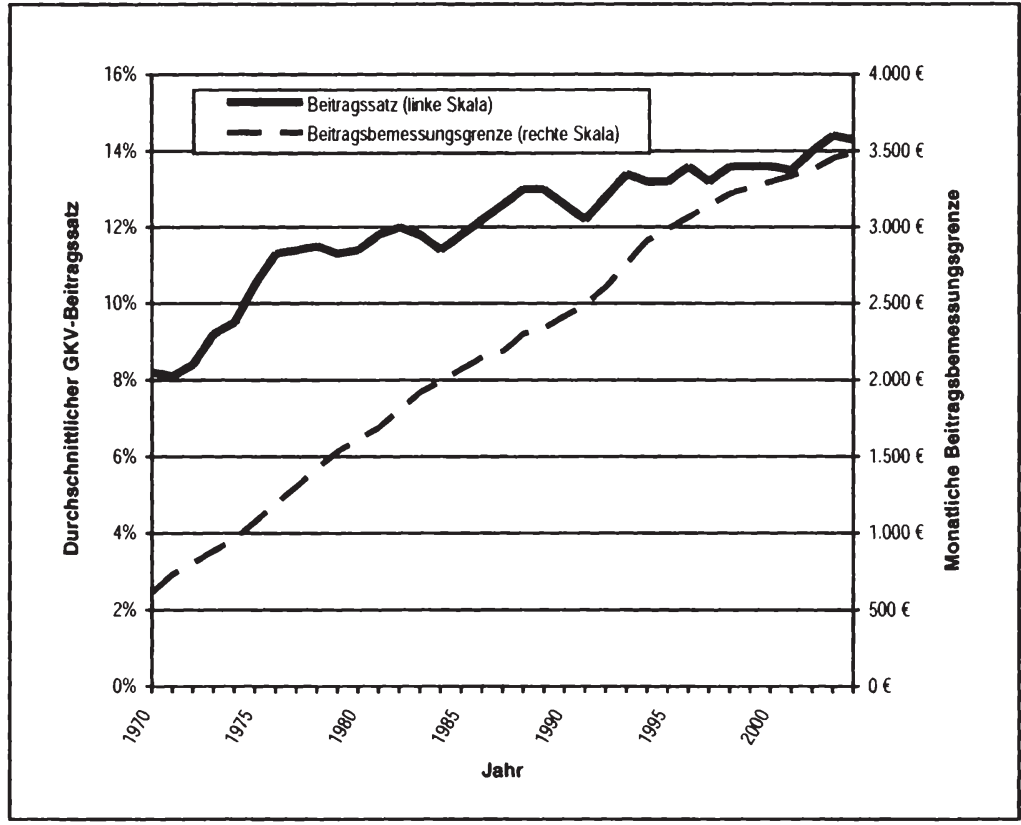

Quelle: Eigene Darstellung; siehe Tabelle 26: Entwicklung von Beitragssatz und Beitragsbemessungsgrenze, im Anhang, S. 263.

\subsubsection{Ausgabenseitiger Beitragssatzeffekt}

Die Ausgaben der GKV (Leistungsausgaben, Verwaltungskosten, Krankengeld und sonstige Ausgaben) sind in den alten Ländern von 13 Mrd. Euro im Jahr 1970 auf 72 Mrd. Euro (1990) gestiegen. Im gesamten Bundesgebiet kann ein Anstieg von 94 Mrd. Euro (1991) auf 140 Mrd. Euro im Jahr 2004 beobachtet werden. Zur Beurteilung dieser Ausgabenentwicklung ist allerdings ein Vergleichsmaßstab notwendig. Dabei ist es üblich, die Ausgaben der GKV jeweils auf das BIP zu beziehen. Die auf diese Weise ermittelte Gesundheitsausgabenquote gibt Auskunft darüber, welcher Anteil des BIP im entsprechenden Jahr für Gesundheitsleistungen der GKV beansprucht wird.

Abbildung 12 zeigt, dass die Wachstumsraten der GKV-Ausgaben lediglich bis 1975 deutlich über denen des BIP lagen. Seit 1976 liegen die Wachstumsraten relativ nahe beieinander. Daraus resultiert auch eine nahezu konstante Gesundheitsausgabenquote von knapp $7 \%$. Im Jahr 2004 sind infolge des GKV-Modernisierungsgesetz die Ausgaben der GKV von 145 Mrd. Euro (2903) Faufs 140 MÄrd3 Farotgesgnken. Das 
Wachstum des nominalen BIP lag deshalb mit 2,3\% deutlich über der Wachstumsrate der Ausgaben (-3,4\%). Die Gesundheitsausgabenquote betrug $20046,4 \%{ }^{258}$

\section{Abbildung 12: Veränderungsraten von GKV-Ausgaben und BIP 1970-2004}

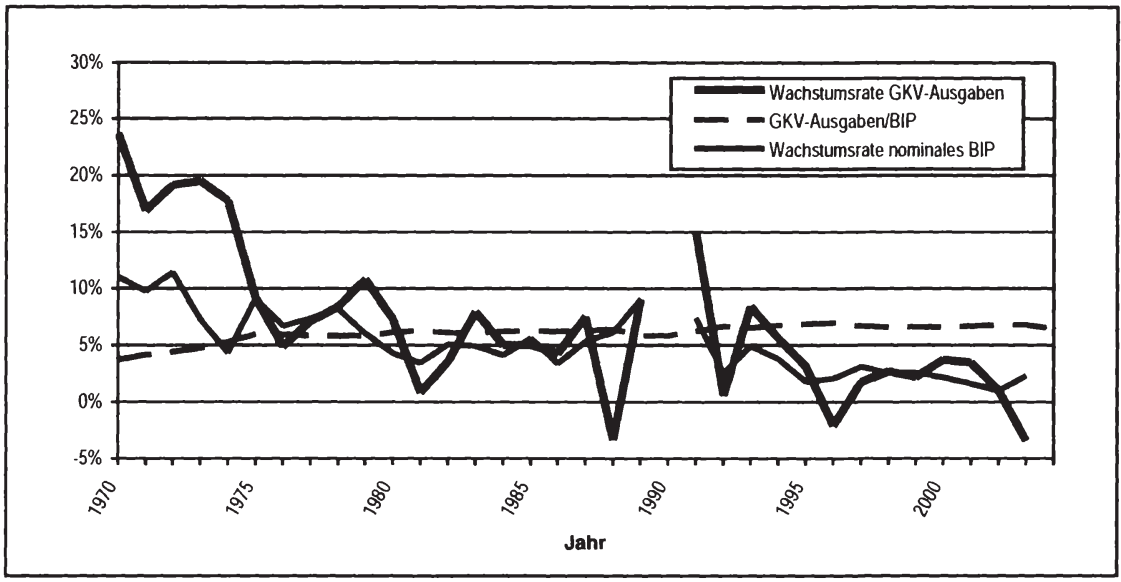

Anmerkung: Bis 1990 früheres Bundesgebiet, ab 1991 Deutschland.

Quelle: Eigene Darstellung und eigene Berechnungen; siehe Tabelle 27: Entwicklung von GKVAusgaben und BIP 1970-2004, im Anhang, S. 264.

Diese Entwicklung ist aber nicht die Folge eines endogenen Prozesses, sondern das Ergebnis zahlreicher diskretionärer Eingriffe des Gesetzgebers. Mit Hilfe von sogenannten Kostendämpfungsmaßnahmen ist es - wie Abbildung 12 zeigt - in den Jahren, in denen eine Maßnahme durchgeführt wurde, immer wieder gelungen, die Wachstumsraten der GKV-Ausgaben unter die des BIP zu drücken. ${ }^{259} \mathrm{Im}$ Einzelnen waren dies: ${ }^{260}$

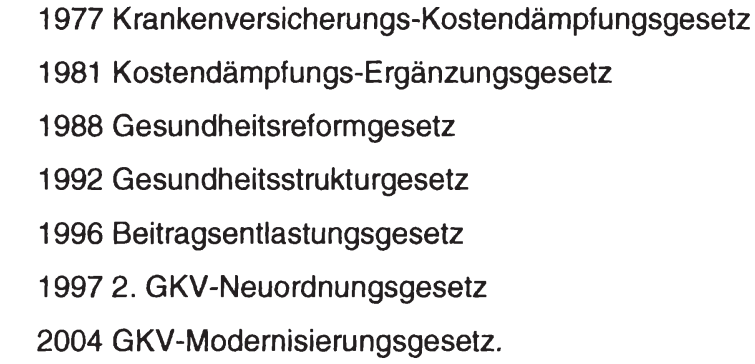

${ }^{258}$ Vgl. SVR KAiG (2003), Ziff. 70ff.; Kühn, H. (2001), S. 4f.; Braun, B.; Kühn, H.; Reiners, H. (1998), S. 23ff. Siehe hierzu auch Tabelle 27: Entwicklung von GKV-Ausgaben und BIP 1970-2004, im Anhang, S. 264.

${ }^{259}$ Vgl. Berié, H.; Fink, U. (1997a), S. 3f.; Wille, E. (1999), S. 15; SVR (2002), Ziff. 238; SVR KAiG (2003), Ziff. $71 f$.

${ }^{260}$ In Anlehnung an Oberender, P.; Hebborn, A.; Zerth, MldROQ2)eSs65f- 978-3-631-75223-4 
Um die von der Ausgabenseite ausgehenden Einflüsse auf den Beitragssatz im Jahr 2004 näher zu analysieren, werden im Folgenden fiktive Ausgaben berechnet, die sich ergeben hätten, wenn die Ausgaben ab einem bestimmten Zeitpunkt (Basisjahr) mit der Rate des nominalen BIP gewachsen wären. ${ }^{261}$ Mit diesen fiktiven Ausgaben lässt sich in Abhängigkeit vom gewählten Basisjahr der Beitragssatzeffekt berechnen, der aus einer Veränderung der Relation von GKV-Ausgaben und BIP resultiert. Wählt man als Basisjahr z.B. das Jahr 1970, dann sind im Jahr 2004 5,44 Prozentpunkte des Beitragssatzes $(14,27 \%)$ in den alten Ländern auf die Veränderung der Gesundheitsausgabenquote zurückzuführen. Um diesen Betrag wäre der Beitragssatz also niedriger, wenn Gesundheitsausgaben und BIP mit der gleichen Rate gewachsen wären. Lediglich für die Basisjahre 1970 bis 1974 lassen sich aufgrund der hohen Zuwachsraten bei den Ausgaben deutliche Beitragssatzeffekte zwischen 1,79 und 5,44 Prozentpunkten feststellen. Ab dem Basisjahr 1975 sind indes nur geringe Effekte festzustellen. Ab 1980 wirkt die Ausgabenentwicklung sogar um bis zu 1,21 Prozentpunkte (Basisjahr 1996) beitragssatzsenkend. ${ }^{262}$

Für die neuen Länder erhält man für den vergleichsweise kurzen Zeitraum 1991 bis 2004 ein ähnliches Ergebnis: In allen Basisjahren außer 1999 und 2001 geht von der Ausgabenseite ein leicht entlastender Effekt auf den Beitragssatz aus. Trotz des Aufholeffekts nach der Wiedervereinigung - von 1991 bis 1996 haben sich die Ausgaben der GKV in den neuen Ländern nahezu verdoppelt - führt die Entwicklung der Ausgaben nicht zu einem Beitragssatzanstieg, weil die Zunahme der Gesundheitsausgaben mit einem starken Wachstum des BIP einherging. ${ }^{263}$

Aus diesen Ergebnissen lässt sich auch für Gesamtdeutschland feststellen: Von der Ausgabenseite ist eher eine beitragssatzsenkende Wirkung ausgegangen ${ }^{264} \mathrm{Bei}$ der Interpretation der Ergebnisse ist jedoch zu berücksichtigen, dass im Jahr 2004 die Ausgaben durch das GMG im Vergleich zum Vorjahr um 3,4\% gesunken sind, was die berechneten Beitragssatzeffekte reduziert, d.h. eher auf einen beitragssatzsenkenden Einfluss schließen lässt. Für das Jahr 2003 ergeben sich daher etwas höhere

${ }^{261}$ In Anlehnung an SVR (2002), Ziff. 246.

${ }^{262}$ Eigene Berechnungen; siehe hierzu Tabelle 28: Einfluss der Ausgabenseite auf den Beitragssatz im Jahr 2004 (Früheres Bundesgebiet), im Anhang, S. 265. Der SVR (2002), Ziff. 241ff., kommt hingegen in seinen Berechnungen zu dem Ergebnis, dass die Gesundheitsausgabenquote seit 1970 um mehr als $80 \%$ gestiegen und daher das Ausgabenwachstum für den Beitragssatzanstieg verantwortlich ist. Das konstatierte Ausgabenwachstum geht allerdings fast ausschließlich auf den starken Anstieg in den Jahren 1970 bis 1975 zurück; vgl. Meinhardt, V.; Schulz, E. (2003), S. 108. Zudem berücksichtigt der SVR in seinen Berechnungen für das gesamte Bundesgebiet in den Basisjahren 1991ff. nicht, dass in den verwendeten Daten mit der Erweiterung auf ganz Deutschland ein Strukturbruch vorliegt. Dieser Strukturbruch wird in den eigenen Berechnungen berücksichtigt, indem die Berechnungen getrennt für das frühere Bundesgebiet und die neuen Bundesländer durchgeführt werden.

${ }^{263}$ Eigene Berechnungen; siehe hierzu Tabelle 29: Einfluss der Ausgabenseite auf den Beitragssatz im Jahr 2004 (Neue Bundesländer), im Anhang, S. 266.

${ }^{264}$ Bemerkenswert ist in diesem Zusammenhang der Vergleich der Gesundheitsausgabenquoten im früheren Bundesgebiet und in den neuen Ländern. Während die Quote im früheren Bundesgebiet seit 1975 rund $6 \%$ beträgt, liegt sie nach starkem Anstieg seit 1995 in den neuen Ländern bei etwa $10 \%$ deutlich höher, was freilich vor allem auf die geringe Wirtschaftsleistung zurückzuführen ist. Im Bundesdurchschnitt liegt die Ausgabenquoletunter 7e\%ske - 978-3-631-75223-4 
Beitragssatzeffekte. ${ }^{265}$ Auch daraus lässt sich jedoch nicht ableiten, der beobachtete Beitragssatzanstieg sei auf die Ausgaben zurückzuführen. Die Ursache muss demnach auf der Einnahmenseite liegen.

\subsubsection{Einnahmenseitiger Beitragssatzeffekt}

Die Beiträge zur GKV werden nach den beitragspflichtigen Einnahmen bemessen, die im Wesentlichen aus Arbeitseinkommen aus versicherungspflichtiger Beschäftigung und Rentenzahlungen bestehen. Im Folgenden wird deshalb die Entwicklung der beitragspflichtigen Einnahmen näher untersucht.

Als Indikator für die Entwicklung der beitragspflichtigen Einnahmen wird in der Literatur häufig die Lohnquote verwendet, die als Verhältnis der Arbeitnehmerentgelte zum Volkseinkommen (Nettosozialprodukt zu Faktorkosten) definiert ist. ${ }^{266}$ Die Lohnquote ist in den alten Ländern von 60,1\% im Jahr 1960 bis 1982 auf 76,1\% angestiegen, bevor sie bis 1991 wieder auf $70,0 \%$ sank. Für das gesamte Bundesgebiet verschob sich aufgrund der besonderen wirtschaftlichen Situation und der relativ geringen Einkommen aus Unternehmertätigkeit in den neuen Ländern das Niveau der Lohnquote mit der Wiedervereinigung nach oben und lag im Jahr 2003 bei $72,0 \% .{ }^{267}$ Empirische Beobachtungen zeigen, dass sich Lohnquote und beitragspflichtige Einnahmen weitgehend parallel entwickeln: In den Jahren 1992 und 1993 nahmen mit einem Ansteigen der Lohnquote auch die beitragspflichtigen Einnahmen stark zu. Außerdem gingen zeitversetzt mit dem Rückgang der Lohnquote seit 1993 auch die jährlichen Wachstumsraten der Beitragsgrundlage zurück. Zudem öffnet sich die „Schere“ zwischen BIP-Wachstum und Zunahme der beitragspflichtigen Einnahmen mit einer zeitlichen Verzögerung von rund drei Jahren zum Absinken der Lohnquote. ${ }^{268}$

Unabhängig davon, ob sich ein Teil der relativen Wachstumsschwäche der beitragspflichtigen Einnahmen durch ein Rückgang der Lohnquote erklären lässt, ist die Lohnquote aber ein wenig geeigneter Indikator für die Entwicklung der beitragspflichtigen Einnahmen. Zwischen dem Zähler der Lohnquote - dem Bruttoeinkommen aus unselbständiger Arbeit - und den beitragspflichtigen Einnahmen als Finanzierungsbasis der GKV bestehen erhebliche Unterschiede: Zum einen sind in den Arbeitnehmerentgelten auch die Sozialbeiträge der Arbeitgeber sowie die Bezüge von Beamten und Soldaten enthalten, auf die keine Beiträge zur GKV erhoben werden. Zum anderen fehlen die Rentenzahlungen der Rentenversicherung, und die Beiträge für Empfänger von Arbeitslosengeld und Arbeitslosenhilfe respektive Arbeitslosengeld II werden nicht berücksichtigt. Hinzu kommt, dass bei den beitragspflichtigen Einnah-

${ }^{265}$ Siehe ausführlich Tabelle 30: Einfluss der Ausgabenseite auf den Beitragssatz im Jahr 2003 (Früheres Bundesgebiet), im Anhang, S. 267; Tabelle 31: Einfluss der Ausgabenseite auf den Beitragssatz im Jahr 2003 (Neue Bundesländer), im Anhang, S. 268.

${ }^{266}$ Vgl. Wille, E. (2001), S. 15ff.; SVR (2002), Ziff. 242ff.; SVR KAiG (2003), Ziff. 56.

${ }^{267}$ Siehe hierzu BMGS (Hrsg.) (2004d), S. 1.9.

${ }^{268}$ Vgl. SVR KAiG (2003), Ziff. 58. Zur Diskussion um die Entwicklung der Lohnquote siehe Kühn, $H$. (2001), S. 5ff.; Kühn, H. (2000), S. 113ff.; Berié, H.; Fink, U. (1997a), S. 5; Berié, H.; Fink, U. (1997b), S. 13ff. 
men eine Beitragsbemessungsgrenze gilt und demzufolge auch die Lohnstruktur ${ }^{269}$ die Höhe der beitragspflichtigen Einnahmen beeinflusst. ${ }^{270}$ In Anbetracht dieser Unterschiede lässt sich - wie der Sachverständigenrat für die konzertierte Aktion im Gesundheitswesen feststellt - „nicht ausschließen, dass die relative Wachstumsschwäche der beitragspflichtigen Einnahmen [...] selbst bei konstanter oder sogar wieder leicht zunehmender Lohnquote anhält" ${ }^{\text {271 }}$. In der folgenden Analyse der Entwicklung der Einnahmen wird deshalb die tatsächliche Beitragsgrundlage - die beitragspflichtigen Einnahmen - verwendet.

Da in der amtlichen Statistik bis zum Jahr 1995 die beitragspflichtigen Einnahmen (Grundlohnsumme) ohne die beitragspflichtigen Einnahmen der Rentner ausgewiesen werden, erfordert dieser Strukturbruch, die Daten für diesen Zeitraum entsprechend zu bereinigen. Dies geschieht anhand folgender Formel: ${ }^{272}$

$$
\frac{\text { Beiträge Mitglieder }+ \text { Beiträge Rentner }}{\text { Durchschnittlicher Beitragssatz }} \cdot 100=\text { Beitragspflichtige Einnahmen }
$$

Durch diese Vorgehensweise enthalten die beitragspflichtigen Einnahmen auch vor dem Jahr 1996 die Einnahmen der Rentner. Dabei kann es allerdings zu Verzerrungen kommen, weil sich zum einen die Beitragssätze zwischen den einzelnen Kassen unterscheiden und damit vom in der Berechnung verwendeten durchschnittlichen Beitragssatz abweichen. Zum anderen werden je nach Krankengeldanspruch differenzierte Beitragssätze erhoben. Der durchschnittliche Beitragssatz ist also nur ein Näherungswert. Dennoch sind die Abweichungen zwischen den geschätzten und den statistisch erfassten beitragspflichtigen Einnahmen nur gering. ${ }^{273} \mathrm{Ab}$ dem Jahr 1996 wird auf amtliche Daten zurückgegriffen.

Um - analog der Vorgehensweise bei der Bestimmung ausgabenseitiger Einflüsse die von der Einnahmenseite ausgehenden Einflüsse auf den Beitragssatz im Jahr 2004 bestimmen zu können, werden fiktive beitragspflichtige Einnahmen berechnet, die sich ergeben hätten, wenn ausgehend von dem jeweiligen Basisjahr die beitragspflichtigen Einnahmen mit der gleichen Rate wie das BIP gewachsen wären. ${ }^{274}$ Auf diese Weise lassen sich die Beitragssatzeffekte berechnen, die auf einer Veränderung der Relation der beitragspflichtigen Einnahmen zum BIP beruhen. Wählt man das Basisjahr 1975, so lässt sich für das frühere Bundesgebiet ein einnahmenseitiger Beitragssatzeffekt in Höhe von 3,11 Prozentpunkten berechnen, d.h. der Beitragssatz im Jahr 2004 (14,27 \%) hätte um diesen Betrag geringer ausfallen können, wenn die beitragspflichtigen Einnahmen mit der Wachstumsrate des BIP gestiegen wären. Insgesamt lässt sich feststellen, dass in allen Basisjahren zwischen

\footnotetext{
${ }^{269}$ Siehe hierzu die Ausführungen zum Einfluss der Versichertenstruktur auf die Beitragseinnahmen in Abschnitt 4.3.2 Abhängigkeit von der Versichertenstruktur, S. 55.

${ }^{270}$ Vgl. Wille, E. (2001), S. 16f.; Wille, E. (2002a), S. 253; SVR (2002), Ziff. 243f.; SVR KAiG (2003), Ziff. 59. Für eine Quantifizierung der einzelnen Abweichungen siehe Berié, H.; Fink, U. (2003), S. $54 \mathrm{ff}$.

${ }^{271}$ SVR KAiG (2003), Ziff. 59.

272 In Anlehnung an Wille, E. (2001), S. 12H.

${ }^{273}$ Vgl. Beriè, H.; Fink, U. (2003), S. 39ff.

${ }^{274}$ In Anlehnung an SVR (2002), Ziff. 246; SVR (2004), ZZitt. 343. ske - 978-3-631-75223-4
} 
1971 und 1987 der Beitragssatzeffekt 1,7 Prozentpunkte, für die Basisjahre 1974 bis 1977 sogar 2,5 Prozentpunkte übersteigt. ${ }^{275}$

Für die neuen Bundesländer ergibt sich ein ähnliches Bild in dem verfügbaren Zeitraum von 1991 bis 2004: Für alle Basisjahre ist ein von der Einnahmenseite ausgehender beitragssatzsteigernder Effekt feststellbar. Bei relativ konstanter Gesundheitsausgabenquote und starkem BIP-Wachstum wirkt die Einnahmenseite beitragssatzsteigernd. Das Wachstum der beitragspflichtigen Einnahmen konnte dem BIP-Wachstum in den neuen Ländern nicht folgen. In den Jahren $1995(-4,6 \%)$, $1997(-0,5 \%), 1998(-1,5 \%), 2000(-0,2 \%), 2003(-1,5 \%)$ und $2004(-0,2 \%)$ sind die beitragspflichtigen Einnahmen im Vergleich zum jeweiligen Vorjahr sogar gesunken. ${ }^{276}$

Somit liegt auch bei einer Betrachtung des gesamten Bundesgebiets eine Wachstumsschwäche der beitragspflichtigen Einnahmen vor. Die Gründe sind vielschichtig. Zu nennen sind hier vor allem die nach wie vor hohe Arbeitslosigkeit sowie geänderte Erwerbsstrukturen und illegale Beschäftigung. Auch die ebenfalls erläuterten Entscheidungen des Gesetzgebers zulasten der GKV und die Wiedervereinigung dämpfen das Wachstum der beitragspflichtigen Einnahmen. Hinzu kommt die Zunahme des Anteils der Rentner.

\subsubsection{Fazit: Einnahmenbedingter Beitragssatzanstieg}

\section{Abbildung 13: Einfluss der Einnahmen- und Ausgabenseite auf den Beitrags- satz im Jahr 2004 (Früheres Bundesgebiet)}

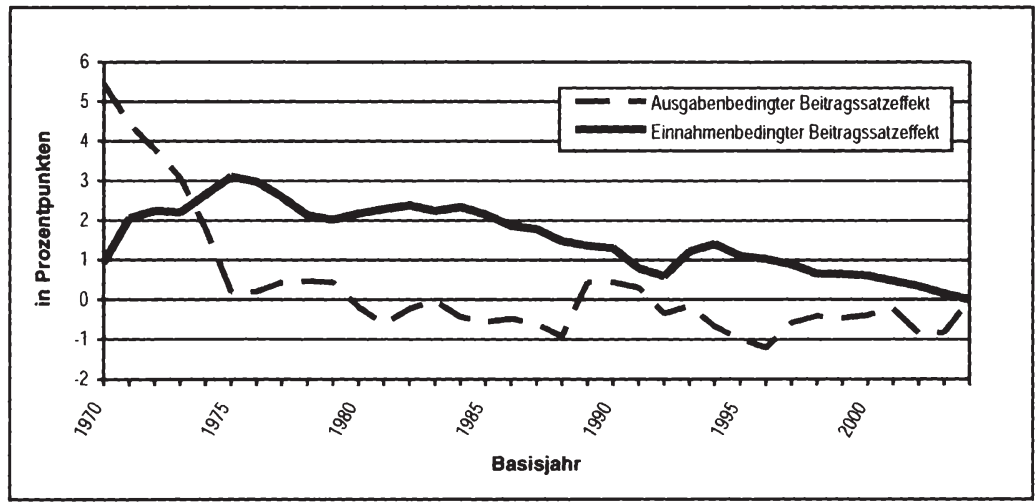

Quelle: Eigene Darstellung und eigene Berechnungen; siehe Tabelle 28: Einfluss der Ausgabenseite auf den Beitragssatz im Jahr 2004 (Früheres Bundesgebiet), im Anhang, S. 265; Tabelle 32: Einfluss der Einnahmenseite auf den Beitragssatz im Jahr 2004 (Früheres Bundesgebiet), im Anhang, S. 269.

${ }^{275}$ Eigene Berechnungen; siehe hierzu Tabelle 32: Einfluss der Einnahmenseite auf den Beitragssatz im Jahr 2004 (Früheres Bundesgebiet), im Anhang, S. 269.

${ }^{276}$ Eigene Berechnungen; siehe hierzu Tabelle 33: Einfluss der Einnahmenseite auf den Beitragssatz im Jahr 2004 (Neue Bundesländer), im Anhang, S. 279 irco Penske - 978-3-631-75223-4 
Abbildung 13 fasst die Ergebnisse für das frühere Bundesgebiet zusammen und zeigt den einnahmenseitigen und ausgabenseitigen Effekt auf den Beitragssatz im Jahr 2004 in Abhängigkeit vom gewählten Basisjahr.

Die Beitragssatzeffekte hängen zwar - wie das Schaubild verdeutlicht - stark von dem gewählten Basisjahr ab, jedoch überwiegt ab dem Basisjahr 1974 der von der Einnahmenseite ausgehende Effekt auf den Beitragssatz. Demzufolge hat die Wachstumsschwäche der beitragspflichtigen Einnahmen im Wesentlichen den Anstieg des Beitragssatzes verursacht. ${ }^{277}$

Die jährlichen Wachstumsraten von beitragspflichtigen Einnahmen und nominalem BIP im Zeitverlauf zeigt Abbildung 14. Anfang der 1970er Jahre lag die jährliche Wachstumsrate der beitragspflichtigen Einnahmen mitunter über der Wachstumsrate des BIP. Dies fiel in den Zeitraum, in dem - wie Abbildung 12 (S. 74) zeigt - auch die GKV-Ausgaben stärker stiegen als das BIP. In den Folgejahren wächst das BIP aber meist stärker als die beitragspflichtigen Einnahmen.

\section{Abbildung 14: Jährliche Wachstumsraten von beitragspflichtigen Einnahmen und BIP 1970-2004}

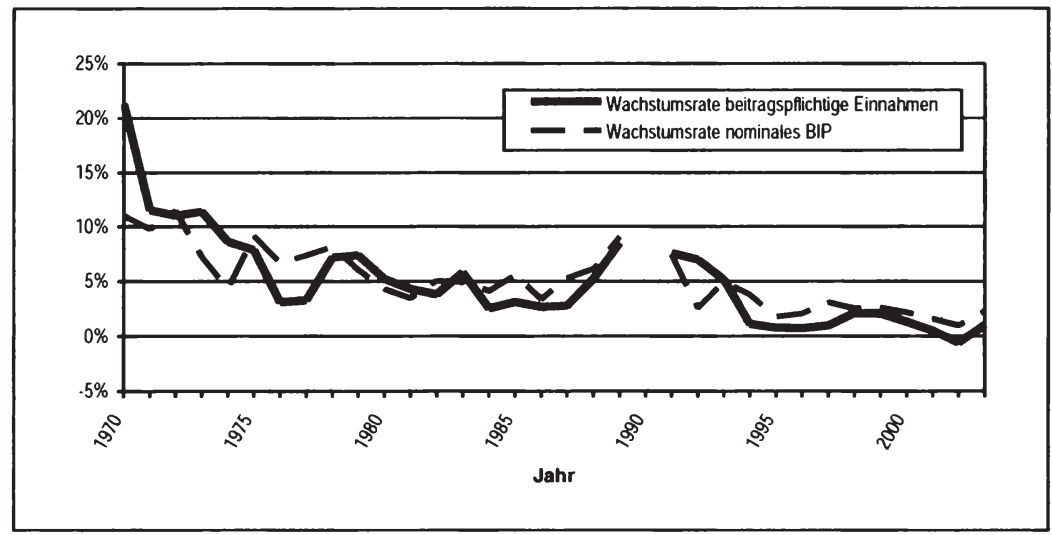

Anmerkung: Bis 1990 früheres Bundesgebiet, ab 1991 Gesamtdeutschland.

Quelle: Eigene Darstellung und eigene Berechnungen; siehe Tabelle 27: Entwicklung von GKVAusgaben und BIP 1970-2004, im Anhang, S. 264; Tabelle 34: Entwicklung von beitragspflichtigen Einnahmen und BIP 1970-2004 (Früheres Bundesgebiet), im Anhang, S. 271.

Die langfristigen Folgen der Wachstumsschwäche zeigt der Vergleich der Entwicklung der beitragspflichtigen Einnahmen und des BIP-Wachstums im früheren Bundesgebiet in Abbildung 15. Bezogen auf das Basisjahr 1975 wuchs bis zum

${ }^{277}$ Zu diesem Ergebnis kommen auch SVR KAiG (2003), Ziff. 53ff.; Cassel, D. (2003), S. 237ff.; Meinhardt, V.; Schulz, E. (2003), S. 105ff.; Wille, E. (2001), S. 13ff.; Kühn, H. (2001), S. 5ff.; Bontrup, H.-J. (1999), S. 87ff.; Braun, B.; Kühn, H.; Reiners, H. (1998), S. 21ff. Kontrovers hierzu Baumann, E.; Weidmann, J. (2003), S. 178ff.; Pimpertz, J. (2003), S. 8ff.; Berié, H.; Fink, U. (1997a), S. 3ff.; SVR (2002), Ziff. 238ff., der allerdings in einem späteren Jahresgutachten auch die Einnahmenschwäche bemängelt; siehe SVR (2004), Ziff. 342fflarco Penske - 978-3-631-75223-4 
Jahr 2004 das nominale BIP um 268,5\%, während die beitragspflichtigen Einnahmen nur um $188,1 \%$ zulegen konnten. ${ }^{278}$ Dies verdeutlicht das Ausmaß der relativen Wachstumsschwäche der Finanzierungsbasis der GKV. ${ }^{279}$ Der Einfluss der Wachstumslücke auf den Beitragssatz lässt sich ermitteln, indem man unterstellt, die beitragspflichtigen Einnahmen hätten von 1975 bis 2004 mit der Wachstumsrate des BIP zugenommen. Bezogen auf das frühere Bundesgebiet übertreffen dann die fiktiven beitragspflichtigen Einnahmen im Jahr 2004 die tatsächlichen Einnahmen um $228 \mathrm{Mrd}$. Euro, was bei gegebenen Ausgaben einem Beitragssatz von 11,16\% anstelle des tatsächlichen in Höhe von $14,27 \%$ entspricht. ${ }^{280}$

\section{Abbildung 15: Entwicklung von beitragspflichtigen Einnahmen und BIP 1970- 2004 zum Basisjahr 1975 (Früheres Bundesgebiet)}

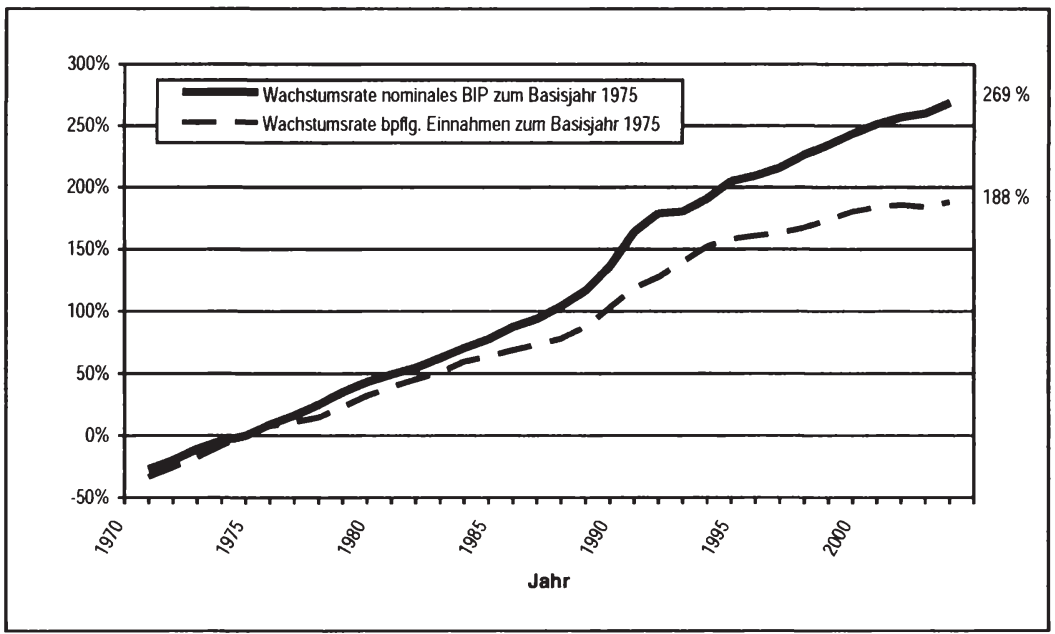

Anmerkung: Ab 1995 einschließlich Berlin-Ost.

Quelle: Eigene Darstellung und eigene Berechnungen; siehe Tabelle 34: Entwicklung von beitragspflichtigen Einnahmen und BIP 1970-2004 (Früheres Bundesgebiet), im Anhang, S. 271.

Soll die Entwicklung der GKV-Leistungen mit dem Wachstum der Produktion von Gütern und Dienstleistungen in der gesamten Volkswirtschaft Schritt halten, ist eine Wachstumsdifferenz zwischen beitragspflichtigen Einnahmen und BIP problematisch; denn bei einem konstanten Beitragssatz müssten dann die GKV-Leistungen trotz der

${ }^{278}$ Auch der Vergleich von Pro-Kopf-Größen, um Effekte einer Veränderung der Mitgliederzahl in der GKV zu berücksichtigen, bestätigt die Wachstumsschwäche; siehe Wille, E. (2002a), S. 254.

${ }^{279}$ Eigene Berechnungen für die neuen Bundesländer kommen zu einem ähnlichen Ergebnis: Im Zeitraum von 1991 bis 2004 sind in den neuen Bundesländern die beitragspflichtigen Einnahmen um 46,2 \% und das BIP um 108,5\% gewachsen; siehe hierzu Tabelle 35: Entwicklung von beitragspflichtigen Einnahmen und BIP 1991-2004 (Neue Bundesländer), im Anhang, S. 272.

${ }^{280}$ In Anlehnung an Wille, E. (2001), S. 13f.; SVR KAiG (2003), Ziff. 55. Siehe hierzu auch Tabelle 34: Entwicklung von beitragspflichtigen Einnahmen und BIP 1970-2004 (Früheres Bundesgebiet), im

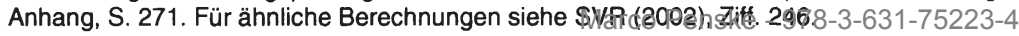


demographischen Entwicklung und des medizinisch-technischen Fortschritts langsamer wachsen als die allgemeine wirtschaftliche Entwicklung. ${ }^{281}$ 
Marco Penske - 978-3-631-75223-4

Downloaded from PubFactory at 01/11/2019 06:54:52AM

via free access 


\section{Zukünftige Entwicklung der GKV-Finanzen}

\section{Demographische Entwicklung und GKV-Finanzen}

Die langfristige Finanzierbarkeit der GKV hängt von Faktoren ab, die sich auf der Ausgabenseite trotz ihrer Wechselwirkungen in angebots- und nachfrageinduzierte Kosteneinflüsse systematisieren lassen. ${ }^{282}$ Von der Angebotsseite führen vor allem die Leistungsausweitung durch angebotsinduzierte Nachfrage, ein negativer Preisstruktureffek ${ }^{283}$ zugunsten von Gesundheitsleistungen und eine zunehmende Leistungsausweitung aufgrund aufwendiger Diagnoseverfahren zu steigenden Kosten. Die Zunahme von Einzelhaushalten, die Veränderung des Krankheitsspektrums hin zu chronischen Erkrankungen, die gestiegene Anspruchshaltung der Bevölkerung und der durch den umfassenden Versicherungsschutz gegebene Anreiz zur übermäBigen Inanspruchnahme medizinischer Leistungen (moral hazard ${ }^{284}$ ) zählen zu den nachfrageseitigen Determinanten der Ausgabenentwicklung. Von zentraler Bedeutung für die künftige Finanzierung der GKV ist in Verbindung mit dem medizinischtechnischen Fortschritt der Einfluss der Veränderung der Bevölkerungsstruktur ${ }^{285}$, der deshalb im Folgenden im Mittelpunkt der Betrachtung steht.

Die Gesundheitsausgaben hängen nicht nur von der absoluten Bevölkerungszahl, sondern infolge der altersspezifischen Inanspruchnahme von Gesundheitsleistungen auch von der Altersstruktur der Bevölkerung ab. ${ }^{286}$ Gleichzeitig werden die Einnahmen der GKV aufgrund der Umlagefinanzierung und der Einkommensabhängigkeit der Beiträge in erheblichem Maße von der Demographie beeinflusst.

Um den Einfluss der demographischen Entwicklung auf den Beitragssatz im Jahr 2003 zu bestimmen, werden Einnahmen und Ausgaben der GKV simuliert, die sich im Jahr 2003 ceteris paribus ergeben hätten, wenn die demographische Zusammensetzung der Versicherten ab einem bestimmten Zeitpunkt (Basisjahr) konstant geblieben wäre. Da die Mitgliederstatistiken der GKV nur die Besetzungsstärke von Altersgruppen erfassen, wird auf nach einzelnen Altersjahren differenzierte Bevölkerungsstatistiken des Statistischen Bundesamtes für die Jahre 1950 bis 2003 zurückgegriffen. Aus der Bevölkerungsstatistik wird die Zahl der GKV-Versicherten nach Alter ermittelt, indem für die verschiedenen Altersgruppen der Anteil der GKV-Versicherten an der gesamten Bevölkerung bestimmt und der entsprechende Anteil mit der Bevölkerungszahl in dem jeweiligen Altersjahr multipliziert wird. Hierbei werden die Verhältnisse des Jahres 2003 zugrunde gelegt. Damit wird u.a. sichergestellt, dass der errechnete Beitragssatzeffekt nicht durch strukturelle Änderungen verzerrt

\footnotetext{
${ }^{282}$ Vgl. Henke, K.-D. (1985), S. 484ff.; SVR KAiG (1995), Ziff. $26 f f$.

${ }^{283}$ Aufgrund fehlender Automatisierungsmöglichkeiten steigt die Arbeitsproduktivität im Gesundheitswesen oder allgemein im Dienstleistungsbereich langsamer als in anderen Wirtschaftssektoren. Folgt die Lohnentwicklung im Gesundheitswesen aber der allgemeinen Lohnentwicklung, dann steigen die Preise für Gesundheitsleistungen stärker als die Preise in anderen Wirtschaftsbereichen; vgl. Hof, B. (2001), S. 30f.

${ }^{284} \mathrm{Zu}$ moral hazard in der Krankenversicherung siehe z.B. Schreyögg, J. (2002), S. 160ff.; Schreyögg, J. (2003a), S. 71ff.; Breyer, F.; Zweifel, P.; Kifmann, M. (2005), S. $222 \mathrm{ff}$.

${ }^{285}$ Vgl. SVR KAiG (1995), Ziff. 35; SVR KAiG (1996), Ziff. 60.

${ }^{286}$ Zum Einfluss der demographischen Entwicklung auf die Struktur der GKV-Ausgaben (ambulante und stationäre Behandlung, zahnärztliche Behandlung, Zahnersatz, Arzneimittel sowie Heil- und Hilfsmittel) siehe SVR KAiG (1994), Ziff. 172ff. Marco Penske - 978-3-631-75223-4
} 
wird. Sodann wird zur Ermittlung des ausgabenbedingten demographischen Beitragssatzeffekts (Ausgabeneffekt) für jedes Basisjahr die Zahl der GKV-Versicherten mit den altersspezifischen RSA-Ausgaben ${ }^{287}$ multipliziert. Die Nettoverwaltungskosten und sonstigen Ausgaben der GKV aus dem Jahr 2003, die nicht in den RSAProfilen enthalten sind, werden anschließend addiert. Als Ergebnis erhält man die Ausgaben, die sich im Jahr 2003 unter der Altersstruktur des gewählten Basisjahres ergeben hätten. Anschließend wird der Beitragssatz berechnet, der zur Deckung der Ausgaben erforderlich gewesen wäre und der Ausgabeneffekt in Prozentpunkten bestimmt. Dabei werden zunächst die Einnahmen nicht an die veränderte Altersstruktur angepasst. Mit dieser Vorgehensweise wird sichergestellt, dass der rein demographisch bedingte Ausgabeneffekt berechnet wird. Würde man auch die beitragspflichtigen Einnahmen sofort anpassen, erhielte man einen fiktiven Beitragssatz, der nicht mehr nach ausgaben- und einnahmenbedingten Einflüssen differenziert werden könnte.

Um den von der Einnahmenseite ausgehenden demographischen Beitragssatzeffekt (Finanzierungseffekt) zu bestimmen, wird ähnlich vorgegangen: Die Zahl der GKVMitglieder ${ }^{288}$ in jedem Altersjahrgang wird ermittelt und mit den altersabhängigen durchschnittlichen beitragspflichtigen Einnahmen ${ }^{289}$ und dem gleichgewichtigen Beitragssatz für das Jahr 2003 multipliziert. Die Summe der so berechneten Beiträge zuzüglich der sonstigen Einnahmen der GKV bilden die GKV-Einnahmen für das Jahr 2003 unter der Bedingung, dass die Mitgliederstruktur des gewählten Basisjahres vorliegen würde. Die Ausgaben werden zunächst konstant gehalten, um die Beitragssatzabweichung in Prozentpunkten zu berechnen, die von dem demographischen Einfluss auf die Einnahmen ausgeht.

Zur Ermittlung des Gesamteinflusses der demographischen Entwicklung auf den Beitragssatz reicht es nicht aus, Ausgaben- und Finanzierungseffekt zu addieren, da beide auf Grundlage von sich jeweils gegenseitig ausschließenden Annahmen ${ }^{290}$ ermittelt wurden. Deshalb sind neue Berechnungen erforderlich. Ausgaben und beitragspflichtige Einnahmen müssen gleichzeitig der geänderten Bevölkerungsentwicklung angepasst und mit Hilfe des Modells dann der Beitragssatz bestimmt werden, der unter der Bevölkerungsstruktur des jeweiligen Basisjahres die Einnahmen an die Ausgaben anpasst. Die Abweichung des errechneten Beitragssatzes für das jeweilige Basisjahr vom gleichgewichtigen Beitragssatz für das Jahr 2003 gibt den Gesamteinfluss der demographischen Entwicklung auf den Beitragssatz in Prozentpunkten an.

Abbildung 16 zeigt, dass die demographische Entwicklung bereits den Beitragssatz beeinflusst. Die Einflüsse von Einnahmen- und Ausgabenseite sind dabei gegenläufig. Während die demographische Entwicklung schon jetzt über die Ausgabenseite

\footnotetext{
${ }^{287}$ Siehe Kapitel II.4.2.4 Intertemporale Inzidenz, S. 41.

${ }^{288} \mathrm{Da}$ zu den Versicherten auch beitragsfrei Versicherte zählen, muss hier - anders als bei der Berechnung der Ausgaben - die Zahl der Mitglieder verwendet werden.

${ }^{289}$ Siehe Kapitel II.4.2.4 Intertemporale Inzidenz, S. 41.

${ }^{290} \mathrm{Um}$ den demographisch bedingten Finanzierungseffekt zu berechnen, wurden die Ausgaben konstant gehalten und umgekehrt für den Ausgabeneffekl die Eipagagmen.978-3-631-75223-4
} 
eher zu einem Beitragssatzanstieg führt ${ }^{291}$, geht von der Einnahmenseite noch eine beitragssatzsenkende Wirkung aus. Würde z.B. noch die Bevölkerungsstruktur des Jahres 1970 vorliegen, müsste der Beitragssatz aufgrund des Einflusses der demographischen Entwicklung auf die GKV-Einnahmen um 2,42 Prozentpunkte angehoben werden, ausgabenbedingt könnte er um 2,17 Prozentpunkte gesenkt werden. Wählt man die Bevölkerungsstruktur des Jahres 1950 ergibt sich sogar ein beitragssatzsenkender Finanzierungseffekt von 3,35 Prozentpunkten und ein beitragssatzerhöhender Ausgabeneffekt von 4,12 Prozentpunkten. Der Gesamteffekt der demographischen Entwicklung von 1950 bis 2003 ist aufgrund gegenläufiger Effekte noch eher verhalten. Für das Basisjahr 1950 beträgt er 1,19 Prozentpunkte, für 1970 sogar minus 0,23 Prozentpunkte. ${ }^{292}$

\section{Abbildung 16: Einfluss der demographischen Entwicklung auf den Beitragssatz im Jahr 2003 (Bundesgebiet)}

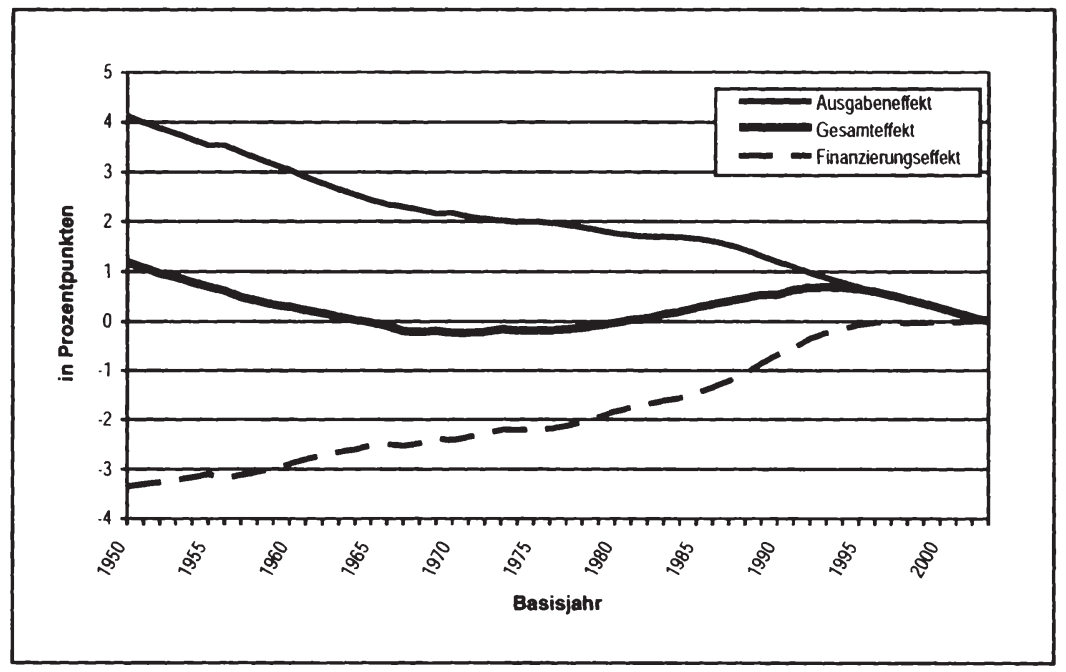

Quelle: Eigene Darstellung und eigene Berechnungen; siehe Tabelle 37: Einfluss der demographischen Entwicklung auf den Beitragssatz im Jahr 2003 (Bundesgebiet), im Anhang, S. 274.

${ }^{291} \mathrm{Zu}$ diesem Ergebnis kommt auch Schulenburg, J.-M. Graf von der (1987), S. 139f., für den Zeitraum 1976 bis 1983.

292 Die Beitragssatzeffekte beziehen sich auf den in den Modellrechnungen ermittelten Beitragssatz in Höhe von $14,94 \%$. Dieser liegt über dem tatsächlichen Beitragssatz. Soll der Beitragssatzeffekt für den tatsächlichen Beitragssatz des Jahres 2003 (14,31\%) berechnet werden, müssen die beitragspflichtigen Einnahmen im Modell erhöht werden. Aufgrund der Datenlage kann dies nur durch die Addition des Fehlbetrags geschehen. Damit würde implizit die nicht unproblematische Annahme getroffen werden, dass die nicht erfassten beitragspflichtigen Einnahmen unabhängig von der Altersstruktur sind. Der demographische Einfluss auf den Beitragssatz wird dadurch etwas schwächer dargestellt, als er tatsächlich ist. Dies bestätigen auch die Ergebnisse. Die Beitragssatzeffekte sind etwas geringer als in der Modelirechnung ohne Korrektur. Insgesamt ändern sich die Ergebnisse durch die Berechnungsanpassung aber nur in der Nachkommastelle, weshalb hier die Ergebnisse der reinen Modellrechnung wiedengegebep everden. 978-3-631-75223-4 
Wird statt der demographisch bedingten Veränderung von Einnahmen und Ausgaben das jährliche KVdR-Defizit ${ }^{293}$ als demographische Belastung angesehen und der ausgabendeckende Beitragssatz in der AKV ohne diesen Subventionsbedarf der $\mathrm{KVdR}$ berechnet, ergeben sich größere Beitragssatzeffekte. Nach Berechnungen von Oberdieck $^{294}$ sind im Jahr 2002 5,4 Prozentpunkte des Beitragssatzes in Höhe von $14,0 \%$ auf den Subventionsbedarf der KVdR zurückzuführen, im Jahr 1970 waren es noch 0,6 Prozentpunkte des damaligen Beitragssatzes von $8,2 \%$. Diese Beitragssatzeffekte sind aber nicht nur auf die demographische Veränderung zurückzuführen, sondern werden verstärkt durch die allgemeine Entwicklung von Einnahmen und Ausgaben z.B. aufgrund von Fremdbelastungen, Rentenanpassungen und Ausgabensteigerungen.

Der demographische Wandel vollzieht sich in Deutschland von zwei Seiten. Zum einen gehen die Geburtenraten zurück („aging at the bottom“), zum anderen nimmt die Lebenserwartung zu („aging at the top"). Man spricht deshalb auch von „double aging“. ${ }^{295}$ Dadurch wird sowohl die absolute Zahl der älteren Menschen als auch deren Anteil an einer schrumpfenden Gesamtbevölkerung wachsen.

Wie sich Bevölkerungszahl und Altersstruktur unter bestimmten Annahmen verändern, zeigt das Statistische Bundesamt anhand von Bevölkerungsvorausberechnungen. In der 10. koordinierten Bevölkerungsvorausberechnung ${ }^{296}$ werden insgesamt neun Varianten mit unterschiedlichen Annahmen bezüglich der Lebenserwartung und Zuwanderung berechnet. In allen Varianten wird die Geburtenhäufigkeit als konstant auf dem bisherigen Niveau von durchschnittlich 1,36 Kindern je Frau unterstellt - zur Bestandserhaltung der Bevölkerung wäre eine Fertilität von $2,08^{297}$ notwendig. Folgende weitere Annahmen ${ }^{298}$ liegen der „mittleren Variante" (Variante 5) der Vorausberechnung zugrunde: $:^{299}$

Die Lebenserwartung bei Geburt steigt bis zum Jahr 2050 für Mädchen auf 86,6 Jahre und für Jungen auf 81,1 Jahre; die „fernere" Lebenserwartung beträgt im Jahr 2050 für 60jährige Frauen 28 weitere Lebensjahre und für gleichaltrige Männer etwa weitere 24 Lebensjahre.

\footnotetext{
${ }^{293}$ Siehe Tabelle 3: Beiträge und Ausgaben für Mitglieder und Rentner 1992-2004, S. 40.

${ }^{294}$ Siehe Oberdieck, V. (1998), S. 139, 202.

${ }^{295}$ Siehe hierzu stellvertretend Glaeske, G. u.a. (1997), S. 46; Buchner, F.; Wasem, J. (2000), S. 2 .

${ }^{296}$ Siehe hierzu Statistisches Bundesamt (Hrsg.) (2003), S. $5 \mathrm{ff}$.

297100 Frauen müssen 101 Mädchen und 107 Knaben, also aufgrund der Geschlechterverteilung insgesamt 208 Kinder gebären, damit eine Müttergeneration vollständig durch eine Töchtergeneration ersetzt wird. Dies entspricht einer Fertilität von 2,08.

${ }^{298}$ Für eine Übersicht zu den Annahmen der neun Varianten siehe Statistisches Bundesamt (Hrsg.) (2003), S. 25. Größter Unsicherheitsfaktor bei der Prognose der Bevölkerungsentwicklung ist neben den Annahmen über Geburtenhäufigkeit und Sterblichkeit die Stärke der Wanderungssalden. Das Statistische Bundesamt berechnet deshalb mehrere Varianten. Da die demographische Entwicklung maßgeblich von der aktuellen Bevölkerungspyramide bestimmt wird, lässt sich der demographische Wandel in den nächsten Jahrzehnten davon abgesehen relativ sicher prognostizieren; vgl. Rürup-Kommission (2003), S. 51; Ulrich, V. (2000), S. 164; Enquete-Kommission Demographischer Wandel (1998), S. 69 f.
}

${ }^{299}$ Soweit nichts anderes angegeben ist, wird im Folgendandjesenkariante veroventet7 5223-4 
Der Außenwanderungssaldo der ausländischen Bevölkerung beträgt jährlich plus 200.000 Personen; die Zahl der zuwandernden Deutschen geht von etwa 80.000 Personen im Jahr 2002 schrittweise zurück bis auf Null im Jahr 2040.

\section{Abbildung 17: Altersaufbau der Bevölkerung nach der 10. koordinierten Bevölkerungsvorausberechnung (mittlere Variante)}

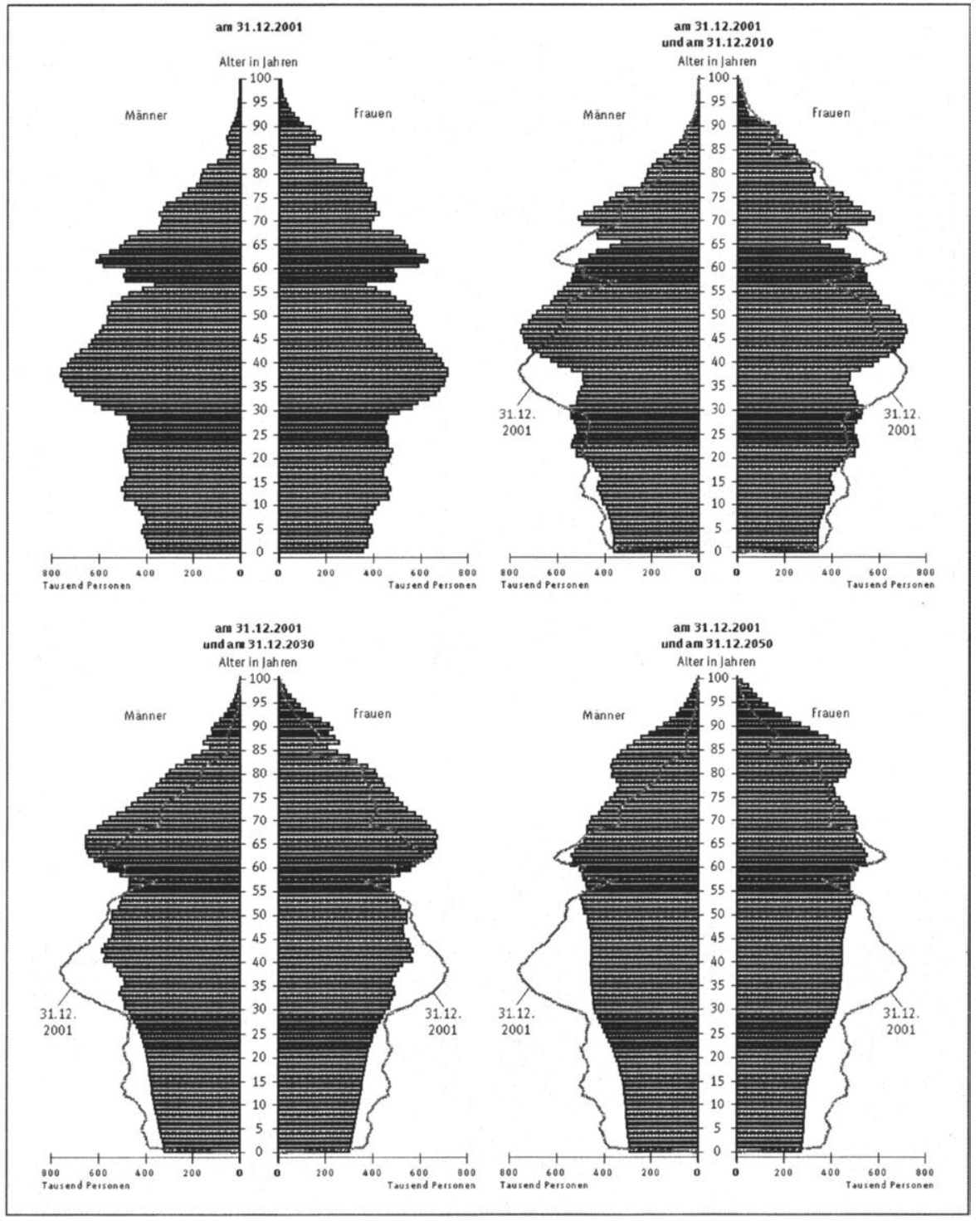

Quelle: Statistisches Bundesamt (Hrsg.) (2003). 
Abbildung 17 zeigt einen Vergleich der Altersstruktur der Bevölkerung im Jahr 2001 mit der vorausberechneten für die Jahre 2010, 2030 und 2050 nach dieser mittleren Variante. Die jungen Altersgruppen bilden nicht mehr den Sockel einer Pyramide. Die Gruppe der unter 19jährigen ist sogar schwächer besetzt als höhere Altersgruppen. Der Sockel wird mithin immer schmaler. Der Übergang in eine „Pilzform“, in der die älteren Jahrgänge stärker besetzt sind als die jüngeren, wird in der Abbildung deutlich.

Tabelle 10: Entwicklung der Bevölkerung Deutschlands bis zum Jahr 2050

\begin{tabular}{|c|c|c|c|c|c|c|}
\hline Am 31.12. des Jahres & 2003 & 2010 & 2020 & 2030 & 2040 & 2050 \\
\hline Bevölkerung & 82.532 & 83.066 & 82.822 & 81.220 & 78.539 & 75.117 \\
\hline in Tausend & 16.904 & 15.524 & 14.552 & 13.927 & 12.874 & 12.094 \\
\hline Anteil in Prozent & 20,5 & 18,7 & 17,6 & 17,1 & 16,4 & 16,1 \\
\hline in Tausend & 45.291 & 46.277 & 44.116 & 39.384 & 38.011 & 35.437 \\
\hline 20 bis 59 Jahre & 54,5 & 55,7 & 53,3 & 48,5 & 48,4 & 47,2 \\
\hline in Tausend & 20.336 & 21.265 & 24.154 & 27.910 & 27.655 & 27.587 \\
\hline Ab 60 Jahre & 24,6 & 25,6 & 29,2 & 34,4 & 35,2 & 36,7 \\
\hline Altenquotient & 44,9 & 46,0 & 54,8 & 70,9 & 72,8 & 77,8 \\
\hline Jugendquotient & 37,3 & 33,5 & 33,0 & 35,4 & 33,9 & 34,1 \\
\hline Gesamtlastenquotient & 82,2 & 79,5 & 87,7 & 106,2 & 106,6 & 112,0 \\
\hline
\end{tabular}

Quelle: Eigene Darstellung; vgl. Statistisches Bundesamt (Hrsg.) (2003), S. 42.

Die Ergebnisse der Bevölkerungsvorausberechnung in Tabelle 10 lassen erwarten, dass die Bevölkerung von 82,5 Mio. Menschen im Jahr 2003 auf 75,1 Mio. Menschen im Jahr 2050 schrumpfen wird. Der Bevölkerungsanteil der unter 19jährigen wird dieser Prognose zufolge im gleichen Zeitraum von $20,5 \%$ auf $16,1 \%$ sinken. Der Rückgang des Bevölkerungsanteils der 20- bis 59jährigen wird von $54,5 \%$ im Jahr 2003 auf $47,2 \%$ im Jahr 2050 geschätzt. In absoluten Zahlen bedeutet dies, dass der Anteil der „aktiven“ Bevölkerung von 45,3 Mio. Menschen im Jahr 2003 auf 35,4 Mio. Menschen im Jahr 2050 abnehmen wird. Der starke Rückgang des Erwerbspersonenpotentials ist besonders ausgeprägt in den Jahren 2020 bis 2030. Allein in diesem Zeitraum sinkt der Anteil an der Gesamtbevölkerung von 53,3 \% auf 48,5\% bzw. von 44,1 Mio. Personen auf 39,4 Mio. Personen. Die prozentual stärkste Veränderung wird für die Altersklasse der über 59jährigen geschätzt. Deren Anteil an der Gesamtbevölkerung steigt von $24,6 \%(2003)$ auf $36,7 \%(2050)$ an. Insbesondere zwischen den Jahren 2010 und 2030 nimmt der Anteil von 25,6\% auf 34,4\% deutlich zu. 
Für die nachhaltige Finanzierbarkeit der GKV ist das Verhältnis der jungen (bis 19 Jahre) und der alten Bevölkerungsgruppe (ab 60 Jahre) zur mittleren Altersgruppe (20 bis 59 Jahre) bedeutend, da im derzeitigen Finanzierungssystem die mittlere (erwerbstätige) Generation sowohl die jüngere Generation versorgt, die noch keine Beiträge an die GKV zahlt, als auch die Beiträge der Rentner subventioniert, die im Durchschnitt unter deren Ausgaben liegen. Das tatsächliche durchschnittliche Rentenzugangsalter von etwa 60 Jahren wird im Folgenden als Altersgrenze für den Renteneintritt verwendet und ein Erwerbsalter zwischen 20 und 59 Altersjahren unterstellt. ${ }^{300}$ Die in Tabelle 10 dargestellten Quotienten werden entsprechend definiert:

$$
\begin{aligned}
& \text { Altenquotient }=\frac{\text { Personen ab } 60 \text { Jahre }}{\text { Personen zwischen } 20 \text { und } 59 \text { Jahren }}(\cdot 100) \\
& \text { Jugendquotient }=\frac{\text { Personen bis } 19 \text { Jahre }}{\text { Personen zwischen } 20 \text { und } 59 \text { Jahren }}(\cdot 100) \\
& \text { Gesamtlastquotient }=\frac{\text { Personen bis } 19 \text { Jahre und Personen ab } 60 \text { Jahre }}{\text { Personen zwischen } 20 \text { und } 59 \text { Jahren }}(\cdot 100)
\end{aligned}
$$

Aus den Bevölkerungsprognosen des Statistischen Bundesamtes lässt sich die Zahl der GKV-Versicherten nicht unmittelbar ablesen. Man kann jedoch davon ausgehen, dass sich ohne gravierende Systemänderungen die Zahl der GKV-Versicherten entsprechend der Bevölkerungsvorausberechnung entwickeln wird ${ }^{301}$; zumal - allerdings mit sinkendem Anteil - nahezu $90 \%$ der Bevölkerung in der GKV versichert sind. Der Vergleich von GKV-Versicherten und Bevölkerung zeigt, dass in der GKV der Anteil der Älteren größer ist als in der Gesamtbevölkerung. Die Gruppe der 20 bis 59jährigen ist in der GKV im Vergleich zur Bevölkerung unterrepräsentiert, während Personen ab 60 Jahren in der GKV überproportional vertreten sind. ${ }^{302}$ Dies ist vor allem darauf zurückzuführen, dass insbesondere Ältere einen Anreiz haben, sich in der GKV zu versichern, weil dort ihre Beiträge von den Erwerbstätigen subventioniert werden. Auch wenn der Altenquotient in Bevölkerung und GKV um die gleiche Rate steigt, nimmt deshalb die Belastung in der GKV stärker zu als in der gesamten Bevölkerung. Abgeschwächt wird dieser Effekt lediglich durch den leichten Rückgang des Anteils der GKV-Versicherten in allen Altersgruppen.

Auf Basis der Bevölkerungsvorausberechnung und der GKV-Versichertenanteile in den einzelnen Altersgruppen im Jahr 2003 gibt Tabelle 11 die Entwicklung der Zahl der GKV-Versicherten bis zum Jahr 2050 wieder. Dabei wird unterstellt, dass die Anteile der unter 19jährigen, der 20- bis 59jährigen und der über 60jährigen GKVVersicherten an der gesamten Bevölkerung auch in Zukunft den Anteilen aus dem Jahr 2003 entsprechen. In Tabelle 11 wird deutlich, dass die demographische Alterung die GKV aufgrund ihrer Versichertenstruktur stärker trifft als die gesamte

\footnotetext{
${ }^{300}$ Siehe dazu auch Statistisches Bundesamt (Hrsg.) (2003), S. 31. Das durchschnittliche Renteneintrittsalter liegt bei 60,2 Jahren; vgl. Rürup-Kommission (2003), S. 58.

${ }^{301}$ Vgl. Knappe, E. (1995), S. 22.

${ }^{302}$ Siehe auch Tabelle 38: Versicherte, Mitglieder, Ausgaben und Beiträge in den Jahren 2003, 2030 und 2050, im Anhang, S. 276. Zu diesem Ergebnis kommt auch Rühl, A. (1990), S. 33ff., der die demographischen Strukturen von Bevölkerung und GKV-Versicherten in den Jahren 1976 bis 1985 vergleicht. 
Bevölkerung. Der Rückgang des Jugendquotienten in den Jahren 2003 bis 2050 von 38,3 auf 34,9 bringt zwar zunächst Entlastung für die GKV-Finanzen. Problematisch für die Finanzlage der GKV ist aber die damit verbundene durchschnittliche Alterung der Bevölkerung und der starke Anstieg des Altenquotienten ${ }^{303}$ in diesem Zeitraum von 49,6 auf voraussichtlich 85,8 .

Tabelle 11: Entwicklung der GKV-Versichertenstruktur bis zum Jahr 2050

\begin{tabular}{|c|c|c|c|c|c|c|}
\hline Am 31.12. des Jahres & 2003 & 2010 & 2020 & 2030 & 2040 & 2050 \\
\hline GKV Versicherte & 70.422 & 71.242 & 71.266 & 70.242 & 67.969 & 65.100 \\
\hline in Tausend & 14.357 & 13.211 & 12.384 & 11.852 & 10.956 & 10.292 \\
\hline in Prozent & 20,4 & 18,7 & 17,5 & 16,8 & 15,5 & 14,6 \\
\hline in Tausend & 37.480 & 38.520 & 36.721 & 32.782 & 31.640 & 29.497 \\
\hline in Prozent & 53,2 & 54,1 & 51,5 & 46,7 & 46,6 & 45,3 \\
\hline in Tausend & 18.584 & 19.511 & 22.161 & 25.607 & 25.374 & 25.311 \\
\hline in Prozent & 26,4 & 27,6 & 31,4 & 36,3 & 35,9 & 35,8 \\
\hline Altenquotient GKV & 49,6 & 50,7 & 60,4 & 78,1 & 80,2 & 85,8 \\
\hline Jugendquotient GKV & 38,3 & 34,3 & 33,7 & 36,2 & 34,6 & 34,9 \\
\hline Gesamtlastenquotient GKV & 87,9 & 84,9 & 94,1 & 114,3 & 114,8 & 120,7 \\
\hline
\end{tabular}

Anmerkung: Unterstellt werden die GKV-Versichertenanteile an der gesamten Bevölkerung aus dem Jahr 2003: Bis 19 Jahre: $84,9 \%, 20$ bis 59 Jahre: $82,8 \%$ und ab 60 Jahre: $91,4 \%$.

Quelle: Eigene Berechnungen; Daten: Statistisches Bundesamt (Hrsg.) (2003), S. 42; BMGS (Hrsg.) (2003b).

Insgesamt steigt der Gesamtlastquotient - gebremst durch den Rückgang des Jugendquotienten - von 87,9 im Jahr 2003 auf 120,7 im Jahr 2050 an, d.h. 100 Versicherte im Erwerbsalter zwischen 20 und 59 Jahren müssen dann für knapp 121 Versicherte in der jüngeren und älteren Altersgruppe mit aufkommen. Aus dem Gesamtlastquotienten, der „mengenmäßige“ Relationen angibt, lassen sich allerdings keine quantitativen Aussagen hinsichtlich der finanziellen Belastung der GKV ableiten. Da unterschiedliche Ausgabenniveaus für Ältere und Kinder vorliegen, kann der belastende Effekt eines Anstiegs des Altenquotienten nicht durch einen zurückgehenden Jugendquotienten kompensiert werden. ${ }^{304}$ Berücksichtigt werden muss zu-

\footnotetext{
${ }^{303}$ Zur Kritik an der Aussagekraft des Altenquotienten über die demographische Entwicklung siehe Dinkel, R.H. (1992), S. 64 f.
}

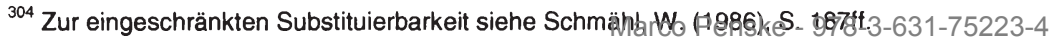


dem, dass Rentner im Gegensatz zu Kindern Beiträge zahlen. Der gleiche Gesamtlastquotient kann daher für die GKV verschiedene finanzielle Belastungen bedeuten. Selbst ein identischer Altenquotient kann je nach Besetzung der ausgabenintensiven hohen Altersjahrgänge die Ausgaben der GKV unterschiedlich beeinflussen.

Der Einfluss des demographischen Wandels auf die GKV wird im Folgenden getrennt für die Ausgaben- und Einnahmenseite analysiert. Im ersten Fall wird dabei zwischen nachfrage- und angebotsseitigen Effekten unterschieden. Bei Letzteren stehen insbesondere der medizinisch-technische Fortschritt und dessen Rückwirkungen auf die Bevölkerungsentwicklung im Mittelpunkt der Betrachtung.

\section{Einflüsse auf die Ausgabenseite}

\subsection{Nachfrageseite}

\subsubsection{Einfluss der Altersstruktur}

Auf der Ausgabenseite ergeben sich aus dem demographischen Wandel Wirkungen, die in entgegengesetzte Richtungen gehen. Die niedrige Geburtenrate führt zusammen mit der längeren Lebenserwartung zu einem Anstieg des Altenquotienten und der durchschnittlichen Ausgaben je Versicherten. Der Rückgang der Bevölkerungszahl aufgrund sinkender Geburtenraten reduziert hingegen die Nachfrage nach Gesundheitsleistungen, was den ausgabensteigernden Effekt der Alterung zumindest teilweise kompensiert.

\section{Abbildung 18: Entwicklung der GKV-Leistungsausgaben bis zum Jahr 2050}

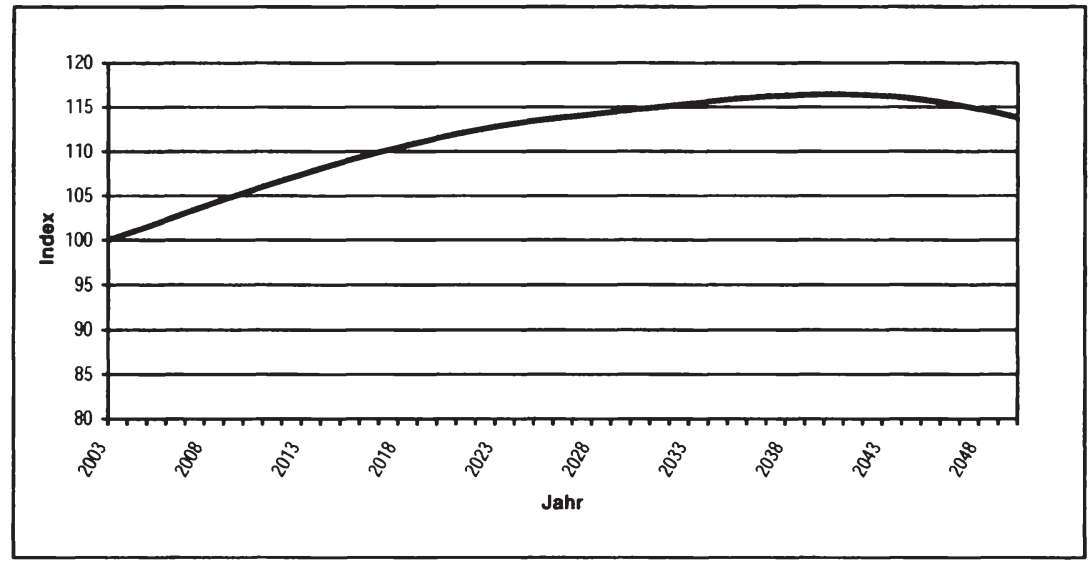

Anmerkung: Index zur Basis im Jahr 2003.

Quelle: Eigene Berechnungen; Daten: BMGS; Statistisches Bundesamt; Bundesversicherungsamt.

Analog zu den Berechnungen im vorigen Abschnitt werden zur Simulation des isolierten Einflusses der Altersstruktur auf die GKV-Ausgaben die RSA-Ausgabenprofile aus dem Jahr 2003 mit der jeweiligen Besetzungsstärke der Altersklassen nach der Bevölkerungsvorausberechnung des Statistischen Bundesamtes für die Jahre 2003

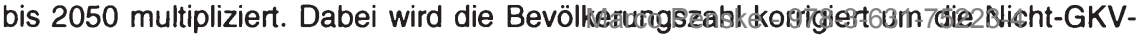


Versicherten entsprechend den Anteilen im Jahr 2003. Nettoverwaltungskosten und sonstige Ausgaben der GKV bleiben unberücksichtigt, weil sie nur einen geringen Anteil an den Gesamtausgaben ausmachen und nicht eindeutig auf die Versicherten nach Alter zuordenbar sind. Die Ergebnisse gibt Abbildung 18 wieder. Bis zum Jahr 2041 wirkt sich der ausgabensteigernde Altersstruktureffekt stärker auf die Gesamtausgaben aus als der Rückgang der Bevölkerung. Die Ausgaben steigen bis zum Jahr 2040 stetig an und liegen dann um 16,4\% über dem Ausgangsniveau im Jahr 2003. Anschließend sinken die Ausgaben leicht. Trotz des Rückgangs liegen die Ausgaben demographisch bedingt im Jahr 2050 aber noch um 13,8\% über dem Niveau im Jahr 2003. ${ }^{305}$

\section{Abbildung 19: GKV-Versicherte und Ausgaben in den Jahren 2003 und 2050}

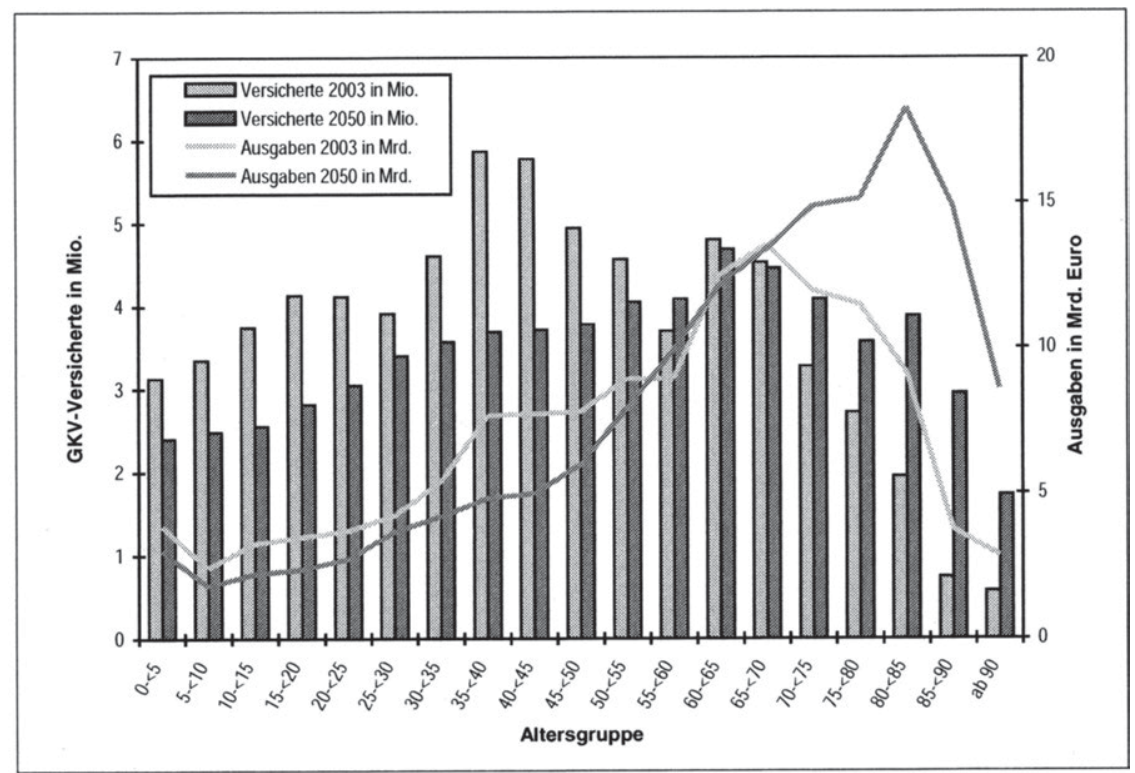

Quelle: Eigene Darstellung und eigene Berechnungen; siehe Tabelle 38: Versicherte, Mitglieder, Ausgaben und Beiträge in den Jahren 2003, 2030 und 2050, im Anhang, S. 276.

Wie sich der demographisch bedingte Ausgabenanstieg auf die einzelnen Altersgruppen verteilt, zeigt Abbildung 19 in einem Vergleich von Ausgaben und Anzahl der GKV-Versicherten in den einzelnen Altersgruppen für die Jahre 2003 und 2050. Die Säulen veranschaulichen die Verschiebung der Altersstruktur der Versicherten in der GKV. Während die Anzahl der Versicherten unter 55 Jahren bis zum Jahr 2050 durchgängig sinkt, wächst die Anzahl der Versicherten in den Altersgruppen ab

${ }^{305}$ Postler, A. (2003), S. 10ff. kommt in einer ähnlichen Modellrechnung mit Durchschnittswerten für Rentner und Erwerbstätige und Daten der 9. koordinierten Bevölkerungsvorausberechnung zu einem geringeren Ausgabeneffekt. Je nach Variante steigen bis zum Jahr 2025 (2030) die

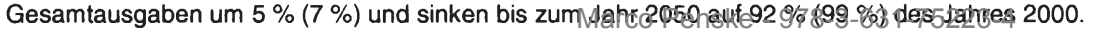




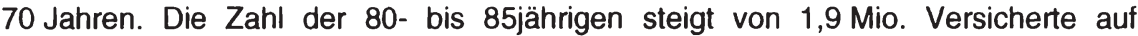
3,9 Mio. Versicherte auf gut das Doppelte an. Die Anzahl der 85- bis 90jährigen wächst auf mehr als das Vierfache von 0,7 Mio. Personen auf 3,0 Mio. Personen. Bei konstanten altersspezifischen Ausgaben verschieben sich - wie die Linien im Diagramm zeigen - wegen der stärkeren Besetzung der höheren Altersklassen die Ausgaben hin zu den Älteren. Während in den Altersgruppen der bis 55jährigen bedingt durch den Rückgang der Gruppenstärke die Ausgaben leicht sinken, steigen die Ausgaben für 65jährige und ältere Versicherte stark an. Insbesondere die Ausgaben für die 80- bis 90jährigen nehmen deutlich zu. Damit wächst der Umverteilungsbedarf für die ältere Generation, während die Zahl der Mitglieder im erwerbsfähigen Alter sinkt.

Die beiden vorstehenden Analysen erfassen nur den rein demographisch bedingten Effekt auf der Ausgabenseite, d.h. alle anderen die Ausgaben beeinflussenden GröBen (z.B. Entwicklung der altersspezifischen Leistungsausgaben, Anteil der GKVVersicherten) werden als konstant angenommen. Die positive Korrelation von Alter und Gesundheitsausgaben ist empirisch belegt und deshalb in der Literatur weitestgehend unstrittig. ${ }^{306}$ Umstritten sind aber die Wirkungen der steigenden Lebensdauer auf die Gesundheitsausgaben, genauer: in welchem Gesundheitszustand ${ }^{307}$ die zusätzlichen Jahre verbracht werden. Davon hängt $a b$, inwieweit die zunehmende Lebenserwartung weitere Finanzierungsprobleme für die GKV aufwirft. Diese Frage wird in der Literatur kontrovers diskutiert. Nach der pessimistischen Medikalisierungsthese werden die gewonnenen Lebensjahre zum großen Teil in Krankheit verbracht. Die optimistische Kompressionsthese geht hingegen davon aus, dass durch neue Behandlungsmethoden das Auftreten von Krankheiten zeitlich nach hinten verschoben wird, die gewonnenen Lebensjahre also überwiegend in Gesundheit verbracht werden. In dem bi-modalen Konzept werden beide - auf den ersten Blick unvereinbaren - Thesen miteinander kompatibel: Zwar verbessert sich der Gesundheitszustand von Generation zu Generation, trotzdem steigt wegen der demographischen Alterung der Anteil der gesundheitlich Beeinträchtigten aber an.

Bei der Analyse der Wirkungen der demographischen Alterung auf die Gesundheitsausgaben werden vier Effekte unterschieden: ${ }^{308}$

Wie die Betrachtung der Altersprofile in Abbildung 6 (S. 43) im Querschnitt gezeigt hat, steigen mit zunehmendem Alter die Gesundheitsausgaben. Die mit dem Lebensalter steigende Morbidität wird als Kalendereffekt (auch Alterseffekt) bezeichnet. Auf diesen Effekt wird insbesondere bei der Diskussion der Medikalisierungsthese näher eingegangen.

Dem gegenüber steht der Restlebenszeiteffekt. Nach diesem ist der in der Querschnittsanalyse festgestellte Unterschied in der Ausgabenhöhe zwischen Jüngeren und Älteren in erster Linie auf die zeitliche Entfernung zum Tod und nicht auf das Lebensalter zurückzuführen. Dieser Effekt ist für die Kompressionsthese entscheidend.

\footnotetext{
${ }^{306}$ Vgl. Krämer, W. (1992), S. 571; Hof, B. (2001), S. 49f.; Kruse, A. u.a. (2003), S. 35.

${ }^{307}$ Zur Messung der Morbidität und der Definition von Gesundheitsindikatoren für die Beurteilung des Gesundheitszustands von Personen siehe Raspe, H. (1999), S. 85ff.

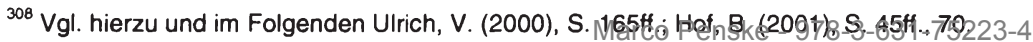


Der Periodeneffekt beschreibt die Abhängigkeit der Ergebnisse von dem gewählten Referenzjahr, so kann z.B. eine Gesundheitsreform die Ergebnisse erheblich beeinflussen. Dieser Periodeneffekt kann auch in einer Längsschnittsbetrachtung auftreten, weil die Ausgabenprofile zu verschiedenen Zeitpunkten erfasst werden.

Hinzu kommt der insbesondere bei Querschnittsanalysen auftretende Kohorteneffekt, da Altersgruppen verschiedener Jahrgänge zu einem Zeitpunkt verglichen werden. Bei diesen Vergleichen anhand von Querschnittsanalysen stammen z.B. die 20jährigen aus einer anderen Kohorte als die 60jährigen. Die unterschiedlichen Ausgabenhöhen können also auch auf die Zugehörigkeit zu verschiedenen Kohorten zurückzuführen sein. Diesen Kohorteneffekt versucht die Längsschnittsanalyse auszuschalten, indem sie einen Geburtsjahrgang im Zeitverlauf beobachtet, bis kein Mitglied dieser Kohorte mehr am Leben ist. In der Praxis gelingt es dabei allerdings nur mit großem Erhebungsaufwand, echte Kohorten zu erfassen. Da z.B. die im Jahr 2000 erfassten 60jährigen mit hoher Wahrscheinlichkeit nicht identisch sind mit den im Jahr 1990 erfassten 50jährigen, spricht man auch von unechten Kohorten. In der Längsschnittsanalyse muss beim Vergleich der Ausgabenentwicklung verschiedener Kohorten der Kohorteneffekt also ebenfalls berücksichtigt werden. Schließlich kann der unterschiedliche Ausgabenverlauf auch hier aus Besonderheiten der Geburtsjahrgänge (z.B. Kriegskohorte) resultieren.

\subsubsection{Medikalisierungsthese}

Die auf Verbrugge ${ }^{309}$ zurückgehende Medikalisierungsthese stützt sich auf den bereits dargestellten Zusammenhang zwischen Alter und Gesundheitsausgaben. Demnach nimmt die Morbidität ${ }^{310}$ mit dem Alter zu und verursacht bei einer steigenden Lebenserwartung einen Anstieg der Gesundheitsausgaben.

„And so, as the elderly's share of the population increases, so too will the demand for health care. ${ }^{311}$

Diese Auffassung ist kompatibel mit der von Gruenberg ${ }^{312}$ und Kramer ${ }^{313}$ zuvor aufgestellten These, dass der Rückgang der Mortalität (Sterblichkeitsrate) nicht auf einen verbesserten Gesundheitszustand, sondern auf eine Verlängerung des Lebens von Personen mit relativ leichten Erkrankungen zurückzuführen ist. Abbildung 20 stellt die repräsentativen Gesundheitsausgaben über den Lebenszyklus nach der Medikalisierungsthese schematisch dar. Theoretisch begründet wird der Zusammenhang zwischen einer steigenden Lebenserwartung und steigenden Gesundheitsausgaben mit der Theorie heterogener Populationen. ${ }^{314}$ Danach setzt sich jede Kohorte aus Neugeborenen mit heterogenen Risiken hinsichtlich der Überlebens-

\footnotetext{
${ }^{309}$ Siehe Verbrugge, L.M. (1984), S. 475ff.

${ }^{310}$ Morbidität ist ein Indikator für den Gesundheitszustand eines Versicherten, der durch die Krankheitshäufigkeit in einer bestimmten Versichertengruppe in einem vorgegebenen Zeitraum gemessen wird.

${ }^{311}$ Longman, P. (1987), S. 88.

${ }^{312}$ Siehe Gruenberg, E.M. (1977), S. 3ff.

${ }^{313}$ Siehe Kramer, M. (1980), S. $382 \mathrm{ff}$.

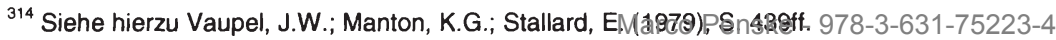


chancen zusammen. Während schlechte Risiken aufgrund ihrer biologischen Anlagen früher sterben, können gute Risiken ein überdurchschnittlich langes Leben erwarten. Trifft diese Theorie $\mathrm{zu}$, dann bestehen mit zunehmendem Alter die Überlebenden einer Kohorte zu einem größer werdenden Anteil aus guten Risiken. Steigt jedoch die Lebenserwartung, reduziert sich die Selektionsgeschwindigkeit und ein deutlich größerer Teil der Kohorte ist auch noch in höherem Alter am Leben, was zu einem größeren Anteil schlechter Risiken führt, die bei einer kürzeren Lebenserwartung nicht mehr am Leben wären. Damit weist die Kohorte einen im Durchschnitt schlechteren Gesundheitszustand auf.

\section{Abbildung 20: Altersausgabenprofil nach der Medikalisierungsthese}

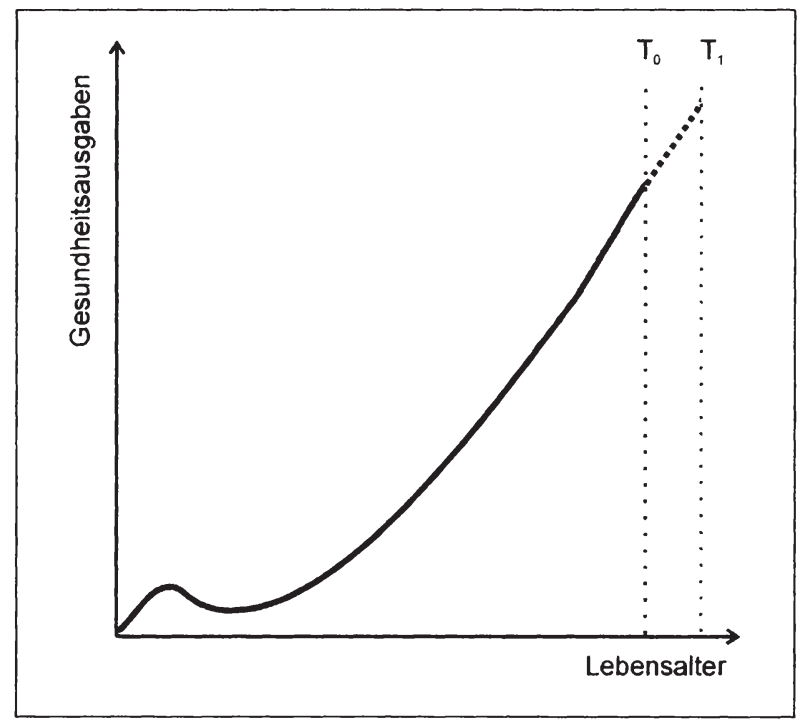

Quelle: Oberdieck, V. (1998), S. 105.

Verbrugge ${ }^{315}$ stellt in einer Untersuchung anhand von Daten des National Health Interview Survey für die USA seit 1957 einen Anstieg der Morbidität von Personen mittleren und höheren Alters fest. Den Zusammenhang von sinkender Mortalität und steigender Morbidität führt Verbrugge im Wesentlichen darauf zurück, dass durch verbesserte Diagnoseverfahren Krankheiten früher erkannt werden, die Menschen daher auch früher Krankheiten wahrnehmen und durch eine verbesserte medizinische Versorgung auch nicht gesunde Menschen bis in höhere Altersstufen überleben. Viele Menschen werden zwar in dieser Periode vor dem Tod gerettet, überleben aber nur mit gesundheitlichen Beeinträchtigungen. Versicherte mit chronischen Krankheiten, die bei schlechter medizinischer Versorgung hätten sterben müssen, sind heute noch am Leben. Dadurch nehmen insbesondere chronische, aber nicht tödliche Krankheiten zu, die mit hohen Ausgaben verbunden sind. 
"Most of these "new survivors" are ill with chronic diseases, though not so ill as those who died. By staying alive longer, they have more years for their illnesses to advance in severity and more time to develop other chronic conditions, both killers and non-killers. ${ }^{316}$

$\mathrm{Zu}$ einem ähnlichen Ergebnis kommen Colvez und Blanchet ${ }^{317}$. In einer Untersuchung anhand von Daten des United States National Health Interview Surveys stellen die Autoren für den Untersuchungszeitraum 1966 bis 1976 einen Anstieg der Lebenserwartung verbunden mit einer Zunahme der Lebensjahre in Krankheit fest. Zurückgeführt wird dieses Ergebnis auf zwei Thesen: Zum einen kann der Anstieg durch Krankheiten bedingt sein, die die Medizin zwar nicht zu heilen vermag, die aber nicht zum Tode führen, zum anderen durch den erleichterten Zugang zu Gesundheitsleistungen durch den Ausbau von Medicare und Medicaid. ${ }^{318}$

Mit der Lebenserwartung steigt nicht nur die Morbidität der gesamten Bevölkerung, sondern auch die altersspezifische Morbidität in allen Altersklassen, zumal viele Krankheiten bereits in jungen Jahren und nicht erst am Lebensende auftreten. Die sinkende Mortalität geht mit steigender Morbidität einher, so dass insbesondere der Anteil chronisch Kranker dadurch zunimmt. ${ }^{319}$

Zu diesem Ergebnis kommt auch Brody, der feststellt:

„Present data indicate a modest gain in healthy years lived and a far greater increase in years of compromised physical, mental and social function. The net increase in survival translates into more years of ill health. ${ }^{320}$

Wilkins und Adams ${ }^{321}$ schätzen, dass in Kanada die zwischen 1951 und 1978 gewonnenen Lebensjahre bei Männern zu $70 \%$ und bei Frauen zu $80 \%$ in Krankheit verbracht wurden. Nach Crimmins, Saito und Ingegneri ${ }^{322}$ bestand der Zugewinn an Lebensjahren zwischen 1970 und 1980 in den USA für 65jährige Männer zu 83 \% und für 85jährige Männer sogar vollständig aus Jahren in gesundheitlicher Beeinträchtigung. Bei 65 jährigen Frauen betrug dieser Anteil $88 \%$, bei 85 jährigen Frauen $63 \%$.

Nach einer schwächeren Form der Medikalisierungsthese verschlechtert sich der Gesundheitszustand nicht über alle Altersklassen, sondern erst mit zunehmendem Alter. ${ }^{323} \mathrm{Ob}$ in der Vergangenheit die Gesundheitsausgaben in allen Altersklassen bzw. nur in höheren Altersklassen angestiegen oder die altersabhängigen Ausgaben

\footnotetext{
${ }^{316}$ Verbrugge, L.M. (1984), S. 507.

${ }^{317}$ Siehe Colvez, A.; Blanchet, M. (1981), S. 464ff.

${ }^{318} \mathrm{Vgl}$. ebenda, S. 469.

${ }^{319} \mathrm{Vgl}$. Hof, B. (2001), S. 43.

${ }^{320}$ Brody, J.A. (1985), S. 464

${ }^{321}$ Siehe Wilkins, R.; Adams, O.B. (1987), S. $227 f$.

${ }^{322}$ Siehe Crimmins, E.M.; Saito, Y.; Ingegneri, D. (1989), S. 235ff., insbes. S. 244f. Nach Dinkel, R.H. (1992), S. 88f., ist die zunehmende Anzahl von Lebensjahren in gesundheitlicher Beeinträchtigung nicht auf die steigende Lebenserwartung zurückzuführen. Da in verschiedenen Altersklassen eine höhere Krankheitshäufigkeit festzustellen sei, liege ein Periodeneffekt vor.
}

${ }^{323}$ Vgl. Robine, J.M.; Mathers, C.D. (1993), S. 272. Marco Penske - 978-3-631-75223-4 
abgeflacht sind, wird im Folgenden anhand von Querschnittsdaten empirisch untersucht. ${ }^{324}$

Seit 1994 erfasst das Bundesversicherungsamt zur Durchführung des RSA Ausgabenprofile nach dem Alter. Berücksichtigt werden die Ausgaben für ambulante ärztliche Behandlung, zahnärztliche Behandlung, stationäre Behandlung im Krankenhaus, Heil- und Hilfsmittel sowie Krankengeldzahlungen. ${ }^{325} \mathrm{Da}$ die Ausgaben für Rentner erst ab 1995 in den RSA-Ausgabenprofilen erfasst sind, werden zur besseren Vergleichbarkeit die Ausgabenprofile von 1995 mit denen aus dem Jahr 2003 verglichen.

\section{Abbildung 21: GKV-Ausgabenprofil in den Jahren 1995 und 2003}

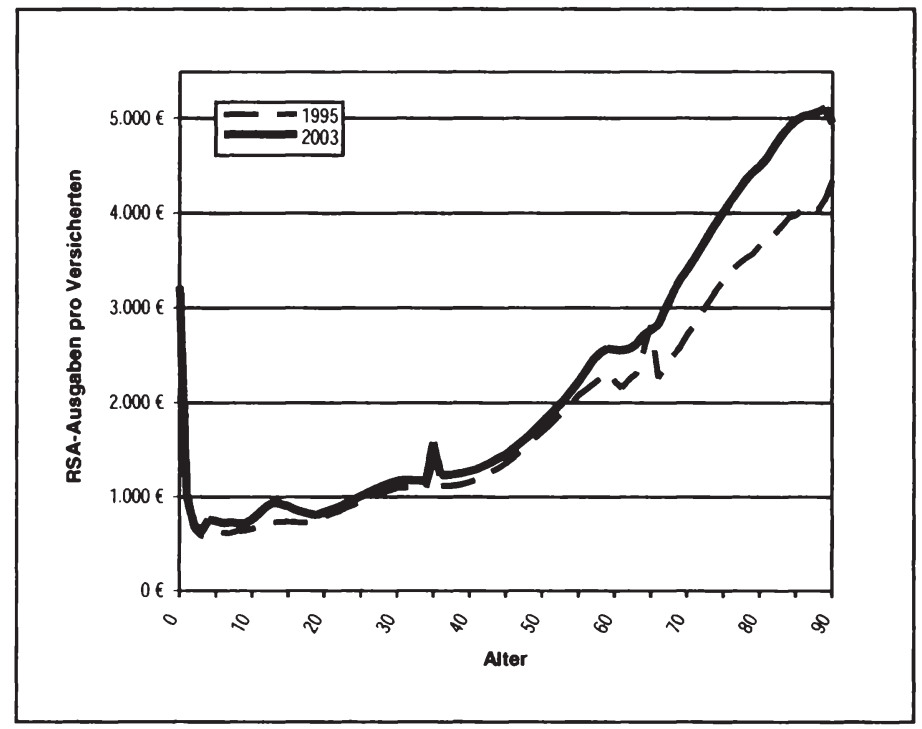

Quelle: Eigene Berechnungen; Daten: Bundesversicherungsamt.

In Abbildung 21 werden die altersabhängigen RSA-Ausgabenprofile in den Jahren 1995 und 2003 für das gesamte Bundesgebiet verglichen. Die Vergleichbarkeit der Ausgabenprofile wird zum Teil eingeschränkt durch im Jahr 2002 in Kraft getretene Änderungen am RSA. Ab 2002 werden nach § 269 SGB V $60 \%$ aller Leistungsausgaben über 20.450 Euro für einen Versicherten von einem Risikopool aller Kassen finanziert. Um diese vom Risikopool finanzierten Ausgaben sind die Ausgabenprofile normalenweise reduziert. Zur besseren Vergleichbarkeit wird deshalb im Folgenden auf Ausgabenprofile zurückgegriffen, die nicht um die Poolausgaben abgesenkt sind. Ebenfalls berücksichtigt wird, dass im Jahr 2003 erstmals für in Disease-Management-Programme eingeschriebene Versicherte die Versicherten-

${ }^{324}$ In Anlehnung an Hof, B. (2001), S. 52ff. Die Profile von Alterskohorten können aufgrund der Datenlage nicht verglichen werden; vgl. für die PKV Buchner, F.; Wasem, J. (2000), S. 8f.; Wasem, J. (1996), S. 130f.

${ }^{325} \mathrm{Vgl}$. Spitzenverbände der am RSA beteiligten Krankenkassen \&H:sg. 
gruppen weiter differenziert wurden. Etwas eingeschränkt bleibt die Vergleichbarkeit allerdings durch ein im Jahr 2002 geändertes Glättungsverfahren. ${ }^{326}$

Der Vergleich der RSA-Ausgabenprofile bestätigt die Medikalisierungsthese. Der Kurvenverlauf deutet auf einen Anstieg der altersabhängigen Ausgaben im Zeitraum von 1995 bis 2003 hin. ${ }^{327}$ Dieser Anstieg ist bis zum 55. Lebensjahr nur moderat. Insbesondere ab dem 65. Lebensjahr ist jedoch ein deutlicher Anstieg der durchschnittlichen Gesundheitsausgaben zu verzeichnen. 1995 verursachte z.B. ein 66jähriger noch jährliche Ausgaben von durchschnittlich 2.263 Euro, im Jahr 2003 betrugen diese schon 2.824 Euro. Für einen 80jährigen stiegen die Ausgaben in diesem Zeitraum von 3.664 Euro auf 4.497 Euro. Der Anstieg liegt damit über dem allgemeinen Preisanstieg. Eine Verbesserung des Gesundheitszustands der Älteren und damit eine Verflachung der Ausgabenprofile kann jedenfalls nicht festgestellt werden.

\subsubsection{Kompressionsthese}

Bei dieser Querschnittsanalyse werden unterschiedliche Altersgruppen zu einem Zeitpunkt verglichen. Daher können die unterschiedlichen Ausgabenhöhen auch auf einen Kohorteneffekt zurückzuführen sein, z.B. stammen die 20jährigen aus einer anderen Kohorte als die 60jährigen. Den Kohorteneffekt vermeidet die Längsschnittsanalyse, indem sie die Ausgabenentwicklung eines Geburtsjahrgangs im Zeitverlauf betrachtet. $^{328}$

Vertreter der Kompressionsthese bezweifeln, dass die aus Querschnittsdaten gewonnenen altersspezifischen Gesundheitsausgaben auch im Zeitverlauf bei einer längeren Lebenserwartung konstant bleiben. Die Differenzen bei den Ausgaben zwischen Jüngeren und Älteren seien nicht allein auf das Lebensalter, sondern im Wesentlichen auf die zeitliche Entfernung zum Tod zurückzuführen. Die Berechnung künftiger Gesundheitsausgaben anhand der aktuellen Ausgabenprofile überschätzt demnach die Gesundheitsausgaben, weil das Verhältnis zwischen „teureren Versterbenden“ und „kostengünstigeren Überlebenden“ als konstant angenommen wird ${ }^{329}$, tatsächlich aber sinkt.

Nach Fries ${ }^{330}$ beruht die steigende Lebenserwartung auf einem verbesserten Gesundheitszustand. Mortalität und Morbidität würden parallel sinken, die gewonnenen Lebensjahre zunehmend in Gesundheit und frei von chronischen Erkrankungen verbracht werden. Lediglich kurz vor dem Tod stiegen die Gesundheitsausgaben stark an. Die mit dem Alter zunehmende Nähe zum Tod sei demzufolge verantwortlich für die Altersabhängigkeit der Gesundheitsausgaben. Die Zunahme der Lebenserwartung verschiebe lediglich die Ausgaben in spätere Lebensabschnitte, über den

\footnotetext{
${ }^{326}$ Zum Glättungsverfahren siehe ausführlich Spitzenverbände der am RSA beteiligten Krankenkassen (Hrsg.) (2003), Anlage 1.8.

${ }^{327}$ Siehe auch Enquete-Kommission Demographischer Wandel (1998), S. 230ff. Zu diesem Ergebnis kommen auch Zweifel, P. (1989), S. 302f., in einer Untersuchung für die Schweiz im Zeitraum 1976 bis 1986 und Barer, M.L. U.a. (1987), S. 854ff., für Kanada im Zeitraum 1971 bis 1982. Der SVR (2004), Kasten 19, stellt indes nur eine geringe Steigerung fest.

${ }^{328}$ Für einen Methodenvergleich siehe Robine, J.M.; Mathers, C.D. (1993), S. $270 f f$.

${ }^{329} \mathrm{Vgl}$. Busse, R. (1996), S. 89.

${ }^{330}$ Siehe Fries, J.F. (1985), S. 47ff. 
gesamten Lebenszyklus betrachtet änderten sich die Pro-Kopf-Ausgaben nicht. Im Zuge der demographischen Entwicklung stiegen die Gesamtausgaben - wenn überhaupt - nur in geringem Maße.

\section{Abbildung 22: Altersausgabenprofil nach der Kompressionsthese}

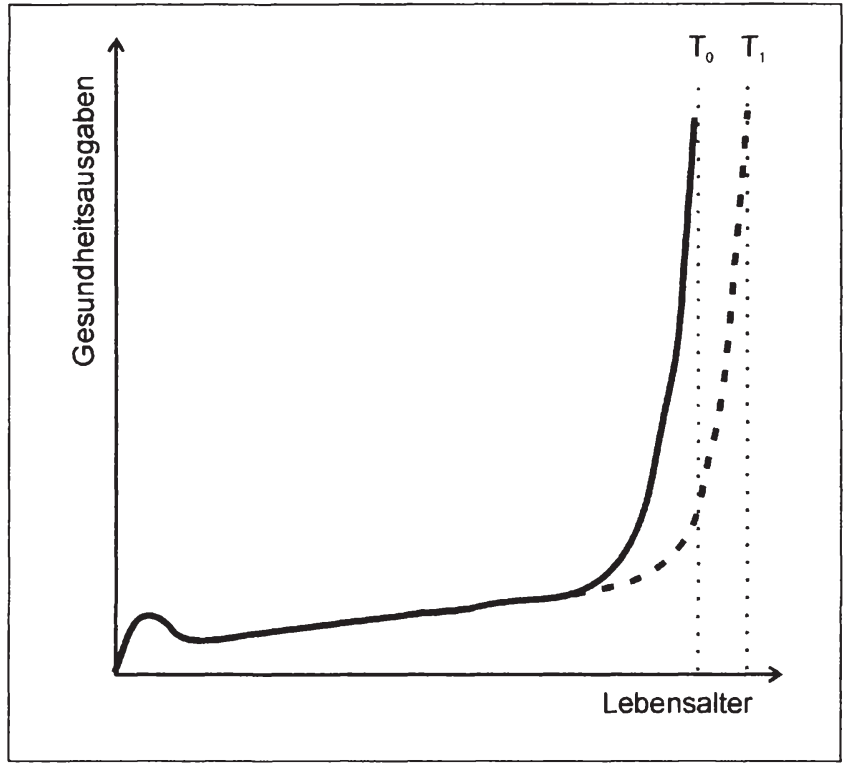

Quelle: Oberdieck, V. (1998), S. 108.

Abbildung 22 veranschaulicht den Zusammenhang: Die Gesundheitsausgaben steigen nach der Kompressionsthese mit dem Alter kaum an, erst in den letzten Lebensjahren ist ein starker Anstieg zu beobachten. Die steigende Lebenserwartung führt dann nicht zu einem steigenden Finanzbedarf, weil die Ausgaben nur später anfallen, die Morbidität insgesamt aber nicht - wie es die Medikalisierungsthese besagt steigt. Während die Lebensspanne genetisch festgelegt ist, kann der Beginn chronischer Krankheiten nach Fries ${ }^{331}$ hinausgezögert werden. Damit sei es möglich, die Zeitspanne zwischen dem Auftreten einer chronischen Krankheit und dem Tod zu verkürzen („komprimierte Morbidität“).

Jüngere empirische Untersuchungen unterstützen die Kompressionsthese. Sie kommen zu dem Ergebnis, dass im Durchschnitt die Gesundheitsausgaben in den beiden letzten Lebensjahren deutlich ansteigen, womit nicht das Alter, sondern die Nähe zum Tod entscheidend für die Gesundheitsausgaben ist. Die positive Korrelation von Pro-Kopf-Ausgaben und Alter beruht dann auf der mit dem Alter steigenden Sterberate. ${ }^{332}$

\footnotetext{
${ }^{331}$ Vgl. Fries, J.F. (1989), S. 19, 24.

${ }^{332}$ Vgl. Zweifel, P.; Felder, S.; Meier, M. (1999), S. 486arco Penske - 978-3-631-75223-4
} 
Mit Querschnittsdaten des Mikrozensus, in dem auch nach der subjektiven Einschätzung des Gesundheitszustands gefragt wird, stellen Doblhammer und Kytir ${ }^{333}$ für den Untersuchungszeitraum 1978 bis 1998 für Österreich mit der steigenden Lebenserwartung eine Zunahme der Anzahl von in Gesundheit verbrachten Lebensjahren und deren Anteil an der gesamten noch verbleibenden Lebenserwartung fest. Je nach Definition eines guten Gesundheitszustands stieg dieser Anteil z.B. für 65jährige Männer von $76 \%$ bzw. $34 \%$ im Jahr 1978 auf $87 \%$ bzw. $52 \%$ im Jahr 1998. Ein ähnlicher Anstieg lässt sich für Männer und Frauen aller untersuchten Jahrgänge feststellen. Die Daten belegen, dass mit der steigenden Lebenserwartung ein verbesserter Gesundheitszustand der Bevölkerung einhergeht - entgegen der Auffassung von Vertretern der Medikalisierungsthese und der hierzu im vorigen Abschnitt (S. 94) dargestellten Untersuchungen, bei denen der Gesundheitszustand der Versicherten anhand objektiver medizinischer Kriterien bewertet wurde. ${ }^{334}$

Die Bedeutung des letzten Lebensjahres zeigen auch Lubitz und Riley ${ }^{335}$ in einer Untersuchung für die USA: Im Jahr 1988 entfielen 28,6\% der Medicare Ausgaben auf $5,1 \%$ der Medicare-Versicherten, die sich in ihrem letzten Lebensjahr befanden. Die jährlichen Pro-Kopf-Ausgaben für einen Verstorbenen betrugen dieser Untersuchung zufolge 13.316 US-Dollar und waren damit siebenmal größer als die für einen Überlebenden (1.924 US-Dollar). Vliet und Lamers ${ }^{336}$ beziffern in einer Untersuchung mit Daten einer niederländischen Krankenkasse für die Jahre 1992 bis 1994 die ProKopf-Ausgaben im letzten Lebensjahr sogar auf das 16-fache der Pro-Kopf-Ausgaben für einen Überlebenden. Die Bedeutung für die Gesamtausgaben zeigt ein weiterer Vergleich: Verstorbene, die einen Anteil von $1 \%$ an den Versicherten einer Krankenkasse ausmachten, verursachten 7,8 \% der Gesamtausgaben dieser Kasse.

Zweifel, Felder und Meier ${ }^{337}$ untersuchen Individualdaten von zwei Schweizer Krankenversicherungen und einer US-amerikanischen Medicare Versicherung. Anhand einer Regressionsanalyse kommen sie zu dem Ergebnis, dass die Pro-Kopf-Gesundheitsausgaben einer Bevölkerung unabhängig von deren Altersaufbau sind. Nicht das Kalenderalter, sondern die Nähe zum Todeszeitpunkt bestimme im Wesentlichen die Gesundheitsausgaben der über 65jährigen. ${ }^{338}$ Bei Medicare-Versicherten entfielen $60 \%$ der Gesamtausgaben auf Versicherte im letzten Quartal unmittelbar vor dem Tod. Bei den beiden untersuchten Schweizer Krankenkassen lagen diese Anteile bei $49 \%$ und $42 \%$. Den geringeren Anteil führen die Autoren darauf zurück, dass die meisten Sterbefälle im Krankenhaus auftreten und diese in der Schweiz von den Kantonen subventioniert werden, so dass die erfassten Ausgaben nicht die Gesamtausgaben wiedergeben.

\footnotetext{
${ }^{333}$ Siehe Doblhammer, G.; Kytir, J. (1999), S. 71ff., insbes. S. 76ff. und die Tabellen 3ff.

${ }^{334}$ Auch die bei dieser Untersuchung verwendete Selbsteinschätzung der eigenen Gesundheit ist ein guter Indikator für den allgemeinen Gesundheitszustand; vgl. Greiner, P.A.; Snowdon, D.A.; Greiner, L.H. (1996), S. 234ff.

${ }^{335}$ Siehe Lubitz, J.; Riley, G.F. (1993), S. 1092ff., insbes. Tabelle 1 f.

${ }^{336}$ Siehe Vliet, R.C.J.A. van; Lamers, L.M. (1998), S. $1454 f$.

${ }^{337}$ Siehe Zweifel, P.; Felder, S.; Meier, M. (1999), S. $485 f f$.

${ }^{338}$ Kontrovers hierzu zeigt Nocera, S. (1996), S. 65ff., ebenfalls für die Schweiz, dass für den stationären Bereich eher die Medikalisierungsthese zuzutreffí日|scheighske - 978-3-631-75223-4
} 
Ein weiterer Zusammenhang lässt sich anhand dieser Daten ermitteln: Mit zunehmendem Alter sinken die in der Nähe zum Tod anfallenden Gesundheitsausgaben. ${ }^{339}$ Zu diesem Ergebnis kommen auch Temkin-Greener u.a. ${ }^{340}: 30 \%$ aller Verstorbenen im Untersuchungszeitraum 1987 und 1988 waren 65 bis 74 Jahre alt und verursachten innerhalb von 18 Monaten vor ihrem Tod $35 \%$ der Kosten aller Versterbenden. Die 85jährigen und Älteren machten demgegenüber zwar $32 \%$ der Versterbenden aus, ihr Kostenanteil lag aber nur bei $26 \%$. Verglichen mit den Ausgaben für alle Versicherten in der jeweils gleichen Altersgruppe fallen für Versterbende deutlich höhere Kosten an, die aber mit zunehmendem Alter sinken. In ihrem Todesjahr verursachten die 65- bis 74jährigen im Vergleich zu allen Versicherten der gleichen Altersgruppe die 12,4fachen Ausgaben, die 75- bis 85jährigen die 7,3fachen und die über 85jährigen die 4,6fachen. Einen relativen Rückgang der Gesundheitsausgaben im letzten Lebensjahr mit zunehmendem Alter stellen auch Vliet und Lamers ${ }^{341}$ bei einem Vergleich der Pro-Kopf-Ausgaben für Sterbende mit den Pro-Kopf-Ausgaben von Überlebenden einer Altersgruppe fest: Dieser Anteil sinkt vom fast 80fachen für

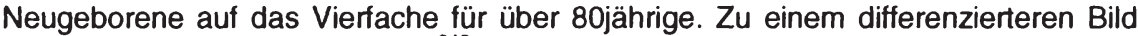
kommen Bleckmann und Rodrig ${ }^{342}$ anhand von Daten der Deutschen Krankenversicherung für das Jahr 1991. Danach lagen die Pro-Kopf-Ausgaben der Verstorbenen in der Altersgruppe von 20 bis 34 Jahren deutlich unter den Ausgaben der bis 19jährigen. Die Gruppe der 35- bis 54jährigen verursachte die höchsten Sterbekosten. Ab dann sanken die Ausgaben im letzten Lebensjahr wieder. Erklärt wird dies durch folgende Zusammenhänge: Während die 20- bis 34jährigen häufig an Unfallfolgen sterben und dadurch relativ geringe Sterbekosten verursachen, leiden die 35- bis 54jährigen vielfach an schweren, kostenintensiven Krankheiten. In höherem Alter versterben die Versicherten meist eines natürlichen Todes, wodurch im Durchschnitt geringere Behandlungskosten entstehen.

Ob von der demographischen Alterung durch die mit dem Alter sinkenden Sterbekosten pro Kopf sogar ein entlastender Effekt auf die Gesundheitsausgaben ausgeht, ist umstritten ${ }^{343}$ Einerseits sinken mit einer längeren Lebenserwartung zwar die Sterbekosten. Andererseits zeigen aber Untersuchungen ${ }^{344}$, dass der Anteil der Kosten für Versterbende an den Gesamtkosten einer Altersgruppe mit zunehmendem Alter und Sterberisiko ansteigt, weshalb die Ausgaben mit dem Alter wachsen. Zudem verursachen ältere Versicherte mit jedem gewonnenen Lebensjahr zusätzliche, mitunter jährlich steigende Kosten. ${ }^{345}$

339 In der Regressionsanalyse von Felder, S.; Meier, M.; Schmitt, H. (2000), S. 689f., wird die Hypothese, dass die Gesundheitsausgaben in den letzten Lebensmonaten für Jüngere höher sind als für Ältere, zwar abgelehnt - dies führen die Autoren aber auf die geringe Stichprobengröße zurück. Die Hypothese, dass ab dem 65. Lebensjahr die Gesundheitsausgaben im letzten Lebensjahr mit zunehmendem Alter sinken, wird hingegen von den Daten gestützt.

${ }^{340}$ Siehe Temkin-Greener, H. U.a. (1992), S. 685ff.

${ }^{341}$ Siehe Vliet, R.C.J.A. van; Lamers, L.M. (1998), S. 1456.

${ }^{342}$ Siehe Bleckmann, N.; Rodrig, S. (1995), S. $53 \mathrm{ff}$.

${ }^{343}$ Vgl. Enquete-Kommission Demographischer Wandel (1998), S. 232. Knappe, E.; Optendrenk, S. (1999), S. 166f.; Buttler, G.; Fickel, N.; Lautenschläger, B. (1999), S. 133, gehen von keinem entlastenden Effekt aus.

344 Siehe hierzu Bleckmann, N.; Rodrig, S. (1995), S. 56ff.

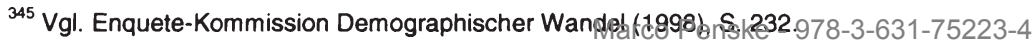


Beide Zusammenhänge - Abhängigkeit der Ausgaben von der Entfernung zum Tod und Altersabhängigkeit der Ausgaben im letzten Lebensjahr - wurden für Deutschland anhand von Versichertendaten der Gmünder Ersatzkasse für die Jahre 1989 bis 1995 untersucht. Für den stationären Bereich finden Busse u.a. ${ }^{346}$ Hinweise auf die Gültigkeit der Kompressionsthese. In einer neueren Untersuchung verwenden Grobe, Dörning und Schwartz ${ }^{347}$ Daten der Gmünder Ersatzkasse aus dem Jahr 2001. $\mathrm{Da}$ insbesondere die Ausgaben für die ambulante ärztliche und zahnärztliche Versorgung nicht versichertenbezogen erfasst werden, bleiben diese unberücksichtigt. Erfasst werden die Ausgaben für Arzneiverordnungen, Heil- und Hilfsmittel, Krankenhausbehandlung sowie Krankengeld, die rund $60 \%$ der Gesamtausgaben der Gmünder Ersatzkasse ausmachen.

\section{Abbildung 23: Ausgaben für Versterbende und Überlebende}

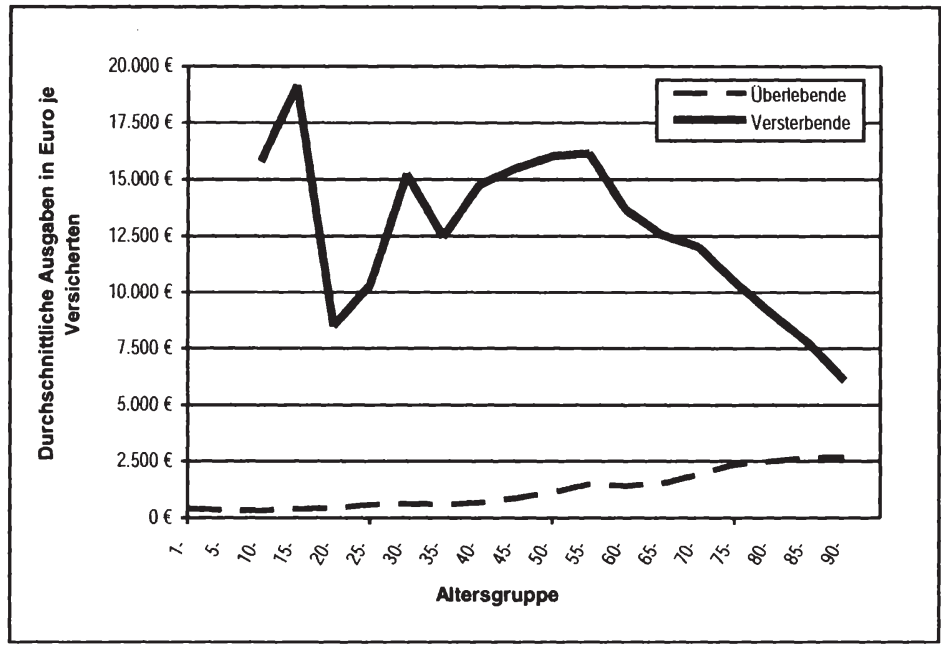

Quelle: In Anlehnung an Grobe, T.G.; Dörning, H.; Schwartz, F.W. (2003), S. 100, $152 f$.

Abbildung 23 stellt die versichertenbezogen erfassten Ausgaben der Gmünder Ersatzkasse im Jahr 2001 für Versterbende und Überlebende nach Altersgruppen dar. Hieraus lassen sich drei Ergebnisse ableiten: ${ }^{348}$

1. Die Leistungsausgaben für Versterbende liegen deutlich über den Ausgaben für Überlebende. Die erfassten Ausgaben z.B. für einen Überlebenden der Altersgruppe 50 bis 55 Jahre liegen bei 1.127 Euro, für einen Versterbenden in der gleichen Altersgruppe betragen diese Kosten 16.030 Euro. Die Pro-KopfAusgaben liegen für die Überlebenden in allen Altersgruppen unter 3.000 Euro, während sie bei den Versterbenden zwischen 6.000 Euro und 16.000 Euro

\footnotetext{
${ }^{346}$ Siehe Busse, R. u.a. (1999), S. 393ff.; Seidler, A.; Busse, R.; Schwartz, F.W. (1996), S. $317 f f$; SVR KAiG (1996), Ziff. $91 \mathrm{ff.}$

${ }^{347}$ Siehe Grobe, T.G.; Dörning, H.; Schwartz, F.W. (2003), S. $89 f f$.

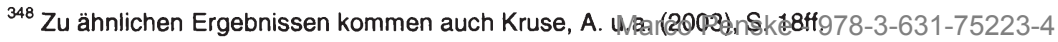


schwanken. Insgesamt entfallen 9,3\% der berücksichtigten Gesamtausgaben auf nur $0,87 \%$ der Versicherten, die im selben Jahr oder im Folgejahr versterben. ${ }^{349}$

2. Ab dem 60. Lebensjahr ist ein stetiger Rückgang der Leistungsausgaben im letzten Lebensjahr festzustellen. Kostet ein Sterbender der Altersgruppe 60 bis 65 Jahre noch durchschnittlich 13.669 Euro, muss die Versicherung für einen über 90jährigen Versicherten nur durchschnittlich 6.090 Euro im letzten Lebensjahr aufwenden.

3. Auch in der Gruppe der Versicherten, die noch mindestens ein Jahr leben, steigen die Ausgaben mit dem Alter an.

Die Ergebnisse bestätigen - wie die dargestellten Studien aus den USA und der Schweiz - den Einfluss der Entfernung zum Tod auf die Gesundheitsausgaben. Sie zeigen zudem, dass die Kosten im letzten Lebensjahr mit zunehmendem Alter im Durchschnitt sinken. Die Kompressionsthese lässt sich indes aber nur teilweise aufrechterhalten, weil auch bei den Überlebenden mit dem Alter zunehmende Leistungsausgaben festzustellen sind, was wiederum die Medikalisierungsthese stützt. Bei den über 85jährigen können z.B. nur $29 \%$ der Ausgaben der zeitlichen Nähe zum Tod zugeschrieben werden. Mit anderen Worten: Selbst in diesen Altersgruppen sind $71 \%$ der Ausgaben unabhängig vom Todeszeitpunkt. ${ }^{350}$ Bei der Interpretation muss aber berücksichtigt werden, dass die Kosten für ambulante Behandlungen nicht erfasst sind.

$\mathrm{Zu}$ einem ebenfalls die Kompressionsthese einschränkenden Ergebnis kommen Untersuchungen ${ }^{351}$ mit Daten der Deutschen Krankenversicherung, in denen die Kosten für ambulante und stationäre Behandlungen berücksichtigt werden. Demnach verursachen Versterbende schon einige Jahre vor ihrem Tod im ambulanten und stationären Bereich höhere Kosten. Die Kosten steigen also nicht nur im letzten Lebensjahr. Bereits sechs Jahre vor dem Tod übersteigen die durchschnittlichen Ausgaben für stationäre (ambulante) Behandlung für einen Versterbenden die Ausgaben für einen Überlebenden um $30 \%(66 \%)$. Weder im stationären noch im ambulanten Bereich ist zudem ein signifikanter Unterschied in den Steigerungsraten der Ausgaben für Überlebende und Sterbende feststellbar, d.h. auch bei Herausrechnung der todesbedingten Ausgaben bleiben die Ausgaben für überlebende Ältere auf hohem Niveau und sinken nicht, wie es die Kompressionsthese unterstellt.

Wie sich der Gesundheitszustand im Zeitverlauf verändert, hat Dinkel $\left.\right|^{352}$ anhand von Längsschnittsdaten aus dem Mikrozensus erstmals für Deutschland untersucht. Für die betrachteten Jahrgänge 1907, 1913 und 1919 hat sich demnach der Gesundheitszustand zwischen den Jahren 1978 und 1995 eindeutig verbessert. Bei Männern stieg der Anteil der gesunden Jahre an allen gelebten Jahren zwischen dem 59. und dem 77. Lebensjahr von $71,7 \%$ für den Jahrgang 1907 auf 73,9 \% für den Jahr-

\footnotetext{
${ }^{349}$ Vgl. Grobe, T.G.; Dörning, H.; Schwartz, F.W. (2003), S. 13.

${ }^{350}$ Vgl. ebenda, S. 101.

${ }^{351}$ Siehe Rodrig, S.; Wiesemann, H.-O. (2004), S. 17ff., insbes. S. 38ff. Siehe hierzu auch Bleckmann, N.; Rodrig, S. (1995), S. 60f.; Boetius, J. (2002), S. 160.

352 Siehe Dinkel, R.H. (1999), S. $61 \mathrm{ff}$. 
gang 1913 und 76,5\% für den Jahrgang 1919. Ähnlich ist das Ergebnis bei Frauen: Hier stieg der Anteil der gesunden an allen gelebten Jahren im gleichen Altersintervall von $68,5 \%$ (Jahrgang 1907) auf $72,1 \%$ (1913) und 76,2\% (1919). Auch wenn aus den Ergebnissen nicht abgeleitet werden kann, genau die gewonnenen Lebensjahre würden in Gesundheit verbracht werden, kommt die Untersuchung zu dem Ergebnis, dass sich der durchschnittliche Gesundheitszustand der Bevölkerung verbessert hat. ${ }^{353}$ Hierbei werden allerdings keine Aussagen über Kosten getroffen. Denkbar ist, dass die Ausgaben auch bei durchschnittlich besserem Gesundheitszustand steigen.

Die Aussagekraft der Kompressionsthese ist bezüglich der Entwicklung der gesamten Gesundheitsausgaben ohnehin stark eingeschränkt, da auf Versicherte im letzten Lebensjahr nur ein Bruchteil der gesamten Gesundheitsausgaben entfallen. Breyer ${ }^{354}$ schätzt diesen Anteil auf $12 \%$, Grobe, Dörning und Schwartz ${ }^{355}$ kommen für die Gmünder Ersatzkasse auf $9,3 \%$ und Bleckmann und Rodrig ${ }^{356}$ für die deutsche Krankenversicherung sogar auf lediglich $7 \%$. Der überwiegende Anteil der Krankheitskosten steht folglich nicht in direktem Zusammenhang mit dem Tod. Die Kompressionsthese beantwortet damit nicht die entscheidende Frage, wie sich die Zunahme der Lebenserwartung auf die gesamten Gesundheitsausgaben auswirkt, weil sie die Entwicklung der Ausgaben für die Überlebenden nicht näher analysiert. ${ }^{357}$ Die Kompressionsthese lässt außer Acht, dass allein der Anstieg des durchschnittlichen Alters der Versicherten aufgrund der höheren Lebenserwartung zu einer Kostensteigerung führt, weil bislang kein Rückgang der altersabhängigen Ausgaben für Überlebende nachgewiesen wurde.

\subsubsection{Bi-modales Konzept als Synthese}

$\mathrm{Hof}^{358}$ stellt anhand der Analyse von PKV-Daten für den stationären Bereich Hinweise auf die Gültigkeit der Medikalisierungsthese fest. Für die ambulante ärztliche Versorgung und den Arzneimittelverbrauch findet Hof Anzeichen, die für die Kompressionsthese sprechen. Nocera ${ }^{359}$ kommt für die Schweiz zu einem ähnlichen Ergebnis: Für den ambulanten Bereich scheint die Kompressionsthese zuzutreffen und für den stationären Bereich die Medikalisierungsthese. Für beide Thesen lassen sich empirische Nachweise anführen.

Eine Synthese der beiden widersprüchlichen Thesen stellt das bi-modale Konzept von Kane ${ }^{360}$ dar. Danach verbessert sich der Gesundheitszustand zwar langfristig, der Anteil kranker und bereits in jungen Jahren gesundheitlich beeinträchtigter Menschen steigt aber. Mit anderen Worten: Die Morbidität sinkt zwar in allen Altersklas-

\footnotetext{
${ }^{353}$ Vgl. Dinkel, R.H. (1999), S. 76ff.; Ulrich, V. (2003), S. 69.

${ }^{354}$ Siehe Breyer, F. (1996), S. 48.

${ }^{355}$ Siehe Grobe, T.G.; Dörning, H.; Schwartz, F.W. (2003), S. 103.

${ }^{356}$ Siehe Bleckmann, N.; Rodrig, S. (1995), S. 44.

${ }^{357}$ Vgl. Ulrich, V. (2000), S. $166 f$.

${ }^{358}$ Siehe Hof, B. (2001), S. $63 \mathrm{ff} .$, insbes. S. 92.

${ }^{359}$ Siehe Nocera, S. (1996), S. $65 f f$.

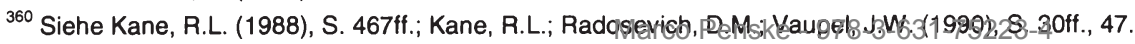


sen, die Gesamtmorbidität der Bevölkerung nimmt aber dennoch zu. In der Literatur wird dieses Phänomen mit dem Begriff „Simpson's Paradox“ beschrieben.

Das folgende Zahlenbeispiel verdeutlicht den Zusammenhang: Im Ausgangszustand gehören 100 Versicherte der Altersgruppe ,jung“ und 20 Versicherte der Altersgruppe "alt" an. In jeder Gruppe gibt es 10 kranke Versicherte. Wird die Morbidität in jeder Altersgruppe als „Kranke/Gruppengröße“ gemessen, beträgt die Morbidität bei den Jungen $10 \%$, bei den Alten $50 \%$ und für alle Versicherten 16,67\% (20 dividiert durch 120 multipliziert mit 100). Sinkt die Morbidität bei den Jungen auf $9 \%$ und bei den Alten auf $42 \%$ und steigt die Zahl der alten Versicherten aufgrund einer längeren Lebenserwartung von 20 auf 50, dann sind 9 junge Versicherte und 21 alte Versicherte krank. Die Morbidität für alle Versicherten beträgt dann 20\% (30 dividiert durch 150 multipliziert mit 100). Obwohl in beiden Altersgruppen die Morbidität gesunken ist, steigt sie aber für die gesamte Bevölkerung. ${ }^{361}$

Sogar bei Gültigkeit der Kompressionsthese ist demnach mit einem Anstieg der durchschnittlichen Leistungsausgaben pro Kopf zu rechnen, da die Anzahl der ausgabenintensiven Älteren mit Erkrankungen steigt. ${ }^{362}$ Selbst einzelne Vertreter ${ }^{363}$ der Kompressionsthese erwarten durch den demographischen Wandel bei einem weiteren Anstieg der Pro-Kopf-Ausgaben im letzten Lebensjahr steigende Gesundheitsausgaben. Strittig bleibt das Ausmaß der Steigerung der Gesamtausgaben, das davon abhängt, ob die Morbidität mit dem Alter (Medikalisierungsthese) oder erst kurz vor dem Tod (Kompressionsthese) steigt. Die Gültigkeit beider Thesen bleibt zu überprüfen. Bisher steht einer empirischen Überprüfung vor allem der Mangel an geeigneten Längsschnittsdaten für die GKV entgegen. ${ }^{364}$

Die Gesundheitsausgaben hängen - neben der Altersstruktur der Versicherten auf der Nachfrageseite - entscheidend von der Veränderung der Ausgabenprofile im Zeitverlauf ab. Die demographische Entwicklung selbst hat hierauf keinen unmittelbaren Einfluss. Die demographische Alterung führt zwar zu einer stärkeren Besetzung höherer Altersklassen und damit ceteris paribus zu einem Anstieg der durchschnittlichen Leistungsausgaben pro Kopf. Mit der demographischen Entwicklung können aber keine altersspezifischen Pro-Kopf-Ausgaben erklärt werden. „Es ist [...] nicht erklärlich, daß sich die Leistungsausgaben für einen einzelnen 80jährigen allein schon aus dem Grund erhöhen sollen, weil es nun relativ oder absolut mehr seiner Altersgenossen gibt. ${ }^{\text {“65 }}$

\footnotetext{
${ }^{361}$ Vgl. Krämer, W. (1992), S. 570.

${ }^{362}$ Vgl. Glaeske, G. u.a. (1997), S. 504; Hilbert, J.; Fretschner, R.; Dülberg, A. (2002), S. 13; Kruse, A. u.a. (2003), S. 35. Nach Zweifel, P.; Felder, S.; Meier, M. (1996), S. 41f., steigen die Gesundheitsausgaben pro Kopf nicht zwangsläufig. Dies unterstellt jedoch implizit, dass die Gesamtausgaben auch bei längerer Lebenserwartung über den gesamten Lebenszyklus konstant bleiben. Für konstante Pro-Kopf-Ausgaben in einer Periode müsste zudem die allein durch den Anstieg der Besetzung der höheren Altersklassen bedingte Zunahme der Pro-Kopf-Ausgaben durch einen Rückgang der durchschnittlichen Ausgaben genau kompensiert werden.

${ }^{363}$ Z.B. Garber, A.M.; MaCurdy, T.E.; McClallen, M.L. (1998), S. 11, für die USA.

${ }^{364}$ Vgl. Ulrich, V. (2003), S. 69; Heigl, A. (2002), S. 525; Enquete-Kommission Demographischer Wandel (2002), S. 184; Hof, B. (2001), S. 48; Fetzer, S.; Moog, S.; Raffelhüschen, B. (2001), S. 11.

${ }^{365}$ Glaeske, G. u.a. (1997), S. 504. 


\subsection{Angebotsseite}

\subsubsection{Medizinisch-technischer Fortschritt}

Die Entwicklung der Altersausgabenprofile wird auf der Angebotsseite vom medizinisch-technischen Fortschritt beeinflusst. Dessen Wirkung auf die Ausgabenprofile ist zunächst unabhängig von der demographischen Entwicklung zu betrachten, da mit dem medizinisch-technischen Fortschritt der wesentliche Bestimmungsfaktor für die altersbezogenen Pro-Kopf-Ausgaben untersucht wird. Sodann werden Rückwirkungen des medizinisch-technischen Fortschritts über die demographische Entwicklung auf die Ausgaben untersucht.

\section{Abbildung 24: Durchschnittlicher Anstieg der altersspezifischen Pro-Kopf- Ausgaben von 1995 bis 2003}

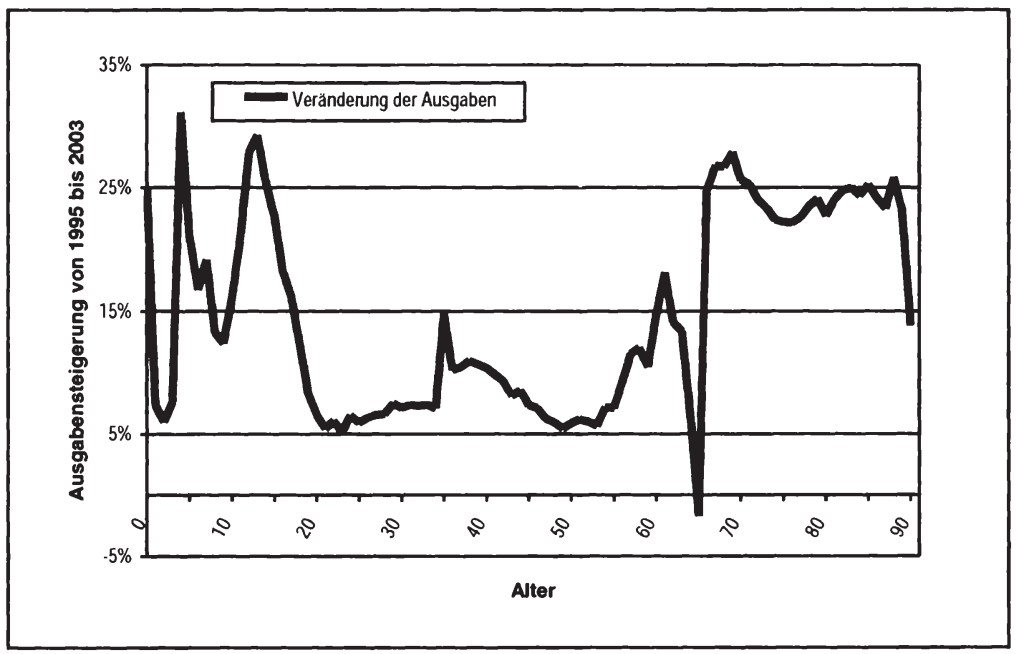

Quelle: Eigene Berechnungen; Daten: Bundesversicherungsamt.

In Abbildung 21 (S. 97) wurde bereits die Veränderung der Ausgabenprofile von 1995 bis 2003 dargestellt. Abbildung 24 geht in der Analyse weiter. Um einen Niveaueffekt auszuschalten - bei gleichem prozentualem Anstieg steigen die Ausgaben für Ältere aufgrund der größeren Ausgangsbasis absolut gesehen stärker als für Jüngere - wird die prozentuale Veränderung der Ausgaben in diesem Zeitraum für die einzelnen Altersjahrgänge dargestellt.

Während bei den 20- bis 55jährigen Versicherten die Ausgaben von 1995 bis 2003 teilweise sogar deutlich weniger als $10 \%$ zunehmen, ist für die über 65jährigen ein Anstieg von über $20 \%$ zu erkennen. Dieses Ergebnis bestätigt die These von einer Versteilerung ${ }^{366}$ der altersspezifischen Ausgaben. Die Leistungsausgaben steigen für ältere Versicherte schneller als für jüngere Versicherte. Da die Versteilerung in der

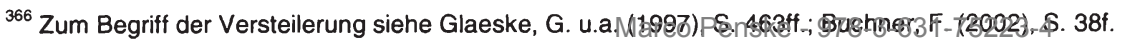


Literatur ausgiebig diskutiert wurde, wird hier auf eine weitere Analyse verzichtet. ${ }^{367}$ Beachtenswert sind die deutlichen Ausgabensteigerungen für unter 18jährige, die gleichfalls auf den medizinisch-technischen Fortschritt zurückzuführen sind, wenn man unterstellt, dass gerade bei Erkrankungen in jungen Jahren zur Behandlung ein besonders großer medizinischer Aufwand betrieben wird.

Kompatibel ist die Versteilerung sowohl mit der Medikalisierungs- als auch mit der Kompressionsthese. Die Medikalisierungsthese unterstellt eine mit steigendem Alter zunehmende Morbidität. Insbesondere wenn man davon ausgeht, dass vor allem im höheren Alter Multimorbidität zunimmt, steigen die Ausgaben für Ältere schneller als für Jüngere. Nach der Kompressionsthese konzentrieren sich die Ausgaben auf das Todesjahr, in den Jahren zuvor nimmt die Morbidität durchschnittlich ab, was im Ergebnis ebenfalls zu einer Versteilerung des Ausgabenprofils führt. In ihrer Wirkung auf die Gesamtausgaben unterscheiden sich die beiden Thesen aber: Die Medikalisierungsthese geht mit einem Kostenanstieg einher. Alterung und zunehmende Behandlungsmöglichkeiten wirken beide ausgabensteigernd. Bei Gültigkeit der Kompressionsthese kommt es zu gegenläufigen Effekten. Ob die Verkürzung der Behandlungsdauer oder aber die mit dem medizinisch-technischen Fortschritt verbundenen Ausgaben die Ausgabenhöhe dominieren, ist theoretisch offen. ${ }^{368}$ In der Querschnittsbetrachtung in Abbildung 24 überwiegt der ausgabensteigernde Effekt. Da es sich aber um nominale Größen handelt, können die altersabhängigen Ausgaben auch real gesunken sein. Zudem bleibt der Kohorteneffekt unberücksichtigt.

Unabhängig von der Gültigkeit einer der beiden Thesen führt vor allem der medizinisch-technische Fortschritt zu der Versteilerung und zu einem Ausgabenanstieg. ${ }^{369}$ Der Sachverständigenrat für die Konzertierte Aktion im Gesundheitswesen ${ }^{370}$ unterscheidet zwischen technischem und medizinischem Fortschritt. Medizinischer Fortschritt führt durch neue und bessere Einsichten in medizinische Zusammenhänge vor allem zu neuen Behandlungsfeldern. Hierzu zählen z.B. bessere Diagnosestellungen und neue Therapieformen. Ein Teil des medizinischen Fortschritts ist nach dieser Auffassung der technische Fortschritt, der zahlreiche neue Behandlungsmethoden erst ermöglicht. Hierzu gehört z.B. die Entwicklung der Computer- und Kernspintomographie. Im Folgenden wird aber nicht zwischen medizinischem und technischem Fortschritt unterschieden, da bessere Kenntnisse über medizinische Zusammenhänge neue Diagnose- und Therapierformen ermöglichen, für die wiederum neue technische Geräte notwendig sein können. ${ }^{371}$ Zudem ist für eine Betrachtung der Wirkungen des Fortschritts auf die Höhe der Ausgaben eine Differenzierung nicht notwendig.

${ }^{367}$ Siehe stellvertretend Knappe, E. (1995), S. 25f.; Glaeske, G. u.a. (1997), S. 463ff.; Enquete-Kommission Demographischer Wandel (1998), S. 230ff.; Knappe, E.; Optendrenk, S. (1999), S. 164ff.; Buchner, F.; Wasem, J. (2000), S. 1ff.; Hof, B. (2001), S. 52ff.; Buchner, F. (2002), S. 19ff.; Kruse, A. u.a. (2003), S. 41f.; Rodrig, S.; Wiesemann, H.-O. (2004), S. 28ff. Kontrovers hierzu stellen Krämer, W. (1992), S. 572f.; Ritter, U.P.; Hohmeier, J. (1999), S. 176f., keine Versteilerung fest.

${ }^{368}$ Vgl. Buchner, F. (2002), S. 144ff.; Rodrig, S.; Wiesemann, H.-O. (2004), S. 21.

${ }^{369}$ Vgl. Kopetsch, T. (2001), S. 22; Knappe, E.; Optendrenk, S. (1999), S. $164 f f$.

${ }^{370}$ Siehe SVR KAiG (1989), Ziff. 118ff.

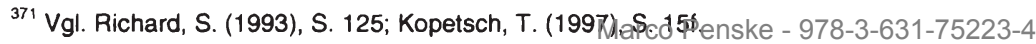


In der Ökonomie wird zwischen Produkt- und Prozessinnovationen unterschieden. Unter Prozessinnovationen werden neue Verfahren verstanden, die durch ein verbessertes Verhältnis von Output zu Input Effizienzsteigerungen herbeiführen. Ein Verfahren wird durch ein neueres ersetzt, womit Kostensenkungen einhergehen. Diese Art der Prozessinnovation tritt in der Medizin aber nur selten auf. ${ }^{372}$ Und selbst wenn Prozessinnovationen zu niedrigeren Fallkosten führen, werden deren Einsparungen meist durch Mengeneffekte überkompensiert. Die Nierensteinentfernung durch extrakorporale Stoßwellenlithotripsie und die Einführung der minimalinvasiven Chirurgie zur Gallenblasenentfernung z.B. haben zwar zu einer Senkung der Fallkosten geführt. Aufgrund des schonenderen Eingriffs werden aber mehr Patienten behandelt: Zum einen Patienten, die kaum Beschwerden haben, zum anderen auch Patienten, bei denen das Risiko für eine Operation zuvor zu groß war. Die Gesamtausgaben für diese Behandlungen haben sich damit sogar erhöht. ${ }^{373}$

In der Medizin liegen vor allem Produktinnovationen vor. Hierunter fallen Diagnoseund Behandlungsverfahren für bisher nicht bekannte bzw. nicht behandelbare Krankheiten. „Add-on“-Technologien, die neue Diagnose- und Therapiemöglichkeiten schaffen, führen zu Ausgabensteigerungen, da meist nur mit einem höheren Ressourcenverbrauch bessere Behandlungsergebnisse erzielt werden können. ${ }^{374}$

Die Unterscheidung in Produkt- und Prozessinnovation ist oftmals nicht eindeutig möglich, weil i.d.R. neue Verfahren (Prozessinnovation) auch zu besseren Ergebnissen (Produktinnovation) führen. Beispielsweise bewirken Neuerungen im medizinischen Bereich für manche Versicherte eine schonendere Behandlung (Prozessinnovation), für andere Versicherte machen sie aber eine Behandlung überhaupt erst möglich (Produktinnovation). ${ }^{375}$

Im Gesundheitswesen der Industrieländer steigen die Möglichkeiten der ärztlichen Behandlung ständig. Früher nicht bekannte oder mögliche Eingriffe, Untersuchungen und Therapieformen werden wegen des zunehmenden Fortschritts machbar. Die moderne Medizin hat in den letzten Jahrzehnten zahlreiche früher unbekannte Wege zur Behandlung von Krankheiten entwickelt. Deutlich wird dies z.B. an den steigenden Möglichkeiten und der Zunahme von Organtransplantationen. Der medizinischtechnische Fortschritt ist entscheidend dafür, dass die unterschwellige Nachfrage nach Gesundheitsleistungen kostenwirksam wird. ${ }^{376}$ Selbst die beste Diagnose und aufwendigste Therapie können Krankheiten und den Tod aber nur aufschieben. Auch in der Medizin gilt das ökonomische Gesetz des abnehmenden Grenznutzens (1. Gossensche Gesetz): Weil sich die medizinischen Möglichkeiten bereits heute auf einem hohen Niveau befinden, sind weitere Fortschritte nur mit hohen Kosten zu erreichen. Nur noch mit immer höheren Ausgaben ist es möglich, den Tod hinauszu-

\footnotetext{
${ }^{372}$ Vgl. SVR KAiG (1989), Ziff. 108ff.; Ulrich, V. (1998), S. 19; Oberender, P. (2002), S. 81.

${ }^{373} \mathrm{Vgl}$. Kopetsch, T. (2000), S. 40f.; Kopetsch, T. (2001), S. 22.

${ }^{374}$ Vgl. SVR KAiG (1989), Ziff. 108f.; SVR KAiG (1995), Ziff. 29; Knappe, E. (1995), S. 25; Oberdieck, V. (1998), S. 24.

${ }^{375}$ Zu den Abgrenzungsproblemen siehe SVR KAiG (1989), Ziff. 108ff.; Richard, S. (1993), S. 126.

${ }^{376} \mathrm{Vgl}$. Kopetsch, T. (2001), S. 22; Kopetsch, T. (1997), S. 16ff. Zu den neuen Technologien siehe u.a. SVR KAiG (1989), Ziff. 118ff.; Richard, S. (1993), S. 128ff.; Krämer, W. (1997), S. 8f.; Oberdieck, V. (1998), S. 26, und die dort jeweils angegebjelgedditeratuske - 978-3-631-75223-4
} 
zögern. ${ }^{377}$ Ein Indiz hierfür ist auch der in Abschnitt 2.1.3 Kompressionsthese (S. 98) analysierte starke Anstieg der Ausgaben für Versicherte in ihrem letzten Lebensjahr.

\subsubsection{Rückwirkungen über die demographische Entwicklung}

Der medizinisch-technische Fortschritt hat nicht nur direkte Wirkungen auf die Gesundheitsausgaben, er kann auch indirekt die Gesundheitsausgaben über Rückwirkungen der demographischen Entwicklung beeinflussen. In einer Untersuchung für Deutschland für die Jahre 1960 bis 1989 stellt Brenner ${ }^{378}$ fest, dass die Mortalität mit steigenden Gesundheitsausgaben sinkt, d.h. aus der zunehmenden Inanspruchnahme von Gesundheitsleistungen resultiert eine höhere Lebenserwartung.

Nach der Multimorbiditätsthese von Krämer ${ }^{379}$ verlängert der medizinisch-technische Fortschritt zwar das Leben, kann Krankheiten aber nicht vollständig heilen. Stattdessen kommen mit zunehmendem Alter weitere Krankheiten hinzu. Aufgrund des medizinisch-technischen Fortschritts erreichen auch Versicherte mit hohem Krankheitsrisiko höhere Altersstufen, womit sich entsprechend dem bi-modalen Konzept (S. 104) der durchschnittliche Gesundheitszustand der Bevölkerung verschlechtert und die Ausgaben steigen.

Nach dem Sisyphus-Syndrom von $Z_{\text {weifel }}{ }^{380}$ verlängern die neuen Behandlungsmöglichkeiten die Lebenserwartung vorwiegend im fortgeschrittenen Alter. Dies führt zu einer Überalterung der Gesellschaft, in der die Älteren die politische Mehrheit haben, um im demokratischen Entscheidungsprozess weitere Ressourcen für Produktinnovationen in die GKV zu lenken, wodurch die Gesundheitsausgaben weiter steigen. Der Medizin wird die Grundlage für weitere Erfolge gegeben und die Lebenserwartung steigt damit weiter. Eine empirische Analyse anhand von OECDDaten bestätigt, dass zusätzliche Gesundheitsaufwendungen die Lebenserwartung in den oberen Altersklassen erhöhen. Ein Einfluss auf politische Entscheidungen im Sinne von höheren Ausgaben für Gesundheitsleistungen ist aber (noch) nicht empirisch nachweisbar.

Die Enquete-Kommission des Deutschen Bundestags „Demographischer Wandel Herausforderungen unserer älter werdenden Gesellschaft an den Einzelnen und die Politik" schreibt in ihrem Abschlussbericht:
„Dabei ergibt sich vor allem aus den Wechselwirkungen zwischen demographischem Wandel und medizinischem Fortschritt ein für die Beitragsentwicklung explosives Wir- kungsgemisch, da sich beide Teilwirkungen gegenseitig verstärken und nicht etwa nur ,addieren'. ${ }^{381}$

Inwieweit der medizinisch-technische Fortschritt auch auf der Nachfrageseite den demographisch bedingten Beitragssatzanstieg durch eine verlängerte Lebenserwartung tatsächlich verstärken wird, hängt davon ab, ob die Medikalisierungsthese oder

\footnotetext{
${ }^{377}$ Vgl. Leu, R.E. (1988), S. 26

${ }^{378}$ Siehe Brenner, M.H. (1999), S. $370 \mathrm{ff}$.

${ }^{379}$ Vgl. Krämer, W. (1997), S. 11ff. Siehe hierzu auch Erbsland, M.; Wille, E. (1995), S. 678.

${ }^{380}$ Siehe Zweifel, P. (1990), S. 373ff.; Breyer, F.; Zweifel, P.; Kifmann, M. (2005), S. 525ff.

${ }^{381}$ Enquete-Kommission Demographischer Wandel (20920 $\$$ S 297ke - 978-3-631-75223-4 
die Kompressionsthese zutrifft. Unbestritten führt der medizinisch-technische Fortschritt über die Angebotsseite aber zu weiteren Ausgabensteigerungen.

Dabei sollten die vom medizinisch-technischen Fortschritt ausgehenden positiven externen Effekte (Senkung der Ausfalltage durch Krankheit, Verbesserung der Lebensqualität, Steigerung der Lebenserwartung etc.) aber auch berücksichtigt werden: Ein verbesserter Gesundheitszustand der Bevölkerung und die rasche Heilung von Krankheiten reduzieren die mit Krankheiten verbundenen indirekten Kosten und erhöhen die gesamte Wohlfahrt. ${ }^{382}$

\section{Einflüsse auf die Einnahmenseite}

\subsection{Differenzierung der beitragspflichtigen Einnahmen}

In der Literatur wird überwiegend der Einfluss der demographischen Entwicklung auf die Ausgaben der GKV thematisiert. Die Bedeutung für die Einnahmen wird dabei meist nur am Rande erwähnt. Wie aber bereits mit Hilfe von Beitragssatzeffekten gezeigt wurde, hat die demographische Entwicklung bislang auf der Einnahmenseite tendenziell beitragssatzsenkend gewirkt. Dennoch ist der Beitragssatz in der GKV aufgrund der schwachen Entwicklung der Einnahmen gestiegen. Die bereits jetzt festzustellende Erosion der Beitragsgrundlage wird in Zukunft durch die demographische Entwicklung sogar noch verstärkt.

Geringe Entlastung ist lediglich von einem Rückgang der Zahl der beitragsfrei Familienversicherten zu erwarten. Selbst wenn die Geburtenrate auf dem niedrigen Niveau verbleibt, sinkt die Anzahl der Neugeborenen weiter, da sich die Zahl der potentiellen Mütter zusehends verringert. Ein leichter Rückgang der Zahl der Familienversicherten ist bereits heute festzustellen. ${ }^{383}$

Um den Einfluss der demographischen Entwicklung auf die Einnahmen der GKV näher zu analysieren, wird im Folgenden zunächst die Entwicklung der beitragspflichtigen Einnahmen in der allgemeinen Krankenversicherung näher betrachtet. Sodann steht die Entwicklung der Zahl der Rentner und die Rentenhöhe - die andere maßgebliche Größe bei der Beitragserhebung nach §§ 226ff. SGB V - im Mittelpunkt der Betrachtung.

Der Einfluss der demographischen Entwicklung auf die beitragspflichtigen Einnahmen in der AKV kann nicht direkt beobachtet werden. Um diesen dennoch zu operationalisieren, wird auf die Bruttolohn- und Gehaltssumme zurückgegriffen, die allerdings etwas von den beitragspflichtigen Einnahmen abweicht. In den beitragspflichtigen Einnahmen sind die Bezüge von Beamten nicht erfasst. Zudem sind Löhne und Gehälter von nicht in der GKV Versicherten nicht enthalten, das gilt auch für die Löhne und Gehälter, die die Beitragsbemessungsgrenze überschreiten. Auf der anderen Seite schlagen sich in der Grundlohnsumme Beiträge von z.B. Transferempfängern und Studenten nieder, die in der Bruttolohn- und Gehaltssumme in geringerem Umfang erfasst werden. Dennoch ist die Bruttolohn- und Gehaltssumme

\footnotetext{
${ }^{382}$ Vgl. SVR KAiG (1989), Ziff. 116f., 139; Richard, S. (1993), S. $125 f$.

${ }^{383}$ Siehe hierzu auch Kapitel II.4.3.2 Abhängigkeit von derá.VerșichertenstoukduB-8355.75223-4
} 
geeignet, den Einfluss der demographischen Veränderung auf die Grundlohnsumme abzuschätzen. Im Zeitraum 1991 bis 2000 ist die Grundlohnsumme durchschnittlich um 3,0\% p.a. gestiegen, die Bruttolöhne und -gehälter um 2,7\% p.a. Die Abweichungen zwischen beiden Größen haben sich zudem seit 1991 deutlich verringert. Im Jahr 1991 lag die Grundlohnsumme noch 14,21\% unter der Bruttolohn- und Gehaltssumme, im Jahr 2000 waren es nur noch $11,52 \%$. ${ }^{384}$

Bestimmt wird die Höhe der Bruttolohn- und Gehaltssumme auf dem Arbeitsmarkt. Nach Angaben des Bundesministeriums für Gesundheit und Soziale Sicherung ${ }^{385}$ erhöht ein Anstieg der Zahl der Beschäftigten um 100.000 Personen die Beitragseinnahmen der GKV um 313 Mio. Euro p.a. Die Beschäftigungshöhe und die gezahlten Arbeitsentgelte werden durch die demographische Entwicklung über die Angebotsund Nachfrageseite beeinflusst. Auf der Angebotsseite des Arbeitsmarktes bestimmt die demographische Entwicklung via Erwerbstätigenpotential die Zahl der möglichen Beitragszahler. Auf der Nachfrageseite hat neben strukturellen Gegebenheiten das Wirtschaftswachstum, das selbst wiederum von der demographischen Entwicklung beeinflusst wird, wesentliche Bedeutung.

\subsection{Bruttolohn- und Gehaltssumme}

\subsubsection{Arbeitskräfteangebot: Erwerbspersonenpotential GKV-Versicherter}

Die Bruttolohn- und Gehaltssumme hängt neben den Einnahmen von freiwillig in der GKV Versicherten im Wesentlichen von der Entwicklung der Zahl der sozialversicherungspflichtig Beschäftigten und deren Arbeitsentgelten ab. Maßgeblich ist auf der Angebotsseite das Erwerbspersonenpotential, das sich aus den Erwerbstätigen, den registrierten Arbeitslosen und der stillen Reserve zusammensetzt. Bestimmt wird das Erwerbspersonenpotential vor allem durch die demographische Entwicklung und die Erwerbsbeteiligung der Bevölkerung. Dabei wird im Folgenden, wie in der Literatur üblich, davon ausgegangen, dass das erwerbsfähige Alter zwischen 15 und 65 Jahren liegt, auch wenn in der GKV durchaus auch Ältere, insbesondere freiwillig Versicherte, Beiträge aus Arbeitseinkommen zahlen. Diese Zahl ist allerdings vernachlässigbar. Im Jahr 2003 waren in der GKV lediglich 113.062 Personen, die älter als 65 Jahre waren, als Pflichtversicherte und 506.855 Personen als freiwillig Versicherte Mitglied in der GKV. Damit lag der Anteil der über 65jährigen an allen erwerbstätigen Beitragszahlern bei nur $1,8 \%{ }^{386}$

$\mathrm{Da}$ als Beitragszahler für die GKV nur diejenigen relevant sind, die auch tatsächlich in der GKV versichert sind, und nicht das üblicherweise ermittelte gesamte Erwerbspersonenpotential, wird zur Berechnung der GKV-Versicherten im enwerbsfähigen Alter in Tabelle 12 die Anzahl der geschätzten Personen in den einzelnen Altersjahrgängen nach der 10. koordinierten Bevölkerungsvorausberechnung des Statistischen Bundesamtes mit dem Anteil der in der jeweiligen Altersgruppe im Jahr 2003 in der GKV Versicherten multipliziert. Damit wird sichergestellt, dass nicht in der GKV Versicherte auch nicht als Beitragszahler ausgewiesen werden. Darüber hinaus

\footnotetext{
${ }^{384}$ Vgl. Berié, H.; Fink, U. (2003), S. 45ff.

${ }^{305}$ Siehe BMGS (Hrsg.) (2005a), S. 2.

${ }^{386}$ Eigene Berechnungen; vgl. BMGS (Hrsg.) (2003bMarco Penske - 978-3-631-75223-4
} 
muss berücksichtigt werden, dass sich unter den Versicherten im erwerbsfähigen Alter auch nicht erwerbstätige Familienversicherte befinden. Im Jahr 2003 waren von insgesamt 46,4 Mio. Versicherten im erwerbsfähigen Alter 9,3 Mio. Personen familienversichert. Rund $20 \%$ aller Versicherten im erwerbsfähigen Alter zahlten demnach keine GKV-Beiträge. Zudem zahlten 3,9 Mio. Versicherte im Alter zwischen 15 und 65 Jahren als Rentner im Jahr 2003 geringere Beiträge. ${ }^{387}$ In den folgenden Berechnungen wird deshalb - um den demographischen Effekt isoliert darzustellen eine im Zeitverlauf konstante Erwerbsbeteiligung der 15- bis 65jährigen von $73,3 \%{ }^{388}$ unterstellt. Trotz dieser Bereinigung kann das in Tabelle 12 ausgewiesene Erwerbspersonenpotential GKV-Versicherter noch immer als obere Grenze angesehen werden, da mitunter auch familienangehörige Erwerbstätige mit einem Einkommen unter 345 Euro nach $\S 10$ Abs. 1 SGB V beitragsfrei versichert sein können.

Tabelle 12: Erwerbspersonenpotential GKV-Versicherter bis zum Jahr 2050

\begin{tabular}{|l|r|r|r|r|r|r|}
\hline & 2003 & \multicolumn{1}{|c|}{2010} & 2020 & 2030 & 2040 & 2050 \\
\hline & \multicolumn{6}{|c|}{ Erwerbspersonenpotential (in Mio. Personen) } \\
\hline $15-30$ Jahre & 8,91 & 9,07 & 8,14 & 7,53 & 7,32 & 6,79 \\
\hline $30-45$ Jahre & 11,91 & 10,24 & 9,74 & 9,39 & 8,42 & 8,05 \\
\hline $45-60$ Jahre & 9,68 & 11,50 & 11,36 & 9,38 & 9,61 & 8,73 \\
\hline $60-65$ Jahre & 3,52 & 3,00 & 3,81 & 4,04 & 3,13 & 3,43 \\
\hline Gesamt & 34,02 & 33,82 & 33,05 & 30,33 & 28,47 & 27,01 \\
\hline & \multicolumn{7}{|c|}{ Erwerbspersonenpotential (in Prozent der Erwerbspersonen) } \\
\hline Anteil 15 - 30 Jahre & $26,20 \%$ & $26,82 \%$ & $24,63 \%$ & $24,81 \%$ & $25,70 \%$ & $25,15 \%$ \\
\hline Anteil 30 - 45 Jahre & $35,01 \%$ & $30,29 \%$ & $29,47 \%$ & $30,95 \%$ & $29,57 \%$ & $29,81 \%$ \\
\hline Anteil 45-60 Jahre & $28,44 \%$ & $34,01 \%$ & $34,36 \%$ & $30,91 \%$ & $33,74 \%$ & $32,33 \%$ \\
\hline Anteil 60 - 65 Jahre & $10,34 \%$ & $8,88 \%$ & $11,53 \%$ & $13,33 \%$ & $10,99 \%$ & $12,72 \%$ \\
\hline & \multicolumn{7}{|c|}{ Durchschnittsalter (in Jahren) } \\
\hline GKV-Versicherte & 42,39 & 43,92 & 45,78 & 47,36 & 48,68 & 49,39 \\
\hline Erwerbsf. GKV-Versicherte & 40,40 & 40,87 & 42,08 & 41,87 & 41,62 & 41,91 \\
\hline
\end{tabular}

Anmerkungen: Für alle Altersgruppen wurde die durchschnittliche Erwerbsquote des Jahres 2003 in Höhe von $73,3 \%$ unterstellt. Die Bevölkerungsentwicklung entstammt der 10. koordinierten Bevölkerungsvorausberechnung. Die GKV-Versicherten wurden anhand der GKV-Versichertenanteile an der gesamten Bevölkerung aus dem Jahr 2003 berechnet; siehe Tabelle 39: Anteil der GKV-Versicherten an der Bevölkerung nach Altersklassen, im Anhang, S. 277.

Quelle: Eigene Berechnungen; Daten: Statistisches Bundesamt (Hrsg.) (2003); SVR (2004), Tabelle 20.

Die Zahl der erwerbsfähigen potentiellen Beitragszahler geht nach diesen Berechnungen von 34,0 Mio. Personen im Jahr 2003 bis zum Jahr 2020 nur marginal auf 33,1 Mio. zurück. Der Rückgang beschleunigt sich auf 30,3 Mio. im Jahr 2030 und 27,0 Mio. Personen 2050. Wie Tabelle 12 auch zeigt, steigt der Anteil der Älteren an den Erwerbspersonen an. Das durchschnittliche Alter der GKV-Versicherten im erwerbsfähigen Alter steigt von 40,4 Jahren im Jahr 2003 bis zum Jahr 2020 auf 42,1 Jahre an. In diesem Zeitraum rücken die stark besetzten Jahrgänge in das fort-

${ }^{387}$ Eigene Berechnungen; vgl. BMGS (Hrsg.) (2003b).

${ }^{388}$ Siehe SVR (2004), Tabelle 20. 
geschrittene Erwerbsalter vor. Bis zum Jahr 2040 geht der Altersdurchschnitt leicht auf 41,6 Jahre zurück und steigt bis zum Jahr 2050 auf 41,9 Jahre - dem Niveau von 2030 - wieder an. Insbesondere der Rückgang der als besonders produktiv geltenden Arbeitskräfte im Alter von 15 bis 30 Jahren von 8,9 Mio. Personen im Jahr 2003 auf 6,8 Mio. (2050) und der 30- bis 45jährigen in diesem Zeitraum von 11,9 Mio. auf 8,1 Mio. Personen wird die Zahl der GKV-Versicherten mit hohen Beiträgen reduzieren. Da insbesondere Ältere häufiger in der GKV versichert sind als Jüngere ${ }^{389}$, steigt das Durchschnittsalter aller GKV-Versicherten deutlich stärker - von 42,4 Jahren im Jahr 2003 auf 49,4 Jahre im Jahr 2050 - als das der erwerbsfähigen Versicherten.

Die Ergebnisse in Tabelle 12 geben allein den demographischen Effekt wieder und unterzeichnen die zu enwartende Alterung des Erwerbspersonenpotentials noch; denn in den Berechnungen wurde eine durchschnittliche und im Zeitverlauf konstante Enwerbsquote für alle Altersgruppen unterstellt. Jedoch ist zu enwarten, dass insbesondere die Erwerbsneigung der über 55jährigen auch aufgrund der Reformen in der GRV steigt. Dadurch kann das Erwerbspersonenpotential zwar erhöht werden, das Durchschnittsalter der Erwerbspersonen dürtte aber deutlich stärker zunehmen als in Tabelle 12 angegeben. ${ }^{390}$

Für die Finanzen der GKV ist letztendlich die Anzahl der sozialversicherungspflichtig Beschäftigten und nicht allein das Erwerbspersonenpotential entscheidend. Wie sich deren Zahl entwickeln wird, hängt von der Beschäftigungssituation ab.

\subsubsection{Arbeitsmarktnachfrage: Wirtschaftswachstum}

Während die demographische Entwicklung und das daraus abgeleitete Arbeitsangebot noch relativ sicher abgeschätzt werden können, müssen zur Schätzung der Arbeitsnachfrage und des daraus resultierenden Beschäftigungsniveaus zahlreiche Annahmen (z.B. über Wachstum, Produktivität, Lohnentwicklung, Arbeitsmarktreformen) getroffen werden. Hinzu kommen Interdependenzen z.B. zwischen Arbeitsnachfrage und Arbeitsangebot, die zur Prognose der Arbeitsmarktentwicklung ein umfassendes gesamtwirtschaftliches Modell erfordern, das weit über den Rahmen dieser Arbeit hinausgehen würde. ${ }^{391}$ Stattdessen soll im Folgenden der Schwerpunkt der Betrachtung auf dem Einfluss der demographischen Entwicklung auf das Wirtschaftswachstum liegen, weil dieses neben dem Produktivitätsfortschritt maßgeblich für die Beschäftigungs- und Lohnentwicklung und damit auch für die Finanzierung der GKV ist.

In der gesamtwirtschaftlichen Produktionsfunktion bestimmen die Produktionsfaktoren Arbeit und Kapital das Wachstum. Der demographische Wandel beeinflusst das

${ }^{389}$ Siehe Tabelle 39: Anteil der GKV-Versicherten an der Bevölkerung nach Altersklassen, im Anhang, S. 277.

${ }^{390}$ Zur Altersstruktur der Erwerbspersonen siehe stellvertretend Fuchs, J.; Thon, M. (1999), S. 4; Enquete-Kommission Demographischer Wandel (2002), S. 70ff.; Rürup-Kommission (2003), S. $57 \mathrm{f}$.

${ }^{391}$ Zur Entwicklung der Zahl der sozialversicherungspflichtig beschäftigten Erwerbstätigen anhand eines gesamtwirtschaftlichen Modells siehe Rürup-Kommission (2003), S. 61ff. Für einen Überblick über umfassende Arbeitsmarktprojektionen siehe Enquete-Kommission Demographischer Wandel (1998), S. $110 \mathrm{ff}$. 
Wirtschaftswachstum von der Nachfrage- und Angebotsseite. ${ }^{392}$ Nach der keynesianischen Stagnationstheorie steigt bei sinkender Bevölkerungszahl und zunächst konstantem Volkseinkommen zwar das Pro-Kopf-Einkommen, aber auch die Sparquote, wodurch die Konsumnachfrage gedämpft wird. Die Unternehmen revidieren ihre Absatzerwartungen nach unten und die Nettoinvestitionen sinken. Nachfrage fällt aus. Diesem theoretischen Zusammenhang steht indes die Empirie gegenüber: Ein Konsumrückgang bei steigendem Pro-Kopf-Einkommen konnte bislang nicht nachgewiesen werden. Zudem ist die aggregierte Konsumnachfrage nicht nur von der Bevölkerungsanzahl abhängig, sondern auch von der Anzahl der Haushalte, da ein nicht unerheblicher Teil der Nachfrage haushaltsgebunden ist (z.B. Einrichtungsgegenstände). Nach Angaben des Mikrozensus ${ }^{393}$ steigt bei Männern (ab dem 75. Lebensjahr) und bei Frauen (ab dem 55. Lebensjahr) mit zunehmendem Alter der Anteil derer, die alleine leben, stark an. Die Zahl der Haushalte nahm vom Jahr 1991 bis zum Jahr 2003 in Deutschland um 11 \% auf 38,9 Mio. Haushalte zu, während der Bevölkerungszuwachs in diesem Zeitraum nur bei rund $3 \%$ lag. Die durchschnittliche Haushaltsgröße sank also, übrigens von 2,27 Personen auf 2,13 Personen. Setzt sich dieser Trend fort, ist auch bei einem Bevölkerungsrückgang aufgrund der damit einhergehenden Alterung mit einer weiteren Zunahme der Anzahl der Haushalte zu rechnen, da Ältere meist in kleineren Haushalten leben. Dann dürfte der haushaltsgebundene Konsum steigen und den Rückgang der personengebundenen Nachfrage mindestens teilweise kompensieren. Prognosen über das Verbrauchsverhalten der "'neuen' Alten“394 sind aber problematisch, da aus den heutigen Einkommens- und Verbrauchsdaten nicht zuverlässig auf das künftige Verbrauchsverhalten geschlossen werden kann. Eine eindeutige Aussage über die Entwicklung des Nachfrageniveaus ist mithin nicht möglich. ${ }^{395}$

Von der Angebotsseite her betrachtet wächst gemäß der neoklassischen Wachstumstheorie das BIP im Gleichgewicht mit der Wachstumsrate des technischen Fortschritts und der Wachstumsrate der Bevölkerung. Die Höhe und auch die Zusammensetzung des Arbeitsangebots bestimmen demnach u.a. das wirtschaftliche Wachstum. Sinkt die Zahl der Erwerbstätigen, dann kann ceteris paribus nur weniger produziert werden. Das Wachstum des BIP ist bei einem Bevölkerungsrückgang im neuen Gleichgewicht geringer als im alten. Dieses Ergebnis wird von der Empirie bestätigt: Unter den OECD-Ländern haben im Zeitraum von Mitte der 1970er bis Mitte der 1980er Jahre die Länder mit einem Bevölkerungsrückgang (z.B. Deutschland, Belgien, Österreich, Schweiz oder Großbritannien) besonders niedrige Wachstumsraten; Länder mit zunehmender Bevölkerung (z.B. Kanada, USA, Australien oder Japan) hingegen hohe. ${ }^{396}$ Für Deutschland erwartet Siebert ${ }^{397}$ allein durch den Rückgang des Arbeitsangebots einen Wachstumsverlust von jährlich 0,4 bis 1,0 Prozentpunkte.

\footnotetext{
${ }^{392}$ Vgl. hierzu und im Folgenden Rürup, B.; Klopfleisch, R. (1999), S. $43 \mathrm{ff}$.

${ }^{393}$ Siehe Statistisches Bundesamt (Hrsg.) (2004a), S. 11ff., $24 \mathrm{f}$.

${ }^{394}$ Rürup, B. (2000), S. 77.

${ }^{395}$ Siehe hierzu und zum Einfluss der demographischen Entwicklung auf die Struktur der Nachfrage auch Enquete-Kommission Demographischer Wandel (1998), S. 129ff.; Rürup, B. (2000), S. $76 f$.

${ }^{396} \mathrm{Vgl}$. Hof, B. (1997), S. 154.

${ }^{397}$ Siehe Siebert, H. (2001), S. 3. 
Da ein Bevölkerungsrückgang bei gegebenem Kapitalstock zu einer verbesserten Pro-Kopf-Ausstattung an Kapital führt, steigt die Arbeitsproduktivität. Im neuen Gleichgewicht sind deshalb Pro-Kopf-Einkommen und Reallohn höher als im alten. Die Wachstumsrate des BIP pro Kopf bleibt gleich, da diese nur vom exogen bestimmten technischen Fortschritt abhängt. Insofern ist der Bevölkerungsrückgang im Hinblick auf das Pro-Kopf-Einkommen nicht problematisch. Dies gilt allerdings nur, solange der Bevölkerungsrückgang und vor allem die Alterung den technischen Fortschritt nicht dämpfen. ${ }^{398}$ Inwiefern das der Fall ist, untersucht die Neue Wachstumstheorie: Für den technischen Fortschritt ist vor allem der Innovationsprozess und damit auch das Humankapital bedeutend, das wiederum von der Altersstruktur und der Größe des Erwerbspersonenpotentials beeinflusst wird.

Der Einfluss der Altersstruktur der Bevölkerung auf das Wachstum ist umstritten. Einerseits nehmen nach herrschender Meinung physische Stärke und kognitive Geschwindigkeit mit dem Alter ab. Vor allem jüngere Arbeitnehmer nehmen neue Technologien leichter auf. Älteren Arbeitnehmern fällt die Umstellung auf neue Techniken hingegen schwerer. Da die schulische und berufliche Qualifikation größtenteils in jungen Jahren erworben wird, veraltet mit zunehmendem Durchschnittsalter der Erwerbstätigen das Wissen, wodurch die Leistungsfähigkeit der Erwerbspersonen abnimmt. Bei technischem Fortschritt wird das Wissen der Älteren noch schneller entwertet, zumal mit zunehmendem Alter die Investitionen in Humankapital abnehmen; denn mit geringerer Restlebenserwartung sinkt der Gegenwartswert künftiger Erträge aus Weiterbildungsmaßnahmen, während die Grenzkosten für Weiterbildung mit dem Alter steigen. Insbesondere wegen des beschriebenen Rückgangs der Zahl der 20- bis 35jährigen sinkt die Zahl der Hauptträger modernen Wissens. Auch die Innovationsanreize können in einer alternden Gesellschaft zurückgehen. Wenn Ältere weniger risikobereit sind, sinkt die Zahl der Produktinnovationen, zumal sich neue Produkte in einer älteren Gesellschaft womöglich schlechter am Markt durchsetzen. Andererseits steigt mit dem Lebensalter die berufs-, branchen- und betriebsspezifische Erfahrung und das Organisationswissen der Arbeitnehmer. Zudem verliert die physische Leistungsfähigkeit im Berufsleben zunehmend an Bedeutung und einem Wissensverlust kann lebenslange Weiterbildung entgegentreten. Die Frage, welche Effekte überwiegen, kann derzeit nicht beantwortet werden, zumal die empirische Untersuchung zur Altersabhängigkeit der Produktivität des Faktors Arbeit erst begonnen hat. ${ }^{399}$

Vom Rückgang der Anzahl der Erwerbspersonen werden negative Auswirkungen auf den technischen Fortschritt enwartet. Im Unterschied zum weltweit zugänglichen technischen Wissen ist Humankapital an Personen gebunden. Der Einsatz von Humankapital im Forschungssektor bestimmt in einer Volkswirtschaft über die Nutzung des weltweit zugänglichen technischen Wissens und erhöht das Wirtschaftswachstum, da die Produktivität der Produktionsfaktoren damit steigt. Höhere Wachstumsraten erfordern demnach einen hohen und gut ausgebildeten Humankapitalbestand. Schrumpft aber eine Bevölkerung, dann geht, wenn der Anteil der höher Begabten in

\footnotetext{
${ }^{398}$ Vgl. Grömling, M. (2005), S. 73ff., 77.

${ }^{399}$ Vgl. Siebert, H. (2001), S. 2ff.; Steinmann, G.; Fuchs, O.; Tagge, S. (2002), S. 473ff.; Schneider, S.; Johnson, P. (2003), S. 23ff.; Krey, K.; Meier, B. (2005), S. 152ff.; Rürup, B.; Klopfleisch, R. (1999), S. 46ff. 
der Bevölkerung konstant bleibt, auch die Zahl derjenigen zurück, die innovative Spitzenleistungen erbringen können. ${ }^{400}$

In Anbetracht dieser Zusammenhänge ist zu enwarten, dass von der demographischen Entwicklung auch ein dämpfender Einfluss auf den technischen Fortschritt und das Wirtschaftswachstum ausgeht. Eine bessere Aus- und Fortbildung können diese Effekte zwar mindern, aber nicht vollständig aufheben. ${ }^{401}$ Siebert kommt zu folgender Einschätzung:

"Insgesamt herrscht damit bei der Alterung einer Gesellschaft eine starke Tendenz vor,
dass der Prozess des wirtschaftlichen Wachstums von selbst erlahmt. "402

Mit dem nachlassenden technischen Fortschritt geht auch die Wachstumsrate des BIP pro Kopf bei einer sinkenden Bevölkerungszahl zurück. Zudem unterstellt die Pro-Kopf-Betrachtung, dass die Anzahl von Einwohnern und Erwerbstätigen in gleichem Ausmaß sinkt. Nach der 10. koordinierten Bevölkerungsvorausberechnung geht die Zahl der Einwohner bis zum Jahr 2050 im Durchschnitt um jährlich 0,3\% zurück. Das Erwerbspersonenpotential hingegen nimmt im gleichen Zeitraum mit $0,6 \%$ um das Doppelte ab. ${ }^{403}$ Allein aus diesem Grund geht die Wachstumsrate des BIP pro Einwohner bei einer schrumpfenden Bevölkerung zurück.

Das BIP pro Kopf spielt bei der Beurteilung von Wohlstandsveränderungen eine besondere Rolle; bei der Betrachtung der Nachfrage nach Arbeitskräften ist hingegen das Wachstum des absoluten BIP von Bedeutung. Das Wachstum des absoluten BIP lässt Aussagen über die Entwicklung der beitragspflichtigen Einnahmen und damit der GKV-Finanzen zu. Wie Abbildung 14 gezeigt hat, haben sich die Wachstumsraten von BIP und beitragspflichtigen Einnahmen seit 1970 nahezu parallel entwickelt. Wie aber auch gezeigt wurde, lag in der Vergangenheit die Wachstumsrate der beitragspflichtigen Einnahmen tendenziell unter der des BIP. Zu der hier beschriebenen demographisch bedingten Wachstumsschwäche kommt für die Einnahmen der GKV also noch hinzu, dass die Beitragsgrundlage hinter der allgemeinen wirtschaftlichen Entwicklung zurückbleibt. Dieser Trend dürfte sich aufgrund von Arbeitslosigkeit, der Zunahme von Teilzeitarbeit, dem Anstieg befristeter oder geringfügiger Beschäftigungsverhältnisse sowie allgemein durch die Zunahme nicht beitragspflichtiger Lohnbestandteile weiter fortsetzen.

\subsubsection{GKV-versicherte Erwerbstätige und Lohneinkommen}

Mit dem gedämpften Wirtschaftswachstum ist eine sinkende Nachfrage nach Arbeitskräften verbunden. Da die Entwicklung auf dem Arbeitsmarkt (Produktivität, Löhne, Beschäftigungshöhe etc.) selbst wiederum Rückwirkungen auf das Wirtschaftswachstum hat, ist die Prognose der Zahl der Erwerbstätigen mit großen Unsicher-

\footnotetext{
${ }^{400}$ Vgl. Plünnecke, A.; Seyda, S. (2005), S. 122ff.; Grömling, M. (2005), S. 79.

${ }^{401}$ Vgl. Rürup, B. (2000), S. 78.

${ }^{402}$ Siebert, H. (2001), S. 4. Vgl. auch Rürup (2000), S. 77.

${ }^{403}$ Vgl. Grömling, M. (2005), S. $77 f$.
}

Marco Penske - 978-3-631-75223-4 
heiten verbunden. Die zahlreichen Schätzungen ${ }^{404}$ gehen deshalb teilweise weit auseinander.

Abbildung 25: GKV-versicherte Erwerbstätige bis zum Jahr 2050

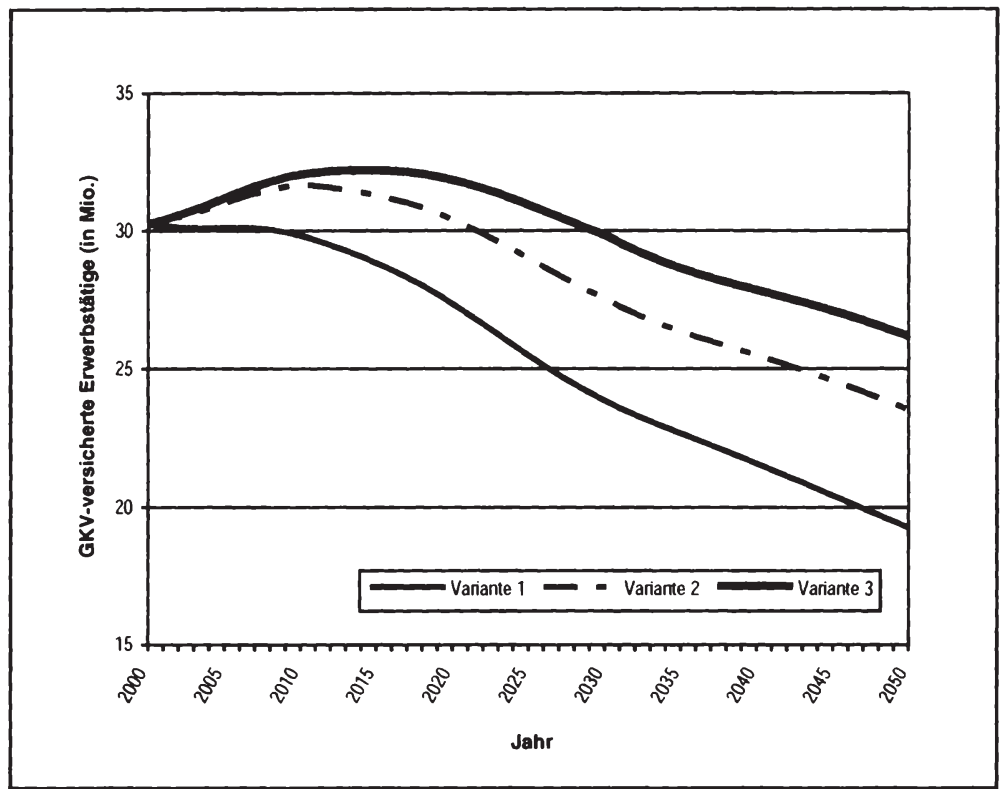

Quelle: Eigene Berechnungen in Anlehnung an Börsch-Supan, A.; Ludwig, A.; Sommer, M. (2003), S. $15 f f$.

Abbildung 25 zeigt aufbauend auf Berechnungen von Börsch-Supan, Ludwig und Sommer ${ }^{405}$ drei Varianten, wie sich die Zahl der in der GKV versicherten Enwerbstätigen bis zum Jahr 2050 entwickeln könnte. Variante 1 unterstellt eine Erwerbstätigenquote auf dem heutigen Niveau. Variante 2 geht von einem Anstieg der Frauenerwerbstätigkeitsquote von $64 \%$ auf $74 \%$, des Rentenzugangsalters von 60 auf 62,5 Jahre und einem Rückgang der Arbeitslosenquote bis zum Jahr 2030 auf $5 \%$ aus. Variante 3 unterstellt einen Anstieg der Frauenerwerbstätigkeitsquote auf $80 \%$, des Rentenzugangsalters auf 65 Jahre und eine Arbeitslosenquote von $4 \%$. Alle Varianten unterstellen Arbeitslosigkeit, da aus dem Rückgang der Zahl der Erwerbspersonen nicht abgeleitet werden kann, dass auch die Arbeitslosigkeit zurückgeht; denn mit dem demographischen Wandel kann auch die Arbeitsnachfrage sinken. Die Größe einer Volkswirtschaft hat keinen systematischen Einfluss auf die herrschende Unterbeschäftigung. ${ }^{406}$

\footnotetext{
${ }^{404}$ Siehe stellvertretend Hof, B. (1997), S. 156ff.; Prognos (Hrsg.) (1998), S. 51ff.; Rürup-Kommission (2003), S. 61ff.; Werding, M.; Kaltschütz, A. (2005), S. $19 f f$.

${ }^{405}$ Siehe Börsch-Supan, A.; Ludwig, A.; Sommer, M. (2003), S. $15 \mathrm{ff}$.

${ }^{406}$ Vgl. Steinmann, G.; Fuchs, O.; Tagge, S. (2002), \$A473 Penske - 978-3-631-75223-4
} 
Da Börsch-Supan, Ludwig und Sommer die Zahl der Erwerbstätigen berechnen, für die GKV aber die Zahl der in der GKV versicherten Erwerbstätigen relevant ist, werden die Ergebnisse entsprechend dem Anteil der GKV-Versicherten an der Bevölkerung im erwerbsfähigen Alter korrigiert. Die Rürup-Kommission geht implizit bei ihren Berechnungen von einem im Zeitverlauf von $83,6 \%$ (2002) auf 84,4 \% im Jahr 2040 steigenden Anteil aus. ${ }^{407}$ Dies beruht auf der Annahme eines sinkenden Anteils der Beamten an allen Beschäftigten und einer konstanten Selbständigenquote. In den Berechnungen zu Abbildung 25 wird ein konstanter Anteil von 83,6\% unterstellt. Dies entspricht dem Anteil der GKV-Versicherten an der enwerbstähigen Bevölkerung im Jahr 2003. ${ }^{408}$

Abbildung 25 zeigt einen deutlichen Rückgang der Zahl der erwerbstätigen GKVVersicherten. In Variante 1 geht die Anzahl stetig zurück von 30,3 Mio. Erwerbstätigen in der GKV im Jahr 2003 auf 19,3 Mio. Personen im Jahr 2050. In den Varianten 2 und 3 steigt die Zahl der Erwerbstätigen noch bis zum Jahr 2010 auf 31,7 Mio. bzw. bis 2015 auf 32,2 Mio. Beschäftigte an. Von da an fällt die Zahl der Erwerbstätigen deutlich ab - bis zum Jahr 2050 auf 23,5 Mio. in Variante 2 und auf 26,2 Mio. Personen in Variante 3. Für die GKV bedeutet diese Entwicklung einen Rückgang der Zahl aktiver Beitragszahler.

Neben der Anzahl der erwerbstätigen GKV-Mitglieder hängt die Summe der beitragspflichtigen Einnahmen der Erwerbstätigen von der Entwicklung der Reallöhne ab. Die Alterung der Bevölkerung wird zu einer Verknappung des Faktors Arbeit führen, woraufhin Arbeit im Produktionsprozess zunehmend durch Kapital substituiert werden wird. Aufgrund des Rückgangs des Arbeitsangebots liegt bei konstantem Reallohn auf dem Arbeitsmarkt ein Nachfrageüberhang vor, der in der neoklassischen Theorie durch einen Reallohnanstieg ausgeglichen wird. Nach dem Gesetz abnehmender Grenzerträge steigt mit sinkendem Faktoreinsatz die Faktorproduktivität, weshalb die Arbeitgeber auch bereit sind, höhere Reallöhne zu zahlen (Grenzproduktivitätstheorie). Die relativen Preise verändern sich zugunsten des knappen Faktors Arbeit. Die Reallöhne steigen. Dem stehen allerdings ein gesunkenes Arbeitsvolumen und ein gestiegener Kapitaleinsatz gegenüber. Welcher Effekt in Bezug auf die gesamten Arbeits- und Kapitaleinkommen letztendlich überwiegt ist a priori nicht vorauszusagen.

Theoretisch möglich wäre es, den negativen Einfluss des Rückgangs der Zahl der Erwerbstätigen auf die GKV-Einnahmen durch einen Reallohnanstieg vollständig zu kompensieren. Dies wäre dann der Fall, wenn das geringere Arbeitsvolumen und der damit verbundene Produktivitätsanstieg in vollem Maße zu Reallohnsteigerungen führen würden. Dies traf aber in der Vergangenheit nicht zu und ist auch in der Zukunft aufgrund des zunehmenden internationalen Standortwettbewerbs nicht zu erwarten. ${ }^{409}$ Langfristig wird infolgedessen sogar eine Abnahme des Lohnwachstums prognostiziert. ${ }^{40}$

\footnotetext{
${ }^{407}$ Eigene Berechnungen; vgl. Rürup-Kommission (2003), S. $61 f$.

${ }^{408}$ Eigene Berechnung; vgl. BMGS (Hrsg.) (2003b); Statistisches Bundesamt (Hrsg.) (2003).

${ }^{409}$ Vgl. Reuter, N. (1997), S. $135 f$.

${ }^{410}$ Siehe hierzu Knappe, E.; Optendrenk, S. (1999), S. 168:co Penske - 978-3-631-75223-4 


\subsection{Renten als beitragspflichtige Einnahmen}

\subsubsection{Steigender Rentneranteil}

Parallel zu dem Rückgang der Zahl der enwerbstätigen Beitragszahler schwächt der steigende Rentneranteil die Einnahmen der GKV. Da sich die Beitragszahlung am Lohn- bzw. Renteneinkommen orientiert, zahlen Rentner aufgrund ihres durchschnittlich geringeren Einkommens einen niedrigeren Krankenversicherungsbeitrag als Erwerbstätige. ${ }^{411}$

Zur Simulierung des Einflusses der Altersstruktur auf die Einnahmen der GKV werden analog zu den Berechnungen oben ${ }^{412}$ die GKV-Beitragseinnahmen berechnet, die sich ergeben, wenn die altersspezifischen GKV-Beiträge aus dem Jahr 2003 mit der jeweiligen Besetzungsstärke der Altersklassen nach der 10. koordinierten Bevölkerungsvorausberechnung des Statistischen Bundesamtes für die Jahre 2003 bis 2050 - bereinigt um die Nicht-GKV-Mitglieder entsprechend den Verhältnissen im Jahr 2003 - multipliziert werden. Auf diese Weise kann der demographisch bedingte Einfluss auf die GKV-Einnahmen berechnet werden. Sonstige Einnahmen der GKV werden nicht berücksichtigt, da diese nur eine geringe Bedeutung haben und weitgehend unabhängig von der Altersstruktur der Mitglieder anfallen.

\section{Abbildung 26: Entwicklung der GKV-Beitragseinnahmen bis zum Jahr 2050}

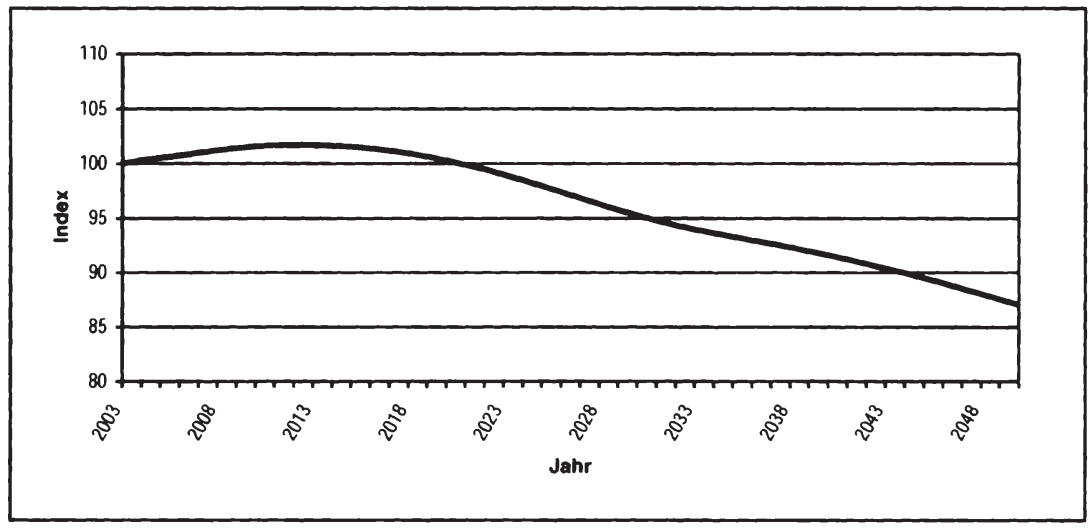

Anmerkung: Index zum Basisjahr 2003.

Quelle: Eigene Berechnungen; Daten: BMGS; Statistisches Bundesamt; Verband Deutscher Rentenversicherungsträger.

Abbildung 26 zeigt, dass der demographische Wandel bis zum Jahr 2050 zu einem Rückgang der Einnahmen um $13 \%$ führt. Dabei steigen die Beiträge bis zum Jahr 2012 noch um 1,7\% gegenüber dem Ausgangsjahr leicht an. Bis zu diesem Zeitpunkt wird der durch einen steigenden Altenquotienten bedingte Einnahmen-

\footnotetext{
${ }^{411}$ Lediglich bei freiwillig Versicherten werden infolge von $\S 240$ Abs. 1 SGB V auch auf Kapitaleinkünfte Beiträge erhoben.

${ }^{412}$ Siehe Abschnitt 1 Demographische Entwicklung undaforoV=Finarzen,9\$883-631-75223-4
} 
ausfall noch durch verschiedene Effekte überkompensiert: Die marginale Zunahme der geschätzten Zahl von GKV-Mitgliedern wirkt bis zum Jahr 2016 isoliert betrachtet einnahmenerhöhend. Hinzu kommt, dass zwischen 2005 und 2015 die relativ schwach besetzten Jahrgänge zwischen 1940 und 1950 in das Rentenalter hineinwachsen. Dadurch findet zunächst nur eine geringe Verschiebung in das Rentenalter statt. Überwiegend altern die enwerbstätigen Versicherten, deren Beiträge zur GKV mit steigendem mittlerem Alter durchschnittlich zunehmen. Mit Eintritt dieser stark besetzten Bevölkerungsgruppen in das Rentenalter wirkt der demographische Wandel dann jedoch einnahmenmindernd. ${ }^{413}$

\section{Abbildung 27: GKV-Mitglieder und Beiträge in den Jahren 2003 und 2050}

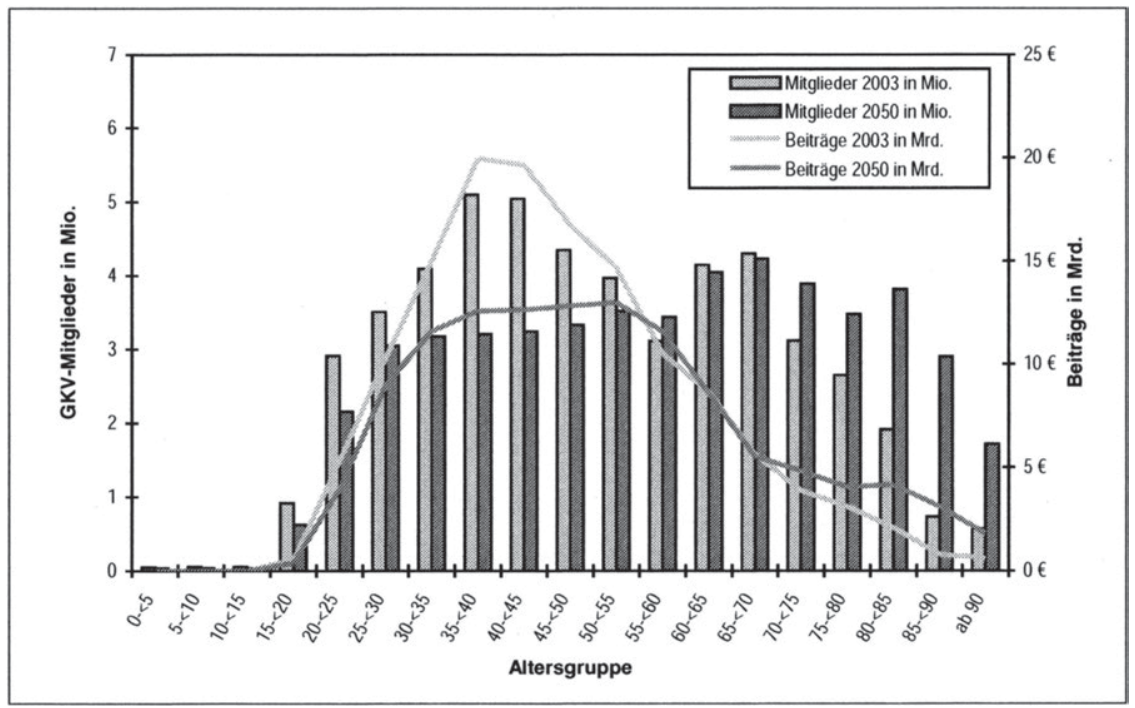

Quelle: Eigene Darstellung und eigene Berechnungen; siehe Tabelle 38: Versicherte, Mitglieder, Ausgaben und Beiträge in den Jahren 2003, 2030 und 2050, im Anhang, S. 276.

Wie sich der demographisch bedingte Einnahmenrückgang auf die einzelnen Altersgruppen verteilt, zeigt Abbildung 27 in einem Vergleich der Beiträge und der Anzahl der GKV-Mitglieder in den einzelnen Altersgruppen für die Jahre 2003 und 2050. Die Säulen zeigen, dass mit der Verschiebung der Altersstruktur der GKV-Mitglieder ein starker Rückgang der Mitglieder im enwerbsfähigen Alter einhergeht. Bei konstanten altersspezifischen Beiträgen zeigen die Linien im Diagramm den damit verbundenen Rückgang der Beiträge der Erwerbstätigen. Mit dem Rückgang der Anzahl der Mitglieder zwischen 25 und 55 Jahren sinken auch die Beiträge zur GKV in diesen Gruppen zum Teil deutlich. Die Beiträge der Gruppe der 35 bis 40jährigen sinken

${ }^{413}$ Postler, A. (2003), S. 10ff., kommt in einer vergleichbaren Modellrechnung mit Daten der 9. koordinierten Bevölkerungsvorausberechnung für die Entwicklung der beitragspflichtigen Einnahmen zu einem ähnlichen Ergebnis. Je nach Variante steigen die beitragspflichtigen Einnahmen bis zum

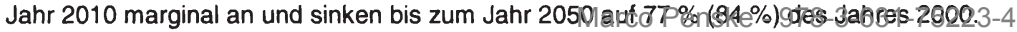


z.B. von 20,0 Mrd. Euro auf 12,6 Mrd. Euro. Dem steht nur ein mäßiger Anstieg der Beiträge der ab 70jährigen gegenüber, am stärksten bei den 80 bis 85 jährigen, von 2,1 Mrd. Euro auf 4,2 Mrd. Euro, und bei den 85 bis 90jährigen von 0,8 Mrd. Euro auf 3,1 Mrd. Euro.

Insgesamt werden die GKV-Einnahmen insbesondere von der Alterung der Mitglieder negativ beeinflusst. Der Rückgang der Zahl der Familienversicherten hat keine Auswirkungen auf die Einnahmen der GKV, da diese ohnehin keine Beiträge zahlen. Die Zahl der Mitglieder und damit der Beitragszahler in der GKV bleibt - im Gegensatz zur Zahl der Versicherten - relativ konstant bei rund 50 Mio. Mitgliedern. Dem Rückgang der Zahl der unter 55jährigen Mitglieder, die nur zu rund $70 \%$ Mitglied in der GKV sind, steht ein starker Anstieg der Zahl der über 65jährigen, die nach den Daten für das Jahr 2003 zu über $85 \%$ in der GKV versichert sind, gegenüber, womit die Zahl der Beitragszahler nahezu konstant bleibt. Ein Einnahmenrückgang entsteht für die GKV durch die Alterung; denn mit dem Renteneintritt gehen die Beiträge zur GKV um durchschnittlich fast die Hälfte zurück.

Diese Analyse erfasst ceteris paribus nur den demographisch bedingten Effekt auf der Einnahmenseite, d.h. alle anderen die Einnahmen beeinflussenden Größen (z.B. Entwicklung der altersspezifischen beitragspflichtigen Einnahmen, Lohnstruktur, Anteil der GKV-Mitglieder an der Bevölkerung) werden als konstant angenommen.

\subsubsection{Sinkendes Rentenniveau}

Neben der Anzahl der Rentner beeinflusst auch das Rentenniveau die Einnahmen der GKV. Von 1992 bis zur Rentenanpassung im Juli 1999 wurde der Beitragssatzanstieg in der GKV durch niedrigere Rentenerhöhungen noch verstärkt: Infolge der Rentenreform 1992 wurden die Renten nicht mehr an die Entwicklung der Bruttolöhne angepasst, sondern an die der Nettolöhne (Bruttolöhne nach Abzug von Steuem und Sozialabgaben). Damit wurde zwar die Abgabenbelastung der Erwerbstätigen berücksichtigt. Beitragssatzsteigerungen der GKV wirkten aber via niedrigeren Nettolöhnen und geringeren Rentensteigerungen negativ auf die Finanzkraft der GKV. ${ }^{414}$ Dieser Automatismus, der in der GKV zu einem sich selbst verstärkenden Beitragssatzanstieg führte, wurde mit dem Gesetz zur Sanierung des Bundeshaushalts vom 22.12.1999 ${ }^{415}$ aufgehoben. Danach sollten die Renten in den Jahren 2000 und 2001 entsprechend der Inflationsrate aus dem jeweiligen Vorjahr angepasst werden. Schon 2001 wurde die Rentenanpassung aber mit dem Gesetz zur Ergänzung des Gesetzes zur Reform der gesetzlichen Rentenversicherung und zur Förderung eines kapitalgedeckten Altersvorsorgevermögens ${ }^{416}$ geändert. Seit Juli 2001 werden die Renten entsprechend der Entwicklung der Bruttolöhne und des Beitragssatzes zur GRV angepasst. Zudem werden Altersvorsorgebeiträge der Erwerbstätigen (RiesterRente) ab 2003 bei der Rentenanpassung berücksichtigt. Nach dem Zweiten Gesetz zur Änderung des Sechsten Buches Sozialgesetzbuch und anderer Gesetze vom

\footnotetext{
${ }^{414} \mathrm{Vgl}$. SVR KAiG (1994), Ziff. 200.

415 Siehe BGBI. 1999, Teil I, Nr. 58, S. 2543.

${ }^{416}$ Siehe BGBI. 2001, Teil I, Nr. 13, S. 405.
} 
27.12.2003 $3^{417}$ wurde die Rentenanpassung für das Jahr 2004 allerdings ausgesetzt. Aufgrund des geringen Wachstums der Lohneinkommen wurden die Renten zum letzten Mal im Jahr 2003 erhöht.

Neben dem Einfluss der vergangenen Rentenanpassungen sind in Zukunft mit dem sinkenden Rentenniveau nach dem Gesetz zur Sicherung der nachhaltigen Finanzierungsgrundlagen der gesetzlichen Rentenversicherung (Rentenversicherungs-Nachhaltigkeitsgesetz) vom 21.07.2004 ${ }^{418}$ Einnahmenverluste für die GKV verbunden. Im Grundsatz orientiert sich die Rentenanpassung zwar auch nach Inkrafttreten dieses Gesetzes an der Entwicklung der Bruttolohn- und Gehaltssumme je beschäftigten Arbeitnehmer. Wegen des eingeführten Nachhaltigkeitsfaktors wird in der neuen Rentenformel aber erstmals die demographische Entwicklung, genauer das gewichtete zahlenmäßige Verhältnis der Beitragszahler zu den Rentenbeziehern, die Höhe der Anpassung mitbestimmen. ${ }^{419}$ Dadurch wird die Rentenanpassung mit zunehmender Alterung der Bevölkerung hinter der Lohnentwicklung zurückbleiben und sich die Schere zwischen den Beiträgen von Beschäftigten und Rentnern weiter öffnen. Bereits mit den Rentenreformgesetzen 1992, 1999 und 2001 sowie dem Wachstumsförderungsgesetz 1996 und dem Haushaltssicherungsgesetz 1999 gingen Leistungseinschränkungen der GRV einher. ${ }^{420}$

Um den Einfluss des Rentenversicherungs-Nachhaltigkeitsgesetzes auf die GKVFinanzen abschätzen zu können, ist die Betrachtung des Bruttorentenniveaus hilfreich. Dieses gibt das Verhältnis von Bruttoeckrente zu jahresdurchschnittlichem Bruttoeinkommen aller Arbeitnehmer an, jeweils vor dem Abzug von Steuern und Sozialversicherungsabgaben. Die Bruttoeckrente ist die Rente, die ein sogenannter Standardrentner bezieht. Hierbei handelt es sich um einen fiktiven Rentner mit 45 Beitragsjahren, der in dieser Zeit das durchschnittliche sozialversicherungspflichtige Arbeitsentgelt bezogen hat. Dieser Rentner hat für seine Rente somit 45 Entgeltpunkte erworben. Im Jahr 2003 betrug in Westdeutschland das durchschnittliche Jahresarbeitsentgelt 28.978 Euro und die jährliche Brutto-Standardrente 14.037 Euro, was einem Bruttorentenniveau von 48,5\% entsprach. ${ }^{421}$ Die tatsächliche Rente der GRV liegt bei vielen Rentnern aber deutlich unter der eines Eckrentners. Männer in Westdeutschland weisen z.B. im Durchschnitt nur 40 Versicherungsjahre auf, deren Bruttorentenniveau lag also nur bei $42,6 \% \mathrm{im}$ Jahr $2003 .{ }^{422}$

Nach Berechnungen des VDR $^{423}$ sinkt das Bruttorentenniveau eines Eckrentners infolge der gesetzlichen Neuregelung von 48,5\% im Jahr 2003 über 43,7\% (2010)

417 Siehe BGBI. 2003, Teil I, Nr. 67, S. 3014.

${ }^{418}$ Siehe BGBI. 2004, Teil I, Nr. 38, S. 1791.

${ }^{419}$ Mit dem Gesetz zur Reform der gesetzlichen Rentenversicherung (Rentenreformgesetz) wurde zwar am 16.12.1997 die Einführung eines Demographiefaktors zum 01.07.1999 beschlossen; siehe BGBI. 1997, Teil I, Nr. 85, S. 2998. Dieser wurde aber nach dem Regierungswechsel mit dem Gesetz zu Korrekturen in der Sozialversicherung und zur Sicherung der Arbeitnehmerrechte (Rentenkorrekturgesetz) zum 01.01.1999 ausgesetzt; siehe BGBI. 1998, Teil I, Nr. 85, S. 3843.

${ }^{420}$ Eine Übersicht hierzu geben Nürnberger, I.; Stapf-Finé, H. (2004), S. 39.

${ }^{421}$ Siehe Verband Deutscher Rentenversicherungsträger (Hrsg.) (2004a), S. 29.

${ }^{422} \mathrm{Vgl}$. Institut der deutschen Wirtschaft (Hrsg.) (2004a), S. 7.

${ }^{423}$ Siehe hierzu Verband Deutscher Rentenversicherungsträger (Hrsg.) (2004d), S. 34; o.V. (2004b), S. 17. 
und $41,9 \%$ (2020) bis auf 39,0\% im Jahr 2030. Damit gehen auch die durchschnittlichen Beiträge der Rentner zur GKV im Vergleich zu denen der Erwerbstätigen zurück. Im Jahr 2003 betrugen die durchschnittlichen beitragspflichtigen Einnahmen eines Rentners im Vergleich zu denen eines Mitglieds in der AKV rund 52,5\%. ${ }^{424}$ Sinkt das Bruttorentenniveau vom Jahr 2003 bis zum Jahr 2030 um 19,6\%, dann sinkt nach einer groben Schätzung ceteris paribus der Anteil der durchschnittlichen Pro-Kopf-Beiträge der Rentner im Vergleich zu denen der Erwerbstätigen in diesem Zeitraum um die gleiche Rate - von $52,5 \%$ auf $42,2 \%$. Damit verstärkt der Rückgang des Rentenniveaus den ohnehin einnahmenmindernden Effekt des Anstiegs der Zahl der Rentner. Das Rentenniveau gibt allerdings keine Auskunft über die absolute Höhe der Renten. Der Zahlbetrag der Rente bei einem niedrigeren Rentenniveau kann bei günstigen wirtschaftlichen Rahmenbedingungen aufgrund höherer Lohnsteigerungen größer sein als die Rentenzahlung auf einem höheren Niveau bei nur geringem Wirtschaftswachstum.

Neben der wirtschaftlichen Entwicklung beeinflussen die individuellen Erwerbsbiographien die künftigen Rentenzahlungen. Aufgrund der Zunahme von Versicherungslücken und atypischen Beschäftigungsverhältnissen wird auch die Zahl derer, die nur einen geringen Rentenanspruch erworben haben, steigen. ${ }^{425}$ Hinzu kommt eine reduzierte rentenrechtliche Bewertung von Zeiten in Arbeitslosigkeit. Das Problem niedriger Rentenansprüche und damit verbunden geringer GKV-Beiträge von Rentnern wird sich auch hierdurch noch verstärken. Die zunehmende Bedeutung der privaten Altersvorsorge kann die Einnahmenverluste nicht ausgleichen, da private Altersrenten bislang sozialabgabenfrei sind. ${ }^{426}$

\section{Beitragssatzprojektionen}

\subsection{Beitragssatzprojektion mit der Bilanzgleichung}

In den beiden vorigen Abschnitten wurde die Wirkung der demographischen Entwicklung auf die GKV getrennt für die Einnahmen- und die Ausgabenseite analysiert. Auf den Beitragssatz wirken beide Seiten gleichzeitig.

Der künftige GKV-Beitragssatz kann mit einer einfachen Gleichung und relativ geringem Datenaufwand grob abgeschätzt werden. Nach dem Umlageverfahren müssen die Ausgaben eines Jahres grundsätzlich durch die Einnahmen desselben Jahres gedeckt werden. Sieht man von Veränderungen der Rücklagen, Kreditaufnahmen und sonstigen Einnahmen ab, setzen sich die Einnahmen aus den Beiträgen der Erwerbstätigen und denen der Rentner zusammen. Entsprechend lassen sich auch die Ausgaben in Ausgaben für Rentner und für Erwerbstätige differenzieren. Dabei ist allerdings zu beachten, dass in den Ausgaben für Erwerbstätige bzw. für Rentner

\footnotetext{
${ }^{424}$ Siehe Anhang 1: Bilanzgleichung, S. 261. Die Differenz zum Bruttorentenniveau ist neben der Konstruktion des Eckrentners vor allem auf Besonderheiten der Beitragserhebung (z.B. Versicherungspflichtgrenze) und beitragspflichtige Altersbezüge neben der Rente aus der GRV (z.B. Betriebsrenten) zurückzuführen.

${ }^{425}$ Vgl. Pfaff, A.B. (1999), S. 46ff., 59.

${ }^{426}$ Vgl. Dräther, H.; Jacobs, K. (2003), S. 106. Versorgungsbezüge von gesetzlich Versicherten sind hingegen gemäß § 229 SGB V beitragspflichtig. Marco Penske - 978-3-631-75223-4
} 
jeweils auch die Ausgaben für deren beitragsfrei mitversicherte Familienangehörige enthalten sind. Diese Zusammenhänge lassen sich in einer Bilanzgleichung abbilden.

Formal ergeben sich die GKV-Einnahmen eines Jahres gemäß der Gleichung: ${ }^{427}$

$$
\begin{aligned}
E=b \cdot\left(L_{z} \cdot L\right. & \left.+R_{z} \cdot R\right) \\
\text { mit: } & E=\text { Einnahmen } \\
\mathrm{b} & =\text { Beitragssatz } \\
\mathrm{L}_{z} & =\text { Zahl der erwerbstätigen Beitragszahler } \\
\mathrm{L} & =\text { durchschnittliches beitragspflichtiges Arbeitseinkommen } \\
\mathrm{R}_{\mathrm{z}} & =\text { Zahl der Rentner } \\
\mathrm{R} & =\text { durchschnittliches beitragspflichtiges Renteneinkommen }
\end{aligned}
$$

Die Ausgabengleichung lautet:

$$
\begin{aligned}
& A=A l \cdot L_{z}+A r \cdot R_{z} \\
& \text { mit: } A=\text { Ausgaben } \\
& \text { Al = durchschnittliche GKV-Ausgaben je erwerbstätigen Beitrags- } \\
& \text { Ar = durchschnittliche GKV-Ausgaben je Rentner (einschließlich }
\end{aligned}
$$

Da sich im Umlageverfahren Einnahmen und Ausgaben eines Jahres entsprechen müssen, erhält man die Budgetrestriktion der GKV durch Gleichsetzen von Einnahmen und Ausgaben:

$$
\text { (3) } E=A
$$

Setzt man die Gleichungen (1) und (2) in die Budgetrestriktion (3) ein und löst nach dem Beitragssatz $b$ auf, erhält man die Bestimmungsfaktoren für den Beitragssatz.

$$
b=\frac{A l \cdot L_{z}+A r \cdot R_{z}}{L_{z} \cdot L+R_{z} \cdot R} \quad \text { oder } \quad \text { (5) } b=\frac{A l}{L} \cdot \frac{1+\frac{A r}{A l} \cdot \frac{R_{z}}{L_{z}}}{1+\frac{R}{L} \cdot \frac{R_{z}}{L_{z}}}
$$

Setzt man die entsprechenden Werte ${ }^{428}$ für das Jahr 2003 in Gleichung (5) ein, erhält man ex post den rechnerischen Beitragssatz (2003) anhand der Bilanzgleichung:

$$
b=0,1001 \cdot \frac{1+1,8539 \cdot 0,4896}{1+0,5251 \cdot 0,4896}=15,19 \%
$$

Dieser übertrifft den tatsächlichen Beitragssatz von 14,31\% um 0,88 Prozentpunkte. Abgesehen von Ungenauigkeiten der obigen Rechnung lässt sich die Differenz auf die sonstigen Einnahmen von 3,3 Mrd. Euro und das Defizit von 4,3 Mrd. Euro im

\footnotetext{
${ }^{427}$ Vgl. Schmähl, W. (1983a), S. $112 \mathrm{ff}$.

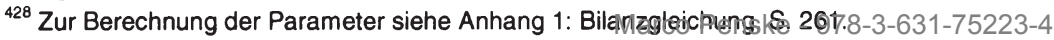


Jahr 2003 zurückführen. ${ }^{429}$ Berücksichtigt man, dass damit 94,8\% der GKV-Ausgaben in Höhe von 145,1 Mrd. Euro durch Beiträge gedeckt werden, ergibt sich ein rechnerischer Beitragssatz von 14,40 \%, der trotz der groben Schätzung anhand der Bilanzgleichung ziemlich genau den tatsächlichen Beitragssatz wiedergibt.

Um den Einfluss der demographischen Entwicklung auf den Beitragssatz zu bestimmen, werden zunächst alle Parameter konstant gehalten und nur das Verhältnis der Rentner zu den Erwerbstätigen verändert. Auf diese Weise erhält man den demographisch bedingten Beitragssatzeffekt. Anschließend werden weitere Annahmen über die Entwicklung von Einnahmen und Ausgaben getroffen und der sich daraus ergebende Beitragssatz für die Jahre 2030 und 2050 berechnet.

Tabelle 13: Beitragssatzprojektionen anhand der Bilanzgleichung

\begin{tabular}{|c|c|c|c|c|c|c|c|}
\hline$\stackrel{\frac{2}{\pi}}{\frac{5}{2}}$ & 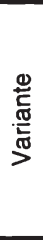 & $\begin{array}{l}\text { Rentner- } \\
\text { quotient } \\
\left(\mathrm{R}_{z} / \mathrm{L}_{z}\right)\end{array}$ & $\begin{array}{l}\text { Beitragsniveau } \\
\text { der Rentner im } \\
\text { Vergleich zu } \\
\text { Erwerbstätigen } \\
\quad(R / L)\end{array}$ & $\begin{array}{l}\text { Leistungsausga- } \\
\text { ben der Erwerbs- } \\
\text { tätigen im Ver- } \\
\text { gleich zu deren } \\
\text { beitragspflichtigen } \\
\text { Einkommen } \\
(\mathrm{Al} / \mathrm{L})\end{array}$ & $\begin{array}{l}\text { Ausgaben- } \\
\text { relation Rent- } \\
\text { ner zu Er- } \\
\text { werbstätigen } \\
\text { (Ar/Al) }\end{array}$ & $\begin{array}{l}\text { Beitrags } \\
\text { satz }\end{array}$ & \begin{tabular}{|c|} 
Beitrags- \\
satzeffekt \\
in \\
Prozent- \\
punkten \\
im Ver- \\
gleich zu \\
$2003^{11}$ \\
\end{tabular} \\
\hline 2003 & & 49,6 & 52,5 & 0,1001 & 1,8539 & $15,2 \%$ & \\
\hline 2030 & \multirow{2}{*}{1} & 78,1 & & & & $17,4 \%$ & 2,1 \\
\hline 2050 & & 85,8 & & & & $17,9 \%$ & 2,6 \\
\hline 2030 & \multirow{2}{*}{2} & 78,1 & 42,2 & 0,1001 & 1,8539 & $18,4 \%$ & 3,2 \\
\hline 2050 & & 85,8 & & & & $19,0 \%$ & 3,8 \\
\hline 2030 & \multirow{2}{*}{3} & 78,1 & 42,2 & $\begin{array}{l}0,1065 \\
(+0,23 \% \text { р.а. })\end{array}$ & 1,8539 & $19,6 \%$ & 4,4 \\
\hline 2050 & & 85,8 & & $\begin{array}{l}0,1116 \\
(+0,23 \% \text { p.a. })\end{array}$ & & $21,2 \%$ & 6,0 \\
\hline 2030 & \multirow{2}{*}{$4 a$} & 78,1 & 42,2 & $\begin{array}{l}0,1065 \\
(+0,23 \% \text { p.a. })\end{array}$ & $\begin{array}{l}2,1041 \\
(+0,47 \% \text { p.a. })\end{array}$ & $21,2 \%$ & 5,9 \\
\hline 2050 & & 85,8 & & $\begin{array}{l}0,1116 \\
(+0,23 \% \text { p.a. })\end{array}$ & $\begin{array}{l}2,3109 \\
(+0,47 \% \text { p.a. })\end{array}$ & $24,4 \%$ & 9,2 \\
\hline 2030 & \multirow{2}{*}{$4 b$} & 78,1 & 42,2 & $\begin{array}{l}0,1065 \\
(+0,23 \% \text { p.a. })\end{array}$ & $\begin{array}{l}3,1227 \\
(+1,95 \% \text { p.a. })\end{array}$ & $27,6 \%$ & 12,3 \\
\hline 2050 & & 85,8 & & $\begin{array}{l}0,1116 \\
(+0,23 \% \text { p.a. })\end{array}$ & $\begin{array}{l}4,5949 \\
(+1,95 \% \text { p.a. })\end{array}$ & $40,5 \%$ & 25,2 \\
\hline
\end{tabular}

1) Abweichung durch Rundung.

Quelle: Eigene Berechnungen.

Einen Überblick über die Annahmen und Ergebnisse gibt Tabelle 13. Diesen eigenen Berechnungen liegen folgende Annahmen zugrunde:

- Der Altenquotient in der GKV steigt entsprechend Tabelle 11 (S. 90) von 49,6 $6^{430}$ im Jahr 2003 auf 78,1 im Jahr 2030 und 85,8 im Jahr 2050.

${ }^{429}$ Siehe BMGS (Hrsg.) (2004a), S. 121, 130.

${ }^{430}$ Die geringfügige Abweichung zu dem in Anhang 1: Bilanzgleichung, S. 261, berechneten Rentnerquotienten in Höhe von 49,0 beruht auf der vereinfachenden Annahme, Versicherte zwischen 20

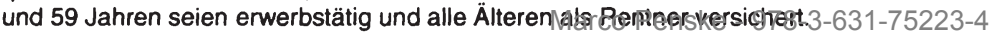


Das Beitragsniveau von Rentnern im Vergleich zu Erwerbstätigen sinkt - wie im vorigen Abschnitt 3.3.2 Sinkendes Rentenniveau (S. 121) erläutert - bis zum Jahr 2030 auf 42,2 \% und bleibt dann auf diesem Niveau.

Die Ausgaben für Erwerbstätige sind im Zeitraum von 1991 bis 2000 um 3,5\% p.a. gestiegen. Dieser Anstieg wird auch für die Zukunft unterstellt. Zudem wird angenommen, dass die beitragspflichtigen Einnahmen der Erwerbstätigen um 3,27\% p.a. steigen. Das Verhältnis der Ausgaben der Erwerbstätigen zu deren beitragspflichtigen Einnahmen steigt demzufolge um $0,23 \%$ p.a. ${ }^{431}$

Aufgrund der Probleme, die mit einer Annahme über die künftige Ausgabenrelation Rentner/Erwerbstätige verbunden sind, wird der Beitragssatz nach zwei Varianten berechnet: Die Ausgabenrelation steigt in Variante 4a um 0,47\% p.a., in Variante 4b um 1,95\% p.a. Dem liegt ein Anstieg der Ausgaben für Erwerbstätige von 3,5\% p.a. und für Rentner von 4,0\% p.a. bzw. 5,5\% p.a. zugrunde. ${ }^{432}$ Allein durch die Veränderung der Bevölkerungsstruktur (Variante 1; demographischer Beitragssatzeffekt) steigt der Beitragssatz bis zum Jahr 2030 (2050) um 2,1 Prozentpunkte $(2,6)$ im Vergleich zum Jahr 2003. Berücksichtigt man zudem in Variante 2, dass das Rentenniveau im beschriebenen Ausmaß sinkt, steigt der Beitragssatz bis 2030 (2050) um 3,2 Prozentpunkte $(3,8)$. Dies zeigt die negative Auswirkung von Rentenreformen auf den Beitragssatz der GKV. ${ }^{433}$ Variante 3 hebt die Annahme im Zeitverlauf konstanter Ausgaben und Einnahmen pro Kopf auf. Stattdessen wird unterstellt, dass bei den Erwerbstätigen die Gesundheitsausgaben auch in Zukunft schneller steigen als die beitragspflichtigen Einnahmen. Für den Beitragssatz bedeutet dies bis zum Jahr 2030 einen Anstieg um 4,4 Prozentpunkte, bis 2050 um 6,0 Prozentpunkte. Dramatisch wird der Beitragssatzanstieg, wenn man die Ausgabenentwicklung der Rentner im Vergleich zu der der Erwerbstätigen berücksichtigt. Bei einem Anstieg der Ausgaben für Rentner auf dem bisherigen Niveau von 4,0\% p.a. steigt in Variante 4a der Beitragssatz bis 2030 um 5,9 Prozentpunkte bzw. bis 2050 um 9,2 Prozentpunkte. Wird wegen des medizinisch-technischen Fortschritts ein höherer Ausgabenanstieg von 5,5\% p.a. (Variante $4 \mathrm{~b}$ ) unterstellt, dann steigt der Beitragssatz bis zum Jahr 2030 um 12,3 Prozentpunkte auf 27,6\%, bis zum Jahr 2050 sogar auf $40,5 \%{ }^{434}$

Die Fortschreibung unveränderter Ausgabenprofile unterstellt implizit, dass tendenziell die Medikalisierungsthese gilt, wonach die Gesundheitsausgaben mit dem Alter steigen. Würde hingegen von der Kompressionsthese ausgegangen, nach der die Ausgaben von der Entfernung zum Tod abhängen, müssten die altersbezogenen Kostenprofile im Zeitverlauf flacher verlaufen. Dies bedeutet - Gültigkeit der Kompressionsthese unterstellt - , dass der demographisch bedingte Beitragssatzeffekt in

\footnotetext{
${ }^{431}$ Siehe Cassel, D.; Postler, A. (2003), S. 441.

${ }^{432}$ Siehe ebenda, S. 441.

${ }^{433}$ Geht das Bruttorentenniveau bis 2050 auf $37,0 \%$ weiter zurück, sinkt ceteris paribus das Beitragsniveau der Rentner auf 40,1\% (2050). Der Beitragssatz steigt dann um 4,1 Prozentpunkte auf 19,3\% im Jahr 2050.

${ }^{434} \mathrm{Zu}$ ähnlichen Ergebnissen kommen auch ältere Berechnungen, denen Daten der 8. oder 9. koordinierten Bevölkerungsvorausberechnung zugrunde liegen; siehe Schmähl, W. (1989), S. 306f.; Knappe, E. (1995), S. 35; Knappe, E.; Rachold, U. (1997), S. 103ff.; Enquete-Kommission Demo-

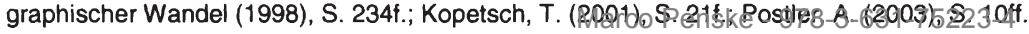


Bezug auf vergangene Bevölkerungsstrukturen eher unterschätzt, in Bezug auf künftige Entwicklungen eher überschätzt wird. Selbst wenn die Kompressionsthese zuträfe, würde aber der Beitragssatz aufgrund des Einflusses der demographischen Entwicklung auf die Einnahmen der GKV steigen. Grundsätzlich sind die berechneten Beitragssätze in großem Maße von den unterstellten Annahmen insbesondere über die Entwicklung der Ausgaben bei medizinisch-technischem Fortschritt abhängig. Wie schwierig es ist, dabei richtige Annahmen zu treffen, zeigen nicht zuletzt ständig revidierte Prognosen über die wirtschaftliche Entwicklung im jeweils kommenden Jahr.

Formal kann die Wirkung der demographischen Entwicklung auf den Beitragssatz an der Bilanzgleichung in einem Zwei-Perioden-Modell gezeigt werden. ${ }^{435}$ Es wird unterstellt, die Bevölkerung wachse stationär mit der Rate $n$. Dann gilt:

$$
L_{z}=(1+n) \cdot R_{z}
$$

Ferner wird unterstellt, das beitragspflichtige Renteneinkommen sei:

(8) $\quad R=\alpha \cdot L \quad$ mit dem Rentenniveau $\alpha, 0<\alpha<1$.

Setzt man die Gleichungen (7) und (8) in Gleichung (4) ein, erhält man:

(9) $\quad b=\frac{A l \cdot(1+n) \cdot R_{z}+A r \cdot R_{z}}{(1+n) \cdot R_{z} \cdot L+R_{z} \cdot a \cdot L}$

$$
\frac{\delta \mathrm{b}}{\delta \mathrm{n}}=\frac{\alpha \cdot A l-A r}{L \cdot(1+n+\alpha)^{2}}
$$

Da die durchschnittlichen Ausgaben für Rentner höher sind als die für Erwerbstätige, ist $\mathrm{Ar}>\mathrm{Al}$ und damit auch $\mathrm{Ar}>\alpha \cdot \mathrm{Al}$, womit

$$
\frac{\delta \mathrm{b}}{\delta \mathrm{n}}<0
$$

gilt. Der Beitragssatz im Umlageverfahren ist demnach umso höher (geringer), je kleiner (größer) die Wachstumsrate der Bevölkerung ist.

Um den Einfluss der Alterung der Bevölkerung auf den Beitragssatz zu bestimmen, wird Gleichung (5) nach dem Altenquotienten abgeleitet. Man erhält:

$$
\frac{\delta \mathrm{b}}{\delta\left(\frac{R_{z}}{L_{z}}\right)}=\frac{\frac{A r}{L}-\frac{R}{L} \cdot \frac{A l}{L}}{\left(1+\frac{R}{L} \cdot \frac{R_{z}}{L_{z}}\right)^{2}}
$$

$\mathrm{Da} \mathrm{Ar}>\mathrm{Al}$ und gemäß Gleichung (8) $0<\frac{R}{L}<1$, weil $0<\alpha<1$ gilt, ist der Zähler größer Null. Der Nenner ist aufgrund der Zweierpotenz ebenfalls positiv. 
Es gilt:

$$
\frac{\delta b}{\delta\left(\frac{R_{z}}{L_{z}}\right)}>0 .
$$

Damit lässt sich auch formal zeigen, dass mit der Alterung der Bevölkerung - in der GKV dem Anstieg des Quotienten aus Rentnern zu Erwerbstätigen - der Beitragssatz steigt.

\subsection{Ausgewählte Beitragssatzprojektionen}

Auch Beitragssatzprojektionen, bei denen differenziertere Annahmen über die Entwicklung von Ausgaben und beitragspflichtigen Einnahmen getroffen werden, zeigen einen Beitragssatzanstieg. Da in der Literatur zahlreiche Beitragssatzprojektionen vorliegen, wird hier auf einen weiteren eigenen Ansatz verzichtet. Stattdessen werden in Tabelle 14 die Ergebnisse einer Auswahl von Berechnungen mit den wesentlichen zugrunde liegenden Annahmen dargestellt.

Tabelle 14: Auswahl an Beitragssatzprojektionen bis zum Jahr 2050

\begin{tabular}{|c|c|c|c|}
\hline Quelle & Jahr & Beitragssatz & Methodik, Annahmen \\
\hline $\begin{array}{l}\text { Schmähl, W. (1986), } \\
\text { S. } 220\end{array}$ & 2030 & $14-15 \%$ & $\begin{array}{l}\text { Konstante Ausgabenstruktur, veränderte Alters- } \\
\text { struktur; rein demographischer Effekt }\end{array}$ \\
\hline $\begin{array}{l}\text { Erbsland, M.; Ried, W.; } \\
\text { Ulrich, V. (1999), S. } 190\end{array}$ & 2040 & $15,5 \%$ & $\begin{array}{l}\text { Konstante Ausgabenstruktur, 8. koordinierte } \\
\text { Bevölkerungsvorausberechnung; rein demogra- } \\
\text { phischer Effekt }\end{array}$ \\
\hline Hof, B. (2001), S. 129 & \begin{tabular}{|l|}
2050 \\
$(2040)$
\end{tabular} & $\begin{array}{l}16,6-19,2 \% \\
(16,3-18,1 \%)\end{array}$ & $\begin{array}{l}\text { Konstante Ausgabenstruktur, 8. koordinierte } \\
\text { Bevölkerungsvorausberechnung; rein demogra- } \\
\text { phischer Effekt }\end{array}$ \\
\hline Erbsland, M. (1995), S. 23 & 2040 & $15,3-15,8 \%$ & $\begin{array}{l}\text { Konstante Ausgabenstruktur, 8. koordinierte } \\
\text { Bevölkerungsvorausberechnung; rein demogra- } \\
\text { phischer Effekt }\end{array}$ \\
\hline Pfaff, A.B. (2002), S. 194 & \begin{tabular}{|l|}
2050 \\
$(2040)$
\end{tabular} & $\begin{array}{l}15,8 \% \\
(15,4 \%)\end{array}$ & $\begin{array}{l}\text { Konstante Ausgaben- und Einnahmenstruktur, } \\
\text { 9. koordinierte Bevölkerungsvorausberechnung; } \\
\text { rein demographischer Effekt }\end{array}$ \\
\hline Postler, A. (2003), S. 15 & $\begin{array}{l}2050 \\
(2040)\end{array}$ & $\begin{array}{l}16,2-16,5 \% \\
(16,0-16,3 \%)\end{array}$ & $\begin{array}{l}\text { Konstante Ausgaben- und Einnahmenstruktur, } \\
\text { 9. koordinierte Bevölkerungsvorausberechnung; } \\
\text { rein demographischer Effekt }\end{array}$ \\
\hline SVR (2004), Tabelle 51 & \begin{tabular}{|l|}
2050 \\
$(2040)$
\end{tabular} & $\begin{array}{l}16,5-18,0 \% \\
(16,2-17,4 \%)\end{array}$ & $\begin{array}{l}\text { Konstante Ausgaben- und Einnahmenstruktur, } \\
\text { 10. koordinierte Bevölkerungsvorausberechnung; } \\
\text { rein demographischer Effekt }\end{array}$ \\
\hline $\begin{array}{l}\text { Buttler, G.; Fickel, N.; } \\
\text { Lautenschläger, B. } \\
\text { (1999), S. 130f. }\end{array}$ & 2040 & $17,6-19,1 \%$ & $\begin{array}{l}\text { Konstante Ausgabenstruktur, veränderte Alters- } \\
\text { struktur, Zuwanderung, Lebenserwartung; rein } \\
\text { demographischer Effekt }\end{array}$ \\
\hline Knappe, E. (1995), S. 32 & 2030 & $25,0 \%$ & $\begin{array}{l}\text { Fortschreibung der bisherigen Ausgaben- und } \\
\text { Einnahmenentwicklung; } 7 \text {. koordinierte Bevölke- } \\
\text { rungsvorausberechnung }\end{array}$ \\
\hline $\begin{array}{l}\text { Breyer, F. u.a. (2001), } \\
\text { S. } 105\end{array}$ & \begin{tabular}{l|}
2050 \\
$(2040)$
\end{tabular} & $\begin{array}{l}19,0-20,3 \% \\
(18,2-19,3 \%)\end{array}$ & 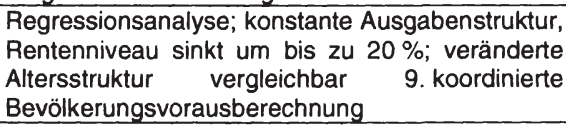 \\
\hline $\begin{array}{l}\text { Prognos (Hrsg.) (1998), } \\
\text { S. } 90\end{array}$ & 2040 & $15,4-15,9 \%$ & $\begin{array}{l}\text { Einnahmenorientierte Ausgabenpolitik; Wachstum } \\
\text { der Pro-Kopf-Ausgaben zwischen } 0,9 \text { und } 1,7 \% \\
\text { p.a.; 8. koordinierte Bevölkerungsvorausberech- } \\
\text { nung }\end{array}$ \\
\hline
\end{tabular}




\begin{tabular}{|c|c|c|c|}
\hline $\begin{array}{l}\text { Werding, M.; Kaltschütz, } \\
\text { A. (2005), S. } 42 f f ., 159\end{array}$ & $\begin{array}{l}2050 \\
(2040)\end{array}$ & $\begin{array}{l}15,7 \% \\
(15,4 \%)\end{array}$ & $\begin{array}{l}\text { Einnahmen und Ausgaben steigen entsprechend } \\
\text { der Arbeitsproduktivität; 10. koordinierte Bevölke- } \\
\text { rungsvorausberechnung }\end{array}$ \\
\hline $\begin{array}{l}\text { Hof, B. (2001), S. 151f., } \\
258 f .\end{array}$ & $\begin{array}{l}2050 \\
(2040)\end{array}$ & $\begin{array}{l}20,9-26,1 \% \\
(19,4-22,3 \%)\end{array}$ & $\begin{array}{l}\text { Differenzierte Fortschreibung der Ausgaben; } \\
\text { 8. koordinierte Bevölkerungsvorausberechnung }\end{array}$ \\
\hline Pfaff, A.B. (2002), S. 195 & $\begin{array}{l}2050 \\
(2040)\end{array}$ & $\begin{array}{l}20,2 \% \\
(18,5 \%)\end{array}$ & $\begin{array}{l}\text { Ausgaben steigen differenziert nach Altersgrup- } \\
\text { pen stärker als die Einnahmen, steigende Frauen- } \\
\text { erwerbsbeteiligung, Rentenniveau sinkt auf } 64 \% \\
\text { im Jahr 2030; 9. koordinierte Bevölkerungsvor- } \\
\text { ausberechnung }\end{array}$ \\
\hline $\begin{array}{l}\text { Dudey, S. (1993), S. 35f., } \\
\text { Anhang, S. } 12\end{array}$ & 2030 & $26,4 \%$ & $\begin{array}{l}\text { Fortschreibung der bisherigen Ausgaben- und } \\
\text { Einnahmenentwicklung (Ausgaben steigen um } \\
1,25 \text { Prozentpunkte p.a. stärker als die beitrags- } \\
\text { pflichtigen Einnahmen); 7. koordinierte Bevölke- } \\
\text { rungsvorausberechnung }\end{array}$ \\
\hline $\begin{array}{l}\text { Oberdieck, V. (1998), } \\
\text { S. 135f. }\end{array}$ & $\begin{array}{l}2040 \\
(2030)\end{array}$ & $\begin{array}{l}31,2 \% \\
(24,8 \%)\end{array}$ & $\begin{array}{l}\text { Fortschreibung der bisherigen Ausgaben- und } \\
\text { Einnahmenentwicklung (Ausgaben AKV }+3,81 \% \\
\text { p.a., KVdR }+6,52 \% \text { p.a.; beitragspflichtige Ein- } \\
\text { nahmen AKV }+4,0 \% \text { p.a., KVdR }+3,05 \% \text { p.a.); } \\
\text { 8. koordinierte Bevölkerungsvorausberechnung }\end{array}$ \\
\hline Postler, A. (2003), S. 20 & \begin{tabular}{|l|}
2050 \\
$(2040)$
\end{tabular} & \begin{tabular}{|l|}
$38,1-39,5 \%$ \\
$(31,0-32,0 \%)$
\end{tabular} & $\begin{array}{l}\text { Fortschreibung der Ausgaben- und Einnahmen- } \\
\text { entwicklung (Ausgaben AKV }+3,50 \% \text { p.a., KVdR } \\
+5,51 \% \text { p.a.; Beitragspflichtige Einnahmen AKV } \\
+3,27 \% \text { p.a., KVdR }+3,53 \% \text { p.a.); } 9 \text {. koordinierte } \\
\text { Bevölkerungsvorausberechnung }\end{array}$ \\
\hline SVR (2004), Tabelle 52 & \begin{tabular}{|l|}
2050 \\
$(2040)$ \\
\end{tabular} & $\begin{array}{l}18,3-19,8 \% \\
(17,4-18,6 \%)\end{array}$ & $\begin{array}{l}\text { Fortschreibung der Ausgaben- und Einnahmen- } \\
\text { entwicklung, Basisszenario (Ausgaben je Ver- } \\
\text { sicherten }+3,70 \% \text { p.a.; beitragspflichtige Einnah- } \\
\text { men je Versicherten }+3,0 \% \text { p.a.); } 10 \text {. koordinierte } \\
\text { Bevölkerungsvorausberechnung, GMG }\end{array}$ \\
\hline SVR (2004), Tabelle 52 & $\begin{array}{l}2050 \\
(2040)\end{array}$ & $\begin{array}{l}27,8-31,6 \% \\
(23,4-25,8 \%)\end{array}$ & $\begin{array}{l}\text { Fortschreibung der Ausgaben- und Einnahmen- } \\
\text { entwicklung, Versteilerungsszenario (Ausgaben je } \\
\text { Versicherten }+4,70 \% \text { p.a.; beitragspflichtige Ein- } \\
\text { nahmen je Versicherten }+3,0 \% \text { p.a.); } 10 \text {. koordi- } \\
\text { nierte Bevölkerungsvorausberechnung, GMG }\end{array}$ \\
\hline SVR (2004), Tabelle 52 & \begin{tabular}{|l|}
2050 \\
$(2040)$
\end{tabular} & $\begin{array}{l}44,5-50,4 \% \\
(33,9-37,3 \%)\end{array}$ & $\begin{array}{l}\text { Fortschreibung der Ausgaben- und Einnahmen- } \\
\text { entwicklung, Versteilerungsszenario (Ausgaben je } \\
\text { Versicherten }+4,70 \% \text { p.a.; beitragspflichtige Ein- } \\
\text { nahmen je Versicherten }+2,0 \% \text { p.a.); } 10 \text {. koor- } \\
\text { dinierte Bevölkerungsvorausberechnung, GMG }\end{array}$ \\
\hline SVR (2003), Kasten 8 & $\begin{array}{l}2050 \\
(2030)\end{array}$ & $\begin{array}{l}22,8 \% \\
(18,5 \%)\end{array}$ & $\begin{array}{l}\text { Gleichgewichtsmodell mit überlappenden Genera- } \\
\text { tionen in einer offenen Volkswirtschaft; Pro-Kopf- } \\
\text { Ausgaben }+0,7 \% \text { p.a.; } 10 . \text { koordinierte Bevölke- } \\
\text { rungsvorausberechnung }\end{array}$ \\
\hline $\begin{array}{l}\text { Breyer, F.; Ulrich, V. } \\
(2000), \text { S. } 14\end{array}$ & \begin{tabular}{|l|}
2040 \\
$(2030)$ \\
\end{tabular} & \begin{tabular}{|l|}
$23,1 \%$ \\
$(20,7 \%)$
\end{tabular} & $\begin{array}{l}\text { Regressionsanalyse mit Wechselwirkungen } \\
\text { zwischen medizinisch-technischem Fortschritt und } \\
\text { demographischer Entwicklung; 8. koordinierte } \\
\text { Bevölkerungsvorausberechnung }\end{array}$ \\
\hline $\begin{array}{l}\text { Breyer, F. u.a. }(2001) \text {, } \\
\text { S. } 114\end{array}$ & 2040 & \begin{tabular}{|l|}
$34,0 \%$ \\
$(22,6 \%$ ohne \\
medizinisch- \\
technischen \\
Fortschritt) \\
\end{tabular} & $\begin{array}{l}\text { Regressionsanalyse; Produktivitätswachstum } \\
2,1 \% \text { p.a.; medizinisch-technischer Fortschritt } \\
\text { 1,0\% p.a.; veränderte Altersstruktur vergleichbar } \\
\text { 9. koordinierte Bevölkerungsvorausberechnung }\end{array}$ \\
\hline
\end{tabular}

Quelle: Eigene Zusammenstellung in Anlehnung an Enquete-Kommission Demographischer Wandel (2002), S. $191 f$. 
Berechnungen, die ausschließlich die Veränderung der Bevölkerung berücksichtigen und von Veränderungen der Ausgaben und Einnahmen absehen, kommen je nach den getroffenen Annahmen zu einem demographisch bedingten Beitragssatzanstieg auf bis zu 19,2\%. Eine Untersuchung von Breyer u.a. ${ }^{436}$, die auf der Einnahmenseite zusätzlich den Rückgang des Rentenniveaus um bis zu $20 \%$ berücksichtigt, kommt auf einen Beitragssatz von bis zu 20,3\% im Jahr 2050. Dabei dürfte der Beitragssatzanstieg aber unterschätzt sein. Da die Ausgaben für Ältere schneller steigen als für Jüngere ${ }^{437}$, ist die Annahme konstanter Ausgaben und damit auch stabiler Ausgabenrelationen unrealistisch.

Diese Kritik wird bei Analysen berücksichtigt, in denen Einnahmen und Ausgaben fortgeschrieben werden. Sie weisen je nach den unterstellten Veränderungsraten Beitragssätze zwischen 20,2 \% und 50,4 \% für das Jahr 2050 aus. Dabei fällt insbesondere die Schätzung von Prognos ${ }^{438}$ aus dem Rahmen. Unter der Annahme, die Ausgaben wüchsen entsprechend den Einnahmen, wird ein Beitragssatz zwischen $15,4 \%$ und $15,9 \%$ im Jahr 2040 ermittelt.

Regressionsanalysen, die Wechselwirkungen zwischen demographischem Wandel und medizinisch-technischem Fortschritt berücksichtigen, kommen je nach Ausmaß des medizinisch-technischen Fortschritts zu Beitragssätzen von 22,6\% (ohne medizinisch-technischen Fortschritt) und 34,0 \% (mit Fortschritt) im Jahr 2040.

Die in Tabelle 14 zusammengestellten Modellrechnungen weisen aufgrund von Unterschieden in der Methodik der Beitragssatzberechnung sowie der Annahmen über demographische Entwicklung, medizinisch-technischen Fortschritt, Erwerbstätigkeit etc. unterschiedliche Beitragssätze aus. Daran zeigt sich, wie sensitiv die Modellrechnungen auf die Annahmen reagieren und mit welchen Unsicherheiten Beitragssatzprojektionen behaftet sind. Dies trifft vor allem für den medizinisch-technischen Fortschritt zu. Sensitivitätsanalysen zeigen, dass von diesem erhebliche Beitragssatzsteigerungen ausgehen können, die noch größer sind als der demographisch bedingte Beitragssatzanstieg. ${ }^{439}$ In Tabelle 14 handelt es sich um keine Prognosen, die versuchen, die tatsächliche Entwicklung vorauszusagen, sondern lediglich um Projektionen des Beitragssatzes unter bestimmten Annahmen. Die ermittelten Beitragssätze sind nur von beschränkter Aussagekraft, da es sich größtenteils um Status quo-Projektionen handelt, die von Reaktionen der Politik auf steigende Ausgaben und sinkende Einnahmen absehen. ${ }^{440}$ Dennoch legen die Berechnungen den Handlungsbedarf offen: Die Projektionen zeigen alle einen deutlichen Beitragssatzanstieg, dessen Ausmaß lediglich umstritten ist.

\footnotetext{
${ }^{436}$ Siehe Breyer, F. u.a. (2001), S. 97ff., 105.

${ }^{437}$ Siehe Abschnitt 2.2.1 Medizinisch-technischer Fortschritt, S. 106.

${ }^{438}$ Siehe Prognos (Hrsg.) (1998), S. 83ff., 90. Zur Kritik an der Vorgehensweise siehe SVR (2000), Kasten 6; Breyer, F.; Ulrich, V. (2000), S. $2 f f$.

${ }^{439}$ Vgl. Werding, M.; Kaltschütz, A. (2005), S. $111 \mathrm{ff}$.

${ }^{440}$ Ausnahme sind die Berechnungen von Prognos, die eine einnahmenorientierte Ausgabenpolitik unterstellen. 


\section{Ziele einer Reform}

\section{GKV-Modernisierungsgesetz nicht hinreichend}

Die derzeitige Finanzierung der GKV ist beschäftigungs- und wachstumsfeindlich und führt zu unerwünschten Verteilungswirkungen. Die Einnahmen sind zudem konjunkturreagibel. $\mathrm{Zu}$ diesen Problemen kommt hinzu, dass die GKV auf die demographische Entwicklung und den medizinisch-technischen Fortschritt nicht vorbereitet ist. Werden keine Reformen auf der Einnahmenseite eingeleitet, steigt zwangsläufig der Beitragssatz oder Gesundheitsleistungen müssen rationiert werden. Während Ersteres aus verteilungs-, beschäftigungs- und wachstumspolitischen Gründen abzulehnen ist, ist Zweites insbesondere aus sozialpolitischen und ethischen Gründen problematisch.

Einige Autoren ${ }^{441}$ halten einen Beitragssatzanstieg für unproblematisch. Ein Beitragssatzanstieg könne aus dem Wachstum des Pro-Kopf-BIP finanziert werden. Nach Angaben der Rürup-Kommission wächst das BIP pro Kopf von 2002 bis 2040 um $92,9 \%$, während der Anteil der über 65jährigen in diesem Zeitraum um 76,3\% ansteigt. Steigende Sozialversicherungsbeiträge bedeuteten nicht zwangsläufig eine reale Mehrbelastung, sie sorgten nur dafür, dass die Einkommen weniger wüchsen.

Selbst wenn sich aber in Deutschland die Produktivität und das Pro-Kopf-Einkommen der Erwerbstätigen nahezu verdoppeln, kann das für die Finanzierung der GKV maßgebliche gesamte Volkseinkommen nach Birg ${ }^{42}$ aufgrund der sinkenden Zahl der 20- bis 60jährigen nur um ein Drittel zunehmen. Zudem vernachlässigt diese Betrachtungsweise die mit dem Alter steigenden Ausgaben und sinkenden Beiträge und die Wirkungen des medizinisch-technischen Fortschritts auf die Ausgaben. Außerdem weist die Nachfrage nach Gesundheitsleistungen eine Einkommenselastizität von über eins auf ${ }^{443}$, so dass mit einem überproportionalen Anstieg der Nachfrage nach Gesundheitsleistungen zu rechnen ist. Unter ökonomischen Gesichtspunkten sind steigende Gesundheitsausgaben nicht problematisch, wenn sie den Präferenzen der Wirtschaftssubjekte entsprechen und die Finanzierung auf einer freien Entscheidung beruht. Dies ist in der GKV aber nicht der Fall, da die Einnahmen in Form von Zwangsbeiträgen erhoben werden. Die Finanzierung und die damit verbundenen Wirkungen werden im demographischen Wandel noch problematischer. Kommt zu dem enwarteten Beitragssatzanstieg in der Gesetzlichen Rentenversicherung und in der Gesetzlichen Pflegeversicherung ein Anstieg des Beitragssatzes zur GKV hinzu, dann steigt der Abgabenkeil zusätzlich. Die daraus resultierende einseitige Belastung kommender Erwerbstätigengenerationen werden Wachstum und Beschäftigung und damit auch die Finanzgrundlage der GKV negativ beeinflussen.

Das GKV-Modernisierungsgesetz (GMG) vom 14.11.2003 ${ }^{444}$ gibt keine Antwort auf die demographische Herausforderung. ${ }^{445}$ Die Reform sieht für die Versicherten auf

\footnotetext{
${ }^{441}$ Siehe Nürnberger, I.; Stapf-Finé, H. (2004), S. 43; Hein, E. u.a. (2004), S. 298; Deml, J. (2002), S. 417; Shiller, R. (2003), S. 9.

442 Siehe Birg, H. (2004a), S. 39.

${ }^{443}$ Siehe Hof, B. (2001), S. 29.

${ }^{444}$ Siehe BGBI. 2003, Teil I, Nr. 55, S. 2229.

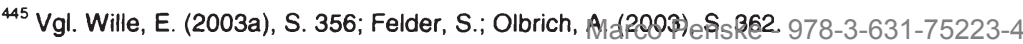


der Ausgabenseite die Ausgrenzung bestimmter Leistungen (z.B. Sterbegeld, nicht verschreibungspflichtige Arzneimittel) in Höhe von jährlich insgesamt 2,5 Mrd. Euro $^{446}$ vor. Struktureffekte sind aus der Zulassung des Versandhandels von Arzneimitteln, der Stärkung von Hausarztmodellen und der Schaffung von medizinischen Behandlungszentren zu erwarten. Durch die Öffnung von Krankenhäusern für ambulante Leistungen bei einer regionalen Unterversorgung und weitere Möglichkeiten für die Kassen, ihren Versicherten Boni, Prämien und Rabatte anzubieten, wird der Wettbewerb zwischen den Leistungserbringern und zwischen den Kassen zunehmen. Insgesamt wird der Wettbewerb im Gesundheitssystem aber nur unzureichend gestärkt $^{447}$, so dass nur geringe Effekte auf der Ausgabenseite zu erwarten sind.

Auf der Einnahmenseite sind neben der bereits erläuterten Einführung eines Bundeszuschusses $^{448}$ im Wesentlichen vier Neuerungen für die GKV von Bedeutung:

1. Im Rahmen des GMG wird durch $\S 28$ Abs. 4 SGB V in der GKV eine sogenannte Praxisgebühr eingeführt. Pro Quartal müssen Versicherte beim ersten Arztbesuch 10 Euro zahlen. Die Gebühr entfällt bei einer Überweisung oder Vorsorgeuntersuchung nach $\S 25$ SGB V. Darüber hinaus sind insbesondere folgende neue Zuzahlungsregeln zu erwähnen: Gemäß § 31 Abs. 3 SGB V wird die Zuzahlung für Arznei- und Verbandmittel je nach Packungsgröße von 4, 4,50 oder 5 Euro auf $10 \%$ des Abgabepreises, mindestens jedoch 5 Euro und höchstens 10 Euro, soweit die Zuzahlung die Kosten des Mittels nicht übersteigt, erhöht. Hinzu kommen höhere Zuzahlungen für Krankenhausbehandlung. Anstelle von maximal 14 Tage lang 9 Euro pro Tag, werden täglich 10 Euro an bis zu 28 Tagen fällig ( 39 Abs. 4 SGB V). Insgesamt sollen die neuen Zuzahlungsregelungen neben Lenkungseffekten jährliche Einnahmen von 3,2 Mrd. Euro ${ }^{449}$ für die GKV bringen. Obwohl davon nur rund 0,4 Mrd. Euro ${ }^{450}$ auf die Praxisgebühr entfallen dürtten, ist insbesondere die Praxisgebühr auf große Kritik gestoßen.

2. Pflichtversicherte ${ }^{451}$ müssen ab dem Jahr 2004 auf Versorgungsbezüge (z.B. Betriebsrenten, Zahlungen aus Direktversicherungen) gemäß § 248 Satz 1 SGB V nicht mehr den halben, sondern den vollen allgemeinen Beitragssatz ihrer Kasse zahlen. Als Einmalauszahlung gewährte Versorgungsbezüge werden zudem nach $\S 229$ Abs. 1 Satz 3 SGB V verteilt auf zehn Jahre beitragspflichtig. Zuvor waren diese nur dann beitragspflichtig, wenn die Versorgungs-

\footnotetext{
${ }^{446}$ Siehe Bundestags-Drucksache 15/1525 vom 08.09.2003, S. 171.

${ }^{447} \mathrm{Vgl}$. Deutsche Bundesbank (Hrsg.) (2004a), S. 23ff.; Felder, S.; Olbrich, A. (2003), S. 362.

${ }^{448}$ Siehe Kapitel II.3.1 Beitragserhebung, S. 27.

449 Siehe Bundestags-Drucksache 15/1525 vom 08.09.2003, S. 171.

${ }^{450}$ Eigene Berechnung; im ursprünglichen Gesetzentwurf wurde bei einer Praxisgebühr von 15 Euro mit Mehreinnahmen von 0,6 Mrd. Euro gerechnet; siehe Bundestags-Drucksache 15/1170 vom 16.06.2003, S. 6, 143.

${ }^{451}$ Freiwillig in der GKV versicherte Erwerbstätige und Rentner haben bereits vorher auf Versorgungsbezüge den vollen Beitragssatz gezahlt. Für diese Versicherten, die keinen Anspruch auf Krankengeld haben, galt allerdings der ermäßigte Beitragssatz. Nach dem GMG müssen auch freiwillig versicherte Rentner ab 2004 den allgemeinen Beitragssatz ihrer Krankenkassen zahlen - ohne Anspruch auf die Zahlung von Krankengeld zu haben. Zu den einzelnen Regelungen siehe BMGS (Hrsg.) (2004b), S. 28. 
bezüge nach Eintritt des Versicherungsfalls (z.B. Erwerbsminderung) durch eine Einmalzahlung ersetzt wurden. Die Mehreinnahmen wurden auf jährlich $1,6 \mathrm{Mrd}$. Euro ${ }^{452}$ bis 2,0 Mrd. Euro ${ }^{453}$ geschätzt. Tatsächlich lagen die Mehreinnahmen 2004 aber bei 0,7 Mrd. Euro. ${ }^{454}$ Die volle Beitragspflicht ist unter Leistungsfähigkeits- und Äquivalenzaspekten zu begrüßen, weil auch Versorgungsbezüge in vollem Umfang die Leistungsfähigkeit erhöhen bzw. die durchschnittlichen Ausgaben für Rentner über deren Beiträgen liegen. Problematisch ist, dass nach dem Altersvermögensgesetz ${ }^{455}$ Beiträge zur betrieblichen Altersvorsorge - sofern sie Beträge aus einer Entgeltumwandlung enthalten - gemäß § 115 SGB IV nur bis zum Jahr 2009 sozialabgabenfrei sind. Anschließend würde auf Einkommen, für das bereits GKV-Beiträge entrichtet wurden, nach dem GMG bei der Auszahlung auf das eingezahlte Kapital ein zweites Mal Beiträge erhoben werden. ${ }^{456}$ Dies wäre ein Verstoß gegen das auch für die GKV geltende Korrespondenzprinzip, wonach auf beitragspflichtiges Einkommen einmal, aber auch nur einmal Beiträge zu erheben sind. ${ }^{457}$

3. Ab 2006 müssen nach $\S 241$ a SBG V alle Mitglieder einen kasseneinheitlichen Sonderbeitragssatz von $0,5 \%$ der beitragspflichtigen Einnahmen zahlen. Begründet wurde diese Maßnahme anfangs mit der Finanzierung des Krankengelds. Die Aufhebung der paritätischen Finanzierung für das Krankengeld lässt sich mit der Belastung der Arbeitgeber durch die Lohnfortzahlung im Krankheitsfall durchaus rechtfertigen. Jedoch wird dann für die letzte am Äquivalenzprinzip orientierte Ausgabe die paritätische Finanzierung aufgehoben, von der die geringsten Verzerrungen auf dem Arbeitsmarkt ausgehen. ${ }^{458}$ Gerade zur Finanzierung des Krankengelds sind lohnbezogene Beiträge adäquat. Im Gesetzestext wird das Krankengeld indes nicht erwähnt. ${ }^{459}$ Anderenfalls hätte der Sonderbeitrag für Rentner, die keinen Anspruch auf Krankengeld haben, kaum gerechtfertigt werden können. ${ }^{460} 5 \mathrm{Mrd}$. Euro ${ }^{461}$ sollen die Kassen ab dem Jahr 2006 zusätzlich einnehmen. An den Ausgaben der GKV ändert sich durch die Umfinanzierung nichts; die Zahlung von Krankengeld bleibt weiter Bestandteil des Leistungskatalogs der GKV. Insofern hätte man auch andere Ausgaben benennen können, um von den Mitgliedern zu-

\footnotetext{
${ }^{452}$ Siehe Bundestags-Drucksache 15/1525 vom 08.09.2003, S. 171.

${ }^{453}$ Siehe SVR (2004), Ziff. 331.

${ }^{454} \mathrm{Vgl}$. Institut der deutschen Wirtschaft (Hrsg.) (2005a), S. 2.

${ }^{455}$ Siehe BGBI. 2001, Teil I, Nr. 31, S. 1310.

${ }^{456}$ Vgl. Rürup, B. (2004), S. 3. Siehe hierzu auch SVR (2004), Ziff. 331.

${ }^{457}$ Siehe hierzu ausführlich Bieback, K.-J. (2004), S. $294 \mathrm{ff}$.

${ }^{458}$ Vgl. Felder, S.; Olbrich, A. (2003), S. 362.

${ }^{459}$ Dass ausgerechnet das Krankengeld ausgewählt wurde, ist vermutlich darauf zurückzuführen, dass Bundeskanzler Gerhard Schröder in seiner Regierungserklärung am 14.03.2003 die Privatisierung der Krankengeldversicherung in Aussicht gestellt hatte. „Anders beurteile ich die Frage der privaten Vorsorge im Hinblick auf das Krankengeld. Hier handelt es sich um einen klar abgrenzbaren Kostenblock, der auch für die Zukunft überschaubar bleibt. Die Kostenbelastung für den Einzelnen durch eine private Versicherung bliebe beherrschbar. Medizinisch notwendige Leistungen würden nicht berührt." Schröder, G. (2003), S. 14.

${ }^{460}$ Vgl. SVR (2003), Ziff. 294; SVR (2004), Ziff. 337; SVR (2005), Ziff. 472.

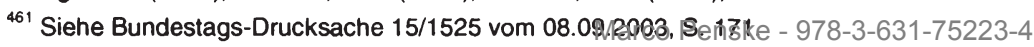


sätzliche Beiträge zu erheben und die Beteiligung der Arbeitgeber zu reduzieren.

4. Nach dem GMG sollten ursprünglich Zahnersatzleistungen ab 2005 aus dem Leistungskatalog herausgenommen werden, die Versicherungspflicht aber bestehen bleiben. Die Versicherten hätten den Zahnersatz entweder bei ihrer gesetzlichen Kasse zu einer bundeseinheitlichen Pauschale oder bei einer privaten Krankenversicherung versichern können. Das Einsparpotential der GKV wurde auf jährlich 3,5 Mrd. Euro ${ }^{462}$ beziffert. Damit wäre für einen Teil der Leistungen der GKV die Lohnbezogenheit der Beiträge aufgehoben worden, da der Beitrag für die Zahnersatzversicherung als Pauschale erhoben worden wäre.

Die Ausgliederung des Zahnersatzes wurde mit dem Gesetz zur Anpassung der Finanzierung von Zahnersatz vom 15.12.2004 ${ }^{463}$ wieder rückgängig gemacht. Begründet wurde dies mit Problemen beim Beitragseinzug von Rentnern und Arbeitslosen; die Verwaltungskosten hätten für diese rund 20 Mio. Versicherten angeblich 250 Mio. Euro betragen. Zudem hätte ein eigener Finanzausgleich nach der Systematik des Risikostrukturausgleichs für den Bereich Zahnersatz eingeführt werden müssen. Auch befürchtete man eine übermäßige Belastung von Geringverdienern. ${ }^{464}$ Entscheidend für die Rücknahme dürfte allerdings gewesen sein, dass die SPDgeführte Bundesregierung kein Präzedenzfall für die Ersetzung einkommensabhängiger Beiträge durch Pauschal-Beiträge schaffen wollte; zumal die CDU gleichzeitig forderte, die Finanzierung der GKV auf pauschale Beiträge umzustellen. ${ }^{465}$

Stattdessen wird entsprechend der Krankengeldfinanzierung die paritätische Finanzierung weiter reduziert. Der Zahnersatz bleibt Leistung der GKV, dafür zahlen die Mitglieder ab 01.07.2005 einen zusätzlichen Beitrag in Höhe von 0,4 Prozentpunkten. Um die beabsichtigten Beitragssatzsenkungen dennoch zu erreichen, muss zudem der Sonderbeitrag von 0,5 Prozentpunkten ebenfalls ab 2005 gezahit werden, so dass Arbeitnehmer, freiwillig Versicherte und Rentner einen zusätzlichen Beitragssatz von $0,9 \%$ zu tragen haben. $\S 241 a$ SGB $\vee$ wurde entsprechend geändert und mit der Vorgabe ergänzt, dass der allgemeine Beitragssatz um 0,9 Prozentpunkte sinken soll. Bezogen auf den allgemeinen Beitragssatz von $14,2 \%$ bedeutet die Neuregelung, dass zunächst der Beitragssatz um 0,9 Prozentpunkte sinkt, was den $\mathrm{Ar}$ beitgeberanteil auf $6,65 \%$ reduziert und die Arbeitgeber um 4,5 Mrd. Euro p.a. entlastet. Für den Arbeitnehmer steigt der Beitragssatz um 0,45 Prozentpunkte auf $7,55 \%$. Bei geringfügig Beschäftigten gilt der zusätzliche Beitragssatz nicht ( $\$ 249 \mathrm{~b}$ SGB V), in der Gleitzone ist der zusätzliche Beitrag nach § 249 Abs. 4 SGB V vom Arbeitnehmer zu zahlen. Bei Empfängern von Arbeitslosengeld II wird der zusätzliche Beitragssatz ab 01.10.2005 erhoben (§ 246 SGB V). Da die Beiträge in voller Höhe vom Bund getragen werden, ändert sich für den Leistungsempfänger nichts. Die Einnahmen der GKV steigen aber in Höhe des zusätzlichen Beitrags, weil der ermäBigte Satz aufgrund der Ausnahmeregelung in § 241a Abs. 2 SGB V für Empfänger

\footnotetext{
${ }^{462}$ Siehe Bundestags-Drucksache 15/1525 vom 08.09.2003, S. 171.

${ }^{463}$ Siehe BGBI. 2004, Teil I, Nr. 69, S. 3445.

${ }^{464} \mathrm{Vgl}$. Bundestags-Drucksache 15/3834 vom 29.09.2004, S. 1.

${ }^{465}$ Vgl. ausführlich SVR (2004), Ziff. 336f.
}

Marco Penske - 978-3-631-75223-4 
von Arbeitslosengeld II nicht gesenkt wird. Für Bezieher von Sozialhilfe und Arbeitslosengeld ändert die Neuregelung nichts; der Sozialhilfeträger bzw. die Bundesagentur für Arbeit zahlen weiterhin den gleichen Beitrag an die GKV.

Die paritätische Finanzierung hätte auch ohne Hinweis auf eine neue Versicherung für den Zahnersatz aufgehoben werden können, so ist in der Neuregelung im SGB V der Zahnersatz auch nicht enwähnt. Mit der jetzt getroffenen Regelung steigt die Intransparenz weiter. Problematisch ist zudem, dass die im Gesetz im Gegenzug zum Sonderbeitrag vorgesehene Beitragssatzsenkung kaum durchsetzbar ist, weil die Krankenkassen ihren Beitragssatz selbst festlegen. Positive Beschäftigungswirkungen sind von der Neuregelung kaum zu erwarten, da hierfür der Gesamtabgabenkeil und nicht die Verteilung der Abgabenlast entscheidend ist. Niedrigere Beitragssätze führen zwar zu einem niedrigeren Produzentenlohn und grundsätzlich zu einer steigenden Arbeitsnachfrage, so dass es kurzfristig zu Beschäftigungseffekten kommen kann. Langfristig sind indes Zweitrundeneffekte entscheidend. Gelingt es den Gewerkschaften, in Lohnverhandlungen höhere Lohnsteigerungen durchzusetzen, um die Einkommensverluste aufgrund höherer Krankenversicherungsbeiträge zu kompensieren, steigen die Arbeitskosten wieder, was die Beschäftigung tendenziell reduziert. Hierzu kann es auch kommen, wenn infolge der Lohneinbußen das Arbeitsangebot sinkt und es dadurch zu steigenden Löhnen kommt. Modelltheoretisch lassen sich diese Zusammenhänge anhand der Irrelevanz der Zahllast zeigen. In der Steuerinzidenzanalyse hängt die ökonomische Traglast nicht von der Zahllast ab; Verschiebungen der Zahllast - hier der Parität - haben demnach keine Beschäftigungswirkungen. ${ }^{466}$

Ziel des GMG und der damit verbundenen Maßnahmen war die Reduktion des durchschnittlichen Beitragssatzes zur GKV von $14,3 \%$ (2003) auf $13,6 \%$ im Jahr 2004, 12,95\% im Jahr 2005 und 12,15\% für die Jahre 2006 und $2007 .{ }^{467}$ Diese Beitragssätze sind nicht mehr zu erreichen. Im Jahr 2004 konnten die Kassen zwar einen Überschuss von $4 \mathrm{Mrd}$. Euro verbuchen, der Beitragssatz sank aber nur leicht auf 14,2\%, da die Überschüsse größtenteils zum Abbau der Verschuldung genutzt wurden und die Einnahmen nur gering wuchsen. ${ }^{468}$ Wegen der Beibehaltung von Umlageverfahren und Lohnkoppelung werden zudem die mit der Beitragserhebung verbundenen Probleme nicht gelöst. Eine nachhaltige Reform der Finanzierung der GKV hat mit dem GMG nicht stattgefunden und ist weiterhin notwendig.

\section{Fiskalische Reformziele}

Die Reduzierung des Beitragssatzes sollte nicht das Hauptziel einer Reform, sondern im derzeitigen Finanzierungssystem höchstens kurzfristiges Ziel sein, um die Arbeitskosten zu senken. Unter fiskalischen Gesichtspunkten muss eine Finanzreform langfristig ausreichende Einnahmen zur Finanzierung der Versorgung der Versicherten mit Gesundheitsleistungen sicherstellen. Dabei ist aufgrund der demographischen

\footnotetext{
${ }^{466}$ Vgl. SVR (2003), Ziff. 331; SVR (2004), Ziff. 337, Kasten 18.

${ }^{467}$ Siehe Bundestags-Drucksache 15/1525 vom 08.09.2003, S. 172.

${ }^{468} \mathrm{Vgl}$. Institut der deutschen Wirtschaft (Hrsg.) (2005a), S. 2; BMGS (Hrsg.) (2005a), S. 1f.; SVR (2005), Ziff. 473. 
Entwicklung und des medizinisch-technischen Fortschritts von einem steigenden Finanzbedarf auszugehen. Für eine nachhaltige Finanzierung muss daher die Frage, wie die Ausgaben langfristig finanziert und damit auch verteilt werden sollen, in den Mittelpunkt der Betrachtung rücken.

Die Finanzwissenschaft kennt zwei Fundamentalprinzipien der Abgabenerhebung das Leistungsfähigkeitsprinzip und das Äquivalenzprinzip. Da sich in der GKV Elemente beider Prinzipien befinden, baut die Finanzierung auf keiner konsistenten ökonomischen Theorie auf, nach deren Vorgaben eine optimale Finanzierung hergeleitet werden könnte. ${ }^{469}$ In Bezug auf die GKV wird überwiegend vom Solidarprinzip gesprochen, das auf die Ausgaben- und Einnahmenseite abstellt. Auf der Einnahmenseite kommt in der GKV größtenteils das Leistungsfähigkeitsprinzip, das mit dem Solidarprinzip korrespondiert, zum Tragen. Derzeit ist die Finanzierung der GKV zusammen mit der Gesetzlichen Pflegeversicherung der Zweig in der Sozialversicherung, der am meisten von dem dem Äquivalenzprinzip entsprechenden Versicherungsprinzip abweicht. Während in der gesetzlichen Renten- und Arbeitslosenversicherung die individuelle Leistungsgewährung trotz zahlreicher Umverteilungen letztendlich von der Beitragshöhe abhängt, gilt dies in der GKV nur für das Krankengeld. Alle anderen Leistungen werden unabhängig von der Beitragszahlung erbracht. Grundsätzlich sind beide Prinzipien zur Finanzierung der GKV geeignet und verfassungsrechtlich wohl unbedenklich. Das Leistungsfähigkeitsprinzip entspricht zwar eher dem in Art. 20 und 28 GG postulierten Sozialstaatsprinzip, aber auch das Äquivalenzprinzip folgt dem Gerechtigkeitsgedanken, da es die Beitragserhebung an die (erwartete) Inanspruchnahme koppelt. ${ }^{470}$

An welchem Prinzip sich eine Reform orientieren sollte, ist bei den politischen Entscheidungsträgern umstritten. Richtet sich eine Reform einseitig nach dem Leistungsfähigkeitsprinzip, wird die Grenze zur Einkommensteuer fließend, da sich Leistungsfähigkeit nicht partiell, sondern nur umfassend unter Berücksichtigung aller Einkünfte nach dem Nettoprinzip bestimmen lässt. ${ }^{471}$ "Eine ausschließliche Orientierung der GKV am Leistungsfähigkeitsprinzip mündet zwangsläufig in eine (einkommen-)steuerfinanzierte Gesundheitsversorgung in Verbindung mit einer Einheitskasse.“472 Eine am Äquivalenzprinzip orientierte Reform hingegen bringt die GKV dem in der privaten Krankenversicherung praktizierten Versicherungsprinzip näher und führt letztendlich zu einer privaten Pflichtversicherung mit risikoäquivalenten Prämien. Die GKV sollte deshalb nach Auffassung des Sachverständigenrates für die konzertierte Aktion im Gesundheitswesen als soziale Versicherung beide Prinzipien verknüpfen. ${ }^{473}$ Damit folgt der Sachverständigenrat der in zahlreichen Untersuchungen $^{474}$ festgestellten Zustimmung der Bevölkerung zu einem umfassenden Solidarprinzip in der GKV, das neben der versicherungsimmanenten Umverteilung auch z.B. die Unterstützung von Beziehern niedriger Einkommen durch Bezieher hoher

\footnotetext{
${ }^{469} \mathrm{Vgl}$. SVR KAiG (2003), Ziff. $37 \mathrm{f}$.

${ }^{470}$ Vgl. SVR KAiG (1995), Ziff. 566; SVR KAiG (1994), Ziff. 468; Bieback, K.-J. (2005), S. $132 f f$.

${ }^{471} \mathrm{Vgl}$. Bofinger, P. (2003), S. 10. Siehe hierzu auch Wissenschaftlicher Beirat beim Bundesministerium der Finanzen (2004), S. $5 f$.

${ }^{472}$ SVR KAiG (2003), Ziff. 37.

${ }^{473}$ Vgl. SVR KAiG (1995), Ziff. 564; SVR KAiG (2003), Ziff. $37 f$.

${ }^{474}$ Für eine Übersicht siehe SVR KAiG (2003), Ziff. 42ff:Marco Penske - 978-3-631-75223-4
} 
Einkommen, Verheirateter und Familien durch Alleinstehende oder Älterer durch Jüngere vorsieht.

Aus ökonomischen Gründen sollte jedoch mit einer Reform das Äquivalenzprinzip verfolgt werden ${ }^{475}$, was den Versicherungsgedanken stärken und den Steuercharakter schwächen würde. In dem Maße, in dem Krankenversicherungsbeiträge als Steuern empfunden werden, entstehen Wohlfahrtsverluste, wenn die Versicherten ihr Arbeitsangebot reduzieren oder auf ein nicht sozialversicherungspflichtiges Arbeitsverhältnis bzw. eine illegale Beschäftigung ausweichen. ${ }^{476}$

Mit einer Stärkung des Äquivalenzprinzips würde die GKV auf ihre eigentliche Aufgabe - die Absicherung gegen die mit Krankheit verbundenen Kosten konzentriert. ${ }^{477}$ Die Versicherten könnten den Versicherungsumfang anhand ihrer Zahlungsbereitschaft selbst bestimmen. Diejenigen (z.B. Bezieher niedriger Einkommen, Ältere), deren Versicherungsbeitrag eine dann noch zu definierende zumutbare Eigenbelastung übersteigt, erhielten einen Transfer. ${ }^{478}$ Umverteilungsaufgaben könnte das dafür konzipierte Steuer- und Transfersystem effektiver und effizienter wahrnehmen als die GKV. Die Allgemeinheit und nicht nur der Kreis der GKV-Mitglieder würde die Umverteilungen finanzieren. Zudem wären die Verteilungswirkungen transparenter als derzeit, was jedoch von einigen Politikern sicher auch als Nachteil gesehen wird. Oft wird argumentiert, dass die Undurchschaubarkeit Umverteilungen erleichtere, die sonst nicht mehrheitsfähig wären. Dieser Verstoß gegen die Präferenzen der Wirtschaftssubjekte kann jedoch nicht als Begründung für die Umverteilungsaufgabe dienen.

Für eine Trennung von Allokation und Distribution spricht: ${ }^{479}$

- Umverteilungen innerhalb des Steuer- und Transfersystems sowie der GKV führen zu zusätzlichen Transaktionskosten. Das Steuer- und Transfersystem kann effektiver und effizienter umverteilen.

- Einkommensumverteilung ist eine gesamtgesellschaftliche Aufgabe, die nicht in Teilen auf Versicherte in der GKV beschränkt sein sollte.

- Einkommensbezogene Beiträge sind mit hohen Erhebungskosten verbunden und behindern den Wettbewerb.

- Ein transparentes Umverteilungssystem ist leichter politisch zu kontrollieren; denn eine größere Transparenz erschwert es Interessenverbänden, Einfluss

\footnotetext{
${ }^{475}$ Siehe stellvertretend SVR (1996), Ziff. 380ff.; SVR (2000), Ziff. 475; Wissenschaftlicher Beirat beim Bundesministerium der Finanzen (2004), S. 9, 31; Kroker, R.; Pimpertz, J. (2005), S. 289.

${ }^{476}$ Die Mehrheit der Versicherten fasst Sozialversicherungsbeiträge als Steuern auf; vgl. BörschSupan, A. (2004), S. 77f., und die dort angegebene Literatur.

${ }^{477}$ Mit der Ankündigung von Bundessozialministerin Ulla Schmidt, „[d]ie gesetzlichen Krankenkassen werden zusätzliche Mittel bereitstellen, um über den Eigenbedarf hinaus auszubilden“, soll die GKV indes mit der Bekämpfung der Ausbildungsmisere eine weitere versicherungsfremde Aufgabe erhalten; siehe BMGS (Hrsg.) (2004e).

${ }^{478}$ Vgl. Bofinger, P. (2003), S. 10. Kontrovers hierzu Kruse, U.; Kruse, S. (2001), S. $91 f$.

${ }^{479}$ In Anlehnung an Wissenschaftlicher Beirat beim Bundesministerium der Finanzen (2004), S. 5f.; Kroker, R.; Pimpertz, J. (2005), S. 290. 
auf die Systemgestaltung zu nehmen, weil die Vorgänge von der breiten Öffentlichkeit besser beurteilt werden können.

- Die Trennung vereinfacht Reformen, da nicht mehr geprüft werden muss, welchen Einfluss eine Reform unter dem Gesichtspunkt der Umverteilung auf die jeweils anderen Teilsysteme hat.

Auch eine nach dem Äquivalenzprinzip finanzierte Krankenversicherung wäre eine Solidargemeinschaft, da ex post immer von gesunden Versicherten zu Versicherten mit Leistungsinanspruchnahme umverteilt würde (versicherungsimmanente Umverteilung). Auf der Ausgabenseite der Krankenversicherung würde zudem weiter das Solidarprinzip gelten: Jeder Versicherte erhält die medizinisch notwendige Versorgung. Die Trennung von Allokation und Distribution wird aus diesen Gründen von der Wissenschaft weitgehend einhellig gefordert. „Krankheit hat nichts mit Einkommen zu tun; man wird nicht durch eine Lohnerhöhung krank ${ }^{\star 480}$, schreibt Raffelhüschen. Die Koppelung an das Einkommen ist unsachgemäß.

\section{Nichtfiskalische Reformziele}

Die Entscheidung für eine Orientierung am Leistungsfähigkeits- oder am Äquivalenzprinzip hat auch Auswirkungen auf nichtfiskalische Zielsetzungen. Diese Ziele einer Reform werden im Folgenden nach Musgrave ${ }^{481}$ in Allokation, Distribution und Stabilisierung differenziert.

Auch wenn aus ordnungspolitischen Gründen mit den GKV-Beiträgen keine distributiven Ziele verfolgt werden sollten, sind die mit einer Reform einhergehenden Einkommensumverteilungen bedeutend für die Beurteilung eines Reformvorschlags nicht zuletzt im Hinblick auf dessen politische Durchsetzbarkeit. Dabei sind die auf dem deutschen Gesundheitssystem beruhenden Verteilungseffekte zunächst auf zwei Ebenen zu differenzieren. Zum einen Verteilungseffekte, die sich aufgrund der Trennung in GKV und PKV ergeben, und zum anderen Verteilungswirkungen innerhalb der GKV.

Die Verteilungseffekte zwischen GKV und PKV werden in der Literatur und der Politik zunehmend kritisiert: Besonders leistungsfähige Versicherte mit einem Einkommen oberhalb der Versicherungspflichtgrenze können sich in der PKV versichern und damit dem solidarischen Ausgleich in der GKV entziehen. Dies gelingt allerdings nur teilweise, da Leistungserbringer die gleiche Leistung bei einem Privatkassenpatienten zu einem höheren Preis abrechnen können, womit eine Quersubventionierung von PKV-Versicherten zu Versicherten der GKV stattfindet. Insgesamt sind die Verteilungswirkungen aber intransparent und nicht zielgenau. Plädiert man für einen $\mathrm{Er}$ halt der PKV, wäre es nahe liegend, die PKV in den RSA einzubeziehen und damit am Solidarausgleich zu beteiligen. ${ }^{482}$ Mit einer Ausweitung des Finanzausgleichs auf

${ }^{480}$ Raffelhüschen, B. (2004), S. 17.

${ }^{481}$ Siehe Musgrave, R.A. (1959), S. $5 \mathrm{ff}$.

${ }^{482}$ Vgl. ausführlich Greß, S.; Wasem, J. (2004), S. 37ff. Vgl. auch Wenzel, D. (1999), S. 103ff.; Greß, S.; Walendzik, A.; Wasem, J. (2005), S. 72. 
die PKV wären aber weitere Probleme verbunden. $\mathrm{Zu}$ den existierenden Mängeln des RSA kämen methodische Probleme bei einer Einbeziehung der PKV hinzu: ${ }^{433}$

Problematisch ist vor allem der Ausgleich der Finanzkraft. Bislang liegen der PKV keine Informationen über die Einkommen ihrer Versicherten vor. Diese Daten müssten zunächst erhoben werden. Bei Arbeitnehmern ist der Bruttolohn noch einfach zu ermitteln. Bei Selbständigen ist jedoch das in der GKV geltende Bruttoprinzip kaum durchsetzbar, da dann Betriebsausgaben unberücksichtigt blieben. Würde man deshalb bei Selbständigen zum Nettoprinzip übergehen, wären diese aber gegenüber Arbeitnehmern bevorzugt. Zur Ermittlung der Finanzkraft der Kassen müsste außerdem ein fiktiver ausgabendeckender Beitragssatz für die PKV kalkuliert werden, um daraus einen durchschnittlichen Beitragssatz für alle Kassen zu berechnen. Darüber hinaus müsste die Prämienkalkulation angepasst werden, weil die PKV Alterungsrückstellungen bildet und daher die Beiträge von GKV und PKV nicht vergleichbar sind. ${ }^{484}$ Zudem sind die Versichertenkreise unterschiedlich. In der PKV liegt Einzelversicherung vor, in der GKV gibt es auch die beitragsfreie Familienversicherung. Vom Ausgleich der Familienlasten müsste also auch die PKV profitieren, was aber kaum umsetzbar ist, weil für die PKV der Ausgleich systemfremd ist, während er in der GKV systemimmanent ist. Technisch schwierig ist die Berücksichtigung der Beiträge von Versicherten mit prozentualen Tarifen, wie sie z.B. Beamte als Ergänzung zu Beihilfeleistungen oft abschließen. Deren beitragspflichtige Einnahmen dürften demnach nicht voll angesetzt werden, was weitere Differenzierungen im RSA verlangt.

Ebenso dürften diese Versicherten wegen ihres geringeren Leistungsumfangs auch nur mit einem geringeren Ausgabenbedarf beim Finanzbedarf angesetzt werden, wodurch die Komplexität des RSA weiter steigt. Zudem müssten die in der PKV gebildeten Alterungsrückstellungen den Finanzbedarf reduzieren, um der PKV über den RSA keine höheren Ausgaben zuzurechnen, als diese aus den laufenden Prämien finanzieren müsste. Dann besteht allerdings für die PKV kein Anreiz, Alterungsrückstellungen zu bilden. Daneben verlangt der Finanzbedarfsausgleich einen einheitlichen Leistungskatalog, da ansonsten Versicherungen mit geringerem Leistungsumfang Versicherungen mit umfangreichem Leistungsangebot teilweise mitfinanzieren würden. Die PKV wäre kaum noch in der Lage, die gleichen Leistungen höher zu vergüten als die GKV. Ein Produktwettbewerb fände auch zwischen den einzelnen privaten Versicherungen nicht mehr statt.

Muss die PKV infolge einer Einbeziehung in den RSA Ausgleichszahlungen leisten, dürften diese nicht nach der PKV-Prämie auf die Mitglieder der PKV verteilt werden, da ansonsten Niedrigverdiener in der PKV Bezieher höherer Einkommen in der GKV subventionieren würden. Die PKV müsste folglich die Ausgleichszahlungen über einkommensabhängige Beiträge aufbringen - entgegen dem bisherigen Kalkulations-

${ }^{483}$ Vgl. Klose, J.; Schellschmidt, H. (2001), S. 38ff.; Breyer, F. U.a. (2001), S. 174f.; SVR (2003), Ziff. 329; Projektgruppe Bürgenversicherung des SPD-Parteivorstandes (2004), S. 55; Pfaff, M.; Stapf-Finé, H. (Hrsg.) (2004), S. 184f., 203f., 208ff.; Bieback, K.-J. (2005), S. 172ff.; Niehaus, F.; Weber, C. (2005), S. 133ff. Zur Kritik am RSA siehe Reschke, P. u.a. (2004), S. 29ff., und die dort angegebene Literatur.

${ }^{484}$ Auf die Finanzierung der PKV wird in Kapitel VI.2 Kapitaldeckungsverfahren am Beispiel der PKV (S. 214) näher eingegangen. 
prinzip. Insgesamt würde „der Charakter der GKV als Steuer-Transfer-System “485 zunehmen.

Die aus der Trennung des Versicherungsmarktes resultierenden distributiven Wirkungen lassen sich nicht durch eine Beteiligung der PKV am RSA beseitigen, weil beide Systeme vollkommen unterschiedlich gestaltet sind. Ursachenadäquat kann die Wahlfreiheit der Versicherten in Kombination mit einem fairen Wettbewerb zwischen GKV und PKV die unerwünschten Verteilungswirkungen beseitigen. Dies setzt aber eine Stärkung des Äquivalenzprinzips und lohnunabhängige Beiträge in der GKV voraus. ${ }^{486} \mathrm{Ob}$ darüber hinaus die Versicherungspflicht auf die gesamte Bevölkerung ausgeweitet werden sollte, wird in Kapitel V.3.4 Kompromissmodelle (S. 199) diskutiert.

Für die Mehrheit der GKV-Versicherten bedeutender sind die durch eine Reform ausgelösten Verteilungswirkungen innerhalb der GKV im Vergleich zum Status quo. Neben der Beseitigung intragenerativer Verteilungswirkungen (insbesondere Einkommensausgleich) sollten mit einer Reform die intergenerativen Verteilungswirkungen zumindest reduziert werden, um die GKV demographiefester zu machen. Dazu müssen die mit dem demographischen Wandel verbundenen Belastungen gleichmäBiger auf die Generationen verteilt werden (intergenerative Verteilungsgerechtigkeit). Problematisch ist dies insbesondere deshalb, weil sich der demographisch bedingte Anstieg der Versorgungslasten pro Kopf durch eine Reform kaum beseitigen, sondern nur anders verteilen lässt ${ }^{487}$ - intertemporal und intergenerativ. Im bisherigen System werden die demographischen Lasten auf die nächste Generation verschoben. Eine Mehrbelastung der heutigen Rentner im Rahmen einer Reform ist aber sowohl unter Leistungsfähigkeits- als auch unter Äquivalenzaspekten zu rechtfertigen: Rentner verfügen heute in stärkerem Maß über ihre Rente hinaus über Miet- und Kapitaleinkünfte. Insofern steigt auch ihre Leistungsfähigkeit. Da Ältere im Durchschnitt höhere Gesundheitsausgaben verursachen, als sie Beiträge zahlen, ist eine höhere Beitragsbelastung auch mit dem Äquivalenzprinzip begründbar.

Aus allokativer Sicht lässt sich die GKV - aber auch ein privates Krankenversicherungssystem - grundsätzlich mit den Wohlfahrtsgewinnen einer Versicherung und den Besonderheiten von Gesundheitsgütern rechtfertigen. Eine Krankenversicherung übernimmt die mit Krankheit verbundene hohe finanzielle Unsicherheit; denn insbesondere bei schweren Erkrankungen können die Behandlungskosten die Finanzierungsmöglichkeiten des Einzelnen schnell übersteigen. Für die Versicherung wird durch das Poolen von einzelnen Risiken das gesamte Risiko kalkulierbar und für den Einzelnen gegen die Zahlung eines sicheren Beitrags aufgehoben, woraus Wohlfahrtsgewinne entstehen. ${ }^{488}$ Ohne Versicherungspflicht hätten insbesondere Wirtschaftssubjekte mit geringem Einkommen einen Anreiz, keine Versicherung abzuschließen, weil sie im Krankheitsfall auf die Unterstützung der Gemeinschaft vertrauen können. Der Versicherungszwang vermeidet die aus diesem „Trittbrettfahrerverhalten" und der Minderschätzung zukünftiger Bedürfnisse resultierenden Ineffizien-

\footnotetext{
${ }^{485}$ Wenzel, D. (1999), S. 105.

${ }^{486}$ Vgl. Brümmerhoff, D. (1991), S. 200f.; Bogs, W. u.a. (1966), S. 207.

${ }^{487}$ Vgl. Birg, H. (2004b), S. 39.

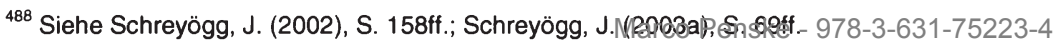


zen. Zudem kann es bei asymmetrischer Information über den Gesundheitszustand der Individuen zu adverser Selektion kommen und der Markt für Krankenversicherungen zusammenbrechen, wenn überwiegend schlechte Risiken eine Versicherung abschließen. ${ }^{489}$ Ein allokationspolitisches Ziel der GKV ist der effiziente Ressourceneinsatz. Für eine bestimmte Verbesserung des Gesundheitszustands ist von allen Erfolg versprechenden Behandlungen diejenige zu wählen, welche die geringsten Kosten verursacht. Über die Effizienz in der Leistungserstellung entscheidet zwar der Wettbewerb unter Leistungserbringern und Kassen und nicht das Finanzierungsverfahren. Die Art der Finanzierung sollte aber keine negativen Rückwirkungen auf die Effizienz haben und nicht den Wettbewerb im Gesundheitswesen behindern. Eine GKVPrämie, die einen Preis für die Versicherungsleistung darstellt (Äquivalenzprinzip), kann den Wettbewerb auf Versicherungsebene fördern, was zugleich der allokativen Forderung nach einem Versicherungsangebot gemäß den Versichertenpräferenzen zugute kommt. Lohnbezogene Beiträge (nach dem Leistungsfähigkeitsprinzip) sind hingegen für einen funktionsfähigen Wettbewerb eher hinderlich, weil Preisrelationen verzerrt werden.

Durch die Lohnkoppelung wird zusätzliches Arbeitseinkommen unterhalb der Beitragsbemessungsgrenze für den Arbeitnehmer um den GKV-Beitrag reduziert, womit Arbeitsanreize und Arbeitsangebot sinken. Für den Arbeitgeber stellen Kassenbeiträge Lohnnebenkosten dar, die die Arbeitsnachfrage reduzieren. Unter allokativen Gesichtspunkten sollte ein dauerhaft tragfähiges Finanzierungssystem aber die reguläre Beschäftigung nicht beeinträchtigen. ${ }^{400}$ Die Abkoppelung des GKV-Beitrags vom Arbeitslohn und Auszahlung des Arbeitgeberbeitrags an die Versicherten wird daher von wissenschaftlicher Seite seit langem gefordert. ${ }^{491}$ Damit würden Zahllast und Traglast bei den Versicherten zusammenfallen. Durch den Arbeitgeberbeitrag liegt zwar ein Teil der Zahllast bei den Unternehmen, die Traglast ist aber abhängig von der Überwälzung. Wird die Belastung als Kostenbestandteil wie indirekte Steuern auf die Preise überwälzt, tragen die Verbraucher der jeweiligen Güter die Last. Gelingt die Rückwälzung auf den Arbeitnehmer, trägt dieser die Beitragslast in Form von niedrigerem Einkommen. Selbst wenn die Überwälzung nicht gelingt, trägt der Arbeitnehmer die Last über ein höheres Beschäftigungsrisiko oder durch Arbeitslosigkeit. Empirisch lässt sich die Inzidenz nicht eindeutig ermitteln; in der Literatur wird aber im Allgemeinen von der Rückwälzung auf den Arbeitnehmer ausgegangen. ${ }^{492}$ Die Arbeitgeberbeteiligung verschleiert in beiden Fällen die tatsächlichen Belastungen. ${ }^{493}$

\footnotetext{
${ }^{489}$ Vgl. Kopetsch, T. (2001), S. 26; Breyer, F.; Zweifel, P.; Kifmann, M. (2005), S. 173ff., $211 \mathrm{ff}$.

${ }^{490}$ Vgl. SVR KAiG (1994), Ziff. 472ff.; Rürup-Kommission (2003), S. 146; Rürup, B. (2003), S. $6 f$.

491 Die Entsendung von Vertretern der Arbeitgeber in die Verwaltungsräte der meisten Krankenkassen würde damit seine Legitimation verlieren; lediglich bei den Ersatzkassen sind die Verwaltungsräte bereits ausschließlich mit Versichertenvertretern besetzt. Der Einfluss der Arbeitgeber auf Z.B. Satzungsleistungen, Beitragssatz und Vorstandsbezüge würde deutlich abnehmen.

${ }^{492}$ Vgl. Wenzel, D. (1999), S. 8ff.; Breyer, F. u.a. (2001), S. 41ff.; Wissenschaftlicher Beirat beim Bundesministerium der Finanzen (2004), S. 11; SVR (1996), Ziff. 381.

${ }^{493}$ Zur Diskussion um den Arbeitgeberbeitrag siehe SVR KAiG (1994), Ziff. 533ff.; SVR KAiG (1995), Ziff. 532ff.; SVR KAiG (1998), Ziff. 590; SVR (2002), Ziff. 518; zur Inzidenz insbes. Wenzel, D. (1999), S. 8ff.; SVR KAiG (1995), Ziff. 545ff. Marco Penske - 978-3-631-75223-4
} 
Um die Belastung der Arbeitgeber zu begrenzen, wird auch diskutiert, den Arbeitgeberbeitragssatz zu fixieren oder eine Obergrenze festzulegen. Bei einer Fixierung des Arbeitgeberbeitrags würden sich - wie bei einer Auszahlung - Beitragssatzsteigerungen nicht mehr in höheren Arbeitskosten niederschlagen ${ }^{494}$ Gleichwohl würden Lohnerhöhungen unterhalb der Beitragsbemessungsgrenze auch für den Arbeitgeber zu absolut steigenden GKV-Beiträgen führen. Für den Arbeitnehmer hätte diese Lösung den Vorteil, dass der Arbeitgeberanteil, wenn er direkt an die Versicherung gezahlt wird, steuerfrei bleibt. Bei einer Auszahlung des Arbeitgeberanteils wäre dieser für den Arbeitnehmer zumindest teilweise steuerpflichtig, da Beiträge zur Krankenversicherung derzeit im Rahmen von Vorsorgeaufwendungen nach $\S 10$ Abs. 4 EStG nur bis zu einem jährlichen Höchstbetrag von insgesamt 2.400 Euro bei Versicherten, die ihre Versicherung nicht vollständig selbst bezahlen, bis 1.500 Euro - als Sonderausgabe bei der Ermittlung des zu versteuernden Einkommens abgezogen werden können. Von Nachteil für den Arbeitnehmer wäre, dass er - wie in allen Modellen, die eine Begrenzung der Arbeitgeberbeiträge oder eine Abkoppelung vorsehen - Beitragssatzsteigerungen zunächst in voller Höhe selbst zu tragen hätte. Die Anreize der Arbeitgeber, die Ausgabenentwicklung zu beeinflussen, würden deutlich geschwächt.

Das Interesse der Arbeitgeber an niedrigen Beitragssätzen könnte durch eine Obergrenze für den Arbeitgeberbeitragssatz erhalten bleiben. Die Obergrenze kann für alle Kassen beim hälffigen Beitragssatz der günstigsten Kasse oder bei der Hälfte des durchschnittlichen Beitragssatzes zur GKV liegen. ${ }^{495}$ Beitragssatzsteigerungen würden dann - soweit der Arbeitgeberbeitragssatz über die Obergrenze steigen würde - nur von den Arbeitnehmern finanziert. Die Obergrenze kann aber auch kassenspezifisch festgelegt werden und zum Umstellungszeitpunkt z.B. $50 \%$ des Beitragssatzes der jeweiligen Kasse betragen. ${ }^{496}$ Wenn im Zeitverlauf die Beiträge eines vorgegebenen Anteils der Versicherten (z.B. $50 \%$ ) die Obergrenzen um einen bestimmten Prozentsatz (z.B. $20 \%$ ) überschreiten, werden die Obergrenzen angehoben, bis nur noch bei einem geringeren Teil der Versicherten (z.B. $25 \%$ ) die Beiträge über der Obergrenze liegen. Trotz des gedämpften Anstiegs der Obergrenzen nähmen aber die Arbeitskosten mit steigenden Beitragssätzen weiter zu. Wettbewerbsverzerrend würde wirken, dass den Kassen, die bei Einführung kassenspezifischer Obergrenzen einen hohen Beitragssatz haben, ein höherer Arbeitgeberbeitrag zugestanden würde als Kassen mit niedrigerem Beitragssatz zum Zeitpunkt der Umstellung.

Sowohl bei der Fixierung des Arbeitgeberanteils als auch bei der Bestimmung von Obergrenzen bleibt der Abgabenkeil zwischen Produzenten- und Konsumentenlohn und damit die beschäftigungsfeindliche Wirkung aber bestehen. Aus allokationspolitischen Gründen ist daher die Auszahlung an die Arbeitnehmer den anderen Varianten vorzuziehen. Nicht zuletzt, weil damit auch der Wettbewerb zwischen den Versicherungen gestärkt wird, wenn die Versicherten ihren Beitrag selbst voll tragen und damit die Wechselbereitschaft steigt.

\footnotetext{
${ }^{494}$ Vgl. SVR KAiG (1995), Ziff. 534ff.; Sehlen, S. u.a. (2004), S. $32 f$.

${ }^{495}$ Vgl. Sehlen, S. u.a. (2004), S. 33.

${ }^{496}$ Vgl. SVR KAiG (1995), Ziff. 537ff. 
Die GKV hat keine Stabilisierungsfunktion, da Gesundheitsleistungen unabhängig vom Konjunkturverlauf nach medizinischer Notwendigkeit erbracht werden müssen. Die GKV eignet sich daher auch nicht zur konjunkturpolitischen Steuerung. Die derzeit am Leistungsfähigkeitsprinzip orientierte Beitragserhebung wirkt sogar eher prozyklisch, wenn es infolge einer Abschwächung der Konjunktur zu einem Beitragssatzanstieg in der GKV kommt. ${ }^{497}$ Deshalb beschränkt sich dieses Reformziel darauf, dass von der Finanzierung keine konjunkturellen Schwankungen verstärkt werden und umgekehrt die Einnahmen der GKV auch nicht mehr von der konjunkturellen Entwicklung abhängen sollten. ${ }^{498}$ Darüber hinaus sollte die Finanzierung Wachstum im Gesundheitssektor ermöglichen, ohne Wachstum außerhalb des Gesundheitssystems zu behindern. Neben den direkten Beschäftigungswirkungen im Gesundheitswesen steigert eine gute Gesundheitsversorgung die Leistungsfähigkeit des Humankapitals und trägt damit zu einem Produktivitätsanstieg und Wachstum in der Volkswirtschaft bei.

${ }^{497}$ Vgl. Oberdieck, V. (1998), S. 23; Rürup-Kommission (2003), S. 13.

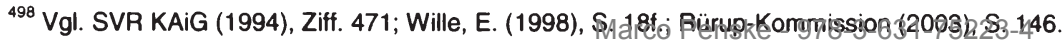


Marco Penske - 978-3-631-75223-4

Downloaded from PubFactory at 01/11/2019 06:54:52AM

via free access 


\section{Reformen unter Beibehaltung des Umlageverfahrens}

\section{Finanzierungsformen und Reformvorschläge im Überblick}

Zur Finanzierung von Gesundheitsleistungen gibt es grundsätzlich fünf Möglichkeiten: 499

1. Intrafamiliales Umlagesystem: Innerhalb der Familie versorgen die Enwerbstätigen mit ihren Einkommen die Familienmitglieder. Dieses System herrschte vor Gründung der Sozialversicherung in Deutschland.

2. Finanzierung durch Zahlungen der Untemehmen: Beispiel hierfür ist das über Arbeitgeberbeiträge finanzierte öffentliche Gesundheitswesen in Italien. Hierzu kann auch der in den USA von Unternehmen für Mitarbeiter angebotene Versicherungsschutz in Health-Maintenance-Organisationen gezählt werden.

3. Intergenerationales steuerfinanziertes Umlagesystem: Aus dem Staatshaushalt wird das Gesundheitssystem finanziert. Beispiele sind Dänemark, wo der staatliche Gesundheitsdienst vollständig steuerfinanziert wird, oder der National Health Service in Großbritannien, bei dem der Staat nahezu vollständig für die Sachleistungen aufkommt.

4. Finanzierung durch eine parastaatliche Institution mit Versicherungspflicht und Beiträgen von Arbeitnehmern und Arbeitgebern: Im Gegensatz zur reinen Steuerfinanzierung haben die Versicherten einen Anspruch auf Leistungen. Diesem Finanzierungssystem folgt die GKV.

5. Individualisiertes Kapitaldeckungsverfahren mit risikoäquivalenten Beiträgen. Dieses wird in der PKV praktiziert.

Das erste Finanzierungsverfahren würde eine Abschaffung der Sozialversicherung bedeuten und die zweite Möglichkeit die Belastungen der Arbeitgeber weiter erhöhen, was das allokative Ziel einer Senkung der Belastung der Arbeitgeber konterkarieren würde. Beide Finanzierungsalternativen werden deshalb hier nicht weiter betrachtet. Eine Reform sollte entweder im derzeitigen umlagefinanzierten System stattfinden oder den Übergang in ein kapitalgedecktes System vorsehen. Dabei sind auch Mischformen möglich und Steuerzuschüsse insbesondere für versicherungsfremde Leistungen denkbar.

Sollen Umlageverfahren und Leistungskatalog beibehalten werden, hat die Politik zwei Möglichkeiten, die langfristige Finanzierbarkeit der GKV sicherzustellen. Sie kann zum einen versuchen, zumindest die demographische Alterung oder deren Folgen abzuschwächen, indem sie auf Faktoren wie Geburtenrate, Migration, Erwerbsbeteiligung, Produktivität und Bildung Einfluss nimmt (Abschnitt 2 Maßnahmen zur Kompensation des demographischen Wandels). Zum anderen kann versucht werden, im Umlageverfahren weitere Einnahmenquellen außerhalb des Beitragssystems zu erschließen (Abschnitt 3.1 Steuerfinanzierung) oder durch neue Finanzierungsformen die Finanzierung sicherzustellen (Abschnitt 3.2 Bürgerversicherung und 3.3 Kopfpauschalen). 
Die Reformvorschläge auf der Finanzierungsseite lassen sich anhand von drei Gestaltungsmerkmalen einordnen:

1. dem Kreis der in der GKV Pflichtversicherten,

2. der Beitragsbemessung und

3. dem Anteil an Kapitaldeckung.

Reformvorschläge im Umlageverfahren unterscheiden sich vor allem im Kreis der Versicherten und der Beitragsbemessung, unter die man auch verschiedene Formen der Versicherung von Familienangehörigen einordnen kann. Kapitaldeckung spielt hier kaum eine Rolle. Beim Kreis der in der GKV Pflichtversicherten reichen die Vorschläge von einer schrittweisen Überführung aller Versicherten in ein privatwirtschaftliches Versicherungssystem bis hin zur sogenannten Bürgerversicherung, in der dem Namen nach alle Bürger - demnach auch Selbständige und Beamte versichert sind.

Ähnlich weit auseinander gehen die Vorschläge zur Beitragsgestaltung. Diese reichen von einer Erhöhung bis zur vollständigen Abschaffung der Beitragsbemessungsgrenze, über die Erweiterung der Beitragspflicht um weitere Einkünfte (in erster Linie Zins- und Kapitaleinkünfte) bis zur Einführung von kasseneinheitlichen Kopfpauschalen oder individuell risikoäquivalenten Prämien. Mit der Beitragsbemessung ist auch die Frage verbunden, ob der Einkommensausgleich innerhalb der GKV oder im Steuersystem angesiedelt sein soll, mithin das Leistungsfähigkeits- oder Äquivalenzprinzip gestärkt wird. In Tabelle 15 werden in der Literatur diskutierte Kombinationen aus Versichertenkreis und Beitragsbemessung systematisiert.

Die Rürup-Kommission ${ }^{500}$ hat im Jahr 2003 zwei alternative Finanzierungskonzepte vorgestellt: Eine am Leistungsfähigkeitsprinzip orientierte Bürgerversicherung und ein dem Äquivalenzprinzip folgendes Konzept pauschaler Gesundheitsprämien mit steuerfinanziertem Sozialausgleich. Wie Tabelle 15 zeigt, sind die beiden Begriffe aber keine Gegenpole. Die Bürgerversicherung stellt auf die Einbeziehung aller Bürger in die GKV, also auf den Versichertenkreis ab. Die Kopfpauschale hingegen mit einem einkommensunabhängigen, einheitlichen Beitrag für die Versicherten einer gesetzlichen Kasse auf die Beitragsbemessung. ${ }^{501}$ Dennoch umspannen die beiden Begriffe weitgehend die aktuell in Wissenschaft und Politik diskutierten Reformalternativen. SPD und Bündnis 90/Die Grünen haben das Konzept einer Bürgerversicherung aufgegriffen, Herzog-Kommission ${ }^{502}$ und CDU das Modell einer Gesundheitsprämie. Die Konzepte, ihre unterschiedlichen Varianten und Möglichkeiten einer Synthese stehen deshalb im Mittelpunkt dieses Kapitels. Daneben wird auch eine stärkere Finanzierung aus Bundeszuschüssen diskutiert.

Für den Übergang zum Kapitaldeckungsverfahren und „Prämien nach versicherungstechnischen Kriterien “503 hat sich die FDP ausgesprochen. Da im Umlageverfahren risikoäquivalente Prämien mit dem Alter stark ansteigen, wären insbesondere ältere

\footnotetext{
${ }^{500}$ Siehe Rürup-Kommission (2003), S. 147ff.

${ }^{501}$ Vgl. Gerken, L.; Raddatz, G. (2003), S. 4ff.; Sehlen, S. u.a. (2004), S. 18.

${ }^{502}$ Siehe Herzog-Kommission (2003), S. $16 \mathrm{ff}$.
}

${ }^{503}$ Freie Demokratische Partei (Hrsg.) (2004), S. 3. Marco Penske - 978-3-631-75223-4 
Versicherte kaum in der Lage, ihre Prämie zu zahlen. Neben gravierenden sozialpolitischen Problemen würde die Finanzierungslast zunehmend auf den Staatshaushalt übergehen. Risikoäquivalente Prämien werden daher nur in Verbindung mit Kapitaldeckung diskutiert. Ob und gegebenenfalls wie eine stärkere Kapitaldeckung die Finanzierbarkeit der GKV langfristig sichern kann, ist Gegenstand von Kapitel VI.

Tabelle 15: Kombinationen aus Versichertenkreis und Beitragsbemessung

\begin{tabular}{|c|c|c|c|}
\hline $\begin{array}{r}\begin{array}{r}\text { Pflichtver- } \\
\text { sicherte }\end{array} \\
\text { Beitrags- } \\
\text { bemessung }\end{array}$ & Absenken der VPG & $\begin{array}{l}\text { VPG entspricht } 75 \% \text { der } \\
\text { BBG in der GRV } \\
\text { (Status quo) }\end{array}$ & $\begin{array}{c}\text { Einbeziehung der } \\
\text { gesamten Bevölkerung } \\
\text { in die derzeitige GKV } \\
\text { (Bürgerversicherung) }\end{array}$ \\
\hline $\begin{array}{l}\text { Alle sieben Ein- } \\
\text { kunftsarten nach } \\
\S 2 \text { Abs. } 1 \text { EStG } \\
\end{array}$ & & & $\begin{array}{l}\text { Sehlen, S. u.a. (2004); } \\
\text { Lauterbach, K.W. (2004) }\end{array}$ \\
\hline $\begin{array}{l}\text { Alle sieben Ein- } \\
\text { kunftsarten nach } \\
\S 2 \text { Abs. } 1 \text { EStG } \\
\text { außer Einkünfte } \\
\text { aus Vermietung } \\
\text { und Verpachtung }\end{array}$ & & & $\begin{array}{l}\text { Projektgruppe } \\
\text { Bürgerversicherung des } \\
\text { SPD-Parteivorstandes } \\
\text { (2004) }\end{array}$ \\
\hline $\begin{array}{l}\text { Einkünfte aus } \\
\text { nichtselbständiger } \\
\text { Arbeit } \\
\text { (Status quo) }\end{array}$ & & Status quo & \\
\hline $\begin{array}{l}\text { Kassenspezifi- } \\
\text { sche Pauschal- } \\
\text { beiträge } \\
\text { (Kopfpauschale) }\end{array}$ & & $\begin{array}{l}\text { SVR }(2002,2003) \text {; Rürup- } \\
\text { Kommission (2003); } \\
\text { Herzog-Kommission } \\
\text { (2003); Rürup, B.; Wille, } \\
\text { E. (2004) }\end{array}$ & $\begin{array}{l}\text { Breyer, F. u.a. (2001); } \\
\text { Henke, K.-D. (2001); } \\
\text { Knappe, E.; Arnold, R. } \\
\text { (2002); Wissenschaft- } \\
\text { licher Beirat beim Bun- } \\
\text { desministerium der Finan- } \\
\text { zen (2004); SVR (2004, } \\
\text { 2005); Initiative mehr } \\
\text { Gesundheit (Hrsg.) (2004) }\end{array}$ \\
\hline $\begin{array}{l}\text { Risikoäquivalente } \\
\text { Prämien nach } \\
\text { Risikogruppen }\end{array}$ & SVR (2000) & & \\
\hline $\begin{array}{l}\text { Individuelle risiko- } \\
\text { äquivalente } \\
\text { Prämien }\end{array}$ & $\begin{array}{l}\text { SVR KAiG (1994, 1995, } \\
\text { 1998); SVR (1996, 2002); } \\
\text { Zweifel, P.; Breuer, M. } \\
\text { (2002); Kronberger Kreis } \\
\text { (2002); Freie Demokrati- } \\
\text { sche Partei (Hrsg.) (2004) }\end{array}$ & & \\
\hline
\end{tabular}

Quelle: Eigene Darstellung.

\section{Maßnahmen zur Kompensation des demographischen Wandels}

\subsection{Verlängerung der Arbeitszeit}

Rein rechnerisch kann der Arbeitsmarkt zwischen den Jahren 2008 und 2010 zwar durch den Abbau der Arbeitslosigkeit und der Stillen Reserve in ein Gleichgewicht gebracht werden. Mittelfristig wird die Arbeitskrättenaghfrageaber @inesßeutere Maß- 
nahmen nicht mehr allein durch das inländische Angebot gedeckt werden können. ${ }^{504}$ Damit stellt sich die Frage, ob und unter welchen Bedingungen verschiedene Maßnahmen geeignet sind, die Auswirkungen des demographischen Wandels auf die Finanzlage der GKV zu kompensieren. Auf die durch den medizinisch-technischen Fortschritt verursachten Ausgabensteigerungen haben diese Maßnahmen ohnehin keinen Einfluss. Auf die Frage, inwieweit der quantitative Bevölkerungsrückgang durch eine qualitative Verbesserung des Humankapitals ausgeglichen werden könnte, wird nicht näher eingegangen. ${ }^{505}$

Der beschriebene quantitative Rückgang des Arbeitsangebots betrachtet ausschließlich die Zahl der Erwerbspersonen. Für das Arbeitsangebot ist aber nicht nur die Zahl der Erwerbspersonen, sondern auch deren Angebot an Arbeitszeit maßgeblich. Theoretisch ist es möglich, das Arbeitsangebotsvolumen auch bei einer sinkenden Zahl von Erwerbspersonen konstant zu halten, wenn die Arbeitszeit in entsprechendem Umfang steigt. Ein internationaler Vergleich für das Jahr 2002 zeigt, dass in Deutschland in einer Verlängerung der Arbeitszeit erhebliches Potential zur Ausweitung des Arbeitsangebotsvolumens liegt.

Die tarifvertraglich vereinbarte Wochenarbeitszeit liegt in Deutschland bei durchschnittlich 37,7 Stunden und damit unter dem EU-Durchschnitt in Höhe von 38,5 Stunden. Nur Finnland (35,7 Stunden), Dänemark (37,0 Stunden), die Niederlande (37,0 Stunden) und Großbritannien (37,2 Stunden) verfügen über eine kürzere tarifvertraglich geregelte Wochenarbeitszeit. ${ }^{506}$ Würde man die tarifliche Arbeitszeit wenigstens auf das europäische Niveau anpassen, könnte das Arbeitsangebotsvolumen ceteris paribus um 2,1\% gesteigert werden.

Die tatsächliche Arbeitszeit hängt aber von weiteren Faktoren wie Urlaub, Krankheit, Feiertage und Anteil der Teilzeitbeschäftigten ab. Werden diese berücksichtigt, liegt auch die durchschnittliche tatsächliche Wochenarbeitszeit in Deutschland mit 35,2 Stunden unter dem entsprechenden EU-Durchschnitt von 36,1 Stunden. In Griechenland (40,2 Stunden), Portugal (39,3 Stunden), Spanien (38,6 Stunden) und Großbritannien (37,2 Stunden) zum Beispiel liegt die durchschnittliche Wochenarbeitszeit aller Beschäftigten deutlich höher. ${ }^{507}$ Rechnerisch könnte durch eine Anpassung der tatsächlichen Arbeitszeit an das europäische Niveau ceteris paribus das Arbeitsangebotsvolumen um 2,6\% gesteigert werden. ${ }^{508}$ In die durchschnittliche Arbeitszeit fließt aber auch die geringere Arbeitszeit Teilzeitbeschäftigter ein, die größtenteils dem Arbeitszeitwunsch der betroffenen Arbeitnehmer entspricht. Da es sich bei den Teilzeitbeschäftigten zu $86 \%$ um Frauen handelt, kann eine längere Arbeitszeit vor allem durch eine Steigerung der Erwerbsbeteiligung von Frauen erreicht werden. ${ }^{509}$

\footnotetext{
${ }^{504}$ Vgl. Heilemann, U.; Löffelholz, H.D. von; Sieveking, K. (2003), S. $44 f$.

${ }^{505}$ Siehe hierzu Kleinhenz, G.D. (2004), S. 88; Plünnecke, A.; Seyda, S. (2005), S. 123ff.; Grömling, M. (2005), S. 79.

${ }^{506}$ Siehe Europäische Kommission (Hrsg.) (2003b), S. 143.

${ }^{507}$ Siehe ebenda.

${ }^{508}$ Bei einer Erhöhung auf das griechische Niveau ist sogar ein Anstieg um gut $14 \%$ möglich.

${ }^{509}$ Vgl. Schäfer, H.; Seyda, S. (2005), S. 114f. Marco Penske - 978-3-631-75223-4
} 


\subsection{Steigerung der Enwerbsbeteiligung}

Der Rückgang des Arbeitsangebots kann teilweise kompensiert werden, wenn es gelingt, die Erwerbsbeteiligung zu steigern. Eine höhere Erwerbsbeteiligung führt dann zu höheren Einnahmen für die GKV, wenn aufgrund einer Verkürzung der Ausbildungszeiten jüngere Versicherte nicht mehr familienversichert oder als Studierende mit ermäßigtem Beitrag versichert sind, sondern normale GKV-Beiträge entrichten. Höhere Einnahmen hat die GKV auch, wenn bislang Familienversicherte eine sozialversicherungspflichtige Beschäftigung aufnehmen und eigene Beiträge zahlen oder im Falle der Erwerbslosigkeit die öffentliche Hand - wenn auch niedrigere - Beiträge an die GKV entrichtet. ${ }^{510}$ Ältere zahlen bei einer Verlängerung der Lebensarbeitszeit höhere GKV-Beiträge, weil die Beitragszahlungen ansonsten mit dem Renteneintritt deutlich sinken. Für alle Fälle gemeinsam gilt aber: Zu einem Einnahmenzuwachs für die GKV kommt es nur dann, wenn durch die Erhöhung der Erwerbsbeteiligung einzelner Gruppen keine andere Beschäftigung verdrängt wird und sozialversicherungspflichtige Beschäftigungsverhältnisse mit entsprechenden Beiträgen an die GKV entstehen oder zumindest Lohnersatzleistungen zu Beiträgen führen.

Die Ausgaben der GKV werden von einer höheren Erwerbsbeteiligung kaum beeinflusst. Im Gegensatz zur GRV, in der die Zahlungen durch den Eintritt in die Rente erst veranlasst werden und eine Verlängerung der Lebensarbeitszeit Einfluss auf Einnahmen und Ausgaben hat, sind die Ausgaben der GKV praktisch unabhängig vom Erwerbsstatus der Versicherten. In der GRV indes erwerben Versicherte mit längeren und damit höheren Beitragszahlungen höhere Rentenansprüche. In der GKV begründet eine gestiegene Erwerbsbeteiligung bis auf eventuell entstehenden Krankengeldanspruch keine höheren Leistungsansprüche. ${ }^{511}$

Der internationale Vergleich zeigt, dass es in Deutschland noch Spielraum gibt, die Erwerbsbeteiligung zu erhöhen. Tabelle 16 gibt einen Überblick über ausgewählte Erwerbsquoten der EU-15, in den Vereinigten Staaten und im OECD-Durchschnitt. Die Erwerbsquote ist definiert als Anteil der Erwerbspersonen (Erwerbstätige und Erwerbslose) an der Gesamtbevölkerung in der jeweiligen Altersgruppe. In Tabelle 16 werden die Erwerbsquoten und nicht die Erwerbstätigenquoten verglichen, damit die Ergebnisse nicht durch unterschiedlich hohe Arbeitslosenquoten in den Vergleichsländern verzerrt werden. ${ }^{512}$

Die Erwerbsbeteiligung ist in Deutschland bestenfalls durchschnittlich. Würde die Erwerbsbeteiligung auf das in Schweden oder in Dänemark vorliegende Niveau angehoben werden, hätte man hierzulande im Jahr 2050 ein zusätzliches Enwerbs-

\footnotetext{
${ }^{510}$ Siehe hierzu auch Kapitel II.4.3.3 Abhängigkeit vom Arbeitsmarkt, S. 58.

${ }^{511} \mathrm{Zu}$ den unterschiedlichen Wirkungen einer Annäherung an das derzeitige Regelrentenalter und einer Erhöhung der Altersgrenze auf die GRV siehe Ehrentraut, O.; Raffelhüschen, B. (2003), S. $628 f$.

${ }^{512}$ Nicht berücksichtigt werden arbeitsmarktnahe Nichterwerbspersonen, die sogenannte Stille Reserve. Diese Nichterwerbspersonen suchen zwar entweder nach einer Arbeitsstelle, stehen aber derzeit dem Arbeitsmarkt nicht zur Vertügung, oder sie würden gerne einer Erwerbstätigkeit nachgehen, suchen aber aufgrund der Arbeitsmarktlage nach keiner Arbeitsstelle. Breiholz, H. (2004), S. 670, schätzt die Stille Reserve im Jahr 2003 auf 1,9 Mio. Personen. Da mit sinkendem Arbeitsangebot, besserer Arbeitsmarktlage und zunehmender Erwerbsbeteiligung die Stille Reserve deutlich abnehmen dürtte, wird hierauf nicht weiter/eingegangene - 978-3-631-75223-4
} 
personenpotential von rund 1,5 Mio. Personen. Im Jahr 2001 wäre sogar ein zusätzliches Potential von 3,7 Mio. Erwerbspersonen möglich gewesen. ${ }^{513} \mathrm{Um}$ den Rückgang des Arbeitsangebots zu mindern, gibt es drei Ansatzpunkte: Die Steigerung der Erwerbsbeteiligung Jugendlicher, Älterer und von Frauen.

Tabelle 16: Erwerbsquoten im EU-Vergleich im Jahr 2003

\begin{tabular}{|l|l|l|l|l|l|l|l|l|l|l|l|l|l|l|}
\hline & \multicolumn{3}{|c|}{$15-64$ Jahre } & \multicolumn{3}{c|}{ 15-24 Jahre } & \multicolumn{3}{c|}{ 25-54 Jahre } & \multicolumn{3}{c|}{ 55-64 Jahre } \\
\hline & Männer & Frauen & Gesamt & Männer & Frauen & Gesam & Männer & Frauen & Gesamt & Männer & Frauen & Gesamt \\
\hline B & 72,6 & 55,8 & 64,3 & 38,1 & 28,8 & 33,5 & 90,4 & 73,1 & 81,8 & 39,4 & 18,0 & 28,5 \\
\hline DK & 84,0 & 74,8 & 79,4 & 68,1 & 63,6 & 65,9 & 92,0 & 83,6 & 87,8 & 70,8 & 55,2 & 63,1 \\
\hline D & 78,0 & 64,5 & 71,3 & 49,9 & 44,9 & 47,4 & 93,0 & 78,9 & 68,0 & 52,0 & 34,3 & 43,1 \\
\hline FIN & 76,1 & 72,1 & 74,1 & 48,5 & 49,7 & 49,1 & 90,1 & 84,8 & 87,5 & 55,8 & 52,4 & 54,1 \\
\hline F & 73,8 & 62,5 & 68,2 & $33,8^{1)}$ & $26,5^{1)}$ & $30,2^{1)}$ & $93,9^{1)}$ & $79,0^{1)}$ & $86,4^{1)}$ & $47,0^{1)}$ & $36,6^{1)}$ & $41,7^{1)}$ \\
\hline EL & 77,0 & 51,0 & 63,8 & 38,7 & 31,5 & 35,1 & 94,1 & 64,5 & 78,9 & 60,7 & 26,8 & 43,2 \\
\hline UK & 83,9 & 69,2 & 76,6 & 71,1 & 63,9 & 67,6 & 91,4 & 76,6 & 84,1 & 67,9 & 47,3 & 57,5 \\
\hline IRL & 78,3 & 57,6 & 68,0 & 53,4 & 45,7 & 49,6 & 90,9 & 67,4 & 79,1 & 66,5 & 34,1 & 50,5 \\
\hline I & 74,8 & 48,3 & 61,6 & 40,5 & 29,9 & 35,3 & 91,5 & 60,9 & 76,3 & 44,4 & 19,3 & 31,5 \\
\hline L & $77,0^{1)}$ & $53,5^{1)}$ & $65,3^{1}$ & $38,2^{11}$ & $31,2^{1)}$ & $34,7^{1)}$ & $95,0^{1)}$ & $66,7^{1)}$ & $81,0^{1)}$ & $37,7^{1)}$ & $18,1^{1)}$ & $27,9^{1)}$ \\
\hline NL & 84,2 & 68,4 & 76,4 & 73,7 & 72,7 & 73,2 & 93,6 & 76,5 & 85,1 & 58,7 & 32,9 & 45,9 \\
\hline A & 79,4 & 63,9 & 71,6 & 59,7 & 49,9 & 54,8 & 94,3 & 79,8 & 87,0 & 42,3 & 20,0 & 30,8 \\
\hline P & 78,5 & 65,6 & 72,0 & 48,5 & 41,3 & 45,0 & 92,5 & 79,3 & 85,9 & 64,7 & 43,5 & 53,4 \\
\hline S & 80,8 & 76,9 & 78,9 & 51,9 & 52,7 & 52,3 & 90,1 & 85,5 & 87,8 & 75,5 & 69,5 & 72,5 \\
\hline E & 81,1 & 55,7 & 68,5 & 53,1 & 41,9 & 47,6 & 92,4 & 66,3 & 79,4 & 62,9 & 25,8 & 43,8 \\
\hline EU-15 & 79,2 & 61,3 & 70,3 & 53,6 & 46,4 & 50,0 & 92,2 & 72,9 & 82,6 & 56,4 & 33,7 & 44,9 \\
\hline USA & 82,2 & 69,7 & 75,8 & 63,9 & 59,2 & 61,6 & 90,6 & 75,6 & 83,0 & 68,7 & 56,6 & 62,4 \\
\hline OECD & 80,2 & 59,6 & 69,8 & 55,1 & 45,5 & 50,3 & 92,0 & 68,0 & 79,9 & 65,4 & 42,0 & 53,4 \\
\hline
\end{tabular}

Länderabkürzungen: B: Belgien, DK: Dänemark, D: Deutschland, FIN: Finnland, F: Frankreich, EL: Griechenland, UK: Großbritannien, IRL: Irland, I: Italien, L: Luxemburg, NL: Niederlande, A: Österreich, P: Portugal, S: Schweden, E: Spanien, USA: Vereinigte Staaten von Amerika.

${ }^{1)}$ Wert aus dem Jahr 2002.

Daten: OECD (Hrsg.) (2004), S. 294ff.

Jugendliche starten in Deutschland vergleichsweise spät in das Berufsleben. Hierzulande haben heute 35- bis 44jährige nach einer Untersuchung der Europäischen Kommission $^{514}$ mit einem Durchschnittsalter von 19,6 Jahren ihre erste Beschäftigung aufgenommen. Dieser Wert liegt zwar knapp unter dem EU-Durchschnitt (19,8 Jahre), aber teilweise deutlich über den Werten von Österreich (17,4 Jahre), Irland (17,7 Jahre), Portugal (18,2 Jahre), Spanien (18,4 Jahre) und Großbritannien (19,0 Jahre). Dieses Bild geben auch die Erwerbsquoten der 15- bis 24jährigen in Tabelle 16 wieder. Die Erwerbsquote dieser Altersgruppe liegt in Deutschland mit 47,4 \% unter dem EU-Durchschnitt von 50,0\% und deutlich hinter den Niederlanden, Großbritannien und Dänemark. Durch eine Verkürzung der Schul- und Studienzeiten könnte nach Berechnungen des Instituts der deutschen Wirtschaft ${ }^{515}$ die Zahl der

\footnotetext{
${ }^{513}$ Vgl. Schäfer, H.; Seyda, S. (2005), S. 110 f.

${ }^{514}$ Siehe Europäische Kommission (Hrsg.) (2003b), S. $170 f$.

${ }^{515}$ Siehe Institut der deutschen Wirtschaft (Hrsg.) (2004kitar So 5. enske - 978-3-631-75223-4
} 
Erwerbspersonen in Deutschland bis zum Jahr 2025 um 400.000 Personen gesteigert werden.

Die Erwerbsquote der 55- bis 64jährigen liegt in Deutschland mit 43,1 \% knapp unter dem EU-Durchschnittsniveau von 44,9\%. Doch auch hier gibt es einige Länder, die höhere Erwerbsquoten aufweisen. In Schweden, Dänemark und Großbritannien stehen z.B. deutlich mehr Ältere dem Arbeitsmarkt zur Verfügung. Das durchschnittliche Erwerbsaustrittsalter in der EU bestätigt dies. Im Durchschnitt scheidet eine Erwerbsperson in Deutschland mit 60,7 Jahren aus dem Erwerbsleben aus. In Großbritannien stehen die Älteren dem Arbeitsmarkt länger zur Verfügung, im Durchschnitt treten sie mit 62,1 Jahren in den Ruhestand. Ähnliches gilt für einige andere EU-Länder wie Irland (63,1 Jahre), Portugal (62,0 Jahre) und Schweden (62,0 Jahre). ${ }^{516}$ Zurückzuführen ist dieser Umstand u.a. auf großzügige Frühverrentungsregeln und Altersteilzeitmodelle in Deutschland. Würde das Rentenalter von 65 Jahren auf 67 Jahre angehoben, ein früherer Renteneintritt zu höheren Abschlägen führen ${ }^{517}$ und würden alle Möglichkeiten zur Frühverrentung abgeschafft, könnten bis zum Jahr 2025 1,3 Mio. Arbeitskräfte mobilisiert werden. ${ }^{518}$

Im internationalen Vergleich in Tabelle 16 liegt die Enwerbsbeteiligung der 15- bis 64jährigen Frauen in Deutschland mit 64,5\% zwar im Mittelfeld und über dem Durchschnitt der EU-15 von 61,3\%. Sie ist aber merklich niedriger als bei den Männern (78,0 \%). Betrachtet man die Altersgruppe der 55- bis 64jährigen ist der Unterschied noch deutlicher. Während bei den Männern mit 52,0 \% in dieser Altersgruppe schon nur ein geringer Anteil dem Arbeitsmarkt zur Verfügung steht, sind es bei den Frauen gerade einmal $34,3 \%$. Das Arbeitsvolumen, das sich bei Männern und Frauen deutlich unterscheidet, bleibt dabei sogar unberücksichtigt. Noch gravierender ist der Unterschied bei einer Betrachtung in Vollzeitäquivalenten, weil bei dieser Methode auch die Arbeitszeit der Beschäftigten berücksichtigt wird. ${ }^{519} \mathrm{Im}$ Jahr 2003 waren 83,3\% der Teilzeitarbeitsplätze von Frauen besetzt. ${ }^{520}$ Insgesamt ergibt sich aus einer Steigerung der Erwerbsbeteiligung von Frauen enormer Spielraum, um den Arbeitskräfterückgang zu mindern. Aufgrund besserer Ausbildung und eines geänderten Rollenverständnisses von Frauen wird ohnehin ein Anstieg der Erwerbsquote von Frauen erwartet. ${ }^{521}$ Die Politik kann z.B. durch eine bessere Vereinbarkeit von Familientätigkeit und Beruf diese Entwicklung unterstützen. Mit einer höheren Erwerbsbeteiligung von Frauen könnten bis zum Jahr 2025 zusätzlich 2,4 Mio. Arbeitskräfte gewonnen werden. ${ }^{522}$ Auch das kann den demographisch bedingten Rückgang des Arbeitsangebots aber nicht ausgleichen. ${ }^{523}$

\footnotetext{
${ }^{516}$ Siehe Europäische Kommission (Hrsg.) (2003a), S. 51.

${ }^{517}$ Die Rentenabschläge in Höhe von $3,6 \%$ pro Jahr, in dem die Rentenzahlung vor dem Alter von 65 Jahren beginnt, liegen noch immer unter einem versicherungsmathematisch kalkulierten Abschlag.

${ }^{518} \mathrm{Vgl}$. Institut der deutschen Wirtschaft (Hrsg.) (2004b), S. 5.

${ }^{519}$ Siehe hierzu Beckmann, P. (2003), S. $1 \mathrm{ff}$.

${ }^{520}$ Siehe OECD (Hrsg.) (2004), S. 310.

${ }^{521}$ Siehe hierzu Enquete-Kommission Demographischer Wandel (2002), S. 71f., und die dort angegebene Literatur.

${ }^{522}$ Vgl. Institut der deutschen Wirtschaft (Hrsg.) (2004b), S. 5.

${ }^{523}$ Vgl. Fuchs, J.; Thon, M. (1999), S. 5. 


\subsection{Zuwanderung}

Neben einer besseren Ausschöpfung des vorhandenen Erwerbspersonenpotentials wird als weitere Maßnahme zur Stabilisierung des Arbeitskräftepotentials über eine arbeitsmarktgesteuerte Zuwanderung diskutiert. ${ }^{524}$ Die aktuellen Regelungen zur Zuwanderung sehen für Personen ohne EU-Staatsangehörigkeit den im Jahr 1973 verhängten Anwerbestopp vor, bei Engpässen auf dem Arbeitsmarkt kann der Bund diesen jedoch für einzelne Berufsgruppen per Verordnung aussetzen. Bürger des europäischen Wirtschaftsraums können aufgrund der Freizügigkeitsrichtlinien der EU in Deutschland bereits einer Erwerbstätigkeit nachgehen. ${ }^{525}$ Für Arbeitnehmer aus den zum 01.05.2004 der EU beigetretenen Staaten Mittel- und Osteuropas ist die Freizügigkeit zunächst bis zum Jahr 2006 ausgesetzt. Diese Regelung kann bis zum Jahr 2010 verlängert werden, um u.a. Zuwanderung in die Sozialsysteme zu verhindern. ${ }^{526}$ Unter ökonomischen Gesichtspunkten hat auch das im Jahr 2004 beschlossene Zuwanderungsgesetz ${ }^{527}$ keine nennenswerten Änderungen für den Arbeitsmarkt gebracht.

Zuwanderung kann - wie Studien ${ }^{528}$ zeigen - nach einer Anpassungsphase Wirtschaftswachstum und Beschäftigung steigern. Theoretisch begründen lässt sich dies durch zwei Effekte: ${ }^{529}$ Nach dem Wachstumseffekt sind Einwanderer potentielle Nachfrager und können für zusätzliche Binnennachfrage sorgen. Zudem erweitern sie das Arbeitsangebot. Beides stimuliert das wirtschaftliche Wachstum. Darüber hinaus verbessert Zuwanderung die Allokation der Ressourcen (Allokationseffekt). Da die wirtschaftliche Motivation für Migration vor allem auf Unterschieden im erwarteten Erwerbseinkommen beruht, wandern Erwerbspersonen - so die neoklassische Theorie - dorthin, wo sie für die gleiche Arbeit einen höheren Lohn erhalten, ihre Grenzproduktivität der Arbeit also am höchsten bewertet wird. Freilich unterliegt diese Argumentation der Annahme, im In- und Ausland stünden ausreichend Arbeitsplätze zur Verfügung. Außerdem baut Zuwanderung Marktunvollkommenheiten teilweise ab. In Deutschland verrichten ausländische Arbeitskräfte z.B. überwiegend Tätigkeiten, für die bisher keine oder in nicht ausreichender Anzahl einheimische Arbeitskräfte gefunden werden konnten. Vor allem Arbeitskräfte aus dem mittel- und osteuropäischen Raum akzeptieren geringere Löhne und schlechtere Arbeitsbedingungen. Damit eröffnen sich gerade im personen- und haushaltsbezogenen Dienstleistungsbereich neue Beschäftigungsmöglichkeiten. Insbesondere dann, wenn durch neue Angebote zusätzliche Nachfragepotentiale geweckt werden, kann Zuwanderung

\footnotetext{
${ }^{524}$ Siehe hierzu stellvertretend Kleinhenz, G.D. (2004), S. 88f.; Heilemann, U.; Löffelholz, H.D. von; Sieveking, K. (2003), S. 44ff.; Bellmann, L.; Leber, U. (2002), S. 98ff.; Laaser, U. (2000), S. $12 f$.

${ }^{525} \mathrm{Vgl}$. Bellmann, L.; Leber, U. (2002), S. 98. Zu den gesetzlichen Rahmenbedingungen für Zuwanderung siehe ausführlich Heilemann, U.; Löffelholz, H.D. von; Sieveking, K. (2003), S. 68ff.; Unabhängige Kommission Zuwanderung (2001), S. $59 f f$.

${ }^{526}$ Nach Sinn, H.-W. (2004) lässt diese Regelung aber die Zuwanderung Nicht-Erwerbstätiger in den Sozialstaat zu. Kontrovers hierzu BMGS (Hrsg.) (2004f). Siehe hierzu auch Richtlinie 2004/38/EG des Europäischen Parlaments und des Rates vom 29.04.2004, Amtsblatt der Europäischen Union, L 158, S. $77 \mathrm{ff}$.

${ }^{527}$ Siehe BGBI. 2004, Teil I, Nr. 41, S. 1950.

${ }^{528}$ Siehe stellvertretend Unabhängige Kommission Zuwanderung (2000), S. $71 \mathrm{ff}$.

${ }^{529}$ Vgl. Sinn, H.-W. u.a. (2001), S. 114ff., und die dort amgeggebeeg diterator.8-3-631-75223-4
} 
sogar Arbeitsplätze schaffen. Andererseits können ausländische Arbeitskräfte aber auch inländische Arbeitskräfte verdrängen und Druck auf die Reallöhne ausüben. Nach den meisten empirischen Studien beeinflusst Zuwanderung jedoch Reallohn und Beschäftigung der Einheimischen kaum. ${ }^{530}$

Sollen die Finanzen der GKV durch Zuwanderung stabilisiert werden, dann sind neben den allgemeinen Anforderungen (Aufnahme einer sozialversicherungspflichtigen Beschäftigung, keine Verdrängung von Beschäftigung) an die Zuwandernden besondere Anforderungen zu stellen: Erstens sollen die Arbeitskräfte in möglichst jungen Jahren zuwandern und bis zum Ende ihrer Erwerbsphase im Inland bleiben. Zweitens müssen sie so gut qualifiziert sein, dass sie die Anforderungen des hiesigen Arbeitsmarktes erfüllen. ${ }^{531}$

Zur ersten Anforderung: Werden ausschließlich direkte Effekte der Zuwanderung auf die Sozialversicherungssysteme und die öffentlichen Haushalte berücksichtigt und keine indirekten Effekte wie die oben beschriebenen Wachstumseffekte, sind nach einer Untersuchung des ifo Instituts ${ }^{532}$ Zuwanderer Nettoempfänger staatlicher Leistungen. Entscheidend dafür, ob ein Zugewanderter zu einem Nettozahler wird, ist seine Aufenthaltsdauer. Die empfangenen Leistungen aus der Sozialversicherung und vom Staat liegen bei einer Aufenthaltsdauer von weniger als 10 Jahren im Durchschnitt jährlich um 2.368 Euro über den gezahlten Sozialversicherungsbeiträgen und Steuern. Bei einer Aufenthaltsdauer von 10 bis 25 Jahren sinkt dieser Betrag auf 1.331 Euro pro Zuwanderer und Jahr. Erst bei einer Aufenthaltsdauer von mehr als 25 Jahren werden Zuwanderer zu Nettozahlern von jährlich 854 Euro pro Kopf, was auf eine erfolgreiche Integration schließen lässt.

In der GKV gehören insbesondere Zuwanderer mit einer Aufenthaltsdauer von weniger als 10 Jahren zu den Nettoleistungsempfängern in Höhe von durchschnittlich 590 Euro p.a. Bei einer Aufenthaltsdauer von 10 bis 25 Jahren (-43 Euro) und länger als 25 Jahren (+49 Euro) ist die Bilanz nahezu ausgeglichen. Dabei liegen die GKV-Beiträge von Zuwanderern im Durchschnitt 5 Prozentpunkte unter denen einheimischer GKV-Mitglieder, was in erster Linie auf die niedrigeren Arbeitsentgelte von Zuwanderern im Vergleich zu Einheimischen zurückzuführen ist. Hinzu kommt, dass aufgrund des im Vergleich zu Inländern geringeren Anteils von enwerbstätigen Ausländern nur $60 \%$ der ausländischen GKV-Versicherten Beitragszahler sind; bei den Einheimischen liegt dieser Anteil bei $70 \%$. Einnahmenschwächend wirken auch GKV-spezifische Merkmale der Zuwanderer: Der Anteil beitragsfrei mitversicherter Familienangehöriger unter den Zuwanderern liegt mit $41 \%$ deutlich höher als bei den Inländern (26\%) und ausländische GKV-Mitglieder sind im Durchschnitt kinderreicher (1,64 Kinder) als deutsche Mitglieder (1,60 Kinder). Dass Zuwanderer dennoch insbesondere dann, wenn sie länger in Deutschland leben, eine fast ausgeglichene GKV-Bilanz aufweisen, liegt an der günstigeren Altersstruktur der Zuwanderer. Der Anteil zugewanderter Rentner liegt mit $16 \%$ deutlich unter dem Anteil einheimischer

\footnotetext{
${ }^{530} \mathrm{Vgl}$. Straubhaar, T. (1997), S. 50ff., und die dort angegebene Literatur.

${ }^{531} \mathrm{Vgl}$. Oberdieck, V. (1998), S. $159 \mathrm{ff}$.

${ }^{532}$ Siehe Sinn, H.-W. u.a. (2001), S. 225ff. Zum gegenteiligen Ergebnis kommen andere Studien; siehe Unabhängige Kommission Zuwanderung (2000), S. 76ff. Diese berücksichtigen aber auch indirekte Wirkungen, was mit methodischen Schwiekigkeitee vektundergist-631-75223-4
} 
Rentner $(29 \%)$ an den GKV-Versicherten. Damit verbunden sind niedrigere durchschnittliche Ausgaben für die Gruppe der Zugewanderten ${ }^{533}$ In Zukunft schwächt sich dieser positive Effekt aber ab. Wie Bevölkerungsprojektionen zeigen, wird auch in der Gruppe der zugewanderten GKV-Versicherten bei einem Wanderungssaldo auf dem bisherigen jährlichen Niveau von plus 170.000 Personen der Altenquotient steigen und sich dem der einheimischen Bevölkerung annähern. ${ }^{534}$

Simulationsrechnungen zeigen zudem, dass die demographische Alterung selbst durch hohe Zuwanderungsüberschüsse nur verlangsamt werden kann. Bei einem jährlichen Wanderungssaldo von 100.000 Personen steigt der Altenquotient von 45 im Jahr 2003 bis zum Jahr 2050 auf 85, bei 200.000 Personen auf 78 und bei zunächst 200.000 Personen und ab dem Jahr 2011300.000 Personen auf $74 .^{535}$ Soll in Deutschland der Altenquotienten bis zum Jahr 2050 stabil gehalten werden, dann müssten nach Berechnungen der Vereinten Nationen ${ }^{536}$ im Zeitraum von 2000 bis 2050182 Mio. ${ }^{537}$ mehr Menschen ein- als auswandern, jährlich 3,6 Mio. Menschen. Die notwendige Zuwanderung ist so hoch, weil auch die Zugewanderten altern. Ein im Alter von 35 Jahren Zugezogener erhöht Z.B. 30 Jahre später den Altenquotienten. Die Bevölkerungszahl würde demnach von 82 Mio. auf 299 Mio. zunehmen. Dies zeigt, dass es nur mit extremem Bevölkerungswachstum möglich wäre, den Altenquotienten stabil zu halten, wobei die dafür erforderliche Einwanderung mit weiteren gesellschaftlichen und wirtschaftlichen Problemen verbunden wäre. Die Bevölkerung würde im Jahr 2050 zu einem Anteil von $80 \%$ aus nach dem Jahr 1995 Zugewanderten bestehen. Um das Erwerbstätigenpotential - die Gruppe der 15- bis 64jährigen - konstant zu halten, wäre vom Jahr 2000 bis zum Jahr 2050 eine NettoZuwanderung von 24 Mio. Personen notwendig. Das entspricht jährlich 0,5 Mio. Menschen. ${ }^{538}$

Nach Berechnungen von Felderer ${ }^{539}$ müssten selbst unter der Annahme von im Zeitverlauf konstanten Ausgabenprofilen bis zum Jahr 2015 und ab 2040 jährlich rund 1,5 Mio. Menschen netto zuwandern, um den Beitragssatz der GKV aus dem Jahr 1992 bis 2050 zu stabilisieren. In dem Zeitraum von 2020 bis 2040 wäre sogar eine jährlich Zuwanderung von bis zu 3,5 Mio. Menschen notwendig. Berücksichtigt man, dass seit 1992 die altersabhängigen Ausgaben bereits zugenommen haben und weiter ansteigen werden, ist eine noch höhere Nettozuwanderung notwendig.

Bislang wurde nur die benötigte Nettozuwanderung erfasst. Im Jahr 2003 standen aber den rund 600.000 Ausländern, die nach Deutschland eingewandert sind, rund 500.000 Personen gegenüber, die Deutschland verlassen haben. Wird dies berücksichtigt und die Bruttozuwanderung betrachtet, überschreitet die benötigte Zuwan-

\footnotetext{
${ }^{533}$ Vgl. Sinn, H.-W. u.a. (2001), S. 190ff., 195.

${ }^{534}$ Vgl. Birg, H. (2001), S. 21f., 51.

${ }^{535}$ Vgl. Statistisches Bundesamt (Hrsg.) (2003), S. 34. Zu ähnlichen Ergebnissen kommt auch Birg, H. (2001), S. 10 f.

${ }^{536}$ Siehe United Nations (Hrsg.) (2000), S. 3.

${ }^{537}$ In der Literatur wird die Zahl der Zuwandernden zumeist mit 188 Mio. Personen beziffert. Diese Angabe bezieht sich auf den Zeitraum 1995 bis 2050.

${ }^{538}$ Vgl. United Nations (Hrsg.) (2000), S. 25, 39.

${ }^{539}$ Siehe Felderer, B. (1994), S. $208 \mathrm{ff}$. 
derung die Integrationsmöglichkeiten noch deutlicher. Mit einer Zuwanderung in der gezeigten Größenordnung wären neben den oben beschriebenen Nettotransfers, die die Zuwanderer in der GKV erhalten, enorme Integrationskosten verbunden.

Nach der zweiten Anforderung sollten die Zuwanderer gut qualifiziert sein, um eine sozialversicherungspflichtige Beschäftigung ausüben zu können. Die Zuwanderung müsste demnach kurzfristig nach den herrschenden Knappheitsverhältnissen am Arbeitsmarkt gesteuert werden. Um die langfristige Integrationsfähigkeit sicherzustellen, müssten zudem Faktoren wie Alter, Ausbildung, Sprachkenntnisse, finanzielle Verhältnisse etc. beispielsweise nach einem Punktesystem berücksichtigt werden. ${ }^{540}$ Zu diesem Ergebnis kam auch die vom Bundesminister des Innern im Jahr 2000 einberufene „Unabhängige Kommission Zuwanderung ${ }^{4541}$, die mit Zuwanderung anhand eines Punktesystems dem demographischen Wandel - allerdings unabhängig von der jeweils aktuellen Lage auf dem Arbeitsmarkt - gegensteuern wollte. Da das Punktesystem im Gesetzgebungsverfahren gescheitert ist, wird hierauf nicht weiter eingegangen. Selbst bei Schaffung entsprechender Zuwanderungsmöglichkeiten durch den Gesetzgeber ist es fraglich, ob Zuwanderung in diesem Ausmaß steuerbar ist. Der Zuzug von Asylbewerbern, Flüchtlingen und Spätaussiedlern beruht auf humanitären und verfassungsrechtlichen Gründen, so dass nur ein Teil der Zuwanderung überhaupt gesteuert werden kann ${ }^{542}$ Darüber hinaus sind vor allem aus zwei Gründen Zweifel angebracht, ob junge und qualifizierte Menschen in dem benötigten $\mathrm{Maß}$ für eine Zuwanderung nach Deutschland zur Verfügung stehen. Erstens sind Arbeitnehmer weitgehend immobil. ${ }^{543}$ Zweitens betrifft die demographische Alterung die gesamte Weltbevölkerung. Der Anteil der über 65jährigen an der globalen Bevölkerung steigt von 7,3\% im Jahr 2005 bis zum Jahr 2050 (2300) auf 15,9\% $(32,3 \%) .{ }^{544}$ Die Weltbevölkerung wird zwar voraussichtlich von 6,5 Mrd. Menschen im Jahr 2005 bis 2050 auf 8,9 Mrd. Menschen wachsen, das Wachstum wird aber jährlich schwächer. Im Zeitraum 2075 bis 2175 wird sogar ein leichter Rückgang der weltweiten Bevölkerung erwartet. ${ }^{545}$ Eine Entlastung für den europäischen Arbeitsmarkt wird auch die Erweiterung der EU um zehn Länder aus Mittel- und Osteuropa im Mai 2004 nicht bringen. In allen neuen Mitgliedsländern schrumpft die Bevölkerung bis zum Jahr 2050 noch stärker als in den 15 alten EU-Ländern, wo die Bevölke-rung im Durchschnitt um 7,8 \% zurückgeht. ${ }^{546}$ Angesichts der hohen strukturellen Arbeitslosigkeit ist zudem zu bezweifeln, dass der deutsche Arbeitsmarkt flexibel genug ist, um die Arbeitskräfte auch aufzunehmen. Derzeit findet eher eine Zuwanderung in die sozialen Sicherungssysteme statt. Obwohl die Zahl der Ausländer in

\footnotetext{
${ }^{540}$ Vgl. Heilemann, U.; Löffelholz, H.D. von; Sieveking, K. (2003), S. 55ft.; Schäfer, H.; Seyda, S. (2005), S. $115 f$.

${ }^{541}$ Siehe Unabhängige Kommission Zuwanderung (2001), S. 84ff.

${ }^{542}$ Vgl. Heilemann, U.; Löffelholz, H.D. von; Sieveking, K. (2003), S. 53f. Wohl aus diesem Grund sah die Unabhängige Kommission Zuwanderung eine arbeitsmarktgesteuerte Zuwanderung über diese - nicht steuerbare - Zuwanderung hinaus vor.

${ }^{543}$ Siehe hierzu Berthold, N.; Neumann, M. (2004), S. 387ff., und die dort angegebene Literatur.

${ }^{544} \mathrm{Vgl}$. United Nations (Hrsg.) (2004), S. 70. Die Projektionen können auch im Internet unter http://esa.un.org/unpp/ abgerufen werden.

${ }^{545} \mathrm{Vgl}$. ebenda, S. 14.

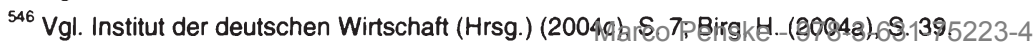


Deutschland stark zugenommen hat, ist kein Anstieg der Zahl der sozialversicherungspflichtig beschäftigten Ausländer festzustellen. ${ }^{547^{\prime}}$

\subsection{Erhöhung der Geburtenrate}

Langfristig gibt es zu einer Politik, die die Geburtenrate auf das bestandserhaltende Niveau von 2,1 Kindern je Frau anhebt, keine Erfolg versprechende Alternative. Zumal sich die Zugewanderten erfahrungsgemäß der niedrigeren Geburtenrate in Deutschland anpassen, würde der Bedarf an Einwanderern stetig steigen. ${ }^{548}$ Hinzu kommt, dass das Arbeitskräftepotential - hier gemessen als die Zahl der 20- bis 60jährigen nach einer Bevölkerungsvorausberechnung des Statistischen Bundesamtes - von 45,3 Mio. Personen im Jahr 2003 auf 44,1 Mio. Personen bis zum Jahr 2020 nur schwach abnimmt. Damit existiert noch ein kurzer Zeitraum, bis sich die Abnahme dramatisch beschleunigt. ${ }^{549}$

Um geeignete Maßnahmen zur nachhaltigen Erhöhung der Geburtenrate treffen zu können, müssen zunächst die Gründe für die niedrige Geburtenrate bekannt sein. Hier kommen die Umfragen zu unterschiedlichen Ergebnissen. Empirisch lassen sich zwei Besonderheiten für Deutschland feststellen: Zum einen entscheiden sich hierzulande die Menschen i.d.R. für zwei Kinder oder gegen Kinder. Zum anderen steigt die Kinderlosigkeit mit einem höheren Bildungsabschluss der Frauen. Die Gründe für die niedrige Geburtenrate sind vielfältig. Lipinski und Stutzer ${ }^{550}$ zählen sechs Gründe auf: Erstens führt der Wertewandel zu vielen Lebensformen, die nicht mit Kindern verbunden sind. Die Entscheidung für Kinder beinhaltet deshalb auch, auf andere Optionen wie Freiheit und Selbstverwirklichung zu verzichten. Zweitens ist eine stabile Partnerschaft die Grundvoraussetzung. Selbst die Ehe wird aber zunehmend als Lebensform für einen Zeitabschnitt betrachtet. Drittens genießen Kinder eine sehr hohe Wertschätzung, was dazu führt, dass zunehmend versucht wird, den idealen Zeitpunkt für den Nachwuchs zu planen. Diese bewusste Planung führt jedoch auch zur Entscheidung gegen Kinder, wenn aus Sicht des Paars keine perfekten Bedingungen vorliegen. Viertens gewinnt neben der Mutterschaft die Erwerbstätigkeit bei Frauen an Bedeutung. Bei der Geburt des ersten Kindes ist eine Frau daher im Durchschnitt älter als 29 Jahre. Die Vereinbarkeit von Familie und Beruf ist indes noch immer unzureichend. Betreuungsangebote und flexible Arbeitszeitmodelle fehlen. Hinzu kommt die problematische Lage auf dem Arbeitsmarkt, die eine Rückkehr in den Beruf und in eine qualifizierte Tätigkeit zusätzlich erschwert. Fünftens setzt der Wunsch nach Kinder Sicherheit und Stabilität voraus, die aufgrund der wirtschaftlichen Herausforderungen und der gesellschaftlichen Veränderungen immer weniger gegeben sind. Sechstens entscheiden sich Paare auch aus finanziellen Gründen gegen Kinder; denn Familien vertügen durchschnittlich über ein geringeres Pro-Kopf-Einkommen als Kinderlose.

\footnotetext{
${ }^{547}$ Vgl. Herzog-Kommission (2003), S. 11.

${ }^{548} \mathrm{Vgl}$. Birg, H. (2004b), S. 13. Für Berechnungen u.a. von Bevölkerungszahl und Altenquotient in Abhängigkeit von Geburtenrate und Zuwanderung für die EU-15 siehe Lutz, W.; Scherbov, S. (2003), S. $11 \mathrm{ff}$.

${ }^{549}$ Vgl. Statistisches Bundesamt (Hrsg.) (2003), S. 42. Siehe auch Birg, H. (2001), S. $16 f$.

${ }^{550}$ Siehe Lipinski, H.; Stutzer, E. (2004), S. 5ff. Marco Penske - 978-3-631-75223-4
} 
Die Handlungsfelder für die Politik sind damit umschrieben: Die Betreuungsangebote sollten ausgebaut und zusammen mit den Arbeitgebern flexible Arbeitszeitmodelle geschaffen werden. Eine stärkere und zielgenaue finanzielle Förderung reichen nicht aus, um die Geburtenrate zu erhöhen. Neben diesen strukturellen Verbesserungen müssen auch die gesellschaftlichen Bedingungen für Familien verbessert werden.

Selbst wenn es aber gelänge, bis zum Jahr 2030 die Geburtenrate auf das bestandserhaltende Niveau zu erhöhen, wäre der Bevölkerungsrückgang erst ab 2080 gestoppt. Bei einer jährlichen Netto-Zuwanderung von 150.000 jüngeren Menschen bliebe die Geburtenbilanz bis zum Jahr 2068 negativ, bei einer jährlichen NettoZuwanderung von 300.000 Menschen auch noch bis zum Jahr $2060 .^{551}$ Wollte man den Anstieg des Altenquotienten allein durch eine Steigerung der Geburtenrate verhindern, wäre eine Erhöhung der Geburtenrate von derzeit 1,4 Kindern je Frau auf 3,8 Kinder erforderlich. Diese Geburtenrate würde sogar noch das weltweit am höchsten liegende Niveau der Entwicklungsländer von durchschnittlich 3,0 Kindem pro Frau übertreffen. ${ }^{52}$ Ursächlich für die Trägheit der demographischen Entwicklung auf Änderungen ist, dass der Bevölkerungsrückgang nicht auf eine weiter sinkende Geburtenrate zurückzuführen ist - diese wird in der verwendeten Bevölkerungsvorausberechnung als konstant angenommen -, sondern dass die zurückgehende Zahl potentieller Eltern in der gegenwärtigen Bevölkerungsstruktur angelegt ist. Dieser Rückgang lässt sich somit durch einen Geburtenanstieg nicht kurztristig stoppen, weil die zusätzlich geborenen Kinder ihrerseits erst wieder Kinder haben müssen, damit die Zahl der Gestorbenen durch Neugeborene ausgeglichen wird. ${ }^{553}$

Für die Finanzen der GKV bringt eine Steigerung der Geburten ohnehin nur langfristig Entlastung. Steigt die Geburtenrate der heimischen Bevölkerung, dann dauert es mindestens 20 Jahre bis die Zahl der Erwerbstätigen und damit die Zahl der Beitragszahler steigt. In der Zwischenzeit müssen die GKV-Ausgaben für Kinder aber auch aus den Beiträgen der Mitglieder finanziert werden. In diesem Zusammenhang hat Migration einen Vorteil für die GKV-Einnahmen: Einwanderer stehen dem Arbeitsmarkt und den Kassen als Beitragszahler grundsätzlich sofort zur Verfügung. Für beide Gruppen gilt jedoch, dass sie gut ausgebildet sein müssen, um die Finanzen der GKV zu entlasten und um das Wirtschaftswachstum positiv zu beeinflussen.

\subsection{Fazit: Demographischer Wandel kaum kompensierbar}

Eine Verlängerung der Arbeitszeit kann - wie gezeigt wurde - aufgrund des großen Einflusses von Teilzeitbeschäftigung im Wesentlichen nur erreicht werden, wenn insbesondere Frauen eine höhere Erwerbsbeteiligung anstreben. Addiert man die oben dargestellten Erwerbspersonenpotentiale, die sich aus einer höheren Erwerbsbeteiligung von Jugendlichen, Älteren und Frauen ergeben, zeigt sich, dass eine bessere Ausschöpfung des Arbeitskräftepotentials bis zum Jahr 2025 4,1 Mio. zusätzliche Erwerbspersonen rekrutieren könnte. Der enwartete Rückgang des Arbeitsangebots um etwa 10 Mio. Beschäftigte bis zum Jahr 2050 kann damit aber nicht kompensiert

\footnotetext{
${ }^{551}$ Vgl. Birg, H. (2004b), S. 13.

${ }^{552}$ Vgl. Birg, H. (2000), S. $22 f$.

${ }^{553}$ Vgl. Birg, H. (2001), S. 7ff.
} 
werden. Die entlastende Wirkung einer höheren Erwerbstätigkeit von Frauen auf den Beitragssatz der GKV hat Dudey ${ }^{554}$ berechnet. Im Vergleich zum Referenzszenario, das konstante Einnahmen und Ausgaben unterstellt und den demographisch bedingten Beitragssatzeffekt abbildet, steigt der Beitragssatz bis zum Jahr 2030 nicht auf $16,7 \%$, sondern bei einer Erhöhung der Erwerbstätigenquote von Frauen um 15 Prozentpunkte auf $15,1 \% .{ }^{555}$ Nicht berücksichtigt werden dabei allerdings negative Rückwirkungen, die dann auftreten können, wenn infolge einer zunehmenden Erwerbsbeteiligung von Frauen die Geburtenrate sinkt.

Angesichts des quantitativen Ausmaßes arbeitsmarktbezogener Zuwanderung und der Probleme, die mit einer Steuerung einhergehen, kann auch Zuwanderung die auf die GKV zukommende demographische Belastung - wenn überhaupt - nur dämpfen, aber keinesfalls vollständig kompensieren ${ }^{556} \mathrm{Nach}$ Berechnungen von Dudey ${ }^{557}$ führt selbst eine Nettoimmigration von jährlich 400.000 Personen nur langfristig und dann auch nur zu geringen Entlastungen. Gegenüber dem demographisch bedingten Beitragssatzanstieg auf 16,7\% im Jahr 2030 sinkt in den Berechnungen der Beitragssatz auf 15,7\%. Dabei wird allerdings unterstellt, dass Zuwanderer die gleiche Qualifikation aufweisen wie in Deutschland bereits beschäftigte Arbeitnehmer, so dass der beitragssatzentlastende Effekt überzeichnet werden dürfte. ${ }^{558}$

Zu keinen wesentlichen Entlastungen für den Beitragssatz führt auch die Steigerung der Fertilität. Sie ist zwar nicht so problembehaftet wie Zuwanderung, hat aber einen gravierenden Nachteil: Die intergenerative Ungleichbehandlung bleibt selbst bei steigender Geburtenrate für die Erwerbstätigengeneration bestehen, weil diese die Gesundheitsleistungen der Rentner und der dann gewachsenen Zahl eigener Kinder finanzieren müsste.$^{559}$ In der Übergangsphase würde sogar der Beitragssatz steigen, da Kinder zunächst nur Leistungen in Anspruch nehmen, ohne eigene Beiträge zu entrichten. Ein deutlicher Anstieg der Nettoreproduktionsrate ${ }^{560}$ von 0,67 im früheren Bundesgebiet und 0,42 in den neuen Bundesländern auf jeweils 0,8 führt nach Berechnungen von Dudey ${ }^{561} \mathrm{im}$ Jahr 2030 zu einem geringen Beitragssatzrückgang auf $16,3 \%$ statt $16,7 \%$. Eine Zunahme der Fertilität würde den durch die demographische Entwicklung verursachten Beitragssatzanstieg - wenn überhaupt - nur langfristig und begrenzt dämpfen.

Selbst die Kombination der beschriebenen Maßnahmen kann allenfalls den Einfluss der demographischen Entwicklung auf die Finanzierung der GKV reduzieren. Dabei ist der beitragssatzsteigernde Effekt des medizinisch-technischen Fortschritts nicht

${ }^{554}$ Siehe Dudey, S. (1993), S. 21ff., 31ff., Anhang, S. 10.

${ }^{555}$ Die Erhöhung der Erwerbstätigenquote von Männern und Frauen um jeweils 2,25 Prozentpunkte liefert bescheidenere Ergebnisse: Der Beitragssatz steigt bis 2030 auf 16,15\%; vgl. Dudey, S. (1993), S. 31f., Anhang, S. 9.

${ }^{556}$ Siehe hierzu stellvertretend Birg, H. (2000), S. 22; Unabhängige Kommission Zuwanderung (2001), S. 69; Ulrich, V. (1995), S. 43f.

${ }^{557}$ Siehe Dudey, S. (1993), S. 26, Anhang, S. 5.

${ }^{558}$ Vgl. Dudey, S. (1993), S. 27.

${ }^{559} \mathrm{Vgl}$. Schulenburg, J.-M. Graf von der (1989b), S. 294.

${ }^{560}$ Zahl der lebendgeborenen Mädchen je Frau.

${ }^{561}$ Siehe Dudey, S. (1993), S. 22, 34, Anhang, S. 11, wobei im Anhang offensichtlich Spalten vertauscht wurden. 
einmal berücksichtigt. Um die mit einem Beitragssatzanstieg verbundenen negativen Wirkungen auf Wachstum und Beschäftigung zu vermeiden und die nachhaltige Finanzierbarkeit zu gewährleisten, sind andere Finanzierungsformen notwendig.

\section{Alternative Finanzierungssysteme im Umlageverfahren}

\subsection{Steuerfinanzierung}

Ein vollkommen steuerfinanziertes Gesundheitssystem, wie es in Großbritannien oder Dänemark existiert, steht in Deutschland als Reformziel nicht zur Diskussion. Dies würde eine vollständige Abkehr vom Äquivalenz- und damit auch vom Versicherungsprinzip bedeuten. Die Versicherten verlören ihre Versicherungsansprüche; denn das Wesen einer allgemeinen Steuer liegt nach § 3 Abs. 1 Abgabenordnung darin, dass sie von den Steuerpflichtigen erhoben werden, „ohne ihnen einen Anspruch auf irgendwelche Gegenleistungen zu gewähren ${ }^{4562}$. Der Zusammenhang zwischen Beitrag und Leistungsinanspruchnahme würde sowohl für die einzelnen Versicherten als auch für das Versichertenkollektiv aufgehoben werden, womit mangelnde Transparenz und weitere Ineffizienzen verbunden wären. Die Verteilungswirkungen wären noch diffuser als im derzeitigen System und die Eigenverantwortung der Versicherten würde abnehmen. Zudem hätten die Versicherten keinen materiellen Anreiz zur Wahl effizienter Versorgungsformen. Der Versicherungswettbewerb würde bei einer Einheitsversicherung abgeschafft. Individuellen Präferenzen könnte ein steuerfinanziertes Gesundheitswesen nicht Rechnung tragen. Der Leistungskatalog wäre eine Folge der jährlichen Haushaltsberatungen und abhängig von staatlichen Einnahmen und konkurrierenden Staatsausgaben. ${ }^{563}$

Zur Senkung des Beitragssatzes und zur Stärkung des Versicherungsgedankens wird allerdings vorgeschlagen, die versicherungsfremden Leistungen der GKV aus Bundeszuschüssen zu finanzieren. ${ }^{564}$ Versicherungsfremde Leistungen lassen sich in einer engen und einer weiten Abgrenzung definieren ${ }^{565} \mathrm{Im}$ engeren Sinne werden Fremdleistungen als "Leistungen definiert, die aus gesellschafts-, sozial- oder familienpolitischen Gründen der GKV vom Gesetzgeber ohne Übernahme der damit verbundenen Ausgaben übertragen worden $\operatorname{sind}^{4566}$. Es handelt sich dabei um Ausgaben, die nicht der Verhütung oder Behandlung von Krankheiten dienen. Versicherungsfremde Leistungen, die nach dem SGB V gewährt werden, z.B. bestimmte Leistungen während der Mutterschaft, beliefen sich nach Berechnungen von Beske und

\footnotetext{
${ }^{562}$ Neumark, F. (1970), S. 18.

${ }^{563} \mathrm{Zu}$ den Gegenargumenten siehe ausführlich SVR KAiG (1994), Ziff. 508ff.; SVR KAiG (1995), Ziff. 559f.; SVR KAiG (1998), Ziff. 540ff., 592, 595.

${ }^{564}$ Vgl. Schmähl, W. (1989), S. 323ff.; SVR (2000), Ziff. 484; Schwarz, W. (2002), S. 54; Beske, F. u.a. (2002), S. 80ff., Bach, S.; Steiner, V.; Teichmann, D. (2002), S. 24; Kroker, R.; Pimpertz, J. (2005), S. 290. Einen Überblick über die Diskussion geben Klose, J.; Schellschmidt, H. (2001), S. $11 \mathrm{ff}$.

${ }^{565}$ Zu unterschiedlichen Definitionsmöglichkeiten siehe Kostorz, P. (1998), S. 125ff. Der SVR (2005), Ziff. 483, unterscheidet zwischen versicherungsfremden Leistungen im Leistungskatalog der GKV und versicherungsfremden Umverteilungselementen. Dies entspricht der hier gewählten Einteilung in versicherungsfremde Leistungen i.e.S. und i.w.S.
}

${ }^{566}$ Beske, F. (2001), S. 107.

Marco Penske - 978-3-631-75223-4 
Drabinski $^{567}$ im Jahr 2004 auf rund 1,64 Mrd. Euro. Die Ausgaben der GKV für versicherungsfremde Leistungen in dieser Abgrenzung fasst Tabelle 17 zusammen.

Tabelle 17: Versicherungsfremde Leistungen i.e.S. im Jahr 2004

\begin{tabular}{|c|c|c|}
\hline Art der Leistung & Gesetzliche Grundlage & $\begin{array}{l}\text { Ausgaben } \\
\text { (in Mrd. Euro) }\end{array}$ \\
\hline Medizinische Vorsorgeleistungen & $\S 23$ SGB V & 0,14 \\
\hline $\begin{array}{l}\text { Medizinische Vorsorge und Rehabilitation für Mütter } \\
\text { und Väter (Kuren) }\end{array}$ & $\S \S 24,41$ SGB V & 0,36 \\
\hline $\begin{array}{l}\text { Empfängnisverhütung sowie Schwangerschaftsabbruch } \\
\text { und Sterilisation außer bei medizinischer Indikation }\end{array}$ & $\S \S 24 a, 24 b$ SGB V & 0,17 \\
\hline Haushaltshilfe & $\S 38$ SGB V & 0,23 \\
\hline Krankengeld bei Erkrankung des Kindes & $\S 45$ SGB V & 0,11 \\
\hline Mutterschaftsgeld & $\S 200$ RVO & 0,62 \\
\hline $\begin{array}{l}\text { Künstliche Befruchtung, hauswirtschaftliche Versor- } \\
\text { gung. Soziotherapie, Förderung von Einrichtungen zur } \\
\text { Verbraucher- und Patientenberatung, Unterstützung der } \\
\text { Versicherten bei Behandlungsfehlern }\end{array}$ & $\S \S 27 a, 37,65 b, 66$ SGB V & 0,01 \\
\hline Summe & & 1,64 \\
\hline
\end{tabular}

Quelle: In Anlehnung an Beske, F.; Drabinski, T. (2004a), S. 29. Für Erläuterungen zu einzelnen Leistungen siehe Beske, F.; Kern, A.O. (2000), S. $18 f f$.

Im Jahr 2004 wurden durch das GMG Sterbegeld und Entbindungsgeld aus dem Leistungskatalog der GKV gestrichen. Diese Leistungen werden deshalb in Tabelle 17 nicht mehr aufgeführt. Außerdem müssen Versicherte seitdem künstliche Befruchtung und Sterilisation teilweise selbst tragen. Die versicherungsfremden Leistungen wurden dadurch im Vergleich zum Jahr 2003 um 0,52 Mrd. Euro reduziert. In der „Verordnung über die Verteilung der pauschalen Abgeltung für Aufwendungen der Krankenkassen für versicherungsfremde Leistungen durch den Bund und zur Änderung der Risikostruktur-Ausgleichsverordnung ${ }^{4568}$ hat der Gesetzgeber versicherungsfremde Leistungen mit einem Volumen von rund 3,2 Mrd. Euro im Jahr 2003 aufgeführt. Die Aufstellung weicht aber von der oben bemühten Definition ab. So werden u.a. ärztliche Betreuung bei Schwangerschaft, Hebammenhilfe, stationäre Entbindung und häusliche Pflege bei Schwangerschaft und Mutterschaft zu den versicherungsfremden Leistungen gezählt. Diese Leistungen in Höhe von rund 2,2 Mrd. Euro werden fortan als Auftragsleistungen der GKV vom Bund finanziert. Andererseits werden aber versicherungsfremde Leistungen in Höhe von rund 0,5 Mrd. Euro für medizinische Vorsorgeleistungen, künstliche Befruchtung und die Unterstützung der Versicherten bei Behandlungsfehlern nicht aufgeführt. ${ }^{569}$

Für versicherungsfremde Leistungen wurde mit dem GMG in §221 SGB V erstmals $^{570}$ ein an die GKV zu zahlender Bundeszuschuss eingeführt. Dieser beträgt

\footnotetext{
${ }^{567}$ Siehe Beske, F.; Drabinski, T. (2004a), S. 27ff. Vgl. auch Beske, F. u.a. (2002), S. 115.

${ }^{568}$ Siehe BGBI. 2004, Teil I, Nr. 19, S. 644.

${ }^{569} \mathrm{Vgl}$. Beske, F.; Drabinski, T. (2004a), S. $29 \mathrm{ff}$.

${ }^{570}$ Mit der Bundesknappschaft erhält zwar ein Träger der GKV bereits Bundeszuschüsse; vgl. Schwarz, W. (2002), S. 54. Dieser Bundeszuschuss von 7,3 Mrd. Euro (2003) wird aber in der knappschaftlichen Rentenversicherung und nicht in der knappschaftlichen Krankenversicherung als Einnahme verbucht; siehe Bundesknappschaft (Hrsgcb(2004) kS.-1955-3-631-75223-4
} 
für das Jahr $20041 \mathrm{Mrd}$. Euro, in 2005 2,5 Mrd. Euro und ab 2006 4,2 Mrd. Euro. Der Bundeszuschuss ist zweckgebunden, er muss nach $\S 220$ Abs. 4 SGB V zu Beitragssatzsenkungen verwendet werden. Ab 2006 übersteigt der Bundeszuschuss allerdings die im Gesetz aufgeführten Ausgaben. Diese Überkompensation ist derzeit nicht geregelt, mithin die vollständige Zahlung unsicher, so dass es auch ab $2006 \mathrm{zu}$ einer Belastung der GKV in Höhe der nicht aufgeführten Leistungen von 0,5 Mrd. Euro kommen kann. Zudem soll der Bundeszuschuss nach dem Koalitionsvertrag ${ }^{571}$ zwischen CDU, CSU und SPD wieder abgeschafft werden. Erlangt das sogenannte Präventionsgesetz ${ }^{572}$ in der vorliegenden Form Gesetzeskraft, würde die GKV sogar zur Finanzierung einer weiteren gesamtgesellschaftlichen Aufgabe herangezogen. Mit zunächst 180 Mio. Euro hätte die GKV Präventionsmaßnahmen zu finanzieren. Insgesamt soll die Gesundheitsvorsorge mit 250 Mio. Euro jährlich gefördert werden, die restlichen Beträge übernehmen die Gesetzliche Rentenversicherung (40 Mio. Euro), Unfallversicherung (20 Mio. Euro) und Pflegeversicherung (10 Mio. Euro).

Aus ordnungspolitischen Gesichtspunkten sollten gesamtgesellschaftliche Aufgaben aus dem Gesamtbudget, mithin nicht nur von den GKV-Mitgliedern, sondern von allen Steuerpflichtigen finanziert werden. Versicherungsfremde Leistungen in der GKV führen zu allokativen Verzerrungen, weil der Beitragssatz als Preis nicht die Knappheit signalisiert. ${ }^{573}$ Zur Finanzierung ist eine gezielte Erhöhung bestimmter Steuern möglich, wobei hier das Non-Affektationsprinzip berücksichtigt werden muss. Eine Zweckbindung von Mitteln z.B. zugunsten der GKV ist nach $\S 7$ Haushaltsgrundsätzegesetz nicht zulässig. Der im GMG beschlossene Bundeszuschuss wird zwar aus dem allgemeinen Steueraufkommen aufgebracht; allerdings wurde dafür eine Erhöhung der Tabaksteuer in mehreren Stufen beschlossen.$^{544}$ Weil gerade vom Rauchen gesundheitsschädliche Wirkungen ausgehen, soll die erhöhte Besteuerung neben dem Einnahmenzweck der Prävention dienen und nicht zuletzt auch Kosten für die GKV sparen. ${ }^{575} \mathrm{Im}$ März und Dezember 2004 sowie im September 2005 wurde die Steuer jeweils um 1,2 Cent je Zigarette erhöht. Die Mehreinnahmen werden aber voraussichtlich nicht ausreichen, um den Bundeszuschuss zu finanzieren. Die Erhöhung kann sogar zu einem Rückgang des Konsums und damit des Tabaksteueraufkommens führen, wenn Raucher stärker auf steuerbegünstigte Produkte (z.B. Feinschnitt) ausweichen oder ihre Zigaretten im grenznahen Ausland oder auf dem Schwarzmarkt kaufen. Für die Jahre 2005 und 2006 wird die Erhöhung des Aufkommens aus der Tabaksteuer auf jeweils lediglich 0,5 Mrd. Euro geschätzt. ${ }^{576}$ Wird an der Höhe der Bundeszuschüsse festgehalten, müssen allgemeine Haushaltsmittel die Finanzierungslücke schließen. Aus ordnungspolitischer Sicht

\footnotetext{
${ }^{571}$ Siehe Christlich Demokratische Union Deutschlands; Christlich-Soziale Union in Bayern; Sozialdemokratische Partei Deutschlands (Hrsg.) (2005), S. 68.

${ }^{572}$ Siehe Bundestags-Drucksache 15/4833 vom 15.02.2005, S. 26.

${ }^{573}$ Vgl. Pimpertz, J. (2002), S. 32.

${ }^{574}$ Siehe BGBI. 2003, Teil I, Nr. 66, S. 2924.

${ }^{575}$ Vgl. Adams, M. (2001), S. 10. Nach Krämer, W. (1997), S. 14; Wigger, B.U. (2005), S. 519, werden die gesellschaftlichen Kosten des Rauchens jedoch überschätzt, weil erstens Raucher früher sterben und damit für die sozialen Sicherungssysteme Kosten sparen und zweitens auch Nichtraucher Sterbekosten verursachen.

${ }^{576}$ Siehe Arbeitsgemeinschaft deutscher wirtschaftswissenschaftlicher Forschungsinstitute e.V. (Hrsg.) (2005b), S. 44. 
wäre es ohnehin besser gewesen, die versicherungsfremden Leistungen vollständig aus der GKV auszugliedern und in den Bundeshaushalt zu übertragen. Mit der nun getroffenen Regelung erhalten nur GKV-Versicherte die von allen Steuerzahlern finanzierten versicherungsfremden Leistungen. Zudem wächst die Intransparenz. ${ }^{577}$

Ein höherer als der im GMG geregelte Bundeszuschuss ist notwendig, wenn besondere Beitragsregelungen infolge des Leistungsfähigkeitsprinzips auch als versicherungsfremde Leistungen aufgefasst werden. Die Mindereinnahmen der GKV, die dadurch entstehen, dass bestimmte Versichertengruppen wie Familienangehörige oder Studenten keine bzw. nur ermäßigte Beiträge zahlen, müssten dann auch aus allgemeinen Haushaltsmitteln gedeckt werden. Für versicherungsfremde Leistungen i.w.S. wäre je nach Schätzung ein weiterer Bundeszuschuss in einer Größenordnung von 20 bis 30 Mrd. Euro p.a. nötig. ${ }^{578}$ Jüngste Berechnungen des Sachverständigenrates zur Begutachtung der gesamtwirtschaftlichen Entwicklung ${ }^{579}$ beziffern die Umverteilung aufgrund der kostenlosen Familienversicherung sogar auf 38,7 Mrd. Euro p.a., wovon 25,0 Mrd. Euro auf Leistungsausgaben für diese Versichertengruppe und 13,7 Mrd. Euro auf nicht gezahlte, darüber hinaus gehende Beiträge entfallen.

Würden die Gesundheitsausgaben für Kinder (2004: 13,9 Mrd. Euro ${ }^{580}$ ) als gesamtgesellschaftliche Aufgabe aus Steuermitteln finanziert werden, könnte der Beitragssatz um etwa 1,5 Prozentpunkte ${ }^{581}$ sinken. Familien könnten jedoch mit einem höheren Kindergeld zielgenauer gefördert werden; denn auch Kinderlose würden von der Beitragssatzsenkung profitieren. ${ }^{582}$ Effizienter wäre es ohnehin, von allen Versichertengruppen äquivalente Beiträge zu erheben und Versicherte, bei denen der Beitrag eine als akzeptabel betrachtete Eigenbelastung übersteigt, mit staatlichen Transfers zu unterstützen.

Ein von Gewerkschaftsseite ${ }^{583}$ vorgeschlagener - über die Finanzierung versicherungsfremder Leistungen hinausgehender - regelgebundener Zuschuss, der sich an der Höhe der Lohnquote orientieren und für stabilere GKV-Einnahmen sorgen soll, ist abzulehnen. Grundsätzlich schwächt eine steuerliche Kofinanzierung der GKV über die versicherungsfremden Leistungen hinaus das Versicherungsprinzip und führt zu den genannten Problemen. Unter wettbewerblichen und verfassungsrechtlichen ${ }^{584}$ Aspekten ist zudem problematisch, dass der Zuschuss unmittelbar den Wettbewerb

${ }^{577}$ Vgl. SVR (2003), Ziff. 292.

${ }^{578}$ Vgl. Beske, F. (2001), S. 107ff; Beske, F.; Drabinski, T. (2004a), S. 48ff. Siehe hierzu auch Kapitel II.4.3.2 Abhängigkeit von der Versichertenstruktur, S. 55.

${ }^{579}$ Siehe SVR (2005), Ziff. 488, 500.

${ }^{580}$ Vgl. Rürup, B.; Wille, E. (2004), S. 14; eigene Berechnung. Vgl. auch Henke, K.-D. (2005), S. 106.

${ }^{581}$ Eigene Berechnung. Ein Beitragssatzpunkt in der GKV entspricht jährlichen Einnahmen von 9,6 Mrd. Euro; siehe BMGS (Hrsg.) (2005a), S. 2.

${ }^{582}$ Vgl. Eekhoff, J. (2005), S. 16; SVR (2005), Ziff. $531 f$.

${ }^{583}$ Vgl. IG Metall (Hrsg.) (2001), S. 375; Vereinte Dienstleistungsgewerkschaft e.V. (Hrsg.) (2001), S. 12. Siehe auch Horn, G.-A. (2005), S. 7. Zu den unterschiedlichen - mit einer stärkeren Steuerfinanzierung verbundenen - Zielsetzungen siehe Wagner, G.G. (2005), S. $283 \mathrm{ff}$.

${ }^{584}$ Zur verfassungsrechtlichen Problematik siehe Bieback, K.-J. (2005), S. 99f. Sodan, H. (2003), $S$. 3ff., hält auch die Steuerfinanzierung versicherungsfremder Leistungen für verfassungswidrig, bleibt allerdings den Nachweis, welche versicherungsfremden Leistungen die PKV erbringt, schuldig. 
zwischen PKV und GKV verzerrt und nur GKV-Versicherte profitieren. Die politische Durchsetzbarkeit ist in Anbetracht defizitärer Haushalte ohnehin gering. In der Vergangenheit ist bis auf die Einführung eines Bundeszuschusses im Rahmen des GMG eher umgekehrt die GKV zugunsten der öffentlichen Haushalte belastet worden. Damit stellt sich die Frage der Finanzierung der Zuschüsse an die GKV und der damit verbundenen gesamtwirtschaftlichen Wirkungen.

Grundgedanke, der hinter allen Vorschlägen einer Finanzierung von Gesundheitsausgaben über Steuern steht, ist es, die für Erwerbstätige bis zur Beitragsbemessungsgrenze wie eine proportionale Lohnsteuer wirkenden GKV-Beiträge zu senken, um damit Arbeitsnachfrage und Arbeitsangebot positiv zu beeinflussen. Die Finanzierung über eine Erhöhung der Einkommensteuer kommt deshalb nicht in Betracht ${ }^{585}$, auch wenn sie unter distributiven Gesichtspunkten gegenüber der Erhöhung einer indirekten Steuer vorzuziehen wäre. ${ }^{586}$ Aus allokativen Gründen wird vorgeschlagen, eine indirekte Steuer zu erhöhen, diskutiert wird vor allem eine Anhebung der Umsatzsteuer.

Da die Mehrwertsteuer der Konzeption nach den Konsum besteuert und Investitionen steuerfrei lässt, werden ihr geringere Wirkungen auf Wachstum und Beschäftigung zugeschrieben als der Einkommensteuer oder der praktizierten Beitragserhebung in der GKV. Tatsächlich wird aber auch ein Teil der gesamtwirtschaftlichen Investitionen besteuert. Der private Hausbau, Investitionen der öffentlichen Hand und Investitionen von nicht umsatzsteuerpflichtigen Unternehmen (z.B. Kleinunternehmen nach § 19 Umsatzsteuergesetz) unterliegen der Mehrwertsteuer. Auf der anderen Seite sind Mieten und ärztliche Leistungen steuerfrei, so dass Teile des Konsums nicht besteuert werden. Außerdem wird die Mehrwertsteuer - sofern die Überwälzung auf die Preise nicht gelingt und kein Gewinn vorliegt - zu einer Substanzsteuer. Gelingt die Überwälzung und steigen die Preise trotz gesunkener Lohnnebenkosten, dann können die gestiegenen Preise zeitverzögert zu höheren Lohnabschlüssen führen, womit der Beschäftigungseffekt geschmälert wird. Demgegenüber nehmen bei einer Senkung der Beiträge zur GKV das verfügbare Einkommen und damit tendenziell auch der Konsum zu, was beschäftigungsfördernd wirkt. Allerdings dürfte bei einer Erhöhung der Umsatzsteuer die Schwarzarbeit steigen, und die ohnehin schon schwache Binnennachfrage könnte durch eine höhere Umsatzsteuer geschwächt werden. ${ }^{587}$ Gleichzeitig werden jedoch Exporte von der Umfinanzierung entlastet, da die Umsatzsteuer grundsätzlich nach dem Bestimmungslandprinzip erhoben wird und Exporte steuerfrei sind. Damit steigt die Wettbewerbsfähigkeit von im Inland produzierenden Unternehmen, was zu einem höheren Außenbeitrag und zusätzlicher Beschäftigung führen kann. ${ }^{588}$

Die Beschäftigungswirkungen einer Erhöhung der Verbrauchsteuern zur aufkommensneutralen Senkung von Sozialversicherungsbeiträgen sind daher umstritten.

\footnotetext{
${ }^{585}$ Vgl. Peffekoven, R. (2005), S. 279.

${ }^{586} \mathrm{Vgl}$. SVR KAiG (1995), Ziff. 560. Zu den allokativen und distributiven Wirkungen einer Erhöhung der Einkommensteuer bei gleichzeitiger Senkung des Beitragssatzes zur GKV siehe SVR (2005), Ziff. $561 \mathrm{ff}$.

${ }^{587}$ Vgl. Peffekoven, R. (2005), S. 280f.; Feil, M.; Zika, G. (2005), S. 3.

${ }^{588}$ Vgl. SVR (2005), Ziff. 552. 
Berechnungen des Sachverständigenrates für die Konzertierte Aktion im Gesundheitswesen ${ }^{589}$ zeigen, dass bei einer Erhöhung des Normalsatzes der Mehrwertsteuer um einen Prozentpunkt und aufkommensneutraler Senkung des Beitragssatzes zur GKV nach drei Jahren die Beschäftigung im gesamten Bundesgebiet um 70.000 Personen ansteigt. Die Wachstumswirkungen sind mit plus 0,2 Prozentpunkten ebenfalls gering. Berechnungen von Feil und Zika ${ }^{590}$ kommen zu ähnlichen Ergebnissen. Langfristig steigt die Beschäftigung um 65.000 bis 90.000 Personen, wenn der Beitragssatz zur Sozialversicherung bei aufkommensneutraler Anhebung der Mehrwertsteuer um einen Prozentpunkt sinkt. Auch andere Studien kommen zu eher geringen, teilweise sogar negativen Wirkungen auf Wachstum und Beschäftigung. ${ }^{591}$

Positivere, wenn auch gleichfalls umstrittene, Beschäftigungseffekte bewirkt eine Erhöhung der Energiebesteuerung zur Senkung der Sozialversicherungsbeiträge. Eine Anhebung des "repräsentativen“ Mineralölsteuersatzes um etwa 1,5 Euro soll langfristig einen Beschäftigungsanstieg von 100.000 Enwerbstätigen zur Folge haben. ${ }^{592}$ Die Finanzierung über eine Erhöhung der speziellen Verbrauchsteuern würde die Wachstumsschwäche der GKV-Einnahmen aber festigen, da diese schwächer als das BIP zunehmen. ${ }^{593}$ Wenn die gewünschten Lenkungseffekte eintreten, sind weitere Steuererhöhungen notwendig. Spezielle Verbrauchsteuern sind daher als langfristige Finanzierungsquelle nicht geeignet.

Problematisch sind die mit der Besteuerung des Verbrauchs verbundenen Verteilungswirkungen. Die Umsatzsteuer hat eine regressive Wirkung, weil Bezieher kleiner Einkommen aufgrund ihrer höheren Konsumquote relativ stark belastet werden. Allerdings wird dieser Effekt dadurch abgeschwächt, dass mit Mieten und Nahrungsmitteln die größten Ausgabenblöcke bei kleineren Einkommen steuerfrei sind bzw. dem ermäßigten Umsatzsteuersatz unterliegen. ${ }^{594}$ Die zahlreichen Steuerermäßigungen in $\S 12$ Abs. 2 Umsatzsteuergesetz führen jedoch zu allokativen Verzerrungen, da sie Anbieter mit Waren zum ermäßigten Umsatzsteuersatz gegenüber denjenigen, deren Güter dem Normalsatz unterliegen, begünstigen. Sie sind zudem wenig zielgenau, da auch Bezieher hoher Einkommen von den Vergünstigungen profitieren. Eine Abschaffung oder zumindest Einschränkung hätte zwar - solange Bedürttige keine entsprechenden Transferzahlungen erhalten - eine leicht regressive Wirkung,

${ }^{589}$ Siehe SVR KAiG (1998), Ziff. 43ff., Tabelle A5.

${ }^{590}$ Siehe Feil, M.; Zika, G. (2005), S. 3f.

${ }^{591}$ Vgl. Hein, E. U.a. (2004), S. 299ff.; Weeber, J. (2004), S. 21f.; SVR (2005), Ziff. 550, und die dort jeweils angegebenen Studien. Nach Berechnungen von Bach, S.; Steiner, V.; Teichmann, D. (2002), S. 2, 23ff., hingegen würde eine Finanzierung der Sozialversicherungssysteme über Steuern und im Wesentlichen lohnunabhängige Beiträge 290.000 bis 1.000 .000 zusätzliche Arbeitsplätze schaffen. Finanziert würden die Bundeszuschüsse allerdings mit einer Erhöhung der Mehrwertsteuer um 4 Prozentpunkte, der Grund- und Erbschaftsteuer um $370 \%$ und einer Verbreiterung der Bemessungsgrundlage der Einkommensteuer.

${ }^{592}$ Vgl. Hein, E. u.a. (2004), S. 298ff., und die dort angegebene Literatur, wobei der Quelle nicht zu entnehmen ist, was mit repräsentativ gemeint ist und was die Bezugsgröße für die Erhöhung ist.

${ }^{593} \mathrm{Vgl}$. Wille, E. (2003b), S. 111.

${ }^{594} \mathrm{Zu}$ den Verteilungswirkungen der Umsatzsteuer siehe Bundesministerium der Finanzen (Hrsg.)

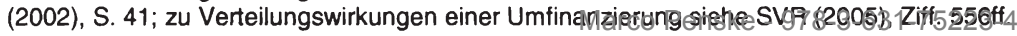


könnte aber ceteris paribus jährliche Mehreinnahmen von $16 \mathrm{Mrd}$. Euro ${ }^{595}$ bringen und wäre einer Anhebung des Normalsatzes vorzuziehen. ${ }^{596}$

Aus allokativer Sicht überzeugend ist die Finanzierung der Zuschüsse über eine Kopfsteuer. Da sich die Wirtschaftssubjekte der Besteuerung kaum entziehen könnten, entstünden keine Substitutionseffekte, also auch keine damit verbundene Zusatzlasten der Besteuerung. Durch den Einkommenseffekt sinkt zwar das verfügbare Einkommen und damit der private Konsum. Dem steht jedoch entgegen, dass infolge niedrigerer Lohnnebenkosten die Preise sinken, was den Konsum wiederum anregt. Langfristig könnte die Beschäftigung um 140.000 Personen zunehmen, wenn durch eine Kopfsteuer der Beitragssatz um einen Prozentpunkt sinkt. ${ }^{597}$ Gegen eine Kopfsteuer sprechen jedoch die damit verbundenen distributiven Wirkungen, da die Kopfsteuer von jedem Einwohner ohne Betrachtung seiner wirtschaftlichen Leistungsfähigkeit zu zahlen wäre.

Gleichfalls unrealistisch, wenn auch angezeigt, ist die Finanzierung über eine Senkung der Staatsausgaben. Langfristig ist dann eine Beschäftigungszunahme zwischen 90.000 und 150.000 Personen möglich. Kurzfristig kann jedoch die Beschäftigung sogar sinken, wenn der Nachfrageanstieg aus privatem Konsum, Investitionen und Export den Ausfall staatlicher Nachfrage nicht kompensiert. ${ }^{588}$ Aus gesamtwirtschaftlicher Sicht ist entscheidend, dass keine wachstumsfördernden Investitionen, sondern staatliche Konsumsausgaben, Transfers oder Subventionen reduziert werden. Die distributiven Wirkungen hängen davon ab, ob Transfers, die vorwiegend von Beziehern niedriger Einkommen empfangen werden, oder Subventionen, die vor allem Beziehern höherer Einkommen zugute kommen, gekürzt werden. ${ }^{599}$

Steuermittel zur Finanzierung von Gesundheitsleistungen würden die auf die GKV zukommenden Belastungen lediglich auf den Bundeshaushalt verschieben. Dies zeigt die Entwicklung des Bundeszuschusses an die GRV. Dieser ist von 3,7 Mrd. Euro im früheren Bundesgebiet im Jahr 1970 (16,5\% der Rentenausgaben) auf 54,4 Mrd. Euro für das gesamte Bundesgebiet im Jahr 2004 gestiegen $(26,3 \%$ der Rentenausgaben). Hinzu kommen Bundeszuschüsse an die knappschaftliche Rentenversicherung und die Erstattung der Beiträge für Kindererziehungszeiten, so dass sich die Staatszuschüsse im Jahr 2004 auf insgesamt 73,3 Mrd. Euro und damit $35,5 \%$ der Rentenausgaben beliefen. ${ }^{600}$ Die Belastungen durch die staatlichen Alterssicherungssysteme werden durch die demographische Entwicklung weiter zunehmen. Bis 2050 wird ein preisbereinigter Anstieg der Ausgaben der GRV von 213 Mrd. Euro im Jahr 2005 auf 508 Mrd. Euro und damit auch ein entsprechend steigender Bundeszuschuss erwartet. Darüber hinaus steigen preisbereinigt die Ausgaben für die Beamtenversorgung von 35 Mrd. Euro (2005) bis zum Jahr 2050 auf voraussicht-

\footnotetext{
${ }^{595}$ Laut Bundesministerium der Finanzen (Hrsg.) (2005), S. 45, entfallen $9 \%$ des Umsatzsteueraufkommens von rund $140 \mathrm{Mrd}$. Euro auf Umsätze, die mit dem ermäßigten Steuersatz von $7 \%$ besteuert werden. Demzufolge würde ceteris paribus ein Umsatz von $180 \mathrm{Mrd}$. Euro mit einem um 9 Prozentpunkte höheren Satz besteuert werden, was Mehreinnahmen von 16,2 Mrd. Euro bringt.

${ }^{596}$ Vgl. Peffekoven, R. (2005), S. 281; SVR (2005), Ziff. 555, und die dort angegebene Literatur.

${ }^{597}$ Vgl. Feil, M.; Zika, G. (2005), S. $2 f$.

${ }^{598} \mathrm{Vgl}$. ebenda, S. $4 f$.

${ }^{599}$ Vgl. SVR (2005), Ziff. 569ff.

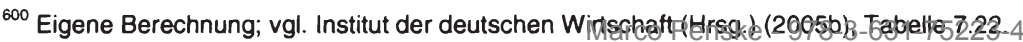


lich 83 Mrd. Euro. ${ }^{601}$ Die Einnahmenseite des Bundeshaushalts wird ohnehin von der demographischen Entwicklung negativ beeinflusst. Berechnungen zeigen, dass die Steuereinnahmen wachstumsbereinigt zwar bis zum Jahr 2020 noch zunehmen, danach jedoch stärker als die Bevölkerung sinken, was zu sinkenden durchschnittlichen Steuereinnahmen je Einwohner führt. Insbesondere die direkten Steuern hängen stark von der Zahl der Erwerbstätigen und damit von der demographischen Entwicklung $a b .^{602}$ Auch die implizite Verschuldung der öffentlichen Haushalte wird aufgrund der Bevölkerungsentwicklung weiter ansteigen. ${ }^{603}$

Höhere Bundeszuschüsse beseitigen nicht die strukturellen Mängel in der GKV und sind kein geeignetes Instrument, um die GKV nachhaltig zu finanzieren. Es handelt „sich dabei im Wesentlichen um ,finanztechnische' Korrekturen, weil steigende Ausgaben immer aus dem laufenden Sozialprodukt gedeckt werden müssen und sich durch diese Maßnahmen am Anstieg der Ausgaben im demographischen Wandel oder gar an der Effizienz der Krankenversicherung und der Gesundheitsversorgung

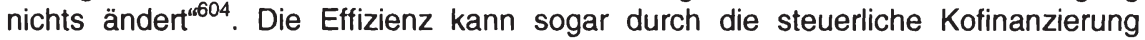
sinken.

\subsection{Bürgerversicherung}

\subsubsection{Konzeption}

Zur Stärkung des Leistungsfähigkeitsprinzips in der GKV liegen in der Literatur zahlreiche Vorschläge vor. Diese sehen im Wesentlichen eine Erhöhung der Versicherungspflichtgrenze und der Beitragsbemessungsgrenze sowie eine Ausweitung der Beitragspflicht über Arbeitsentgelte hinaus vor. ${ }^{605}$ Mit der Konzeption einer Bürgerversicherung haben die Rürup-Kommission ${ }^{606}$ und vor allem Lauterbach ${ }^{607}$ ein in sich geschlossenes Modell vorgelegt, das diese Vorschläge wieder aufgreift. Damit wurde auch die Grundlage für weitere konzeptionelle Arbeiten - insbesondere von einer Projektgruppe des SPD-Parteivorstandes ${ }^{608}$ und von Sehlen u.a. ${ }^{609}$ - gelegt.

Ausgangspunkt der Bürgerversicherung ist die strukturell bedingte Wachstumsschwäche der Einnahmen, die dazu geführt hat, dass die beitragspflichtigen Einnahmen hinter der allgemeinen wirtschaftlichen Entwicklung zurückgeblieben sind. Hinzu

${ }^{601}$ Vgl. Werding, M.; Kaltschütz, A. (2005), S. 31ff.

${ }^{602}$ Vgl. ausführlich Bach, S. u.a. (2002), S. 86ff. Zu den Auswirkungen des demographischen Wandels auf die öffentlichen Finanzen siehe auch Werding, M.; Kaltschütz, A. (2005), S. $31 \mathrm{ff}$.

${ }^{603}$ Vgl. SVR (2003), Ziff. 447f. Für ausführliche Berechnungen siehe ebenda, Ziff. 439ff., 765ff.

${ }^{604}$ Enquete-Kommission Demographischer Wandel (2002), S. 208.

${ }^{605} \mathrm{Vgl}$. stellvertretend SVR KAiG (1995), Ziff. 568ff.; Wille, E. (1998), S. 19ff.; Wenzel, D. (1999), S. 105ff.; Klose, J.; Schellschmidt, H. (2001), S. 42ff.; Breyer, F. U.a. (2001), S. 173ff.; Kruse, U.; Kruse, S. (2001), S. 92ff.; Wille, E. (2002a), S. 258ff.

${ }^{606}$ Siehe Rürup-Kommission (2003), S. $149 f f$.

${ }^{607}$ Siehe Lauterbach, K.W. (2004), S. 48ff.; Lauterbach, K.W. u.a. (2004a), S. 26f.; Lauterbach, K.W. u.a. (2004b), S. $594 f f$.

${ }^{608}$ Siehe Projektgruppe Bürgerversicherung des SPD-Parteivorstandes (2004).

${ }^{609}$ Siehe Sehlen, S. u.a. (2004). Die Autoren untersuchen mehrere Kombinationen, die im Wesentlichen von den Vorschlägen der Rürup-Kommission und der Projektgruppe Bürgerversicherung des SPD-Parteivorstandes abgedeckt werden. Auf eine Darstellung im Einzelnen wird daher hier

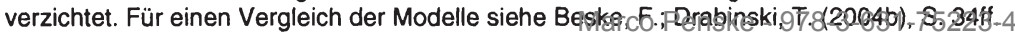


kommen insbesondere die beschriebenen ineffizienten intragenerativen Verteilungswirkungen und die demographische Abhängigkeit. ${ }^{610}$ Kritisiert wird auch die „parallele Existenz zweier vollständig unterschiedlich finanzierten Vollversicherungssysteme, zwischen denen nur bestimmte, insbesondere gut verdienende Personengruppen auswählen können “611. Die Konzepte zur Bürgerversicherung fordern deshalb übereinstimmend, die Versicherungspflicht auf alle Bürger auszuweiten und die PKV auf Zusatzversicherungen zu beschränken. Auf die Vor- und Nachteile einer Ausweitung des Versichertenkreises wird in Abschnitt 3.4 Kompromissmodelle (S. 199) noch näher eingegangen.

Unterschiede gibt es hinsichtlich der Beitragsbemessung: Die Modelle differieren in Vorliegen und Höhe von Beitragsbemessungsgrenzen und darin, ob alle sieben Einkunftsarten der Einkommensteuer beitragspflichtig sein sollen oder nur bestimmte Einkunftsarten. Das Modell der Rürup-Kommission sieht eine Ausweitung der Beitragspflicht auf alle Einkunftsarten vor. ${ }^{612}$ Dies entspricht den beitragspflichtigen Einnahmen freiwilliger Mitglieder (§240 Abs. 1 SGB V) und den nach $\S 2$ Abs. 1 EStG der Einkommensteuer unterliegenden Einkünften. Im Einzelnen sind dies:

(1) Einkünfte aus Land- und Forstwirtschaft

(2) Einkünfte aus Gewerbebetrieb

(3) Einkünfte aus selbständiger Arbeit

(4) Einkünfte aus nichtselbständiger Arbeit

(5) Einkünfte aus Kapitalvermögen

(6) Einkünfte aus Vermietung und Verpachtung und

(7) sonstige Einkünfte nach § 22 EStG (z.B. steuerpflichtiger Rentenanteil)

Die Einkünfte (1) bis (3) sind die nach den Richtlinien des EStG ermittelten Gewinne. Sie sollen nach § 15 SGB IV dem Arbeitseinkommen gleichgestellt werden und wie Lohneinkommen (4) beitragspflichtig sein, d.h. auf diese Einkünfte wird der volle Beitragssatz erhoben. Auf die die Einkünfte (5) und (6) umfassenden Vermögenseinkommen und die sonstigen Einkünfte (7) wird ebenfalls der volle Beitragssatz angewendet. ${ }^{613}$ Bei Lohneinkommen (4) bleibt es bei der paritätischen Finanzierung und dem Bruttoprinzip, d.h. Werbungskosten oder im Steuerrecht gewährte Vergünstigungen bleiben unberücksichtigt. Für alle anderen Einkünfte gilt das Nettoprinzip. Bei den Gewinneinkommen hat das zur Folge, dass Arbeitgeberbeiträge als Betriebsausgabe bei der Ermittlung des GKV-Beitrags von der Bemessungsgrundlage abgezogen werden können. Dies gilt allerdings nicht für "Arbeitgeberbeiträge“ bei Vermögenseinkommen. Bei Kapitaleinkünften schlägt die Rürup-Kommission unter Berücksichtigung von Werbungskosten einen Freibetrag von 1.601 Euro ${ }^{614}$

\footnotetext{
${ }^{610}$ Vgl. stellvertretend Sehlen, S. u.a. (2004), S. 12ff.; Lauterbach, K.W. (2004), S. $48 f$.

${ }^{611}$ Projektgruppe Bürgerversicherung des SPD-Parteivorstandes (2004), S. 19.

${ }^{612}$ Vgl. Rürup-Kommission (2003), S. 149, 154.

${ }^{613} \mathrm{Da}$ bei diesen Einkunftsarten kein Anspruch auf Krankengeld erworben wird, schlagen Sehlen, S. u.a. (2004), S. 44, vor, den ermäßigten Beitragssatz zu erheben.

${ }^{614}$ Der Sparerfreibetrag beträgt nach Abzug der Werbungskosten in Höhe von 51 Euro ( $\$ 9 a \mathrm{EStG}$ ) ab 2004 gemäß § 20 Abs. 4 EStG 1.370 Euro für einzsilnd Veradlagte - 978-3-631-75223-4
} 
entsprechend der Regelung in der Einkommensteuer vor. ${ }^{615}$ Mitunter ist auch ein Freibetrag für Einkünfte aus nichtselbständiger Arbeit vorgesehen. ${ }^{616}$ Dadurch soll das Nettoprinzip bei dieser Einkunftsart ebenfalls durchgesetzt werden, zumal die Ermittlung der Löhne und Gehälter nach Abzug der tatsächlichen Werbungskosten ansonsten aufwendig ist. Eine wie im Steuerrecht existierende und systematisch richtige Verrechnung von positiven mit negativen Einkünften ist indes nicht vorgesehen, um nachträgliche Beitragsanpassungen zu vermeiden. ${ }^{617}$

Die Beitragsbemessungsgrenze wird auf 5.100 Euro und damit das Niveau der GRV angehoben. Die beitragsfreie Mitversicherung des Ehepartners kann beibehalten oder durch ein negatives Ehegattensplitting ersetzt werden. „Beim negativen Ehegattensplitting wird das beitragspflichtige Haushaltseinkommen halbiert und jeweils auf beide Teile der Krankenversicherungsbeitrag erhoben." ${ }^{\text {“618 }}$ Damit wird die regressive Wirkung der Beitragsbemessungsgrenze abgeschwächt. Verheiratete GKV-Mitglieder mit einem beitragspflichtigen Einkommen über der Beitragsbemessungsgrenze werden durch das negative Ehegattensplitting jedoch schlechter gestellt, worauf die Bezeichnung „negativ" beruht.

Während die Rürup-Kommission eine einheitliche Beitragsbemessungsgrenze vorschlägt, sieht das Modell der Projektgruppe des SPD-Parteivorstandes ${ }^{619}$ ein „ZweiSäulen-Beitragsverfahren“ vor, das in zwei Varianten durchgeführt werden kann. Bei beiden Varianten werden in der ersten Säule die Einkünfte aus den Einkunftsarten (1) bis (4) addiert. Diese sind bis zur Beitragsbemessungsgrenze beitragspflichtig. Abweichend von der Systematik im Einkommensteuerrecht werden auch Rentenzahlungen ( $\$ 22$ EStG) und (ansonsten steuerfreie ${ }^{620}$ ) Lohnersatzleistungen dem Erwerbseinkommen zugeordnet ${ }^{621}$; sie werden in der ersten Säule verbeitragt. Einkünfte aus Vermietung und Verpachtung (6) unterliegen nicht der Beitragspflicht. In Variante 1 wird auf Einkünfte aus Kapitalvermögen (5) und sonstige Einkünfte nach § 22 EStG (außer Rentenzahlungen) in einer zweiten Säule der Beitrag erhoben, wobei ein Freibetrag von 1.340 Euro vorgesehen werden kann. Die Beitragshöhe soll über die Einkommensteuererklärung beim Finanzamt festgesetzt werden. Für beide Säulen gibt es Beitragsbemessungsgrenzen, die nicht identisch sein müssen. Die zweite Säule wird vorgeschlagen, damit die Ausweitung der Beitragspflicht auf weitere Einkünfte nicht nur Bezieher von Löhnen und Gehältern unterhalb der Beitragsbemessungsgrenze belastet.

In der weiterentwickelten Variante 2 ändert sich an der ersten Säule nichts. Die zweite Säule besteht indes nur noch aus den Einkünften aus Kapitalvermögen. ${ }^{622}$

\footnotetext{
${ }^{615}$ Vgl. Rürup-Kommission (2003), S. 154, 157f.; Bork, C. (2003), S. $12 f$.

${ }^{616}$ Siehe Sehlen, S. u.a. (2004), S. 63.

${ }^{617}$ Vgl. Rürup-Kommission (2003), S. 158. Sehlen, S. u.a. (2004), S. 23, sehen hingegen eine Verrechnungsmöglichkeit vor.

${ }^{618}$ Rürup-Kommission (2003), S. 170.

${ }^{619}$ Siehe Projektgruppe Bürgerversicherung des SPD-Parteivorstandes (2004), S. $23 \mathrm{ff}$.

${ }^{620}$ Arbeitslosengeld wird allerdings bei der Ermittlung des Steuersatzes berücksichtigt, sogenannter Progressionsvorbehalt ( $(23 \mathrm{~b} \mathrm{EStG}$ ).

${ }^{621}$ Siehe Projektgruppe Bürgerversicherung des SPD-Parteivorstandes (2004), S. 11.

${ }^{622}$ Die sonstigen Einkünfte nach $§ 22$ EStG werden in diesem Modell nicht mehr gesondert aufgeführt, müssten aber der ersten Beitragssäule zugeordnet wexden.Penske - 978-3-631-75223-4
} 
Sollte eine Abgeltungssteuer auf Kapitaleinkommen eingeführt werden, wird auf diese ein Zuschlag erhoben, der von den Kreditinstituten an die Kassen abgeführt wird. Die Kreditinstitute würden dann neben der Abgeltungssteuer auf Kapitaleinkommen auch die Beiträge zur Bürgerversicherung erheben, die über den RSA an die Kassen verteilt würden. Nicht in der GKV Versicherte - ausländische Anleger oder in der Übergangsphase noch privat Versicherte - müssten eine „Befreiungsbescheinigung" vorlegen. ${ }^{623}$ Vorgeschlagen wird auch, dass das Finanzamt den Zuschlag auf die Abgeltungssteuer erhebt. ${ }^{62}$

\subsubsection{Beitragssatzeffekte}

Nach Berechnungen der Rürup-Kommission kann durch eine Einbeziehung aller Einkunftsarten bei einem Freibetrag auf Kapitaleinkünfte von 1.601 Euro ein allgemeiner Beitragssatz zur GKV in Höhe von 14,4\% um 0,5 Prozentpunkte gesenkt werden. Eine Erhöhung der Beitragsbemessungsgrenze auf das Niveau der GRV von 5.100 Euro würde eine zusätzliche Beitragssatzentlastung von 0,8 Prozentpunkten bringen. Durch die Ausweitung des Versichertenkreises auf alle Einwohner könnte der Beitragssatz langfristig um weitere 0,7 Prozentpunkte gesenkt werden, so dass der Beitragssatz des Jahres 2003 bei Einführung einer Bürgerversicherung insgesamt von $14,4 \%$ auf $12,4 \%$ sinken könnte. ${ }^{625}$

Ein etwas größeres Beitragssatzsenkungspotential zeigen Sehlen u.a. ${ }^{626}$ Die Einbeziehung aller Einkünfte bei einem Freibetrag für Kapitaleinkünfte in Höhe von 1.340 Euro würde den Beitragssatz um 0,8 Prozentpunkte reduzieren, weitere 0,6 Prozentpunkte brächte die Ausweitung des Versichertenkreises, so dass selbst unter Beibehaltung der Beitragsbemessungsgrenze von 3.487,50 Euro eine Senkung des Beitragssatzes von 14,1\% im Jahr 2004 auf 12,7\% möglich wäre. Würde zudem die Beitragsbemessungsgrenze auf 5.150 Euro angehoben, könnte der Beitragssatz auf $11,8 \%$ weiter abgesenkt werden, bei einer Aufhebung der Beitragsbemessungsgrenze sogar auf $10,7 \%$. Alternativ wird auch das Beitragssatzsenkungspotential berechnet, wenn neben der Beitragsbemessungsgrenze für Arbeitseinkommen eine Beitragsbemessungsgrenze für Vermögenseinkommen eingeführt wird. Liegen beide Beitragsbemessungsgrenzen bei 3.487.50 Euro, kann der Beitragssatz statt auf $12,7 \%$ auf $12,1 \%$ reduziert werden.

Nach Berechnungen der Projektgruppe Bürgerversicherung des SPD-Parteivorstan$\operatorname{des}^{627}$ führt bei einer Beibehaltung des aktuellen Versichertenkreises die Einführung einer zweiten Beitragsbemessungsgrenze in Höhe von 3.487,50 Euro für Kapitaleinkünfte bei einem Freibetrag von 1.340 Euro zu einer Beitragssatzsenkung von $14,1 \%$ auf $13,4 \%$; die Erhöhung beider Beitragsbemessungsgrenzen auf 5.100 Euro (4.000 Euro) zu einem Rückgang auf $12,7 \%(13,1 \%)$. Erweitert man den Versichertenkreis auf alle Einwohner, sinkt der Beitragssatz bei einheitlichen Beitrags-

\footnotetext{
${ }^{623}$ Vgl. Rürup-Kommission (2003), S. 157.

${ }^{624}$ Siehe Projektgruppe Bürgerversicherung des SPD-Parteivorstandes (2004), S. $27 f$.

${ }^{625}$ Vgl. Bork, C. (2003), S. 24f.; Rürup-Kommission (2003), S. 159.

${ }^{626}$ Siehe Sehlen, S. u.a. (2004), S. 36ff., 58ff.

${ }^{627}$ Siehe Projektgruppe Bürgerversicherung des SPD-Parteivorstandes (2904) 6 S.129. 223-4 
bemessungsgrenzen von 3.487,50 Euro und ohne Freibetrag auf $12,3 \%$, bei 4.000 Euro auf $11,9 \%$ und bei 5.100 Euro auf 11,6\%. In der Variante 2 dieses Modells lässt sich bei einer Ausweitung der Versicherungspflicht auf die gesamte Bevölkerung durch einen Zuschlag auf die pauschale Abgeltungssteuer in Höhe von 7 Prozentpunkten der Beitragssatz um 1,6 Prozentpunkte reduzieren. Dabei wird eine Beitragsbemessungsgrenze von 3.487,50 Euro für die erste Säule und ein Freibetrag für Kapitaleinkünfte von 1.340 Euro unterstellt. Bei einer Beitragsbemessungsgrenze von 4.000 Euro beträgt der Beitragssatzeffekt 2,0 Prozentpunkte, bei einer Grenze von 5.100 Euro 2,4 Prozentpunkte.

Tabelle 18: Entlastungseffekte bei unterschiedlichen Ausgestaltungen einer Bürgerversicherung

\begin{tabular}{|c|c|c|c|c|c|c|}
\hline & $\begin{array}{l}\text { BBG } \\
3.487,50 €\end{array}$ & $\begin{array}{l}\text { BBG } \\
5.100 €\end{array}$ & $\begin{array}{l}\text { BBG1: } \\
3.487,50 € \\
\text { BBG2: } \\
3.487,50 €\end{array}$ & $\begin{array}{l}\text { BBG1: } \\
4.000 € \\
\text { BBG2: } \\
4.000 €\end{array}$ & $\begin{array}{l}\text { BBG2: } \\
5.100 € \\
\text { BBG2: } \\
5.100 €\end{array}$ & $\begin{array}{l}\text { Ohne } \\
\text { BBG }\end{array}$ \\
\hline & \multicolumn{6}{|c|}{ Alle Angaben in Prozentpunkten } \\
\hline $\begin{array}{l}\text { Bisherige Beitrags- } \\
\text { bemessungs- } \\
\text { grundlage }\end{array}$ & Status quo & 0,8 & & & & \\
\hline $\begin{array}{l}\text { Alle Einkunftsarten } \\
\text { außer Einkünfte aus } \\
\text { Vermietung und } \\
\text { Verpachtung }\end{array}$ & & & 0,7 & 1,0 & 1,4 & \\
\hline Alle Einkunftsarten & $0,5-0,8$ & 1,3 & 0,6 & & 1,35 & \\
\hline $\begin{array}{l}\text { Versichertenkreis: } \\
\text { Alle Einwohner }\end{array}$ & $0,6-0,7$ & $\begin{array}{c}0,7 \\
\left(0,9^{2}\right)\end{array}$ & $\begin{array}{c}0,6-1,1^{3} \\
\left(0,6^{2}\right)\end{array}$ & $1,2^{3}$ & $0,75-1,2^{3}$ & $\left(2,0^{2}\right)$ \\
\hline Bürgerversicherung & 1,4 & $2,0-2,3$ & $1,8^{3}-2,0$ & $2,2^{3}$ & $2,6^{3}$ & 3,4 \\
\hline
\end{tabular}

${ }^{1}$ Nach Ausweitung der Beitragsbemessungsgrundlage auf alle Einkommen.

${ }^{2}$ Beitragssatzeffekte bei Änderung der Beitragsbemessungsgrenze und konstantem Versichertenkreis.

${ }^{3}$ ohne Freibetrag bei Einkünften aus Kapitalvermögen.

Quelle: Eigene Darstellung und eigene Berechnungen in Anlehnung an Bork, C. (2003), S. 25; RürupKommission (2003), S. 159; Krämer, R. (2003), S. 412f.; Sehlen, S. u.a. (2004), S. 38f., 74f.; Projektgruppe Bürgerversicherung des SPD-Parteivorstandes (2004), S. 30.

Tabelle 18 gibt einen Überblick über die Beitragssatzeffekte der einzelnen Elemente einer Bürgerversicherung, sofern Berechnungen vorliegen oder die Effekte der einzelnen Maßnahmen anhand der vorliegenden Berechnungen selbst ermittelt werden konnten. Da sich die Effekte einzelner Maßnahmen überlagern, ist es problematisch, vom Gesamteffekt auf die einzelnen Effekte zurück zu schließen. Bei der Betrachtung handelt es sich um ein dreidimensionales System. Gleichzeitig wird die Beitragsbemessungsgrundlage variiert, der Versichertenkreis ausgeweitet und die Beitragsbemessungsgrenze erhöht. Dies erschwert eine übersichtliche Darstellung und die Berechnung der Effekte einzelner Maßnahmen, zumal deren Größe auch von der Schrittfolge der Berechnung abhängt. Wird z.B. zuerst die Beitragsbemessungsgrenze erhöht und dann der Versichertenkreis erweitert, geht von der Erweiterung des Versichertenkreises ein größerer Beitragssatzeffekt aus als bei umgekehrter Berechnungsreihenfolge. Der Überblick in Tabelle 18 zeigt, dass von einer Erweiterung des Versichertenkreises - dem „Keknärceinambürgenßersichierung3-4 isoliert 
betrachtet nur eine bescheidene beitragssatzsenkende Wirkung von bis zu 0,7 Prozentpunkten ausgeht, obwohl bereits eine Ausweitung der Beitragsbemessungsgrundlage auf alle Einkunftsarten unterstellt ist.

Bei getrennten Beitragsbemessungsgrenzen von 5.100 Euro wird immerhin ein Beitragssatzeffekt von bis zu 1,2 Prozentpunkten durch die Ausweitung der Versicherungspflicht auf die gesamte Bevölkerung erwartet. Durch die Erweitung der Beitragsbemessungsgrundlage auf alle Einkünfte kann bei getrennten Beitragsbemessungsgrenzen von jeweils 3.487,50 Euro der Beitragssatz um 0,6 Prozentpunkte im Vergleich zum Status quo gesenkt werden. Bleiben Einkünfte aus Vermietung und Verpachtung beitragsfrei, steigt der Beitragssatzeffekt auf 0,7 Prozentpunkte, weil die Einkünfte aus Vermietung und Verpachtung gesamtfiskalisch negativ sind. ${ }^{628}$ Die Werte in Klammern zeigen die Beitragssatzeffekte bei konstantem (erweitertem) Versichertenkreis an, wenn die Beitragsbemessungsgrenze verändert wird. Der Beitragssatz in einer Bürgerversicherung kann allein durch die Erhöhung der Beitragsbemessungsgrenze von $3.487,50$ Euro auf 5.100 Euro um 0,9 Prozentpunkte gesenkt werden; bei einer Aufhebung der Beitragsbemessungsgrenze um 2,0 Prozentpunkte. Im Ergebnis senkt die Einführung einer Bürgerversicherung je nach Ausgestaltungsvariante den Beitragssatz zwischen 1,4 und 3,4 Prozentpunkten im Vergleich zum Status quo.

Nicht berücksichtigt ist bei diesen Beitragssatzeffekten, dass das Zurückdrängen der PKV auch negative Rückwirkungen auf die GKV haben kann. In dem Maße, in dem es den Leistungserbringern gelänge, die reduzierte Quersubventionierung der PKV von etwa 5 bis 6 Mrd. Euro p.a. auf die GKV zu überwälzen, wäre mit steigenden Ausgaben der GKV und einer geringeren Beitragssatzsenkung zu rechnen. ${ }^{629}$

\subsubsection{Auswirkungen auf die öffentlichen Haushalte}

Bislang sind nur wenige Beamte und Richter in der GKV versichert; denn wenn ein Beamter die Versicherung in der GKV wählt, verzichtet er auf Beihilfe, erhält aber dennoch keinen Arbeitgeberbeitrag zur GKV, sondern muss den vollen Beitrag selbst zahlen, was für die große Mehrheit der Beamten teurer ist als die Kombination aus PKV und Beihilfe. Die Bürgerversicherung sieht vor, dass auch Beamte, Richter und Soldaten in der GKV versicherungspflichtig werden. Für die öffentlichen Arbeitgeber bedeutet dies, dass einerseits auf Dienstbezüge oder Pensionen künftig Arbeitgeberbeiträge zu entrichten sind, andererseits aber die Zahlungen für Beihilfe und Freie Heilfürsorge ${ }^{630}$ entfallen. Im Jahr 2003 waren von 1,6 Mio. Beamten und Richtern 1,3 Mio. Personen bei den Ländern, 180.000 bei den Gemeinden und 130.000 beim Bund beschäftigt. Auf Bundesebene kamen noch 190.000 Berufs- und Zeitsoldaten hinzu, so dass alle Gebietskörperschaften zusammen 1,8 Mio. Personen in der GKV

\footnotetext{
${ }^{628}$ Nach den aktuell verfügbaren Daten standen im Jahr 2001 im Durchschnitt positiven Einkünften aus Vermietung und Verpachtung in Höhe von 8.242 Euro negative Einkünfte von 8.811 Euro gegenüber. In den Jahren 1995 und 1998 lag der durchschnittliche Verlust sogar bei 3.855 Euro bzw. 2.991 Euro; siehe Bundesministerium der Finanzen (Hrsg.) (2005), S. 17.

${ }^{629} \mathrm{Vgl}$. Zipperer, M. (2003a), S. 17; Schulte, R. (2004), S. 10. Siehe auch Beck, J. (2004), S. $391 f$.

${ }^{630}$ Polizeibeamte, Soldaten und Zivildienstleistende enhalten freje, Heilfg̈rßorge $631-75223-4$
} 
versichern müssten ${ }^{631}$ Berücksichtigt werden müssen auch die Versorgungsempfänger. Im Jahr 2003 erhielten beim Bund 160.000 Personen - davon 80.000 Soldaten oder deren Angehörige -, bei den Ländern 570.000 und bei den Gemeinden 110.000 Personen entweder Ruhegehalt oder als Hinterbliebene Versorgungsbezüge oder Waisengeld. ${ }^{632}$

Für den Bund beliefen sich die Beihilfeausgaben im Jahr 2002 für Beamte und Richter auf 258,1 Mio. Euro und die Ausgaben für Versorgungsempfänger auf 763,3 Mio. Euro. ${ }^{633}$ Diese würde der Bund bei einer Bürgerversicherung einsparen. Dafür müsste er aber Arbeitgeberbeiträge zahlen. Bei einer Arbeitgeberbeteiligung von $7 \%$ zur GKV wären 328,2 Mio. Euro für Beamte und Richter sowie 342,8 Mio. Euro für Versorgungsempfänger an die GKV zu entrichten. Eingesparten Beihilfeausgaben von 1,021 Mrd. Euro ständen Mehrausgaben von 671,0 Mio. Euro gegenüber. Der Bundeshaushalt würde demnach um 350,4 Mio. Euro entlastet. Dies entspricht bezogen auf das Ausgabenvolumen von gut $250 \mathrm{Mrd}$. Euro einer Entlastung von 0,14\%. Obwohl unterstellt wird, dass alle Aktiven und Versorgungsempfänger ohne Übergangsfristen sofort in der GKV versichert werden, ist die Entlastung für den Bundeshaushalt gering. Geht man davon aus, dass kurzfristig nur die aktiven Beamten in die Bürgerversicherung wechseln, würde der Bund sogar mit 70,1 Mio. Euro belastet.

Einige Bürgerversicherungs-Modelle sehen eine Beibehaltung der Freien Heilfürsorge vor. ${ }^{634}$ Werden Soldaten, die gut die Hälfte der versicherungspflichtig werdenden Beschäftigten und Versorgungsempfänger des Bundes ausmachen, dennoch in die Bürgerversicherung einbezogen, entfallen für den Bund die Ausgaben für die Freie Heilfürsorge der 190.000 Berufs- und Zeitsoldaten. Dem stehen aber Arbeitgeberbeiträge für diese Soldaten und weitere 80.000 Versorgungsempfänger nach Soldatenversorgungsrecht gegenüber, so dass der Bundeshaushalt insgesamt sogar belastet werden kann.

Von der Ausweitung der Versicherungspflicht auf Personen im öffentlichen Dienst sind insbesondere die Länderhaushalte betroffen. Für das Land Nordrhein-Westfalen liegen hierzu Berechnungen vor. Einem Kostenvergleich aus dem nordrhein-westfälischen Finanzministerium ${ }^{635}$ zufolge betrugen im Jahr 2002 die Ausgaben des Landes für Beihilfe 1,088 Mrd. Euro und für Freie Heilfürsorge der Polizei 54 Mio. Euro. Würden die Beschäftigten und Versorgungsempfänger stattdessen in der GKV versichert, müsste das Land Beiträge in Höhe von 1,195 Mrd. Euro zahlen, was zu einer jährlichen Belastung von 53 Mio. Euro führt. Wird angenommen, dass die Versorgungsempfänger nicht in der GKV versichert werden, sondern weiter Beihilfe erhalten, wird das Land sogar mit 543,3 Mio. Euro belastet.

$\mathrm{Zu}$ ähnlichen Ergebnissen kommen Berechnungen der Projektgruppe Bürgerversicherung des SPD-Parteivorstandes ${ }^{636}$ für das Jahr 2003. Eine Versicherungspflicht

\footnotetext{
${ }^{631}$ Siehe Statistisches Bundesamt (Hrsg.) (2004b), Tabelle 1.1.

${ }^{632}$ Siehe Statistisches Bundesamt (Hrsg.) (2004c), Tabelle IV.1.

${ }^{633}$ Siehe Bundestags-Drucksache 15/2312 vom 08.01.2004, S. 2f.; Bundestags-Drucksache 15/116 vom 29.11.2002, S. $7 f$.

${ }^{634}$ Siehe z.B. Projektgruppe Bürgerversicherung des SPD-Parteivorstandes (2004), S. 46.

${ }^{635}$ Siehe Finanzministerium des Landes Nordrhein-Westfalen (Hrsg.) (2003), S. $1 f$.

${ }^{636}$ Siehe Projektgruppe Bürgenversicherung des SPD-Pagteivorstandes (2904) 3 S6 46ff.5223-4
} 
aller Beschäftigten zu einem Stichtag würde das Land Nordrhein-Westfalen bei einem GKV-Beitragssatz von 14,3 \% mit 15,3 Mio. Euro belasten. Den Zahlungen an Beihilfe für Beamte und Versorgungsempfänger sowie Freie Heilfürsorge der Polizei in einer Gesamthöhe von 966,6 Mio. Euro ständen Arbeitgeberbeiträge von 981,9 Mio. Euro gegenüber. Wird die Beitragsbemessungsgrenze auf 5.100 Euro angehoben, steigt die Belastung sogar auf 70 Mio. Euro an. Bei einer schrittweisen Umstellung in der Form, dass nur die neu eingestellten Beamten in der Bürgerversicherung versichert werden, kommt es in der Übergangsphase zu zunächst steigenden und dann abnehmenden Mehrbelastungen des Landeshaushalts. Am höchsten ist die Belastung mit etwa 96 Mio. Euro nach rund 25 Jahren. Nach der Übergangsphase von rund 50 Jahren entstehen die gleichen Wirkungen wie bei einer sofortigen Umstellung. Bei einem auf 12,0 \% gesunkenen Beitragssatz würde der Landeshaushalt dann 149 Mio. Euro, bei Erhöhung der Beitragsbemessungsgrenze auf 5.100 Euro einen Betrag von 100 Mio. Euro einsparen.

Insgesamt ergibt sich für die Haushalte von Bund, Ländern und Gemeinden mit einem schrittweisen Übergang selbst bei einem Beitragssatz von 12,2 \% im Einführungsjahr eine Mehrbelastung von 224 Mio. Euro. Diese steigt in den nächsten 20 Jahren bei einem Beitragssatz von 12,0\% auf 807 Mio. Euro an und sinkt nach 40 Jahren auf 450 Mio. Euro (Beitragssatz: 11,9\%). Nach der Übergangsphase werden die öffentlichen Haushalte allerdings um 736 Mio. Euro entlastet. ${ }^{637}$

Wie sich die Effekte auf die Gruppe der aktiven Beamten und der Versorgungsempfänger verteilen, zeigen Berechnungen von Gasche ${ }^{638}$. Bei einer sofortigen Einbeziehung aller aktiven Beamten in die Bürgerversicherung würden die Haushalte der Gebietskörperschaften Beihilfezahlungen von 2,7 Mrd. Euro einsparen. Dem stünden Arbeitgeberbeiträge von 3,7 Mrd. Euro gegenüber, so dass die Einbeziehung der Beamten die Gebietskörperschaften mit rund 1,0 Mrd. Euro belastet. Bei einer Beitragsbemessungsgrenze von 5.100 Euro würde die Netto-Belastung durch die höheren Arbeitgeberbeiträge auf 1,3 Mrd. Euro steigen. Entlastet werden die Haushalte von Bund, Ländern und Gemeinden durch die Einbeziehung der Versorgungsempfänger. Für diese muss die öffentliche Hand 1,1 Mrd. Euro an Arbeitgeberbeiträgen zahlen. Dem stehen eingesparte Beihilfeausgaben von 3,0 Mrd. Euro gegenüber, so dass die Gebietskörperschaften durch die Versicherung der Versorgungsempfänger in der GKV um 1,9 Mrd. Euro entlastet werden. Unter der Bedingung, dass alle Personen ohne Übergangsfristen in der Bürgerversicherung versichert werden, ergibt sich somit eine Entlastung von 830 Mio. Euro bei Beibehaltung der Beitragsbemessungsgrenze, bei einer Erhöhung der Beitragsbemessungsgrenze auf 5.100 Euro sinkt die Entlastung auf 590 Mio. Euro. Eine Mehrbelastung für die Gebietskörperschaften entsteht hingegen, wenn - wovon auszugehen ist - Versorgungsempfänger weiter Beihilfe erhalten.

Damit kommen die Berechnungen übereinstimmend zu folgendem Ergebnis: In der Übergangsphase werden die öffentlichen Haushalte durch die Einführung einer Bürgerversicherung belastet, langfristig entlastet. Der Grund für die Belastungen liegt darin, dass insbesondere bei den jüngeren Beschäftigten für die Gebietskörperschaf-

\footnotetext{
${ }^{637}$ Vgl. Sehlen, S. u.a. (2004), S. 53ff.; eigene Berechnungen.

${ }^{638}$ Siehe Gasche, M. (2004), S. $290 \mathrm{ff}$.

Marco Penske - 978-3-631-75223-4
} 
ten die Zahlung von Beihilfe günstiger ist als die Zahlung von Arbeitgeberbeiträgen zur Krankenversicherung. Die Aussage Zipperers ${ }^{639}$, wonach die fiktiven Arbeitgeberbeiträge das 1,5fache der Beihilfeausgaben betragen, können zwar nur für den Bund in dieser Höhe bestätigt werden, die Ausgaben für Beihilfe liegen aber im Durchschnitt für Beschäftigte im öffentlichen Dienst deutlich unter den in der GKV anfallenden Arbeitgeberbeiträgen.

Für die GKV entsteht durch die Einbeziehung der Beamten der umgekehrte Effekt. Kurzfristig dürfte die Ausweitung der Versicherungspflicht auf den öffentlichen Dienst die GKV-Finanzen entlasten, da in der Übergangsphase tendenziell gute Risiken versicherungspflichtig werden. Die Entlastung der GKV kann dabei sogar über den Belastungen der Haushalte der Gebietskörperschaften liegen. Die Beihilfe erstattet zwar die Hälfte der Ausgaben, die Beihilfezahlungen beruhen aber i.d.R. auf Leistungsabrechnungen mit dem 2,3fachen Satz. Zudem ist in der Bürgerversicherung das Leistungsniveau für die öffentlich Bediensteten niedriger, so dass für die GKV geringere Pro-Kopf-Ausgaben als für die Gebietskörperschaften zu erwarten sind. Würden alle öffentlich Bediensteten ohne Übergangsfrist gleich in der GKV versichert, könnte die GKV in Anbetracht der Altersstruktur der Beamten auch kurzfristig belastet werden. Die Altersjahrgänge 1950 bis 1955 bilden die mit Abstand größte Gruppe der Beamten. Damit wären die neuen Versicherten eher ausgabenintensiv. Fraglich ist daher, ob die Beiträge der Beamten die durch sie verursachten Ausgaben decken können, zumal $27 \%$ der Beamten dem einfachen und mittleren Dienst angehören und somit von diesen keine überdurchschnittlich hohen Beitragszahlungen zu erwarten sind. ${ }^{640}$ Berechnungen unter Berücksichtigung der Altersstruktur und der RSA-Ausgabenprofile zeigen jedoch, dass bei einer Beitragsbemessungsgrenze von 5.100 Euro der GKV-Beitragssatz um fast 0,45 Prozentpunkte gesenkt werden kann, wenn alle Beamten versicherungspflichtig werden. Selbst wenn alle Beamten, deren Bezüge über der Versicherungspflichtgrenze liegen, in der PKV bleiben, könnte der Beitragssatz um gut 0,4 Prozentpunkte sinken. ${ }^{64}$

Langfristig wird die GKV aber von der Einbeziehung aller Beamten und Versorgungsempfänger in die Versicherungspflicht eher belastet. Sehlen u.a. ${ }^{642}$ beziffern den Beitragssatzanstieg, der von einer Einbeziehung der Pensionäre in der letzten Umsetzungsstufe der Bürgerversicherung ausgeht, immerhin auf 0,1 Prozentpunkte. ${ }^{643}$ Hinzu kommen weitere Faktoren, die die GKV belasten: ${ }^{644} \mathrm{Da}$ Beamtenfamilien im Durchschnitt kinderreicher als der Rest der Bevölkerung sind, steigt für die GKV der Anteil der Familienversicherten, die Leistungen in Anspruch nehmen, ohne Beiträge zu zahlen. Zudem liegt im öffentlichen Dienst der Anteil der Teilzeitbeschäftigten über dem in der gewerblichen Wirtschaft. Teilzeitbeschäftigte haben aber auch in

\footnotetext{
${ }^{639}$ Siehe Zipperer, M. (2003a), S. 14, und die dort angegebene Literatur.

${ }^{640} \mathrm{Vgl}$. Farhauer, O.; Borchardt, K. (2004), S. $26 \mathrm{ff}$.

${ }^{641}$ Vgl. Gasche, M. (2004), S. $292 f$.

${ }^{642}$ Siehe Sehlen, S. u.a. (2004), S. $55 f$.

${ }^{643}$ Gasche, M. (2004), S. 296ff., kommt hingegen in einer statischen Betrachtung zu dem Ergebnis, dass auch langfristig ein entlastender Beitragssatzeffekt auftreten kann. Dabei werden allerdings u.a. die altersabhängigen Ausgaben als im Zeitverlauf konstant angenommen und damit vom medizinisch-technischen Fortschritt abstrahiert.
}

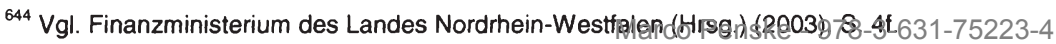


einer Bürgerversicherung vollen Leistungsanspruch bei unterdurchschnittlichen Beiträgen.

\subsubsection{Bewertung}

\subsubsection{Allokation}

Hinsichtlich der allokativen Wirkungen einer Bürgerversicherung ist insbesondere die Belastung der Arbeitgeber entscheidend. Für den Arbeitgeberbeitrag gibt es verschiedene Optionen ${ }^{645}$ Auch in einer Bürgerversicherung ist es möglich, für den Arbeitgeber die Lohnkoppelung aufzuheben und den Arbeitgeberbeitrag mit dem Bruttolohn auszuzahlen oder einen Arbeitgeberbeitragssatz festzuschreiben. Ein Anstieg der Beitragssätze würde sich dann nicht mehr direkt in den Arbeitskosten niederschlagen. Ein Beitragssatzanstieg könnte jedoch indirekt über Lohn- und Tarifverhandlungen an die Arbeitgeber weitergegeben werden. Der Großteil der Befürworter einer Bürgerversicherung will aber an der heutigen paritätischen Finanzierung der Beiträge festhalten. ${ }^{646}$ Dann wird der Faktor Arbeit zwar kurzfristig entlastet, da auf weitere, dem Konzept nach beitragspflichtige, Einnahmen kein Arbeitgeberbeitrag anfällt und bei gleichen Ausgaben und verbreiterter Bemessungsgrundlage der Beitragssatz sinkt. Die Entlastung wirkt allerdings nur einmalig. Anschließend wird der Faktor Arbeit von steigenden Beitragssätzen wie bereits zuvor belastet. ${ }^{647}$

Die Erhöhung der Abgaben auf Kapitaleinkünfte ist unter allokativen Aspekten ebenfalls ein schwer wiegender Einwand gegen die Bürgerversicherung. Eine zusätzliche Belastung von Kapitaleinkünften mit Sozialversicherungsbeiträgen steht den Vorschlägen ${ }^{648}$, gerade deren Belastung für mehr Wachstum und Beschäftigung zu senken, diametral entgegen. Stattdessen ist wegen zunehmender Kapitalflucht mit Beitragsausfällen zu rechnen. ${ }^{649}$ Zudem wird der Anreiz zur notwendigen privaten Altersvorsorge geschwächt, wenn später auf Kapitaleinkünfte Beiträge erhoben werden. Außerdem ist fraglich, warum den Krankenkassen die Erfassung der Kapitaleinkommen besser gelingen sollte als den Finanzämtern. ${ }^{650}$ Die Kassen haben an einer lückenlosen Erfassung weiterer Einkünfte kein Interesse, weil auch in einer Bürgenversicherung unterschiedlich hohe beitragspflichtige Einnahmen zwischen den Kassen ausgeglichen werden müssen, um Risikoselektion ${ }^{651} \mathrm{zu}$ vermeiden. Dann bieten jedoch unterschiedliche Kontrollpraktiken bei guten und schlechten Risiken für die Kassen Möglichkeiten zur Risikoselektion, was für eine Erhebung der Beiträge auf Vermögenseinkommen durch das Finanzamt spricht. Hierdurch entstünden aller-

\footnotetext{
${ }^{645} \mathrm{Vgl}$. Sehlen, S. u.a. (2004), S. 30ff.; SVR (2002), Ziff. $518 f$.

${ }^{646}$ Siehe stellvertretend Projektgruppe Bürgerversicherung des SPD-Parteivorstandes (2004), S. 5; Lauterbach, K.W. (2004), S. $57 f$.

${ }^{647}$ Vgl. Osterkamp, R. (2003), S. 12.

${ }^{648}$ Z.B. die Einführung einer dualen Einkommensteuer; siehe SVR (2003), Ziff. 584ff.

${ }^{649}$ Vgl. Peffekoven, R. (2004a), S. 6; Peffekoven, R. (2004b), S. 35.

${ }^{650} \mathrm{Vgl}$. Deutsche Bundesbank (Hrsg.) (2004a), S. $27 f$.

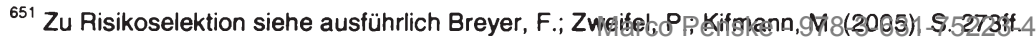


dings weitere Probleme; so müssten diejenigen, die keine Einkommensteuererklärung abgeben, zu einem Selbstauskunftsverfahren verpflichtet werden. ${ }^{652}$

Nach Einführung einer Abgeltungssteuer auf Kapitaleinkünfte ist die Erhebung aufgrund der unzureichenden Datenlage mit weiteren Inkassoproblemen verbunden. Für diesen Fall wird ein Zuschlag auf die Abgeltungssteuer vorgeschlagen ${ }^{653}$, was gleichfalls problematisch ist. ${ }^{64}$ Die von der Projektgruppe Bürgerversicherung des SPDParteivorstandes ${ }^{655}$ vorgesehene Erhebung durch das Finanzamt ist nicht ohne weiteres möglich, da hierzu das Finanzamt über Kapitaleinkünfte und Kasse des Versicherten informiert sein müsste. Dies widerspricht aber gerade der Idee einer Abgeltungssteuer, wonach die Finanzämter gerade keine Kontrollmitteilungen erhalten. Die Kreditinstitute müssten daher den Zuschlag erheben. Eine Zuordnung der Beiträge auf inländische Kapitaleinkommen zu den einzelnen Kassen ist dann jedoch ohne Mitwirkung der Kreditinstitute nicht möglich. Für die Kreditinstitute wäre damit aber ein enormer Verwaltungsaufwand verbunden, wenn der erhobene Zuschlag nach Kassen differenziert erfasst werden müsste. Die Beiträge auf Kapitaleinkommen müssten deshalb von den Kreditinstituten einheitlich erhoben werden und über den RSA an die Kassen fließen. Problematisch bleibt aber die Erfassung von Kapitaleinkommen unterhalb der geltenden Steuerfreibeträge ${ }^{656}$ Gelingt es nicht durchzusetzen, dass auch ausländische Kreditinstitute den Kassen-Zuschlag auf die Abgeltungssteuer erheben, würde zudem auf im Ausland erzielte Kapitaleinkünfte kein Beitrag anfallen, da deren Besteuerung mit einer EU-weit einheitlichen Abgeltungssteuer abgeschlossen wäre und diese Einkünfte nicht an das Finanzamt gemeldet würden. Dies würde Umgehungsmöglichkeiten eröffnen und hätte eine Diskriminierung von inländischen Kapitaleinkünften zur Folge. Kapitalanleger aus dem Ausland müssten ohnehin keine Zuschläge an die Bürgerversicherung zahlen, was Kapitalanleger mit Wohnsitz im Inland benachteiligt.

Neben dieser Diskriminierung und Umsetzungsproblemen ${ }^{657}$ ist die Bürgerversicherung insbesondere wegen ihrer Beschäftigungswirkungen umstritten. Die Arbeitgeberbeiträge sinken zwar zunächst; je nach Lohnstruktur des Unternehmens kann die Erhöhung der Beitragsbemessungsgrenze aber zu einer Mehrbelastung führen. ${ }^{658}$ Die erweiterte Beitragsbemessungsgrundlage und die Erhöhung der Beitragsbemessungsgrenze können auch die Arbeitnehmer stärker belasten, was die Arbeitsanreize beeinträchtigt. Trotz Ausweitung der Bemessungsgrundlage hängen $95 \%$ der Beiträge weiter vom Produktionsfaktor Arbeit ab. ${ }^{659}$ Die Einbeziehung der Beam-

\footnotetext{
${ }^{652}$ Vgl. SVR (2003), Ziff. 321

${ }^{653}$ Siehe Projektgruppe Bürgerversicherung des SPD-Parteivorstandes (2004), S. 27f.; Rürup-Kommission (2003), S. 157.

${ }^{654} \mathrm{Zu}$ damit verbundenen verfassungsrechtlichen Problemen siehe Bieback, K.-J. (2005), S. $154 \mathrm{ff}$.

${ }^{655}$ Siehe Projektgruppe Bürgerversicherung des SPD-Parteivorstandes (2004), S. 27.

${ }^{656} \mathrm{Vgl}$. Rürup-Kommission (2003), S. 157.

${ }^{657}$ Siehe hierzu auch Zipperer, M. (2003b), S. 5ff.

${ }^{658}$ Zur Belastung der Arbeitgeber in einzelnen Branchen siehe Rürup-Kommission (2003), S. 161.

${ }^{659}$ Vgl. SVR (2003), Ziff. 319; Rürup, B. (2003), S. 14. Marco Penske - 978-3-631-75223-4
} 
ten trägt zwar wegen deren Unkündbarkeit zur Stabilisierung der Einnahmen bei ${ }^{660}$, die Konjunkturabhängigkeit bleibt aber weitgehend bestehen.

Die Versicherungspflicht von Beamten und Selbständigen in der GKV führt für diese Personengruppen zu einer steigenden Grenzbelastung mit Sozialversicherungsbeiträgen, wodurch Arbeitsanreize und Beschäftigung sinken. Mit sinkender Beschäftigung sinkt auch die Kapitalproduktivität, da diese vom Faktor Arbeit positiv abhängig ist. Die Investitionen gehen zurück. Zunächst steigen die Bruttolöhne zwar, da sich das Arbeitsangebot verringert hat, langfristig schlägt sich der gesunkene Kapitaleinsatz aber in niedrigeren Löhnen nieder, da die Produktivität des Faktors Arbeit wiederum von der Kapitalausstattung abhängt. Eine Erhöhung der Beitragsbemessungsgrenze würde diese Effekte noch verstärken. Durch eine Ausweitung der Bemessungsgrundlage auf Vermögenseinkommen würde zudem die Nettoverzinsung von Kapitalanlagen sinken und deshalb der Wert der Humankapitalausstattung steigen. Durch diesen Vermögenseffekt sinkt das Arbeitsangebot weiter. ${ }^{661}$

Tabelle 19: Beschäftigungseffekte der Bürgerversicherung

\begin{tabular}{|c|c|c|c|c|}
\hline \multirow[b]{3}{*}{ Jahr } & \multicolumn{2}{|c|}{ Geschlossene Volkswirtschaft } & \multicolumn{2}{|c|}{ Offene Volkswirtschaft } \\
\hline & Schritt 1 & Schritt 2 & Schritt 2 & Schritt 3 \\
\hline & $\begin{array}{l}\text { Einbeziehung der } \\
\text { Beamten und } \\
\text { Selbständigen }\end{array}$ & $\begin{array}{c}\text { Schritt 1+ } \\
\text { Erhöhung der } \\
\text { Beitragsbemes- } \\
\text { sungsgrenze } \\
\end{array}$ & $\begin{array}{c}\text { Schritt } 1+ \\
\text { Erhöhung der Bei- } \\
\text { tragsbemessungs- } \\
\text { grenze } \\
\end{array}$ & $\begin{array}{c}\text { Schritt } 2+ \\
\text { Einbeziehung von } \\
\text { Vermögens- } \\
\text { einkommen } \\
\end{array}$ \\
\hline 2005 & $-0,8 \%$ & $-2,3 \%$ & $-1,9 \%$ & $-3,0 \%$ \\
\hline 2010 & $-0,8 \%$ & $-2,5 \%$ & $-2,6 \%$ & $-3,2 \%$ \\
\hline 2020 & $-0,8 \%$ & $-3,0 \%$ & $-0,2 \%$ & $+0,2 \%$ \\
\hline 2035 & $-0,8 \%$ & $-3,5 \%$ & $-4,7 \%$ & $-2,8 \%$ \\
\hline 2050 & $-0,8 \%$ & $-3,7 \%$ & $-5,1 \%$ & $-3,7 \%$ \\
\hline 2100 & $-0,9 \%$ & $-3,0 \%$ & $-3,6 \%$ & $-3,3 \%$ \\
\hline
\end{tabular}

Anmerkung: Veränderung der Beschäftigung im Vergleich zum Entwicklungspfad der Volkswirtschaft ohne Änderung des GKV-Finanzierungssystems.

Quelle: SVR (2003), Tabelle 44.

Ausgehend von diesen Wirkungszusammenhängen hat der Sachverständigenrat zur Begutachtung der gesamtwirtschaftlichen Entwicklung ${ }^{662}$ für die Bürgerversicherung - mit der von der Rürup-Kommission vorgeschlagenen Ausgestaltung (Beitragsbemessungsgrenze von 5.100 Euro, alle Einkunftsarten) - einen deutlichen Beschäftigungsrückgang von bis zu 3,0\% im Umstellungsjahr berechnet. Mittelfristig ist im Vergleich zur Entwicklung ohne Änderungen im Finanzierungssystem der GKV eine leichte Beschäftigungszunahme von bis zu 0,2\% zu erwarten. Langfristig sinkt aber die Beschäftigung um 3,3 Prozent. Die Ergebnisse gibt Tabelle 19 wieder. „Wenngleich die Ergebnisse des Simulationsmodells in quantitativer Hinsicht nicht eins zu eins auf die Realität übertragen werden können, ist die Tendenz doch eindeutig: Die

\footnotetext{
${ }^{660}$ Vgl. Gasche, M. (2004), S. 298.

${ }^{661} \mathrm{Vgl}$. SVR (2003), Kasten 8.

${ }^{662}$ Siehe ebenda.
} 
Pauschalprämie erhöht die Beschäftigung, die Bürgerversicherung verringert die Beschäftigung. ${ }^{6663}$

Den negativen Beschäftigungswirkungen wird entgegengehalten, im europäischen Vergleich verzeichneten Länder wie z.B. Österreich, Schweden oder Großbritannien mit Krankenversicherungssystemen, die einer Bürgerversicherung ähnlich seien, relativ niedrige Arbeitslosenquoten und höhere BIP-Wachstumsraten. ${ }^{664}$ Dieser Vergleich ist aber nur bedingt geeignet, da er andere wesentliche Einflussfaktoren auf die Beschäftigung wie das Steuerrecht und die Regelungen am Arbeitsmarkt vernachlässigt. Zudem wird kein direkter Zusammenhang zwischen Bürgerversicherung sowie Wachstum und Beschäftigung aufgezeigt.

\subsubsection{Distribution}

Hauptaugenmerk einer Bürgerversicherung gilt den distributiven Wirkungen. Im Modell der Rürup-Kommission werden Erwerbstätige und Rentner durch die Senkung des Beitragssatzes zunächst entlastet, sofern sie nicht über weitere Einkünfte verfügen, die über der derzeitigen Beitragsbemessungsgrenze (2005: 3.525 Euro p.m.) liegen und beitragspflichtig werden. Bezieher von Einkünften über der aktuellen Beitragsbemessungsgrenze werden daher tendenziell mehr belastet. Welcher Effekt überwiegt, kann im Vorhinein nicht gesagt werden. Dies hängt ab von der Höhe der Einkünfte und des Senkungspotentials für den Beitragssatz.

\section{Abbildung 28: Verteilungseffekte der Bürgerversicherung}

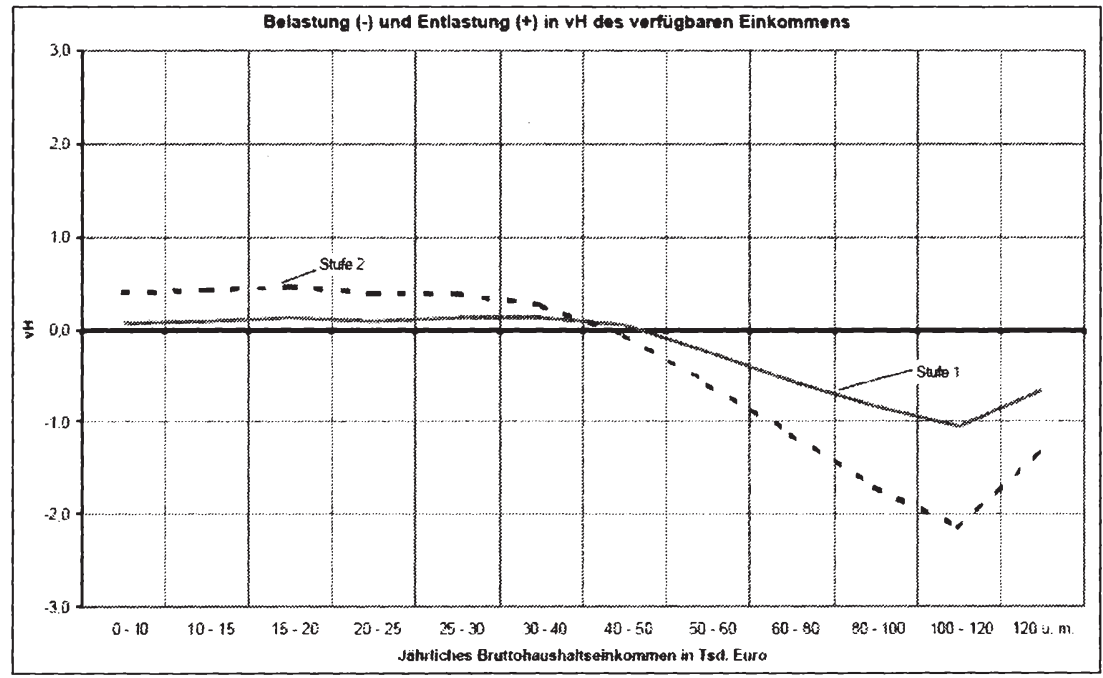

Quelle: Bork, C. (2003), S. 41.

${ }^{663}$ SVR (2003), Ziff. 325.

${ }^{664}$ Siehe Lauterbach, K.W. u.a. (2004b), S. 602f.; Projektgruppe Bürgenversicherung des SPD-Parteivorstandes (2004), S. 43 ff. 
Abbildung 28 zeigt die Verteilungswirkungen im Vergleich zum Status quo in zwei Stufen. Die erste Stufe umfasst die Erweiterung der Bemessungsgrundlage auf alle Einkommensarten und eine Anhebung der Beitragsbemessungsgrenze auf monatlich 5.100 Euro bei gleichzeitiger aufkommensneutraler Senkung des Beitragssatzes. In Stufe 2 wird die Versicherungspflichtgrenze aufgehoben und damit die gesamte Bevölkerung in die GKV einbezogen. Haushalte mit einem Jahreseinkommen bis zur Beitragbemessungsgrenze von 41.850 Euro (2004) werden geringfügig entlastet. In diesem Einkommensbereich wird die Entlastung aufgrund des gesunkenen Beitragssatzes durch die Einbeziehung weiterer Einkunftsarten teilweise kompensiert. Die Anhebung der Beitragsbemessungsgrenze belastet Haushalte mit einem Einkommen über der alten Grenze. Haushalte mit einem Jahreseinkommen von rund 110.000 Euro werden mit durchschnittlich $1,0 \%$ des verfügbaren Einkommens am stärksten belastet. $^{665}$

Die Einbeziehung der gesamten Bevölkerung (Stufe 2) führt insbesondere für Bezieher hoher Einkommen zu höheren Belastungen als in der ersten Stufe, da diese zuvor in der PKV Versicherten tendenziell über hohe Einkommen verfügen. Dadurch übertrifft der Beitrag dieser Haushalte zur Bürgerversicherung die zuvor gezahlten PKV-Prämien. Haushalte mit einem Einkommen von rund 110.000 Euro p.a. werden im Durchschnitt mit insgesamt 2,2\% des verfügbaren Einkommens am stärksten belastet. Entlastet werden Haushalte mit einem Einkommen unter der alten Beitragsbemessungsgrenze mit bis zu 0,5\% des verfügbaren Einkommens.

Differenziert nach sozialer Stellung sind die Auswirkungen von Stufe 1 gering. Arbeiter und Angestellte mit einem Bruttojahreseinkommen unter 50.000 Euro werden geringfügig entlastet, bei höheren Einkommen werden Arbeitnehmerhaushalte mit bis zu $1,1 \%$ des verfügbaren Einkommens belastet. Haushalte von Beamten, Pensionären sowie Arbeitslosen, Studenten und sonstigen Nichterwerbstätigen sind kaum betroffen. Mit starken Einbußen müssen hingegen Selbständige rechnen. Wird darüber hinaus Stufe 2 berücksichtigt, werden Arbeiter und Angestellte mit einem Bruttoeinkommen von bis zu 60.000 Euro p.a. durchschnittlich um bis zu 1,0\% des verfügbaren Einkommens entlastet. Belastet werden Selbständige, Pensionäre und Beamte; Selbständige mit höherem Einkommen mit rund $3,0 \%$, Pensionäre mit bis zu 4,0 \% und Beamte mit bis zu 2,3\% des verfügbaren Einkommens. Diese Gruppen verfügen im Durchschnitt über relativ hohe Gesamteinkommen, so dass die Beiträge in der Bürgerversicherung die PKV-Prämien mitunter deutlich übersteigen.

Für alle Modelle der Bürgerversicherung gilt, dass vor allem Bezieher von Einkommen über der bisherigen Beitragsbemessungsgrenze und Haushalte mit Einkommen aus anderen Einkunftsarten tendenziell belastet werden. Insbesondere Haushalte mit hohem Einkommen und zuvor in der PKV Versicherte müssen in der Bürgerversicherung höhere Beiträge zahlen als im Status quo. Wird die Beitragsbemessungsgrenze aufgehoben, ist die progressive Verteilungswirkung maximal; der Beitragssatz kann am stärksten gesenkt werden. Haushalte, die lediglich über Einkommen aus unselbständiger Arbeit bis zur alten Beitragsbemessungsgrenze verfügen, werden von der Beitragssatzsenkung dann am stärksten entlastet. Liegen die Einkünfte aber über der alten Beitragsbemessungsgrenze oder Einkünfte aus anderen Einkunftsarten vor, 
kann keine generelle Aussage darüber getroffen werden, ob der jeweilige Haushalt belastet oder entlastet wird. Eine zweite Beitragsbemessungsgrenze für Vermögenseinkommen führt dazu, dass insbesondere Bezieher von Kapitaleinkünften, die bereits über ein hohes Arbeitseinkommen verügen, stärker belastet werden. Diese Versichertengruppe würde bei einer einheitlichen Beitragsbemessungsgrenze auf dem bisherigen Niveau auch bei einer Ausweitung der Beitragspflicht auf weitere Einkommen keine höheren Beiträge zahlen. Wird zur Beitragspflicht von Kapitaleinkünften ein Zuschlag auf eine Abgeltungssteuer erhoben, belastet dies Bezieher hoher Kapitaleinkommen noch stärker, da der Beitrag dann auf Kapitaleinkünfte ohne Beitragsbemessungsgrenze erhoben wird. Insgesamt steigt das Ausmaß der Umverteilung in der GKV in allen Modellen mit einer Ausweitung des Leistungsfähigkeitsprinzips an. ${ }^{666}$

Sofern die Beitragsbemessungsgrenze aufgehoben wird, zahlen Versicherte mit gleichem Gesamteinkommen in der Bürgerversicherung unabhängig von der Zusammensetzung ihres Einkommens den gleichen Beitrag. Ungerechtfertigte intragenerative Verteilungseffekte sind damit zwar beseitigt, soweit alle Einkünfte auch tatsächlich erfasst werden, was neben der Erfassung von Kapitaleinkünften insbesondere bei Einkünften, die unterhalb der Steuerfreibeträge liegen, problematisch ist. ${ }^{667}$ Der Steuercharakter nimmt aber zu. Durch Zweckbindung, Leistungsanspruch und die organisatorische Abwicklung außerhalb des Steuersystems unterscheidet sich der Beitrag zwar noch von einer Steuer ${ }^{668}$, der Beitrag entspricht aber unterhalb der Beitragsbemessungsgrenze einer zweiten (proportionalen) Einkommensteuer, die die Leistungsfähigkeit nicht angemessen ermittelt, weil bei Arbeitseinkünften Werbungskosten nicht berücksichtigt werden. Zudem müssen nach dem Leistungsfähigkeitsprinzip negative Einkünfte mit positiven Einkünften verrechnet werden können, womit die Beiträge aber gestaltbar würden. Privilegierungen des Steuerrechts müssten zwar nicht übernommen werden, so dass nicht zwangsläufig Ungleichbehandlungen aus dem Steuerrecht (z.B. Steuerfreiheit von Zuschlägen für Sonntags-, Feiertagsund Nachtarbeit, §3b EStG) auf die Beiträge zur Bürgerversicherung übertragen würden. Unterschiedliche Interpretationen des Leistungsfähigkeitsprinzips für das Steuersystem und die Sozialversicherung sind aber sachlich nicht zu begründen. ${ }^{669}$ Da mit den Krankenkassen und den Finanzämtern zwei unterschiedliche Verwaltungsträger zwei Abgaben (Bürgerversicherungsbeitrag und Einkommensteuer) mit ähnlicher Bemessungsgrundlage erhöben, entstünden zudem vermeidbare Erhebungskosten. Ein direkt steuerfinanziertes System könnte dies umgehen, ist aber mit anderen, bereits erläuterten, gravierenden Problemen verbunden. Darüber hinaus hätten Beitragssatzsteigerungen in der Bürgerversicherung aufgrund des Steuercharakters der Beiträge ähnlich negative Effekte auf Wachstum und Beschäftigung wie eine Erhöhung der Einkommensteuer. ${ }^{670}$

\footnotetext{
${ }^{666} \mathrm{Zu}$ den konkreten Verteilungswirkungen anderer Modelle siehe Projektgruppe Bürgerversicherung des SPD-Parteivorstandes (2004), S. 35ff.; Sehlen, S. u.a. (2004), S. $43 \mathrm{ff}$.

${ }^{667} \mathrm{Zu}$ den Problemen einer Erfassung von weiteren Einkünfte siehe Zipperer, M. (2003b), S. 5ff.

${ }^{668} \mathrm{Vgl}$. Bieback, K.-J. (2003), S. 419; Wenzel, D. (1999), S. 112, und die dort jeweils angegebenen Quellen.

${ }^{669}$ Vgl. Kirchhof, F. (2004), S. 5; Nullmeier, F. (2005), S. 60ff.

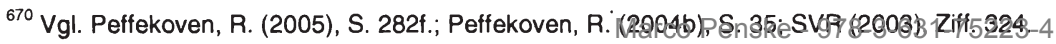


Insbesondere zur Abschwächung des Steuercharakters sehen die meisten Bürgerversicherungs-Modelle die Einführung einer oder mehrerer Beitragsbemessungsgrenzen vor. Um die dadurch verursachten Belastungsunterschiede von Ehepaaren mit gleichem Haushaltseinkommen bei ungleicher Verteilung der Einkommen auf die Partner zu beseitigen, wird ein negatives Ehegattensplitting nach dem Vorbild der Einkommensteuer vorgeschlagen. ${ }^{671}$ Werden Beitragsbemessungsgrenze (2005: 3.525 Euro p.m.) und Versicherungspflichtgrenze (2005: 3.900 Euro p.m.) in der derzeitigen Höhe beibehalten, ist vom Splitting keine nennenswerte Beitragssatzentlastung zu erwarten. Ein großer Teil der betroffenen Versicherten könnte in die private Krankenversicherung wechseln, da ihr Einkommen meist auch über der Versicherungspflichtgrenze liegt. ${ }^{672} \mathrm{Im}$ Rahmen einer Bürgerversicherung könnte der Beitragssatz durch ein negatives Ehegattensplitting um bis zu 0,9 Prozentpunkte gesenkt werden. Mit dem Splittingverfahren ist allerdings eine systematische Benachteiligung der Ehe verbunden, was gegen Art. 6 GG verstoßen dürfte, da dann Ehepaare im Vergleich zu nichtehelichen Lebensgemeinschaften bei gleichem Gesamteinkommen einen höheren Beitrag zahlen müssen, wenn ein Einkommen oberhalb der Beitragsbemessungsgrenze liegt. Hinzu kommen Umsetzungsprobleme: Es ist unklar, welcher Beitragssatz bei erwerbstätigen Ehepartnern, die in Kassen mit unterschiedlichen Beitragssätzen versichert sind, angewendet werden soll. Da dem Arbeitgeber nur Informationen über Beitragssatz und Einkommen des bei inm Beschäftigten vorliegen, ist auch das bisher praktizierte Quellenabzugsverfahren nicht mehr möglich. Problematisch ist zudem die Erhebung eines Arbeitgeberbeitrags bei nicht Erwerbstätigen. ${ }^{673}$

Getrennte Beitragsbemessungsgrenzen für Arbeits- und Vermögenseinkommen sind ebenso abzulehnen, da sie gegen die horizontale Beitragsgerechtigkeit verstoßen. Trotz gleichen Gesamteinkommens würden Versicherte mit Einkünften aus verschiedenen Quellen einen höheren Beitrag zahlen als Versicherte mit einem Einkommen über der Beitragsbemessungsgrenze. ${ }^{674}$ Einkunftsartbezogene Freibeträge werden mit dem verhältnismäßig hohen Erfassungsaufwand bei geringen Vermögenseinkommen und der Analogie zum Steuerrecht begründet. ${ }^{675}$ In Relation zu den zu zahlenden Beiträgen entlasten Freibeträge in der Krankenversicherung insbesondere Versicherte mit kleinerem Einkommen, die absolute Entlastung ist aufgrund des proportionalen Satzes unabhängig vom Einkommen. Auch in einer Bürgerversicherung gelten aber die gleichen Argumente gegen einkunftsbezogene Freibeträge wie sie in der synthetischen Einkommensteuer gegen den Sparerfreibetrag vorgebracht werden. ${ }^{676}$ Einkünfte aus Kapitalvermögen erhöhen die wirtschaftliche Leistungsfähigkeit und müssen konsequenterweise in einer Bürgerversicherung vollständig beitragspflichtig sein. Gleiches gilt für Modelle ${ }^{677}$, die eine Beitragsfreiheit von Ein-

\footnotetext{
${ }^{671}$ Siehe Sehlen, S. u.a. (2004), S. 9, $65 \mathrm{ff}$.

${ }^{672}$ Vgl. Eekhoff, J. (2005), S. 16.

${ }^{673} \mathrm{Vgl}$. SVR (2002), Ziff. 514f.; Rürup-Kommission (2003), S. 170 f.

${ }^{674}$ Vgl. Sehlen, S. u.a. (2004), S. 59f.; Rürup-Kommission (2003), S. 158.

${ }^{675} \mathrm{Vgl}$. Rürup-Kommission (2003), S. 158.

${ }^{676}$ Zum Sparerfreibetrag in einer synthetischen Einkommensteuer siehe SVR (2003), Ziff. 499ff.; Peffekoven, R. (2002), S. 27ff.

${ }^{677}$ Siehe Projektgruppe Bürgerversicherung des SPQ-Parteivorstandes (2904) 6 S.1245223-4
} 
künften aus Vermietung und Verpachtung vorsehen. Auch wenn diese Einkünfte aufgrund der damit verbundenen steuermindernden Ausgaben und Förderungsmaßnahmen gesamtfiskalisch negativ sind ${ }^{678}$, widerspricht es dem Leistungsfähigkeitsprinzip, diese individuell beitragsfrei zu stellen. Darüber hinaus verstößt die Vermischung von Brutto- und Nettoprinzip gegen den Grundsatz der Gleichbehandlung aller Einkunftsarten. Einkünfte aus nichtselbständiger Tätigkeit unterliegen z.B. ohne Abzug von Werbungskosten der Beitragspflicht, bei Kapitaleinkünften hingegen gilt das Nettoprinzip. Die Begünstigung einzelner Einkunftsarten beeinträchtigt die Entscheidungsneutralität und führt zu allokativen Verzerrungen und Wohlstandsverlusten.

Dies zeigt den Zielkonflikt zwischen allokativen und distributiven Zielen in der Bürgerversicherung: Sollen Ungleichbehandlungen vermieden und das Leistungsfähigkeitsprinzip gestärkt werden, ist eine Beitragsbemessungsgrenze abzulehnen, mithin die gleiche Bemessungsgrundlage wie bei der Einkommensteuer zu wählen. Wird der dann zunehmende Steuercharakter aber aus allokativen Gründen abgelehnt, ist die Beitragsbemessungsgrenze beizubehalten und distributive Ungerechtigkeiten müssen in Kauf genommen werden.

Die intergenerative Gerechtigkeit sehen Befürworter der Bürgerversicherung dadurch gestärkt, dass weitere Einkunftsarten einbezogen werden. ${ }^{679}$ Der demographische Wandel wirkt schwächer auf die Einnahmen als im derzeitigen Finanzierungssystem, da insbesondere ältere Versicherte stärker zur Finanzierung herangezogen werden und der steigenden Bedeutung von Kapitaleinkünften Rechnung getragen wird. Zudem wird die einseitige Belastung der Arbeitsentgelte zumindest gemindert. Die Erweiterung der Beitragsbemessung und die Einbeziehung weiterer Bevölkerungsgruppen in die GKV sind zwar geeignet, kurzfristig die Finanzierung zu sichern. Die Schwäche des Finanzierungssystems - demographische Abhängigkeit und ineffiziente Verteilungswirkungen - bleiben aber bestehen. Die langfristige Beitragssatzdynamik wird nicht gedämpft.

Mit der Ausweitung der Versicherungspflicht wird zwar die intragenerative Gerechtigkeit gestärkt, die intergenerative Ungleichbehandlung nimmt aber durch den Wegfall der PKV zu, weil der Bevölkerungsteil, der zuvor in der PKV Kapital angesammelt und damit eigene Vorsorge betrieben hat, auch in ein umlagefinanziertes System gezwungen wird. Die Ausweitung des Umlageverfahrens auf alle Bürger würde eine weitere Lastverschiebung auf künftige Generationen bewirken und die demographische Abhängigkeit sogar verstärken. ${ }^{880}$

Insgesamt sinkt die Nachhaltigkeitslücke der GKV im Vergleich zum Status quo zwar durch die Einführung einer Bürgerversicherung von $236 \%$ des BIP 2000 auf $197 \%$. Betrachtet man jedoch die Ausweitung des Versichertenkreises auf alle Bürger und

${ }^{678}$ Siehe Bundesministerium der Finanzen (Hrsg.) (2005), S. 17; Fußnote 628 (S. 171).

${ }^{679}$ Vgl. Rürup-Kommission (2003), S. 150, 155; Projektgruppe Bürgerversicherung des SPD-Parteivorstandes (2004), S. 53f.; Lauterbach, K.W. u.a. (2005), S. $76 f$.

${ }^{680}$ Vgl. SVR (2002), Ziff. 513, 524; SVR (2003), Ziff. 318; Kifmann, M. (2003), S. 5; Osterkamp, R. (2003), S. 13; Rürup, B. (2003), S. 13; Felder, S.; Kifmann, M. (2003), S. 6ff.; Farhauer, O.; Borchardt, K. (2004), S. 29; Peffekoven, R. (2004b), S. 35; Breyer, F.; Zweifel, P.; Kifmann, M. (2005), S. 202; Peffekoven, R. (2005), S. 283. 
damit das wesentliche Element einer Bürgerversicherung, steigt die Nachhaltigkeitslücke sogar im Vergleich zum Status quo auf $247 \%{ }^{681}$ Die gesamtstaatliche Nachhaltigkeitslücke steigt von $415 \%$ des BIP 2001 auf $452 \% .{ }^{682}$

\subsubsection{Verfassungsrechtliche Gesichtspunkte}

Hinsichtlich der Ausweitung des Versichertenkreises bestehen verfassungsrechtliche Bedenken. Die allgemeine Versicherungspflicht kann insofern gegen das Grundgesetz verstoßen, als das Sozialstaatsprinzip aus Art. 20 und 28 GG eine Bedürttigkeit für Sozialleistungen voraussetzt. Eine allgemeine Versicherungspflicht auch für Selbständige und Beamte stellt daher einen Verstoß gegen das Subsidiaritätsprinzip dar, da diese ihre Gesundheitsrisiken selbst tragen oder absichern können. ${ }^{683}$ Dem wird entgegengehalten, dass auch zunehmend Selbständige schutzbedürttig seien, wenn sie aufgrund ihrer Einkommenssituation sich nicht selbst ausreichend gegen die mit Krankheit verbundenen Kosten versichern könnten. ${ }^{684}$ Die Schutzbedürftigkeit sei zudem bei der Ausgestaltung der Sozialversicherung nicht entscheidend. Mit einer Einbeziehung der Selbständigen werde zum einen deren Absicherung verbindlich geregelt und zum anderen auch diese Gruppe am sozialen Ausgleich beteiligt. Aus Sicht des Bundesverfassungsgerichts sei eine Ausweitung des Versichertenkreises möglich, wenn dadurch die Funktionsfähigkeit des Systems erhalten bliebe. ${ }^{685}$ Nach ökonomischen Gesichtspunkten trifft dies für die Bürgerversicherung jedoch gerade nicht zu. Die Nachhaltigkeitslücke steigt sogar durch die Ausweitung des Versichertenkreises, was die Finanzierbarkeit beeinträchtigt. Die Beteiligung aller Gruppen am sozialen Ausgleich kann zudem effizienter und effektiver über das Steuer- und Transfersystem erreicht werden. Abgesehen davon legitimiert nach Kirchhofs ${ }^{686}$ Auffassung das fiskalische Ziel nicht die Zwangsmitgliedschaft und damit den Eingriff in die Handlungsfreiheit aus Art. 2 GG.

Insbesondere die Verfassungsmäßigkeit einer Einbeziehung der Beamten in die Versicherungspflicht ist umstritten. ${ }^{687}$ Eine Zwangsversicherung in der GKV verstoße gegen die Vorsorgefreiheit und damit die persönliche Unabhängigkeit der Beamten. Zudem sei die Alimentationspflicht der öffentlichen Arbeitgeber nicht teilbar und müsse amtsangemessen den Lebensstandard sichern. Die GKV biete aber lediglich eine Mindestsicherung. Art. 33 Abs. 5 GG verlange zudem die Absicherung der Beamten innerhalb des Beamtenverhältnisses. Eine Einbeziehung der Beamten in die GKV sei

\footnotetext{
${ }^{681}$ Vgl. Hagist, C.; Raffelhüschen, B. (2003), S. 6. Siehe auch Rürup-Kommission (2003), S. 177f. Zur Nachhaltigkeitslücke siehe auch Kapitel II.4.2.5 Generationenbilanzierung in der GKV, S. 46.

${ }^{682}$ Vgl. Raffelhüschen, B.; Hagist, C.; Fetzer, S. (2004), S. 6; Fetzer, S. u.a. (2004), S. 7.

${ }^{683}$ Vgl. ausführlich Zipperer, M. (2003a), S. 3, 9f. Siehe auch Hajen, L.; Paetow, H.; Schumacher, H. (2000), S. 122f.; Boetius, J. (1999), S. 12; SVR KAiG (1998), Ziff. 460ff.; Boetius, J.; Wiesemann, H.-O. (1998), S. $31 \mathrm{ff}$.

${ }^{684} \mathrm{Vgl.}$ Bieback, K.-J. (2005), S. $84 f$.

${ }^{685}$ Vgl. Bieback, K.-J. (2003), S. 419f.; Projektgruppe Bürgerversicherung des SPD-Parteivorstandes (2004), S. 60f.; Beck, J. (2004), S. 388f.; Bieback, K.-J. (2005), S. 88, und die dort jeweils angegebene Literatur.

${ }^{686}$ Siehe Kirchhof, F. (2004), S. $2 f$.

${ }^{687}$ Einen Überblick über wesentliche Argumente geben Farhaver, O.; Borchardt, K. (2004), S. $23 f f$. Siehe hierzu auch Gasche, M. (2004), S. 298. Marco Penske - 978-3-631-75223-4
} 
daher verfassungswidrig. ${ }^{688}$ Dem wird jedoch entgegengehalten, es sei dem öffentlichen Arbeitgeber überlassen, wie er seiner Alimentationspflicht nachkomme. ${ }^{689} \mathrm{Ob}$ es eine Vorsorgefreiheit gebe, habe das Bundesverfassungsgericht bislang in seiner Rechtsprechung offen gelassen. Die Beihilfe könne also durchaus durch andere Systeme ersetzt werden, sofern diese einen ausreichenden Versicherungsschutz böten.

Ein weiterer Einwand zielt auf die PKV ab. Wegen des aus Art. 14 Abs. 1 GG abgeleiteten Bestands- und Vertrauensschutzes ist es nach herrschender Meinung nicht möglich, bereits privat Versicherte in die GKV zu zwingen. ${ }^{690}$ Deshalb stehen auch die in der PKV gebildeten Alterungsrückstellungen einer Bürgerversicherung nicht zur Verfügung, weder zur Bildung eines Kapitalstocks in der GKV noch für Beitragssatzsenkungen. ${ }^{691}$ Für die GKV folgt aus dem Bestandsschutz für Altkunden, dass in der Übergangszeit die ohnehin nur geringe Beitragssatzentlastung von 0,7 Prozentpunkten ${ }^{692}$, die aus der Ausweitung der Versicherungspflicht resultiert, kaum erreicht werden kann. Räumt man deshalb den bisher privat Versicherten ein Wechselrecht in die GKV ein ${ }^{693}$, dürften überwiegend schlechte Risiken - z.B. Rentner mit hohen Ausgaben und dementsprechend hoher PKV-Prämie - in die GKV wechseln, was eher beitragssatzsteigernd wirken würde. Gerade aus diesem Grund hat der Gesetzgeber die Rückkehr von privat Versicherten in die GKV erschwert. ${ }^{694}$ Nach § 6 Abs. 3a SGB V z.B. ist für einen in der PKV Versicherten, der nach Vollendung des 55. Lebensjahres versicherungspflichtig wird, der Wechsel in die GKV ausgeschlossen, wenn er in den fünf Jahren zuvor nicht in der GKV versichert war, davon mindestens 2,5 Jahre freiwillig. Ebenso ist ein Wechsel von der PKV in den Status des freiwilligen GKV-Mitglieds nicht möglich (§ 9 Abs. 1 SGB V).

Gravierend wären trotz des Bestandsschutzes für Altkunden die Einschnitte für die PKV. Bei Einführung einer Bürgerversicherung würde die PKV bei Neukunden auf Zusatzversicherungen beschränkt. Formal könnte die PKV zwar weiter auch Vollversicherungen anbieten, allerdings unter den Bedingungen einer Bürgerversicherung, also mit einkommensabhängigen Beiträgen, Kontrahierungszwang, einheitlichem Leistungskatalog und Finanzausgleich. ${ }^{695}$ Die Erfahrungen aus der Schweiz zeigen, dass bei einer Ausweitung der Versicherungspflicht auf die gesamte Bevölkerung nur

${ }^{688}$ Vgl. Zipperer, M. (2003a), S. $6 f f$.

${ }^{689}$ Vgl. Bieback, K.-J. (2003), S. 421; Kirchhof, F. (2004), S. 3; Beck, J. (2004), S. 390; Bieback, K.-J. (2005), S. 124ff. Siehe hierzu auch SVR (2004), Ziff. 531; der SVR bezieht sich zwar auf das Modell einer Bürgerprämie, die Argumentation ist aber auf die Bürgerversicherung übertragbar.

${ }^{690}$ Vgl. Zipperer, M. (2003a), S. 14; Bieback, K.-J. (2003), S. 423f.; Lauterbach, K.W. (2004), S. 52; Farhauer, O.; Borchardt, K. (2004), S. 29; SVR (2004), Ziff. 531; Kirchhof, F. (2004), S. 5; Beck, J. (2004), S. 391; Bieback, K.-J. (2005), S. 106f., 113.

${ }^{691}$ Z.B. Schräder, W.F.; Sehlen, S.; Hofmann, J. (2004), S. 10ff., schlagen vor, den auf den GKV-Leistungskatalog entfallenden Anteil der Alterungsrückstellungen zur Finanzierung der Bürgerversicherung zu verwenden.

${ }^{692}$ Siehe Tabelle 18: Entlastungseffekte bei unterschiedlichen Ausgestaltungen einer Bürgerversicherung, S. 170.

${ }^{693}$ Dies sieht Z.B. die Projektgruppe Bürgenversicherung des SPD-Parteivorstandes (2004), S. 23, vor.

${ }^{694}$ Vgl. Schräder, W.F.; Sehlen, S.; Hofmann, J. (2004), S. 7; Beck, J. (2004), S. 390; Greß, S.; Walendzik, A.; Wasem, J. (2005), S. 19ff.

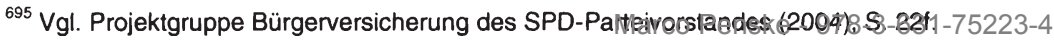


wenige private Versicherungen auf diesem Versicherungsmarkt bleiben. ${ }^{696}$ Das derzeitige Geschäftsmodell mit risikoäquivalenten Prämien wäre in der praktizierten Form nicht mehr möglich, weil gesetzlich Versicherte schon allein aus finanziellen Gründen keine zweite Vollversicherung in der PKV abschließen würden. Die Bürgerversicherung verstieße damit gegen die in Art. 12 GG in Verbindung mit Art. 14 GG garantierte Berufsfreiheit und den Schutz des Gewerbebetriebs. ${ }^{697}$ Das hiergegen vorgebrachte Argument, der PKV ergäben sich neue Geschäftsfelder durch eine Rückführung von Leistungen der $\mathrm{GKV}^{698}$, überzeugt indes nicht. Zum einen beinhaltet das Konzept einer Bürgerversicherung keine Begrenzung der GKV-Leistungen, zum anderen ist fraglich, ob für die PKV neue Märkte für Zusatzversicherungen den Marktverlust in der Vollversicherung überhaupt kompensieren können. Aus der Teilversicherung erzielte die PKV im Jahr 2004 lediglich 12,4\% ihrer Beitragseinnahmen. Der weitaus größte Teil entfiel mit $71,6 \%$ auf die Vollversicherung. ${ }^{699}$ Die Vollversicherung kann daher nicht nur als Teilbereich der PKV aufgefasst werden. Ansonsten würde nach Becks ${ }^{700}$ Argumentation kein Eingriff in die Berufsfreiheit vorliegen, sondern lediglich die Berufsausübung geregelt werden, was verfassungsrechtlich zulässig wäre.

In einer Bürgerversicherung kommt für die PKV durch das Ausbleiben von Neukunden erschwerend hinzu, dass sich in der Vollversicherung die Risikomischung in der PKV verschlechtern würde. Der daraus resultierende Prämienanstieg wird jedoch auf lediglich $5 \%$ innerhalb von zehn Jahren geschätzt. Die Prämien steigen nur moderat, weil die Risikoselektion anhand von Gesundheitsprüfungen der PKV nur in den ersten zehn Versicherungsjahren Selektionsersparnisse bringt, die die Prämien reduzieren. Langfristig verschlechtert sich mit dem Alter auch der Gesundheitszustand von bei Eintritt in die PKV guten Risiken, so dass die Selektionsgewinne vergehen. ${ }^{701}$ Darüber hinaus ist jedoch aufgrund der Umlageelemente in der Finanzierung der PKV mit einem Prämienanstieg zu rechnen, wenn junge Versicherte ausbleiben. ${ }^{702}$ Auf die Wirkungen eines Anstiegs des durchschnittlichen Alters auf die PKV-Prämie wird in Kapitel VI.2.2.2 Demographische Abhängigkeit (S. 217) noch näher eingegangen.

Neben der Ausweitung der Versicherungspflicht ist auch die große Ähnlichkeit des Beitrags zur Einkommensteuer verfassungsrechtlich problematisch. Die Belastung gemäß der finanziellen Leistungsfähigkeit begründet nach Kirchhofs ${ }^{703}$ Auffassung bereits die allgemeine Steuerlast und kann deshalb nicht noch eine Art Sozialversicherungsteuer rechtfertigen. Zudem ist die Ertragskompetenz in Art. $106 \mathrm{GG}$ nicht geregelt, folglich der Beitrag gemäß Art. 108 GG von der staatlichen Finanzverwaltung zu erheben. Die Krankenversicherungen würden dann die benötigten Mittel als

\footnotetext{
${ }^{696}$ Vgl. Greß, S.; Walendzik, A.; Wasem, J. (2005), S. 69.

${ }^{697}$ Vgl. Zipperer, M. (2003a), S. 2ff., 8f.; SVR (2004), Ziff. 529, 532; Kirchhof, F. (2004), S. 4f.; Boetius, J. (1999), S. 13; Boetius, J.; Wiesemann, H.-O. (1998), S. $36 f f$.

${ }^{698}$ Siehe Bieback, K.-J. (2003), S. 423; Bieback, K.-J. (2005), S. 109.

${ }^{699}$ Siehe Verband der privaten Krankenversicherung e.V. (Hrsg.) (2005), S. 25.

${ }^{700}$ Siehe Beck, J. (2004), S. 389. Siehe hierzu auch Bieback, K.-J. (2005), S. 109 f.

${ }^{701} \mathrm{Vgl}$. Schönfels, R. von (2002), S. 133. Siehe hierzu auch Beer, H. (1995), S. 695.

${ }^{702}$ Vgl. Beck, J. (2004), S. 391.

${ }^{703}$ Siehe Kirchhof, F. (2004), S. 6. 
Zuweisung vom Staat erhalten. Als Zwecksteuer entspricht der Beitrag darüber hinaus nicht der Finanzverfassung, da Steuern infolge des Non-Affektationsprinzips ${ }^{704}$ nicht zweckgebunden erhoben werden dürfen und die Einnahmen auch nicht dem Gemeinwesen, sondern einem "intermediären Fonds“705 ${ }^{4 u f l i e ß e n .}{ }^{706}$ Neben den ökonomischen bestehen also erhebliche verfassungsrechtliche Bedenken gegen die Einführung einer Bürgerversicherung.

\subsection{Kopfpauschalen}

\subsubsection{Konzeption}

$\mathrm{Da}$ auch in einer Bürgerversicherung die Lohnkoppelung bestehen bleibt, mithin steigende Kosten im Gesundheitswesen weiter zu einem Anstieg der Arbeitskosten führen und damit Wachstum und Beschäftigung behindern, wird von weiten Teilen der Wissenschaft die Einführung einer Kopfpauschale ${ }^{707}$ gefordert.

Die Diskussion um Kopfpauschalen in der GKV ist nicht neu. Bereits im Jahr 1966 diskutierte die Sozialenquete-Kommission ${ }^{708}$ die Einführung einheitlicher Beiträge. Innerhalb des Systems der GKV werden Kopfpauschalen auch bereits angewandt. Im Bereich der ambulanten Versorgung erhalten die Kassenärztlichen Vereinigungen die Vergütung von den Kassen derzeit auf Basis von Kopfpauschalen. ${ }^{709}$ Ab 2007 sollen die Vertragsärzte allerdings anhand morbiditätsorientierter Merkmale von den Krankenkassen bezahlt werden. Als Beispiel für die Umstellung eines Krankenversicherungssystems auf Kopfpauschalen dient die Schweiz. Dort wurden im Jahr 1996 pauschale Gesundheitsprämien mit einer sogenannten Prämienverbilligung eingeführt. ${ }^{710}$

In der Literatur liegen zahlreiche neuere Vorschläge zur Finanzierung der GKV über einkommensunabhängige Kopfpauschalen vor; z.B. der Sachverständigenrat zur Begutachtung der gesamtwirtschaftlichen Entwicklung, Teile der Rürup-Kommission, der Wissenschaftliche Beirat beim Bundesministerium der Finanzen, die HerzogKommission, Henke, Knappe und Arnold, Rürup und Wille sowie Breyer, Franz, Homburg, Schnabel und Wille sprechen sich für einkommensunabhängige Beiträge aus. ${ }^{711}$ Die Modelle unterscheiden sich im Wesentlichen hinsichtlich des Kreises der

\footnotetext{
${ }^{704}$ Siehe hierzu auch Neumark, F. (1970), S. 5, 48.

${ }^{705}$ Zipperer, M. (2003a), S. 5.

${ }^{706}$ Vgl. ebenda, S. 5f.; kontrovers hierzu Bieback, K.-J. (2003), S. 425; Bieback, K.-J. (2005), S. 60ff., $134 \mathrm{ff}$.

${ }^{707}$ In der Literatur werden Kopfpauschalen und Gesundheitsprämien häufig als Synonyme verwendet. Der Begriff Prämie ist allerdings nicht ganz korrekt, weil normalerweise risikoäquivalente Versicherungsbeiträge als Prämie bezeichnet werden.

${ }^{708}$ Siehe Bogs, W. u.a. (1966), S. 245ff. Vgl. auch Schneider, W. (2003), S. 47.

${ }^{709}$ Zur Vergütung ambulanter Leistungen siehe Rosenbrock, R.; Gerlinger, T. (2004), S. 120.

${ }^{710}$ Zur Reform in der Schweiz siehe SVR (2000), Kasten 7; Gerlinger, T. (2003), S. 7ff.; Lauterbach, K.W. u.a. (2004b), S. 603.

${ }^{711}$ Vgl. SVR (2002), Ziff. 520ff.; SVR (2003), Ziff. 307ff.; SVR (2004), Ziff. 495ff.; Rürup-Kommission (2003), S. 161ff.; Wissenschaftlicher Beirat beim Bundesministerium der Finanzen (2004), S. 23ff.; Herzog-Kommission (2003), S. 16ff.; Henke, K.-D. (2001), S. 5ff.; Knappe, E.; Arnold, R. (2002),

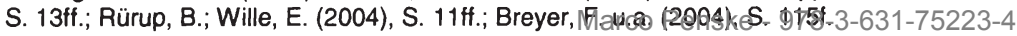


Versicherten und des Anteils der Kapitaldeckung. Auf Ersteres wird in Abschnitt 3.4 Kompromissmodelle (S. 199), auf Letzteres in Kapitel VI Einführung von Kapitaldeckung in der GKV (S. 209) noch eingegangen.

Die Kernelemente und Ziele aller Modelle sind identisch. Demnach sollen alle Versicherten einer Kasse einen gleich hohen Beitrag zahlen, der den durchschnittlichen Pro-Kopf-Kosten der Kasse entspricht. Damit wird das Äquivalenzprinzip gestärkt. Die Beiträge unterscheiden sich von Kasse zu Kasse je nach Effizienz in der Leistungserbringung und der Verwaltung. Die beitragsfreie Versicherung des Ehepartners entfällt. Eine Differenzierung der Prämien nach Alter, Geschlecht, Gesundheitszustand oder Vorerkrankungen ist wie im bisherigen Finanzierungssystem den Kassen untersagt. Zudem besteht Kontrahierungszwang. Um die Finanzierung der GKV von den Löhnen abzukoppeln, wird der Arbeitgeberbeitrag dem Bruttolohn zugeschlagen und versteuert. ${ }^{72}$ Der soziale Ausgleich wird in das Steuer- und Transfersystem verlagert und die Krankenversicherung auf ihre Versicherungsfunktion konzentriert, womit allokative und distributive Aufgaben getrennt werden. ${ }^{313}$ Die Einkommensumverteilung von Beziehern hoher zu Beziehern niedriger Einkommen wird aus der GKV eliminiert. Neben dem versicherungsimmanenten Ausgleich bleiben der Risikoausgleich zwischen guten und schlechten Risiken sowie der Altersausgleich zwischen jungen und alten Versicherten indes erhalten.

Für die Finanzierung der Beiträge von Kindern gibt es drei Varianten: ${ }^{714}$

Erstens kann von Kindern der gleiche Beitrag erhoben werden, den auch Erwachsene zahlen. Dadurch würde kein Familienleistungsausgleich mehr in der GKV stattfinden. Kinder würden sogar zur Senkung des Beitrags für Ältere, die im Allgemeinen höhere Kosten verursachen, beitragen, mithin kinderreiche Familien von der intergenerativen Umverteilung stärker belastet werden als kinderlose Versicherte. Diese Umverteilung würde den staatlichen Umverteilungsvorstellungen zuwiderlaufen.

Zweitens könnten Kinder als Teil des Familienleistungsausgleichs in der GKV beitragsfrei versichert werden, um positive externe Effekte auf den Fortbestand der umlagefinanzierten GKV auszugleichen. Dann würden allerdings Familien zum Teil Kinderlasten selbst tragen, zudem wäre die Finanzierung auf die GKV-Mitglieder beschränkt.

Drittens könnten Kinder zu einem Beitrag versichert werden, der ihren durchschnittlichen Leistungsausgaben entspricht. Die intergenerative Umverteilung zugunsten Älterer würde dadurch im Vergleich zur Zahlung des gesamtdurchschnittlichen Beitrags entfallen. Sieht man den Familienleistungsausgleich als gesamtgesellschaftliche Aufgabe, dann sollten die Kinderbeiträge steuerfinanziert sein.

${ }^{712}$ Der SVR (2002), Ziff. 521, plädierte anfangs für eine steuerfreie Auszahlung des Arbeitgeberanteils, spricht sich jedoch in seinen späteren Gutachten für eine Versteuerung aus; siehe SVR (2003), Ziff. 309ff.; SVR (2004), Ziff. $511 \mathrm{ff.}$ Zur Umwandlung der Arbeitgeberbeiträge unter Beachtung der Tarifautonomie siehe ausführlich Rürup, B.; Wille, E. (2004), S. 24ff.

${ }^{713}$ Zur technischen Abwicklung des Sozialausgleichs siehe Ulrich, V.; Schneider, U. (2004), S. 20ff.; Rürup, B.; Wille, E. (2004), S. 17f.

${ }^{714}$ Vgl. Knappe, E.; Arnold, R. (2002), S. 16f. Marco Penske - 978-3-631-75223-4 
Das Ausgabenvolumen der GKV von 140 Mrd. Euro im Jahr 2004 könnte mit einer durchschnittlichen Pauschale von 210 Euro p.m. von den rund 56 Mio. Versicherten, die älter als 20 Jahre sind, gedeckt werden. Kinder wären dann beitragsfrei versichert. ${ }^{715}$ Erhebt man auch von Kindern den vollen Beitrag, berücksichtigt die Auswirkungen des GMG und nimmt das Krankengeld (2004: 6,4 Mrd. Euro) aus dem Leistungskatalog der GKV heraus, weil diese lohnabhängige Leistung weiter über lohnbezogene Beiträge finanziert werden sollte, kann das jährliche Ausgabenvolumen von rund $130 \mathrm{Mrd}$. Euro mit einer durchschnittlichen Kopfpauschale von 155 Euro p.m. von allen rund 70 Mio. GKV-Versicherten finanziert werden. Streicht man darüber hinaus den Zahnersatz (2004: 3,7 Mrd. Euro), Leistungen infolge von privaten Unfällen (10,4 Mrd. Euro) und versicherungsfremde Leistungen aus dem Leistungskatalog der GKV, könnte die durchschnittliche Pauschale bei beitragsfreier Versicherung von Kindern auf 165 Euro sinken. ${ }^{716}$ Ein durchschnittlicher Beitrag von 169 Euro für Erwachsene und 78 Euro für Kinder würde ein Leistungsvolumen von 129 Mrd. Euro finanzieren, wenn lediglich Krankengeldzahlungen aus dem Leistungskatalog gestrichen und die Einsparungen durch das GMG berücksichtigt werden. ${ }^{717}$ Wären Kinder weiter beitragsfrei versichert, läge dann die Kopfpauschale bei 186 Euro. ${ }^{718}$

\subsubsection{Finanzierung des sozialen Ausgleichs}

Die Versicherten, deren Beitrag einen bestimmten Anteil - genannt werden $12 \%$ bis $16 \%$ - ihres Bruttoeinkommens übersteigt, erhalten einen sozialen Ausgleich. Würde dieser über die Pauschale finanziert, müssten alle GKV-Versicherten bei beitragsfreier Versicherung von Kindern für ein jährliches Leistungsvolumen von $120 \mathrm{Mrd}$. Euro monatlich einen Beitrag von 345 Euro zahlen. ${ }^{719}$ Bei einer als zumutbar angesehenen Eigenbelastung von $12 \%$ des Bruttoeinkommens wären dann jedoch $84 \%$ der GKV-Versicherten ausgleichsberechtigt und damit für einen Großteil der Versicherten die Beiträge weiter einkommensabhängig. Zudem würde die Trennung von Allokation und Distribution nicht erreicht. Deshalb muss der soziale Ausgleich aus dem Steueraufkommen finanziert werden.

Wie Tabelle 20 illustriert, schwanken die steuerfinanzierten Beitragszuschüsse dann bei einer Beibehaltung des derzeitigen Versichertenkreises in den quantifizierten Modellen je nach Belastungsgrenze und Höhe der Kopfpauschale zwischen 15,6 Mrd. Euro und 28,4 Mrd. Euro p.a. Wenn man Familienpolitik als gesamtgesellschaftliche Aufgabe auffasst, dann sollte aus ordnungspolitischen Gründen auch für Kinder ein

\footnotetext{
${ }^{715}$ Vgl. Rürup-Kommission (2003), S. 171; Bork, C. (2003), S. 9f., 21ff. Zur Versichertenzahl siehe BMGS (Hrsg.) (2003b).

${ }^{716}$ Vgl. SVR (2002), Ziff. 490ff.; SVR (2003), Ziff. 307, wobei die Ausgaben für versicherungsfremde Leistungen nicht beziffert werden. Die Ausgaben für Krankengeld und Zahnersatz sind BMGS (Hrsg.) (2005a), S. 1, entnommen.

${ }^{717}$ Vgl. Rürup, B.; Wille, E. (2004), S. 12.

${ }^{718} \mathrm{Vgl}$. Henke, K.-D. (2005), S. $105 f$.

${ }^{719} \mathrm{Vgl}$. ausführlich Fritzsche, B. (2004), S. 52ff., 71; eigene Berechnung. Die Initiative mehr Gesundheit (Hrsg.) (2004), S. 5f., errechnet eine monatliche Pauschale von 205 Euro, wenn die Kosten für Kinder und der soziale Ausgleich systemintern über den Beitrag finanziert werden, unterstellt dabei aber fiktiv 10 Mio. Bedürftige und leitet daraus einen Transferbedarf von 11,2 Mrd. Euro ab, der deutlich unter dem Finanzbedart in den anderenvertiegendenkBerectrmungen liegt:23-4
} 
(ermäßigter) Beitrag erhoben und dieser ebenfalls aus dem Steueraufkommen finanziert werden. Allein dafür sind bei einer monatlichen Pauschale von 78 Euro für in der GKV versicherte Kinder Mittel in Höhe von 13,9 Mrd. Euro p.a. erforderlich. Sollen privat Versicherte Kinder nicht benachteiligt werden, werden weitere 1,9 Mrd. Euro für deren Beitragsentlastung fällig.

Tabelle 20: Transferbedarf für den sozialen Ausgleich

\begin{tabular}{|c|c|c|c|c|}
\hline & $\begin{array}{l}\text { Kopfpa } \\
\text { Erwachsene }\end{array}$ & $\begin{array}{l}\text { ischale } \\
\text { Kinder }\end{array}$ & $\begin{array}{l}\text { Belastungsgrenze } \\
\text { des Bruttoeinkommens) }\end{array}$ & Transferbedarf \\
\hline$a$ & 345 Euro & Beitragsfrei & $12,0 \%$ & Über Pauschale finanziert \\
\hline b & 144 Euro & 144 Euro & $15,0 \%$ & 28,2 Mrd. Euro \\
\hline c & 165 Euro & Beitragsfrei & $13,3 \%$ & 15,6 Mrd. Euro \\
\hline d & 159 Euro & 76 Euro & $15,0 \%$ & 26,1 Mrd. Euro \\
\hline e & 169 Euro & 78 Euro & $12,5 \%$ & $\begin{array}{l}\text { Beitragszuschüsse: } \\
\text { 22,5 Mrd. Euro } \\
\text { Erstattung Kinderbeiträge: }^{1} \\
\text { 15,8 Mrd. Euro }{ }^{2}\end{array}$ \\
\hline$f$ & 180-200 Euro & Beitragsfrei & $15,0 \%$ & 25,0-26,1 Mrd. Euro \\
\hline$g$ & 210 Euro & Beitragsfrei & $13,3 \%$ & 28,4 Mrd. Euro \\
\hline $\mathrm{h}$ & 210 Euro & Beitragsfrei & $\begin{array}{l}\text { Von } 13,3 \% \text { auf } 16 \% \text { anstei- } \\
\text { gend; Freigrenze von } 210 \text { Euro }\end{array}$ & 22,6 Mrd. Euro \\
\hline$i$ & 264 Euro $^{3}$ & Beitragsfrei & $15,0 \%{ }^{4}$ & 27,3 Mrd. Euro \\
\hline
\end{tabular}

'Davon entfallen 18,8 Mrd. Euro auf Beitragszuschüsse und 3,7 Mrd. Euro auf Steuerausfälle infolge einer Anpassung der abziehbaren Vorsorgeaufwendungen zur Entlastung Bezieher niedriger, aber bereits steuerpflichtiger Einkommen.

${ }^{2}$ Die Erstattung der Beiträge für Kinder verteilt sich auf 13,9 Mrd. Euro für in der GKV versicherte Kinder und 1,9 Mrd. Euro für Kinder in der PKV.

${ }^{3} \mathrm{Im}$ Jahr 2013 ohne Krankengeld und Zahnbehandlung. Für über 45jährige wird ein zuvor gebildeter Kapitalstock aufgelöst.

${ }^{4}$ Diese Angabe entstammt Medienberichten, im Bericht der Herzog-Kommission ist keine Belastungsgrenze angegeben.

Quelle: Eigene Darstellung; vgl. [b, d, f] Breyer, F. u.a. (2001), S. 177ff.; [f] SVR (2002), Ziff. 522; [c, g] SVR (2003), Ziff. 308; [g, h] Rürup-Kommission (2003), S. 172; [i] Herzog-Kommission (2003), S. 19, 23; [e] Rürup, B.; Wille, E. (2004), S. 14ff; [a] Fritzsche, B. (2004), S. 71.

Zur Finanzierung des sozialen Ausgleichs soll nach herrschender Meinung das zusätzliche Aufkommen an Einkommensteuer (inklusive Solidaritätszuschlag) aus der Besteuerung der ausgezahlten Arbeitgeberbeiträge verwendet werden. Auf Grundlage des Einkommensteuertarifs 2005 werden die Mehreinnahmen mit 15,6 Mrd. Euro bis 17,0 Mrd. Euro beziffert, wovon 2,5 Mrd. Euro auf PKV-Versicherte entfallen. ${ }^{720} \mathrm{Da}$ der zusätzliche Bruttolohn bei Versicherungspflichtigen in den anderen Zweigen der Sozialversicherung bis zur jeweiligen Beitragsbemessungsgrenze beitragspflichtig wäre, könnten deren Beitragssätze gesenkt werden. Das Beitragssatzsenkungspotential $^{721}$ wird in der GRV auf 0,4 bis 1,1 Prozentpunkte, in der

${ }^{720}$ Die Aufteilung des Aufkommens aus der Lohnsteuer und der veranlagten Einkommensteuer auf Bund $(42,5 \%)$, Länder (42,5\%) und Gemeinden (15\%) bleibt unberücksichtigt.

${ }^{721}$ Siehe Bork, C. (2003), S. 22ff.; Rürup-Kommission (2003), S. 172; Rürup, B.; Wille, E. (2004),

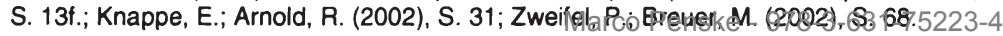


Arbeitslosenversicherung auf 0,2 bis 0,4 Prozentpunkte und in der Gesetzlichen Pflegeversicherung auf 0,1 Prozentpunkte geschätzt.

Nach Zweifel und Breuer ${ }^{722}$ fallen durch die Umstellung auf Kopfpauschalen darüber hinaus auf Basis von Daten aus dem Jahr 2000 Einsparungen von bis zu 20 Mrd. Euro bei anderen Sozialversicherungsträgern an. Da z.B. auch Empfänger von Leistungen der Arbeitslosenversicherung oder der Rentenversicherung in das System integriert würden, könnten Beiträge der Sozialversicherungsträger an die GKV eingespart und ebenfalls zur Finanzierung des sozialen Ausgleichs verwendet werden. Die genannte Summe dürtte indes bei weitem nicht zu erzielen sein. Mit rund 12,0 Mrd. Euro entfällt der größte Teil auf die Beiträge der Rentenversicherung für Rentenbezieher. Diese Beiträge würden aber der Rente zugeschlagen werden und damit nicht mehr zur Verfügung stehen. Auch die Einsparung der Beiträge in Höhe von 5,0 Mrd. Euro, die die Arbeitslosenversicherung für Bezieher von Arbeitslosengeld an die GKV zahlt, ist unsicher. Zum einen sind die Beiträge inzwischen weiter abgesenkt worden, zum anderen ist unklar, ob diese als Arbeitgeberbeiträge nicht wie in der GRV an die Empfänger ausgezahlt werden. Freilich würde dann der Finanzbedarf für den sozialen Ausgleich sinken, allerdings nur im Umfang der als zumutbar angesehen Eigenbelastung. Außerdem sind in den Zahlungen des Bundes an die GKV in Höhe von 3,6 Mrd. Euro auch Erstattungen an die GKV enthalten, z.B. für die Krankenversicherung der Landwirte, so dass auch hier die Beiträge nicht in vollem Umfang eingespart werden können.

Die Mehreinnahmen aus der Versteuerung der Arbeitgeberbeiträge und aus eingesparten Quersubventionierungen dürtten nicht einmal ausreichen, um die Beitragszuschüsse für Erwachsene bei einer Prämie von 165 Euro zu finanzieren, da davon auszugehen ist, dass auch einige Versicherte die Beiträge für dann ausgegliederte Leistungen wie Zahnersatz und Krankengeld nicht selbst tragen können. Zudem sollten die Beiträge für Kinder als gesamtgesellschaftliche Aufgabe aus dem Steueraufkommen finanziert werden, was weiterer Finanzmittel bedarf.

Größtes Problem der Pauschalbeiträge ist somit die Finanzierung der Entlastung für Geringverdiener (sozialer Ausgleich) und der Beiträge für Kinder aus den öffentlichen Haushalten. Die Mittel können grundsätzlich über Ausgabensenkungen, Kredite und Steuererhöhungen aufgebracht werden. Ausgabensenkungen wären auch hier der richtige Weg. ${ }^{723} \mathrm{Da}$ die Kürzung von Ausgaben in dem erforderten Ausmaß aber politisch kaum durchsetzbar ist, wird hierauf nicht weiter eingegangen. Die Finanzierung des sozialen Ausgleichs über Kredite lässt sich ökonomisch nicht rechtfertigen, weil weder die objektbezogene - es handelt sich um keine Investitionsausgaben - noch die situationsorientierte Begründung - der soziale Ausgleich dient nicht der Glättung von Konjunkturschwankungen - trägt. ${ }^{724}$ Sie scheidet zudem aufgrund der desolaten Staatsfinanzen als Finanzierungsalternative aus. Zum einen beschränkt der Stabilitäts- und Wachstumspakt gemäß der Entschließung des Europäischen Rates von Amsterdam und den Verordnungen des Rates Nr. 1466/97 und Nr. 1467/97 die Defizitquote außer bei Vorliegen einer schweren Rezession auf $3 \%$ des BIP, zum

\footnotetext{
${ }^{722}$ Siehe Zweifel, P.; Breuer, M. (2002), S. 69f. Siehe auch Ulrich, V.; Schneider, U. (2004), S. $10 f f$.

${ }^{723}$ Vgl. Peffekoven, R. (2005), S. 282; Peffekoven, R. (2004c), S. 12.

${ }^{724}$ Siehe Kapitel II.3.2 Kreditaufnahmeverbot, S. 30. Marco Penske - 978-3-631-75223-4
} 
anderen darf nach Art. 115 GG die Nettokreditaufnahme außer zur Abwehr einer Störung des gesamtwirtschaftlichen Gleichgewichts die Investitionsausgaben nicht überschreiten. Beide Grenzen sind schon jetzt überschritten. Als Alternative bleibt die Finanzierung über Steuern.

Hierzu werden verschiedene Varianten diskutiert: ${ }^{725}$ Die Erhöhung der Umsatzsteuer, die Anhebung des Solidaritätszuschlags auf die Einkommensteuerschuld und die Anhebung (Parallelverschiebung) des Einkommensteuertarifs. Mit einem Beitragszuschlag in Höhe von 2,9\% auf das monatliche beitragspflichtige Einkommen bis 4.105 Euro könnten zwar 26 Mrd. Euro erzielt werden. Dieser Vorschlag wird jedoch nicht näher betrachtet, da damit die wesentlichen Ziele einer Kopfpauschale Aufgabe der Lohnkoppelung und Beschränkung der GKV auf ihre allokative Funktion - konterkariert würden.

Die Umsatzsteuer ist mit einem jährlichen Aufkommen von rund 140 Mrd. Euro eine aufkommensstarke Gemeinschaftsteuer. Eine Erhöhung des Normalsatzes von $16 \%$ auf $18,5 \%$ könnte Steuermehreinnahmen von 22,5 Mrd. Euro p.a. bringen. Kommt es im Jahr 2007 zu der im Koalitionsvertrag ${ }^{726}$ zwischen CDU, CSU und SPD vorgesehenen Erhöhung des Normalsatzes der Mehrwertsteuer auf $19 \%$, müsste der Normalsatz c.p. sogar auf 21,5\% steigen. Unter allokativen Gesichtspunkten ist die Erhöhung der Mehrwertsteuer gegenüber einer höheren Einkommensteuer vorzuziehen, da dem Konzept nach der Konsum besteuert wird, womit die Umsatzsteuer wachstums- und beschäftigungsfreundlicher ist als die Einkommensteuer. Dennoch sind die allokativen Wirkungen einer Erhöhung der Umsatzsteuer umstritten. ${ }^{727}$ Kritisiert werden ebenso die regressiven Verteilungswirkungen der Umsatzsteuer. Dadurch werden Bezieher niedriger Einkommen vergleichsweise stärker zur Finanzierung des sozialen Ausgleichs herangezogen als Bezieher höherer Einkommen. Da der ermäßigte Satz $(7 \%)$ auch zu unerwünschten Verteilungseffekten und allokativen Verzerrungen führt, sollte vor einer Erhöhung des Normalsatzes auch hier zunächst der ermäßigte Satz abgeschafft und durch personengebundene Transfers an Bedürttige ersetzt werden. In beiden Fällen muss jedoch die Verteilung des Mehrwertsteueraufkommens durch ein Bundesgesetz, das der Zustimmung des Bundesrates bedarf (Art. 106 Abs. $3 \mathrm{GG}$ ), geändert werden, um dem Bund die Mehreinnahmen auch tatsächlich zu sichern. Derzeit bekommt gemäß $\S 1$ Finanzausgleichsgesetz der Bund vorab 5,63\% des Aufkommens als Ausgleich für einen zusätzlichen Bundeszuschuss an die GRV. Vom Rest erhalten die Gemeinden 2,2\%. Das dann noch verbleibende Aufkommen wird zu Anteilen von 50,4 \% auf die Länder und von $49,6 \%$ an den Bund verteilt.

Distributive Gründe sprechen für eine Erhöhung des Solidaritätszuschlags. Eine Anhebung um 11,9 Prozentpunkte von 5,5\% auf 17,4\% würde ebenfalls zu Mehreinnahmen von 22,5 Mrd. Euro führen. Diese stünden gemäß Art. 106 Abs. 1 Nr. 6 GG dem Bund alleine zu. Bezieher hoher Einkommen wären nicht nur absolut, sondern

\footnotetext{
${ }^{725}$ Vgl. im Folgenden SVR (2003), Ziff. 330; SVR (2004), Ziff. 521ff.; Rürup, B.; Wille, E. (2004), S. 16ff.; Peffekoven, R. (2004c), S. 12; Peffekoven, R. (2005), S. 282.

${ }^{726}$ Siehe Christlich Demokratische Union Deutschlands; Christlich-Soziale Union in Bayern; Sozialdemokratische Partei Deutschlands (Hrsg.) (2005), S. 68.

${ }^{727}$ Siehe Abschnitt 3.1 Steuerfinanzierung, S. 159. Marco Penske - 978-3-631-75223-4
} 
auch relativ stärker an der Finanzierung des sozialen Ausgleichs beteiligt. Distributiven Zielvorstellungen wäre damit Genüge getan. Problematisch sind aber die allokativen Wirkungen: Durch die Steuererhöhung sinken Arbeitsanreize und Arbeitsangebot. Da der Solidaritätszuschlag auch Einkünfte aus unternehmerischer Tätigkeit belastet $^{728}$, werden zudem Investitionsbereitschaft und Arbeitsnachfrage negativ beeinflusst.

Ähnlich negative allokative Wirkungen treten bei einer Erhöhung (Parallelverschiebung) des Einkommensteuertarifs auf. Allerdings werden Bezieher hoher Einkommen in geringerem Maße belastet, weil bei einer Verschiebung des Tarifs die Grenzbelastungen über den gesamten Tarif um den gleichen Betrag in Prozentpunkten steigen. Bei einer Erhöhung des Solidaritätszuschlags hingegen ist der Einkommensteuertarif inklusive Solidaritätszuschlag zwischen Grundfreibetrag und Spitzensteuersatz im Vergleich zu einer Parallelverschiebung des Tarifs steiler, die Grenzsteuersätze nehmen mithin bis zum Erreichen des Spitzensteuersatzes vergleichsweise stärker zu. Die Effizienzverluste sind daher geringer, wenn man den Tarif parallel nach oben verschiebt. Da nach Art. 106 Abs. 3 GG das Aufkommen aus der Einkommensteuer nach Abzug des Gemeindeanteils Bund und Ländern je zur Hälfte zusteht, ist jedoch eine Grundgesetzänderung erforderlich. Diese bedarf einer Zwei-Drittel-Mehrheit in Bundestag und Bundesrat (Art. 79 Abs. 2 GG).

\subsubsection{Bewertung}

\subsubsection{Allokation}

Allokative Ziele stehen bei der Einführung einer Kopfpauschale im Vordergrund. Die Abkoppelung der GKV-Beiträge vom Arbeitseinkommen dürfte positiv auf Arbeitsnachfrage und Arbeitsangebot wirken: ${ }^{729}$ In einem über Kopfpauschalen finanzierten Gesundheitswesen haben für den Arbeitnehmer die GKV-Beiträge nicht mehr den Charakter einer Lohnsteuer. Ohne Sozialausgleich sinkt die Grenzbelastung des Arbeitseinkommens mit Einkommensteuer, Solidaritätszuschlag und Sozialversicherungsbeiträgen deutlich, womit der Anreiz zur Aufnahme einer sozialversicherungspflichtigen Beschäftigung steigt. Entsprechend der Steuertheorie ist auch bei der Finanzierung der GKV der Übergang von einer Lohn- auf eine Kopfsteuer mit Effizienzgewinnen verbunden. Verzerrungen, die dadurch hervorgerufen werden, dass Versicherte ihren Beitrag durch inr Verhalten auf dem Arbeitsmarkt beeinflussen können, werden beseitigt. Gerade aufgrund des mit der demographischen Entwicklung verbundenen Kostenanstiegs wird die Abkoppelung vom Lohneinkommen erforderlich sein.

Wie Abbildung 29 zeigt, werden diese positiven allokativen Effekte durch den sozialen Ausgleich geschmälert, was den Konflikt zwischen allokativen und distributiven Zielen deutlich macht. Lässt man zunächst die Finanzierung des sozialen Ausgleichs außer Betracht, steigt die Grenzbelastung mit Sozialausgleich bis zur Zuschussgren-

\footnotetext{
${ }^{728}$ Der Solidaritätszuschlag wird als Ergänzungsabgabe nach Art. 106 Abs. 1 Nr. 6 GG auch auf die Körperschaftsteuerschuld erhoben.

${ }^{729}$ Vgl. hierzu und im Folgenden Gerken, L.; Raddatz, G. (2003), S. 6ff.; Rürup-Kommission (2003),

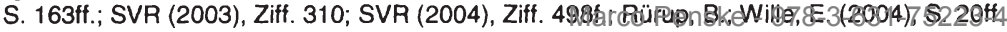


ze im Vergleich zur Pauschale ohne Ausgleich an. In diesem Einkommensbereich hängen die (Netto-)Beiträge für die Versicherten auch nach einer Umstellung auf Kopfpauschalen im Wesentlichen vom Arbeitsentgelt ab. Steigt das Einkommen, reduziert sich für die Versicherten der Zuschuss um den Eigenbelastungssatz, wodurch höhere Grenzbelastungen als ohne Sozialausgleich entstehen. Wird der Sozialausgleich über die Versteuerung der Arbeitgeberbeiträge und eine Anhebung des Einkommensteuertarifs finanziert, steigt die Grenzbelastung aus Steuern und Sozialversicherungsbeiträgen im unteren Einkommensbereich sogar über die Grenzbelastungen im Status quo. Im mittleren Einkommensbereich hingegen sinken auch unter Berücksichtigung des sozialen Ausgleichs und dessen Finanzierung durchweg die Grenzbelastungen im Vergleich zum Status quo. In Abbildung 29 wird ausschließlich die Grenzbelastung des Arbeitseinkommens dargestellt. Die Finanzierung des Sozialausgleichs durch eine Erhöhung der Einkommensteuer kann indes die Grenzbelastung des Faktors Kapital erhöhen, was die positiven allokativen Wirkungen beeinträchtigt.

\section{Abbildung 29: Grenzbelastungen der Arbeitnehmerentgelte bei einer Kopfpauschale im Vergleich zum Status quo}

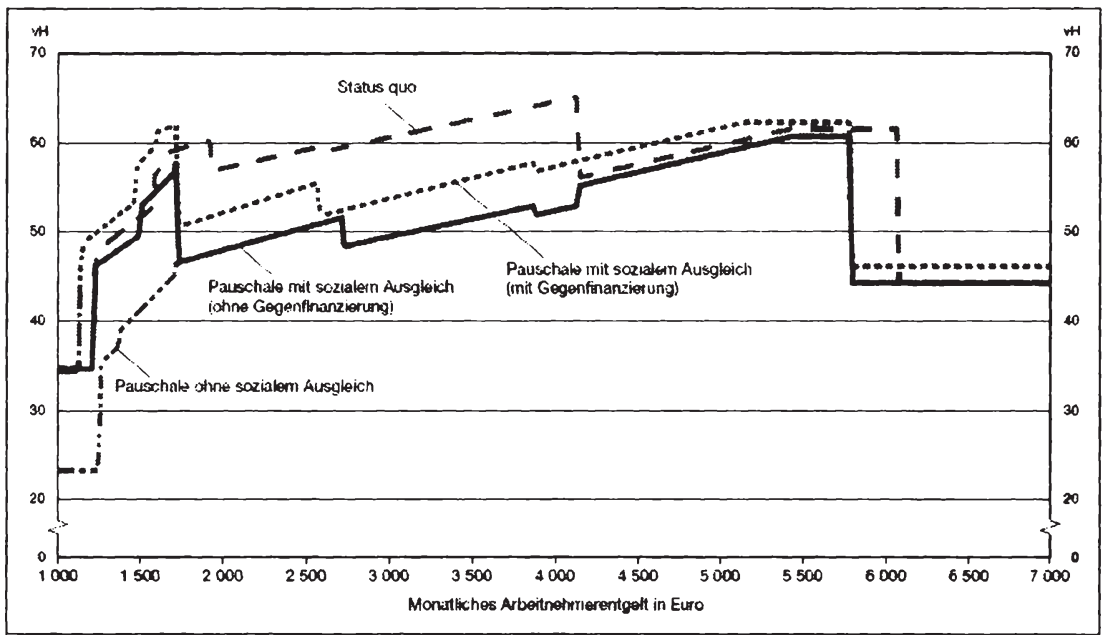

Anmerkung: Der Pauschalbeitrag beträgt 198 Euro, der Eigenanteilssatz 13\%. Das Arbeitnehmerentgelt ist definiert als Bruttolohn zuzüglich des Arbeitgeberbeitrags zu den Sozialversicherungen.

Quelle: SVR (2004), Schaubild 123.

Auf die Arbeitsnachfrage hat die Abkoppelung der Beiträge vom Arbeitslohn kurzfristig kaum Einfluss, da der Arbeitgeberbeitrag voll an den Versicherten ausgeschüttet wird und sich dadurch zum Zeitpunkt der Umstellung die Arbeitskosten für den Arbeitgeber nicht ändern. Für die Arbeitsnachfrage ist entscheidend, dass steigende Gesundheitsausgaben nicht mehr automatisch zu höheren Lohnnebenkosten führen. Gewerkschaften können zwar mit zeitlicher Verzögerung in Tarifverhandlungen Lohnerhöhungen in entsprechendem Ausmaß fordern. Bei hoher Arbeitslosigkeit und der damit verbundenen geringen Gewerkschaftsmacht ist aber nicht davon auszugehen, dass es den Gewerkschaften gelingt, ihre Lohnforderungen durchzusetzen. Der Automatismus wird jedenfalls aufgehoben, Iweshathendie Acbeitsriachrlage langfristig 
nicht weiter negativ beeinträchtigt wird. Der durch die GKV verursachte Abgabenkeil zwischen Produzenten- und Konsumentenlohn wird beseitigt, was Beschäftigung und Wachstum positiv beeinflusst.

Tabelle 21: Beschäftigungseffekte des Kopfpauschalen-Modells

\begin{tabular}{|c|c|c|c|c|c|c|}
\hline \multirow{4}{*}{ Jahr } & \multicolumn{4}{|c|}{ Geschlossene Volkswirtschaft } & \multicolumn{2}{|c|}{ Offene Volkswirtschaft } \\
\hline & \multirow{3}{*}{$\begin{array}{c}\text { Variante } 1^{1)} \\
\begin{array}{c}\text { Ohne } \\
\text { Zuschuss }\end{array}\end{array}$} & \multicolumn{2}{|c|}{ Variante $2^{2)}$} & Variante $3^{3)}$ & Variante $2^{2)}$ & Variante $3^{3)}$ \\
\hline & & \multicolumn{5}{|c|}{ mit Zuschuss } \\
\hline & & \multirow{2}{*}{$\begin{array}{c}\begin{array}{c}\text { Konsum- } \\
\text { steuer }\end{array} \\
36 \%\end{array}$} & \multicolumn{2}{|c|}{ Solidaritätszuschlag ${ }^{5}$} & \multicolumn{2}{|c|}{ Solidaritätszuschlag ${ }^{5}$} \\
\hline 2005 & $5,0 \%$ & & $2,9 \%$ & $3,3 \%$ & $2,4 \%$ & $1,7 \%$ \\
\hline 2010 & $4,8 \%$ & $2,6 \%$ & $2,0 \%$ & $3,2 \%$ & $1,3 \%$ & $2,0 \%$ \\
\hline 2020 & $3,2 \%$ & $1,2 \%$ & $0,5 \%$ & $1,3 \%$ & $3,3 \%$ & $3,8 \%$ \\
\hline 2035 & $4,7 \%$ & $2,2 \%$ & $1,4 \%$ & $3,3 \%$ & $2,2 \%$ & $6,2 \%$ \\
\hline 2050 & $5,5 \%$ & $2,7 \%$ & $1,8 \%$ & $4,1 \%$ & $1,7 \%$ & $6,7 \%$ \\
\hline 2100 & $5,6 \%$ & $2,4 \%$ & $1,5 \%$ & $4,8 \%$ & $-0,5 \%$ & $2,6 \%$ \\
\hline
\end{tabular}

Anmerkung: Veränderung der Beschäftigung im Vergleich zum Entwicklungspfad der Volkswirtschaft ohne Änderung des GKV-Finanzierungssystems.

\footnotetext{
1) Kein Prämienzuschuss.

2) Fester Eigenanteilssatz in Höhe von 13,3\% des Bruttoarbeitseinkommens.

${ }^{3)}$ Variabler Eigenanteilssatz, der ausgehend von 13,3\% des Bruttoarbeitseinkommens im gleichen $\mathrm{Maße}$ wie der Beitragssatz in der Basissimulation steigt.

${ }^{4)}$ Die Finanzierungslücke wird durch eine Umsatzsteuererhöhung geschlossen.

${ }^{5)}$ Die Finanzierungslücke wird durch eine Erhöhung des Solidaritätszuschlags geschlossen.
}

Quelle: SVR (2003), Tabelle 43.

Tabelle 21 zeigt die Veränderung der Beschäftigung bei einer Umstellung des GKVFinanzierungssystems auf ein Kopfpauschalen-Modell im Vergleich zur Entwicklung ohne Finanzreform. Am größten sind die Beschäftigungseffekte nach Berechnungen des Sachverständigenrates zur Begutachtung der gesamtwirtschaftlichen Entwicklung ${ }^{730}$, wenn auf den sozialen Ausgleich verzichtet wird, dann steigt die Beschäftigung am stärksten (Variante 1), da in diesem Fall die Arbeitsanreize besonders stark zunehmen. Zum einen müssen Bezieher niedriger Einkommen die Beiträge selbst aufbringen und zum anderen verursacht die Finanzierung des sozialen Ausgleichs keine Verzerrungen. Mit Sozialausgleich gehen bei einer konstanten Belastungsgrenze von $13,3 \%$ des Einkommens (Variante 2) die positiven Beschäftigungseffekte im Zeitverlauf zurück, weil mit einem Ansteigen der Kopfpauschale auch das zu finanzierende Transfervolumen steigt. Variante 3 unterstellt einen steigenden Eigenanteilssatz. Da die Verzerrungen durch den sozialen Ausgleich und dessen Finanzierung geringer sind als in Variante 2, sind die Beschäftigungseffekte größer. Aufgrund der zahlreichen Annahmen, die diesen Berechnungen zugrunde liegen, haben die quantitativen Ergebnisse nur begrenzte Aussagekraft. Der beschäftigungserhöhende Effekt ist jedoch eindeutig.

Neben den positiven Beschäftigungswirkungen sind aus allokativer Sicht Wachstumseffekte zu begrüßen. Zum einen sorgt die zunehmende Beschäftigung für ein 
steigendes Wirtschaftswachstum. Zum anderen können sich die Wachstumspotentiale im Gesundheitsmarkt freier entfalten als unter dem Primat der Beitragssatzstabilität, so dass auch vom Gesundheitswesen Wachstumsimpulse ausgehen. ${ }^{731}$

Einkommensunabhängige Beiträge und mehr Transparenz intensivieren den Wettbewerb unter den Versicherungen. Auf der Nachfrageseite nimmt durch die gestiegene Transparenz die Wechselbereitschaft zu, da die Versicherten mit den Beiträgen direkt und in voller Höhe belastet werden. Damit auch Empfänger von Ausgleichszahlungen Interesse an der Wahl einer günstigen Kasse haben, sollte sich der Sozialausgleich an der durchschnittlichen Pauschale und nicht der kassenindividuellen Kopfpauschale orientieren. Auf der Anbieterseite können Kassen bei pauschalen Beiträgen Leistungskataloge entsprechend den Präferenzen der Versicherten anbieten und besser kostenäquivalent kalkulieren. Bei lohnbezogenen Beiträgen ist es kaum möglich, den Risikoanteil von dem Anteil, der für die Einkommensumverteilung bestimmt ist, zu unterscheiden. Bei der Abwahl von Leistungen oder der Wahl einer Selbstbeteiligung sinkt somit auch der Umverteilungsbeitrag, obwohl nur der Risikoanteil des Beitrags reduziert werden dürfte. Bei lohnbezogenen Beiträgen haben deshalb insbesondere Bezieher hoher Einkommen ein Interesse an der Abwahl von Leistungen, weil sie sich damit der Einkommensumverteilung zu einem Teil entziehen können. Bezieher niedriger Einkommen haben als Profiteure der Umverteilung hingegen nur ein geringes Interesse. Die Folge ist adverse Selektion. Bei pauschalen Beiträgen profitieren gesunde Versicherte zwar immer noch stärker von dem Verzicht auf Wahlleistungen als schlechte Risiken, adverse Selektion tritt aber bei einkommensunabhängigen Beiträgen deutlich seltener auf, weil die Beitragsersparnis nicht mehr vom Einkommen abhängig ist. ${ }^{732}$

Auch verlieren Kassen den Anreiz zur aktiven Risikoselektion auf der Einnahmenseite. Bislang lohnt es sich für sie, besonders um Versicherte mit hohem Einkommen zu werben, da der Finanzausgleich zwischen den Kassen Einnahmenunterschiede nicht vollständig ausgleicht. Die Umstellung hat dabei den weiteren Vorteil, dass der Finanzkraftausgleich entfallen kann, was den Finanzausgleich zwischen den Kassen vereinfacht und auf $30 \%$ bis $50 \%$ seines Volumens in Höhe von 13,6 Mrd. Euro (2004) reduziert. ${ }^{733}$ Die Schätzung und der anreizverträgliche Ausgleich von unterschiedlichen Ausgaben aufgrund der Versichertenstruktur bleiben jedoch problematisch. ${ }^{734}$

Durch die Pauschale steigt die Wettbewerbsfähigkeit der GKV gegenüber der PKV, zumal die Prämien in der PKV aufgrund der Rücklagenbildung tendenziell über den umlagefinanzierten Kopfpauschalen in der GKV liegen müssten. Vor allem für Bezieher hoher Einkommen könnten die Beiträge in der GKV durch eine Umstellung auf

\footnotetext{
731 Vgl. Rürup-Kommission (2003), S. 163.

${ }^{732}$ Vgl. Gerken, L.; Raddatz, G. (2003), S. 9; Rürup-Kommission (2003), S. 165f.; Wissenschaftlicher Beirat beim Bundesministerium der Finanzen (2004), S. 25, 33.

${ }^{733}$ Die Schätzungen variieren. Breyer, F. u.a. (2001), S. 168, schätzen, dass das RSA-Volumen auf $30 \%$ sinkt. Dem schließt sich die Rürup-Kommission (2003), S. 166, an. Der SVR (2003), Ziff. 310, und Rürup, B.; Wille, E. (2004), S. 29, erwarten einen Rückgang auf $40 \%$. Reschke, P. u.a. (2004), S. 29, beziffern den Finanzkraftausgleich auf $50 \%$ des RSA-Volumens.

${ }^{734}$ Zur Bestimmung des Beitragsbedarfs in einem morbiditätsorientierten RSA siehe Reschke, P. u.a. (2004), S. $49 f f$. 
Pauschalbeiträge unter die risikoadäquaten PKV-Beiträge sinken und sich ein Wechsel oder Verbleib in der GKV lohnen. Weil Versicherte mit beeinträchtigtem Gesundheitszustand in der PKV eine höhere Prämie als in der GKV zahlen müssen, ist allerdings nicht ausgeschlossen, dass die GKV vornehmlich schlechte Risiken mit einem negativen Deckungsbeitrag anzieht. Dies gilt insbesondere für die Versicherten, deren PKV-Prämie unter dem derzeitigen lohnbezogenen, aber über dem pauschalen Beitrag liegt. Jedoch wählen bereits heute die schlechten Risiken meist die GKV; nach Angaben des Sachverständigenrates zur Begutachtung der gesamtwirtschaftlichen Entwicklung ${ }^{735}$ zahlen lediglich $5 \%$ der PKV-Versicherten aufgrund von Vorerkrankungen einen Risikoaufschlag.

\subsubsection{Distribution}

Bei einer Umstellung auf Kopfpauschalen bleibt das krankenversicherungsbezogene Solidarprinzip - der versicherungsimmanente Ausgleich zwischen Gesunden und Kranken und, da auf risikoäquivalente Prämien verzichtet wird, zwischen Versicherten mit niedrigen und hohen Gesundheitsrisiken - erhalten. Einkommens- und familienbezogene Umverteilungen werden indes in das zielgenauere Steuer- und Transfersystem verlagert. Für die Beurteilung der Sozialverträglichkeit ist es sachgemäß, das Gesamteinkommen heranzuziehen und nicht Lohn- und Kapitaleinkünfte unterschiedlich zu bewerten, zumal das Lohneinkommen zunehmend an Bedeutung verliert. Zugleich werden auch privat Versicherte mit ihrem Gesamteinkommen an der Finanzierung des sozialen Ausgleichs beteiligt. Entscheidet man sich dafür, dass die öffentlichen Haushalte die Beiträge für Kinder übernehmen, werden privat Versicherte auch in den Familienleistungsausgleich voll einbezogen: Sie finanzieren über ihre Steuerzahlungen die Kinderbeiträge mit und erhalten die gleichen Zuschüsse pro Kind wie ein gesetzlich Versicherter.

Der Einwand, die Finanzierung des sozialen Ausgleichs sei nicht auf Dauer sichergestellt, ist zwar nicht unberechtigt, kann aber relativiert werden. Wird der Sozialausgleich in einem Leistungsgesetz festgeschrieben, ist er dem Einfluss des Finanzministers entzogen und nur durch eine parlamentarische Mehrheit änderbar. Insbesondere dann, wenn die Zahl der Transferempfänger steigt, wäre für eine Kürzung des Ausgleichs kaum eine Mehrheit zu finden. ${ }^{736}$

Kritisiert werden an der Kopfpauschale vor allem die intragenerativen Umverteilungswirkungen. ${ }^{737}$ Bei einheitlichen Kopfbeiträgen entstehen in Bezug auf das Bruttoeinkommen regressive Belastungswirkungen. Im Vergleich zum Status quo würden Gutverdienende tendenziell entlastet und Geringverdiener belastet. ${ }^{738}$ Diese Betrachtung lässt jedoch die durch die externe Finanzierung des sozialen Ausgleichs hervorgerufenen Verteilungswirkungen außer Acht. Außerdem zeigen Untersuchungen

\footnotetext{
${ }^{735}$ Siehe SVR (2003), Ziff. 310.

${ }^{736}$ Vgl. Wagner, G.G. (2005), S. 286.

${ }^{737} \mathrm{Zu}$ den Umverteilungswirkungen siehe ausführlich Bork, C. (2003), S. 27ff.; Rürup-Kommission (2003), S. 171ff.; SVR (2003), Ziff. 311ff.
}

${ }^{738}$ Siehe hierzu stellvertretend Projektgruppe Bürgerversicherung des SPD-Parteivorstandes (2004), S. 55; Lauterbach, K.W. (2004), S. 60 f. 
über die Verteilungswirkungen, dass die Effekte eher moderat sind. Bei einer durchschnittlichen Kopfpauschale von 210 Euro p.m. und einer Eigenbelastung von $13 \%$ werden Haushalte mit einem Jahreseinkommen zwischen 10.000 und 25.000 Euro mit 0,3 bis $0,6 \%$ ihres verfügbaren Einkommens belastet. Im Einkommensbereich 20.000 bis 40.0000 Euro bleiben die Belastungen weitgehend gleich. Entlastet werden Haushalte mit einem Einkommen zwischen 60.000 und 80.000 Euro - im Maximum um $2 \%$ ihres verfügbaren Einkommens. Ab einem Einkommen von 80.000 Euro nehmen die relativen Entlastungen ab, weil ab diesem Einkommen aufgrund der Beitragsbemessungsgrenze die Beiträge auch im Status quo nicht mehr mit dem Einkommen steigen, die absolute Entlastung somit konstant bleibt, in Relation zum verfügbaren (steigenden) Einkommen aber sinkt.

\section{Abbildung 30: Verteilungseffekte der Kopfpauschale}

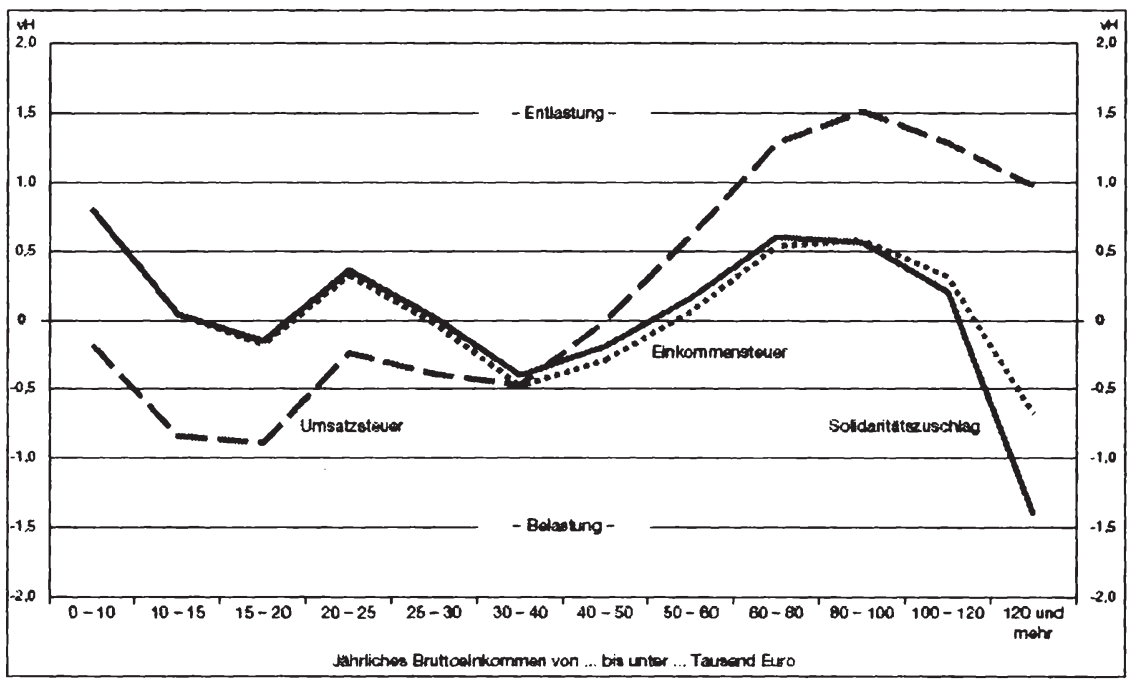

Quelle: SVR (2004), Schaubild 124.

Die konkreten Umverteilungswirkungen von Kopfpauschalen hängen im Wesentlichen von deren Höhe, der zugemuteten Eigenbelastung für Bezieher niedriger Einkommen und der Finanzierung des sozialen Ausgleichs ab. Die Umverteilungseffekte einer Kopfpauschale im Vergleich zum Status quo in Abhängigkeit von der Finanzierung des sozialen Ausgleichs fasst Abbildung 30 zusammen. Bei einem pauschalen Beitrag von 198 Euro und einer zugemuteten Eigenbelastung von $13 \%$ werden Bezieher kleiner Einkommen entlastet, soweit der soziale Ausgleich über eine höhere Einkommensteuer finanziert wird. Nach Berechnungen des Sachverständigenrates zur Begutachtung der gesamtwirtschaftlichen Entwicklung ${ }^{739}$ werden dann insbesondere Bezieher von Einkommen zwischen 30.000 und 50.000 Euro sowie über 120.000 Euro p.a. belastet. Wird zur Finanzierung des sozialen Ausgleichs die 
Umsatzsteuer erhöht, werden Empfänger von einem Einkommen unter 45.000 Euro mit bis zu 1,0\% ihres Bruttoeinkommens belastet, Bezieher höherer Einkommen im Vergleich zum Status quo stark entlastet. Die maximale Entlastung liegt bei einem Einkommen von 90.000 Euro bei 1,5\% des Einkommens.

Diese intragenerativen Verteilungswirkungen dominieren insbesondere die politische Diskussion. Dabei werden die durch eine Umstellung verursachten Verteilungseffekte zwar weitgehend richtig beschrieben ${ }^{740}$, doch zu Unrecht kritisiert. Nach dem Äquivalenzprinzip müssen die Beiträge des einzelnen zumindest die Durchschnittskosten widerspiegeln, die er verursacht. Daher ist es konsequent, die Lohnkoppelung abzuschaffen. Beim Vergleich der Umverteilungswirkungen wird zudem unzulässigerweise der Status quo als Vergleichsmaßstab herangezogen. Wie gezeigt wurde, verursacht die einkommensabhängige Finanzierung jedoch inkonsistente Verteilungseffekte und ist daher als Referenzsystem ungeeignet. ${ }^{741}$

Zur Beurteilung der Nachhaltigkeit einer Reform müssen die intergenerativen Verteilungswirkungen betrachtet werden. Da die Gesundheitsausgaben in diesem Kopfpauschalensystem weiter umlagefinanziert sind, bleibt eine Umverteilung der jeweils jungen zur älteren Generation bestehen. Auf der Einnahmenseite wird allerdings die demographische Abhängigkeit reduziert, weil die Beiträge nicht mehr mit dem Renteneintritt sinken. Auch Änderungen des Rentenniveaus haben keinen direkten Einfluss mehr auf die GKV-Beiträge. Die von der Einnahmenseite ausgehende intergenerative Umverteilung sinkt, weil Rentner mit einem pauschalen Beitrag stärker belastet werden. Die Deckungsquote der KVdR dürfte dadurch von derzeit fast $50 \%$ auf $65 \%$ steigen. Auf der Ausgabenseite wird die Umverteilung allenfalls gemindert, soweit es gelingt, durch einen intensiveren Wettbewerb und Änderungen am Leistungskatalog den Anstieg der Ausgaben insbesondere für Ältere abzuschwächen. Ansonsten bremst die Einführung einer Kopfpauschale jedoch nicht die Zunahme der Gesundheitsausgaben. ${ }^{742}$

Bei steigenden Kopfpauschalen werden höhere staatliche Transfers benötigt, wodurch Belastungen auf künftige Haushalte verschoben werden. Wird die bisherige Entwicklung der Ausgaben und Einkommen fortgeschrieben und die Bevölkerungsvorausberechnung des Statistischen Bundesamtes zugrunde gelegt, steigt der Transferbedarf nach Berechnungen von Hof und Schlömer ${ }^{743}$ bei einer Eigenbelastungsgrenze von $12,5 \%$ des Bruttoeinkommens eines Haushalts von (nominal) 18,7 Mrd. Euro im Jahr 2004 auf über 72 Mrd. Euro im Jahr 2025 und 361 Mrd. Euro 2050 an. Im Jahr 2050 würden demnach $44 \%$ der Gesundheitsausgaben über Steuern finanziert. Im Vergleich zum Status quo wächst die Nachhaltigkeitslücke bei Einführung einer Kopfpauschale von 169 Euro für Erwachsene und 78 Euro für Kinder unter Berücksichtigung aller Zahlungsströme und der expliziten Staatsverschuldung von $415 \%$ auf $428 \%$ des BIP $2001 .{ }^{744}$ Bei einer höheren Pauschale wäre die Nach-

\footnotetext{
${ }^{740}$ Siehe stellvertretend Lauterbach, K.W. u.a. (2005), S. $78 f$.

${ }^{741} \mathrm{Vgl}$. SVR (2004), Ziff. 499

${ }^{742}$ Vgl. SVR (2003), Ziff. 310; Knappe, E.; Arnold, R. (2002), S. 21.

${ }^{743}$ Siehe Hof, B.; Schlömer, C. (2005), S. 198.

${ }^{744} \mathrm{Da}$ bei Kopfpauschalen der soziale Ausgleich über den Bundeshaushalt finanziert wird, ist die

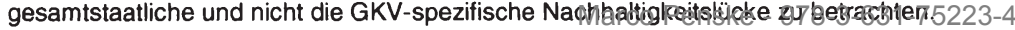


haltigkeitslücke freilich geringer. Mit einer Kopfpauschale von 203 Euro für Erwachsene und gleichem Kinderbeitrag würde sie auf $371 \%$ des BIP 2001 sinken. Damit schneidet die Kopfpauschale besser ab als die Bürgerversicherung, in der die gesamtstaatliche Nachhaltigkeitslücke sogar auf $452 \%$ steigt. Beide Konzepte sind aber nicht geeignet, die GKV nachhaltig zu finanzieren. ${ }^{745}$

\subsubsection{Verfassungsrechtliche Gesichtspunkte}

Wie bereits gezeigt wurde, ist eine stärkere Orientierung am Äquivalenzprinzip verfassungsrechtlich möglich. ${ }^{746}$ Kopfpauschalen hält man eher für "europatauglich“, weil ausländische Anbieter leichter Versicherungen in Deutschland anbieten könnten, als dies gegenwärtig bei lohnbezogenen Beiträgen der Fall ist. ${ }^{74}$ Vorgebracht werden aber auch europarechtliche Bedenken: ${ }^{748}$ Das Versicherungsmonopol der GKV verstoße nach europäischer Rechtsprechung nicht gegen den EG-Vertrag, solange der soziale Ausgleich die Versicherung präge, d.h. die Beiträge nach der Leistungsfähigkeit der Versicherten erhoben würden. Wesentliche Markteingriffe der GKV wie die Festbetragsregelungen nach $\S \S 35 f$. SGB V und Kollektivverträge mit Ärzten und Krankenhäusem seien nur deshalb europarechtlich zulässig. In einem über Kopfpauschalen finanzierten Gesundheitssystem werde der soziale Ausgleich aber in das Steuer- und Transfersystem verlagert, folglich müsse auch das Wettbewerbsrecht auf die GKV angewendet werden. Gegen diese Sichtweise lässt sich einwenden, dass die GKV weiterhin eine solidarische Umverteilungskomponente von jungen zu älteren Versicherten und von niedrigen zu höheren Risiken enthält. Wird das europäische Wettbewerbsrecht trotzdem angewendet, ist dies aus ökonomischer Sicht eher zu befürworten, da mehr Wettbewerb sowohl zwischen den Versicherungen als auch unter den Leistungserbringern unter den richtigen Rahmenbedingungen effizienzsteigernd wirkt. Im Übrigen beziehen sich die Einwände nicht auf die rechtliche Zulässigkeit einer Kopfpauschale, sondern auf mögliche Folgen für den Wettbewerb zwischen den Akteuren im Gesundheitswesen.

\subsection{Kompromissmodelle}

Wie gezeigt wurde, kann eine steuerliche Kofinanzierung die Einnahmen der GKV nicht dauerhaft sichern, weil die strukturellen Finanzierungsprobleme damit nicht gelöst werden. Die Aufbringung der notwendigen Mittel hat zudem negative gesamtwirtschaftliche Wirkungen.

Sowohl Bürgerversicherung als auch Kopfpauschalen sind in sich geschlossene Konzeptionen, die die fast ausschließliche Orientierung der GKV-Beiträge am Lohneinkommen mindern bzw. aufheben und andere Einkunftsarten zur Finanzierung von Gesundheitsleistungen heranziehen. Dabei richtet sich das Hauptaugenmerk einer

\footnotetext{
${ }^{745}$ Vgl. Fetzer, S. u.a. (2004), S. 7f.; Raffelhüschen, B.; Hagist, C.; Fetzer, S. (2004), S. 6.

${ }^{746}$ Siehe Kapitel IV.2 Fiskalische Reformziele, S. 135. Vgl. auch SVR (2004), Ziff. 530.

${ }^{747} \mathrm{Vgl.}$ Rürup-Kommission (2003), S. 166f.

${ }^{748}$ Vgl. Bieback, K.-J. (2003), S. 424f.; Projektgruppe Bürgenversicherung des SPD-Parteivorstandes (2004), S. 61f.; Bieback, K.-J. (2005), S. 114ff., 162ff., und die dort jeweils angegebene Literatur.

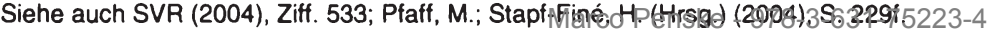


Kopfpauschale auf die Allokationseffizienz, während eine Bürgerversicherung die Verteilungsgerechtigkeit betont. Tabelle 22 gibt einen Überblick über die wichtigsten Merkmale der beiden Modelle im Vergleich zum Status quo.

Tabelle 22: Vergleich von Status quo, Bürgerversicherung und Kopfpauschale

\begin{tabular}{|l|l|l|l|}
\hline & \multicolumn{1}{|c|}{ Status quo } & Bürgerversicherung & \multicolumn{1}{|c|}{ Kopfpauschale } \\
\hline $\begin{array}{l}\text { Versicherten- } \\
\text { kreis }\end{array}$ & $\begin{array}{l}\text { Arbeitnehmer, deren } \\
\text { sozialversicherungspflich- } \\
\text { tiges Einkommen unter } \\
\text { der Versicherungspflicht- } \\
\text { grenze liegt; } \\
\text { freiwillig Versicherte }\end{array}$ & Alle Bürger & Wie Status quo \\
\hline $\begin{array}{l}\text { Beitrags- } \\
\text { bemessung }\end{array}$ & $\begin{array}{l}\text { Prozentualer Beitrag auf } \\
\text { Arbeitseinkommen bis zur } \\
\text { grenze; } \\
\text { paritätisch finanziert }\end{array}$ & $\begin{array}{l}\text { Prozentualer Beitrag auf } \\
\text { alle Einkunftsarten; evtl. } \\
\text { bis zur Beitragsbemes- } \\
\text { sungsgrenze; } \\
\text { bei Lohneinkommen und } \\
\text { Rentenzahlungen der } \\
\text { GRV paritätisch finanziert }\end{array}$ & $\begin{array}{l}\text { Pauschaler kassen- } \\
\text { einheitlicher Beitrag; } \\
\text { steuerpflichtige } \\
\text { Auszahlung des } \\
\text { Arbeitgeberanteils }\end{array}$ \\
\hline $\begin{array}{l}\text { Einkommens- } \\
\text { umverteilung }\end{array}$ & $\begin{array}{l}\text { Über Versicherungs- } \\
\text { beiträge auf im Wesent- } \\
\text { lichen Arbeitseinkommen } \\
\text { bis zur Beitragsbemes- } \\
\text { sungsgrenze }\end{array}$ & $\begin{array}{l}\text { Über Versicherungs- } \\
\text { beiträge auf alle Einkünfte; } \\
\text { evtl. bis zur Beitrags- } \\
\text { bemessungsgrenze }\end{array}$ & $\begin{array}{l}\text { Über Zuschüsse aus dem } \\
\text { allgemeinen Steuer- } \\
\text { aufkommen }\end{array}$ \\
\hline $\begin{array}{l}\text { Finanzierung } \\
\text { Solidar- } \\
\text { ausgleich }\end{array}$ & \begin{tabular}{l} 
GKV-Mitglieder \\
\hline
\end{tabular} & Alle Bürger & Alle Bürger \\
\hline
\end{tabular}

Quelle: Eigene Darstellung.

Unter allokativen, aber auch unter distributiven Gesichtspunkten ist die Kopfpauschale der Bürgerversicherung vorzuziehen. Während die Bürgerversicherung die Lohnkoppelung auch beibehalten will, um den Anstieg der Gesundheitsausgaben zu begrenzen, lässt die Kopfpauschale Wachstum auf dem Gesundheitsmarkt entsprechend den Versichertenpräferenzen gerade zu. Damit sind positive Wirkungen auf Wachstum und Beschäftigung verbunden. Die Verlagerung des sozialen Ausgleichs auf das Steuer- und Transfersystem ist zudem zielgenauer als in einer Bürgerversicherung. Auch wenn sich bei einer Kopfpauschale privat Versicherte über das Steuer- und Transfersystem an der Finanzierung des sozialen Ausgleichs beteiligen, bleibt jedoch die künstliche und wissenschaftlich nicht fundierte Separierung des Krankenversicherungsmarktes in GKV und PKV an der "Friedensgrenze" (Versicherungspflichtgrenze) aus distributiver Sicht problematisch. Da Leistungserbringer für Versicherte der PKV die gleiche Leistung höher als bei GKV-Versicherten abrechnen können, besteht ein Anreiz zur Überversorgung von PKV-Versicherten, bei GKVVersicherten zur Unterversorgung, wodurch Fehlallokationen entstehen.

Soll die Trennung des Versicherungsmarktes in GKV und PKV und gleichzeitig die Lohnkoppelung aufgehoben werden, ist das ModelPeineteBürgresparschalesoder Bür- 
gerprämie eine adäquate Lösung ${ }^{79}$, die eine Synthese aus den Modellen Kopfpauschale und Bürgerversicherung darstellt. Hierin könnte auch ein Kompromiss zwischen den Koalitionsparteien für die für das Jahr 2006 in Aussicht gestellte Finanzierungsreform ${ }^{750}$ liegen: Von der Seitens der SPD angestrebten Bürgerversicherung wird die Ausweitung der Versicherungspflicht auf die gesamte Bevölkerung übernommen und die Beiträge werden nach den Vorstellungen der Unionsparteien als Kopfpauschalen erhoben. Die allokativen und distributiven Wirkungen entsprechen aufgrund der pauschalen Beitragserhebung grundsätzlich dem Modell einer Kopfpauschale. Unterschied zum Modell der Kopfpauschale ist der Versichertenkreis.

Begründet wird die allgemeine Versicherungspflicht mit externen Effekten. Aus altruistischen Gründen werden einer Person, auch wenn sie über keinen Versicherungsschutz verfügt, notwendige medizinische Leistungen gewährt. Dies führt dazu, dass insbesondere Personen mit geringem Einkommen keinen ausreichenden Versicherungsschutz abschließen und die ersparten Beiträge für Konsum verwenden, weil sie sich im Krankheitsfall darauf verlassen, dass der Staat innen die notwendigen Leistungen finanziert. ${ }^{751}$ Aus dieser strategischen Unterversicherung lässt sich jedoch keine Versicherungspflicht in der GKV ableiten. Dagegen spricht zudem das Subsidiaritätsprinzip. Danach ist der Versichertenkreis mit rund $90 \%$ der Bevölkerung schon heute zu weit gefasst und eine Ausweitung des Versichertenkreises nicht angemessen. Da ein größerer Teil der Bevölkerung seinen Versicherungsschutz eigenverantwortlich regeln könnte, wäre es konsequent, eine Ausscheidegrenze einzuführen, die vorschreibt, dass ab einer bestimmten Einkommenshöhe die GKV zu verlassen und eine private Versicherung abzuschließen ist. Die derzeitige Wahlmöglichkeit für Bezieher von Einkommen über der Versicherungspflichtgrenze zwischen GKV und PKV lässt sich auch mit dem Subsidiaritätsprinzip nicht begründen. ${ }^{752}$ Von einer Ausscheidegrenze würde jedoch die GKV zunächst belastet werden. Geht man von einem Bestandsschutz für die über 65jährigen freiwillig in der GKV Versicherten aus, ständen nach Berechnungen von Hagist und Raffelhüschen ${ }^{753}$ bei einer Ausscheidegrenze in Höhe der Versicherungspflichtgrenze des Jahres 2004 (46.350 Euro p.a.) im derzeitigen einkommensabhängigen Finanzierungssystem Mindereinnahmen von 19,5 Mrd. Euro lediglich ein Rückgang der Ausgaben um 8,7 Mrd. Euro gegenüber. Bei einer durchschnittlichen Kopfpauschale von monatlich 199 Euro würden die Mindereinnahmen bei gleicher Ausgabenersparnis immerhin auf 9,5 Mrd. Euro sinken. Langfristig würde die GKV indes profitieren, weil die ausgeschiedenen Versicherten mit zunehmendem Alter auch höhere Kosten verursachen. Der Systemwettbewerb zwischen PKV und GKV würde jedoch beseitigt werden, weil kein Versicherter mehr zwischen beiden Systemen wählen könnte.

\footnotetext{
${ }^{749}$ Siehe Henke, K.-D. (2001), S. 5ff.; Knappe, E.; Arnold, R. (2002), S. 13ff.; Wissenschaftlicher Beirat beim Bundesministerium der Finanzen (2004), S. 23ff.; SVR (2004), Ziff. 495ff.; Breyer, F. u.a. (2004), S. 85f., 115f.; Henke, K.-D. (2005), S. 105f.; SVR (2005), Ziff. 534ff.

${ }^{750}$ Siehe Christlich Demokratische Union Deutschlands; Christlich-Soziale Union in Bayern; Sozialdemokratische Partei Deutschlands (Hrsg.) (2005), S. 87.

${ }^{751}$ Vgl. Wambach, A.; Wigger, B.U. (2003), S. 9f.; SVR (2004), Ziff. 493; Breyer, F.; Zweifel, P.; Kifmann, M. (2005), S. $183 f$.

${ }^{752} \mathrm{Vgl}$. SVR (2004), Ziff. 488.

${ }^{753}$ Siehe Hagist, C.; Raffelhüschen, B. (2004), S. 196ffarco Penske - 978-3-631-75223-4
} 
Bislang wird adverse Selektion innerhalb der GKV durch den zu rund $95 \%$ vorgeschriebenen Leistungskatalog in Verbindung mit Kontrahierungszwang und Versicherungspflicht verhindert. Die Aufhebung der Versicherungspflicht in der GKV könnte die Funktionsfähigkeit des Marktes für Krankenversicherungen aber beeinträchtigen. Liegt asymmetrische Information vor, dann kennen Versicherungskunden ihr Krankheitsrisiko besser als die Versicherungsunternehmen. Sie nutzen diesen Informationsvorsprung aus, wodurch adverse Selektion entsteht. Überwiegend schlechte Risiken wählen eine Versicherung in der GKV, weil für sie der zu zahlende Beitrag unter den von ihnen erwarteten Gesundheitsausgaben liegt. Im Extremfall ist es sogar möglich, dass sich nur noch schlechte Risiken versichern und die GKV zusammenbricht. ${ }^{754}$ Dem wird entgegnet, empirische Studien zeigten, dass adverse Selektion bislang auf dem Krankenversicherungsmarkt eher von geringer Bedeutung sei. Zudem könnten Versicherte wie bereits in der PKV verpflichtet werden, Vorerkrankungen offen zu legen. Mit Selbstbehalten stehe außerdem ein Instrument zur Verfügung, um den Gesundheitszustand der Versicherten besser in Erfahrung zu bringen. ${ }^{755}$ Jedoch sind auch in den Modellen mit Kopfpauschalen keine Risikozuschläge vorgesehen, weitergehende Informationen über den Gesundheitszustand des zu Versichernden daher für die Versicherung wertlos. Die Wahlmöglichkeit für Bezieher von Einkommen oberhalb der Versicherungspflichtgrenze zwischen GKV und PKV führt bereits zur Risikoentmischung. Dieses Problem wird auch mit pauschalen Beiträgen allenfalls gemindert, was für eine Ausweitung der Versicherungspflicht in der GKV spricht. ${ }^{756}$

Als weiteres Argument für die Ausweitung der Versicherungspflicht wird die Beteiligung von bisher in der PKV Versicherten und damit ökonomisch besonders Leistungsfähigen am sozialen Ausgleich in der GKV angeführt. ${ }^{757}$ Mit der Einführung einer Kopfpauschale und der Verlagerung des sozialen Ausgleichs in das Steuerund Transfersystem wären jedoch PKV-Versicherte bereits an der Finanzierung beteiligt. Auch das Argument, eine Ausweitung der Versicherungspflicht auf die gesamte Bevölkerung verhindere eine Zwei-Klassen-Medizin ${ }^{758}$, überzeugt nicht. Selbst wenn die gesamte Bevölkerung in der GKV versicherungspflichtig wäre, könnten sich gerade Versicherte mit höherem Einkommen eine bessere Versorgung leisten. ${ }^{759}$

Als Vorteil einer Trennung des Versicherungsmarktes zwischen GKV und PKV gilt der Systemwettbewerb. ${ }^{760}$ Wettbewerb setzt jedoch Wahlfreiheit der Versicherten voraus. Ein Großteil der Versicherten kann sich aber nicht in der PKV versichern, weil sein Arbeitseinkommen unterhalb der Versicherungspflichtgrenze liegt. Inwiefern der Wettbewerb zwischen GKV und PKV überhaupt Erfolg versprechend ist, ist aufgrund der beschriebenen - wenn auch bei Kopfpauschalen reduzierten - strukturellen Nachteile der GKV gegenüber der PKV fraglich. Eine Einbeziehung der privaten

\footnotetext{
${ }^{754}$ Vgl. Breyer, F.; Zweifel, P.; Kifmann, M. (2005), S. 185ff., und die dort angegebene Literatur.

${ }^{755}$ Vgl. Wambach, A.; Wigger, B.U. (2003), S. 9 .

${ }^{756} \mathrm{Vgl}$. SVR (2004), Ziff. 489.

${ }^{757}$ Siehe stellvertretend Projektgruppe Bürgerversicherung des SPD-Parteivorstandes (2004), S. 18f.; Lauterbach, K.W. (2004), S. 48; Sehlen, S. u.a. (2004), S. 19.

${ }^{758}$ Siehe Lauterbach, K.W. (2004), S. 58 f.

${ }^{759}$ Vgl. Rürup-Kommission (2003), S. 149, 167; SVR (2004), Ziff. $491 f$.

${ }^{760}$ Vgl. Rürup-Kommission (2003), S. 170. Zum Systemwattbewerbssiehegugsh Sy/3i (2002)3ZZiff. 531.
} 
Kassen in den RSA, um unterschiedliche Risikostrukturen auszugleichen, ist insbesondere wegen der Unterschiede in der Beitragserhebung sowie in den Leistungskatalogen und Vergütungen kaum umsetzbar. ${ }^{76}$ Der Verzicht auf risikoäquivalente Beiträge in der PKV ist für einen einheitlichen Versicherungsmarkt notwendig ${ }^{762}$, womit aber das wesentliche Element der PKV aufgegeben würde, was einer Abschaffung gleich käme.

Neben den im Zusammenhang mit einer Bürgerversicherung bereits diskutierten verfassungsrechtlichen Bedenken, sind die in der PKV gebildeten Alterungsrückstellungen das ökonomische Hauptargument gegen eine Abschaffung der PKV. Mit der Ausweitung der Versicherungspflicht in der GKV werde der Teil der Bevölkerung, der bislang im kapitalgedeckten System Eigenvorsorge betrieben hat, in das Umlageverfahren gezwungen, womit die Belastung künftiger Generationen steige. Jedoch können auch im Modell einer Bürgerprämie kapitalgedeckte Elemente integriert werden. ${ }^{763}$ Den Zielkonflikt in der Bürgerversicherung zwischen intragenerativer und intergenerativer Umverteilung könnte eine mit Kapitaldeckung kombinierte Finanzreform aufheben.

Die Entscheidung zwischen einer Bürgerprämie und einer auf den derzeitigen Versichertenkreis beschränkten Kopfpauschale resultiert aus einem Abwägen der oben genannten Argumente. Entscheidet man sich für eine Bürgerprämie, könnte der durchschnittliche Beitrag beim derzeitigen Leistungskatalog und einer Ausgliederung der Krankengeldzahlung bei 198 Euro für Erwachsene liegen. Kinder bis 20 Jahre wären beitragsfrei versichert. Der Zuschussbedarf für den sozialen Ausgleich würde sich bei einer maximalen Eigenbelastung von $13 \%$ des Bruttoeinkommens auf 30 Mrd. Euro belaufen. 31 Mio. Personen und damit $38 \%$ der Bevölkerung wären zuschussberechtigt. Wird für Kinder ein steuertinanzierter Beitrag von 86 Euro erhoben, sinkt der Beitrag für Erwachsene auf 171 Euro. ${ }^{764}$

Einen weiteren Versuch, Bürgerversicherung und Kopfpauschale miteinander zu verknüpfen, stellt das "Solidarische Gesundheitsprämien-Modell“ von CDU und CSU ${ }^{765}$ dar. Danach wird unter Beibehaltung des derzeitigen Pflichtversichertenkreises der Arbeitgeberbeitrag auf $6,5 \%$ des Bruttolohns festgeschrieben. Die Beiträge der Arbeitgeber ( $48 \mathrm{Mrd}$. Euro) sowie der Renten- und Sozialversicherungsträger (17 Mrd. Euro) in Höhe von insgesamt rund 65 Mrd. Euro p.a. werden an eine Clearingstelle abgeführt. Die Versicherten zahlen einen durchschnittlichen Beitrag von monatlich 109 Euro, der sich je nach Kasse unterscheidet. Zusätzlich erhalten die Kassen monatlich 60 Euro je Versicherten aus der Clearingstelle, insgesamt 41 Mrd. Euro p.a. Aus den verbleibenden Mitteln der Clearingstelle soll der Zuschuss für Versicherte, deren Beitrag $7 \%$ ihres Bruttoeinkommens übersteigt, finanziert werden

${ }^{761}$ Siehe ausführlich Breyer, F. u.a. (2001), S. 174f.; Klose, J.; Schellschmidt, H. (2001), S. 38ff.; SVR (2003), Ziff. 329; Projektgruppe Bürgerversicherung des SPD-Parteivorstandes (2004), S. 55; Lauterbach, K.W. u.a. (2004), S. 27. Kontrovers hierzu Wenzel, D. (1999), S. $99 f f$.

${ }^{762} \mathrm{Vgl}$. SVR (2005), Ziff. 533.

${ }^{763}$ Vgl. Rürup-Kommission (2003), S. 167; SVR (2004), Ziff. 491. Siehe auch Kapitel VI.3.1 Teilweise kapitalgedeckte Finanzierungssysteme, S. 225.

${ }^{764}$ Vgl. SVR (2004), Ziff. 512, 518. Siehe auch Initiative mehr Gesundheit (Hrsg.) (2004), S. $5 f$.

${ }^{765}$ Siehe Christlich Demokratische Union Deutschlands; Christlich-Soziale Union in Bayern (Hrsg.)

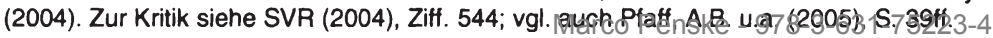


(16 Mrd. Euro p.a.). Die Beitragsfreiheit für Kinder (78 Euro p.m. je Kind) wird zum Teil aus Steuermitteln finanziert. Jährlich $8 \mathrm{Mrd}$. Euro stammen dafür aus der Clearingstelle, die fehlenden 7 bis 8 Mrd. Euro sollen durch eine Steuererhöhung aufgebracht werden. Diese Finanzströme stellt Abbildung 31 dar. Darüber hinaus wird von den Versicherten für das Krankengeld ein Beitrag in Höhe von $1 \%$ des beitragspflichtigen Arbeitseinkommens erhoben, der bei der Belastungsgrenze berücksichtigt wird. Der Zahnersatz bleibt Bestandteil des Leistungskatalogs.

\section{Abbildung 31: Finanzströme der „Solidarischen Gesundheitsprämie“}

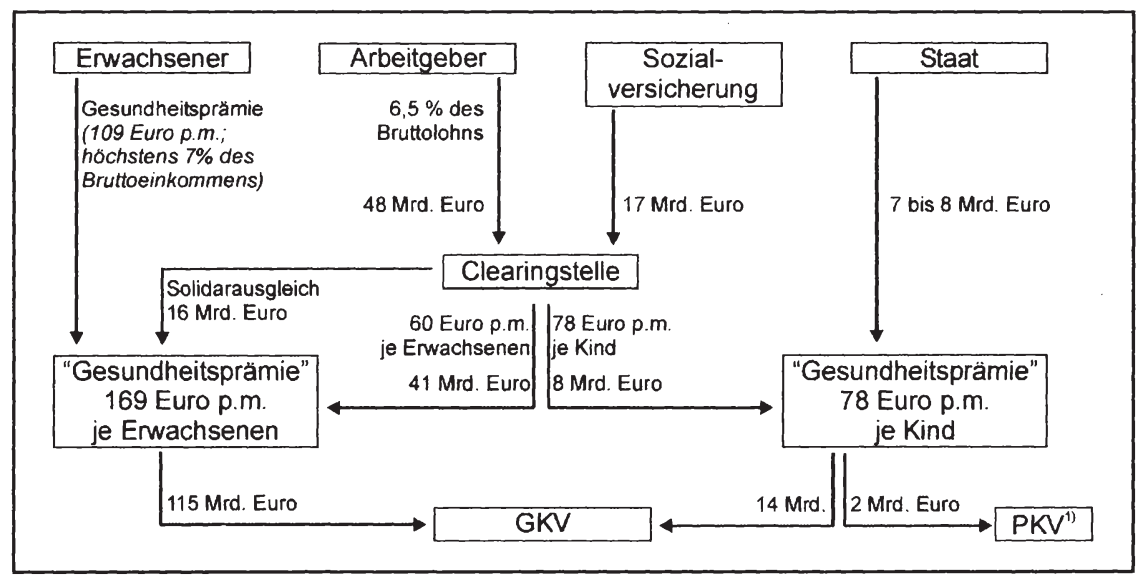

1) Beitragszuschuss für in der PKV versicherte Kinder.

Quelle: Eigene Darstellung.

Die Union kalkuliert demnach Einnahmen für die GKV in Höhe von 129 Mrd. Euro p.a. Tatsächlich betrugen im Jahr 2004 die Ausgaben der GKV aber $140 \mathrm{Mrd}$. Euro, wovon 6,4 Mrd. Euro auf die Zahlung von Krankengeld entfielen. ${ }^{766}$ Damit sind knapp $5 \mathrm{Mrd}$. Euro der GKV-Leistungen nicht durch Einnahmen gedeckt. Außerdem liegen nach Angaben von Rürup ${ }^{767}$ die Arbeitgeberbeiträge bei $45,5 \mathrm{Mrd}$. Euro und die Beiträge der Sozialversicherungsträger bei 13,5 Mrd. Euro, so dass die Einnahmen um 6 Mrd. Euro zu hoch angesetzt sind. Folglich sind insgesamt 11 Mrd. Euro im Modell der Union nicht finanziert. Selbst unter Berücksichtigung des Bundeszuschusses von 4,2 Mrd. Euro p.a. ab 2006 ( 221 SGB V), dessen Finanzierung nicht sichergestellt ist, verbleibt eine Finanzierungslücke von gut 6 Mrd. Euro.

Wird ein paritätisch finanzierter GKV-Beitragssatz in Höhe von $14 \%$ vor der Reform unterstellt, werden alle Versicherten mit einem monatlichen Arbeitseinkommen von über 1.557 Euro $^{768}$ entlastet. Bezieher niedrigerer Einkommen zahlen de facto einen Beitrag von $7 \%$ ihres beitragspflichtigen Einkommens, für sie bleibt der Beitrag damit

\footnotetext{
${ }^{766}$ Siehe BMGS (Hrsg.) (2005a), S. 1.

${ }^{767}$ B. Rürup bei der Vorstellung des Jahresgutachtens des SVR vor der Bundespressekonferenz am 17.11.2004; siehe auch O.V. (2004c), S. 6.
}

${ }^{768} 109$ Euro/0,07=1.557 Euro. 
weiter einkommensabhängig und auf gleichem Niveau wie vor der Reform. Für Arbeitnehmer, bei denen die Pauschale unter der Eigenbelastungsgrenze von $7 \%$ ihres Einkommens liegt, sind die Beiträge lohnunabhängig. Das stärkt den Wettbewerb zwischen den Versicherungen und setzt positive Arbeitsanreize. Da die Kassen von jedem Versicherten den gleichen kassenspezifischen Beitrag erhalten, entfältt der einnahmenseitige Finanzausgleich. Der Beitrag des Versicherten von 109 Euro hat jedoch keinen Bezug zu den im Durchschnitt verursachten Kosten.

Kopfpauschalenmodelle sehen zur Finanzierung des sozialen Ausgleichs i.d.R. die Auszahlung des Arbeitgeberbeitrags mit dem Arbeitslohn und anschließende Versteuerung vor. Hiervon profitieren trotz Besteuerung Mitglieder mit höherem Einkommen, deren Gesundheitsprämie unter dem derzeit zu zahlenden Gesamtbeitrag liegt. Die Zahlung der Arbeitgeberanteile an eine Clearingstelle wird daher von Pfaff u.a. ${ }^{969}$ als zielgenauer gesehen. Das bisherige Finanzierungssystem mit seinen diffusen Verteilungswirkungen ist jedoch kein geeigneter Vergleichsmaßstab. Außerdem bleibt für die Arbeitgeber die Lohnkoppelung der Beiträge erhalten. Bei Bruttolohnzuwächsen steigen die absoluten Lohnnebenkosten weiter; lediglich die Dynamik künftig steigender Beitragssätze wird aus dem System genommen und der Abgabenkeil reduziert. Während die Beiträge für Arbeitnehmer auf 109 Euro begrenzt sind, können die Arbeitgeberbeiträge jedoch auf bis zu 6,5\% der Beitragsbemessungsgrenze (2005: 3.525 Euro) und damit 230 Euro steigen. Anstelle der paritätischen Finanzierung würden dann die Arbeitgeber zwei Drittel der Beiträge eines GKV-Versicherten mit Arbeitseinkommen in Höhe der Beitragsbemessungsgrenze aufbringen.

Problematisch ist auch, dass der soziale Ausgleich größtenteils aus Arbeitgeberbeiträgen finanziert wird. Damit bleibt der Solidarausgleich auf Arbeitseinkünfte von GKV-Versicherten bis zur Beitragsbemessungsgrenze beschränkt. Lediglich an der Finanzierung des Steuerzuschusses von 7 bis 8 Mrd. Euro sind auch privat Versicherte beteiligt. Diese erhalten zwar dem Modell nach und auch zu Recht einen Beitragszuschuss zur Kinderversicherung, dieser wird aber teilweise aus GKV-Beiträgen aufgebracht. Zudem müssen die Arbeitgeber - deren Belastung gerade dauerhaft gesenkt werden soll - die vor allem im Sozialausgleich liegende Ausgabendynamik finanzieren. Nach Berechnungen von Hof und Schlömer ${ }^{7 / 0}$ würde der Anteil der Haushalte mit Zuschussbedarf von $44 \%$ im Jahr 2004 auf $78 \%$ im Jahr 2050 steigen und im gleichen Zeitraum der durch den Sozialausgleich finanzierte Anteil an den GKV Ausgaben von rund $13 \%$ auf über $40 \%$ wachsen. Die Begrenzung der Arbeitgeberbeiträge auf $6,5 \%$ des Bruttolohns wird damit mittelfristig in Frage gestellt. Besser wäre es, den Solidarausgleich als gesamtgesellschaftliche Aufgabe aus Steuermitteln zu finanzieren, wobei sich aber auch hier in Anbetracht eines steigenden Transfervolumens die Frage der langfristigen Finanzierung stellt. Letztendlich bleiben die Einnahmen der GKV von der konjunkturellen Entwicklung abhängig, die Fiktion der Arbeitgeberbeteiligung wird aufrechterhalten und das System wird noch intransparenter als im Status quo.

\footnotetext{
${ }^{769}$ Siehe Pfaff, A.B. u.a. (2005), S. 47.

${ }^{770}$ Siehe Hof, B.; Schlömer, C. (2005), S. 200f. Marco Penske - 978-3-631-75223-4
} 
Die gesamtstaatliche Nachhaltigkeitslücke steigt durch dieses „Hybridmodel ${ }^{4771}$ im Vergleich zum Status quo von $415 \%$ des BIP 2001 auf $443 \%$ und liegt damit zwischen den für eine Kopfpauschale (428\%) und eine Bürgerversicherung (453\%) berechneten Nachhaltigkeitslücken. ${ }^{772}$

Ein weiteres Kompromissmodell zwischen Bürgerversicherung und Kopfpauschale hat der Wissenschaftliche Beirat beim Bundesministerium der Finanzen ${ }^{773}$ vorgelegt. Demnach sollen Arbeitgeber- und Arbeitnehmerbeiträge an eine neu zu gründende Inkassostelle abgeführt werden. Von dieser erhält jeder Versicherte eine Gutschrift in Höhe des durchschnittlichen Beitrags, gleichzeitig verpflichtet er sich zum Abschluss einer Krankenversicherung. Die frei wählbaren Versicherungen erheben einkommensunabhängige Pauschalbeiträge. Liegt der Versicherungsbeitrag über der Gutschrift, muss der Versicherte zuzahlen, umgekehrt bekommt er eine Rückerstattung. Dieses Modell eignet sich, den Wettbewerb zwischen den Versicherungen zu intensivieren und auf den Finanzkraftausgleich im RSA zu verzichten. Die Beitragsfinanzierung wird aber nicht wesentlich geändert.

Die Koalitionsparteien CDU, CSU und SPD haben zwar vereinbart, im Laufe des Jahres 2006 über eine Finanzreform zu entscheiden. ${ }^{774}$ Welcher Kompromiss dabei zwischen den Modellen Kopfpauschale und Bürgerversicherung gefunden wird, ist jedoch bei Drucklegung dieser Arbeit noch offen. Den öffentlichen Verlautbarungen der Koalitionsparteien zufolge könnte die Finanzierung der Krankenversicherung ähnlich der Reform in den Niederlanden geändert werden. ${ }^{775}$ Demnach würde der Arbeitgeberbeitragssatz auf 6,5\% des Bruttolohns festgeschrieben. Gleiches würde für die „Arbeitgeberbeiträge" der Gesetzlichen Rentenversicherung gelten, so dass die Arbeitgeberbeiträge insgesamt rund $60 \mathrm{Mrd}$. Euro (40\% der Gesamtausgaben der GKV) betragen würden. Bei den Versicherungspflichtigen würde die Beitragsbemessungsgrundlage um weitere Einkunftsarten erweitert werden. Die Arbeitnehmerbeiträge von geschätzt $67,5 \mathrm{Mrd}$. Euro (45\% der Gesamtausgaben) würden wie die Arbeitgeberbeiträge an das Bundesversicherungsamt fließen. Zudem würde die PKV in den RSA einbezogen werden, was zu zusätzlichen Einnahmen von rund 7,5 Mrd. Euro im RSA führen würde, so dass das Bundesversicherungsamt insgesamt rund $135 \mathrm{Mrd}$. Euro über den RSA an die Kassen verteilen könnte. Die restlichen $15 \mathrm{Mrd}$. Euro würden über eine Kopfpauschale finanziert werden. Jeder erwachsene Versicherte hätte dann monatlich bis zu 50 Euro an seine Kasse zu zahlen.

Würde dieses Modell realisiert werden, würde der Wettbewerb zwischen den Kassen sogar abnehmen, weil die Kassen $90 \%$ ihrer Einnahmen als Transfer aus dem RSA erhielten. Darüber hinaus lässt die Beitragspflicht für weitere Einkunftsarten die Beiträge kaum noch von der Einkommensteuer unterscheiden, was zu gravierenden

\footnotetext{
${ }^{771}$ SVR (2004), Ziff. 544.

772 Vgl. Fetzer, S. u.a. (2004), S. 9.

${ }^{773}$ Siehe Wissenschaftlicher Beirat beim Bundesministerium der Finanzen (2005). Siehe auch Richter, W.F. (2005), S. 694ff.

${ }^{774}$ Siehe Christlich Demokratische Union Deutschlands; Christlich-Soziale Union in Bayern; Sozialdemokratische Partei Deutschlands (Hrsg.) (2005), S. 87.

${ }^{775}$ Siehe Drabinski, T. (2006), S. 3 ff. 
allokativen und distributiven Problemen führt. ${ }^{776}$ Die Ausweitung der Versicherungspflicht in der GKV auf alle abhängig Beschäftigten verschärft die mit dem demographischen Wandel verbundenen Probleme sogar, weil die PKV zurückgedrängt wird. Zudem wirt die Einbeziehung der PKV in den RSA zahlreiche methodische Probleme auf. ${ }^{777}$

Die diskutierten Reformvorschläge konzentrieren sich auf Gerechtigkeits- und Beschäftigungsaspekte. Sie geben aber keine Antwort auf die Frage, wie die durch den demographischen Wandel und den medizinisch-technischen Fortschritt wachsende Schere zwischen Einnahmen und Ausgaben der GKV finanziert werden soll. Soll die Rationierung von Leistungen und eine Überforderung von künftigen Erwerbstätigen vermieden werden, können kapitalgedeckte Elemente die Belastungen auf verschiedene Generationen (intergenerativ) und im Zeitverlauf (intertemporal) verteilen. Kapitaldeckung wird allerdings nicht die Ausgaben der Krankenversicherung reduzieren.

\footnotetext{
${ }^{776}$ Siehe hierzu ausführlich Kapitel V.3.2.4.1 Allokation, S. 175, und Kapitel V.3.2.4.2 Distribution, S. 178.

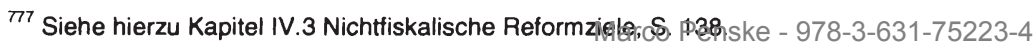


Marco Penske - 978-3-631-75223-4

Downloaded from PubFactory at 01/11/2019 06:54:52AM

via free access 


\section{Einführung von Kapitaldeckung in der GKV}

\section{Umlageverfahren versus Kapitaldeckungsverfahren}

Gesundheitsleistungen können nach dem Umlageverfahren oder dem Kapitaldeckungsverfahren finanziert werden. Im Umlageverfahren werden die jährlichen Ausgaben durch laufende Beiträge finanziert. Grundlage in der GKV ist ein Generationenvertrag, wonach die Erwerbstätigen mit ihren Beiträgen die Ausgaben auch für nicht erwerbstätige Versicherte - vor allem Rentner - teilweise finanzieren. Im Kapitaldeckungsverfahren hingegen werden die Beiträge nicht vollständig in der laufenden Periode verausgabt, sondern ein Kapitalstock aufgebaut, der zuzüglich Zinsen der Finanzierung späterer Ausgaben dient. Der Budgetausgleich wird nicht jährlich vorgenommen, sondern über den Lebenszyklus. Die Vor- und Nachteile der beiden Systeme wurden in der Literatur insbesondere im Hinblick auf die GRV ausführlich erörtert. ${ }^{778}$ Diese Diskussion soll nicht wiederholt werden, stattdessen werden die wesentlichen Unterschiede von Kapitaldeckungsverfahren und Umlageverfahren im Hinblick auf die Krankenversicherung kurz dargestellt und anschließend die Einführung kapitalgedeckter Elemente in der GKV mitsamt ihren gesamtwirtschaftlichen Wirkungen diskutiert.

Die beiden Finanzierungsverfahren unterscheiden sich im Wesentlichen in drei Punkten: ${ }^{779}$ Erstens entstehen im in der GKV praktizierten Umlageverfahren intergenerative Transfers. Die Ausgaben werden im Querschnitt auf die einzelnen Generationen verteilt, so dass Jüngere mit ihren Beiträgen die Ausgaben für Ältere mitfinanzieren. Im Kapitaldeckungsverfahren werden die Ausgaben durch intertemporale Umverteilungen finanziert. Jede Generation bildet einen Kapitalstock, aus dem künftige, die eigenen Beiträge übersteigende Gesundheitsleistungen bezahlt werden. Damit werden die Ausgaben im Zeitverlauf im Längsschnitt verteilt und die Beiträge weitgehend konstant gehalten. Zweitens unterscheiden sich die Determinanten der Rendite. Im Umlageverfahren hängt die Rendite von Lohnsatz und Beschäftigtenzahl und damit letztendlich von Arbeitsproduktivität und Wachstum der erwerbstätigen Bevölkerung ab. Im Kapitaldeckungsverfahren bestimmen die Kapitalerträge die Rendite. Drittens werden die Beiträge im Umlageverfahren aus nationalen Einkommen finanziert. Das Kapitaldeckungsverfahren hingegen bietet die Möglichkeit, auch auf ausländische Kapitalerträge zuzugreifen, soweit ein Teil des Kapitalstocks im Ausland angelegt wurde.

Beide Verfahren beruhen jedoch - wenn auch in unterschiedlichem Ausmaß - auf der Bildung von Humankapital: Im Umlageverfahren trägt die junge Generation direkt zur Finanzierung der Ausgaben der Älteren bei, im Kapitaldeckungsverfahren erwirt-

${ }^{778}$ Siehe Homburg, S. (1988), S. 5ff.; SVR (1996), Ziff. 404ff.; Deutsche Bundesbank (Hrsg.) (1999), S. 15ff.; Börsch-Supan, A. (2000), S. 1ff.; Breyer, F. (2000), S. 383ff.; Wissenschaftlicher Beirat beim Bundesministerium der Finanzen (2004), S. 12ff.; Lampert, H.; Althammer, J. (2004), S. 241ff. Für die Krankenversicherung: SVR KAiG (1998), Ziff. 577; Oberdieck, V. (1998), S. 164ff; Pimpertz, J. (2001), S. 162ff.; Cassel, D. (2003), S. 244ff.

${ }^{79} \mathrm{Vgl}$. Börsch-Supan, A. (2000), S. 2, der die Unterschiede im Kontext der GRV darstellt. Anders als in der GRV zahlen in der GKV zwar auch Rentner Beiträge, die Ergebnisse sind aber auch auf

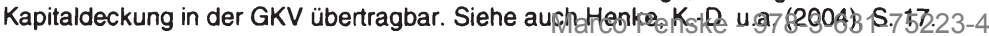


schaften die Jungen die Kapitalerträge. ${ }^{780}$ Trotzdem ist die viel zitierte These von Mackenroth $^{781}$, nach der sich Umlageverfahren und Kapitaldeckungsverfahren realwirtschaftlich entsprächen, da Konsum der Älteren nur durch Konsumverzicht der Jüngeren, mithin der Sozialaufwand nur aus dem laufenden Volkseinkommen (Nettosozialprodukt zu Faktorkosten) finanziert werden könne, nicht zutreffend. Durch den Verzicht auf Erhaltungsinvestitionen kann auch der Kapitalbestand verbraucht werden. In diesem Fall könnten Konsum und Sozialausgaben das Volkseinkommen in Höhe der unterlassenen Abschreibungen übersteigen, womit das Bruttosozialprodukt zu Faktorkosten die Obergrenze wäre. Außerdem kann durch die Produktion langlebiger Güter (z.B. Wohnhäuser, Fahrzeuge) Konsum in die Zukunft verschoben werden. In einer offenen Volkswirtschaft besteht darüber hinaus die Möglichkeit, durch Kapitalexporte einen Kapitalstock im Ausland aufzubauen und diesen durch spätere Kapitalimporte zu verbrauchen. Besonders problematisch ist aber die implizite Annahme der Mackenroth-These, die Höhe des BIP sei unabhängig von dem Finanzierungsverfahren. Infolge der Einführung kapitalgedeckter Elemente zur Finanzierung der GKV steigt der Kapitalbestand im Vergleich zum Umlageverfahren. Denkbar ist zwar auch, dass die gesamtwirtschaftliche Ersparnis konstant bleibt. Die vollständige Substitution freiwilligen Sparens durch Pflichtsparen setzt jedoch voraus, dass kein Wirtschaftssubjekt seinen Konsum aufgrund der Sparverpflichtung einschränkt, was eher unrealistisch erscheint. Nach herrschender Meinung steigen Sparquote und Ersparnis. Demzufolge sinkt der Realzins, womit positive Wachstumseffekte verbunden sind. Gerade in einer Volkswirtschaft, in der die Zahl der Erwerbstätigen zurückgeht, kann das Konsumniveau durch gestiegene Importe und eine höhere Arbeitsproduktivität sichergestellt werden. Für beides ist die Bildung von Kapital förderlich. Kapitalbildung im Ausland erleichtert die Produktion und Finanzierung von Importen und eine höhere Kapitalintensität steigert die Arbeitsproduktivität. Wird eine neoklassische Produktionsfunktion unterstellt, sinkt bei gestiegenem Kapitaleinsatz die Kapitalproduktivität und die totale Faktorproduktivität bleibt konstant. In neueren endogenen Wachstumsmodellen steigt die totale Faktorproduktivität jedoch, da aufgrund positiver Rückwirkungen vom Arbeits- und Kapitalmarkt auch die Kapitalproduktivität steigt. Die Volkswirtschaft gelangt dann auf einen höheren und steileren Wachstumspfad. Mit anderen Worten: Mit einem größeren Kapitalstock lassen sich ein höheres BIP erwirtschaften und Gesundheitsausgaben leichter finanzieren. ${ }^{782}$

Kapitalgedeckte Elemente in der GKV können die demographisch bedingten intergenerativen Verteilungswirkungen abschwächen; dafür müssen heutige Generationen jedoch auf Konsum verzichten. In der Literatur werden weitere Einwände gegen Kapitaldeckung in der GKV genannt: ${ }^{783}$ Auf der Angebotsseite sind die Kosten des

\footnotetext{
${ }^{780}$ Vgl. Börsch-Supan, A. (2000), S. 2f.; Cassel, D. (2003), S. $245 f$.

${ }^{781}$ Siehe Mackenroth, G. (1952), S. $41 \mathrm{ff}$.

${ }^{782}$ Zur Widerlegung der Mackenroth-These siehe Homburg, S. (1988), S. 66ff.; Dudey, S. (1996), S. 131ff.; Oberdieck, V. (1998), S. 169f.; Wissenschaftlicher Beirat beim Bundesministerium für Wirtschaft (1998), S. 49ff.; Deutsche Bundesbank (Hrsg.) (1999), S. 20; Breyer, F. (2000), S. 386; Lueg, T.; Ruprecht, W.; Wolgast, M. (2003), S. 4ff.; Wissenschaftlicher Beirat beim Bundesministerium der Finanzen (2004), S. 15f., 50ff.; Lampert, H.; Althammer, J. (2004), S. 242; Börsch-Supan, A. (2004), S. $74 \mathrm{ff}$.
}

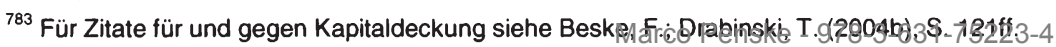


medizinisch-technischen Fortschritts in Verbindung mit der demographischen Entwicklung für die Krankenversicherung kaum absehbar und deshalb der benötigte Kapitalstock nicht zu beziffern. Zudem müssen auf der Nachfrageseite die individuellen Alterungsrückstellungen übertragbar sein. Ohne die Mitgabe von angemessenen Alterungsrückstellungen werden der Versicherungswechsel und damit der Wettbewerb zwischen den Versicherungen erschwert, wenn sich der Gesundheitszustand der Versicherten mit zunehmendem Alter verschlechtert. ${ }^{784}$ Darüber hinaus steigen auch im Kapitaldeckungsverfahren die Beiträge an und sind keineswegs alterskonstant, wie die Beitragsentwicklung in der PKV zeigt. ${ }^{785}$

Außerdem sei die demographische Belastung in der GKV deutlich geringer als in der GRV oder auch in der Pflegeversicherung. Im Gegensatz zur GRV zahlt auch ein Rentner weiter Beiträge an die GKV und die Ausgaben steigen in der GKV nicht sprunghaft mit dem Renteneintritt an. ${ }^{786}$ Lauterbach $^{787}$ Z.B. will die Kapitaldeckung in der GRV stärken. Zum einen sei die demographische Belastung deutlich höher als in der GKV, zum anderen der Finanzbedarf in der GRV besser kalkulierbar und kapitalgedeckte Elemente über bereits existierende Instrumente (z.B. Riester-Rente) einfacher zu implementieren. Die höheren, späteren Rentenzahlungen führten zudem zu steigenden Beitragseinnahmen in der GKV und stabilisierten die GKV-Finanzen, weil sie im Alter und damit zu einem Zeitpunkt anfielen, an dem die Ausgaben tendenziell höher lägen. Dies setzt allerdings die Beitragspflicht für alle Alterseinkünfte voraus, wodurch es zu einer Doppelbelastung mit Beiträgen kommen kann. Außerdem ist in der GRV die Verschiebung des Renteneintrittsalters dazu geeignet, den Beitragssatz von der Einnahmen- und Ausgabenseite her systemimmanent zumindest in Grenzen zu stabilisieren. ${ }^{788}$ In der GKV können damit die Ausgaben nicht beeinflusst werden.

Anders als in der GRV können in der GKV aber die Belastungen künftiger Generationen auch reduziert werden, indem die Beiträge der Älteren entsprechend ihrer Kostenentwicklung angepasst werden. Dafür ist in der GKV Kapitaldeckung nicht notwendig. Auch eine umlagefinanzierte GKV ist bei altersdifferenzierten Beiträgen grundsätzlich ohne intergenerative Transfers möglich. ${ }^{789}$ Freilich steigt aber ohne Rückstellungen die Belastung für die Versicherten im Alter stark an. In dem Maße, in dem staatliche Transferzahlungen an diejenigen notwendig werden, die ihre Beiträge dann nicht mehr selbst aufbringen können, werden wegen des Verzichts auf Kapitalbildung Steuerlasten in die Zukunft verschoben. Mit anderen Worten: Kapitalbildung könnte die implizite Verschuldung der GKV reduzieren. Soll insbesondere ab 2030 das schon durch die demographische Entwicklung gedämpfte wirtschaftliche Wachstum nicht durch einen steigenden Finanzbedarf der GKV zusätzlich behindert werden, müssen heutige Generationen Kapital bilden, um zukünftige Beitragslasten

\footnotetext{
${ }^{784}$ Vgl. Zweifel, P.; Breuer, M. (2002), S. 28, 47ff.

${ }^{785} \mathrm{Vgl.} \mathrm{Rürup-Kommission} \mathrm{(2003),} \mathrm{Kasten} \mathrm{4-3;} \mathrm{Breyer,} \mathrm{F.} \mathrm{U.a.} \mathrm{(2004),} \mathrm{S.} \mathrm{84;} \mathrm{Bundestags-Drucksache}$ $15 / 1859$ vom 31.10.2003, S. $27 \mathrm{ff}$.

${ }^{786}$ Vgl. Sehlen, S. u.a. (2004), S. 18 f.

${ }^{787}$ Siehe Lauterbach, K.W. (2004), S. 50f.; Lauterbach, K.W. u.a. (2004a), S. 27.

${ }^{788} \mathrm{Vgl}$. Schulte, R. (2004), S. 6.

${ }^{789}$ Vgl. Felder, S.; Kifmann, M. (2003), S. 13ff.; SVR (2004), Ziff. 508; Breyer, F.; Zweifel, P.; Kifmann, M. (2005), S. 534f., 539. 
vorzufinanzieren. ${ }^{790}$ Auch wenn die intergenerativen Umverteilungen in der GRV reduziert werden sollten, ist dies kein überzeugendes Argument dafür, auf eine nachhaltig finanzierbare GKV mit kapitalgedeckten Elementen zu verzichten.

Für die GKV gibt es inzwischen zahlreiche Vorschläge, wie kapitalgedeckte Elemente eingeführt werden können. Zum einen kann Kapital innerhalb der GKV gebildet werden. ${ }^{791}$ Dabei lassen sich grundsätzlich zwei Kategorien unterscheiden: Erstens kann das Umlageverfahren beibehalten und um kollektive oder individuelle Kapitaldeckung ergänzt werden. Zweitens kann vom Umlageverfahren zu einer vollständigen individuellen Kapitaldeckung übergegangen werden. Zum anderen kann Kapital auch außerhalb der Krankenversicherung gebildet werden. ${ }^{792} \mathrm{Da}$ aus den Zinsen und der Auflösung des Kapitalstocks die individuelle Beitragsbelastung über die Lebensdauer geglättet werden soll, ist dann kollektive Kapitalbildung nicht sinnvoll, sondern sollte auf individueller Ebene extern angespart werden.

\section{Abbildung 32: Systematisierung von Reformvorschlägen nach dem Anteil an Kapitaldeckung}

\begin{tabular}{|c|c|c|c|}
\hline \multicolumn{2}{|c|}{ Risikoäquivalenz } & & \\
\hline Risikoaquivalent & $\begin{array}{l}\text { Zuricher Modell } \\
\text { (Zweifel/Breuer) }\end{array}$ & & $\begin{array}{l}\text { Risikoaquivalente Pramien } \\
\text { (z.B. Kronberger Kreis; SVR } \\
(1996,2002) \text {; FDP) }\end{array}$ \\
\hline Altersabhängig & $\begin{array}{l}\text { Altersdifferenzierte } \\
\text { Beitrăge (z.B. } \\
\text { Felder/Kifmann) }\end{array}$ & $\begin{array}{l}\text { Modell eines zukunfts- } \\
\text { sicheren Systems, } \\
\text { Variante } 2 \text { (Deutsche } \\
\text { Krankenversicherung) }\end{array}$ & $\begin{array}{l}\text { Modell eines zukunfts- } \\
\text { sicheren Systems, } \\
\text { Variante } 1 \text { (Deutsche } \\
\text { Krankenversicherung) }\end{array}$ \\
\hline Pauschal & $\begin{array}{l}\text { Kopfpauschale } \\
\text { (z.B. Rürup; Knap- } \\
\text { pe/Arnold; SVR } \\
\text { (2003)) } \\
\text { Solidarisches Ge- } \\
\text { sundheitsprämien- } \\
\text { modell (CDU/CSU) }\end{array}$ & $\begin{array}{l}\text { Gesundheitsprämie } \\
\text { oder Bürgerpauschale } \\
\text { (z.B. Herzog-Kommis- } \\
\text { sion; SVR (2004)) }\end{array}$ & $\begin{array}{l}\text { Zukunftsmodell für ein effi- } \\
\text { zientes Gesundheitswesen } \\
\text { (z.B. Vereinte Krankenver- } \\
\text { sicherung; Rumm; Henke) }\end{array}$ \\
\hline \multirow[t]{2}{*}{$\begin{array}{l}\text { Einkommens- } \\
\text { abhängig }\end{array}$} & $\begin{array}{l}\text { Bürgerversicherung } \\
\text { (z.B. Lauterbach; } \\
\text { SPD) }\end{array}$ & $\begin{array}{l}\text { Demographiereserve } \\
\text { (z.B. Cassel/Oberdieck) }\end{array}$ & \\
\hline & & & Anteil Kapitaldeckung \\
\hline
\end{tabular}

Quelle: Eigene Darstellung.

Reformvorschläge zur Bildung von Kapital innerhalb der GKV werden im Folgenden anhand des Anteils an Kapitaldeckung systematisiert. Auf die Unterscheidung des Umfangs des kapitalgedeckten Finanzierungsvolumens und des im Kapitaldeckungsverfahren gewährten Leistungsumfangs wird im Folgenden verzichtet. Bei Letzterem

\footnotetext{
${ }^{790}$ Vgl. Schulte, R. (2004), S. 6; Deutsche Bundesbank (Hrsg.) (2004a), S. 31. Zur Kapitaldeckung in der GRV siehe Börsch-Supan, A. (2004), S. 83.

${ }^{791}$ Siehe Abschnitt 3 Interne Kapitaldeckung, S. 225.

${ }^{792}$ Siehe Abschnitt 4 Externe Kapitalbildung mit Gesundheitsspaskpriten, 87844.631-75223-4 
wird lediglich ein bestimmter Teilbereich des Leistungsvolumens im Kapitaldeckungsverfahren finanziert. Für die Betrachtung intergenerativer Verteilungsvorgänge, und damit der nachhaltigen Finanzierbarkeit der GKV, ist aber der Kapitaldeckungsanteil am gesamten Finanzierungsvolumen entscheidend. ${ }^{793}$

In Abbildung 32 werden die Reformvorschläge nach dem Grad der Risikoäquivalenz in der Beitragsbemessung und dem Anteil an Kapitaldeckung innerhalb der GKV systematisiert. Sofern Vorschläge die Bildung von Kapital außerhalb der GKV vorsehen (Züricher Modell, Altersdifferenzierte Beiträge nach Felder und Kifmann), werden diese in der Abbildung unter Umlageverfahren eingestuft, weil innerhalb der GKV keine Kapitalbildung beabsichtigt ist.

Die Herzog-Kommission ${ }^{794}$ hatte angeregt, in einem Übergangzeitraum von zehn Jahren einen Kapitalstock aufzubauen, um anschließend zu einem voll kapitalgedeckten Prämienmodell überzugehen. Der Vorschlag unterscheidet sich im Ausmaß der Kapitaldeckung und im Versichertenkreis vom noch zu diskutierenden Modell einer kapitalgedeckten Bürgerpauschale, das sowohl mit kollektiver als auch mit individueller Kapitaldeckung vereinbar ist. Auf das von der Deutschen Krankenversicherung ${ }^{795}$ entwickelte "Modell eines zukunftssicheren Systems" wird ebenfalls nicht näher eingegangen, weil sich der Reformvorschlag je nach Variante in seinen Grundzügen nicht von dem Prämienmodell der Herzog-Kommission bzw. einer Bürgerpauschale unterscheidet.

Individuelle Kapitaldeckung führt ebenfalls zu altersabhängigen Beiträgen, die allerdings während des Übergangs mit zunehmenden Eintrittsalter sinken, was die Berechnungen zur Bürgerpauschale ${ }^{796}$ noch zeigen werden. Da Ältere aufgrund ihrer kürzeren Restlebensdauer nicht der vollen Beitragssteigerung ausgesetzt sind, reichen geringere Sparbeträge aus als bei Jüngeren, die für den vollen Beitragsanstieg mehr Kapital bilden müssen. ${ }^{77}$ Beim Wechsel in ein vollständig kapitalgedecktes System steigen die Beiträge hingegen in Abhängigkeit vom Alter, weil entsprechend hohe Alterungsrückstellungen in einem kürzeren Zeitraum nachfinanziert werden müssen. ${ }^{798}$ Die Altersabhängigkeit der Beiträge ist in beiden Fällen auf den Aufbau eines Kapitalstocks zurückzuführen.

Anders zu bewerten sind die z.B. von Felder und Kifmann ${ }^{799}$ vorgeschlagenen altersabhängigen Beiträge im Umlageverfahren. Dadurch könnten zwar intergenerative Transfers beseitigt werden, weil jede Altersgruppe ihre Gesundheitsleistungen selbst finanziert. Die Kosten einer Altersgruppe sollten aber nicht auf dieselbe verteilt werden, da dann der versicherungsimmanente Ausgleich auf die einzelnen Gruppen beschränkt bleibt, womit Wohlfahrtsverluste entstehen. Bei altersdifferenzierten Beiträgen dürften vielmehr nur die Kosten auf die Älteren umgelegt werden, die auf

\footnotetext{
${ }^{793}$ Vgl. Henke, K.-D. u.a. (2004), S. $17 f$.

794 Siehe Herzog-Kommission (2003), S. $22 \mathrm{ff}$.

${ }^{795}$ Siehe Boetius, J. (1999), S. 17ff. Vgl. auch Henke, K.-D. u.a. (2004), S. 11.

${ }^{796}$ Siehe Tabelle 23: Bürgerpauschale bei Bildung eines individuellen Kapitalstocks, S. 228.

${ }^{797} \mathrm{Vgl}$. SVR (2004), Ziff. 514.

${ }^{798}$ Siehe Grabka, M.M. u.a. (2002), S. 13.

${ }^{799}$ Siehe Felder, S.; Kifmann, M. (2003), S. 13f. Vgl. auch Breyer, F.; Zweifel, P.; Kifmann, M. (2005), S. 539. 
den Anstieg des Anteils der Älteren an allen Versicherten zurückzuführen sind, was technisch allerdings schwierig ist und Werturteile über die intergenerative Umverteilung verlangt. ${ }^{800}$

Das „Zukunftsmodell für ein effizientes Gesundheitswesen“ der Vereinten Krankenversicherung $^{801}$ sieht in der Endphase einheitliche Kopfpauschalen vor und unterscheidet sich dadurch nur im Ausmaß der Kapitaldeckung von dem Bürgerpauschalen-Modell, weshalb es nicht näher betrachtet wird. Würden auch während des Systemwechsels einheitliche Beiträge erhoben, käme es ohne Änderungen im Finanzausgleich zwischen den Kassen zu Wettbewerbsverzerrungen, weil dann die Pauschale einer Kasse von dem insgesamt aufzubauenden Kapitalstock und damit von der Altersstruktur ihrer Versicherten abhängig wäre.

Auf den am weitesten gehenden Vorschlag - die Einführung risikoäquivalenter Prämien - wird ausführlich eingegangen. Risikoäquivalente Prämien werden in einem vollständig kapitalgedeckten Finanzierungssystem, wie z.B. vom Kronberger Kreis ${ }^{802}$ vorgeschlagen, diskutiert. Zur Gestaltung des Übergangs werden dabei auch Vorschläge aufgegriffen, die zur Einführung vollständig kapitalgedeckter Kopfpauschalen gemacht wurden. Die im „Züricher Modell“ von Zweifel und Breuer ${ }^{803}$ vorgeschlagenen umlagefinanzierten risikoäquivalenten Prämien führen ohne die Bildung von Alterungsrückstellungen zu einem starken Prämienanstieg im Alter, womit das demographische Risiko in weiten Teilen nur auf das Steuer- und Transfersystem verlagert wird. Deshalb sollte dann wie auch bei altersdifferenzierten Beiträgen Kapital außerhalb der GKV angespart werden. Hierauf wird in Abschnitt 4 Externe Kapitalbildung mit Gesundheitssparkonten (S. 244) näher eingegangen.

\section{Kapitaldeckungsverfahren am Beispiel der PKV}

\subsection{Finanzierung der PKV}

Als Referenzsystem für ein kapitalgedecktes Krankenversicherungssystem dient die PKV. Für den Beitrag zur PKV ist das Krankheitsrisiko und nicht wie in der GKV das individuelle Einkommen maßgeblich. Die Prämie wird risikoäquivalent nach den Vorgaben der Kalkulationsverordnung ${ }^{804}$ ermittelt. ${ }^{805}$ Versicherte mit identischem Leistungskatalog und gleichen Risikomerkmalen (vor allem Eintrittsalter und Geschlecht) werden in einem Kollektiv zusammengefasst. Aus den alters- und geschlechtsabhän-

\footnotetext{
${ }^{800}$ Vgl. Buchholz, W. u.a. (2001), S. 15, 19 f.

${ }^{801}$ Siehe Rumm, U. (2000), S. 2ff.; Henke, K.-D. (2001), S. 5ff.; Grabka, M.M. u.a. (2002), S. 6ff.; Henke, K.-D. u.a. (2002), S. 13ff.; Henke, K.-D. u.a. (2004), S. $12 f$.

${ }^{802}$ Siehe Kronberger Kreis (2002), S. 28ff., 44ff.; Gerken, L.; Raddatz, G. (2003), S. 10f. Vgl. auch Henke, K.-D. u.a. (2004), S. 13; SVR (2004), Ziff. 536ff.

${ }^{803}$ Siehe Zweifel, P.; Breuer, M. (2002), S. 33ff.

${ }^{804}$ Siehe BGBI. 1996, Teil I, Nr. 61, S. 1783.

${ }^{805}$ Zur Kalkulation der Prämie in der PKV siehe Meier, V. u.a. (2004), S. 9ff.; Kommission zur Reform des Versicherungsvertragsrechts (2004), S. 141ff.; Beske, F.; Drabinski, T. (2004b), S. 109ff.; Rosenbrock, R.; Gerlinger, T. (2004), S. 105; Oberender, P.; Hebborn, A.; Zerth, J. (2002), S. 33f.; Pimpertz, J. (2001), S. 165ff.; Meyer, U. (2001), S. 2ff.; SVR (1996), Kasten 8; Expertenkommission (1996), S. 4f., $59 f f$. 
gigen Ausgaben je Tarif wird der Leistungsbedarf in den einzelnen Personen-, Tarifund Altersgruppen ermittelt. Dividiert man diesen Betrag durch die Zahl der Versicherten der jeweiligen Gruppe, erhält man den sogenannten „Pro-Kopf-Schaden“. Dieser Risikoteil ist die Kalkulationsgrundlage für die Nettoprämie. Hinzu kommen ein Kostenbeitrag für das Unternehmen und ein Sicherheitszuschlag von mindestens $5 \%$ der Bruttoprämie. Bei Vorerkrankungen kann die PKV darüber hinaus Risikozuschläge erheben oder die Versicherung verweigern. Dem Äquivalenzprinzip folgend wird keine beitragsfreie Familienversicherung angeboten.

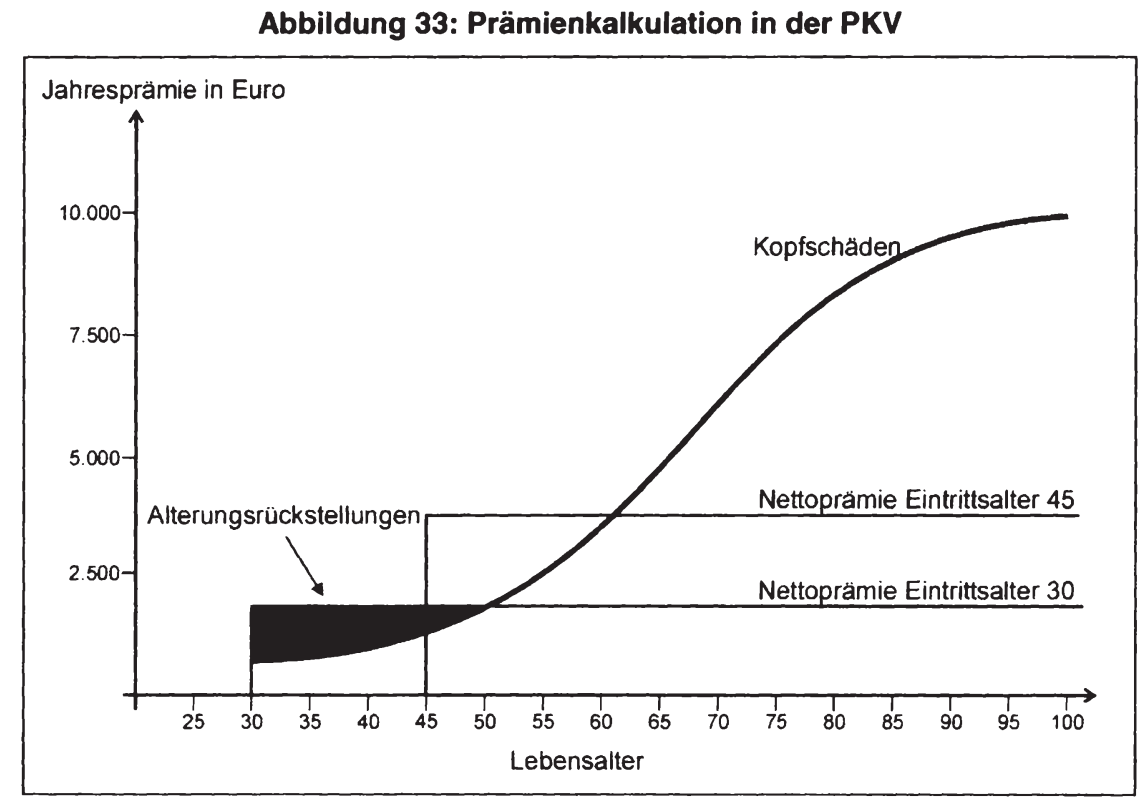

Quelle: In Anlehnung an Meyer, U. (2001), S. 3.

Die Prämien werden nicht nur risikoäquivalent kalkuliert, sondern sollen - trotz mit steigendem Alter wachsender Leistungsausgaben - nicht aufgrund des Älterwerdens der Versicherten steigen, vorausgesetzt die ursprünglich angesetzten Berechnungsgrundlagen, insbesondere der Krankheitskostenverlauf in Abhängigkeit vom Alter und die Sterbewahrscheinlichkeiten, bleiben konstant. Der Beitrag zur PKV wird über die gesamte Versicherungsdauer so kalkuliert, dass er - wie Abbildung 33 zeigt - in jungen Jahren über den tatsächlichen Leistungsausgaben liegt. Die auf diese Weise gebildeten Alterungsrückstellungen decken im Alter die Leistungsausgaben, die die Prämien übersteigen, ab. Durch Verzinsung der Alterungsrückstellungen, Sterben von Versicherten und Stornierungen reicht der relativ geringe Sparanteil in Abbildung 33 aus, um die deutlich die Prämie übersteigenden durchschnittlichen Krankheitskosten im Alter abzudecken. Über die gesamte Vertragsdauer soll für das Kollektiv versicherungstechnische Äquivalenz erfüllt sein, d.h. der Barwert der zukünftigen Beiträge einschließlich der Alterungsrückstellungen dem Barwert der erwarteten Leistungsausgaben entsprechen. Die Nettoprämie wird dazu auf Grundlage eines Risiko- und eines Sparanteils kalkuliert. 
Der Gesetzgeber schreibt den privaten Kassen vor, bei jüngeren Versicherten mit einem Sparanteil Alterungsrückstellungen zu bilden, die inklusive einer garantierten Verzinsung von höchstens 3,5\% die Beiträge im Alter begrenzen. Liegt die tatsächliche Verzinsung über $3,5 \%$, müssen nach $\S 12$ a Versicherungsaufsichtsgesetz (VAG) $90 \%$ dieser „Überzinsen" zur Beitragsentlastung im Alter verwendet werden, wobei ein wesentlicher Teil sofort für die Beitragsentlastung von Versicherten benötigt wird, die älter als 65 Jahre sind. Infolge des GKV-Gesundheitsreformgesetzes $2000^{806}$ wird dieser Anteil nach $\S 12$ a Abs. 2 und 3 VAG kontinuierlich bis zum Jahr 2025 abgebaut. Dann werden die Überzinsen zu vollen $90 \%$ in die Alterungsrückstellungen für alle Versicherten eingestellt. Die restlichen Überzinsen können in den Unternehmensgewinn fließen, Beitragsrückerstattungen finanzieren oder auch Prämienerhöhungen für Ältere sofort reduzieren. ${ }^{807}$ Zudem wurde durch das GKVGesundheitsreformgesetz als zusätzliche Altersvorsorgemaßnahme ein Beitragszuschlag eingeführt. Seit dem Jahr 2000 müssen in der PKV Neuversicherte gemäß $\S 12$ Abs. 4a VAG zwischen ihrem 21. und 60. Lebensjahr einen Zuschlag von $10 \%$ auf ihren Beitrag zahlen. Mit dem dadurch gebildeten Kapitalstock werden Beitragserhöhungen $a b$ dem 65 . Lebensjahr begrenzt. Ab dem 80 . Lebensjahr müssen die Beiträge gesenkt werden, wenn noch Mittel vorhanden sind.

\subsection{Problematik}

\subsubsection{Kostensteigerungen}

Trotz Alterungsrückstellungen werden die Beiträge in der PKV angepasst, wenn sich die Kalkulationsgrundlagen ändern. Nach der Beitragsanpassungsklausel in $\S 12 b$ VAG müssen die Beiträge sogar angepasst werden, wenn die Kalkulation nicht nur vorübergehend um mehr als $10 \%$ von den tatsächlichen Werten abweicht. Änderungen können durch die demographische Entwicklung oder Kostensteigerungen auftreten. Die Versicherungsunternehmen berücksichtigen zwar, dass die Gesundheitsausgaben mit dem Alter steigen, es ist ihnen aber untersagt, weitere Kostensteigerungen im Gesundheitswesen z.B. aufgrund des medizinisch-technischen Fortschritts bei der Prämienkalkulation zu berücksichtigen. ${ }^{808}$

Kostensteigerungen führen in einem System mit alterskonstanten Beiträgen für Bestandsversicherte zu höheren Prämienanpassungen als für Neukunden. Während sich bei einem neuen Vertrag nur die gegenwärtigen und künftigen Mehrausgaben in höheren Prämien niederschlagen, müssen für einen Bestandskunden darüber hinaus auch die Alterungsrückstellungen entsprechend erhöht werden, so dass für Altversicherte systembedingt ein höherer Prämienanstieg notwendig ist. ${ }^{809}$

${ }^{806}$ Siehe BGBI. 1999, Teil I, Nr. 59, S. 2626.

${ }^{807}$ Für eine vollständige Zuführung in die Alterungsrückstellungen plädiert Meyer, U. (1999), S. $16 f$.

${ }^{808} \mathrm{Vgl}$. Enquete-Kommission Demographischer Wandel (1998), S. 240t; Knappe, E.; Arnold, R. (2002), S. 12f.; Meier, V. u.a. (2004), S. 14ff.; Breyer, F.; Zweifel, P.; Kifmann, M. (2005), S. 536.

${ }^{809} \mathrm{Vgl}$. Expertenkommission (1996), S. 15, 61; Enquete-Kommission Demographischer Wandel (1998), S. 240f.; Knappe, E.; Optendrenk, S. (1999), S. 174ff.; Meyer, U. (2001), S. 6f.; Meier, V. u.a. (2004), S. $14 f$. 
Bei den Kostensteigerungen ist zwischen allgemeiner Kostensteigerung (Inflation) und speziellen Kostensteigerungen aufgrund des medizinisch-technischen Fortschritts im Gesundheitswesen zu unterscheiden. Die garantierte Verzinsung von bis zu 3,5\% ist zum Inflationsausgleich nicht geeignet. Diese Verzinsung der Alterungsrückstellungen wird zur Stabilisierung der Beiträge im Alter verwendet und ist entsprechend in der Kalkulation bereits beitragssenkend berücksichtigt. Sofern sich die am Kapitalmarkt erreichbare Verzinsung aber weiterhin parallel zur Inflationsrate entwickelt, kann die inflationsbedingte Entwertung der Alterungsrückstellungen durch Zuführung der Überzinsen an die Alterungsrücklage ausgeglichen werden. Die Prämien sind dann in Höhe der allgemeinen Kostensteigerung anzupassen und bleiben real konstant. ${ }^{810}$

Die Kostensteigerungen im Gesundheitswesen liegen jedoch über der Inflationsrate. Spezielle Kostensteigerungen im Gesundheitswesen können Modellrechnungen ${ }^{811}$ zufolge durch den im Jahr 2000 eingeführten Beitragszuschlag von $10 \%$ weitgehend ausgeglichen werden. ${ }^{812}$ Systemgerechter wäre es allerdings, spezielle Kostensteigerungen gleich bei der Kalkulation der Prämie zu berücksichtigen. ${ }^{813}$

Davon abgesehen fehlen der PKV derzeit auch wirksame Instrumente zur Kostenkontrolle, so legt der Gesetzgeber z.B. auch für die PKV die Entgelte für ärztliche Leistungen in der Gebührenordnung für Ärzte und der Gebührenordnung für Zahnärzte fest. Einzelne Verträge mit Ärzten oder Arztgruppen sind der PKV nicht gestattet. $^{814}$

\subsubsection{Demographische Abhängigkeit}

Trotz der Bildung von Alterungsrückstellungen ist die PKV nicht vollkommen unabhängig von der demographischen Entwicklung. Im reinen Anwartschaftsdeckungsverfahren entspricht für jede Kohorte der Barwert der erwarteten gesamten Leistungsausgaben über die Versicherungsdauer dem Barwert der erwarteten Prämieneinnahmen. Dadurch gibt es der Idee nach weder intragenerative noch intergenerative Umverteilungen; die Finanzierung ist unabhängig von der Geburtenentwicklung. In der PKV hingegen existieren bei einer Querschnittsbetrachtung Umlageelemente: Die Verwaltungskosten werden seit 1991 als altersunabhängige Kostenzuschläge abgerechnet, obwohl für Ältere aufgrund des höheren Leistungsbedarfs im Durchschnitt auch höhere Verwaltungskosten anfallen ${ }^{815}$ Außerdem wird ein Teil der Überzinsen nicht den Alterungsrückstellungen aller Versicherten zugeführt, sondern nach $\S 12 a$ Abs. 3 VAG zur Beitragsentlastung der über 65jährigen genutzt. In dem Maße, in dem auch Alterungsrückstellungen der jüngeren Versicherten für Beitragsentlastungen der Älteren verwendet werden, findet eine Umverteilung von Jüngeren zu

\footnotetext{
${ }^{810} \mathrm{Vgl}$. Expertenkommission (1996), S. 21f.; Meyer, U. (2001), S. 7ff.; Meier, V. U.a. (2004), S. $15 f$.

${ }^{811}$ Siehe Expertenkommission (1996), S. 34ff., 64ff.

${ }^{812}$ Vgl. Meyer, U. (2001), S. 12f.; Meier, V. u.a. (2004), S. 15f. Nicht berücksichtigt ist dabei jedoch eine Versteilerung der Ausgabenprofile; vgl. Buchner, F.; Wasem, J. (2000), S. $32 f$.

${ }^{813}$ Vgl. Meyer, U. (1999), S. $17 \mathrm{ff}$.

${ }^{814}$ Für Reformvorschläge zur besseren Kostensteuerung in der PKV siehe Kommission zur Reform des Versicherungsvertragsrechts (2004), S. 164ff.; Expertenkommission (1996), S. 52ff.

${ }^{815}$ Vgl. Beer, H. (1995), S. 692.

Marco Penske - 978-3-631-75223-4
}

Downloaded from PubFactory at 01/11/2019 06:54:52AM 
Älteren statt. Die Prämienentwicklung in der PKV ist deshalb nicht vollkommen unabhängig von der Geburtenentwicklung. ${ }^{816}$

Eine steigende Lebenserwartung führt auch im reinen Anwartschaftsdeckungsverfahren zu steigenden Prämien, wie Abbildung 34 zeigt. Ähnlich den Folgen eines Kostenanstiegs steigt mit zunehmender Lebensenwartung der Barwert der künftigen Leistungsausgaben. Das Verschieben der Lebenserwartung verursacht ein Defizit, das für alterskonstante Prämien höhere Rücklagen und damit Prämiensteigerungen erfordert. $\mathrm{Da}$ auch die bereits gebildeten Alterungsrückstellungen angepasst werden müssen, steigen die Beiträge für Altkunden wiederum stärker als für Neuversicherte. ${ }^{817}$ Zudem ist in der Prämienberechnung einkalkuliert, dass aufgrund von Stornierungen und Versterben Sparanteile auf die verbleibenden Versicherten übergehen. Werden Alterungsrückstellungen aufgrund eines Rückgangs der Storno- oder Sterbequote in geringerem Umfang "vererbt“, müssen die Prämien auch angepasst werden. ${ }^{818}$

\section{Abbildung 34: Auswirkungen einer steigenden Lebenserwartung auf die Prämie}

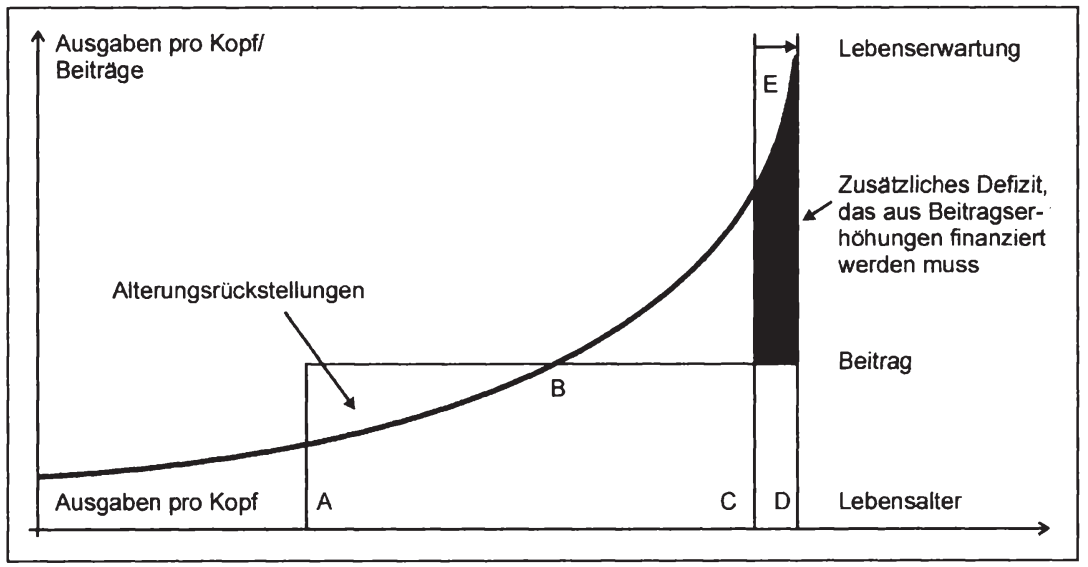

Anmerkung: Unterstellt wird offensichtlich die Gültigkeit der Medikalisierungsthese. Träfe die Kompressionsthese zu, müsste die Ausgabenkurve bei einer Verlängerung der Lebenserwartung zunächst flacher verlaufen und im letzten Lebensjahr dafür steil ansteigen; siehe Abbildung 22: Altersausgabenprofil nach der Kompressionsthese, S. 99.

Quelle: Enquete-Kommission Demographischer Wandel (1998), S. 242.

Die PKV ist aber weitaus besser auf demographische Veränderungen vorbereitet als die GKV. In der GKV wirkt der demographische Wandel auch auf der Einnahmenseite beitragssatzsteigernd, während er sich in der PKV auf die Ausgabenseite beschränkt. Zudem werden in der PKV Alterungsrückstellungen gebildet. Die Beitrags-

${ }^{816}$ Vgl. Beer, H. (1995), S. 692; Enquete-Kommission Demographischer Wandel (1998), S. 239f.; Breyer, F.; Zweifel, P.; Kifmann, M. (2005), S. 536.

${ }^{817}$ Vgl. Enquete-Kommission Demographischer Wandel (1998), S. 241f.; Knappe, E.; Optendrenk, S. (1999), S. 176.

${ }^{818}$ In Anlehnung an Enquete-Kommission Demographischer Wandel (1998), S. 239; Meyer, U. (2001), S. 2f.; Meier, V. u.a. (2004), S. 10. 
einnahmen (2004: 24,5 Mrd. Euro), die nicht der Finanzierung von laufenden Ausgaben (16,0 Mrd. Euro) dienen, werden zur Stabilisierung der Beiträge eingesetzt. Im Jahr 2004 wurden $34,7 \%$ der Beitragseinnahmen in der PKV ohne Pflegeversicherung für die Altersvorsorge verwendet. Die Alterungsrückstellungen betrugen für die 8,3 Mio. PKV-Versicherten 80,4 Mrd. Euro. ${ }^{819}$ Zum Vergleich: In der GKV betragen beide Vorsorgewerte Null. Deshalb unterscheiden sich die intergenerativen Verteilungswirkungen zwischen PKV und GKV deutlich. Während Prämiensteigerungen in der PKV vor allem die Älteren betreffen und intergenerativ verteilungsneutral sind, werden in der GKV insbesondere die Erwerbstätigen und damit die Jüngeren von einem Beitragssatzanstieg belastet.

\subsection{3 Übertragbarkeit von Alterungsrückstellungen}

Problematisch in der PKV ist die fehlende Übertragbarkeit der Alterungsrückstellungen beim Wechsel des Versicherers. Der Versicherungswechsel wird daher mit zunehmender Vertragslaufzeit für die Versicherten unattraktiv, weil sie bei der neuen Versicherung Alterungsrückstellungen in einem kürzeren Zeitraum mit einer deutlich höheren Prämie neu aufbauen müssten. Hinzu kommt, dass der Wechsler einer erneuten Risikoprüfung unterliegt, was bei einer mit zunehmendem Alter wahrscheinlichen Verschlechterung des Gesundheitszustands zu einer höheren Prämie führen wird. Der Wettbewerb beschränkt sich daher in der PKV auf den Neuzugang. Die privaten Versicherungen haben sogar einen Vorteil, wenn sie Bestandskunden verlieren, weil sie die dann "geerbten Alterungsrückstellungen“ verwenden können, um mit niedrigeren Prämien Neukunden anzuwerben. ${ }^{820}$ Problematisch wird der Verlust an Versicherten indes für den Versicherer, wenn ein sich selbst verstärkender Prozess beginnt, in dem gute Risiken zunehmend die Versicherung verlassen und es zu einer Risikoentmischung einhergehend mit steigenden Prämien für die verbleibenden Versicherten kommt. ${ }^{821}$

Bessere Wechselmöglichkeiten für ältere Versicherte würden den Wettbewerb intensivieren. Die Versicherer hätten vor allem ein größeres Interesse, die Prämiensteigerungen im Alter zu begrenzen. Im Wettbewerb würden sich die effizientesten Versicherer durchsetzen, die langfristig die günstigsten Prämien bei einem attraktiven Leistungskatalog anbieten. Ohne Übertragbarkeit können sich hingegen Versicherer mit zu geringen Alterungsrückstellungen und damit heute niedrigeren Prämien einen Wettbewerbsvorteil verschaffen (Zeitinkonsistenzproblem). ${ }^{822}$

Die Übertragbarkeit von Alterungsrückstellungen wird deshalb in der Literatur intensiv diskutiert. ${ }^{823} \mathrm{Da}$ die Alterungsrückstellungen nicht individuell, sondern für ein Kol-

${ }^{819}$ Eigene Berechnungen; vgl. Verband der privaten Krankenversicherung e.V. (Hrsg.) (2005), S. 11, $24,34,37,39$.

${ }^{820} \mathrm{Vgl}$. Kommission zur Reform des Versicherungsvertragsrechts (2004), S. 143; SVR (2002),

Ziff. 527ff.; SVR (1996), Kasten 8; Meyer, U. (2001), S. 10f.; Pimpertz, J. (2001), S. 168f.; Expertenkommission (1996), S. $42 f$.

${ }^{821} \mathrm{Vgl}$. Kronberger Kreis (2002), S. 43, 47f.

${ }^{822}$ Vgl. SVR (1996), Kasten 8; Expertenkommission (1996), S. 42f.; Meyer, U. (2001), S. $19 f f$.

${ }^{823}$ Einen Überblick geben Kommission zur Reform des Versicherungsvertragsrechts (2004), S. 144ff.; Meier, V. u.a. (2004), S. $21 \mathrm{ff}$. 
lektiv gebildet werden, wäre es technisch am einfachsten, bei einem Wechsel die durchschnittlichen kalkulatorischen Alterungsrückstellungen mitzugeben. Dann wäre jedoch nur für gute Risiken der Wechsel vorteilhaft. Gute Risiken könnten nach einem Wechsel niedrigere Prämien erwarten, weil ihre Alterungsrückstellungen über den enwarteten Ausgaben lägen. Schlechte Risiken müssten hingegen mit höheren Prämien rechnen. Im Ergebnis würden überwiegend gute Risiken wechseln. Es käme zu Risikoselektion und Risikoentmischung. ${ }^{824}$ Dies könnte nur verhindert werden, wenn auch die PKV einem Kontrahierungszwang für einen gesetzlich vorgeschriebenen Leistungskatalog unterliegen würde. Gleichzeitig müssten dann auch die Risikozuschläge begrenzt werden, weil ansonsten ebenfalls nur gute Risiken wechseln würden. Die Abkehr von risikoäquivalenten Prämien verlangt aber einen Risikoausgleich, um Versicherungen mit ungünstiger Versichertenstruktur im Wettbewerb nicht zu benachteiligen. Bei unterschiedlichen Leistungskatalogen würden jedoch die Versicherer mit begrenztem Leistungskatalog Ausgaben von Versicherungen mit umfangreicheren Leistungen teilweise mittinanzieren. Finanzausgleich und Kontrahierungszwang setzen deshalb einen einheitlichen Leistungskatalog voraus, was allerdings den Leistungswettbewerb einschränkt. ${ }^{825}$ Die Alternative wäre, auch den Finanzausgleich auf den Basiskatalog zu beschränken. Wahlleistungen wären dann aber vom Ausgleich ausgenommen, so dass es in diesem Bereich wieder zu Risikoselektion käme.

Insbesondere Meyer, der Kronberger Kreis und die Rürup-Kommission ${ }^{826}$ schlagen deshalb vor, individuelle prospektive Alterungsrückstellungen beim Wechsel zu übertragen. Berechnet wird die individuelle Alterungsrückstellung als Differenz aus dem Barwert der erwarteten Versicherungsleistungen und dem Barwert der enwarteten künftigen Prämien. Vorausgesetzt die Alterungsrückstellungen sind für das jeweilige Kollektiv richtig ermittelt, verändert sich die Summe der Alterungsrückstellungen durch die individuelle Zurechnung nicht. Versicherten, deren Gesundheitszustand zum Zeitpunkt des Wechsels schlechter (besser) als der durchschnittliche Gesundheitszustand ist, wird eine entsprechend höhere (niedrigere) Alterungsrückstellung mitgegeben. Die abgebende Versicherung verliert bei dem Wechsel eines schlechten Risikos zwar überdurchschnittlich hohe Alterungsrückstellungen, in gleichem Maße sinkt aber in Folgeperioden die erwartete Belastung aus der Differenz von Ausgaben und Prämieneinnahmen. Umgekehrt steigen bei der aufnehmenden Versicherung die enwarteten Leistungsausgaben, wofür die Versicherung aber entsprechend hohe Alterungsrückstellungen erhält. Weder für das aufnehmende noch für das abgebende Unternehmen sind mit dem Wechsel ökonomische Nachteile verbunden. Für die Versicherten besteht kein Anreiz mehr, die Versicherung zu wechseln, nur weil sie gute Risiken sind; denn die Alterungsrückstellung wäre bei einem Wechsel entsprechend niedrig. Schlechte Risiken erhalten durch die Mitgabe individueller Alterungsrückstellungen die Möglichkeit zum Versicherungswechsel. Indem die Höhe

\footnotetext{
${ }^{824}$ Vgl. Expertenkommission (1996), S. 43; Meyer, U. (2001), S. 13f.; SVR (2002), Ziff. 529; Kronberger Kreis (2002), S. 47ff.; Rürup-Kommission (2003), Kasten 4-4; Meier, V. u.a. (2004), S. 21ff.; Kommission zur Reform des Versicherungsvertragsrechts (2004), S. $147 \mathrm{f}$.

${ }^{825}$ Vgl. Expertenkommission (1996), S. 44; Wasem, J. (1996), S. 154f.; Meier, V. u.a. (2004), S. 23 .

${ }^{826}$ Siehe Meyer, U. (2001), S. 14ff.; Kronberger Kreis (2002), S. 49ff.; Rürup-Kommission (2003), Kasten 4-4. 
der Alterungsrückstellung unterschiedliche Risiken neutralisiert, wird aktive und passive Risikoselektion vermieden. Leistungsangebot und Prämie entscheiden über einen Wechsel.

Den Versicherungswechsel und damit den Wettbewerb behindern könnten Informationsasymmetrien zwischen abgebender und aufnehmender Versicherung. Die Versicherungen müssen deshalb über die gleichen Informationen verfügen und der alte Versicherer verpflichtet werden, dem neuen Versicherer seine Versichertendaten zur Verfügung zu stellen. Dennoch können die Versicherer aufgrund abweichender Kalkulationen zu unterschiedlichen Ergebnissen kommen. Hinzu kommen gegenläufige Anreize: Der aufnehmende Versicherer wird versuchen, eine möglichst hohe Alterungsrückstellung $\mathrm{zu}$ verlangen, der abgebende hingegen versuchen, sie möglichst gering zu halten. Gleichzeitig sind die Versicherer aber am Wechsel interessiert. Die Unternehmen haben deshalb keinen Anreiz, die Alterungsrückstellungen falsch auszuweisen.

Setzt ein Versicherer für ein gutes Risiko die Alterungsrückstellung zu gering an, um den Versicherten im Bestand zu halten, dann ist das erwartete künftige Defizit aus Ausgaben und Prämien für diesen Versicherten größer, als inn die Mitgabe der Alterungsrückstellung kostet. Der Verbleib des guten Risikos ist für den Versicherer nicht vorteilhaft. Solange die Alterungsrückstellung noch unter dem tatsächlich erwarteten künftigen negativen Deckungsbeitrag liegt, profitiert der Versicherer von der Mitgabe einer höheren Rückstellung, wenn es dadurch zum Wechsel kommt. Die potentielle neue Versicherung wird aber erst zur Aufnahme des Versicherten bereit sein, wenn die Alterungsrückstellung zumindest dem erwarteten Ausgabenüberschuss entspricht. Vorausgesetzt die Summe der Alterungsrückstellungen ist richtig ermittelt und entspricht der Summe der individuellen Alterungsrückstellungen, dann sind, wenn die individuellen Alterungsrückstellungen für gute Risiken zu niedrig angesetzt sind, die für schlechte Risiken zu hoch. Beim Wechsel eines schlechten Risikos gibt der Versicherer einen größeren Betrag an Alterungsrückstellung mit, als er erwartet, dass die künftigen Ausgaben die Prämien übersteigen. Werden hingegen guten Risiken zu hohe Alterungsrückstellungen mitgegeben, wird der Versicherer gute Risiken verlieren, weil er einen größeren Betrag mitgibt, als die erwarteten Ausgaben die Prämien übersteigen. Umgekehrt behält er schlechte Risiken, wenn deren Alterungsrückstellungen geringer sind als das erwartete Defizit zwischen Ausgaben und Prämien. Für den Versicherer sind beide Fälle mit einem Verlust verbunden. Die Unternehmen haben deshalb im Wettbewerb einen Anreiz, die Alterungsrückstellungen richtig zu ermitteln. ${ }^{827}$ Bei Streitfragen zwischen den Versicherern bezüglich der Höhe der mitzugebenden Alterungsrückstellung könnte ein unabhängiger Gutachter entscheiden. ${ }^{828}$

Entscheidend ist, dass die Summe der Alterungsrückstellungen richtig ermittelt wird, Versicherer könnten sonst versuchen, für schlechte Risiken die Alterungsrückstellungen richtig zu bemessen, für gute Risiken jedoch zu gering anzusetzen. Deshalb müssen die Versicherer verpflichtet werden, für Versicherte gleichen Krankheits-

\footnotetext{
${ }^{827}$ Vgl. Kronberger Kreis (2002), S. $51 f$.

${ }^{828} \mathrm{Vgl}$. Rürup-Kommission (2003), Kasten 4-4. Der Rechtsweg muss dabei aber offen bleiben; vgl.

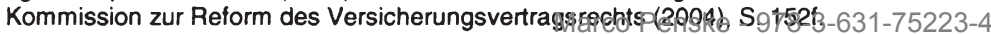


risikos bei Aufnahme und bei Abgabe die gleichen individuellen Alterungsrückstellungen zu veranschlagen. ${ }^{829}$ In Zusammenhang mit Kontrahierungszwang haben die Versicherer dann einen Anreiz, auch für gute Risiken die Prämien richtig zu ermitteln. Ansonsten wären Sie gezwungen, vermeintlich gute Risiken aufzunehmen, deren Alterungsrückstellung unter dem erwarteten Defizit aus künftigen Ausgaben und Prämien liegt. Kontrahierungszwang sorgt auch dafür, dass schlechte Risiken den Versicherer wechseln können. Aufgrund großer Unsicherheit über die Kostenentwicklung bei schlechten Risiken könnten sonst Versicherer geneigt sein, trotz überdurchschnittlicher Alterungsrückstellungen die Aufnahme schlechter Risiken zu verweigern. Ein Finanzausgleich zwischen den Kassen ist bei der Übertragung von individuellen Alterungsrückstellungen nicht notwendig. ${ }^{830}$

Eingewendet wird auch, bei guten Risiken könnten die erwarteten Prämien die erwarteten Ausgaben übersteigen, so dass sich beim Wechsel eine negative Alterungsrückstellung ergebe, die der Versicherte entweder direkt nachzahlen oder in Form höherer Prämien nach dem Wechsel tragen müsste. Ursächlich hierfür ist jedoch, dass in der PKV auch für gute Risiken ein durchschnittlicher Kostenverlauf unterstellt wird. Eine risikoäquivalente Prämienkalkulation verlangt bei geringerem Risiko aber niedrigere Prämien. Die Alterungsrückstellungen wären dann auch nicht negativ. ${ }^{831}$ Selbst wenn man die bisherige Praxis beibehält, kann man den Wechsel guter Risiken erleichtern, indem auf den Ausgleich negativer Alterungsrückstellungen verzichtet wird. Der Wechsel guter Risiken auch ohne Austrittszahlung stellt schon in der bisherigen Praxis für die PKV kein besonderes Problem dar. Ohnehin werden die Kassen nur bei wenigen, insbesondere jungen und außergewöhnlich gering krankheitsanfälligen Versicherten negative Alterungsrückstellungen ausweisen. ${ }^{832}$

Umgekehrt wird vorgebracht, bei schlechten Risiken mit kurzer Versicherungsdauer könnten die Alterungsrückstellungen deutlich über den bisherigen Prämien des Versicherten liegen. ${ }^{833}$ Dies ist aber für Versicherungen nicht unüblich. Gerade in Risikoversicherungen liegt bei frühem Schadenseintritt die Versicherungsleistung um ein Vielfaches über den gezahlten Prämien.

Bemängelt wird auch ein durch die Übertragbarkeit verursachter Prämienanstieg. Bei übertragbaren Alterungsrückstellungen können die Versicherer die Stornoquote nicht mehr prämienmindernd berücksichtigen, so dass abhängig vom Eintrittsalter mit einem durchschnittlichen Prämienanstieg von 10 bis $20 \%{ }^{834}$ gerechnet wird. Insgesamt müssen die Prämien jedoch nicht steigen, da zugunsten von Wechslern, deren Versicherungsprämien bei übertragbaren Alterungsrückstellungen in der aufnehmenden Kasse geringer sind als im Status quo, umverteilt wird. Steigen können die Transaktionskosten durch zusätzliche Risikobewertungen. Höhere Abschlusskosten vor allem aufgrund von Provisionen sind vermeidbar, wenn die Provisionshöhe an die

\footnotetext{
${ }^{829}$ Dies fordert auch die Rürup-Kommission (2003), Kasten 4-4.

${ }^{830}$ Vgl. Pimpertz, J. (2001), S. 168f.; Kronberger Kreis (2002), S. 71f. Kontrovers hierzu Wasem, J. (1996), S. 156.

${ }^{831}$ Vgl. Meier, V. u.a. (2004), S. $31 f$.

${ }^{832} \mathrm{Vgl}$. Kronberger Kreis (2002), S. 551.

${ }^{833} \mathrm{Vgl}$. Kommission zur Reform des Versicherungsvertragsrechts (2004), S. 150.

${ }^{834}$ Siehe Rürup-Kommission (2003), Kasten 4-4. Marco Penske - 978-3-631-75223-4
} 
Vertragsdauer angepasst wird. ${ }^{835}$ Künftige Prämiensteigerungen können jedoch Versicherte mit erhöhtem Krankheitsrisiko nach einem Versicherungswechsel stärker belasten, weil für diese Versicherten nach dem Wechsel die Prämie nicht nur - wie vor dem Wechsel - auf Grundlage des Normalbeitrags, sondern auch auf Basis des neu ermittelten und höheren Risikozuschlag angepasst wird. Den Versicherten kann nur die zum Zeitpunkt des Wechsels ermittelte Alterungsrückstellung mitgegeben werden, so dass der abgebende Versicherer zwar die Einstufungskorrektur finanziert, anschließend müssen die Versicherten aber die auf den neuen Risikozuschlag erhobenen Prämiensteigerungen selbst tragen. Schlechte Risiken könnten deshalb keinen Anreiz zum Versicherungswechsel haben. Dann käme es wie bei der Übertragung durchschnittlicher Alterungsrückstellungen zu adverser Selektion. ${ }^{836}$ Die Mitgabe individueller Alterungsrückstellungen ermöglicht aber gerade allen Versicherten einen Versicherungswechsel. Ist für die Versicherten mit verschlechtertem Gesundheitszustand ein stärkerer Anstieg der Prämie nach dem Versicherungswechsel absehbar und wechseln deshalb vorwiegend gute Risiken den Versicherer, müssen diesem Nachteil die aus einer Zunahme des Wettbewerbs um Bestandskunden resultierenden positiven Wirkungen gegenübergestellt werden. Diese dürften auch den Prämienanstieg dämpfen; denn zu einem Wechsel kommt es nur, wenn die Prämie beim neuen Versicherer deutlich unter der alten Prämie liegt.

Die Expertenkommission, Wasem, die Kommission zur Reform des Versicherungsvertragsrechts und Milbrodt ${ }^{837}$ sehen erhebliche Schwierigkeiten bei der Berechnung individueller Alterungsrückstellungen. Auf der Ausgabenseite seien vor allem bei Multimorbidität die erwarteten Kosten kaum abschätzbar. Zudem müssten spezielle Kostensteigerungen zutreffend ermittelt werden und in die Kalkulation einfließen, um auch schlechten Risiken den Versicherungswechsel zu ermöglichen. Auf der Einnahmenseite ist der Barwert der individuellen Prämieneinnahmen zu schätzen. Dazu müssen künftige Prämienerhöhungen richtig berücksichtigt werden und zudem die individuelle Restlebenswahrscheinlichkeit bestimmt werden. Meier u.a. und inzwischen auch der Sachverständigenrat zur Begutachtung der gesamtwirtschaftlichen Entwicklung ${ }^{838}$ halten diese Probleme aber für lösbar. Die Abschätzung von Risiken unter unvollständiger Information gehört zu den Kernaufgaben einer Versicherung. Schon heute bestimmen die Versicherer den individuellen Gesundheitszustand, um Risikozuschläge festzustellen. Zudem wird die PKV die Forschungsergebnisse ${ }^{839}$ für den morbiditätsorientierten RSA nutzen können, der ab 2007 in der GKV gelten soll. Gemäß $\S 178 f$ Versicherungsvertragsgesetz werden bei einem Wechsel in einen anderen Tarif beim gleichen privaten Versicherer bereits durchschnittliche Alterungsrückstellungen übertragen, was allerdings zu Risikoselektion zwischen den Tarifen führen kann. In diesem Zusammenhang gibt es Hinweise, dass auch Vertreter der

\footnotetext{
${ }^{835} \mathrm{Vgl}$. Expertenkommission (1996), S. 43; Meier, V. u.a. (2004), S. $24 \mathrm{f}$.

${ }^{836}$ Vgl. Milbrodt, H. (2005), S. 34 f.

${ }^{837}$ Siehe Expertenkommission (1996), S. 45ff.; Wasem, J. (1996), S. 155f.; Kommission zur Reform des Versicherungsvertragsrechts (2004), S. 150; Milbrodt, H. (2005), S. 34.

${ }^{838}$ Siehe hierzu und im Folgenden Meier, V. u.a. (2004), S. 29ff.; SVR (2002), Ziff. 529f.; SVR (2004), Ziff. 536. Im Jahresgutachten 1996/97 überwogen für den SVR (1996), Ziff. 443, noch die praktischen Schwierigkeiten. Meier, V. u.a. (2004), S. 56, 304, sehen als Hauptproblem, den aktuellen Gesundheitszustand kostengünstig und gerichtsfest zu bestimmen.
}

${ }^{839}$ Siehe z.B. Reschke, P. u.a. (2004), S. 49ff. Marco Penske - 978-3-631-75223-4 
PKV entgegen anders lautender öffentlicher Bekundungen die Ermittlung individueller Alterungsrückstellungen für möglich halten. ${ }^{840}$ Auch nach dem Koalitionsvertrag $^{841}$ zwischen CDU, CSU und SPD sollen individuelle Alterungsrückstellungen in Zukunft übertragen werden können.

Ein jüngerer Vorschlag der PKV $\mathrm{PH}^{842}$ sieht vor, dass Neuversicherte mit einem standardisierten Basisschutz in der PKV beim Wechsel des Versicherers keiner erneuten Gesundheitsprüfung unterliegen sollen und durchschnittliche Alterungsrückstellungen mitnehmen können. Nach dem Willen der PKV sollen alle freiwillig in der GKV-Versicherten bis zum 55. Lebensjahr in diesen Basistarif wechseln können, bei Älteren wird diese Möglichkeit auf einen Übergangszeitraum von einem Jahr begrenzt. Für den Basisschutz sind Kontrahierungszwang und ein Poolausgleich vorgesehen. Der Finanzausgleich ist jedoch mit den aus dem Risikostrukturausgleich in der GKV bekannten Problemen verbunden: Ein Ausgabenausgleich vermeidet Risikoselektion, reduziert aber Wirtschaftlichkeitsanreize. Werden hingegen Unterschiede in der Versichertenstruktur anhand von durchschnittlichen Ausgaben ausgeglichen, bleiben zwar Anreize zur Kostenersparnis bestehen, die Versicherer profitieren aber von Risikoselektion.

Bestandsversicherte sollen dem PKV-Angebot zufolge bei einem Wechsel den gesetzlichen Beitragszuschlag von $10 \%$ mitnehmen können. Damit würde aber nur ein Teil der Alterungsrückstellungen übertragen werden. Im Jahr 2004 wurden bei Beitragseinnahmen der PKV in Höhe von insgesamt 26,4 Mrd. Euro 8,7 Mrd. Euro $(33,0 \%)$ der Alterungsrückstellung zugeführt. ${ }^{843}$ Die Versicherten würden also bei einem Wechsel weiter einen großen Teil ihrer Alterungsrückstellungen verlieren. Ein zunehmender Wettbewerb um Bestandskunden ist nicht zu erwarten. Die Vorschläge der PKV reichen daher nicht aus.

Die Übertragbarkeit von Alterungsrückstellungen ist die wesentliche Voraussetzung für ein wettbewerbsorientiertes kapitalgedecktes Krankenversicherungssystem. Die Umsetzung ist zwar mit praktischen Problemen verbunden, kann aber insbesondere von der PKV erreicht werden. Bislang hat die PKV aus verständlichen Gründen kein Interesse an übertragbaren Alterungsrückstellungen. Ist die Übertragbarkeit unter den genannten Rahmenbedingungen gesetzlich vorgeschrieben ${ }^{844}$, haben die Versicherer bei individuellen prospektiven Alterungsrückstellungen auch einen Anreiz, die individuellen Rückstellungen hinreichend genau zu ermitteln. ${ }^{845}$ Auf Erfahrungen aus dem Ausland kann dabei allerdings nicht zurückgegriffen werden. Weil ein substitutives privates Krankenversicherungssystem neben dem staatlichen Gesundheitssystem dort nicht üblich ist, werden im Ausland keine Alterungsrückstellungen in nennenswertem Umfang gebildet. In Ländern, in denen private Versicherungsver-

\footnotetext{
${ }^{840}$ Vgl. Meyer, U. (2001), S. $16 f$.

${ }^{841}$ Siehe Christlich Demokratische Union Deutschlands; Christlich-Soziale Union in Bayern; Sozialdemokratische Partei Deutschlands (Hrsg.) (2005), S. 88.

${ }^{842}$ Siehe Schulte, R. (2004), S. 8ff.; O.V. (2004d), S. 51f.; auch Boetius, J. (1999), S. 21f. Für andere Ansätze siehe Meier, V. u.a. (2004), S. 32ff.

${ }^{843}$ Siehe Verband der privaten Krankenversicherung e.V. (Hrsg.) (2005), S. 47.

${ }^{844}$ Zu verfassungsrechtlichen Problemen siehe Meier, V. u.a. (2004), S. 68ff.; SVR (2002), Ziff. 530.

${ }^{845} \mathrm{Vgl}$. Kronberger Kreis (2002), S. 59.

Marco Penske - 978-3-631-75223-4
} 
träge eine Rolle spielen (insbesondere in den USA und Australien) dominieren Gruppenverträge oder werden - wie in den Niederlanden - ältere Versicherte in ein subventioniertes Versicherungssystem überführt, so dass keine Alterungsrückstellungen im privaten System notwendig sind. Das Problem der Übertragbarkeit der Alterungsrückstellungen stellt sich vor allem noch in Österreich und der Schweiz und ist dort analog zu Deutschland geregelt, betrifft aber ein deutlich kleineres Marktsegment. ${ }^{846}$

\section{Interne Kapitaldeckung}

\subsection{Teilweise kapitalgedeckte Finanzierungssysteme}

\subsubsection{Systemkonforme Ergänzung: Demographiereserve}

Eine Möglichkeit, kapitalgedeckte Elemente in das Umlageverfahren zu integrieren, bietet der in der Literatur vor allem von Casse ${ }^{847}$ vertretene Vorschlag, eine solidarische Alterungsreserve aufzubauen. Demnach sind die Beiträge weiter einkommensbezogen, die Beitragssätze werden aber um kasseneinheitliche Beitragssatzaufschläge erhöht. Aus den Mehreinnahmen wird ein kollektiver Kapitalstock aufgebaut, der am Kapitalmarkt verzinslich angelegt und in Zukunft zur Stabilisierung der Beitragssätze eingesetzt wird.

\section{Abbildung 35: Beitragssatzentwicklung mit und ohne Demographiereserve}

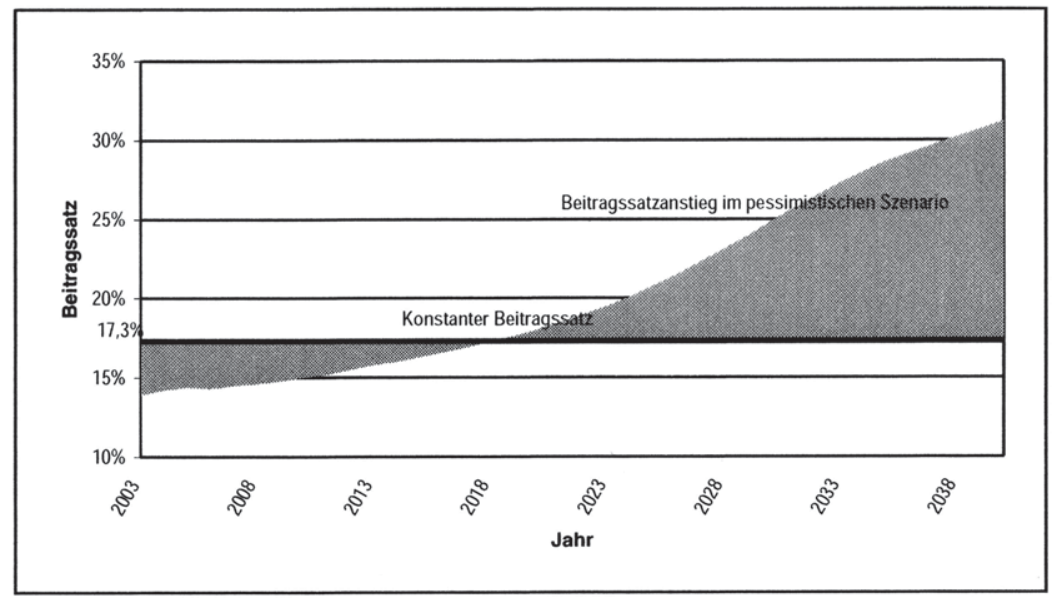

Quelle: In Anlehnung an Cassel, D.; Oberdieck, V. (2002), S. 19; Cassel, D. (2003), S. $252 f$.

\footnotetext{
${ }^{846} \mathrm{Vgl}$. ausführlich Meier, V. u.a. (2004), S. $75 \mathrm{ff}$.

${ }^{847}$ Siehe Cassel, D. (2003), S. 250ff.; Cassel, D.; Oberdieck, V. (2002), S. 16ff. Vgl. auch Schulen-

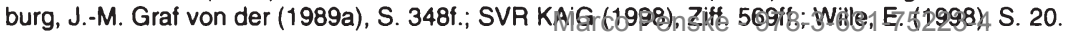


In einem pessimistischen Szenario von Oberdieck ${ }^{848}$ steigt der Beitragssatz in der GKV bis zum Jahr 2040 auf $31,2 \%$. Modellrechnungen ${ }^{849}$ zufolge könnte durch einen Aufschlag von 3,4 Beitragssatzpunkten auf einen Beitragssatz von 13,9\% im Jahr 2003 bei einer Kapitalrendite von $4 \%$ der Beitragssatz bis zum Jahr 2040 konstant auf $17,3 \%$ gehalten werden. Wie Abbildung 35 zeigt, liegt der Beitragssatz bis zum Jahr 2017 über dem ausgabendeckenden Niveau ohne Demographiereserve. Aus der Differenz wird der Kapitalstock aufgebaut. Aufgrund der Verzinsung steigt der Kapitalstock noch bis zum Jahr 2027 auf sein Maximum von 724,1 Mrd. Euro, ehe er bis zum Jahr 2040 auf einen Restkapitalstock von 25,1 Mrd. Euro abgebaut ist.

In einem optimistischeren Szenario von $\mathrm{Hof}^{850}$ steigt der Beitragssatz von $14,5 \%$ (2003) bis zum Jahr 2040 auf 20,5\%. Dann ist ein Aufschlag von 1,4 Prozentpunkten ausreichend, um den Beitragssatz bis 2040 auf $15,9 \%$ zu stabilisieren. Dem Kapitalstock fließen bis 2015 Mittel zu, durch Zinsen wächst er noch bis zum Jahr 2027 auf insgesamt 259 Mrd. Euro. Anschließend wird dieser Kapitalstock aus Beiträgen und Zinsen bis zum Jahr 2040 auf 57,3 Mrd. Euro abgebaut. Nach einer weiteren Simulationsrechnung von Casse ${ }^{851}$ hätte der Beitragssatz bis zum Jahr 2050 auf 17,8 \% anstelle eines Anstiegs auf $39,5 \%$ - stabilisiert werden können, wenn ab dem Jahr 2000 ein Beitragssatzaufschlag von 4,2 Prozentpunkten erhoben worden wäre.

Möglich ist es auch, den Kapitalstock nicht vollständig zu verzehren, sondern begrenzte Beitragssatzsteigerungen zuzulassen. Der Beitragssatz kann dann dauerhaft unter dem ausgabendeckenden Niveau liegen. Zudem wird ein sprunghafter Anstieg des Beitragssatzes, wenn der Kapitalstock aufgebraucht ist, vermieden. ${ }^{852}$

Wie die Berechnungen zeigen, sind die Beitragssatzaufschläge moderat in Anbetracht des ansonsten bevorstehenden Beitragssatzanstiegs. In dem Maße, in dem der Kapitalstock höher verzinst wird, reichen auch geringere Beitragssatzaufschläge aus. Im Vergleich zur PKV ist die angenommene Kapitalrendite mit $4 \%$ relativ niedrig angesetzt. Die PKV erzielte zwischen 1990 und 2004 eine nominale Nettoverzinsung zwischen $4,5 \%$ und 7,8\%, im Durchschnitt lag die Nettoverzinsung in diesem Zeitraum bei $6,8 \%{ }^{853}$

Bei einer Pool-Lösung, d.h. der Kapitalstock wird kassenübergreifend aufgebaut, stellt sich nicht das Problem der Portabilität von Alterungsrückstellungen wie bei risikoäquivalenten Prämien. Der Kassenwechsel wird nicht erschwert. ${ }^{854}$ Cassel und Oberdieck ${ }^{855}$ schlagen vor, die Rückstellungen später über mehrere Perioden hinweg nach der Zahl der jeweils versicherten Rentner an die Kassen auszuschütten. Bei pauschalen Entlastungszahlungen je Rentner würden aber Kassen mit jüngeren Rentnern im Vergleich zu Kassen mit älteren und ausgabenintensiveren Rentnern

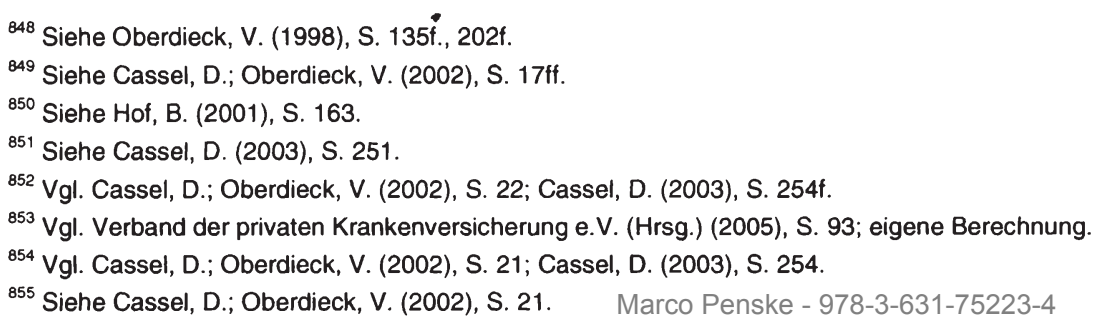


stärker entlastet werden und einen ungerechtfertigten Wettbewerbsvorteil erlangen. Systemkonform wäre es daher, die Alterungsrückstellungen über den RSA zu verteilen. Entsprechend würde der Ausgleichsbedarfssatz im RSA für alle Kassen sinken. ${ }^{856}$ Dies würde Wettbewerbsverzerrungen infolge des Abbaus der Demographiereserve vermeiden.

Mit einer Demographiereserve können kapitalgedeckte Elemente in das derzeitige Finanzierungssystem oder in eine Bürgerversicherung implementiert werden, um die Abhängigkeit von der demographischen Entwicklung zu reduzieren. Dabei handelt es sich um ein systemkonformes Modell, das im Vergleich zu risikoäquivalenten Prämien oder teilkapitalgedeckten Kopfpauschalen wahrscheinlich leichter umsetzbar ist. Problematisch sind allerdings die mit der einkommensbezogenen Beitragsbemessung verbundenen allokativen und distributiven Mängel. ${ }^{857}$

\subsubsection{Systemumstellung: Teilkapitalgedeckte Kopfpauschalen}

Die Umstellung der Finanzierung auf teilkapitalgedeckte Kopfpauschalen mit Kontrahierungszwang wird u.a. vom Sachverständigenrat zur Begutachtung der gesamtwirtschaftlichen Entwicklung und vom Wissenschaftlichen Beirat beim Bundesministerium der Finanzen ${ }^{858}$ vorgeschlagen. Die Erfahrungen aus der Schweiz zeigen jedoch, dass auch bei einer Umstellung auf Kopfpauschalen die Beiträge weiter steigen. ${ }^{859}$

\section{Abbildung 36: Entwicklung der Bürgerpauschale}

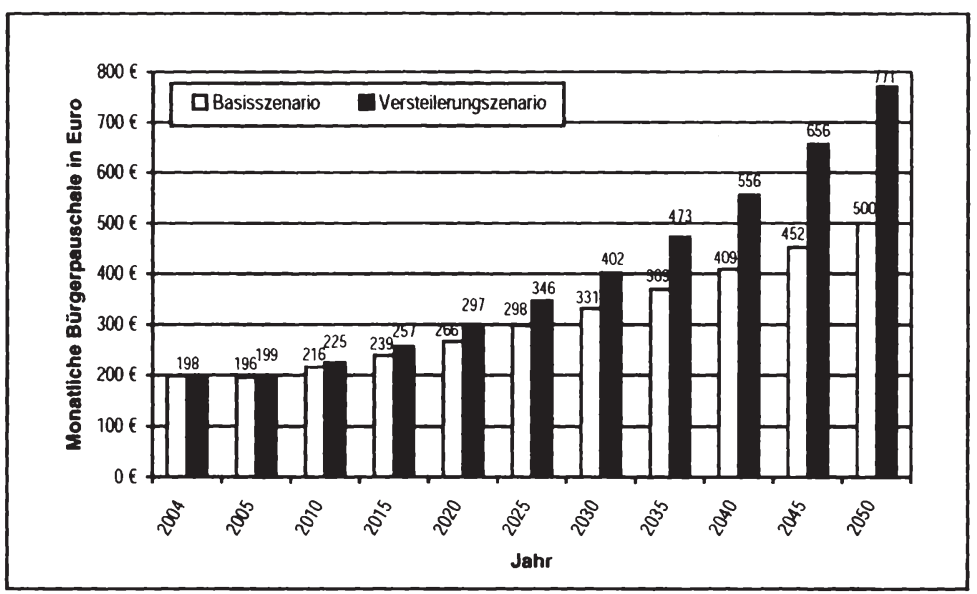

Daten: SVR (2004), Tabelle 84.

\footnotetext{
${ }^{856}$ Siehe hierzu Felder, S. (2003), S. $61 \mathrm{ff}$.

${ }^{857}$ Siehe Kapitel II.4 Problematik, S. 33.

${ }^{858}$ Siehe SVR (2004), Ziff. 511ff.; Wissenschaftlicher Beirat beim Bundesministerium der Finanzen (2004), S. 26ff. Vgl. hierzu auch Enquete-Kommission Demographischer Wandel (2002), S. 215; Initiative mehr Gesundheit (Hrsg.) (2004), S. 2ff.

${ }^{859}$ Vgl. SVR (2000), Kasten 7; Lauterbach, K.W. u.a. (2R9p4b). S. 9P3.- 978-3-631-75223-4
} 
Die Entwicklung der Bürgerpauschale im demographischen Wandel gemäß der Bevölkerungsvorausberechnung des Statistischen Bundesamtes wird in Abbildung 36 dargestellt. Im Basisszenario, in dem die bisherige Entwicklung von Ausgaben und Einnahmen fortgeschrieben wird, steigt die monatliche (reale) Kopfpauschale von 198 Euro im Jahr 2004 bis zum Jahr 2050 auf 500 Euro. Wird unterstellt, dass die Ausgaben für Ältere stärker wachsen als für Jüngere, steigt die Kopfpauschale im Versteilerungsszenario bis 2050 sogar auf monatlich 771 Euro in heutigen Preisen. ${ }^{860}$ Zur "Untertunnelung" des Beitragsanstiegs kann wie bei der Demographiereserve auch bei einer Kopfpauschale zeitweise ein höherer Beitrag, als zur Deckung der laufenden Ausgaben erforderlich ist, erhoben werden.

Tabelle 23: Bürgerpauschale bei Bildung eines individuellen Kapitalstocks

\begin{tabular}{|c|r|r|r|r|}
\hline \multirow{2}{*}{$\begin{array}{c}\text { Eintritts- } \\
\text { alter }\end{array}$} & \multicolumn{2}{|c|}{ Mann } & \multicolumn{2}{|c|}{ Frau } \\
\hline 20 & Pauschale & davon Sparanteil & Pauschale & davon Sparanteil \\
\hline 30 & $224 €$ & $26 €$ & $227 €$ & $29 €$ \\
\hline 40 & $220 €$ & $22 €$ & $223 €$ & $25 €$ \\
\hline 50 & $214 €$ & $16 €$ & $218 €$ & $20 €$ \\
\hline 60 & $208 €$ & $10 €$ & $211 €$ & $13 €$ \\
\hline 70 & $203 €$ & $5 €$ & $206 €$ & $8 €$ \\
\hline
\end{tabular}

Daten: SVR (2004), Tabelle 85.

Lässt man einen jährlichen Anstieg der Bürgerpauschale um nominal $3 \%$ zu, dann müsste der Sparanteil bei kollektiver Kapitaldeckung 22 Euro betragen, damit bei einem Wachstum des Durchschnittseinkommens von $3 \%$ p.a. die relative Belastung konstant bleibt. Alle Mitglieder hätten dann zum Zeitpunkt der Umstellung eine Pauschale von 220 Euro zu zahlen. Beim Aufbau eines individuellen Kapitalstocks wäre zur Finanzierung der laufenden Ausgaben ebenfalls eine einheitliche Pauschale von 198 Euro notwendig. Wie Tabelle 23 zeigt, unterscheiden sich aber je nach Eintrittsalter die zu zahlenden Beiträge, weil ältere Versicherte aufgrund ihrer kürzeren erwarteten Restlebensdauer weniger ansparen müssen ${ }^{861} \mathrm{Im}$ Einführungsjahr muss z.B. ein 20jähriger Mann einen Beitrag von 224 Euro und ein 70jähriger 199 Euro zahlen, damit die Beitragszahlung in Relation zum Durchschnittseinkommen konstant bleibt. Für später in die Versicherung Eintretende steigt der Beitrag hingegen. „Die individuelle Kapitalbildung schützt (...) vor einem Anstieg des individuellen Belastungspfads, aber nicht vor einer Niveauverschiebung des Pfads selbst, bei Betrachtung verschiedener Alterskohorten. “862

Die mit einer lohnabhängigen Beitragsbemessung verbundenen Probleme werden mit der Bürgerpauschale umgangen und künftige Beitragssteigerungen aufgrund der demographischen Entwicklung mit einem Kapitalstock weitgehend vorfinanziert. Zudem kann die künstliche Trennung des Versicherungsmarktes in GKV und PKV

${ }^{860}$ Vgl. SVR (2004), Ziff. 513. Zu ähnlichen Ergebnissen kommen auch Hof, B.; Schlömer, C. (2005), S. $195 \mathrm{ff}$.

${ }^{861}$ Vgl. SVR (2004), Ziff. $514 f f$.

${ }^{862}$ Ebenda, Ziff. 509. 
aufgehoben werden, ohne auf Kapitaldeckung zu verzichten. In der Literatur wird daher überwiegend eine Versicherungspflicht für die gesamte Bevölkerung vorgeschlagen. ${ }^{863}$ Soll die PKV erhalten bleiben, müssten aber für einen fairen Wettbewerb einheitliche Bedingungen für alle dann privatwirtschaftlich geführten Versicherer gelten und die GKV müsste auf ihre steuerrechtlichen und wettbewerbsrechtlichen Vorteile (z.B. Zwangsrabatte, Kollektivverträge) verzichten. Die derzeitige PKV könnte im Gegensatz zu einer Bürgerversicherung weiter Vollversicherungen anbieten. Bei pauschalen Beiträgen mit Kapitaldeckung befürworten deshalb die privaten Versicherer einen einheitlichen Versicherungsmarkt mit allgemeiner Mindestversicherungspflicht, Kontrahierungszwang und Risikoausgleich eher, was die Umsetzung erleichtert. ${ }^{864}$ Für die PKV wäre damit allerdings die Abkehr von risikoäquivalenten Prämien verbunden.

Kollektive Alterungsrückstellungen können wie im Modell der Demographiereserve kassenübergreifend aufgebaut werden und über den RSA später an die Kassen zurückfließen. Problematisch ist wiederum die politische Entscheidung über den Zeitpunkt, ab dem die Alterungsrückstellungen abgebaut werden sollen, da damit die Höhe der Pauschale maßgeblich beeinflusst wird. Bei individueller interner Kapitaldeckung stellen sich diese Probleme nicht. ${ }^{865}$ Dafür muss aber sichergestellt sein, dass die Alterungsrückstellungen portabel sind, was wesentlich einfacher umsetzbar ist als im derzeitigen PKV-System. In Anbetracht von einheitlichen Beiträgen, Kontrahierungszwang und Finanzausgleich wäre es ausreichend, den tatsächlich vom Versicherten gebildeten Kapitalstock inklusive der angefallenen Zinsen zu übertragen.

Da die Pauschale durch den Sparanteil höher ist als in umlagefinanzierten Systemen, steigt in der Einführungsphase aber der Transferbedarf im Vergleich zu rein umlagefinanzierten Kopfpauschalen. Bei einer Eigenbelastungsgrenze von $13 \%$ des Bruttoeinkommens der Versicherten erhöht sich das Zuschussvolumen von $30 \mathrm{Mrd}$. Euro für den sozialen Ausgleich im Modell ohne Kapitaldeckung auf 38,5 Mrd. Euro bei kollektiven Alterungsrückstellungen oder 34,5 Mrd. Euro bei individueller Kapitaldeckung. Aufgrund der Kapitaldeckung wird der Anstieg der Bürgerpauschale im Zeitverlauf jedoch gebremst, wodurch das künftige Transfervolumen geringer sein wird als ohne Kapitaldeckung. ${ }^{866}$

\subsection{Vollständig kapitalgedeckte Systeme: Risikoäquivalente Prämien}

Der Übergang zum Kapitaldeckungsverfahren mit risikoäquivalenten Prämien nach dem Vorbild der PKV mit übertragbaren, individuellen Alterungsrückstellungen wird von weiten Teilen der Wissenschaft als marktwirtschaftliche Lösung gefordert ${ }^{867}$ Für

\footnotetext{
${ }^{863}$ Vgl. Henke, K.-D. (2001), S. 5f.; SVR (2004), Ziff. 494; Wissenschaftlicher Beirat beim Bundesministerium der Finanzen (2004), S. 27.

${ }^{864} \mathrm{Vgl}$. Henke, K.-D. u.a. (2002), S. 14f.; Rumm, U. (2000), S. 2ff.; Boetius, J. (1999), S. $20 f f$.

${ }^{865}$ Der SVR (2004), Ziff. 516, spricht sich deshalb für individuelle Kapitaldeckung aus.

${ }^{866}$ Vgl. SVR (2004), Ziff. $518 f f$.

${ }^{867}$ Siehe stellvertretend SVR KAiG (1994), Ziff. 503ff.; SVR KAiG (1995), Ziff. 561ff.; SVR KAiG (1998), Ziff. 580ff.; SVR (1996), Ziff. 440ff.; Kronberger Kreis (2002), S. 25ff.; Gerken, L.; Raddatz, G. (2003), S. 10f. Von politischer Seite fordert die FDP den Umstieg auf Kapitaldeckung; siehe Freie Demokratische Partei (Hrsg.) (2004), S. 3ff. Marco Penske - 978-3-631-75223-4
} 
die gesamte Bevölkerung besteht demnach Versicherungspflicht bei einem privaten Versicherungsunternehmen für einen vom Gesetzgeber bestimmten Regelleistungskatalog. Die Prämie ist ein Marktpreis für die Risikoübernahme durch den Versicherer und muss vom Versicherten voll getragen werden. Die beitragsfreie Familienversicherung wird abgeschafft. Versicherte, deren Prämie einen bestimmten Anteil am Bruttoeinkommen übersteigt, erhalten einen staatlich finanzierten Prämienzuschuss. Der bisherige Arbeitgeberanteil wird an die Versicherten ausbezahlt. Steigende Prämien schlagen sich dadurch nicht mehr direkt in den Arbeitskosten nieder. Damit auch schlechte Risiken eine Versicherung finden, gilt für die Versicherer bezüglich des Grundleistungskatalogs Kontrahierungszwang. Für Hochrisiken erhalten die Versicherer die Möglichkeit der Rückversicherung.

Aus distributiver Sicht zu begrüßen ist, dass im Unterschied zum Status quo bis auf die versicherungsimmanente Umverteilung von Versicherten ohne Erkrankung zu Versicherten mit Leistungsinanspruchnahme in der Krankenversicherung keine Umverteilungen mehr stattfinden. Die Umverteilungsaufgaben nimmt das Steuer- und Transfersystem effektiver und effizienter wahr. Zudem wird die künstliche Trennung des Versicherungsmarktes in GKV und PKV aufgehoben, da für alle Bürger eine einheitliche Versicherungspflicht gilt. Die Kassen müssen allerdings private Rechtsformen annehmen und können dann keine hoheitlichen Aufgaben mehr übernehmen. Als Körperschaft des öffentlichen Rechts ist die GKV derzeit neben administrativen Aufgaben z.B. zusammen mit den kassenärztlichen Vereinigungen für die ärztliche Versorgung zuständig und gibt gemeinsam mit dem medizinischen Dienst der Krankenkassen Stellungnahmen als Voraussetzung für die Gewährung bestimmter Leistungen (z.B. Feststellen der Pflegestufe im Rahmen der Pflegeversicherung) ab. Zudem dürtte die kartellrechtliche Stellung der GKV als Sozialversicherungsträger z.B. bei Festbetragsregelungen gemäß $\S \S 35 f$. SGB V nach EU-Recht nicht mehr zulässig sein. Bislang werden die Markteingriffe noch mit dem Vorrang des Sozialrechts vor dem Kartellrecht begründet. ${ }^{868}$

Unter allokativen Aspekten ist positiv zu bewerten, dass Anreize zur Risikoselektion beseitigt werden und somit der Finanzausgleich zwischen den Kassen überflüssig wird, weil die Versichertenstruktur nicht mehr den Beitrag beeinflusst. Aufgrund des vorgesehenen Kontrahierungszwangs für den Grundleistungskatalog sind die Prämien jedoch nicht vollständig risikoäquivalent, wenn die Versicherer nicht die Möglichkeit haben sollen, den Kontrahierungszwang durch hohe Risikozuschläge auf die Prämien zu umgehen. Der effizienzsteigernde Wettbewerb zwischen den Versicherern nimmt bei risikogerechten Versicherungsprämien zu. Die Versicherten erhalten zudem weitere Möglichkeiten, Verträge nach ihren Präferenzen abzuschließen, was der einheitliche Leistungskatalog im Status quo und in den Modellen mit pauschalen Beiträgen verhindert. Damit auch der Wettbewerb um Bestandskunden zum Tragen kommt, müssen allerdings individuelle Alterungsrückstellungen beim Versicherungswechsel übertragen werden, was - wie gezeigt wurde - möglich ist. ${ }^{869}$ Dann sind risikoäquivalente Prämien unter allokativen Gesichtspunkten vorzuziehen: Der Wettbewerb der Versicherer wird intensiviert - stärker als im System mit Kopfpauschalen

\footnotetext{
${ }^{868}$ Siehe hierzu ausführlich Reichert, R. (2004), insbes. S. 184ff.

${ }^{869}$ Siehe hierzu Abschnitt 2.2.3 Übertragbarkeit von Alte/ungsröckstellungeng \$-8 39 -75223-4
} 
oder im Status quo. Zudem wird das Gesundheitssystem unabhängig von Konjunktur und Arbeitsmarkt finanziert. Die negativen Rückwirkungen der GKV-Finanzierung auf Wachstum und Beschäftigung werden vor allem deshalb abgebaut, weil risikoäquivalente Prämien keinen Steuercharakter haben. Die Transaktionskosten sind jedoch höher als bei anderen Formen der Beitragsbemessung, da risikoäquivalente Prämien mit einer kostenintensiven Informationsbeschaffung und Tarifierung verbunden sind. Insbesondere die Abschlusskosten sind deutlich höher. In der PKV entfielen von 3,1 Mrd. Euro Verwaltungskosten im Jahr 2003 2,3 Mrd. Euro auf die Abschlusskosten. Entsprechend betrugen die Verwaltungskosten 2003 in der PKV pro Vollversicherten 376 Euro und in der GKV 162 Euro pro Mitglied, bezogen auf die Beitragseinnahmen entspricht dies 13,3\% bzw. 6,0\%. ${ }^{870}$ Bei diesem Vergleich fehlen allerdings in der GKV die Verwaltungskosten, die bei den kassenärztlichen Vereinigungen für die Vergütung von ambulanten Leistungen anfallen.

Die Einführung risikoäquivalenter Prämien ist indes nicht unproblematisch:

Wie beim Kopfpauschalen-Modell müssten bei risikoäquivalenten Prämien Mittel für den Sozialausgleich außerhalb der Krankenversicherung aufgebracht werden. Bei einer Belastungsgrenze von (angenommen) $15 \%$ des Bruttoeinkommens werden die Ausgaben für den sozialen Ausgleich auf jährlich $35,5 \mathrm{Mrd}^{\text {. Euro }}{ }^{871}$ geschätzt - ohne die aus der Bildung von Alterungsrückstellungen resultierenden Belastungen, auf die noch näher eingegangen wird. ${ }^{872}$ Zudem hätten die Versicherer einen Anreiz, für Versicherte, bei denen absehbar ist, dass sie ihre Prämie nicht selbst zahlen können, eine höhere Prämie festzulegen, um die eigene Gewinnmarge zulasten der öffentlichen Haushalte zu steigern. Diese Missbrauchsanfälligkeit könnte den Finanzbedarf für den Sozialausgleich weiter erhöhen.

Liegt bei einem zu Versichernden bereits von Geburt an eine erhebliche Beeinträchtigung des Gesundheitszustands vor, dann ist die Prämie schwierig zu ermitteln und dürfte die zumutbare Eigenbelastung überschreiten. Vorgeschlagen wird deshalb, Kinder unabhängig von ihrem Gesundheitszustand mit einer Pauschale zu versichern ${ }^{873}$ Solange diese Versicherten in ihrer Versicherung bleiben, zahlen sie dann aber Kopfpauschalen, was gegen die geforderte Risikoäquivalenz verstößt. Entscheiden sich schlechte Risiken später zum Versicherungswechsel, müssen sie mit risikoäquivalenten und damit deutlich höheren Prämien rechnen, so dass in diesem Teilbereich der Wechsel erschwert wird. Bereits heute wechseln aber auch zwischen den gesetzlichen Kassen überwiegend gute Risiken. Außerdem könnte eine Poollösung bei Versicherten mit extremen gesundheitlichen Beeinträchtigungen die Prämien begrenzen. Bei chronisch Kranken sind bestimmte Krankheitskosten keine stochastische Größe, sondern sichere Ausgaben, so dass es ansonsten zu Leistungsausschlüssen oder zu für die Versicherten unbezahlbaren Prämien käme.

\footnotetext{
${ }^{870}$ Eigene Berechnungen; vgl. Verband der privaten Krankenversicherung e.V. (Hrsg.) (2005), S. 11 , 24, 43; BMGS (Hrsg.) (2004a), S. 121, 130, 140. Siehe auch Bundestags-Drucksache 15/1859 vom 31.10.2003, S. 29ff.

${ }^{871}$ Siehe Zweifel, P.; Breuer, M. (2002), S. 68. Die Berechnungen basieren auf umlagefinanzierten risikoäquivalenten Prämien.

${ }^{872}$ Siehe Abschnitt 3.3.1 Übergangsproblematik, S. 233.

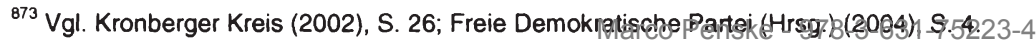


Vor allem kinderreiche Familien werden stärker belastet als im derzeitigen System, weil die beitragsfreie Familienversicherung enttällt. ${ }^{874}$ Die distributiven Effekte entsprechen grundsätzlich den regressiven Verteilungswirkungen bei Einführung einer Kopfpauschale, wobei Ältere und Versicherte mit schlechtem Gesundheitszustand bei risikoäquivalenten Prämien stärker belastet werden. Die Regressionswirkung wird jedoch durch den staatlich finanzierten Sozialausgleich weitgehend kompensiert. ${ }^{875}$ Die Zielgenauigkeit der Umverteilung wäre dann größer als bei dem Modell einer Kopfpauschale und dem Status quo.

Bezüglich der Bildung von Alterungsrückstellungen tritt zu dem Problem der Portabilität das Zeitinkonsistenzproblem. Die Versicherer könnten versuchen, sich mit zu geringen Alterungsrückstellungen einen Wettbewerbsvorteil zu verschaffen, weil die dann im Alter stärker steigenden Prämien die Versicherten erst später belasten. ${ }^{876}$

Im derzeitigen Finanzierungssystem mit einkommensabhängigen Beiträgen und weitgehend gleichem Leistungskatalog sind Gentests für die GKV unbedeutend. Die PKV verzichtet nach einer Selbstverpflichtungserklärung bis 2011 freiwillig auf die Vorlage von Gentests. Wird die gesamte Bevölkerung zu risikoäquivalenten Prämien versichert und gilt Kontrahierungszwang, dürfte das Interesse der Versicherer an Gentests zunehmen, weil die Versicherungen damit die erwarteten Ausgaben genauer schätzen und ihr Risiko minimieren könnten. ${ }^{877}$ Die Entscheidung darüber, ob den Versicherungsunternehmen der Zugriff auf Informationen von Gentests ermöglicht werden soll, führt zu einem Zielkonflikt. Einerseits entsteht für die Versicherten ein Prämienrisiko bis hin zur Unversicherbarkeit, wenn sie verpflichtet werden, Erkenntnisse aus Gentests ihrer Versicherung mitzuteilen. Andererseits könnte es zu adverser Selektion kommen, wenn nur die Versicherten Ergebnisse von Gentests kennen.

Vor allem Versicherte mit hoher Erkrankungswahrscheinlichkeit würden sich umfangreich versichern, weil für sie die zu zahlende Prämie unter dem Erwartungswert der Leistungen läge. Umgekehrt würden Personen, die von einem geringen Erkrankungsrisiko ausgehen, weitgehend auf Versicherungsschutz verzichten, anstatt überhöhte Prämien zu zahlen. Die Versicherung müsste entweder die Prämien für alle Versicherten erhöhen oder mit hohen Selbstbehalten versuchen, schlechte Risiken abzuhalten. Beides führt zu Ineffizienzen. Daraus lässt sich jedoch nicht die Forderung ableiten, Versicherungen sollten bei Vertragsabschluss einen Gentest verlangen dürfen. Adverse Selektion beruht auf Informationsasymmetrie. Wenn Versicherte vorhandene Ergebnisse ihrer Krankenversicherung bekannt geben, haben beide Vertragspartner den gleichen Informationsstand. Zwangstests würden den Versicherten hingegen vermeidbare Risikozuschläge auferlegen und wären ineffizient und wohlfahrtsmindernd. ${ }^{878}$ Der Risikoausgleich zwischen den Versicherten käme zum Erliegen, weil die Versicherung anhand von Gentests die individuell erwarteten Gesund-

\footnotetext{
${ }^{874}$ Vgl. SVR KAiG (1995), Ziff. 562; Kronberger Kreis (2002), S. $36 f$.

${ }^{875} \mathrm{Vgl}$. SVR (2000), Ziff. 477.

${ }^{876} \mathrm{Vgl}$. SVR (2004), Ziff. 540.

${ }^{877} \mathrm{Vgl}$. Kopetsch, T. (2001), S. 26. Eine "gnadenlose Risikoselektion“ ist aber auch bei Gentests nicht zu erwarten. Die Versicherer haben gerade bei risikoäquivalenten Prämien das gleiche Interesse an jedem Versicherten.
}

${ }^{878} \mathrm{Vgl}$. Wambach, A. (2004), S. 165f., $170 \mathrm{f}$. 
heitskosten als Prämie fordern könnte. ${ }^{879}$ Im Endeffekt würde das Behandlungskostenrisiko durch ein Prämienrisiko ersetzt werden. Die Aufgabe einer Versicherung ist es aber gerade, Risiken zu übernehmen und durch Poolen auszugleichen. Gentests stünden zudem dem Recht der Versicherten auf Nichtwissen und informationelle Selbstbestimmung entgegen. Auch aus ethischen Gründen sollte von Versicherten keine höhere Prämie aufgrund des Ergebnisses eines Gentests verlangt werden, da die Versicherten auf ihre Gene keinen Einfluss haben. ${ }^{800}$

Wenn die Versicherung mit der Geburt einsetzt und zu diesem Zeitpunkt keine Erkrankungen vorliegen, entsprechen risikoäquivalente Prämien bei lebenslangen Verträgen Kopfpauschalen. ${ }^{881}$ In einem System mit Kopfpauschalen werden Umverteilungen aufgrund von Merkmalen, die mit der Geburt feststehen (z.B. Geschlecht, Erbkrankheiten), als eine Art Versicherung aufgefasst und sind daher mit dem Äquivalenzprinzip vereinbar. ${ }^{882}$ Auch deshalb spricht sich die Mehrheit des Sachverständigenrates zur Begutachtung der gesamtwirtschaftlichen Entwicklung ${ }^{83}$ in seinem Jahresgutachten 2004/05 gegen risikoäquivalente Prämien aus. Risikoäquivalente Prämien hätten nur dann eine effizienzsteigernde Wirkung, wenn der Versicherte wie in der Kraftfahrzeugversicherung das Risiko und damit die Prämie beeinflussen könnte. Dies sei beim Gesundheitszustand nur begrenzt möglich. Jedoch ist auch das Gesundheitsrisiko durch z.B. bewusste Ernährung, Bewegung und die Vermeidung von Risikosportarten durchaus langfristig beeinflussbar. Niedrigere Prämien können entsprechende Anreize für die Versicherten setzen. Aber auch über die Angebotsseite sind risikoäquivalente Prämien durch die Intensivierung des Wettbewerbs effizienzsteigernd, weil auf einen Finanzausgleich zwischen den Kassen verzichtet werden könnte.

\subsection{Bewertung}

\subsection{1 Übergangsproblematik}

Die theoretische Diskussion um einen Pareto-optimalen Übergang vom Umlageverfahren zum Kapitaldeckungsverfahren wurde für die GRV in der Literatur ausführlich geführt. ${ }^{884}$ Umstritten ist dabei vor allem die Frage, ob die mit der Kapitaldeckung verbundenen Effizienzgewinne die Übergangskosten kompensieren können, so dass keine Generation schlechter gestellt wird. Nach Fenge ${ }^{885}$ ist für Systeme mit Teilha-

\footnotetext{
${ }^{879}$ Vgl. Buchholz, W. u.a. (2001), S. 4.

${ }^{880} \mathrm{Vgl}$. SVR (2000), Ziff. 478; Buchholz, W. u.a. (2001), S. 7 f.

${ }^{881} \mathrm{Vgl}$. Enquete-Kommission Demographischer Wandel (2002), S. 214; SVR (2002), Ziff. 525; Raffelhüschen, B.; Hagist, C.; Fetzer, S. (2004), S. 5.

${ }^{862} \mathrm{Vgl}$. Wissenschaftlicher Beirat beim Bundesministerium der Finanzen (2004), S. 10.

${ }^{883}$ Siehe SVR (2004), Ziff. 542. Ein Mitglied plädiert für risikoäquivalente Prämien; siehe ebenda, Ziff. 555. Der SVR hat im Zeitverlauf seine Forderung nach risikoäquivalenten Prämien aus dem Gutachten 1996/97 aufgegeben. Im Jahresgutachten 2000/01 forderte er nur noch nach Alter und Geschlecht differenzierte risikoäquivalente Prämien, im Gutachten 2002/03 wurden risikoäquivalente Prämien dann als eine Alternative neben Kopfpauschalen diskutiert; siehe SVR (1996), Ziff. 440ff.; SVR (2000), Ziff. 475ff.; SVR (2002), Ziff. 524ff.

${ }^{884}$ Siehe stellvertretend Deutsche Bundesbank (Hrsg.) (1999), S. 21f.; Breyer, F. (2000), S. 393H.; Börsch-Supan, A. (2004), S. 74ff.

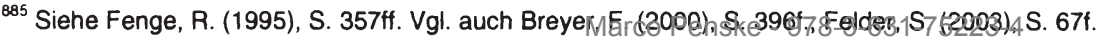


beäquivalenz, d.h. die Versicherungsbeiträge sind weitgehend proportional zu den Leistungen, ein Pareto-optimaler Übergang aufgrund der mit der Kompensation der Übergangsgeneration verbundenen Lasten - sofern die Mittel nicht mit einer weniger verzerrenden Kopfsteuer finanziert werden - nicht möglich. Teilhabeäquivalenz liegt aber wegen der zahlreichen Umverteilungen in der GKV nicht vor. ${ }^{886}$ Felder $^{887}$ zeigt, dass in der GKV ein Pareto-optimaler Systemwechsel unter besonderen Annahmen theoretisch möglich ist. Dazu müsste jedoch die Finanzierung der Übergangskosten das Arbeitsangebot weniger verzerren als die bisherigen Beiträge. Der Wohlfahrtsgewinn beruht dann aber auf der Änderung der Beitragsbemessung und nicht auf einem Umstieg zur Kapitaldeckung.

Kapitalbildung kann die Belastung künftiger Generationen reduzieren und in die Gegenwart verlagern. Die implizite Verschuldung der GKV wird dadurch sichtbar und künftige Generationen werden entlastet. Die Übergangsgeneration wird jedoch doppelt belastet, wenn sie neben ihren Beiträgen zur Finanzierung der laufenden Ausgaben zusätzlich Kapital ansparen muss. Am höchsten ist die Belastung bei einem Übergang auf ein vollständig kapitalgedecktes System mit risikoäquivalenten Prämien. Neben den jährlichen Ausgaben für den sozialen Ausgleich von 35,5 Mrd. Euro ${ }^{888}$ bei einer Belastungsgrenze von $15 \%$ des Bruttoeinkommens müssten bei einem Systemwechsel Alterungsrückstellungen nachfinanziert werden. Werden auf der $\mathrm{Ba}$ sis von Daten aus dem Jahr 2004 die Alterungsrückstellungen der privaten Krankheitsvollversicherung ohne Pflegeversicherung von 9.732 Euro pro Versicherten auf 70,3 Mio. GKV-Versicherte hochgerechnet, ergibt sich ein fehlender Kapitalstock in Höhe von 684 Mrd. Euro. ${ }^{889}$ Der Kronberger Kreis ${ }^{890}$ beziffert den fehlenden Kapitalstock auf 400 Mrd. Euro, berücksichtigt dabei aber offensichtlich nur die GKV-Mitglieder ohne Familienangehörige. Der tatsächlich zu finanzierende Kapitalstock dürfte zwischen den beiden genannten Werten liegen. Genauere Berechnungen liegen auch in den Reformkonzepten bislang nicht vor. ${ }^{891}$

Um die Übergangsbelastung zu reduzieren, kann in Stufen auf Kapitaldeckung umgestellt werden: Zu einem Stichtag wechseln z.B. alle unter 60jährigen in eine kapitalgedeckte Versicherung. Die über 60jährigen bleiben im Umlagesystem und zahlen weiter einkommensabhängige Beiträge. Unter der vereinfachten Annahme, die über $60 j a ̈ h r i g e n$ seien in der KVdR versichert, ergibt sich auf Basis der Daten aus dem Jahr 2004 ein Zuschussbedarf von rund 33 Mrd. Euro, da die Beiträge in der KVdR

\footnotetext{
${ }^{886}$ Vgl. Schreyögg, J. (2003a), S. $95 f$.

${ }^{887}$ Siehe Felder, S. (2003), S. 67f., und die dort angegebene Literatur.

${ }^{888}$ Siehe Zweifel, P.; Breuer, M. (2002), S. 68. Die Berechnungen basieren auf umlagefinanzierten risikoäquivalenten Prämien.

${ }^{889}$ Eigene Berechnungen; vgl. Verband der privaten Krankenversicherung e.V. (Hrsg.) (2005), S. 11, 34, 39. Die Methodik basiert auf einem Vortrag von M.J.M. Neumann, gehalten auf einer Tagung der Stiftung Marktwirtschaft am 21.05.2003 in Berlin. Beske, F.; Drabinski, T. (2004b), S. 116, beziffern den fehlenden Kapitalstock auf 661,9 Mrd. Euro - offensichtlich inklusive Pflegeversicherung. Die Initiative mehr Gesundheit (Hrsg.) (2004), S. 6, schätzt die Nachhaltigkeitslücke auf 800 Mrd. Euro.

${ }^{890}$ Siehe Kronberger Kreis (2002), S. 82.

${ }^{891}$ Vgl. Beske, F.; Drabinski, T. (2004b), S. 116. Der SVR (2004), Ziff. 541, bleibt vage: „Der dafür erforderliche Finanzbedart beläuft sich auf mehrere huridertdMilliardes E@rog"-3-631-75223-4
} 
nur rund $50 \%$ der jährlichen Ausgaben von 65 Mrd. Euro decken ${ }^{892}$ Für die in das Kapitaldeckungsverfahren wechselnden Älteren verbleibt wenig Zeit zum Aufbau von Alterungsrückstellungen, so dass der Sparbetrag und damit die Prämie entsprechend hoch sein müssen. Versicherte, die den Aufbau der Alterungsrückstellungen nicht alleine finanzieren können, müssten deshalb Zuschüsse erhalten, womit höhere Mittel für den Solidarausgleich erforderlich wären.

Die Übergangsbelastung kann auf mehrere Jahre verteilt werden, wenn die jüngeren Versicherten nicht sofort, sondern schrittweise in das Kapitaldeckungsverfahren wechseln müssen, sofern ihr Einkommen oberhalb einer Ausscheidegrenze liegt. Dazu kann die Ausscheidegrenze z.B. über einen Zeitraum von 8 Jahren linear auf null gesenkt werden. Nach dem Übergangszeitraum sind dann lediglich diejenigen, die zum Zeitpunkt des Systemwechsels älter als 60 Jahre alt waren, noch im Umlageverfahren. Der Transferbedarf für die Versicherten, deren Kopfpauschale im Kapitaldeckungsverfahren die Belastungsgrenze von $15 \%$ des Bruttoeinkommens übersteigt, und für die im Umlagesystem verbleibenden Versicherten steigt dann von $11 \mathrm{Mrd}$. Euro im Umstellungsjahr kontinuierlich auf $70 \mathrm{Mrd}$. Euro im achten Jahr. Wird der Übergangszeitraum durch eine entsprechend geringere Senkung der Ausscheidegrenze auf 16 Jahre verlängert, steigt der Transferbedart langsamer und beträgt in der Endphase 66,1 Mrd. Euro. ${ }^{893}$

Eine andere Möglichkeit, die Übergangsbelastung zeitlich zu strecken, hat die Herzog-Kommission ${ }^{694}$ vorgeschlagen. Über einen Zeitraum von zehn Jahren soll wie bei der Demographiereserve ${ }^{895}$ über einen Beitragssatzaufschlag ein Kapitalstock gebildet werden. Beim Übergang zu kapitalgedeckten Prämien wird der Kapitalstock dann aufgelöst, um die Beiträge der über 45jährigen Versicherten zu subventionieren, die anderenfalls überaus hohe Beiträge zu zahlen hätten, um den Kapitalstock nachträglich aufzubauen. Der notwendige Beitragssatzaufschlag wird jedoch nicht näher beziffert. Durch diese Vorfinanzierung kann die Übergangsbelastung wie beim schrittweisen Wechsel der Versicherten zwar auf mehrere Jahre verteilt werden, dies ändert jedoch nichts daran, dass letztendlich die GKV-Mitglieder die Übergangslast größtenteils tragen. Der Systemwechsel dürte aber auch bei einer Vorfinanzierung kaum ohne öffentliche Mittel finanzierbar sein.

Geringer ist die Belastung beim Übergang zu teilkapitalgedeckten Modellen. Der Beitragssatzaufschlag würde bei der Demographiereserve je nach Annahmen zwischen 1,4 und 4,2 Prozentpunkten liegen und könnte von den GKV-Mitgliedern finanziert werden. Auf eine Arbeitgeberbeteiligung sollte allerdings verzichtet werden, um die mit der Arbeitgeberbelastung verbundenen allokativen Verzerrungen zu vermeiden. Zudem ist es nicht Aufgabe der Arbeitgeber, die finanziellen Folgen des demographischen Wandels zu finanzieren. ${ }^{896}$ Deutlich höher ist der Transferbedarf beim Übergang zu teilkapitalgedeckten Kopfpauschalen, da neben den Übergangskosten vom

\footnotetext{
${ }^{892}$ Siehe Tabelle 3: Beiträge und Ausgaben für Mitglieder und Rentner 1992-2004, S. 40. Der SVR (2004), Ziff. 541, beziffert diese Umstellungskosten auf 40 Mrd. Euro.

${ }^{893}$ Vgl. ausführlich Grabka, M.M. u.a. (2002), S. 15ff.; Henke, K.-D. u.a. (2002), S. $20 f$.

${ }^{894}$ Siehe Herzog-Kommission (2003), S. 22f., 68.

${ }^{895}$ Siehe Abschnitt 3.1.1 Systemkonforme Ergänzung: Demographiereserve, S. 225.

${ }^{896}$ Vgl. Cassel, D.; Oberdieck, V. (2002), S. 21. Marco Penske - 978-3-631-75223-4
} 
Umlageverfahren zu einer kapitalgedeckten Krankenversicherung der soziale Ausgleich dauerhaft aus den öffentlichen Haushalten finanziert werden müsste. Die mit der Einführung von Kapitaldeckung verbundenen Kosten könnten zwar den GKVMitgliedern auferlegt werden, ohne Ausgleichsmaßnahmen wären die derzeitigen Mitglieder aber wieder doppelt belastet, wenn sie selbst Kapital ansparen und gleichzeitig Beiträge für Leistungen im Umlageverfahren zahlen sollen.

Zur Finanzierung der mit der Einführung kapitalgedeckter Elemente verbundenen Umstellungskosten gibt es grundsätzlich drei Möglichkeiten: Die beste Lösung wäre es, öffentliche Ausgaben in entsprechendem Umfang zu kürzen, was jedoch unrealistisch ist.

Zweitens könnten die für den Systemwechsel benötigten Mittel durch Privatisierungserlöse aufgebracht werden, da die Kosten nur übergangsweise anfallen. Aufgrund der Beteiligungsverkäufe in den vergangenen Jahren hat der Bund aber kaum noch Privatisierungsmöglichkeiten. Dies weckt Begehrlichkeiten auf die Goldreserven der Deutschen Bundesbank. Diese belaufen sich auf rund 3.400 Tonnen, was einem Wert von rund $43 \mathrm{Mrd}$. Euro entspricht. ${ }^{897}$ Die Entscheidung über die Verwendung der Goldreserven obliegt jedoch der Bundesbank, die zudem nach einer Vereinbarung führender Notenbanken in den nächsten fünf Jahren jährlich maximal 120 Tonnen veräußern darf.

Drittens wird deshalb neben Steuererhöhungen vorwiegend eine Kredittinanzierung vor allem beim Umstieg auf ein vollständig kapitalgedecktes System diskutiert. ${ }^{898}$ Beim schrittweisen Systemwechsel könnte das Defizit der im Umlageverfahren verbleibenden Älteren oder beim sofortigen Umstieg der Aufbau des fehlenden Kapitalstocks für die älteren Versicherten ganz oder teilweise kreditfinanziert werden. Der Gegenwartswert aus impliziter und expliziter Verschuldung würde sich durch die Kreditaufnahme nicht ändern. Staatsverschuldung verschiebt allerdings die Steuerlast in die Zukunft. Nach der Ricardianischen Äquivalenz bilden die Wirtschaftssubjekte deshalb bei einer Kreditaufnahme Ersparnisse in Höhe des Gegenwartswertes künftig höherer Abgabenbelastungen, die notwendig werden, um die Kredite zurückzuzahlen. Die Finanzierung über Steuern oder Kredite wäre dann in ihrer Wirkung gleich. Dagegen spricht jedoch, dass die Wirtschaftssubjekte kaum in der Lage sind, die aus der Staatsverschuldung resultierenden Belastungen für sich abzuschätzen. Außerdem ist der Planungshorizont der Wirtschaftssubjekte kürzer als die Dauer der Staatsverschuldung ${ }^{899}$ Zinsen und Tilgung müssten aus dem allgemeinen Haushalt über Steuern, durch eine Umlage aller GKV-Mitglieder oder Kombinationen aus Steuern und Beiträgen aufgebracht werden. Die Entscheidung hierüber hängt davon ab, wer belastet werden soll. Bei einer ausschließlichen Finanzierung über Beiträge würden wiederum nur die GKV-Mitglieder die Übergangskosten tragen, bei einer Steuerlösung alle Steuerpflichtigen, mithin auch in der PKV Versicherte, die aber bereits eigene Alterungsrückstellungen gebildet haben.

\footnotetext{
${ }^{897}$ Siehe Deutsche Bundesbank (Hrsg.) (2005c), S. 72.

${ }^{898} \mathrm{Vgl}$. Kronberger Kreis (2002), S. 82f. Zur Finanzierung eines Systemwechsels in der GRV über Verschuldung siehe SVR (1996), Ziff. 421f.; Wissenschaftlicher Beirat beim Bundesministerium für Wirtschaft (1998), S. 25, 42ff.; Deutsche Bundesbank (Hrsg.) (1999), S. $21 f$.
}

${ }^{899} \mathrm{Vgl}$. Andel, N. (1998), S. 172 f. 
Staatsverschuldung könnte die Finanzierungslast auf mehrere Generationen verteilen, was angesichts der Entlastung künftiger Generationen durch die Einführung kapitalgedeckter Elemente auch vertretbar ist. Wenn die Belastungen aus der Deckung des Defizits der Älteren im Zeitverlauf sinken, könnten die Kredite über mehrere Perioden getilgt und insgesamt ein relativ konstanter Belastungspfad erreicht werden. Dennoch ist die höhere Staatsverschuldung nicht unproblematisch. Mit der Kreditaufnahme wird eine implizite Schuld durch eine explizite ersetzt, deren Last künftige Generationen tragen müssen, während die implizite Verschuldung in der GKV immerhin grundsätzlich auch innerhalb des Systems beseitigt werden kann. ${ }^{900}$ Der offene Ausweis bisher impliziter Staatsverschuldung kann zudem einen weiteren Vertrauensverlust in die Finanzpolitik verursachen. Artikel 115 GG, der eine Nettokreditaufnahme unterhalb der Höhe der Ausgaben für Investitionen vorschreibt, wäre bei den derzeitigen Staatsfinanzen erst recht nicht einzuhalten. Bei einem kredittinanzierten Übergang zu mehr Kapitaldeckung in der GKV könnten außerdem Fordenungen aufkommen, andere Sozialversicherungszweige ebenfalls über Kredite zu finanzieren. Eine weiter ausufernde Staatsverschuldung wäre kaum noch zu bremsen. ${ }^{901}$

Die im Stabilitäts- und Wachstumspakt vorgegebene Defizitquote von $3 \%$ des BIP würde bei einem kreditfinanzierten Übergang noch deutlicher verfehlt werden. Seit 2002 wird bereits die Defizitgrenze nicht eingehalten und auch für die Jahre 2005 und 2006 wird ein Überschreiten der Defizitquote prognostiziert. ${ }^{902}$ Spätestens seit den Beschlüssen der Europäischen Staats- und Regierungschefs ${ }^{903}$ vom März 2005 stellt der Pakt jedoch keine wirksame Begrenzung der Staatsverschuldung mehr dar. In Zukunft sollen auch Strukturreformen, die kapitalgedeckte Elemente stärken, bei der Beurteilung der öffentlichen Finanzen defizitmindernd berücksichtigt werden. Explizit aufgeführt sind zwar nur Rentenreformen. Gleiches dürfte aber auch für die Einführung von Kapitaldeckung im Gesundheitswesen gelten. Vielmehr ist zu befürchten, dass die durch Kapitaldeckung entstehenden Überschüsse in der GKV hinsichtlich der im Stabilitäts- und Wachstumspakt vorgegebenen Defizitgrenze neue Verschuldungsspielräume im Staatshaushalt eröffnen, die - werden sie genutzt kommende Generationen belasten.

Insgesamt lässt sich feststellen: je schneller und je umfassender kapitalgedeckte Elemente eingeführt werden, desto unabhängiger wird die Finanzierung von der demographischen Entwicklung, desto größer ist aber die Übergangsbelastung. ${ }^{904}$ Kreditfinanzierung kann helfen, die Belastung auf verschiedene Generationen zu verteilen. Im Extremfall ist jedoch dann der gleiche Belastungsverlauf wie im Umlageverfahren möglich. Neben den erheblichen Übergangskosten sollten auch aufgrund der vielen mit einem Systemwechsel verbundenen Probleme und um Verwaltung, Krankenversicherungen und Versicherte nicht zu überlasten, kapitalgedeckte Elemente schritt-

\footnotetext{
${ }^{900} \mathrm{Vgl}$. SVR (2004), Ziff. 506.

901 In Anlehnung an Wissenschaftlicher Beirat beim Bundesministerium für Wirtschaft (1998), S. 42ff.

${ }^{902} \mathrm{Vgl}$. Arbeitsgemeinschaft deutscher wirtschaftswissenschaftlicher Forschungsinstitute e.V. (Hrsg.) (2005b), S. 22.

${ }^{903}$ Siehe Rat der Europäischen Union (2005), S. 23 .

${ }^{904} \mathrm{Vgl}$. Deutsche Bundesbank (Hrsg.) (1999), S. 21; Enquete-Kommission Demographischer Wandel (2002), S. 215; Henke, K.-D. u.a. (2004), S. 18. Marco Penske - 978-3-631-75223-4
} 
weise eingeführt werden. Um die Durchführung sicherzustellen, müsste der Übergang jedoch verbindlich geregelt werden. ${ }^{905}$

\subsubsection{Verteilungswirkungen}

Risikoäquivalente Beiträge eliminieren sämtliche versicherungsfremden Umverteilungen aus der Krankenversicherung, bestehen bleiben würde die versicherungsimmanente Umverteilung. Unabhängig von der Frage, ob Einkommensumverteilung überhaupt zu den Aufgaben der GKV zählt, hat der Übergang zur Kapitaldeckung intragenerative Verteilungswirkungen. Durch das größere Kapitalangebot sinkt der Zinssatz, während die Arbeitsproduktivität und dadurch die Reallöhne steigen, was die funktionelle Einkommensverteilung zugunsten des Produktionsfaktors Arbeit verschiebt. Auch die personelle Vermögensverteilung verändert sich: Besonders Vermögende beziehen ihr Einkommen zu großen Teilen aus Kapitalerträgen. Sinken die Zinsen infolge des größeren Kapitalangebots, steigen deren Einkommen langsamer als die Einkommen von Beziehern niedriger Einkommen, die vorwiegend über Arbeitsentgelte verfügen. Beide Verteilungswirkungen wirken egalisierend und sind sozialpolitisch erwünscht. ${ }^{906}$

Bei der Einführung von Kapitaldeckung im Modell der Demographiereserve und der Gesundheitsprämie stehen die intergenerativen Verteilungswirkungen im Mittelpunkt. Mit kollektiver Kapitaldeckung können intergenerative Transfers reduziert und das Belastungsniveau im Zeitverlauf geglättet werden. Die Bildung eines Kapitalstocks begrenzt die Beiträge für künftige Generationen und kann damit die Gesundheitsausgaben generationengerechter verteilen ${ }^{907}$ Bislang zählt die heutige Erwerbstätigengeneration, weil sie nicht ausreichend Humankapital gebildet hat, zu den Verteilungsgewinnern im Umlageverfahren zulasten der nachkommenden Generation. Wird die heutige Generation zur Bildung von Realkapital verpflichtet, kann die intergenerative Umverteilung, die aus der zu geringen Bildung von Humankapital resultiert, zumindest reduziert werden. ${ }^{908}$ Rentner mit einer statistischen Restlebenserwartung von weniger als 15 Jahren sollten hingegen aus Gründen der intergenerativen Gerechtigkeit nicht mit der Finanzierung des Kapitalstocks belastet werden, da sie von der Beitragsentlastung nicht mehr profitieren und selbst ausreichend Humankapital gebildet haben. ${ }^{909}$

Bei kollektiver Kapitalbildung darf aber nur für demographisch bedingte Kosten, die aus dem Zusammenwirken von demographischer Entwicklung und medizinisch-technischem Fortschritt entstehen, ein Kapitalstock gebildet werden. Für eine verbesserte allgemeine Versorgungsqualität sollten keine Rückstellungen gebildet werden, da dies zu neuen intergenerativen Ungerechtigkeiten führen würde; denn die erste kapi-

${ }^{905}$ Für eine grundsätzliche Diskussion um Pro und Contra eines schrittweisen oder sofortigen Systemwechsels siehe Zweifel, P.; Breuer, M. (2002), S. 52ff.

${ }^{906}$ Vgl. Homburg, S. (1988), S. $95 \mathrm{ff}$.

${ }^{907} \mathrm{Vgl}$. SVR (2004), Ziff. 508 f.

${ }^{908}$ Vgl. Schulenburg, J.-M. Graf von der (1989a), S. 348f.; Cassel, D. (2003), S. 250.

${ }^{909}$ Vgl. Cassel, D.; Oberdieck, V. (2002), S. $21 . \quad$ Marco Penske - 978-3-631-75223-4 
talbildende Generation würde durch ihren Konsumverzicht dann auch Leistungsverbesserungen nachfolgender Generation finanzieren. ${ }^{910}$

Mit intergenerativen Verteilungswirkungen verbunden ist auch die Entscheidung über die Verwendung eines kollektiven Kapitalstocks. Werden nur die Zinserträge zur Beitragsentlastung verwendet und der Kapitalstock nicht aufgezehrt, sind die Beitragsentlastungen zwar gering, dafür aber dauerhaft. Nach Bevölkerungsvorausberechnungen der Vereinten Nationen ${ }^{911}$ steigt das Medianalter in Deutschland von 39,9 Jahren (2000) bis 2050 auf 46,8 Jahre, sinkt dann bis zum Jahr 2100 auf 44,9 Jahre. Anschließend steigt das Medianalter bis 2300 kontinuierlich auf 52,6 Jahre an. Die Bevölkerungszahl geht bis 2100 stetig auf 73 Mio. Menschen zurück, steigt dann bis 2300 wieder auf 85 Mio. Personen an. Obwohl Bevölkerungsvorausberechnungen relativ robust sind, unterliegen dermaßen langfristige Projektionen jedoch zahlreichen Unsicherheiten, unterstellt wird z.B. ein langfristiger Anstieg der Fertilität auf das bestandserhaltende Niveau von 2,1 Kindern je Frau. Aussagen über die langfristige demographische Entwicklung sind daher problematisch.

Ist der demographische Wandel aber zeitlich begrenzt, kann der Kapitalstock aufgebraucht und eine entsprechend größere Beitragsentlastung finanziert werden. Problematisch ist dann jedoch die Entscheidung über den Zeitpunkt, ab dem bei kollektiver Kapitalbildung der Kapitalstock abgeschmolzen wird. Generationen, die vorher versterben, erhalten keine Beitragsentlastung. Um die Generationengerechtigkeit zu stärken, muss die heutige (erste) Generation aber einen Teil der Lasten tragen, will man nicht umgekehrt einseitig nachfolgende Generationen belasten. Gleichfalls haben Generationen, die folgen nachdem der Kapitalstock aufgebraucht ist, zwar angespart, profitieren aber nicht von niedrigeren Beiträgen. Für sie steigt der Beitragssatz sogar sprunghaft. ${ }^{912}$ Bis der Kapitalstock vollständig verzehrt ist, bestehen jedoch Handlungsmöglichkeiten, die den Beitragssatzanstieg dämpfen können. Zu denken ist beispielsweise an eine steuerfinanzierte Familienversicherung, die weitere Erschließung von Wirtschaftlichkeitspotentialen und die - wenn auch begrenzte - Möglichkeit zur Ausgliederung von Leistungen. ${ }^{913}$ Bei einkommensabhängigen Beiträgen könnten außerdem eine positive Entwicklung auf dem Arbeitsmarkt sowie eine höhere Enwerbsbeteiligung im Alter und von Frauen zumindest geringe Entlastung bringen.

Diese Fragen stellen sich bei risikoäquivalenten Prämien mit individuellen Alterungsrückstellungen nicht, da keine intergenerative Umverteilung stattfindet. Die Finanzierung der GKV wäre weitestgehend - eine längere Lebensdauer kann trotz Alterungsrückstellungen zu steigenden Prämien führen - von der demographischen Entwicklung unabhängig. Auch von der Bildung eines individuellen Kapitalstocks in Verbindung mit pauschalen Beiträgen in einem teilkapitalgedeckten Modell gehen keine Umverteilungseffekte zwischen den Generationen aus, da jeder Versicherte Alterungsrückstellungen bildet, um die eigene Beitragsbelastung über die Lebensdauer zu glätten. Zu intergenerativen Verteilungseffekten kann es indes kommen, wenn

\footnotetext{
${ }^{910}$ Vgl. SVR (2004), Ziff. 506.

${ }^{111}$ Siehe United Nations (Hrsg.) (2004), S. 199, 209, 229.

${ }^{912} \mathrm{Vgl}$. SVR (2004), Ziff. 506ft.

${ }^{913}$ Vgl. Cassel, D.; Oberdieck, V. (2002), S. 22; Cassel lapc(2003)
} 
Alterungsrückstellungen in der Übergangsphase aus dem allgemeinen Haushalt finanziert werden: Bei Kreditfinanzierung werden wieder künftige Generationen belastet. Werden die Mittel über Steuererhöhungen aufgebracht, ist für die intergenerativen Verteilungseffekte entscheidend, ob bestimmte Altersgruppen davon besonders betroffen sind.

Intergenerative Verteilungswirkungen sind mit der Umstellung der Beitragsbemessung unabhängig von der Kapitaldeckung verbunden. Risikoäquivalente Prämien führen zu einer stärkeren Belastung der Älteren, weil sich ein größeres Ausgabenrisiko - anders als in einkommensabhängigen Beitragssystemen - auch in höheren Prämien widerspiegelt. Durch die Einführung von umlagefinanzierten risikoäquivalenten Prämien könnte die gesamtstaatliche Nachhaltigkeitslücke von $339,1 \%$ des BIP 2000 in Abhängigkeit von der unterstellten Verteilung der Prämiensubvention auf die verschiedenen Altersgruppen auf Werte zwischen $117,9 \%$ und $143,3 \%$ des BIP 2000 sinken. Die Mehrbelastung künftiger Generationen würde von 140.300 Euro pro Kopf auf bis zu 48.900 Euro pro Kopf reduziert. ${ }^{914}$

\subsection{3 Ökonomische Risiken}

Während die Einnahmen im derzeitigen Umlageverfahren maßgeblich von der Entwicklung der Arbeitsentgelte und der Zahl der Beschäftigten abhängen, unterliegt das Kapitaldeckungsverfahren Kapitalmarktrisiken. Dabei sind kurzfristige Schwankungen an den Aktienmärkten unproblematisch, weil die langfristige Rendite entscheidend ist. Durch Inflation kann der Kapitalstock jedoch entwertet werden. Dazu müssen die Inflationsraten allerdings deutlich über der erwarteten und in der Verzinsung des Kapitalstocks berücksichtigten Preissteigerung liegen. Angesichts der von der Deutschen Bundesbank und auch der Europäischen Zentralbank verkörperten Stabilitätskultur ist das Inflationsrisiko derzeit gebannt. Eine weiter steigende Staatsverschuldung und die Aufweichung des Stabilitäts- und Wachstumspaktes stellen jedoch eine nicht zu unterschätzende Gefahr für die Stabilität des Euro dar. Bei internationaler Kapitalanlage kann das Inflationsrisiko zwar reduziert werden und das Inland am wirtschaftlichen Wachstum insbesondere von Schwellenländern teilhaben; an die Stelle des inländischen Inflationsrisikos tritt dann allerdings ein Länderrisiko und bei Anlagen außerhalb des Euro-Raums zusätzlich ein Wechselkursrisiko.

Der demographische Wandel beeinflusst nicht nur das Umlageverfahren, sondern auch das Kapitaldeckungsverfahren. Die Annahme, dass es in einer alternden Gesellschaft zu einem Rückgang der Kapitalmarktrenditen ${ }^{915}$ kommt, ist zunächst plausibel: Bei schrumpfender Bevölkerungszahl wird der Faktor Arbeit im Vergleich zum Faktor Kapital knapper, womit der relative Preis für Kapital sinkt. Stehen nicht ausreichend Arbeitskräfte zur Verfügung, um Maschinen und Anlagen zu bedienen, werden aufgrund der Angebotsbedingungen Überkapazitäten abgebaut. Außerdem reduzieren die Unternehmen ihre Kapitalausstattung, wenn mit abnehmender Bevölkerung die Konsumnachfrage zurückgeht. Die Kapitalnachfrage sinkt und bei gleich

\footnotetext{
${ }^{914}$ Vgl. ausführlich Fetzer, S.; Mevis, D.; Raffelhüschen, B. (2003), S. $24 \mathrm{ff}$.

${ }^{915}$ Auf die Unterscheidung zwischen Renditen von Aktien, festverzinslichen Wertpapieren und Sachinvestitionen wird im Folgenden weitgehend verzichteMarco Penske - 978-3-631-75223-4
} 
bleibendem Angebot auch die Kapitalrendite. Darüber hinaus nimmt an den Börsen und sonstigen Wertpapiermärkten die Nachfrage nach Kapitalanlagen ab, weil die Zahl der jungen Sparer zurückgeht. Gleichzeitig wächst aber das Angebot an Anlagemöglichkeiten, da wegen der zunehmenden Alterung immer mehr Rentner Ersparnisse auflösen, um ihren Lebensstandard zu erhalten. Wachsende Anlagemöglichkeiten und sinkende Nachfrage führen dann zu deutlich niedrigeren Wertpapierkursen (Asset-Market-Meltdown). ${ }^{916}$

Die Auswirkungen der Bevölkerungsalterung auf die Kapitalmärkte sind aber wesentlich vielschichtiger. Zunächst ist denkbar, dass die gesunkene Kapitalnachfrage durch das aufgrund der Alterung gesunkene Kapitalangebot kompensiert wird und der Zins konstant bleibt.

Außerdem kann die Erhöhung der Erwerbsquoten von Älteren und Frauen die relative Knappheit des Faktors Arbeit zumindest teilweise reduzieren. Da die Zahl der Erwerbstätigen dennoch zurückgehen wird, muss kapitalintensiver produziert werden, um das Konsumniveau zu halten, womit die Nachfrage nach Realkapital aber steigt. ${ }^{917}$ Demzufolge werden die Renditen von Aktien und Industrieanleihen relativ zu anderen Anlageformen steigen. Die Rendite von festverzinslichen Anleihen dürfte hingegen deutlich abnehmen, da Ältere normalerweise über sicherere Anlageformen verfügen, die sie im Alter dann auflösen. ${ }^{918}$ Ob die demographische Alterung auch zu sinkenden Aktienkursen führt, ist hingegen ungewiss, da die Älteren überwiegend festverzinsliche Wertpapiere veräußern. Ein steigendes Angebot an Aktien ist daher nicht zu erwarten. Zudem kann aufgrund der Einführung kapitalgedeckter Elemente in den Systemen der sozialen Sicherung die Nachfrage nach Anlagemöglichkeiten sogar steigen. Der Wert einer Aktie oder Industrieanleihe bestimmt sich außerdem nicht nach dem zahlenmäßigen Verhältnis von Anbietern und Nachfragern auf den Finanzmärkten, sondern im Wesentlichen aus den Ertragserwartungen. ${ }^{919}$ Steigende Gewinne und Aktienkurse werden insbesondere für die Wachstumsbranchen in einer alternden Gesellschaft (z.B. Pharma, Medizintechnik) erwartet.

Darüber hinaus besteht die Möglichkeit, Kapital im Ausland anzulegen. Die demographische Alterung betrifft zwar die gesamte Weltbevölkerung, diese wächst jedoch. Selbst innerhalb der Europäischen Union altert die Bevölkerung nicht einheitlich. Deutschland kann als relativ stark alterndes Land von den höheren Renditen in Ländern mit langsamerer Alterung profitieren, so dass die Renditen deutlich weniger sinken als wäre Deutschland eine geschlossene Volkswirtschaft. Auch für das bei Einführung kapitalgedeckter Elemente in der GKV wachsende Kapitalangebot bietet das Ausland Anlagemöglichkeiten, wodurch der Rückgang der Rendite abgeschwächt werden kann. ${ }^{920}$ Eingeschränkt wird die Kapitalanlage im Ausland jedoch

\footnotetext{
${ }^{916}$ Heigl, A. (2001) z.B. vertritt diese These. Einen Überblick über die Literatur geben Börsch-Supan, A.; Ludwig, A.; Sommer, M. (2003), S. 19ff.; Matthes, J.; Römer, C. (2005), S. 294ff. Vgl. auch Lueg, T.; Ruprecht, W.; Wolgast, M. (2003), S. 6ff., die die Demographieanfälligkeit des Kapitaldeckungsverfahrens als neue Mackenroth-These bezeichnen.

${ }^{917}$ Vgl. Börsch-Supan, A.; Ludwig, A.; Sommer, M. (2003), S. 3.

${ }^{918} \mathrm{Vgl}$. ebenda, S. $55 \mathrm{ff}$.

${ }^{919} \mathrm{Vgl}$. Matthes, J.; Römer, C. (2005), S. 305; Lueg, T.; Ruprecht, W.; Wolgast, M. (2003), S. $10 f f$.

${ }^{920} \mathrm{Vgl}$. Börsch-Supan, A.; Ludwig, A.; Sommer, M. (2003), S. 3; Lueg, T.; Ruprecht, W.; Wolgast, M.

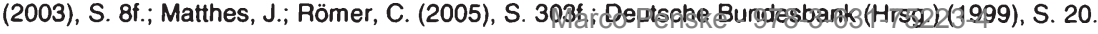


insbesondere in den Schwellenländern durch begrenzte Aufnahmefähigkeiten und unterentwickelte Finanzmärkte. ${ }^{921}$ Die Kapitalanlage im Ausland hat auch Auswirkungen auf die Kapitalbilanz und damit die Leistungsbilanz, deren Saldo in einer offenen Volkswirtschaft der Differenz zwischen Ersparnis und Investition entspricht. Wird im Inland mehr gespart als investiert, dann wird Vermögen im Ausland aufgebaut. Dadurch entsteht ein Kapitalbilanzdefizit (Kapitalexport), dem ein Leistungsbilanzüberschuss gegenüber steht. Im Zuge der demographischen Alterung werden die Auslandsersparnisse dann aufgelöst und das Inland kann mehr konsumieren als es produziert, indem es auf das ausländische Bruttoinlandsprodukt zugreift. Dadurch entsteht allerdings ein Leistungsbilanzdefizit, das tendenziell zu einer Abwertung der inländischen Währung und damit zu einer Verteuerung der Importe führt. Zu einer Abwertung muss es indes nicht zwangsläufig kommen, wenn es - wie in den USA gelingt, ausländisches Kapital anzuziehen, mit dem das Leistungsbilanzdefizit finanziert wird. ${ }^{922}$

Die Annahme einer dramatischen Auflösung der Ersparnisse in einer alternden Gesellschaft basiert auf der Lebenszyklustheorie, wonach Individuen durch Ersparnisse ihren Konsum über die Lebenszeit glätten wollen. Die Erwerbstätigen sparen in jungen Jahren und lösen im Ruhestand ihre Ersparnisse auf, so dass dann die Sparquote negativ wird. Empirisch lässt sich zwar ein Rückgang der Sparquote mit dem Alter feststellen. Die durchschnittliche Sparquote im Alter wird aber nicht negativ, da es neben der Konsumglättung weitere Sparmotive (Vererbung, Vorsichtssparen etc.) gibt. Die Lebenszyklustheorie überzeichnet damit den Renditerückgang. ${ }^{923}$ Bis zum Jahr 2050 bauen außerdem mehr junge Versicherte Alterungsrückstellungen auf, als Ältere ihren Kapitalstock verzehren. Damit steht dem gestiegenen Angebot an Vermögensanlagen auch eine wachsende Nachfrage gegenüber, was den Einfluss auf Rendite und Kurse deutlich mindert. ${ }^{924}$

Börsch-Supan, Ludwig und Sommer ${ }^{925}$ quantifizieren mit Hilfe eines Simulationsmodells den demographisch bedingten Rückgang der Kapitalrendite in einer geschlossenen Volkswirtschaft von 7,75\% im Jahr 2000 auf 6,59 \% im Jahr 2035 und 7,05\% im Jahr 2050. Bei internationaler Kapitalanlage innerhalb der EU wird der Effekt bis zum Jahr 2035 um 0,15 Prozentpunkte auf 6,74\% reduziert. Ein höheres Kapitalangebot aufgrund von Reformen in der GRV würde die Kapitalrendite in der geschlossenen Volkswirtschaft um 0,45 Prozentpunkte auf 6,14\% im Jahr 2035 sinken lassen. Durch internationale Kapitalanlage im EU-Raum und den USA kann der Rückgang aber fast vollständig kompensiert werden. Nach den Berechnungen liegt die Kapitalrendite dann trotz gestiegenen Kapitalangebots im Jahr 2050 bei 6,97\%.

Der demographische Wandel findet zudem nicht plötzlich statt. Da für den Kapitalmarkt die Veränderungen absehbar sind, werden die Renditen langfristig und über

\footnotetext{
${ }^{921}$ Vgl. Heigl, A. (2001), S. 6; Matthes, J.; Römer, C. (2005), S. 304.

${ }^{922}$ Vgl. Heigl, A. (2001), S. 6; Matthes, J.; Römer, C. (2005), S. $307 \mathrm{ff}$.

${ }^{923}$ Vgl. Börsch-Supan, A.; Ludwig, A.; Sommer, M. (2003), S. 24f.; Lueg, T.; Ruprecht, W.; Wolgast, M. (2003), S. 10f.; Matthes, J.; Römer, C. (2005), S. 298ff., 311f. Siehe hierzu auch Heigl, A. (2001), S. 2 ff.

${ }^{924}$ Vgl. Börsch-Supan, A.; Ludwig, A.; Sommer, M. (2003), S. 6.

${ }^{925}$ Siehe ebenda, S. $46 f$.

Marco Penske - 978-3-631-75223-4
} 
einen längeren Zeitraum verteilt angepasst werden, so dass ein plötzlicher Renditerückgang unwahrscheinlich ist. ${ }^{926}$ Auch wenn ein gravierender Rückgang der Renditen nicht zu erwarten ist, haben kontinuierlich sinkende Kapitalrenditen erhebliche Auswirkungen auf den langfristig gebildeten Kapitalstock. ${ }^{927}$ Zusätzliche Kapitaldeckung in der GKV kann den moderaten Renditerückgang zwar verstärken. Das Kapitaldeckungsverfahren ist jedoch deutlich weniger demographieanfällig als das Umlageverfahren.

\subsubsection{Ordnungspolitische Eignung}

Ordnungspolitische Bedenken bestehen bei der Bildung kollektiver Alterungsrückstellungen. Die Kapitalreserve könnte von der Politik zweckentfremdet oder für eine Ausweitung der GKV-Leistungen verwendet und damit der kapitalgedeckte Anteil wieder reduziert werden. Selbst wenn die Verwaltung einer unabhängigen Institution übertragen würde, wäre der Kapitalstock nicht vor dem Zugriff der Politik geschützt. ${ }^{928}$ Ein politisches Risiko besteht aber auch im Umlageverfahren; denn in der GKV begründet die Beitragszahlung nur einen Anspruch „dem Grunde nach“, Einschränkungen der Leistungen und Erhöhungen von Zuzahlungen sind daher jederzeit möglich, wenn auch politisch nicht opportun.

Während bei risikoäquivalenten Prämien in erster Linie das Problem der Portabilität von individuellen Alterungsrückstellungen beim Versicherungswechsel gelöst werden muss, sind bei den Vorschlägen mit kollektiver Teilkapitaldeckung organisatorische Fragen offen. Ungeklärt ist, wer über Zuschläge und anschließenden Abbau des Kapitalstocks entscheidet und von wem das Kapital verwaltet wird. ${ }^{929}$ Aufgrund des Zeitinkonsistenzproblems müssten alle Kassen verpflichtet werden, einen kasseneinheitlichen Beitragsaufschlag zu erheben. Die Entscheidung über die Höhe des Kapitalstocks und ab wann dieser zur Stabilisierung der Beiträge verwendet wird, könnte vom Gesetzgeber auf das Bundesversicherungsamt, das derzeit den Finanzausgleich zwischen den Kassen durchführt, übertragen werden. Politischer Druck könnte jedoch das Bundesversicherungsamt veranlassen, die Beiträge über den demographisch bedingten Anstieg hinaus zu senken, womit der für den demographischen Wandel vorgesehen Kapitalstock zweckentfremdet würde. Problematisch ist auch die Frage, wer die Alterungsrückstellungen am Kapitalmarkt anlegt. Wird dies von den einzelnen Kassen übernommen, erhalten diese neben ihrem eigentlichen Tätigkeitsfeld eine zusätzliche Aufgabe, in der die gesetzlichen Kassen bislang über keine Erfahrung verfügen. Der Finanzausgleich müsste zudem angepasst werden, weil die Kassen neben Beitragseinnahmen auch Erträge aus dem gebildeten Kapitalstock erzielen. Mit einer kassenübergreifenden Pool-Lösung für die kollektiven Alterungsrückstellungen könnten diese Probleme umgangen werden. ${ }^{930}$ Dann würde aber wirt-

\footnotetext{
${ }^{926}$ Vgl. Lueg, T.; Ruprecht, W.; Wolgast, M. (2003), S. 11; Börsch-Supan, A.; Ludwig, A.; Sommer, M. (2003), S. $5 f$.

${ }^{927} \mathrm{Vgl}$. Matthes, J.; Römer, C. (2005), S. 306.

${ }^{928} \mathrm{Vgl}$. Wissenschaftlicher Beirat beim Bundesministerium für Wirtschaft (1998), S. 30f., 39f.; SVR (2004), Ziff. 506; Breyer, F.; Zweifel, P.; Kifmann, M. (2005), S. 539.

${ }^{929} \mathrm{Vgl}$. Cassel, D. (2003), S. 251.

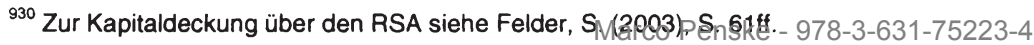


schaftlicher Einfluss bei einer halbstaatlichen Institution konzentriert, die wesentlichen Einfluss auf die Kapitalallokation ausüben würde, womit nicht nur ökonomische, sondern auch politische Überlegungen die Anlageentscheidung beeinflussen könnten. Zudem steht die Pool-Lösung in Widerspruch zu bisherigen Bestrebungen, die private Altersvorsorge zu stärken, und ist wettbewerbspolitisch bedenklich. Auf die effizienzsteigernde Wirkung des Wettbewerbs verschiedener Kapitalanleger würde verzichtet und den Versicherten die Möglichkeit genommen, eine Kapitalanlage nach ihren eigenen Präferenzen zu wählen. Diese ordnungspolitischen Bedenken bestehen nicht bei individueller Kapitaldeckung.

\section{Externe Kapitalbildung mit Gesundheitssparkonten}

\subsection{Erfahrungen aus dem Ausland}

Eine Alternative zur Kapitaldeckung innerhalb der GKV stellt die Bildung eines Kapitalstocks außerhalb der Krankenversicherung dar. Da die Versicherten mit den Ersparnissen künftig steigende Beiträge teilweise finanzieren sollen, kommt bei der externen Kapitalbildung die kollektive Kapitaldeckung nicht in Betracht, sondern nur die auf individueller Ebene. ${ }^{931}$ Zur Finanzierung von Gesundheitsleistungen wurden bereits Gesundheitssparkonten (medical savings accounts) in Singapur, Südafrika, China und den USA eingeführt. ${ }^{932}$ Auf Gesundheitskonten sparen die Individuen Kapital an, das am Kapitalmarkt angelegt wird und mit dem sie medizinische Behandlungen finanzieren. Das Krankheitsrisiko trägt der Einzelne selbst. Darüber hinaus übernimmt eine steuerfinanzierte oder beitragsfinanzierte Hochrisikoversicherung Krankheitskosten, die den Einzelnen überfordern würden.

Mit dieser Finanzierungsform werden vor allem zwei Ziele verfolgt: Erstens wird die Abhängigkeit der Finanzierung von der demographischen Entwicklung durch den Aufbau individueller Alterungsrückstellungen reduziert. Zweitens soll der Ausgabenanstieg gedämpft werden, indem die Versicherten bei einer Selbstbeteiligung den Anreiz haben, Kosten zu vermeiden, womit die Gefahr von moral hazard sinkt. ${ }^{933} \mathrm{Im}$ Vergleich zu reinen Selbstbehalten senken Selbstbeteiligungen in Kombination mit Gesundheitskonten darüber hinaus den Anreiz für Versicherte, medizinische Behandlungen zu verschleppen, weil sie eventuelle Folgekosten zumindest partiell selbst tragen müssen. Gleichzeitig wird jedoch der Steuerungseffekt geschmälert, da die Versicherten zum Zeitpunkt der Inanspruchnahme nicht finanziell belastet werden. ${ }^{934}$

Unter allokativen Gesichtspunkten sollten insbesondere Gesundheitsleistungen, bei denen die Nachfrage preiselastisch ist, von den Individuen selbst finanziert werden, weil es gerade in diesem Bereich zu moral hazard und damit zu Wohlfahrtsverlusten

${ }^{931} \mathrm{Vgl.} \mathrm{SVR} \mathrm{(2004),} \mathrm{Ziff.} 507$.

${ }^{932}$ Für einen Überblick siehe Hanvoravongchai, P. (2002), S. 36; Dixon, A. (2002), S. $410 \mathrm{ff}$.;

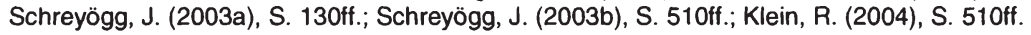

${ }^{933} \mathrm{Vgl}$. Schreyögg, J. (2003a), S. 69ff.; Schreyögg, J. (2003b), S. 510. Für eine ausführliche Analyse der Wirkungen einer Selbstbeteiligung auf Allokation und Distribution siehe Schulenburg, J.-M. Graf von der (1987), S. 40ff.

${ }^{934}$ Vgl. Pütz, C. (2004), S. 524; Bornemann, S.; DaumamrarEo(20055) א.44478-3-631-75223-4 
kommt. Die Versicherungsleistungen sind auf den preisunelastischen Nachfragebereich zu beschränken. Aufgrund der Ergebnisse von Studien über die Preiselastizität der Nachfrage nach Gesundheitsleistungen sollten wenig kostenintensive ambulante Leistungen vom Einzelnen selbst getragen werden, um nicht die Gesundheitskonten für diese - mit Anreizen zur übermäßigen Inanspruchnahme verbundenen - Leistungen aufzubrauchen. Gesundheitskonten finanzieren demnach nur kostenintensivere ambulante sowie wenig kostenintensive stationäre Leistungen. Die Krankenversicherung übernimmt die Ausgaben für chronische Krankheiten und kostenintensive stationäre Behandlungen. Entscheidend für die Abgrenzung dieser Bereiche ist die Preiselastizität der Nachfrage und nicht die Höhe der mit der Leistung verbundenen Kosten. Eine Schönheitsoperation Z.B. ist mit hohen Kosten verbunden, dennoch dürfte die Preiselastizität der Nachfrage hoch sein, da es sich um keine lebensnotwendige Leistung handelt. Eine Blinddarmoperation kann im Vergleich dazu günstig sein, die Nachfrage ist aber preisunelastisch. Mit einer Abgrenzung nach den Kosten wären deshalb Fehlallokationen verbunden. Aus distributiven Aspekten sollte das mit einer Leistungsinanspruchnahme verbundene finanzielle Risiko den Einzelnen nicht überfordern und sichergestellt sein, dass erforderliche Behandlungen für die Individuen jederzeit finanzierbar sind. ${ }^{935}$ Die dafür notwendige zeitliche Trennung zwischen der Inanspruchnahme medizinischer Leistungen und der finanziellen Belastung gelingt umso besser, je mehr der Einzelne auf seinem Gesundheitskonto angespart hat. Um insbesondere Bezieher niedriger Einkommen und chronisch Kranke nicht zu überfordern, sind aber staatliche Transferleistungen notwendig. ${ }^{936}$

Entsprechend diesen Anforderungen wurden erstmals im Jahr 1984 in Singapur Gesundheitskonten - "Medisave" genannt - eingeführt. Das Gesundheitskonto ist Teil des von jedem Erwerbstätigen zu führenden Vorsorge-Sparkontos (Central Provident Fund), das darüber hinaus aus einem Bausparkonto (Ordinary Account) und einem Konto für Rentenzahlungen und Notsituationen (Special Account) besteht. Insgesamt müssen Arbeitnehmer und Arbeitgeber jeweils $20 \%$ des Bruttolohns bis zur monatlichen Beitragsbemessungsgrenze von $5.000 S \$^{937}(2005)$ auf das staatlich verwaltete Vorsorge-Sparkonto einzahlen. Die davon auf das Gesundheitskonto entfallenden Beträge sind altersabhängig. Bei unter 35jährigen fließen $6 \%$, bei 35 - bis 44jährigen $7 \%$, bei 45 - bis 60 jährigen $8 \%$ und bei über 60 jährigen $8,5 \%$ des Bruttoeinkommens dem Gesundheitskonto zu. Übersteigt der Kontostand auf dem Gesundheitskonto $32.500 \$ \$$, werden die darüber liegenden Beträge dem Bausparkonto gutgeschrieben. Im Jahr 2005 muss jeder Enwerbstätige bis zum 55. Lebensjahr mindestens $88.000 \mathrm{~S} \$$ auf seinem Vorsorge-Sparkonto angespart haben, um Ausgaben im Alter zu finanzieren. Dieser Betrag steigt zum Inflationsausgleich bis 2013 auf 120.000 S\$ an. Der Kapitalstock wird vom Staat am Kapitalmarkt angelegt und verzinst und ist im Todesfall vererbbar. Mit dem Gesundheitskonto können stationäre und ausgewählte ambulante Behandlungen des Inhabers und seiner Familienangehörigen finanziert werden. Kleinere ambulante Behandlungen müssen die Einzelnen selbst bezahlen. Bei chronischen Erkrankungen und kostenintensiven stationären

\footnotetext{
${ }^{935}$ Vgl. Schreyögg, J. (2002), S. 163ff.; Schreyögg, J. (2003a), S. 74ff.; Bornemann, S.; Daumann, F. (2005), S. 43f.

${ }^{936}$ Vgl. Klein, R. (2004), S. 519; Hanvoravongchai, P. (2002), S. $37 f$.

${ }^{937}$ Ein Singapur-Dollar (S\$) entspricht 0,50 Euro (StandirNevembere 2005j) 8-3-631-75223-4
} 
Leistungen übernimmt seit 1990 eine Hochrisikoversicherung - „MediShield“ - 80 \% der Kosten oberhalb eines Selbstbehalts. Dafür zahlen die Erwerbstätigen altersabhängige Beiträge von ihren Gesundheitskonten. Für Individuen, die Gesundheitskonten und Behandlungskosten nicht selbst finanzieren können, wurde 1993 aus staatlichen Mitteln „Medifund" eingeführt, woraus Behandlungskosten auf Antrag übernommen werden können. Darüber hinaus subventioniert der Staat die Basisversorgung in Krankenhäusern, um günstigere Behandlungen zu ermöglichen. ${ }^{938}$

Die Erfahrungen in Singapur sind überwiegend positiv. Bei einem mit Deutschland vergleichbaren Pro-Kopf-Einkommen und Lebensstandard liegen die Gesundheitsausgaben in Singapur mit rund $3 \%$ des BIP deutlich unter dem Niveau in Deutschland $(11 \%)$. Dennoch ist die Lebenserwartung höher und die Kindersterblichkeit niedriger als hierzulande. Auch beim Vergleich mit anderen Gesundheitssystemen schneidet Singapur gut ab. Es gibt Anhaltspunkte, dass durch die Einführung von Gesundheitskonten die Präventionsmaßnahmen zugenommen haben. Zumindest haben die Individuen dazu einen stärkeren Anreiz, weil sie die mit Krankheit verbundenen Kosten wenigstens teilweise selbst tragen müssen. Ob Gesundheitskonten zu geringeren Ausgaben führen, ist indes umstritten, zumal die Systeme Medisave, MediShield and Medifund nur rund $9 \%$ der Gesundheitsausgaben finanzieren. ${ }^{939}$ Beim Ausgabenvergleich muss zudem berücksichtigt werden, dass Singapur nicht nach OECD-Standards die Gesundheitsausgaben ermittelt und im Vergleich zu anderen entwickelten Ländern weniger ältere und damit weniger ausgabenintensive Einwohner hat. Außerdem ist insbesondere für chronisch Kranke und Individuen mit geringem Einkommen aufgrund der hohen Selbstbeteiligungen die ärztliche Versorgung unzureichend. Insgesamt übt der Staat großen Einfluss auf die Gesundheitsversorgung aus, indem er Z.B. über die erstattungsfähigen Kosten und die Zahl der Ärzte entscheidet. ${ }^{940}$

Weitere Länder haben Gesundheitskonten eingeführt: In Südafrika können die Versicherten seit 1994 durch freiwillige und überwiegend steuerfreie Ersparnisse Selbstbehalte der privaten Krankenversicherung von i.d.R. 1.100 Euro p.a. bei Inanspruchnahme ambulanter Leistungen finanzieren. Die Gesundheitskonten werden von den Versicherern geführt. Kosten für chronische Krankheiten und ausgabenintensive stationäre Behandlungen übernehmen die privaten Versicherungen voll. Die private Krankenversicherung erhebt risikoäquivalente Beiträge und hat rund $20 \%$ der Bevölkerung versichert. Von den privat Krankenversicherten verfügt die Hälfte bereits über ein Gesundheitssparkonto. $80 \%$ der Bevölkerung erhalten jedoch Leistungen aus der steuerfinanzierten Gesundheitsversorgung. Erste empirische Studien stellen keine adverse Selektion zwischen privaten Versicherungen mit Gesundheitskonten und traditionellen privaten Versicherungen fest; Versicherte mit Gesundheitskonto sind im Durchschnitt weder jünger noch gesünder. Auch eine mögliche Substitution ambulanter durch voll erstattungstähige stationäre Behandlungen wird bislang

${ }^{938}$ Vgl. Barr, M.D. (2001), S. 711ff.; Hanvoravongchai, P. (2002), S. 10ff.; Dixon, A. (2002), S. $410 f . ;$ Schreyögg, J. (2003a), S. 37ff.; Schreyögg, J. (2003b), S. 510ff.; Henke, K.-D. u.a. (2004), S. 14; Ministry of Health Singapore (Hrsg.) (2005).

${ }^{939}$ Vgl. Hanvoravongchai, P. (2002), S. 16ff.; Schreyögg, J. (2002), S. 169ff.; Schreyögg, J. (2003a), S. 82ff.; Schreyögg, J. (2003b), S. 513f.; Henke, K.-D. u.a. (2004), S. 14.

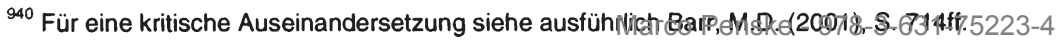


empirisch nicht bestätigt. Die durchschnittlichen Ausgaben für ambulante Behandlungen sind bei Versicherten mit Gesundheitssparkonten aber niedriger als bei Vollversicherten. ${ }^{941}$

In China wurden im Jahr 1995 in zwei Städten Gesundheitskonten eingeführt. 1996 wurde das Pilotprojekt auf weitere 56 Städte ausgeweitet. Beabsichtigt ist, die Gesundheitskonten auf die gesamte urbane Bevölkerung (350 Mio. Personen) auszuweiten. Abgesehen von kleineren Unterschieden zwischen den einzelnen Städten unterscheidet sich das Grundkonzept nicht: Arbeitgeber und Arbeitnehmer zahlen einen lohnabhängigen Beitrag für das individuelle Gesundheitskonto und für die Sozialversicherung. Die Versicherung übernahm anfangs die Ausgaben für kostenintensive Behandlungen erst, wenn das Gesundheitskonto aufgebraucht war. Inzwischen erstattet die Versicherung Leistungen des Hochrisikobereichs, sobald eine Selbstbeteiligungsgrenze überschritten ist. Die Versicherungsleistung ist jedoch auf das Vierfache des jährlichen Lohneinkommens des Versicherten beschränkt. Die Städte entscheiden darüber, ob nur Leistungen aus dem Hochrisikobereich oder alle stationären Leistungen von der Versicherung finanziert werden. Die übrigen Behandlungskosten muss der Versicherte selbst übernehmen oder durch sein Gesundheitskonto begleichen. Das Kapital wird nicht verzinst, ist aber vererbbar. Aufgrund organisatorischer und administrativer Mängel existieren nur wenige Gesundheitskonten, weshalb eine empirische Bewertung derzeit nur eingeschränkt möglich ist. In den beiden Städten, in denen zuerst Gesundheitskonten eingeführt wurden, sind die Kosten für die Versicherten mit Gesundheitskonten zwar zurückgegangen. Es ist aber offen, ob die Kosten nicht von den Leistungserbringern lediglich auf unversicherte Personen verschoben wurden. Deren Behandlungsausgaben nahmen nämlich gleichzeitig zu. ${ }^{942}$

Seit 2004 kann jeder US-Bürger bis zur Höhe des Selbstbehalts in seiner Krankenversicherung Beiträge auf ein Gesundheitskonto steuerfrei einzahlen. Die Gesundheitskonten sind zur Finanzierung des Selbstbehalts an eine private Krankenversicherung mit hohem Selbstbehalt gekoppelt. Ursprüngliches Ziel der Einführung im Jahr 1997 war es, private Krankenversicherungen mit Eigenbeteiligungen durch steuerfreie Gesundheitsrücklagen attraktiver zu machen, um eine übermäßige Inanspruchnahme medizinischer Leistungen zu verhindern. Außerdem sollten durch die damit möglichen Beitragssenkungen Krankenversicherungen für größere Bevölkerungsteile finanzierbar werden. Da die Zahl der Gesundheitskonten bis zum Jahr 2004 gesetzlich auf 750.000 beschränkt war, liegen noch keine aussagekräftigen Untersuchungen über die Auswirkungen vor. Adverse Selektion wird empirisch bislang nicht bestätigt. Umstritten ist, ob Gesundheitskonten in den USA den Ausgabenanstieg dämpfen. Dass rund $40 \%$ der Individuen, die sich für ein Gesundheitskonto entschieden haben, zuvor nicht versichert waren, deutet jedoch darauf hin,

${ }^{941}$ Vgl. Matisonn, S. (2000), S. 1ff.; Dixon, A. (2002), S. 413f.; Schreyögg, J. (2003a), S. 130ff.; Schreyögg, J. (2003b), S. 514ff.; Henke, K.-D. u.a. (2004), S. 14, und die dort jeweils angegebene Literatur.

942 Vgl. Hanvoravongchai, P. (2002), S. 31ff.; Dixon, A. (2002), S. 411f.; Schreyögg, J. (2003a),

S. 135ff.; Schreyögg, J. (2003b), S. 516ff.; Klein, RA (2929) 
dass mit günstigeren Prämien auch für sozial Schwache eine Versicherung bezahlbar wurde. ${ }^{943}$

Obwohl die allokativen und distributiven Wirkungen von Gesundheitskonten bislang empirisch nicht eindeutig festgestellt werden konnten, planen weitere Länder wie Australien, Hongkong, Kanada und Malaysia die Einführung von Gesundheitskonten. 944

\subsection{Einführung von Gesundheitssparkonten}

In der Diskussion um eine Reform der GKV spielen Gesundheitskonten bislang in Deutschland keine Rolle. Dabei gibt es viele Möglichkeiten, Gesundheitskonten einzuführen. Die Gesundheitskonten können freiwillig (USA, Südafrika) oder verpflichtend (China, Singapur) sein. Der Kapitalstock kann staatlich (China, Singapur) oder von privaten Versicherungen (USA, Südafrika) angelegt werden. Mit den Gesundheitskonten können absolute Selbstbehalte (USA, Südafrika) oder direkt Gesundheitsleistungen (China, Singapur) finanziert werden, wobei sich die beiden letzten Möglichkeiten bei einer Leistungsinanspruchnahme unterhalb des Selbstbehalts nicht unterscheiden.

Unter den derzeit bestehenden Rahmenbedingungen könnten Kassen als Modellvorhaben nach § 63 SGB V einen Wahltarif mit Selbstbehalt und Gesundheitskonto anbieten. Tatsächlich bieten einige Kassen (z.B. Techniker Krankenkasse, Deutsche Angestellten-Krankenkasse und die meisten Allgemeinen Ortskrankenkassen) Wahltarife an - allerdings ohne Gesundheitskonto, weil sich auch mit reinen Selbstbehalten die gewünschten Steuerungseffekte erreichen lassen. Zudem sind Versicherte, die sich für einen Selbstbehalt entscheiden, tendenziell risikofreudig. Aus Sicht einer Kasse ist es deshalb nicht sinnvoll, dieser Gruppe ein Versicherungsprodukt anzubieten, das gleichzeitig durch Ansparen Sicherheit vermittelt und eher risikoaverse Versicherte anspricht. ${ }^{945}$

Dem theoretischen Konzept nach müsste zur Einführung von Gesundheitskonten in der GKV die Nachfrage nach Gesundheitsleistungen in die drei genannten Bereiche aufgeteilt werden: Kostenintensive Leistungen, deren Nachfrage preisunelastisch ist, würden weiter von der GKV und einfache Maßnahmen mit geringen Kosten und preiselastischer Nachfrage von den Versicherten selbst finanziert werden. Das obligatorische Gesundheitskonto würde den dazwischen liegenden Nachfragebereich abdecken. ${ }^{946}$ Leichter umsetzbar wäre es, in der GKV Selbstbehalte einzuführen, die über ein individuelles obligatorisches Gesundheitskonto finanziert würden. ${ }^{947}$ Dann müsste der Leistungskatalog nicht aufgeteilt werden und die Selbstbehalte ließen

\footnotetext{
${ }^{943}$ Vgl. Dixon, A. (2002), S. 412f.; Hanvoravongchai, P. (2002), S. 28ff.; Schreyögg, J. (2003a), S. 132ff.; Schreyögg, J. (2003b), S. 519ff.; Klein, R. (2004), S. 511, und die dort jeweils angegebene Literatur.

${ }^{944}$ Vgl. Schreyögg, J. (2003a), S. 137f.; Schreyögg, J. (2003b), S. 522ff.; Hanvoravongchai, P. (2002), S. $33 f$.

${ }^{945}$ Vgl. Pütz, C. (2004), S. $523 \mathrm{ff}$.

${ }^{946} \mathrm{Vgl}$. Bornemann, S.; Daumann, F. (2005), S. 45.

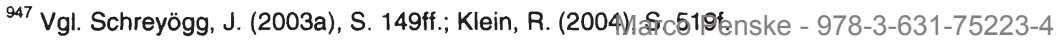


sich einfacher in der GKV integrieren. Kapital zur Finanzierung des Beitragsanstiegs im Alter würde in dem Umfang gebildet werden, in dem die Einzahlungen über den aus dem Gesundheitskonto finanzierten Gesundheitsausgaben liegen. Bei Überschreiten des Selbstbehalts würde die GKV jedoch wieder zur Vollversicherung, womit dann keine Steuerungswirkung mehr einträte. ${ }^{948}$

Spreemann ${ }^{949}$ schlägt vor, Gesundheitsleistungen in Deutschland direkt über Gesundheitskonten zu finanzieren. Demnach soll es neben der Versicherung in der GKV oder PKV eine dritte Möglichkeit zur Finanzierung von Gesundheitsleistungen geben. In diesem dritten System muss jeder Erwerbstätige - paritätisch finanziert mindestens $10 \%$ seines Bruttolohns auf ein Gesundheitskonto einzahlen. Bei Rentnern übernimmt der Rentenversicherungsträger die Zahlung. Dafür wird die gesetzliche Rente um 5 \% gekürzt. Entsprechendes gilt für Empfänger von Arbeitslosengeld oder Sozialhilfe. Für Kinder und Jugendliche zahlt der Staat auf das Gesundheitskonto der Eltern 20.000 Euro je Kind ein. Für nichterwerbstätige Ehepartner muss offensichtlich der erwerbstätige Partner ansparen. Ist ein nicht weiter bestimmtes Sparziel erreicht, endet die Beitragspflicht. Die Einzahlungen auf das Gesundheitskonto sind steuerfrei. Der individuelle Kapitalstock wird von einem privaten Finanzinstitut verwaltet und ist vererbbar. Mit dem Gesundheitskonto dürfen ausschließlich Gesundheitsleistungen bezahlt werden. Besonders kostenintensive Behandlungen genannt wird ein Betrag von 20.000 Euro p.a. - und Leistungen, die nicht mehr durch das Gesundheitskonto gedeckt sind, übernimmt eine Krankheitsrisikoversicherung, welche von den heutigen Kassen angeboten werden könnte. Finanziert wird die Risikoversicherung über einheitliche Beiträge aus dem Gesundheitskonto.

An dieser Ausgestaltung von Gesundheitskonten ist vor allem zu kritisieren, dass dauerhaftes Ansparen bis zum 65. Lebensjahr besser geeignet wäre, den Kostenanstieg im Alter vorzufinanzieren und damit die Abhängigkeit von der demographischen Entwicklung zu reduzieren. ${ }^{950}$ Zudem kann das Nebeneinander von GKV, PKV und Gesundheitskonten zu adverser Selektion führen, wenn überwiegend Versicherte mit gutem Gesundheitszustand die Absicherung über Gesundheitskonten wählen, weil sie mit einer geringen Inanspruchnahme von Leistungen rechnen. Der dadurch nach Spreemanns ${ }^{951}$ Auffassung steigende Druck auf GKV und PKV, Wirtschaftlichkeitspotentiale auszuschöpfen, überzeugt aufgrund der unterschiedlichen Wettbewerbsbedingungen nicht.

Die allokativen Vorteile von Gesundheitssparkonten sind verbunden mit einem Abbau des Krankenversicherungsumfangs und einer zunehmenden privaten Übernahme von Gesundheitsrisiken. Dem stehen die historische Entwicklung der GKV und der Solidaritätsgedanke entgegen. ${ }^{952}$ Selbstbeteiligungen können zwar die intergenerative Gerechtigkeit stärken ${ }^{953}$, führen aber $\mathrm{Zu}$ intragenerativen ex post Umverteilun-

\footnotetext{
${ }^{948}$ Vgl. Bornemann, S.; Daumann, F. (2005), S. 45.

${ }^{949}$ Siehe Spreemann, B. (2004), S. $50 f f$.

${ }^{950}$ Vgl. Klein, R. (2004), S. 517.

${ }^{951}$ Siehe Spreemann, B. (2004), S. 52.

952 Vgl. Pütz, C. (2004), S. 526.

${ }^{953}$ Vgl. Schulenburg, J.-M. Graf von der (1987), S. 177; Schreyögg, J. (2003a), S. 154; Bornemann, S.; Daumann, F. (2005), S. 44. 
gen ${ }^{954}$ von Versicherten mit Leistungsinanspruchnahme zu gesund gebliebenen Versicherten. Vor allem gesundheitlich beeinträchtigte Versicherte würden durch $\mathrm{Ge}$ sundheitskonten schlechter gestellt werden. Bezieher niedriger Einkommen müssten außerdem Transfers erhalten, um selbst Kapital in ausreichender Höhe zur Finanzierung von Gesundheitsleistungen ansparen zu können. Die Diskussion über die Einführung einer vergleichsweise geringen Praxisgebühr im Rahmen des GMG zeigt, dass aufgrund der distributiven Wirkungen die Realisierungschancen für deutlich höhere Selbstbeteiligungen gering sind.

Auch unter Beibehaltung des derzeitigen Versicherungsumfangs lassen sich $\mathrm{Ge}$ sundheitssparkonten als externe Kapitaldeckung im deutschen Gesundheitssystem einführen, um die Beiträge intertemporal zu glätten. Dann wird allerdings weniger die nachfragesteuernde und ausgabendämpfende Wirkung von Selbstbeteiligungen als vielmehr die Reduzierung der demographischen Abhängigkeit bezweckt. Mit der Bildung eines Kapitalstocks außerhalb der GKV lassen sich die bei individuellen Alterungsrückstellungen mit der Übertragbarkeit und bei Bildung eines kollektiven Kapitalstocks die mit der Verwendung verbundenen Probleme umgehen und ordnungspolitische Bedenken gegenüber der internen Kapitaldeckung ausräumen. Kompatibel ist die externe Kapitaldeckung sowohl mit Pauschalbeiträgen als auch mit risikoäquivalenten Prämien. Bei lohnabhängigen Beiträgen ist Kapitaldeckung außerhalb der GKV hingegen systemfremd, stattdessen empfiehlt sich dann die kollektive Kapitalbildung innerhalb der GKV über eine Demographiereserve.

Die externe Kapitalbildung geht einher mit einer Trennung der Prämie in ihre einzelnen Bestandteile. ${ }^{955}$ Der an die Krankenversicherung zu zahlende Beitrag deckt die Risikoübernahme in der laufenden Periode und - sofern bei risikoäquivalenten Prämien keine jährliche Gesundheitsprüfung stattfindet - das Prämienänderungsrisiko bei einer unvorhersehbaren dauerhaften Verschlechterung des individuellen Gesundheitszustands $a b$. Darüber hinaus werden Rückstellungen für mit dem Alter vorhersehbar steigende Ausgaben gebildet. Diese rein altersbedingt steigenden Kosten könnten mit einem externen Sparanteil vorfinanziert und die Belastungen damit intertemporal geglättet werden. Dafür wäre ein Sparanteil in Höhe der Altersvorsorge ${ }^{956}$ der PKV von etwa einem Drittel der Prämie, vermindert um den davon in der PKV auf das Prämienänderungsrisiko entfallenden Anteil, ausreichend. Im Gegensatz zu den individuellen Alterungsrückstellungen in der PKV stellt sich das Problem der Portabilität nicht, weil die Alterungsrückstellungen extern gebildet würden und damit auch bei einem Versicherungswechsel der Anspruch gewahrt bliebe. Ganz unproblematisch ist der Wechsel wegen des Prämienänderungsrisikos dennoch nicht.

Wird die risikoäquivalente Prämie nicht jährlich individuell neu ermittelt, dann kann das Prämienänderungsrisiko grundsätzlich auf zwei Arten finanziert werden: Entweder werden die höheren Kosten der Versicherten, die im Zeitverlauf zu schlechten Risiken geworden sind, auf alle Versicherten umgelegt, so dass Versicherte mit

\footnotetext{
${ }^{954}$ Ex ante Umverteilungen aufgrund von Selbstbeteiligungen lassen sich grundsätzlich durch entsprechende Beitragsabschläge kompensieren; vgl. Schulenburg, J.-M. Graf von der (1987), S. 124.

${ }^{955}$ Vgl. Kronberger Kreis (2002), S. 46ff.; Meier, V. u.a. (2004), S. 286ff.; Breyer, F.; Zweifel, P.; Kifmann, M. (2005), S. $536 f$.

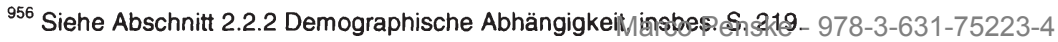


unverändert altersabhängigem Gesundheitszustand die höheren Ausgaben mitfinanzieren. Oder in der Prämienversicherung werden von Vertragsabschluss an aus den Beiträgen Rückstellungen gebildet, die die ansonsten nicht durch Prämienzahlungen abgedeckten unvorhersehbaren höheren Pro-Kopf-Ausgaben von Versicherten, deren Gesundheitszustand sich während der Vertragslaufzeit verschlechtert hat, finanzieren sollen. Im ersten Fall werden Versicherte mit verschlechterter Gesundheit nach einem Versicherungswechsel höhere Prämien zahlen müssen, weil die Prämie dann dem verschlechterten Gesundheitszustand angepasst wird. Beim zweiten Fall stellt sich wieder die Frage der Portabilität - wenn auch nur für einen Teil der Alterungsrückstellungen. Ohne Portabilität wird der Versicherte mit verschlechtertem Gesundheitszustand nach einem Wechsel ebenfalls eine höhere Prämie zu zahlen haben, so dass auch in diesem Modell für schlechte Risiken nur schwache Anreize bestehen, den Versicherer zu wechseln. Bei erheblichen Kostensteigerungen insbesondere für zu schlechten Risiken gewordene Versicherte ist es zudem für die Versicherer schwieriger, die Rückstellungen in der Prämienversicherung aus den Alterungsrückstellungen mitzufinanzieren, weil diese extern gebildet werden. Dann notwendige allgemeine Prämienerhöhungen können gute Risiken zum Wechsel in Kassen mit günstigerer Versichertenstruktur veranlassen und den Krankenversicherungsmarkt destabilisieren (adverse Selektion). ${ }^{957}$

Eine Alternative wäre es, auf die Prämienversicherung zu verzichten und die risikoäquivalente Prämie jährlich dem aktuellen Gesundheitszustand anzupassen. ${ }^{958}$ Das Problem der Portabilität würde sich dann nicht stellen. Jedoch ginge das Prämienänderungsrisiko voll zulasten des Versicherten, mithin würden von Versicherten, deren Gesundheitszustand sich verschlechtert hat, Prämien verlangt, die mitunter die zumutbare Eigenbelastung übertreffen. Insbesondere Ältere wären mit für sie unbezahlbaren Prämien konfrontiert. In diesen Fällen würde das Prämienänderungsrisiko auf den Staat verschoben werden, der für den sozialen Ausgleich aufkommen müsste. Dabei ist es gerade die Funktion einer Versicherung, nicht vorhersehbare unterschiedliche Risiken zu poolen und damit kalkulierbar zu machen. Kann der Versicherte die Entwicklung seines Gesundheitszustands in weiten Teilen nicht beeinflussen ${ }^{959}$, ist auch unter Gerechtigkeitsaspekten die mit der Prämienversicherung stattfindende Umverteilung von guten zu schlecht gewordenen Risiken zu befürworten. Nach dem Konzept des Schleiers des Unwissens ${ }^{960}$ ist eine Umverteilung dann gerecht, wenn sich die Personen in Unkenntnis über ihr eigenes Risiko für die Versicherung entschieden hätten. Da die meisten Individuen risikoavers sind, würden sie einer Versicherung zustimmen. Unter Effizienzaspekten ist die Prämienversicherung dennoch nicht unproblematisch: Die Entwicklung des Gesundheitszustands ist durch eine gesundheitsbewusste Lebensweise in Teilen beeinflussbar. Wird das Prämienänderungsrisiko aber vollständig vom Kollektiv getragen, kann es zu moral hazard kommen. Die Versicherten berücksichtigen dann die finanziellen Folgen von gesundheitsschädlichen Handlungen nur unzureichend, wodurch die Prämie für das Kollektiv steigt. Die Gesundheitsausgaben sind höher als notwendig, Ressourcen

\footnotetext{
${ }^{957}$ Vgl. Meier, V. u.a. (2004), S. $288 \mathrm{ff}$.

${ }^{958}$ Siehe Zweifel, P.; Breuer, M. (2002), S. 33ff.

${ }^{959}$ Vgl. SVR (2004), Ziff. 542.

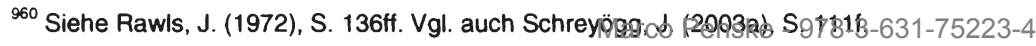


werden ineffizient alloziiert und es entstehen Wohlfahrtsverluste. Bei einem Verzicht auf die Prämienversicherung müsste jedoch jährlich der Gesundheitszustand aller Versicherten ermittelt und die jeweilige Prämie neu berechnet werden. Dies wäre mit einer kostenintensiven Informationsbeschaffung und mit hohen Transaktionskosten verbunden. Zudem stellt sich angesichts von rund 80 Mio. zu versichernden Personen die Frage der Praktikabilität.

Bei Pauschalprämien ist der Wechsel für gute und schlechte Risiken auch bei externer Kapitalbildung gleichermaßen möglich, weil die Kassen einheitliche Prämien verlangen und unter Kontrahierungszwang stehen. Steigen die Ausgaben aufgrund einer Verschlechterung des Gesundheitszustands einzelner Versicherter, werden die für alle Versicherten einheitlichen Beiträge gegebenenfalls erhöht. Um die Kassen mit ungünstigerer Versichertenstruktur nicht zu benachteiligen und Anreize zur Risikoselektion zu schmälern, sind aber ein ausgabenseitiger Finanzausgleich zwischen den Kassen und dafür ein einheitlicher Leistungskatalog weiter notwendig.

Während die Kapitalbildung innerhalb der Krankenversicherung obligatorisch ist, weil der Sparanteil bereits im Beitrag enthalten ist, kann ein externer Kapitalstock auch auf freiwilliger Basis angespart werden. Ein ähnliches Konzept wird in der GRV mit der Riester-Rente seit 2002 verfolgt. Mit Steuererleichterungen und staatlichen Zulagen wird der Aufbau eines privaten Kapitalstocks gefördert, der später die Reduktion von Leistungen der GRV kompensieren soll. Trotz der staatlichen Förderung wurden bis zum Jahr 2004 von 40 Mio. förderberechtigten Personen aber nur 4,1 Mio. Riester-Verträge abgeschlossen, was teilweise auf die starken Reglementierungen zurückzuführen sein dürtte. ${ }^{961}$ Bei einer freiwilligen Lösung ist auch in der GKV damit zu rechnen, dass Versicherte mit geringem Einkommen kein Kapital ansparen, weil sie nicht über den notwendigen finanziellen Spielraum verfügen oder darauf vertrauen, später von der Gemeinschaft Zuschüsse zu erhalten, wenn sie die Beiträge selbst nicht mehr aufbringen können. Die spätere Finanzierung dieser Transfers führt jedoch zu Wohlfahrtsverlusten, was eine Sparpflicht für Bezieher niedriger Einkommen rechtfertigt. Für Bezieher hoher Einkommen lässt sich aus dieser Argumentation jedoch keine Sparpflicht ableiten. In dieser Versichertengruppe könnten sogar präferenzgerechte Sparformen durch das Gesundheitskonto substituiert werden. Auch Versicherte mit hohem Einkommen können aber mit der eigenverantwortlichen Bildung von Kapital überfordert sein, weil sie nicht die nötige Kraft aufbringen, auf heutigen Konsum zugunsten späterer Beitragsentlastungen zu verzichten. Aufgrund dieser Minderschätzung künftiger Bedürfnisse kann eine Pflichtlösung meritorisch begründet sein, um den Lebensstandard zu sichern. Bilden alle Versicherten Kapitalrücklagen, steht im Alter ein höheres Einkommen zur Finanzierung der Prämien zur Verfügung. Steigen die Prämien schneller als die Einkommen, ist dann ein geringeres Zuschussvolumen notwendig als im Fall freiwilliger Ersparnisse. Dafür werden heute aber höhere Zuschüsse benötigt, da die Zahl der Versicherten, deren Krankenversicherungsbeitrag zuzüglich des Sparanteils die Eigenbelastungsgrenze übersteigt, bei einer verpflichtenden Kapitalbildung größer ist als bei einer freiwilligen Regelung. Die obligatorische Kapitalbildung reduziert deshalb auf Kosten heutiger

${ }^{961}$ Vgl. SVR (2004), Ziff. 324; SVR (2002), Ziff. 231. Marco Penske - 978-3-631-75223-4 
Steuer- und Beitragszahler die intertemporale Steuerlastverteilung zugunsten der künftigen Generation. ${ }^{962}$

Im Vergleich zur Bildung eines kollektiven Kapitalstocks ist der Steuercharakter bei externer individueller Kapitalbildung schwächer, weil auch bei einem Obligatorium die Sparanteile den einzelnen Versicherten gutgeschrieben werden. Insbesondere Bezieher hoher Einkommen, die nicht mit einem späteren Beitragszuschuss rechnen, empfinden den Beitrag daher weniger als Steuer, was die wachstums- und beschäftigungsfeindlichen Folgen gegenüber der kollektiven Kapitaldeckung insbesondere bei einkommensabhängigen Beiträgen reduziert. Jedoch können die Transaktionskosten bei einer individuellen Lösung höher sein als bei einer Kollektivlösung. ${ }^{963}$ Sie können aber reduziert werden, wenn das auch für die GRV und die Pflegeversicherung notwendige Kapital zusammen angespart wird. ${ }^{964}$ Singapur dient dafür als Beispiel.

Intergenerative Transfers innerhalb der Krankenversicherung werden durch die externe individuelle Kapitalbildung im Gegensatz zur kollektiven Kapitalbildung nicht reduziert, weil es keine Generation gibt, die Kapital bildet und nicht von der Auflösung des Kapitalstocks profitiert. Stattdessen findet eine intertemporale Lastverschiebung statt. Die Beitragsbelastung wird für diejenigen, die Kapital sparen, über den Zeitverlauf geglättet. Diese Mitglieder zahlen heute vergleichsweise höhere Beiträge und können mit dem gesparten Kapital ihre individuelle Beitragsbelastung in der Zukunft reduzieren. Die Beiträge steigen aber für künftige Generationen wie unter Beibehaltung des Umlageverfahrens, weil individuelle Kapitalbildung nicht das Belastungsniveau insgesamt senkt, sondern nur für die einzelnen Versicherten intertemporal anders verteilt. ${ }^{965}$ Die intergenerativen Umverteilungen bleiben bestehen, werden allerdings durch die Art der Beitragsbemessung reduziert. Bei risikoäquivalenten Beiträgen finden keine intergenerativen Transfers statt und bei Kopfpauschalen sind diese im Vergleich zum Status quo erheblich geringer.

\footnotetext{
${ }^{962}$ Vgl. SVR (2004), Ziff. 325ff., 517, 520; Meier, V. u.a. (2004), S. $290 f$.

${ }^{963}$ Vgl. SVR (2004), Ziff. 509.

${ }^{964} \mathrm{Vgl}$. Wissenschaftlicher Beirat beim Bundesministerium der Finanzen (2004), S. 29.

${ }^{965}$ Vgl. SVR (2004), Ziff. 507ff. 
Marco Penske - 978-3-631-75223-4

Downloaded from PubFactory at 01/11/2019 06:54:52AM

via free access 


\section{Zusammenfassung und Schlussfolgerungen}

Die GKV ist der mit Abstand größte Träger der Finanzierung von Gesundheitsausgaben. Fast $90 \%$ der Bevölkerung sind in der GKV versichert. Die Finanzierung der GKV folgt aber keiner konsistenten ökonomischen Theorie. Das Leistungsfähigkeitsprinzip - in der GKV auch als Solidarprinzip bezeichnet - dominiert zwar die Finanzierung. Beitragsbemessungsgrenze und Krankengeldzahlungen sind aber Folgen der ursprünglich am Äquivalenzprinzip orientierten Finanzierung. Schon diese Vermischung ist problematisch.

Die Einkommensbezogenheit der Beiträge führt in der GKV zu einem Risiko-, Einkommens- und Familienlastenausgleich mit kaum kontrollierbaren und nicht zielgenauen Umverteilungen innerhalb einer Generation. Darüber hinaus führt die praktizierte Umlagefinanzierung ${ }^{966}$ zu intergenerativen Umverteilungen und zu einer Abhängigkeit der GKV von der demographischen Entwicklung, weil jüngere Versicherte mit ihren Beiträgen die Ausgaben für ältere mitfinanzieren. Zudem ist die Lohnkoppelung der Beiträge von Erwerbstätigen beschäftigungsfeindlich. Das daraus resultierende Ziel der Beitragssatzstabilität behindert jedoch Wachstum und Beschäftigung im Gesundheitssektor.

Die Einnahmen der GKV sind infolge der Koppelung an das Einkommen auch von Arbeitsmarkt und Versichertenstruktur sowie von Entscheidungen des Gesetzgebers (Verschiebebahnhöfe) abhängig. Die Analyse des Beitragssatzanstiegs in der GKV hat gezeigt, dass dieser in erster Linie auf eine Einnahmenschwäche zurückzuführen ist, da die beitragspflichtigen Einnahmen seit 1975 i.d.R. langsamer gewachsen sind als das BIP. Die Ausgabenseite ist - nicht zuletzt aufgrund von Kostendämpfungsgesetzen - bislang nicht für den Beitragssatzanstieg verantwortlich. Der Anteil der GKV-Ausgaben am BIP ist seit 1975 (5,9\%) kaum gestiegen (2004: 6,4\%). Eine Kostenexplosion kann in der GKV also nicht festgestellt werden.

Eine Stärkung des Äquivalenzprinzips kann die ineffektiven Umverteilungen und die strukturell bedingte Einnahmenschwäche beseitigen. Dem folgt der Vorschlag, die GKV über pauschale Beiträge zu finanzieren. Insbesondere aus allokativer Sicht ist die Kopfpauschale eine geeignete Finanzierungsform, weil der negative Einfluss der Lohnkoppelung auf die Beschäftigung beseitigt und Wachstum der Gesundheitsmärkte zugelassen wird. Der Übergang zu einkommensunabhängigen Prämien macht die Einnahmen der GKV unabhängig von der Konjunktur sowie weniger anfällig für Verschiebebahnhöfe und die Folgen der demographischen Entwicklung. Zudem wird der Wettbewerb unter den Versicherungen intensiviert und die Abwahl von Leistungen erleichtert. Risikostrukturbedingte Ausgabenunterschiede müssen allerdings weiter über den RSA ausgeglichen werden, ein einnahmenseitiger Finanzausgleich ist indes nicht mehr notwendig. Problematisch ist der soziale Ausgleich. Für diejenigen, deren Beitrag einen als zumutbar angesehenen Anteil am Einkommen übersteigt, ist ein Transfer notwendig. Damit steigt für diese Gruppe die Grenzabgabenbelastung sogar im Vergleich zum Status quo, weil sich bei steigendem Einkommen für diese Versicherten der Zuschuss um den Eigenbelastungssatz

${ }^{966}$ Das Umlageverfahren führt nicht zwangsläufig zu intergenerativen Umverteilungen, entscheidend dafür sind die altersunabhängigen Beiträge; vgl. Breyer, F.; Zweifel, P.; Kifmann, M. (2005), S. 202, 539. 
reduziert. Problematisch ist zudem die Finanzierung des sozialen Ausgleichs. Die notwendigen Mittel dafür müssen aus dem Bundeshaushalt aufgebracht werden. Können dafür notwendige Ausgabenkürzungen in einem Umfang von bis zu $30 \mathrm{Mrd}$. Euro nicht durchgesetzt werden, sind Steuererhöhungen unausweichlich. Aus allokativen Gründen ist dann die Finanzierung über die Umsatzsteuer vorzuziehen, unter distributiven Gesichtspunkten eine Anhebung der Einkommensteuer. Deshalb muss eine nachhaltige Reform der Krankenversicherung auch auf das Steuersystem abgestimmt sein. Die bislang diskutierten Modelle zur Reform der Einkommensteuer berücksichtigen die Finanzierung des sozialen Ausgleichs nur unzureichend, sie sehen sogar meist eine deutliche Senkung der Steuerbelastung vor.

Unabhängig von der Art der Beitragsbemessung könnten die Ausgaben für Kinder als gesamtgesellschaftliche Leistung aus dem Steueraufkommen finanziert werden. Dies wäre zwar zielungenauer als eine Erhöhung des Kindergelds, Arbeitnehmer und Arbeitgeber könnten aber sofort entlastet werden. Abzulehnen ist ein - über die versicherungsfremden Leistungen hinaus - aus Steuern finanziertes Gesundheitswesen. Auch bei Steuerzuschüssen zur Senkung des Beitragssatzes werden Belastungen nur auf den Bundeshaushalt verschoben. Die strukturellen Probleme der GKV werden aber nicht gelöst und die Finanzierung der Zuschüsse ist wiederum mit negativen Beschäftigungswirkungen verbunden.

Die künstliche Trennung des Versicherungsmarktes in GKV und PKV führt zu ungewünschten Umverteilungen und einer ineffizienten Allokation. Mit der Verlagerung der Einkommensumverteilungen und des Familienleistungsausgleichs in den Bundeshaushalt wären auch PKV-Versicherte an der Finanzierung des sozialen Ausgleichs beteiligt. Darüber hinaus könnte eine Ausscheidegrenze die aus dem Wahlrecht zwischen GKV und PKV für Bezieher von Einkommen über der Versicherungspflichtgrenze resultierenden Effekte beseitigen. Hiervon würde die GKV jedoch zunächst belastet und der Systemwettbewerb beseitigt werden. Die oft geforderte Einbeziehung der PKV in den RSA ist schon aufgrund der geringen Praktikabilität keine anzustrebende Alternative. Der dysfunktionale Wettbewerb zwischen GKV und PKV kann nur durch einen einheitlichen Versicherungsmarkt und eine Ausweitung der Versicherungspflicht auf die gesamte Bevölkerung vermieden werden. Bei pauschalen Beiträgen entspricht dies dem Modell einer Bürgerpauschale (Bürgerprämie). Die PKV dürfte dann jedoch keine risikoäquivalenten Prämien mehr verlangen, womit auf ein marktwirtschaftliches Krankenversicherungssystem verzicintet würde.

Neben der Ausweitung des Versichertenkreises wird aus distributionspolitischen Erwägungen auch eine gleichzeitige Erweiterung der beitragspflichtigen Einnahmen auf alle Einkünfte gefordert. Dieses - dem Leistungsfähigkeitsprinzip folgende Modell einer Bürgerversicherung würde jedoch die Finanzierung der GKV zu einer zweiten Einkommensteuer machen, womit allokative Nachteile verbunden sind, zumal von der Einführung einer Bürgerversicherung nur geringe Beitragssatzeffekte ausgehen. Auch distributive Ziele kann ein über das Steuer- und Transfersystem abgewickelter Sozialausgleich besser erfüllen. Ein Finanzausgleich zwischen den Kassen auf der Einnahmen- und Ausgabenseite wäre weiter notwendig. Aus ökonomischer Perspektive ist das Modell einer Bürgerprämie dem einer Bürgerversicherung also eindeutig überlegen. Dennoch werden nach den Erkenntnissen der politischen Ökonomie des Gesundheitswesens einkommensabhängige Beiträge gegenüber pauschalen Beiträgen bevorzugt, weil diel Mehifkeitkkonodiesern1Firbanzierungs- 
system geringere Beiträge erwartet. Nicht zuletzt ist die Entscheidung über die Finanzierungsform auch eine normative Frage: Werden Krankenversicherung und Gesundheitsleistungen als Güter aufgefasst, sind hiertür äquivalente Preise (Prämien) zu erheben. Verteilungsaufgaben sind dann vom Steuer- und Transfersystem wahrzunehmen. Fasst man hingegen die GKV als Grundrecht auf Krankenversorgung auf, ist eine steuerähnliche Finanzierung unter dem Aspekt der Leistungsfähigkeit angebracht.

Der Einfluss des demographischen Wandels auf die Entwicklung der Ausgaben ist umstritten. Das Ausmaß hängt auf der Nachfrageseite davon ab, ob die längere Lebenserwartung mit gesundheitlichen Beeinträchtigungen einhergeht (Medikalisierungsthese) oder die gewonnenen Lebensjahre weitgehend gesund verbracht werden, die Ausgaben demnach von der Entfernung zum Tod bestimmt werden (Kompressionsthese). Beide Thesen werden von empirischen Untersuchungen gestützt, wobei die Kompressionsthese mit den Ausgaben in den letzten Lebensjahren aber nur einen Teil der Gesundheitsausgaben erklärt. Nach dem bi-modalen Konzept einer Synthese aus Medikalisierungs- und Kompressionsthese - können die zusätzlichen Lebensjahre zwar weitgehend in Gesundheit verbracht werden, durch die steigende Lebenserwartung steigt aber der Anteil gesundheitlich beeinträchtigter Versicherter und damit die durchschnittlichen Pro-Kopf-Ausgaben. Insgesamt ist davon auszugehen, dass die Nachfrage nach Gesundheitsleistungen aufgrund des demographischen Wandels steigt. Die Entwicklung der altersspezifischen Gesundheitsausgaben im Zeitverlauf wird von der Angebotsseite beeinflusst. Wegen des medizinisch-technischen Fortschritts werden die Altersprofile steiler und die Ausgaben weiter steigen. Unter polit-ökonomischer Betrachtung kann der medizinische Fortschritt und der auch dadurch steigende Anteil Älterer an der Gesamtbevölkerung dazu führen, dass sich wachsende Mehrheiten für eine Ausweitung des GKVLeistungskatalogs und damit für weiter steigende Gesundheitsausgaben entscheiden, was die Bevölkerungsalterung verstärkt und die Finanzierungsproblematik zusätzlich verschärft. Die bislang nicht festzustellende Kostenexplosion ist dann wahrscheinlich.

Die demographische Entwicklung hat auch Auswirkungen auf die Einnahmen der GKV. Die Zahl der Erwerbsfähigen und das Wirtschaftswachstum werden demographisch bedingt sinken, womit auch die Zahl der enwerbstätigen GKV-Versicherten zurückgeht. Bei einkommensabhängigen Beiträgen sinken deshalb die Beitragseinnahmen. Die Zahl der älteren Mitglieder und damit deren Beiträge werden zwar in der Summe zunehmen. Die wachsenden Einnahmen in der KVdR werden aber nicht ausreichen, die sinkenden Einnahmen in der AKV zu kompensieren. Infolge des sinkenden Rentenniveaus werden die durchschnittlichen Rentner-Beiträge sogar im Verhältnis zu den Beiträgen von Erwerbstätigen weiter sinken.

Modellrechnungen zeigen, dass die demographische Entwicklung bereits den GKVBeitragssatz beeinflusst. Bislang ist der Einfluss noch relativ gering, da einem beitragssatzsteigernden Ausgabeneffekt ein beitragssatzsenkender Finanzierungseffekt gegenübersteht. Die Erhöhung von Zuwanderung, Geburtenrate und Erwerbsbeteiligung sowie eine Verlängerung der Arbeitszeit können den demographischen Wandel nicht neutralisieren. Ab dem Jahr 2020 wird die demographische Entwicklung von der Einnahmenseite und - verstärkt durch den medizinisch-technischen Fortschritt - von der Ausgabenseite her beitragssatzsteigernd wirken. Projektionen auf Basis des Status quo ermitteln im ungünstigsten FallarBeitragssatzsiaigerangenzauf bis zu 
50,4\% im Jahr 2050. ${ }^{967}$ Auch bei der Kopfpauschale bleibt die demographische Abhängigkeit bestehen, wird aber auf der Einnahmenseite reduziert. Der Ausgabenanstieg kann allenfalls aufgrund zunehmenden Wettbewerbs infolge von pauschalen Beiträgen gebremst werden. Bei einer Bürgerversicherung steigt die demographische Abhängigkeit sogar, weil alle Modelle einer Bürgerversicherung die Abschaffung der PKV vorsehen, womit die Kapitaldeckung langfristig reduziert würde.

Wenn künftige Generationen nicht übermäßig belastet und Leistungseinschnitte vermieden werden sollen, dann sind kapitalgedeckte Elemente in der GKV notwendig. Die Kapitalmarktrendite dürfte zwar infolge des demographischen Wandels sinken, der Rückgang ist aber moderat und verteilt über einen langen Zeitraum. Das Kapitaldeckungsverfahren ist wesentlich demographieresistenter als das Umlageverfahren. Zudem sind die durch einen zunehmenden Kapitalstock ausgelösten distributiven Effekte sozialpolitisch enwünscht, weil sie egalisierend auf die Einkommensverteilung wirken. Das Hauptproblem ist die Finanzierung des Übergangs, da eine Generation selbst Kapital bilden, gleichzeitig aber die Ausgaben für ältere Versicherte mitfinanzieren muss. Werden alle Versicherten sofort in das Kapitaldeckungsverfahren überführt, müssen die Alterungsrückstellungen für die Älteren entweder über Steuern oder über Beiträge zumindest teilweise nachfinanziert werden. Die Übergangsbelastung kann auch auf einen längeren Zeitraum verteilt werden, indem die Versicherten schrittweise in das Kapitaldeckungsverfahren wechseln. Dann werden die Ausgaben für die Älteren während der Übergangsphase weiter umlagefinanziert. Eine andere Möglichkeit wäre, die fehlenden Alterungsrückstellungen der Älteren über Kredite zu finanzieren und damit die Finanzierungslast auf mehrere Generationen zu verteilen. Aus der impliziten Verschuldung der GKV würde dann eine explizite Schuld. Damit könnte jedoch ein weiterer Vertrauensverlust in die Finanzpolitik einhergehen, zumal Art. 115 GG nicht einzuhalten wäre. Reduziert werden kann die Übergangsbelastung, wenn das Umlageverfahren nur mit kapitalgedeckten Elementen ergänzt wird. Die Finanzierung der GKV bleibt dann aber abhängiger von der demographischen Entwicklung als bei einem vollständigen Umstieg auf das Kapitaldeckungsverfahren.

Auch eine Bürgerversicherung kann mit Kapitaldeckung ergänzt werden. Aufgrund der mangelnden Verwirklichung des Äquivalenzprinzips haben die Versicherten in einer Bürgerversicherung wie auch im Status quo jedoch kaum Anreize, einen eigenen Kapitalstock aufzubauen, da die Zahlungen als Steuer empfunden werden. Bleibt man - trotz der vorgebrachten Bedenken - bei der einkommensabhängigen Finanzierung, kann kollektive und verpflichtende Kapitaldeckung die intergenerativen Belastungen wenigstens reduzieren. Das Kapital muss bei kollektiver Kapitaldeckung aber innerhalb der GKV kumuliert werden.

Unter ökonomischen Gesichtspunkten sind risikoäquivalente Prämien mit individuellen Alterungsrückstellungen überzeugend, zumal dann auf den RSA verzichtet werden kann. Insbesondere eine Differenzierung der Prämie nach Alter, Geschlecht und Gesundheitsrisiko dürfte aber politisch kaum durchsetzbar sein. Hinzu kommen hohe Übergangskosten beim Umstieg auf ein vollständig kapitalgedecktes System und bei der Kapitalbildung innerhalb der Krankenversicherung Probleme mit der Übertragung 
von Alterungsrückstellungen, die allerdings lösbar sind. Wird das Kapital außerhalb der GKV gebildet, ist die Absicherung des Prämienänderungsrisikos problematisch. Werden hierfür keine Rückstellungen gebildet, steigt für schlechte Risiken beim Versicherungswechsel die Prämie. Werden hingegen Rückstellungen gebildet, stellt sich wieder die Frage der Portabilität.

Eine Kopfpauschale mit Teilkapitaldeckung ist leichter umsetzbar. Aufgrund von Kontrahierungszwang und Diskriminierungsverbot haben schlechte Risiken auch bei individueller Kapitaldeckung einen Anreiz, die Kasse zu wechseln, was den Wettbewerb fördert. Alterungsrückstellungen können individuell oder kollektiv gebildet werden. Wesentlicher Unterschied sind die intergenerativen Verteilungseffekte. Während kollektive Kapitaldeckung die intergenerativen Transfers zugunsten künftiger Generationen reduziert, hat individuelle Kapitaldeckung keine intergenerativen Verteilungseffekte, weil die Beitragslast lediglich intertemporal geglättet wird. Da bei kollektiver Kapitaldeckung die Entscheidung über den Zeitpunkt der Auflösung und die Kapitalkumulation innerhalb der GKV problematisch sind, empfiehlt sich die Bildung von individuellen Alterungsrückstellungen.

Auch aus ordnungspolitischen Gründen sollte das Kapital außerhalb der GKV individuell auf Gesundheitskonten angespart werden, nicht zuletzt um den Kapitalstock vor politischer Zweckentfremdung zu schützen. Beispiele aus dem Ausland zeigen, wie Gesundheitskonten die demographische Abhängigkeit reduzieren können. Werden sie zudem mit höheren Selbstbehalten verknüpft, steigen die Anreize zur kostenbewussten Inanspruchnahme medizinischer Leistungen. Analog zur Riester-Rente in der GRV sollte auch in der GKV eine - allerdings verbindliche - individuelle Kapitalrücklage zur Finanzierung künftiger Beitragssteigerungen eingeführt werden. Diese Gesundheitskonten hätten den Vorteil, dass eigene - wenn auch obligatorische Ersparnisse weniger als Steuer empfunden würden als kollektive Kapitalbildung, weshalb die wachstums- und beschäftigungsfeindlichen Folgen geringer sind als bei kollektiver Kapitaldeckung im Rahmen von einkommensabhängigen Beiträgen. Die Problematik der Portabilität der Alterungsrückstellungen würde sich zudem nicht stellen, da die Rücklage nicht in der Krankenversicherung gebildet wird. Die intertemporale Steuerlastverteilung auf künftige Steuerzahler würde durch die Pflichtlösung gemindert. Um Transaktionskosten zu sparen, könnte das gewünschte Maß an Kapitaldeckung für alle Zweige der Sozialversicherung in einem Ansparvertrag gebildet werden. ${ }^{968}$

Ein Mischsystem aus Kapitaldeckung und Umlageverfahren würde die Übergangskosten deutlich senken. Zudem wäre ein Mischsystem weniger risikobehaftet. Die Kapitalmarkttheorie zeigt, dass bei der Kombination von zwei nicht vollständig korrelierten Anlageformen das Risiko geringer ist als bei Beschränkung auf eine Anlage. ${ }^{969}$ Gesundheitskonten in Kombination mit pauschalen Beiträgen wären praktikabel und geeignet, die Finanzierung der GKV langfristig zu sichern. Steigende Kopfpauschalen würden dann durch Gesundheitskonten und eine höhere Eigenbelastung der Versicherten flankiert von einem Sozialausgleich finanziert werden.

\footnotetext{
${ }^{968} \mathrm{Vgl}$. Wissenschaftlicher Beirat beim Bundesministerium der Finanzen (2004), S. 29. Siehe hierzu auch Pimpertz, J. (2001), S. 167; Henke, K.-D. (2005), S. 107.

${ }^{969}$ Vgl. Börsch-Supan, A. (2004), S. 81. 
Marco Penske - 978-3-631-75223-4

Downloaded from PubFactory at 01/11/2019 06:54:52AM

via free access 


\section{Anhang}

\section{Anhang 1: Bilanzgleichung}

Tabelle 24 zeigt eine Zusammenstellung der benötigten GKV-Daten zur Berechnung des Beitragssatzes für das Jahr 2003 nach der Bilanzgleichung.

Tabelle 24: GKV: Einnahmen, Ausgaben, Mitglieder im Jahr 2003

\begin{tabular}{|c|c|c|c|}
\hline & $\begin{array}{c}\text { Früheres } \\
\text { Bundesgebiet }\end{array}$ & $\begin{array}{c}\text { Neue } \\
\text { Bundesländer }\end{array}$ & Bundesgebiet \\
\hline \multicolumn{4}{|l|}{$\begin{array}{l}\text { Beitragspflichtige Einnahmen } \\
\text { (in Tausend) }\end{array}$} \\
\hline Mitglieder (ohne Rentner) & 654.678.493 Euro & 104.744.119 Euro & 759.422.612 Euro \\
\hline Rentner & 151.113.649 Euro & 44.124.315 Euro & 195.237.964 Euro \\
\hline \multicolumn{4}{|l|}{ Beiträge (pro Kopf) } \\
\hline Mitglieder (ohne Rentner) & 3.300 Euro & 2.486 Euro & 3.158 Euro \\
\hline Rentner & 1.806 Euro & 1.747 Euro & 1.793 Euro \\
\hline \multicolumn{4}{|l|}{ GKV-Mitglieder } \\
\hline Mitglieder (ohne Rentner) $\left(L_{2}\right)$ & 28.110 .204 & 5.963 .427 & 34.073 .631 \\
\hline Rentner $\left(R_{z}\right)$ & 13.118 .637 & 3.562 .181 & 16.680 .818 \\
\hline Gesamt & 41.228 .841 & 9.525 .608 & 50.754 .449 \\
\hline \multicolumn{4}{|l|}{ Ausgaben (in Tausend) } \\
\hline Mitglieder (ohne Rentner) & 59.983.531 Euro & 10.129.052 Euro & 70.112 .582 Euro \\
\hline Rentner & 53.160 .586 Euro & 12.950.127 Euro & 66.110.714 Euro \\
\hline Nerwaltungskosten & 6.859 .475 Euro & 1.346.070 Euro & 8.205.544 Euro \\
\hline Sonstige Ausgaben & 472.732 Euro & 193.253 Euro & 665.985 Euro \\
\hline Summe GKV & 120.476.323 Euro & 24.618.502 Euro & 145.094.825 Euro \\
\hline
\end{tabular}

Quelle: Eigene Darstellung; vgl. BMGS (Hrsg.) (2004a), S. 10f., 70f., 130 f.

Aus Tabelle 24 lassen sich die benötigten Parameter für die Bilanzgleichung berechnen. Die Verwaltungskosten und sonstigen Ausgaben werden berücksichtigt, indem diese pro Kopf auf die Versicherten verteilt werden. Damit wird implizit unterstellt, dass diese Ausgaben unabhängig von den Leistungsausgaben für jeden Versicherten in gleicher Höhe anfallen. Vergleichsberechnungen zeigen, dass man auch mit einer Verteilung proportional zu der Höhe der Leistungsausgaben ähnliche Beitragssätze erhält.

Für die Bilanzgleichung ergeben sich die folgenden Schätzparameter:

$$
\begin{aligned}
& A \mathrm{I}=\frac{76.043 .216 \text { Euro }}{34.073 .631}=2.232 \text { Euro } \\
& \mathrm{Ar}=\frac{69.014 .067 \text { Euro }}{16.680 .818}=4.137 \text { Euro } \\
& L=\frac{759.422 .612 \text { Euro }}{34.073 .631}=22.288 \text { Euro } \\
& \mathrm{R}=\frac{195.237 .964 \text { Euro }}{16.680 .818}=11.704 \text { Euro }
\end{aligned}
$$$$
\frac{A l}{L}=\frac{2.232 \text { Euro }}{22.288 \text { Euro }}=0,1001
$$$$
\frac{\mathrm{Ar}}{\mathrm{Al}}=\frac{4.137 \text { Euro }}{2.232 \text { Euro }}=1,8539
$$$$
\frac{\mathrm{R}}{\mathrm{L}}=\frac{11.704 \text { Euro }}{22 \cdot 288 \text { Euro }}=0,5251
$$$$
\frac{R_{z}}{L_{\text {Marco Penske }}-978-3-631-752}=\frac{16 \cdot 680 \cdot 818}{34.073 .631}=0,4896
$$ 


\section{Anhang 2: Datenmaterial}

Tabelle 25: Beiträge und Leistungen der GKV nach Alter im Jahr 2003

\begin{tabular}{|c|c|c|c|c|c|c|c|c|c|c|c|}
\hline Alter & $\begin{array}{c}\text { Beiträge } \\
B_{t}\end{array}$ & $\begin{array}{c}\text { Ausgaben } \\
\mathbf{A}_{t}\end{array}$ & $B_{t}-A_{t}$ & Alter & $\begin{array}{c}\text { Beiträge } \\
B_{t}\end{array}$ & $\begin{array}{c}\text { Ausgaben } \\
A_{t}\end{array}$ & $B_{t}-A_{t}$ & Alter & \begin{tabular}{|c|} 
Beiträge \\
$\mathbf{B}_{1}$
\end{tabular} & $\begin{array}{c}\text { Ausgaben } \\
A_{t}\end{array}$ & $B_{t}-A_{t}$ \\
\hline 0 & 0 E & $3.226 €$ & -3.226 目 & 31 & $3.419 €$ & $1.179 \mathrm{G}$ & $2.239 \notin$ & 62 & $1.965 \mathrm{f}$ & 2.568 而 & -603 \\
\hline 1 & $0 €$ & $23 €$ & -1.023 G & 32 & $513 €$ & 178 自 & $2.335 €$ & 63 & 788 目 & 617 目 & 329 \\
\hline 2 & $0 €$ & $97 €$ & $997 €$ & 33 & 583 - & 175 ध & $2.408 €$ & 64 & 625 五 & .716 五 & -1.091 \\
\hline 3 & $0 €$ & $27 €$ & $-627 €$ & 34 & $3.661 €$ & 70 帛 & $2.491 €$ & 65 & 1.316 目 & 2.765 目 & $-1.449 €$ \\
\hline 4 & 0 目 & 754 € & $-754 €$ & 35 & $3.706 €$ & 1.582 目 & 2.125 ( & 66 & $1.250 €$ & 2.824 开 & -1.575 \\
\hline 5 & $0 €$ & $44 €$ & 44 目 & 36 & 53 目 & 31 自 & $2.522 \notin$ & 67 & 246 百 & 01 开 & 1.756 \\
\hline 6 & 0 छ & $20 €$ & .720 日 & 37 & 65 € & 236 光 & $2.529 €$ & 68 & 1.235 开 & 3.156 目 & -1.920 \\
\hline 7 & 0 E & $30 €$ & $-730 €$ & 38 & 69 目 & 42 目 & $2.527 \mathrm{G}$ & 69 & 219 开 & 94 目 & -2.075 \\
\hline 8 & $0 €$ & $18 €$ & $.718 €$ & 39 & 62 - & 53 目 & $2.508 €$ & 70 & 188 目 & $3.407 €$ & $-2.219 €$ \\
\hline 9 & $0 €$ & $718 €$ & -718 E & 40 & $3.757 €$ & $1.273 \mathrm{\theta}$ & $2.484 €$ & 71 & $1.181 €$ & $3.522 €$ & -2.341 \\
\hline 10 & $0 €$ & $31 €$ & -761 @ & 41 & 32 є & 97 百 & $2.435 \notin$ & 72 & 95 目 & 55 目 & -2.460 \\
\hline 11 & $0 €$ & $828 €$ & $-828 €$ & 42 & 3.725 & 1.330 छ & $2.394 \notin$ & 73 & $1.190 \mathrm{\theta}$ & $3.780 €$ & -2.590 \\
\hline 12 & $0 €$ & $898 €$ & $-898 \notin$ & 43 & 6 6 & 0 目 & 2.335 & 74 & 83 目 & 399 且 & $-2.716 €$ \\
\hline 13 & $0 €$ & $944 €$ & $-944 €$ & 44 & 3.710 五 & 1.416 目 & $2.295 €$ & 75 & 1.171 目 & $4.014 €$ & -2.843 \\
\hline 14 & $0 €$ & $924 €$ & -924 国 & 45 & 10 目 & 57 ध & $2.253 \epsilon$ & 76 & 45目 & 29 目 & $-2.984 €$ \\
\hline 15 & $36 €$ & $899 €$ & $-613 \notin$ & 46 & $3.712 \mathrm{E}$ & $1.516 €$ & 2.196 G & 77 & 1.116 目 & 4.238 目 & $-3.121 €$ \\
\hline 16 & $356 €$ & $864 €$ & -508 ध & 47 & $3.700 €$ & 75 目 & $2.126 \notin$ & 78 & 93 目 & 486 目 & -3.256 \\
\hline 17 & $21 \epsilon$ & $840 €$ & $-320 €$ & 48 & $3.674 €$ & 641 至 & $2.033 €$ & 79 & 059 目 & 4.432 目 & $-3.372 €$ \\
\hline 18 & 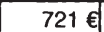 & $816 €$ & -95 元 & 49 & $3.645 €$ & 1.718 ध & $1.928 \Leftrightarrow$ & 80 & 47 目 & 4.497 @ & -3.450 \\
\hline 19 & $39 €$ & $808 €$ & 31 ध & 50 & $3.607 €$ & $1.794 €$ & $1.813 €$ & 81 & 1.044 目 & $4.586 €$ & $-3.542 €$ \\
\hline 20 & $1.202 €$ & $836 €$ & $367 €$ & 51 & 3.566 目 & $1.873 €$ & $1.693 \notin$ & 82 & $1.040 €$ & $4.710 €$ & -3.670 目 \\
\hline 21 & $1.489 €$ & $864 €$ & 25 目 & 52 & 3.525 目 & $1.949 \notin$ & 1.576 目 & 83 & .049 开 & 4.826 目 & $-3.777 €$ \\
\hline 22 & $1.771 €$ & $895 €$ & 76 目 & 53 & 3.483 五 & 331 目 & $1.452 \notin$ & 84 & 042 ध & 4.911 而 & -3.869 日 \\
\hline 23 & 35 皿 & $929 €$ & $1.106 €$ & 54 & $3.475 €$ & 2.126 ध & $1.349 \notin$ & 85 & .034 & 4.979 目 & $-3.945 €$ \\
\hline 24 & $242 €$ & $968 €$ & $1.274 €$ & 55 & 3.419 目 & $2.227 \emptyset$ & 1.192 目 & 86 & 1.031 目 & $5.027 €$ & -3.996 \\
\hline 25 & $432 €$ & $1.007 €$ & $1.425 \notin$ & 56 & 3.323 छ & $2.335 €$ & 988 ध & 87 & 1.026 目 & $5.042 \notin$ & $-4.016 €$ \\
\hline 26 & $2.621 €$ & $1.047 €$ & $1.574 €$ & 57 & 3.238 目 & $2.451 €$ & $787 €$ & 88 & $1.014 \mathrm{G}$ & 5.074 目 & $-4.059 €$ \\
\hline 27 & $2.835 €$ & $1.083 €$ & $1.753 €$ & 58 & $3.102 €$ & $2.529 \notin$ & 573 € & 89 & $1.007 €$ & $5.112 €$ & -4.105 五 \\
\hline 28 & $22 €$ & $15 €$ & $1.907 \mathrm{E}$ & 59 & $3.063 €$ & 2.568 日 & 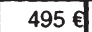 & 90 & 1.006 ध & 4.957 ( & $-3.951 €$ \\
\hline 29 & $3.173 €$ & $1.148 €$ & $2.025 \notin$ & 60 & 2.464 目 & $2.560 €$ & $-96 €$ & & & & \\
\hline 30 & $3.303 €$ & 1.170 五 & 2.132 छ & 61 & 2.299 छ & $2.550 €$ & $-250 \div$ & & & Summe & 26.493 \\
\hline
\end{tabular}

Quelle: Eigene Berechnungen; Daten: Verband Deutscher Rentenversicherungsträger (Hrsg.) (2004b); Verband Deutscher Rentenversicherungsträger (Hrsg.) (2004c); Bundesversicherungsamt (Hrsg.) (2004). 
Tabelle 26: Entwicklung von Beitragssatz und Beitragsbemessungsgrenze 1970-2004

\begin{tabular}{|c|c|c|c|c|}
\hline \multirow{2}{*}{ Jahr } & \multicolumn{2}{|c|}{ Früheres Bundesgebiet } & \multicolumn{2}{|c|}{ Neue Bundesländer } \\
\hline & Beitragssatz & BBG (je Monat) & Beitragssatz & BBG (je Monat) \\
\hline 1970 & $8,2 \%$ & $614 €$ & & \\
\hline 1971 & $8,2 \%$ & $729 €$ & & \\
\hline 1972 & $8,4 \%$ & $805 €$ & & \\
\hline 1973 & $9,2 \%$ & $882 €$ & & \\
\hline 1974 & $9,5 \%$ & $959 €$ & & \\
\hline 1975 & $10,5 \%$ & $1.074 €$ & & \\
\hline 1976 & $11,3 \%$ & $1.189 €$ & & \\
\hline 1977 & $11,4 \%$ & $1.304 €$ & & \\
\hline 1978 & $11,4 \%$ & $1.419 €$ & & \\
\hline 1979 & $11,2 \%$ & $1.534 €$ & & \\
\hline 1980 & $11,4 \%$ & $1.611 €$ & & \\
\hline 1981 & $11,8 \%$ & $1.687 €$ & & \\
\hline 1982 & $12,0 \%$ & $1.802 €$ & & \\
\hline 1983 & $11,8 \%$ & $1.917 €$ & & \\
\hline 1984 & $11,4 \%$ & $1.994 €$ & & \\
\hline 1985 & $11,8 \%$ & $2.071 €$ & & \\
\hline 1986 & $12,2 \%$ & $2.147 €$ & & \\
\hline 1987 & $12,6 \%$ & $2.186 €$ & & \\
\hline 1988 & $12,9 \%$ & $2.301 €$ & & \\
\hline 1989 & $12,9 \%$ & $2.339 €$ & & \\
\hline 1990 & $12,6 \%$ & $2.416 €$ & & \\
\hline 1991 & $12,2 \%$ & $2.493 €$ & $12,8 \%$ & $1.150 €$ \\
\hline 1992 & $12,7 \%$ & $2.608 €$ & $12,6 \%$ & $1.841 €$ \\
\hline 1993 & $13,4 \%$ & $2.761 €$ & $12,6 \%$ & $2.032 €$ \\
\hline 1994 & $13,2 \%$ & $2.914 €$ & $13,0 \%$ & $2.262 €$ \\
\hline 1995 & $13,2 \%$ & $2.991 €$ & $12,8 \%$ & $2.454 €$ \\
\hline 1996 & $13,5 \%$ & $3.068 €$ & $13,5 \%$ & $2.608 €$ \\
\hline 1997 & $13,5 \%$ & $3.144 €$ & $13,9 \%$ & $2.723 €$ \\
\hline 1998 & $13,6 \%$ & $3.221 €$ & $14,0 \%$ & $2.684 €$ \\
\hline 1999 & $13,5 \%$ & $3.259 €$ & $13,9 \%$ & $2.761 €$ \\
\hline 2000 & $13,5 \%$ & $3.298 €$ & $13,8 \%$ & $2.723 €$ \\
\hline 2001 & $13,6 \%$ & $3.336 €$ & $13,7 \%$ & $3.336 €$ \\
\hline 2002 & $14,0 \%$ & $3.375 €$ & $13,9 \%$ & $3.375 €$ \\
\hline 2003 & $14,4 \%$ & $3.450 €$ & $14,1 \%$ & $3.450 €$ \\
\hline 2004 & $14,3 \%$ & $3.488 €$ & $14,0 \%$ & $3.488 €$ \\
\hline
\end{tabular}

Quelle: Eigene Darstellung; Daten: BMGS. 
Tabelle 27: Entwicklung von GKV-Ausgaben und BIP 1970-2004

\begin{tabular}{|c|c|c|c|c|c|}
\hline \multirow{2}{*}{ Jahr } & \multicolumn{2}{|c|}{ GKV-Ausgaben ${ }^{11,2)}$} & \multicolumn{2}{|c|}{ Nominales BIP ${ }^{2)}$} & \multirow{2}{*}{$\begin{array}{c}\text { GKV-Ausgaben } \\
\text { / BIP }\end{array}$} \\
\hline & in Mio. Euro & Wachstumsrate & in Mio. Euro & Wachstumsrate & \\
\hline 1970 & 12.874 & & 345.275 & & $3,73 \%$ \\
\hline 1971 & 15.922 & $23,67 \%$ & 383.367 & $11,03 \%$ & $4,15 \%$ \\
\hline 1972 & 18.612 & $16,89 \%$ & 420.844 & $9,78 \%$ & $4,42 \%$ \\
\hline 1973 & 22.173 & $19,13 \%$ & 469.008 & $11,44 \%$ & $4,73 \%$ \\
\hline 1974 & 26.490 & $19,47 \%$ & 503.060 & $7,26 \%$ & $5,27 \%$ \\
\hline 1975 & 31.184 & $17,72 \%$ & 524.892 & $4,34 \%$ & $5,94 \%$ \\
\hline 1976 & 34.033 & $9,14 \%$ & 572.903 & $9,15 \%$ & $5,94 \%$ \\
\hline 1977 & 35.700 & $4,90 \%$ & 611.147 & $6,68 \%$ & $5,84 \%$ \\
\hline 1978 & 38.239 & $7,11 \%$ & 656.243 & $7,38 \%$ & $5,83 \%$ \\
\hline 1979 & 41.447 & $8,39 \%$ & 709.878 & $8,17 \%$ & $5,84 \%$ \\
\hline 1980 & 45.931 & $10,82 \%$ & 752.642 & $6,02 \%$ & $6,10 \%$ \\
\hline 1981 & 49.284 & $7,30 \%$ & 784.818 & $4,28 \%$ & $6,28 \%$ \\
\hline 1982 & 49.710 & $0,86 \%$ & 811.978 & $3,46 \%$ & $6,12 \%$ \\
\hline 1983 & 51.483 & $3,57 \%$ & 853.111 & $5,07 \%$ & $6,03 \%$ \\
\hline 1984 & 55.567 & $7,93 \%$ & 895.216 & $4,94 \%$ & $6,21 \%$ \\
\hline 1985 & 58.342 & $5,00 \%$ & 932.177 & $4,13 \%$ & $6,26 \%$ \\
\hline 1986 & 61.287 & $5,05 \%$ & 984.385 & $5,60 \%$ & $6,23 \%$ \\
\hline 1987 & 63.910 & $4,28 \%$ & 1.017 .716 & $3,39 \%$ & $6,28 \%$ \\
\hline 1988 & 68.705 & $7,50 \%$ & 1.071 .658 & $5,30 \%$ & $6,41 \%$ \\
\hline 1989 & 66.431 & $-3,31 \%$ & 1.137 .338 & $6,13 \%$ & $5,84 \%$ \\
\hline 1990 & 72.427 & $9,03 \%$ & 1.240 .394 & $9,06 \%$ & $5,84 \%$ \\
\hline 1991 & 93.588 & & 1.502 .200 & & $6,23 \%$ \\
\hline 1992 & 107.625 & $15,00 \%$ & 1.613 .201 & $7,39 \%$ & $6,67 \%$ \\
\hline 1993 & 108.282 & $0,61 \%$ & 1.654 .200 & $2,54 \%$ & $6,55 \%$ \\
\hline 1994 & 117.391 & $8,41 \%$ & 1.735 .500 & $4,91 \%$ & $6,76 \%$ \\
\hline 1995 & 124.005 & $5,63 \%$ & 1.801 .300 & $3,79 \%$ & $6,88 \%$ \\
\hline 1996 & 127.921 & $3,16 \%$ & 1.833 .700 & $1,80 \%$ & $6,98 \%$ \\
\hline 1997 & 125.293 & $-2,05 \%$ & 1.871 .600 & $2,07 \%$ & $6,69 \%$ \\
\hline 1998 & 127.473 & $1,74 \%$ & 1.929 .400 & $3,09 \%$ & $6,61 \%$ \\
\hline 1999 & 130.918 & $2,70 \%$ & 1.978 .600 & $2,55 \%$ & $6,62 \%$ \\
\hline 2000 & 133.824 & $2,22 \%$ & 2.030 .000 & $2,60 \%$ & $6,59 \%$ \\
\hline 2001 & 138.807 & $3,72 \%$ & 2.074 .000 & $2,17 \%$ & $6,69 \%$ \\
\hline 2002 & 143.628 & $3,47 \%$ & 2.107 .300 & $1,61 \%$ & $6,81 \%$ \\
\hline 2003 & 145.095 & $1,02 \%$ & 2.128 .200 & $0,99 \%$ & $6,81 \%$ \\
\hline 2004 & 140.180 & $-3,39 \%$ & 2.177 .000 & $2,29 \%$ & $6,44 \%$ \\
\hline
\end{tabular}

1) Leistungsausgaben, Verwaltungskosten, Krankengeld und sonstige Ausgaben ohne RSA.

2) Bis 1990 früheres Bundesgebiet, ab 1991 Deutschland.

Quelle: Eigene Berechnungen; Daten: BMGS; Statistisches Bundesamt. 
Tabelle 28: Einfluss der Ausgabenseite auf den Beitragssatz im Jahr 2004 (Früheres Bundesgebiet)

\begin{tabular}{|c|c|c|c|c|c|c|c|c|}
\hline $\begin{array}{l}\text { Basis } \\
\text {-jahr }\end{array}$ & $\begin{array}{c}\text { Ausgaben } \\
\text { in Mio. } \\
\text { Euro" }\end{array}$ & $\begin{array}{c}\text { Nomi- } \\
\text { nales BIP } \\
\text { in Mio. } \\
\text { Euro }^{2)}\end{array}$ & $\begin{array}{c}\text { Gesund- } \\
\text { heits- } \\
\text { ausgaben } \\
\text { quote }\end{array}$ & $\begin{array}{c}\text { Fiktive } \\
\text { Ausgaben } \\
\text { im Jahr } \\
2004^{3)} \text { in } \\
\text { Mio. Euro }\end{array}$ & $\begin{array}{l}\text { Tatsäch- } \\
\text { liche } \\
\text { Ausgaben } \\
\text { im Jahr } \\
2004 \text { in } \\
\text { Mio. Euro }\end{array}$ & $\begin{array}{c}\text { Ausgaben } \\
\text { differenz } \\
\text { in Mio. } \\
\text { Euro }\end{array}$ & $\begin{array}{c}\text { Beitrags- } \\
\text { pflichtige Ein- } \\
\text { nahmen } \\
\text { im Jahr } 2004 \\
\text { in Mio. Euro }\end{array}$ & $\begin{array}{l}\text { Beitrags- } \\
\text { satzeffekt } \\
\text { in } \\
\text { Prozent- } \\
\text { punkten }\end{array}$ \\
\hline & (1) & (2) & $\begin{array}{c}(3)= \\
(1) /(2)\end{array}$ & $\begin{array}{c}(4)= \\
(2)_{2004}^{*}(3)\end{array}$ & (5) & $\begin{array}{c}(6)= \\
(5)-(4)\end{array}$ & (7) & $\begin{array}{c}(8)= \\
(6) /(7)\end{array}$ \\
\hline 1971 & 12.874 & 345.275 & $3,73 \%$ & 72.121 & \multirow{35}{*}{116.490} & 44.369 & \multirow{35}{*}{816.000} & 5,44 \\
\hline 1971 & 15.922 & 383.367 & $4,15 \%$ & 80.333 & & 36.157 & & 4,43 \\
\hline 1972 & 18.612 & 420.844 & $4,42 \%$ & 85.542 & & 30.948 & & 3,79 \\
\hline 1973 & 22.173 & 469.008 & $4,73 \%$ & 91.444 & & 25.046 & & 3,07 \\
\hline 1974 & 26.490 & 503.060 & $5,27 \%$ & 101.853 & & 14.637 & & 1,79 \\
\hline 1975 & 31.184 & 524.892 & $5,94 \%$ & 114.915 & & 1.575 & & 0,19 \\
\hline 1976 & 34.033 & 572.903 & $5,94 \%$ & 114.905 & & 1.585 & & 0,19 \\
\hline 1977 & 35.700 & 611.147 & $5,84 \%$ & 112.990 & & 3.500 & & 0,43 \\
\hline 1978 & 38.239 & 656.243 & $5,83 \%$ & 112.710 & & 3.780 & & 0,46 \\
\hline 1979 & 41.447 & 709.878 & $5,84 \%$ & 112.935 & & 3.555 & & 0,44 \\
\hline 1980 & 45.931 & 752.642 & $6,10 \%$ & 118.043 & & -1.553 & & $-0,19$ \\
\hline 1981 & 49.284 & 784.818 & $6,28 \%$ & 121.466 & & -4.976 & & $-0,61$ \\
\hline 1982 & 49.710 & 811.978 & $6,12 \%$ & 118.418 & & -1.928 & & $-0,24$ \\
\hline 1983 & 51.483 & 853.111 & $6,03 \%$ & 116.729 & & -239 & & $-0,03$ \\
\hline 1984 & 55.567 & 895.216 & $6,21 \%$ & 120.062 & & -3.572 & & $-0,44$ \\
\hline 1985 & 58.342 & 932.177 & $6,26 \%$ & 121.062 & & -4.572 & & $-0,56$ \\
\hline 1986 & 61.287 & 984.385 & $6,23 \%$ & 120.427 & & -3.937 & & $-0,48$ \\
\hline 1987 & 63.910 & 1.017 .716 & $6,28 \%$ & 121.468 & & -4.978 & & $-0,61$ \\
\hline 1988 & 68.705 & 1.071 .658 & $6,41 \%$ & 124.009 & & -7.519 & & $-0,92$ \\
\hline 1989 & 66.431 & 1.137 .338 & $5,84 \%$ & 112.979 & & 3.511 & & 0,43 \\
\hline 1990 & 72.427 & 1.240 .394 & $5,84 \%$ & 112.943 & & 3.547 & & 0,43 \\
\hline 1991 & 81.711 & \begin{tabular}{|c|}
1.385 .769 \\
\end{tabular} & $5,90 \%$ & 114.054 & & 2.436 & & 0,30 \\
\hline 1992 & 90.435 & 1.464 .635 & $6,17 \%$ & 119.434 & & -2.944 & & $-0,36$ \\
\hline 1993 & 89.661 & 1.472 .241 & $6.09 \%$ & 117.800 & & -1.310 & & $-0,16$ \\
\hline 1994 & 96.265 & 1.526 .592 & $6,31 \%$ & 121.973 & & -5.483 & & $-0,67$ \\
\hline 1995 & 103.070 & 1.600 .479 & $6,44 \%$ & 124.567 & & -8.077 & & $-0,99$ \\
\hline 1996 & 106.133 & 1.624 .431 & $6,53 \%$ & 126.377 & & -9.887 & & $-1,21$ \\
\hline 1997 & 103.966 & \begin{tabular}{|l|}
1.657 .569 \\
\end{tabular} & $6,27 \%$ & 121.322 & & -4.832 & & $-0,59$ \\
\hline 1998 & 106.080 & 1.711 .689 & $6,20 \%$ & 119.875 & & -3.385 & & $-0,41$ \\
\hline 1999 & 109.030 & 1.754 .051 & $6,22 \%$ & 120.233 & & -3.743 & & $-0,46$ \\
\hline 2000 & 111.585 & 1.803 .103 & $6,19 \%$ & 119.703 & & -3.213 & & $-0,39$ \\
\hline 2001 & 115.670 & 1.844 .014 & $6,12 \%$ & 118.367 & & -1.877 & & $-0,23$ \\
\hline 2002 & 119.431 & 1.872 .659 & $6,38 \%$ & 123.361 & & -6.871 & & $-0,84$ \\
\hline 2003 & 120.476 & 1.890 .205 & $6,37 \%$ & 123.285 & & -6.795 & & $-0,83$ \\
\hline 2004 & 116.490 & 1.934 .281 & $6,02 \%$ & 116.490 & & 0 & & 0,00 \\
\hline
\end{tabular}

1) Leistungsausgaben, Verwaltungskosten, Krankengeld und sonstige Ausgaben ohne RSA. Ab 1995 wird Berlin-Ost dem Früheren Bundesgebiet zugerechnet.

2) Ab 1995 wird Berlin-Ost in den Statistiken der GKV dem Früheren Bundesgebiet zugerechnet. Da BIP-Daten nach dem Europäischen System Volkswirtschaftlicher Gesamtrechnungen (ESVG 1995) nicht getrennt für Berlin-West und Berlin-Ost vorliegen, wurde für die Jahre 1991-1994 das BIP von Berlin anhand von Eurostat-Daten nach der ESVG 1979 anteilig auf Berlin-West und Berlin-Ost verteilt und das BIP von Berlin-West dem BIP des Früheren Bundesgebiets hinzugerechnet. 
3) Ausgaben der GKV, die sich im Jahr 2004 ergeben hätten, wenn seit dem Basisjahr die Gesundheitsausgabenquote konstant geblieben wäre oder m.a.W., wenn seit dem Basisjahr die Ausgaben um die gleiche Rate zugenommen hätten wie das nominale BIP.

Quelle: Eigene Berechnungen in Anlehnung an SVR (2002), Ziff. 246; Daten: Arbeitskreis Volkswirtschaftliche Gesamtrechnungen der Länder; BMGS; Statistisches Bundesamt.

\section{Tabelle 29: Einfluss der Ausgabenseite auf den Beitragssatz im Jahr 2004 (Neue Bundesländer)}

\begin{tabular}{|c|c|c|c|c|c|c|c|c|}
\hline $\begin{array}{l}\text { Basis } \\
\text {-jahr }\end{array}$ & $\mid \begin{array}{c}\text { Ausgaben } \\
\text { in Mio. } \\
\text { Euro }\end{array}$ & $\begin{array}{c}\text { Nomi- } \\
\text { nales BIP } \\
\text { in Mio. } \\
\text { Euro }^{2)}\end{array}$ & $\begin{array}{c}\text { Gesund- } \\
\text { heits- } \\
\text { ausgaben } \\
\text { quote }\end{array}$ & $\begin{array}{c}\text { Fiktive } \\
\text { Ausgaben } \\
\text { im Jahr } \\
2004^{3)} \text { in } \\
\text { Mio. Euro }\end{array}$ & $\begin{array}{l}\text { Tatsäch- } \\
\text { liche } \\
\text { Ausgaben } \\
\text { im Jahr } \\
2004 \text { in } \\
\text { Mio. Euro }\end{array}$ & $\begin{array}{c}\text { Ausgaben } \\
\text { differenz } \\
\text { in Mio. } \\
\text { Euro }\end{array}$ & $\begin{array}{c}\text { Beitrags- } \\
\text { pflichtige Ein- } \\
\text { nahmen } \\
\text { im Jahr } 2004 \\
\text { in Mio. Euro }\end{array}$ & $\begin{array}{l}\text { Beitrags- } \\
\text { satzeffekt } \\
\text { in } \\
\text { Prozent- } \\
\text { punkten }\end{array}$ \\
\hline & (1) & (2) & $\begin{array}{c}(3)= \\
(1) /(2)\end{array}$ & $\begin{array}{c}(4)= \\
(2)_{2004}^{*}(3)\end{array}$ & (5) & $\begin{array}{c}(6)= \\
(5)-(4)\end{array}$ & (7) & $\begin{array}{c}(8)= \\
(6) /(7)\end{array}$ \\
\hline 1991 & 11.877 & 116.431 & $10,20 \%$ & 24.760 & \multirow{14}{*}{23.690} & -1.070 & \multirow{14}{*}{148.600} & $-0,72$ \\
\hline 1992 & 17.190 & 148.566 & $11,57 \%$ & 28.084 & & -4.394 & & $-2,96$ \\
\hline 1993 & 18.621 & 181.959 & $10,23 \%$ & 24.839 & & -1.149 & & $-0,77$ \\
\hline 1994 & 21.126 & 208.908 & $10,11 \%$ & 24.545 & & -855 & & $-0,58$ \\
\hline 1995 & 20.935 & 200.821 & $10,42 \%$ & 25.303 & & -1.613 & & $-1,09$ \\
\hline 1996 & 21.788 & 209.269 & $10,41 \%$ & 25.271 & & -1.581 & & $-1,06$ \\
\hline 1997 & 21.327 & 214.031 & $9,96 \%$ & 24.186 & & -496 & & $-0,33$ \\
\hline 1998 & 21.393 & 217.711 & $9,83 \%$ & 23.850 & & -160 & & $-0,11$ \\
\hline 1999 & 21.888 & 224.549 & $9,75 \%$ & 23.659 & & 31 & & 0,02 \\
\hline 2000 & 22.239 & 226.897 & $9,80 \%$ & 23.790 & & -100 & & $-0,07$ \\
\hline 2001 & 23.137 & 229.986 & $9,72 \%$ & 23.596 & & 94 & & 0,06 \\
\hline 2002 & 24.197 & 234.641 & $10,31 \%$ & 25.030 & & -1.340 & & $-0,90$ \\
\hline 2003 & 24.619 & 237.995 & $10,34 \%$ & 25.108 & & -1.418 & & $-0,95$ \\
\hline 2004 & 23.690 & 242.719 & $9,76 \%$ & 23.690 & & 0 & & 0,00 \\
\hline
\end{tabular}

1) Leistungsausgaben, Verwaltungskosten, Krankengeld und sonstige Ausgaben ohne RSA. Ab 1995 wird Berlin-Ost dem Früheren Bundesgebiet zugerechnet.

${ }^{2)}$ Ab 1995 wird Berlin-Ost in den Statistiken der GKV dem Früheren Bundesgebiet zugerechnet. Da BIP-Daten nach dem Europäischen System Volkswirtschaftlicher Gesamtrechnungen (ESVG 1995) nicht getrennt für Berlin-West und Berlin-Ost vorliegen, wurde für die Jahre 1991-1994 das BIP von Berlin anhand von Eurostat-Daten nach der ESVG 1979 anteilig auf Berlin-West und Berlin-Ost verteilt und das BIP von Berlin-Ost dem BIP der Neuen Bundesländer hinzugerechnet.

3) Ausgaben der GKV, die sich im Jahr 2004 ergeben hätten, wenn seit dem Basisjahr die Gesundheitsausgabenquote konstant geblieben wäre oder m.a.W., wenn seit dem Basisjahr die Ausgaben um die gleiche Rate zugenommen hätten wie das nominale BIP.

Quelle: Eigene Berechnungen in Anlehnung an SVR (2002), Ziff. 246; Daten: Arbeitskreis Volkswirtschaftliche Gesamtrechnungen der Länder; BMGS; Statistisches Bundesamt. 
Tabelle 30: Einfluss der Ausgabenseite auf den Beitragssatz im Jahr 2003 (Früheres Bundesgebiet)

\begin{tabular}{|c|c|c|c|c|c|c|c|c|}
\hline $\begin{array}{l}\text { Basis } \\
\text {-jahr }\end{array}$ & $\begin{array}{c}\text { Ausgaben } \\
\text { in Mio. } \\
\text { Euro }\end{array}$ & $\begin{array}{c}\text { Nomi- } \\
\text { nales BIP } \\
\text { in Mio. } \\
\text { Euro }^{2)}\end{array}$ & $\begin{array}{c}\text { Gesund- } \\
\text { heits- } \\
\text { ausgaben } \\
\text { quote }\end{array}$ & $\begin{array}{c}\text { Fiktive } \\
\text { Ausgaben } \\
\text { im Jahr } \\
2003^{3)} \text { in } \\
\text { Mio. Euro }\end{array}$ & $\begin{array}{l}\text { Tatsäch- } \\
\text { liche } \\
\text { Ausgaben } \\
\text { im Jahr } \\
2003 \text { in } \\
\text { Mio. Euro }\end{array}$ & $\begin{array}{c}\text { Ausgaben } \\
\text { differenz } \\
\text { in Mio. } \\
\text { Euro }\end{array}$ & $\begin{array}{c}\text { Beitrags- } \\
\text { pflichtige Ein- } \\
\text { nahmen } \\
\text { im Jahr } 2003 \\
\text { in Mio. Euro }\end{array}$ & $\begin{array}{l}\text { Beitrags- } \\
\text { satzeffekt } \\
\text { in } \\
\text { Prozent- } \\
\text { punkten }\end{array}$ \\
\hline & (1) & (2) & $\begin{array}{c}(3)= \\
(1) /(2)\end{array}$ & $\begin{array}{c}(4)= \\
(2)_{2003}^{*}(3)\end{array}$ & (5) & $\begin{array}{c}(6)= \\
(5)-(4)\end{array}$ & (7) & $\begin{array}{c}(8)= \\
(6) /(7)\end{array}$ \\
\hline 1970 & 12.874 & 345.275 & $3,73 \%$ & 70.478 & \multirow{34}{*}{120.476} & 49.998 & \multirow{34}{*}{805.792} & 6,20 \\
\hline 1971 & 15.922 & 383.367 & $4,15 \%$ & 78.502 & & 41.974 & & 5,21 \\
\hline 1972 & 18.612 & 420.844 & $4,42 \%$ & 83.593 & & 36.883 & & 4,58 \\
\hline 1973 & 22.173 & 469.008 & $4,73 \%$ & 89.361 & & 31.115 & & 3,86 \\
\hline 1974 & 26.490 & 503.060 & $5,27 \%$ & 99.532 & & 20.944 & & 2,60 \\
\hline 1975 & 31.184 & 524.892 & $5,94 \%$ & 112.297 & & 8.179 & & 1,02 \\
\hline 1976 & 34.033 & 572.903 & $5,94 \%$ & 112.287 & & 8.189 & & 1,02 \\
\hline 1977 & 35.700 & 611.147 & $5,84 \%$ & 110.416 & & 10.060 & & 1,25 \\
\hline 1978 & 38.239 & 656.243 & $5,83 \%$ & 110.141 & & 10.335 & & 1,28 \\
\hline 1979 & 41.447 & 709.878 & $5,84 \%$ & 110.361 & & 10.115 & & 1,26 \\
\hline 1980 & 45.931 & 752.642 & $6,10 \%$ & 115.353 & & 5.123 & & 0,64 \\
\hline 1981 & 49.284 & 784.818 & $6,28 \%$ & 118.699 & & 1.777 & & 0,22 \\
\hline 1982 & 49.710 & 811.978 & $6,12 \%$ & 115.720 & & 4.756 & & 0,59 \\
\hline 1983 & 51.483 & 853.111 & $6,03 \%$ & 114.069 & & 6.407 & & 0,80 \\
\hline 1984 & 55.567 & 895.216 & $6,21 \%$ & 117.326 & & 3.150 & & 0,39 \\
\hline 1985 & 58.342 & 932.177 & $6,26 \%$ & 118.303 & & 2.173 & & 0,27 \\
\hline 1986 & 61.287 & 984.385 & $6,23 \%$ & 117.683 & & 2.793 & & 0,35 \\
\hline 1987 & 63.910 & 1.017 .716 & $6,28 \%$ & 118.700 & & 1.776 & & 0,22 \\
\hline 1988 & 68.705 & 1.071 .658 & $6,41 \%$ & 121.183 & & -707 & & $-0,09$ \\
\hline 1989 & 66.431 & 1.137 .338 & $5,84 \%$ & 110.405 & & 10.071 & & 1,25 \\
\hline 1990 & 72.427 & 1.240 .394 & $5,84 \%$ & 110.369 & & 10.107 & & 1,25 \\
\hline 1991 & 81.711 & 1.385 .769 & $5,90 \%$ & 111.455 & & 9.021 & & 1,12 \\
\hline 1992 & 90.435 & 1.464 .635 & $6,17 \%$ & 116.712 & & 3.764 & & 0,47 \\
\hline 1993 & 89.661 & 1.472 .241 & $6,09 \%$ & 115.115 & & 5.361 & & 0,67 \\
\hline 1994 & 96.265 & 1.526 .592 & $6,31 \%$ & 119.194 & & 1.282 & & 0,16 \\
\hline 1995 & 103.070 & 1.600 .479 & $6,44 \%$ & 121.728 & & -1.252 & & $-0,16$ \\
\hline 1996 & 106.133 & 1.624 .431 & $6,53 \%$ & 123.497 & & -3.021 & & $-0,37$ \\
\hline 1997 & 103.966 & 1.657 .569 & $6,27 \%$ & 118.557 & & 1.919 & & 0,24 \\
\hline 1998 & 106.080 & 1.711 .689 & $6,20 \%$ & 117.143 & & 3.333 & & 0,41 \\
\hline 1999 & 109.030 & 1.754 .051 & $6,22 \%$ & 117.493 & & 2.983 & & 0,37 \\
\hline 2000 & 111.585 & 1.803 .103 & $6,19 \%$ & 116.975 & & 3.501 & & 0,43 \\
\hline 2001 & 115.670 & 1.844 .014 & $6,12 \%$ & 115.670 & & 4.806 & & 0,60 \\
\hline 2002 & 119.431 & 1.872 .659 & $6,38 \%$ & 120.550 & & -74 & & $-0,01$ \\
\hline 2003 & 120.476 & 1.890 .205 & $6,37 \%$ & 120.476 & & 0 & & 0,00 \\
\hline
\end{tabular}

1) Leistungsausgaben, Verwaltungskosten, Krankengeld und sonstige Ausgaben ohne RSA. Ab 1995 wird Berlin-Ost dem Früheren Bundesgebiet zugerechnet.

2) Ab 1995 wird Berlin-Ost in den Statistiken der GKV dem Früheren Bundesgebiet zugerechnet. Da BIP-Daten nach dem Europäischen System Volkswirtschaftlicher Gesamtrechnungen (ESVG 1995) nicht getrennt für Berlin-West und Berlin-Ost vorliegen, wurde für die Jahre 1991-1994 das BIP von Berlin anhand von Eurostat-Daten nach der ESVG 1979 anteilig auf Berlin-West und Berlin-Ost verteilt und das BIP von Berlin-West dem BIP des Früheren Bundesgebiets hinzugerechnet. 
3) Ausgaben der GKV, die sich im Jahr 2003 ergeben hätten, wenn seit dem Basisjahr die Gesundheitsausgabenquote konstant geblieben wäre oder m.a.W., wenn seit dem Basisjahr die Ausgaben um die gleiche Rate zugenommen hätten wie das nominale BIP.

Quelle: Eigene Berechnungen in Anlehnung an SVR (2002), Ziff. 246; Daten: Arbeitskreis Volkswirtschaftliche Gesamtrechnungen der Länder; BMGS; Statistisches Bundesamt.

Tabelle 31: Einfluss der Ausgabenseite auf den Beitragssatz im Jahr 2003 (Neue Bundesländer)

\begin{tabular}{|c|c|c|c|c|c|c|c|c|}
\hline $\begin{array}{c}\text { Basis } \\
\text {-jahr }\end{array}$ & $\begin{array}{c}\text { Ausgaben } \\
\text { in Mio. } \\
\text { Euro' }\end{array}$ & $\begin{array}{c}\text { Nomi- } \\
\text { nales BIP } \\
\text { in Mio. } \\
\text { Euro }^{2}\end{array}$ & $\begin{array}{l}\text { Gesund- } \\
\text { heits- } \\
\text { ausgaben } \\
\text { quote }\end{array}$ & $\begin{array}{c}\text { Fiktive } \\
\text { Ausgaben } \\
\text { im Jahr } \\
2003^{3)} \text { in } \\
\text { Mio. Euro }\end{array}$ & $\begin{array}{l}\text { Tatsäch- } \\
\text { liche } \\
\text { Ausgaben } \\
\text { im Jahr } \\
2003 \text { in } \\
\text { Mio. Euro }\end{array}$ & $\begin{array}{c}\text { Ausgaben } \\
\text { differenz } \\
\text { in Mio. } \\
\text { Euro }\end{array}$ & $\begin{array}{c}\text { Beitrags- } \\
\text { pflichtige Ein- } \\
\text { nahmen } \\
\text { im Jahr } 2003 \\
\text { in Mio. Euro }\end{array}$ & $\begin{array}{l}\text { Beitrags- } \\
\text { satzeffekt } \\
\text { in } \\
\text { Prozent- } \\
\text { punkten }\end{array}$ \\
\hline & (1) & (2) & $\begin{array}{c}(3)= \\
(1) /(2)\end{array}$ & $\begin{array}{c}(4)= \\
(2)_{2003}^{*}(3)\end{array}$ & (5) & $\begin{array}{c}(6)= \\
(5)-(4)\end{array}$ & (7) & $\begin{array}{c}(8)= \\
(6) /(7)\end{array}$ \\
\hline 1991 & 11.877 & 116.431 & $10,20 \%$ & 24.278 & \multirow{13}{*}{24.619} & 341 & \multirow{13}{*}{148.868} & 0,23 \\
\hline 1992 & 17.190 & 148.566 & $11,57 \%$ & 27.538 & & -2.919 & & $-1,96$ \\
\hline 1993 & 18.621 & 181.959 & $10,23 \%$ & 24.356 & & 263 & & 0,18 \\
\hline 1994 & 21.126 & 208.908 & $10,11 \%$ & 24.067 & & 552 & & 0,37 \\
\hline 1995 & 20.935 & 200.821 & $10,42 \%$ & 24.810 & & -191 & & $-0,13$ \\
\hline 1996 & 21.788 & 209.269 & $10,41 \%$ & 24.779 & & -160 & & $-0,11$ \\
\hline 1997 & 21.327 & 214.031 & $9,96 \%$ & 23.715 & & 904 & & 0,61 \\
\hline 1998 & 21.393 & 217.711 & $9,83 \%$ & 23.386 & & 1.233 & & 0,83 \\
\hline 1999 & 21.888 & 224.549 & $9,75 \%$ & 23.199 & & 1.420 & & 0,95 \\
\hline 2000 & 22.239 & 226.897 & $9,80 \%$ & 23.327 & & 1.292 & & 0,87 \\
\hline 2001 & 23.137 & 229.986 & $9,72 \%$ & 23.137 & & 1.482 & & 1,00 \\
\hline 2002 & 24.197 & 234.641 & $10,31 \%$ & 24.543 & & 76 & & 0,05 \\
\hline 2003 & 24.619 & 237.995 & $10,34 \%$ & 24.619 & & 0 & & 0,00 \\
\hline
\end{tabular}

1) Leistungsausgaben, Verwaltungskosten, Krankengeld und sonstige Ausgaben ohne RSA. Ab 1995 wird Berlin-Ost dem Früheren Bundesgebiet zugerechnet.

2) Ab 1995 wird Berlin-Ost in den Statistiken der GKV dem Früheren Bundesgebiet zugerechnet. Da BIP-Daten nach dem Europäischen System Volkswirtschaftlicher Gesamtrechnungen (ESVG 1995) nicht getrennt für Berlin-West und Berlin-Ost vorliegen, wurde für die Jahre 1991-1994 das BIP von Berlin anhand von Eurostat-Daten nach der ESVG 1979 anteilig auf Berlin-West und Berlin-Ost verteilt und das BIP von Berlin-Ost dem BIP der Neuen Bundesländer hinzugerechnet.

3) Ausgaben der GKV, die sich im Jahr 2003 ergeben hätten, wenn seit dem Basisjahr die Gesundheitsausgabenquote konstant geblieben wäre oder m.a.W., wenn seit dem Basisjahr die Ausgaben um die gleiche Rate zugenommen hätten wie das nominale BIP.

Quelle: Eigene Berechnungen in Anlehnung an SVR (2002), Ziff. 246; Daten: Arbeitskreis Volkswirtschaftliche Gesamtrechnungen der Länder; BMGS; Statistisches Bundesamt. 
Tabelle 32: Einfluss der Einnahmenseite auf den Beitragssatz im Jahr 2004 (Früheres Bundesgebiet)

\begin{tabular}{|c|c|c|c|c|c|c|c|c|}
\hline $\begin{array}{c}\text { Basis } \\
\text {-jahr }\end{array}$ & $\begin{array}{c}\text { Nomi- } \\
\text { nales BIP } \\
\text { in Mio. } \\
\text { Euro }\end{array}$ & \begin{tabular}{|} 
Beitrags- \\
pflichtige \\
Einnahmen \\
in Mio. \\
Euro
\end{tabular} & Quote & $\begin{array}{c}\text { Beitrags- } \\
\text { einnahmen } \\
\text { im Jahr } \\
2004 \text { in } \\
\text { Mio. Euro }\end{array}$ & \begin{tabular}{|c|} 
Fiktive \\
beitrags- \\
pflichtige \\
Einnahmen \\
im Jahr \\
2004 in Mio. \\
Euro $^{4}$
\end{tabular} & $\begin{array}{c}\text { Fiktiver } \\
\text { Beitrags- } \\
\text { satz }\end{array}$ & $\begin{array}{c}\text { Durchschnitt- } \\
\text { licher } \\
\text { Beitragssatz } \\
\text { im Jahr } 2004\end{array}$ & $\begin{array}{l}\text { Beitrags- } \\
\text { satzeffekt } \\
\text { in } \\
\text { Prozent- } \\
\text { punkten }\end{array}$ \\
\hline & (1) & (2) & $\begin{array}{c}(3)= \\
(2) /(1)\end{array}$ & (4) & $\begin{array}{c}(5)= \\
(1)_{2004}^{*} \text { (3) }\end{array}$ & $\begin{array}{c}(6)= \\
(4) /(5)\end{array}$ & (7) & $\begin{array}{c}(8)= \\
(7)_{2004}-(6)\end{array}$ \\
\hline 1970 & 345.275 & 155.731 & $45,10 \%$ & \multirow{35}{*}{116.443} & 872.428 & $13,35 \%$ & \multirow{35}{*}{$14,27 \%$} & 0,92 \\
\hline 1971 & 383.367 & 189.012 & $49,30 \%$ & & 953.663 & $12,21 \%$ & & 2,06 \\
\hline 1972 & 420.844 & 210.778 & $50,08 \%$ & & 968.774 & $12,02 \%$ & & 2,25 \\
\hline 1973 & 469.008 & 234.012 & $49,90 \%$ & & 965.111 & $12,07 \%$ & & 2,20 \\
\hline 1974 & 503.060 & 260.674 & $51,82 \%$ & & 1.002 .301 & $11,62 \%$ & & 2,65 \\
\hline 1975 & 524.892 & 283.219 & $53,96 \%$ & & 1.043 .690 & $11,16 \%$ & & 3,11 \\
\hline 1976 & 572.903 & 305.488 & $53,32 \%$ & & 1.031 .414 & $11,29 \%$ & & 2,98 \\
\hline 1977 & 611.147 & 315.037 & $51,55 \%$ & & 997.091 & $11,68 \%$ & & 2,59 \\
\hline 1978 & 656.243 & 325.418 & $49,59 \%$ & & 959.172 & $12,14 \%$ & & 2,13 \\
\hline 1979 & 709.878 & 348.859 & $49,14 \%$ & & 950.574 & $12,25 \%$ & & 2,02 \\
\hline 1980 & 752.642 & 374.622 & $49,77 \%$ & & 962.773 & $12,09 \%$ & & 2,18 \\
\hline 1981 & 784.818 & 394.259 & $50,24 \%$ & & 971.701 & $11,98 \%$ & & 2,29 \\
\hline 1982 & 811.978 & 411.230 & $50,65 \%$ & & 979.626 & $11,89 \%$ & & 2,38 \\
\hline 1983 & 853.111 & 426.976 & $50,05 \%$ & & 968.093 & $12,03 \%$ & & 2,24 \\
\hline 1984 & 895.216 & 451.764 & $50,46 \%$ & & 976.120 & $11,93 \%$ & & 2,34 \\
\hline 1985 & 932.177 & 463.218 & $49,69 \%$ & & 961.183 & $12,11 \%$ & & 2,16 \\
\hline 1986 & 984.385 & 477.721 & $48,53 \%$ & & 938.704 & $12,40 \%$ & & 1,87 \\
\hline 1987 & \begin{tabular}{|l|}
1.017 .716 \\
\end{tabular} & 490.489 & $48,20 \%$ & & 932.228 & $12,49 \%$ & & 1,78 \\
\hline 1988 & 1.071 .658 & 504.164 & $47,05 \%$ & & 909.988 & $12,80 \%$ & & 1,47 \\
\hline 1989 & 1.137 .338 & 530.539 & $46,65 \%$ & & 902.293 & $12,91 \%$ & & 1,36 \\
\hline 1990 & 1.240 .394 & 575.665 & $46,41 \%$ & & 897.696 & $12,97 \%$ & & 1,30 \\
\hline 1991 & 1.385 .769 & 619.069 & $44,67 \%$ & & 864.107 & $13,48 \%$ & & 0,79 \\
\hline 1992 & 1.464 .635 & 644.479 & $44,00 \%$ & & 851.136 & $13,68 \%$ & & 0,59 \\
\hline 1993 & 1.472 .241 & 679.176 & $46,13 \%$ & & 892.324 & $13,05 \%$ & & 1,22 \\
\hline 1994 & 1.526 .592 & 714.699 & $46,82 \%$ & & 905.565 & $12,86 \%$ & & 1,41 \\
\hline 1995 & 1.600 .479 & 731.832 & $45,73 \%$ & & 884.466 & $13,17 \%$ & & 1,10 \\
\hline 1996 & 1.624 .431 & 738.471 & $45,46 \%$ & & 879.330 & $13,24 \%$ & & 1,03 \\
\hline 1997 & 1.657 .569 & 745.662 & $44,99 \%$ & & 870.142 & $13,38 \%$ & & 0,89 \\
\hline 1998 & 1.711 .689 & 756.755 & $44,21 \%$ & & 855.165 & $13,62 \%$ & & 0,65 \\
\hline 1999 & 1.754 .051 & 775.226 & $44,20 \%$ & & 854.881 & $13,62 \%$ & & 0,65 \\
\hline 2000 & 1.803 .103 & 794.591 & $44,07 \%$ & & 852.398 & $13,66 \%$ & & 0,61 \\
\hline 2001 & 1.844 .014 & 804.525 & $43,63 \%$ & & 843.908 & $13,80 \%$ & & 0,47 \\
\hline 2002 & 1.872 .659 & 809.311 & $43,22 \%$ & & 835.942 & $13,93 \%$ & & 0,34 \\
\hline 2003 & 1.890 .205 & 805.792 & $42,63 \%$ & & 824.582 & $14,12 \%$ & & 0,15 \\
\hline 2004 & 1.934 .281 & 816.000 & $42,19 \%$ & & 816.000 & $14,27 \%$ & & 0,00 \\
\hline
\end{tabular}

1) Ab 1995 wird Berlin-Ost in den Statistiken der GKV dem Früheren Bundesgebiet zugerechnet. Da BIP-Daten nach dem Europäischen System Volkswirtschaftlicher Gesamtrechnungen (ESVG 1995) nicht getrennt für Berlin-West und Berlin-Ost vorliegen, wurde für die Jahre 1991-1994 das BIP von Berlin anhand von Eurostat-Daten nach der ESVG 1979 anteilig auf Berlin-West und Berlin-Ost verteilt und das BIP von Berlin-West dem BIP des Früheren Bundesgebiets hinzugerechnet.

2) Ab 1995 wird Berlin-Ost dem Früheren Bundesgebiet zugerechnet. Bis 1995 wurden die beitragspflichtigen Einnahmen selbst berechnet, ab 1996 der amtlichen Statistik entnommen. 
3) Um den Einfluss der Entwicklung der beitragspflichtigen Einnahmen auf den Beitragssatz zu schätzen, werden hier die Beitragseinnahmen verwendet, die sich bei Anwendung des Beitragssatzes auf die Beitragsbemessungsgrundlage ergeben. Weil der durchschnittliche Beitragssatz nach der Zahl der entsprechenden Mitglieder gewichtet wird und nicht nach den jeweiligen beitragspflichtigen Einnahmen, kommt es zu Abweichungen von den tatsächlichen Beitragseinnahmen. Diese betrugen im Jahr 2004 119.100 Mio. Euro.

4) Beitragspflichtige Einnahmen, die sich im Jahr 2004 ergeben hätten, wenn seit dem Basisjahr die beitragspflichtigen Einnahmen um die gleiche Rate zugenommen hätten wie das nominale BIP.

Quelle: Eigene Berechnungen in Anlehnung an SVR (2002), Ziff. 246; SVR (2004), Ziff. 343; Daten: Arbeitskreis Volkswirtschaftliche Gesamtrechnungen der Länder; BMGS; Statistisches Bundesamt.

\section{Tabelle 33: Einfluss der Einnahmenseite auf den Beitragssatz im Jahr 2004 (Neue Bundesländer)}

\begin{tabular}{|c|c|c|c|c|c|c|c|c|}
\hline $\begin{array}{l}\text { Basis } \\
\text {-jahr }\end{array}$ & $\begin{array}{l}\text { Nomi- } \\
\text { nales BIP } \\
\text { in Mio. } \\
\text { Euro }\end{array}$ & $\begin{array}{c}\text { Beitrags- } \\
\text { pflichtige } \\
\text { Einnahmen } \\
\text { in Mio. } \\
\text { Euro }^{2)}\end{array}$ & Quote & $\begin{array}{c}\text { Beitrags- } \\
\text { einnahmen } \\
\text { im Jahr } \\
2004 \text { in } \\
\text { Mio. Euro }^{3)}\end{array}$ & $\begin{array}{c}\text { Fiktive } \\
\text { beitrags- } \\
\text { pflichtige } \\
\text { Einnahmen } \\
\text { im Jahr } \\
2004 \text { in Mio. } \\
\text { Euro }^{4)}\end{array}$ & $\begin{array}{c}\text { Fiktiver } \\
\text { Beitrags- } \\
\text { satz }\end{array}$ & $\begin{array}{c}\text { Durchschnitt- } \\
\text { licher } \\
\text { Beitragssatz } \\
\text { im Jahr } 2004\end{array}$ & $\begin{array}{l}\text { Beitrags- } \\
\text { satzeffekt } \\
\text { in } \\
\text { Prozent- } \\
\text { punkten }\end{array}$ \\
\hline & (1) & (2) & $\begin{array}{c}(3)= \\
(2) /(1)\end{array}$ & (4) & $\begin{array}{c}(5)= \\
(1)_{2004}^{*}(3)\end{array}$ & $\begin{array}{c}(6)= \\
(4) /(5)\end{array}$ & (7) & $\begin{array}{c}(8)= \\
(7)_{2004}-(6)\end{array}$ \\
\hline 1991 & 116.431 & 101.628 & $87,29 \%$ & \multirow{14}{*}{20.834} & 211.861 & $9,83 \%$ & \multirow{14}{*}{$14,02 \%$} & 4,19 \\
\hline 1992 & 148.566 & 130.956 & $88,15 \%$ & & 213.949 & $9,74 \%$ & & 4,28 \\
\hline 1993 & 181.959 & 150.372 & $82,64 \%$ & & 200.585 & $10,39 \%$ & & 3,63 \\
\hline 1994 & 208.908 & 157.656 & $75,47 \%$ & & 183.172 & $11,37 \%$ & & 2,65 \\
\hline 1995 & 200.821 & 150.393 & $74,89 \%$ & & 181.770 & $11,46 \%$ & & 2,56 \\
\hline 1996 & 209.269 & 150.653 & $71,99 \%$ & & 174.734 & $11,92 \%$ & & 2,10 \\
\hline 1997 & 214.031 & 149.963 & $70,07 \%$ & & 170.064 & $12,25 \%$ & & 1,77 \\
\hline 1998 & 217.711 & 147.781 & $67,88 \%$ & & 164.756 & $12,65 \%$ & & 1,37 \\
\hline 1999 & 224.549 & 148.634 & $66,19 \%$ & & 160.661 & $12,97 \%$ & & 1,05 \\
\hline 2000 & 226.897 & 148.375 & $65,39 \%$ & & 158.721 & $13,13 \%$ & & 0,89 \\
\hline 2001 & 229.986 & 150.988 & $65,65 \%$ & & 159.347 & $13,07 \%$ & & 0,95 \\
\hline 2002 & 234.641 & 151.077 & $64,39 \%$ & & 156.278 & $13,33 \%$ & & 0,69 \\
\hline 2003 & 237.995 & 148.868 & $62,55 \%$ & & 151.823 & $13,72 \%$ & & 0,30 \\
\hline 2004 & 242.719 & 148.600 & $61,22 \%$ & & 148.600 & $14,02 \%$ & & 0,00 \\
\hline
\end{tabular}

1) Ab 1995 wird Berlin-Ost in den Statistiken der GKV dem Früheren Bundesgebiet zugerechnet. Da BIP-Daten nach dem Europäischen System Volkswirtschaftlicher Gesamtrechnungen (ESVG 1995) nicht getrennt für Berlin-West und Berlin-Ost vorliegen, wurde für die Jahre 1991-1994 das BIP von Berlin anhand von Eurostat-Daten nach der ESVG 1979 anteilig auf Berlin-West und Berlin-Ost verteilt und das BIP von Berlin-Ost dem BIP der Neuen Bundesländer hinzugerechnet.

${ }^{2)}$ Ab 1995 wird Berlin-Ost dem Früheren Bundesgebiet zugerechnet. Bis 1995 wurden die beitragspflichtigen Einnahmen selbst berechnet, ab 1996 der amtlichen Statistik entnommen.

3) Um den Einfluss der Entwicklung der beitragspflichtigen Einnahmen auf den Beitragssatz zu schätzen, werden hier die Beitragseinnahmen verwendet, die sich bei Anwendung des Beitragssatzes auf die Beitragsbemessungsgrundlage ergeben. Weil der durchschnittliche Beitragssatz nach der Zahl der entsprechenden Mitglieder gewichtet wird und nicht nach den jeweiligen beitragspflichtigen Einnahmen, kommt es zu Abweichungen von den tatsächlichen Beitragseinnahmen. Diese betrugen im Jahr 200421.010 Mio. Euro.

4) Beitragspflichtige Einnahmen, die sich im Jahr 2004 ergeben hätten, wenn seit dem Basisjahr die beitragspflichtigen Einnahmen um die gleiche Rate zugenommen hätten wie das nominale BIP.

Quelle: Eigene Berechnungen in Anlehnung an SVR (2002), Ziff. 246; SVR (2004), Ziff. 343; Daten:

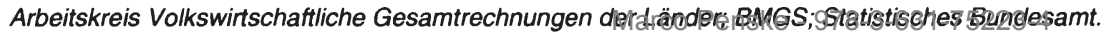


Tabelle 34: Entwicklung von beitragspflichtigen Einnahmen und BIP 1970-2004 (Früheres Bundesgebiet)

\begin{tabular}{|c|c|c|c|c|c|c|c|c|}
\hline \multirow{3}{*}{ Jahr } & \multicolumn{2}{|c|}{ Nominales BIP } & \multicolumn{4}{|c|}{ Beitragspflichtige Einnahmen } & \multicolumn{2}{|c|}{ Beitragssatz } \\
\hline & $\begin{array}{l}\text { in Mio. } \\
\text { Euro }\end{array}$ & $\begin{array}{c}\text { Wachs- } \\
\text { tumsrate zum } \\
\text { Basisjahr } \\
1975\end{array}$ & $\begin{array}{l}\text { in Mio. } \\
\text { Euro }^{2 j}\end{array}$ & $\begin{array}{c}\text { Wachs- } \\
\text { tumsrate } \\
\text { zum } \\
\text { Basisjahr } \\
1975\end{array}$ & $\begin{array}{c}\text { Fiktive } \\
\text { beitrags- } \\
\text { pflichtige } \\
\text { Einnahmen } \\
\text { in Mio. Euro }{ }^{3)}\end{array}$ & Differenz & $\begin{array}{l}\text { Allge- } \\
\text { meiner } \\
\text { Beitrags- } \\
\text { satz }\end{array}$ & $\begin{array}{c}\text { Fiktiver } \\
\text { Beitrags- } \\
\text { satz }\end{array}$ \\
\hline & (1) & $\begin{array}{c}(2)= \\
\left((1)-(1)_{1975}\right) \\
/(1)_{1975}\end{array}$ & (3) & (4) & $\begin{array}{c}(5)= \\
(5)_{1975}+ \\
(5)_{1975}^{*}(2)\end{array}$ & $\begin{array}{c}(6)= \\
(3) \cdot(5)\end{array}$ & (7) & $\begin{array}{c}(8)= \\
(7) *(3) \\
/(5)\end{array}$ \\
\hline 1970 & 345.275 & & 155.731 & & & & $8,20 \%$ & \\
\hline 1971 & 383.367 & $-26,96 \%$ & 189.012 & $-33,26 \%$ & & & $8,10 \%$ & \\
\hline 1972 & 420.844 & $-19,82 \%$ & 210.778 & $-25,58 \%$ & & & $8,40 \%$ & \\
\hline 1973 & 469.008 & $-10,65 \%$ & 234.012 & $-17,37 \%$ & & & $9,20 \%$ & \\
\hline 1974 & 503.060 & $-4,16 \%$ & 260.674 & $-7,96 \%$ & & & $9,50 \%$ & \\
\hline 1975 & 524.892 & $0,00 \%$ & 283.219 & $0,00 \%$ & 283.219 & 0 & $10,50 \%$ & $10,50 \%$ \\
\hline 1976 & 572.903 & $9,15 \%$ & 305.488 & $7,86 \%$ & 309.124 & -3.636 & $11,30 \%$ & $11,17 \%$ \\
\hline 1977 & 611.147 & $16,43 \%$ & 315.037 & $11,23 \%$ & 329.760 & -14.723 & $11,40 \%$ & $10,89 \%$ \\
\hline 1978 & 656.243 & $25,02 \%$ & 325.418 & $14,90 \%$ & 354.092 & -28.674 & $11,50 \%$ & $10,57 \%$ \\
\hline 1979 & 709.878 & $35,24 \%$ & 348.859 & $23,18 \%$ & 383.032 & -34.173 & $11,30 \%$ & $10,29 \%$ \\
\hline 1980 & 752.642 & $43,39 \%$ & 374.622 & $32,27 \%$ & 406.107 & -31.485 & $11,40 \%$ & $10,52 \%$ \\
\hline 1981 & 784.818 & $49,52 \%$ & 394.259 & $39,21 \%$ & 423.468 & -29.209 & $11,80 \%$ & $10,99 \%$ \\
\hline 1982 & 811.978 & $54,69 \%$ & 411.230 & $45,20 \%$ & 438.123 & -26.893 & $12,00 \%$ & $11,26 \%$ \\
\hline 1983 & 853.111 & $62,53 \%$ & 426.976 & $50,76 \%$ & 460.317 & -33.342 & $11,80 \%$ & $10,95 \%$ \\
\hline 1984 & 895.216 & $70,55 \%$ & 451.764 & $59,51 \%$ & 483.036 & -31.272 & $11,40 \%$ & $10,66 \%$ \\
\hline 1985 & 932.177 & $77,59 \%$ & 463.218 & $63,55 \%$ & 502.979 & -39.762 & $11,80 \%$ & $10,87 \%$ \\
\hline 1986 & 984.385 & $87,54 \%$ & 477.721 & $68,68 \%$ & 531.150 & -53.429 & $12,20 \%$ & $10,97 \%$ \\
\hline 1987 & 1.017 .716 & $93,89 \%$ & 490.489 & $73,18 \%$ & 549.134 & -58.645 & $12,60 \%$ & $11,25 \%$ \\
\hline 1988 & 1.071 .658 & $104,17 \%$ & 504.164 & $78,01 \%$ & 578.240 & -74.075 & $13,00 \%$ & $11,33 \%$ \\
\hline 1989 & 1.137 .338 & $116,68 \%$ & 530.539 & $87,32 \%$ & 613.679 & -83.140 & $13,00 \%$ & $11,24 \%$ \\
\hline 1990 & 1.240 .394 & $136,31 \%$ & 575.665 & $103,26 \%$ & 669.286 & -93.621 & $12,60 \%$ & $10,84 \%$ \\
\hline 1991 & 1.385 .769 & $164,01 \%$ & 619.069 & $118,58 \%$ & 747.726 & -128.658 & $12,22 \%$ & $10,12 \%$ \\
\hline 1992 & 1.464 .635 & $179,04 \%$ & 644.479 & $127,56 \%$ & 790.280 & -145.801 & $12,46 \%$ & $10,16 \%$ \\
\hline 1993 & 1.472 .241 & $180,48 \%$ & \begin{tabular}{|l|}
679.176 \\
\end{tabular} & $139,81 \%$ & 794.384 & -115.209 & $13,42 \%$ & $11,47 \%$ \\
\hline 1994 & 1.526 .592 & $190,84 \%$ & 714.699 & $152,35 \%$ & 823.711 & -109.012 & $13,40 \%$ & $11,63 \%$ \\
\hline 1995 & 1.600 .479 & $204,92 \%$ & 731.832 & $158,40 \%$ & 863.578 & -131.746 & $13,20 \%$ & $11,19 \%$ \\
\hline 1996 & 1.624 .431 & $209,48 \%$ & 738.471 & $160,74 \%$ & 876.502 & -138.031 & $13,40 \%$ & $11,29 \%$ \\
\hline 1997 & 1.657 .569 & $215,79 \%$ & 745.662 & $163,28 \%$ & 894.383 & -148.721 & $13,50 \%$ & $11,26 \%$ \\
\hline 1998 & 1.711 .689 & $226,10 \%$ & 756.755 & $167,20 \%$ & 923.584 & -166.829 & $13,55 \%$ & $11,10 \%$ \\
\hline 1999 & 1.754 .051 & $234,17 \%$ & 775.226 & $173,72 \%$ & 946.442 & -171.216 & $13,54 \%$ & $11,09 \%$ \\
\hline 2000 & 1.803 .103 & $243,52 \%$ & 794.591 & $180,56 \%$ & 972.909 & -178.318 & $13,52 \%$ & $11,04 \%$ \\
\hline 2001 & 1.844 .014 & $251,31 \%$ & 804.525 & $184,06 \%$ & 994.984 & -190.459 & $13,56 \%$ & $10,96 \%$ \\
\hline 2002 & 1.872 .659 & $256,77 \%$ & 809.311 & $185,75 \%$ & 1.010 .440 & -201.129 & $14,00 \%$ & $11,21 \%$ \\
\hline 2003 & 1.890 .205 & $260,11 \%$ & 805.792 & $184,51 \%$ & 1.019 .907 & -214.115 & $14,35 \%$ & $11,34 \%$ \\
\hline 2004 & 1.934 .281 & $268,51 \%$ & 816.000 & $188,12 \%$ & 1.043 .690 & -227.690 & $14,27 \%$ & $11,16 \%$ \\
\hline
\end{tabular}

1) Ab 1995 wird Berlin-Ost in den Statistiken der GKV dem Früheren Bundesgebiet zugerechnet. Da BIP-Daten nach dem Europäischen System Volkswirtschaftlicher Gesamtrechnungen (ESVG 1995) nicht getrennt für Berlin-West und Berlin-Ost vorliegen, wurde für die Jahre 1991-1994 das BIP von Berlin anhand von Eurostat-Daten nach der ESVG 1979 anteilig auf Berlin-West und Berlin-Ost verteilt und das BIP von Berlin-West dem BIP des Früheren Bundesgebjets.shinzugerechnet. 
2) Ab 1995 wird Berlin-Ost dem Früheren Bundesgebiet zugerechnet. Bis 1995 wurden die beitragspflichtigen Einnahmen selbst berechnet, ab 1996 der amtlichen Statistik entnommen.

3) Beitragspflichtige Einnahmen, die sich ergeben hätten, wenn die beitragspflichtigen Einnahmen seit 1975 mit der gleichen Rate gewachsen wären wie das nominale BIP.

Quelle: Eigene Berechnungen in Anlehnung an Wille, E. (2001), S: 13f.; Daten: Arbeitskreis Volkswirtschattliche Gesamtrechnungen der Länder; BMGS; Statistisches Bundesamt.

Tabelle 35: Entwicklung von beitragspflichtigen Einnahmen und BIP 1991-2004 (Neue Bundesländer)

\begin{tabular}{|c|c|c|c|c|c|c|c|c|}
\hline \multirow{3}{*}{ Jahr } & \multicolumn{2}{|c|}{ Nominales BIP } & \multicolumn{4}{|c|}{ Beitragspflichtige Einnahmen } & \multicolumn{2}{|c|}{ Beitragssatz } \\
\hline & $\begin{array}{l}\text { in Mio. } \\
\text { Euro }\end{array}$ & $\mid \begin{array}{c}\text { Wachs- } \\
\text { tumsrate zum } \\
\text { Basisjahr } \\
1991\end{array}$ & $\begin{array}{l}\text { in Mio } \\
\text { Euro }^{2)}\end{array}$ & $\begin{array}{l}\text { Wachs- } \\
\text { tumsrate } \\
\text { zum } \\
\text { Basisjahr } \\
1991\end{array}$ & $\begin{array}{c}\text { Fiktive } \\
\text { beitrags- } \\
\text { pflichtige } \\
\text { Einnahmen } \\
\text { in Mio. Euro }\end{array}$ & Differenz & $\begin{array}{l}\text { Allge- } \\
\text { meiner } \\
\text { Beitrags- } \\
\text { satz }\end{array}$ & $\begin{array}{l}\text { Fiktiver } \\
\text { Beitrags- } \\
\text { satz }\end{array}$ \\
\hline & (1) & $\begin{array}{c}(2)= \\
\left((1)-(1)_{1991}\right) \\
/(1)_{1991}\end{array}$ & (3) & (4) & $\begin{array}{c}(5)= \\
(5)_{1975}+ \\
(5)_{1975}^{*}(2)\end{array}$ & $\begin{array}{c}(6)= \\
(3)-(5)\end{array}$ & (7) & $\begin{array}{c}(8)= \\
(7) *(3) \\
/(5)\end{array}$ \\
\hline 1991 & 116.431 & & 101.628 & & 101.628 & 4 & $12,80 \%$ & $12,80 \%$ \\
\hline 1992 & 148.566 & $7,60 \%$ & 130.956 & 28 , & 9.678 & 1.278 & 12 & 86 \\
\hline 1993 & 181.959 & $8 \%$ & 150.372 & 47 & 58.825 & -8.453 & 12 & 87 \\
\hline 1994 & 208.908 &, $43 \%$ & 157.656 & 55 & 182.349 & -24.693 & $12,97 \%$ & $11,21^{\circ}$ \\
\hline 1995 & 200.821 & $72,48 \%$ & 150.393 & $47,98 \%$ & 175.289 & -24.896 & $12,84 \%$ & $11,02^{\circ}$ \\
\hline 1996 & 209.269 & $79,74 \%$ & 150.653 & $48,24 \%$ & 182.663 & -32.010 & $13,28 \%$ & $10,95^{\circ}$ \\
\hline 1997 & 214.031 & $83,83 \%$ & 149.963 & $47,56 \%$ & 186.820 & -36.857 & $13,73 \%$ & $11,02^{\circ}$ \\
\hline 1998 & 217.711 & $99 \%$ & 147.781 & & 190.032 & -42.251 & $13,95 \%$ & $10,85^{\circ}$ \\
\hline 1999 & 224.549 & $92,86 \%$ & 148.634 & $46,25 \%$ & 196.001 & -47.367 & $13,92 \%$ & 10,56 \\
\hline 2000 & 226.897 & $94,88 \%$ & 148.375 & $46,00 \%$ & 198.050 & -49.675 & $13,81 \%$ & 10,35 \\
\hline 2001 & 229.986 & $97,53 \%$ & 150.988 & $48,57 \%$ & 200.746 & -49.758 & $13,67 \%$ & 10,28 \\
\hline 2002 & 234.641 & $101,53 \%$ & 151.077 & $48,66 \%$ & 204.810 & -53.733 & $13,88 \%$ & $10,24^{\circ}$ \\
\hline 2003 & 237.995 & $4,41 \%$ & 148.868 & $46,48 \%$ & 207.737 & -58.869 & $14,12 \%$ & $10,12^{\circ}$ \\
\hline 2004 & 242.719 & $108,47 \%$ & 148.600 & $46,22 \%$ & 211.861 & -63.261 & $14,02 \%$ & $9,83 \%$ \\
\hline
\end{tabular}

1) Ab 1995 wird Berlin-Ost in den Statistiken der GKV dem Früheren Bundesgebiet zugerechnet. Da BIP-Daten nach dem Europäischen System Volkswirtschaftlicher Gesamtrechnungen (ESVG 1995) nicht getrennt für Berlin-West und Berlin-Ost vorliegen, wurde für die Jahre 1991-1994 das BIP von Berlin anhand von Eurostat-Daten nach der ESVG 1979 anteilig auf Berlin-West und Berlin-Ost verteilt und das BIP von Berlin-Ost dem BIP der Neuen Bundesländer hinzugerechnet.

2) Ab 1995 wird Berlin-Ost dem Früheren Bundesgebiet zugerechnet. Bis 1995 wurden die beitragspflichtigen Einnahmen selbst berechnet, ab 1996 der amtlichen Statistik entnommen.

3) Beitragspflichtige Einnahmen, die sich ergeben hätten, wenn die beitragspflichtigen Einnahmen seit 1991 mit der gleichen Rate gewachsen wären wie das nominale BIP.

Quelle: Eigene Berechnungen in Anlehnung an Wille, E. (2001), S: 13f.; Daten: Arbeitskreis Volkswirtschaftliche Gesamtrechnungen der Länder; BMGS; Statistisches Bundesamt. 
Tabelle 36: GKV-Mitgliederstruktur 1991-2004

\begin{tabular}{|r|r|r|r|r|r|r|r|r|}
\hline & & \multicolumn{3}{|c|}{ Darunter } & \multicolumn{3}{|c|}{ Wachstum (1991=100) } \\
\cline { 2 - 9 } & $\begin{array}{c}\text { Mitglieder } \\
\text { gesamt } \\
\text { (in 1.000) }\end{array}$ & $\begin{array}{c}\text { Pflicht- } \\
\text { versicherte } \\
\text { Mitglieder } \\
\text { ohne } \\
\text { Rentner } \\
\text { (in 1.000) }\end{array}$ & $\begin{array}{c}\text { Pflicht- } \\
\text { versicherte } \\
\text { Rentner und } \\
\text { Renten- } \\
\text { bewerber } \\
\text { (in 1.000) }\end{array}$ & $\begin{array}{c}\text { Freiwillig } \\
\text { versicherte } \\
\text { Mitglieder } \\
\text { (in 1.000) }\end{array}$ & $\begin{array}{c}\text { Mitglieder } \\
\text { gesamt }\end{array}$ & $\begin{array}{c}\text { Pflicht- } \\
\text { versicherte } \\
\text { Mitglieder } \\
\text { ohne } \\
\text { Rentner }\end{array}$ & $\begin{array}{c}\text { Pflichtver- } \\
\text { sicherte } \\
\text { Rentner } \\
\text { und } \\
\text { Renten- } \\
\text { bewerber }\end{array}$ & $\begin{array}{c}\text { Freiwillig } \\
\text { versi- } \\
\text { cherte } \\
\text { Mitglieder }\end{array}$ \\
\hline 1991 & 50.692 & 31.334 & 14.178 & 5.178 & 100,00 & 100,00 & 100,00 & 100,00 \\
\hline 1992 & 51.025 & 31.351 & 14.344 & 5.330 & 100,66 & 100,06 & 101,17 & 102,93 \\
\hline 1993 & 50.878 & 30.806 & 14.505 & 5.565 & 100,37 & 98,32 & 102,31 & 107,47 \\
\hline 1994 & 50.755 & 30.477 & 14.697 & 5.581 & 100,12 & 97,26 & 103,66 & 107,77 \\
\hline 1995 & 50.888 & 30.219 & 14.960 & 5.708 & 100,39 & 96,44 & 105,52 & 110,24 \\
\hline 1996 & 50.996 & 29.878 & 15.081 & 6.037 & 100,60 & 95,35 & 106,36 & 116,57 \\
\hline 1997 & 50.982 & 29.677 & 15.174 & 6.131 & 100,57 & 94,71 & 107,02 & 118,40 \\
\hline 1998 & 50.881 & 29.453 & 15.224 & 6.205 & 100,37 & 94,00 & 107,37 & 119,83 \\
\hline 1999 & 51.202 & 29.622 & 15.265 & 6.315 & 101,01 & 94,54 & 107,67 & 121,94 \\
\hline 2000 & 51.201 & 29.328 & 15.310 & 6.564 & 101,01 & 93,60 & 107,98 & 126,75 \\
\hline 2001 & 51.122 & 29.158 & 15.302 & 6.662 & 100,85 & 93,05 & 107,93 & 128,65 \\
\hline 2002 & 51.133 & 28.955 & 16.583 & 5.595 & 100,87 & 92,41 & 116,96 & 108,05 \\
\hline 2003 & 50.373 & 28.738 & 16.606 & 5.029 & 99,37 & 91,72 & 117,13 & 97,11 \\
\hline 2004 & 50.491 & 28.591 & 16.831 & 5.069 & 99,60 & 91,25 & 118,71 & 97,89 \\
\hline
\end{tabular}

Quelle: Eigene Berechnungen; Daten: BMGS, Mitgliederstatistik KM 6; SVR (2004), Tabelle 82. 
Tabelle 37: Einfluss der demographischen Entwicklung auf den Beitragssatz im Jahr 2003 (Bundesgebiet)

\begin{tabular}{|c|c|c|c|}
\hline Basisjahr & $\begin{array}{c}\text { Ausgabeneffekt } \\
\text { in Prozentpunkten") }\end{array}$ & $\begin{array}{l}\text { Finanzierungseffekt } \\
\text { in Prozentpunkten }\end{array}$ & $\begin{array}{c}\text { Gesamteffekt } \\
\text { in Prozentpunkten }\end{array}$ \\
\hline 1950 & 4,12 & $-3,35$ & 1,19 \\
\hline 1951 & 4,00 & $-3,30$ & 1,08 \\
\hline 1952 & 3,88 & $-3,27$ & 0,97 \\
\hline 1953 & 3,78 & $-3,22$ & 0,89 \\
\hline 1954 & 3,65 & $-3,17$ & 0,79 \\
\hline 1955 & 3,54 & $-3,10$ & 0,70 \\
\hline 1956 & 3,54 & $-3,18$ & 0,62 \\
\hline 1957 & 3,40 & $-3,13$ & 0,49 \\
\hline 1958 & 3,28 & $-3,06$ & 0,42 \\
\hline 1959 & 3,16 & $-2,99$ & 0,34 \\
\hline 1960 & 3,04 & $-2,90$ & 0,30 \\
\hline 1961 & 2,90 & $-2,80$ & 0,23 \\
\hline 1962 & 2,77 & $-2,72$ & 0,17 \\
\hline 1963 & 2,65 & $-2,65$ & 0,10 \\
\hline 1964 & 2,55 & $-2,60$ & 0,03 \\
\hline 1965 & 2,44 & $-2,53$ & $-0,02$ \\
\hline 1966 & 2,35 & $-2,50$ & $-0,09$ \\
\hline 1967 & 2,30 & $-2,53$ & $-0,19$ \\
\hline 1968 & 2,24 & $-2,48$ & $-0,21$ \\
\hline 1969 & 2,16 & $-2,38$ & $-0,19$ \\
\hline 1970 & 2,17 & $-2,42$ & $-0,23$ \\
\hline 1971 & 2,10 & $-2,35$ & $-0,23$ \\
\hline 1972 & 2,06 & $-2,29$ & $-0,21$ \\
\hline 1973 & 2,02 & $-2,22$ & $-0,16$ \\
\hline 1974 & 1,99 & $-2,21$ & $-0,18$ \\
\hline 1975 & 2,00 & $-2,21$ & $-0,18$ \\
\hline 1976 & 1,98 & $-2,19$ & $-0,18$ \\
\hline 1977 & 1,94 & $-2,13$ & $-0,16$ \\
\hline 1978 & 1,89 & $-2,06$ & $-0,13$ \\
\hline 1979 & 1,83 & $-1,96$ & $-0,08$ \\
\hline 1980 & 1,76 & $-1,84$ & $-0,03$ \\
\hline 1981 & 1,73 & $-1,75$ & 0,03 \\
\hline 1982 & 1,70 & $-1,69$ & 0,06 \\
\hline 1983 & 1,70 & $-1,62$ & 0,15 \\
\hline 1984 & 1,69 & $-1,57$ & 0,20 \\
\hline 1985 & 1,66 & $-1,47$ & 0,28 \\
\hline 1986 & 1,61 & $-1,35$ & 0,35 \\
\hline 1987 & 1,54 & $-1,22$ & 0,41 \\
\hline 1988 & 1,44 & $-1,05$ & 0,47 \\
\hline 1989 & 1,32 & $-0,86$ & 0,54 \\
\hline 1990 & 1,20 & $-0,69$ & 0,54 \\
\hline 1991 & 1,10 & $-0,54$ & 0,64 \\
\hline 1992 & 0,97 & $-0,36$ & 0,68 \\
\hline 1993 & 0,87 & $-0,24$ & 0,69 \\
\hline 1994 & 0,79 & $-0,16$ & 0,68 \\
\hline 1995 & 0,69 & $-0,07$ & 0,65 \\
\hline 1996 & 0,59 & $-0,03$ & 0,60 \\
\hline 1997 & 0,51 & $-0,02$ & 0,53 \\
\hline 1998 & 0,45 & $-0,03$ & 0,44 \\
\hline 1999 & 0,36 & $-0,03$ & 0,36 \\
\hline 2000 & 0,27 & $-0,02$ & 0,27 \\
\hline 2001 & 0,18 & $-0,01$ & 0.18 \\
\hline
\end{tabular}




\begin{tabular}{|l|l|l|l|}
\hline 2002 & 0,09 & 0,00 & 0,09 \\
\hline 2003 & 0,00 & 0,00 & 0,00 \\
\hline
\end{tabular}

Anmerkungen:

Ein positiver Beitragssatzeffekt bedeutet einen beitragssatzsteigernden Effekt der demographischen Entwicklung und umgekehrt.

In den Jahren 1950 bis 1990 wurde die Bevölkerungszahl der ehemaligen DDR zu der der BRD addiert. Damit kann der Einfluss der demographischen Entwicklung für das gesamte Bundesgebiet bestimmt werden. Die fiktiven Ausgaben bzw. Einnahmen ergeben sich ceteris paribus für das Jahr 2003 unter Anwendung der demographischen Struktur des jeweiligen Basisjahres.

1) Im Modell belaufen sich die RSA-Ausgaben zuzüglich Verwaltungskosten in der Summe auf 140.840 Mio. Euro. Die amtlich veröffentlichten Leistungsausgaben für das Jahr 2003 betragen hingegen 145.095 Mio. Euro. Diese Abweichung beruht auf Abgrenzungsunterschieden. In der Modellrechnung wird aus Gründen der Praktikabilität mit der Anzahl der Versicherten gerechnet. Das Bundesversicherungsamt hingegen ermittelt die standardisierten Leistungsausgaben in den einzelnen Jahrgängen anhand von Versichertentagen. Z.B. würde im Extremfall ein Versicherter, der im Jahr 2003 nur einen Tag in der GKV versichert war, in den Berechnungen des Bundesversicherungsamts auch nur mit einem Tag berücksichtigt werden, in den Modellrechnungen hingegen mit 365 Tagen. Aus Wettbewerbsgründen sind zudem bestimmte Leistungen im RSA nicht berücksichtigungsfähig (z.B. Satzungsleistungen wie Behandlung im Ausland nach $\S 18$ Abs. 1 und 2 SGB V; siehe hierzu Spitzenverbände der am RSA beteiligten Krankenkassen (Hrsg.) (2003), Anlage 1.1). Da keine Informationen über die Altersverteilung dieser Ausgaben vorliegen, werden diese wie die Verwaltungskosten in der Summe zu den im Modell berechneten Ausgaben addiert. Diese Vorgehensweise ist plausibel, da davon ausgegangen werden kann, dass diese Ausgaben altersunabhängig sind.

2) $\mathrm{Zu}$ den im Modell errechneten Einnahmen wurden die sonstigen Einnahmen der GKV in Höhe von 3,27 Mrd. Euro im Jahr 2003 addiert, da diese altersunabhängig anfallen. Die beitragspflichtigen Einnahmen von Mitgliedern und Rentnern werden nicht nach einzelnen Altersjahrgängen für die GKV statistisch erfasst. Deshalb wird auf Daten des VDR zurückgegriffen, die für die GRV erhoben werden. Da die Beitragsbemessungsgrenze in der GRV die der GKV übersteigt, werden die Beiträge einerseits zu hoch ausgewiesen, zumal auch die (höheren) beitragspflichtigen Einnahmen von in der PKV Versicherten einfließen. Andererseits fehlen Angaben über die beitragspflichtigen Einnahmen der freiwillig versicherten Mitglieder, für die deshalb ebenfalls die aus der VDR-Statistik entnommenen Arbeitsentgelte und Rentenzahlungen der GRV unterstellt werden, die im Durchschnitt geringer sein dürtten als die tatsächlichen beitragspflichtigen Einnahmen. Insgesamt betragen die modellierten Einnahmen bei Anwendung des Beitragssatzes des Jahres 2003 in Höhe von 14,31\% 134.930 Mio. Euro und liegen unter den tatsächlichen Einnahmen von 140.770 Mio. Euro. Zur Berechnung der Beitragssatzeffekte wird daher der im Modell errechnete Beitragssatz von 14,94\% verwendet.

${ }^{3)}$ Bei der Bestimmung des Gesamteffekts werden Einnahmen und Ausgaben angepasst und das Defizit der GKV im Jahr 2003 in Höhe von 4.325 Mio. Euro für alle Basisjahre unterstellt.

Quelle: Eigene Berechnungen; Daten: BMGS; Statistisches Bundesamt; Bundesversicherungsamt; Verband Deutscher Rentenversicherungsträger. 
Tabelle 38: Versicherte, Mitglieder, Ausgaben und Beiträge in den Jahren 2003, 2030 und 2050

\begin{tabular}{|c|c|c|c|c|c|c|c|c|c|c|c|c|}
\hline \multirow{2}{*}{$\begin{array}{l}\text { Alter von } \\
\ldots . \text { bis } \\
\text { unter ... } \\
\text { Jahren }\end{array}$} & \multicolumn{3}{|c|}{\begin{tabular}{|c|} 
Anzahl Versicherte \\
in Mio. \\
\end{tabular}} & \multicolumn{3}{|c|}{ Ausgaben in Mio. Euro } & \multicolumn{3}{|c|}{\begin{tabular}{|c|} 
Anzahl Mitglieder \\
in Mio.
\end{tabular}} & \multicolumn{3}{|c|}{ Beiträge in Mio. Euro } \\
\hline & 2003 & 30 & 550 & 2003 & 030 & 050 & 2003 & 2030 & 2050 & 2003 & 2030 & 2050 \\
\hline $0-5$ & & & & & & & & 4 & 4 & & & \\
\hline $5-10$ & & 8 & 48 & & & & 05 & 04 & 0,04 & & & - \\
\hline $10-15$ & 74 & 3,41 & 2,56 & & & & 0,06 & 05 & 0,04 & & & - \\
\hline $15-20$ & 3 & 3,66 & 82 & & & & 0,92 & 0,72 & 0,62 & & & $7<$ \\
\hline $20-25$ & 4,12 & 4,32 & 3,05 & & & & 2,91 & 2,37 & 2,16 & & & 69 \\
\hline $25-30$ & & & 40 & & & & 1 & 27 & 05 & & & 97 \\
\hline $30-35$ & 60 & 4,17 & 3,57 & & & & 4,09 & 3,54 & 3,17 & & & 99 \\
\hline $35-40$ & & & 3,69 & & & & 0 & 3,59 & 3,21 & & & 68 \\
\hline $40-45$ & 8 & 9 & 3,72 & & & & 04 & 4,09 & 3,25 & & & 334 \\
\hline $45-50$ & 4 & 5 & 3,78 & & & & 4,35 & 3,89 & 3,33 & & & 25 \\
\hline $50-55$ & & 5 & 4,05 & & & & 3,97 & 3,67 & 3,52 & & & 977 \\
\hline $55-60$ & 3,70 & 4,61 & 4,09 & & 2 & & 3,11 & 3,49 & 3,44 & & & 591 \\
\hline $60-65$ & & & 4,69 & & & & 4,15 & 4,77 & 4,05 & & & 599 \\
\hline $65-70$ & 4,53 & 4,04 & 4,45 & & & 0 & 4,30 & 5,54 & 4,23 & & & 537 \\
\hline $70-75$ & 7 & 4,6 & 4,08 & & & & 3,12 & 4,63 & 3,89 & & 39 & 825 \\
\hline $75-80$ & 2,72 & 3,07 & 3,57 & & & & 2,65 & 3,65 & 3,48 & & & .056 \\
\hline $80-85$ & 1,95 & 2,31 & 3,88 & & 12.446 & & 1,91 & 2,61 & 3,81 & 2.089 & 2.851 & 162 \\
\hline $85-90$ & 0,74 & 1,42 & 2,95 & & & & 0,73 & 1,68 & 2,90 & & & .104 \\
\hline $90-$ & 0,57 & 0,20 & 1,73 & 2.837 & 6.154 & 8.581 & 0,57 & 1,23 & 1,72 & 594 & 1.288 & 1.796 \\
\hline
\end{tabular}

Quelle: Eigene Berechnungen; Daten: BMGS; Bundesversicherungsamt; Statistisches Bundesamt; Verband Deutscher Rentenversicherungsträger. 
Tabelle 39: Anteil der GKV-Versicherten an der Bevölkerung nach Altersklassen 1992-2003

\begin{tabular}{|c|c|c|c|c|c|c|c|c|c|c|c|c|}
\hline \multirow{2}{*}{$\begin{array}{l}\text { Alter von } \\
\ldots \text { bis } \\
\text { unter ... } \\
\text { Jahren }\end{array}$} & 92 & 1993 & 1994 & 1995 & 1996 & 1997 & 1998 & 1999 & 2000 & 2001 & 2002 & 2003 \\
\hline & \multicolumn{12}{|c|}{ alle Angaben in Prozent } \\
\hline $1-15$ & 85,15 & ,22 & 87,12 & 87,25 & 87,61 & 87,22 & 85,07 & 85,03 & 4,94 & 4,51 & 4,27 & 4,08 \\
\hline $15-20$ & 94,24 & 3,96 & 1,45 & 1,67 & 1,60 & 88,61 & 88,65 & 88,09 & 88,00 & 87,41 & 87,30 & 7,14 \\
\hline $20-25$ & 1,19 & 9,99 & 7,79 & 8,15 & 38,28 & 86,19 & 86,00 & 35,97 &, 22 & 34 & 86 & 4,40 \\
\hline $25-30$ & 88,87 & 7,87 & 86,88 & 86,56 & 86,46 & 85,60 & 85,44 & 85,52 & & & 67 & 15 \\
\hline $30-35$ & 86,34 & 85,97 & 85,61 & 86,00 & 86,50 & 86,09 & 85 & 85 & 75 & 8 & 32 &, 40 \\
\hline &, 61 & 4 & 35 & & & 1 & & & & & 36 & 2,37 \\
\hline 40 & 84,53 & 4,06 & 30 & 24 & & 83,03 & 83 & & & & 10 & 2,80 \\
\hline 45 & 85,58 & 4,66 & 83,75 & 83 & 83 & 83,15 & 8 & 83 & 30 & & 21 & 82,16 \\
\hline & 89,33 & 6 & 97 & 4 & & 4 & & & & & & 68 \\
\hline 60 & 91,80 & 0,96 & 0,28 & 9,57 & & 88,46 & 3 & 86 & & & 15 & 3,70 \\
\hline & 3,12 & 3,11 & 2,62 & 92,28 & & 9 & & & 33 & & 46 & 87,64 \\
\hline 70 & 93,11 & 92,90 & 2,51 & 2,53 & 92 & 8 & 34 & & 32 & & 80 & 1,23 \\
\hline $70-75$ & 93,09 & 93,08 & 92,71 & 92,37 & 92 & 91 & & & 30 & & 15 & 3,23 \\
\hline & 93,66 & 3,14 & 92,50 & 92,28 & 92,24 & 92,25 & 93,47 & 93,09 & 2,95 & 84 & 71 & 2,62 \\
\hline $80-85^{1}$ & 95,36 & 5,40 & 94,53 & 94,41 & 93,99 & 93,66 & 94,30 & 93,97 & 80 & 30 & 97 & 4,02 \\
\hline & & & & & & & & & & & 41 & 95,44 \\
\hline $90-$ & & & & & & & 96,79 & 96 & 84 & 68 & 79 & 95,65 \\
\hline & & 83 & & & & & & & & & & 4,93 \\
\hline $20-60$ & 87,81 & 87,00 & 86,07 & & & & & & & & 3,24 & 82,75 \\
\hline $60-$ & 93,61 & 93,51 & 92,98 & 92,76 & 92,57 & 92,26 & 93,05 & 92,66 & 92,38 & 92,05 & 91,75 & 91,38 \\
\hline samt & 89 & 88,72 & 87,95 & 87,87 & 87,95 & 87,26 & 87,04 & 86,88 & 86,62 & 86,06 & 85,70 & 85,33 \\
\hline
\end{tabular}

'Für die Jahre 1991 bis 1997 werden 80jährige und Ältere in der GKV-Mitgliederstatistik in einer Gruppe erfasst. Die angegebenen Werte gelten daher für die über 80jährigen.

Quelle: Eigene Berechnungen; Daten: Statistisches Bundesamt; BMGS. 
Marco Penske - 978-3-631-75223-4

Downloaded from PubFactory at 01/11/2019 06:54:52AM

via free access 


\section{Literaturverzeichnis}

Adams, M. (2001): Der blaue Dunst kommt den Staat teuer zu stehen, in: Handelsblatt, Nr. 234 vom 04.12.2001, S. 10

Amelung, V.; Glied, S.; Topan, A. (2001): Die Finanzierung der Gesetzlichen Krankenversicherung über den Arbeitsmarkt - das Ende einer Erfolgsstory?, in: Sozialer Fortschritt, 50. Jg., Nr. 12, S. 280-288

Andel, N. (1975): Verteilungswirkungen der Sozialversicherung am Beispiel der gesetzlichen Krankenversicherung in der Bundesrepublik Deutschland, in: Dreißig, W. (Hrsg.), Öffentliche Finanzwirtschaft und Verteilung, Schriften des Vereins für Socialpolitik, N. F., Bd. 75, Berlin, S. 39-82

Andel, N. (1998): Finanzwissenschaft, 4. Aufl., Tübingen

Arbeitsgemeinschaft deutscher wirtschaftswissenschaftlicher Forschungsinstitute e.V. (Hrsg.) (2005a): Die Lage der Weltwirtschaft und der deutschen Wirtschaft im Frühjahr 2005, Kiel

Arbeitsgemeinschaft deutscher wirtschaftswissenschaftlicher Forschungsinstitute e.V. (Hrsg.) (2005b): Die Lage der Weltwirtschaft und der deutschen Wirtschaft im Herbst 2005, Essen

Auerbach A.J.; Gokhale, J.; Kotlikoff, L.J. (1991): Generational Accounts: A Meaningful Alternative to Deficit Accounting, in: Bradford, D. (Hrsg.), Tax Policy and the Economy, Vol. 5, Cambridge, Massachusetts, S. 55-110

Auerbach A.J.; Gokhale, J.; Kotlikoff, L.J. (1992): Generational Accounting: A New Approach to Understanding the Effects of Fiscal Policy on Saving, in: The Scandinavian Journal of Economics, Vol. 94, S. 303-318

Auerbach A.J.; Gokhale, J.; Kotlikoff, L.J. (1994): Generational Accounting: A Meaningful Way to Evaluate Fiscal Policy, in: The Journal of Economic Perspectives, Vol. 8, S. 73-94

Bach, H.-U.; Spitznagel, E. (2003): Was kostet uns die Arbeitslosigkeit?, IAB Kurzbericht, Nr. 10, Nürnberg

Bach, S. u.a. (2002): Demographischer Wandel und Steueraufkommen, in: DIWMaterialien, Nr. 20, Berlin

Bach, S.; Steiner, V.; Teichmann, D. (2002): Berechnungen zum Reformvorschlag „Arbeit für viele“, Gutachten des DIW im Auftrag des Nachrichtenmagazins DER SPIEGEL, Berlin

Barer, M.L. U.a. (1987): Aging and Health Care Utilization: New Evidence on old Fallacies, in: Social Science and Medicin, Vol. 24, S. 851-862

Barr, M.D. (2001): Medical Savings Accounts in Singapore: A Critical Inquiry, in: Journal of Health Politics, Policy and Law, Vol. 26, Nr. 4, S. 709-726

Baumann, E.; Weidmann, J. (2003): Finanzierungsprobleme in der GKV: Folge eines veränderten Erwerbsverhaltens, in: Wirtschaftsdienst, 83. Jg., Nr. 3, S. 178-187 
Beck, J. (2004): Bürgerversicherung: Steht die Verfassung ihrer Einführung entgegen?, in: Soziale Sicherheit - Zeitschrift für Arbeit und Soziales, 53. Jg., Nr. 11, S. 386-392

Beckmann, P. (2003): Auch richtige Zahlen können in die Irre führen, IAB Kurzbericht, Nr. 11, Nürnberg

Beer, H. (1995): Bevölkerungsentwicklung und Finanzierung der Privaten Krankenversicherung, in: Zeitschrift für die gesamte Versicherungswissenschaft, Bd. 84, S. $687-696$

Behrens, C.S. (1991): Intertemporale Verteilungswirkungen in der gesetzlichen Krankenversicherung der Bundesrepublik Deutschland, Finanzwissenschaftliche Schriften, Bd. 45, Frankfurt am Main u.a.

Beise, M.; Hoffmann, A. (2002): Rot-Grün kneift bei Gesundheitsreform, in: Süddeutsche Zeitung, Nr. 235 vom 11.10.2002, S. 19

Bellmann, L.; Leber, U. (2002): Weiterbildung und Zuwanderung als mögliche Strategien zur Überwindung des Fachkräftemangels, in: Politische Studien, 53. Jg., Nr. 2, S. 87-105

Berié, H.; Fink, U. (1997a): Wo liegen die finanziellen Probleme der gesetzlichen Krankenversicherung, Hennigsdorf

Berié, H.; Fink, U. (1997b): Die Lohnquote, Hennigsdorf

Berié, H.; Fink, U. (2003): Grundlohnentwicklung und Ausgaben der GKV, Gutachten im Auftrag des AOK-Bundesverbands, Berlin

Berthold, N. (1991): Ansätze einer ökonomischen Theorie der Sozialpolitik, Normative und positive Aspekte, in: Duwendag, D.; Rose, K.; Wille, E. (Hrsg.), Jahrbuch für Sozialwissenschaft, Bd. 42, Göttingen, S. 145-178

Berthold, N.; Neumann, M. (2004): Der gemeinsame Europäische Arbeitsmarkt, Wunschdenken oder Realität?, in: WiSt - Wirtschaftswissenschaftliches Studium, 33. Jg., Nr. 7, S. 386-393

Beske, F. (2001): Neubestimmung und Finanzierung des Leistungskatalogs der gesetzlichen Krankenversicherung, Kieler Konzept, Berlin u.a.

Beske, F.; Drabinski, T. (2004a): Zu Lasten der gesetzlichen Krankenversicherung Politische Entscheidungen 1977-2004 und andere Tatbestände, Schriftenreihe des Fritz Beske Instituts für Gesundheits-System-Forschung, Bd. 101, Kiel

Beske, F.; Drabinski, T. (2004b): Veränderungsoptionen in der gesetzlichen Krankenversicherung - Bürgenversicherung, Kopfpauschale und andere Optionen im Test, Schriftenreihe des Fritz Beske Instituts für Gesundheits-System-Forschung, Bd. 102, Kiel

Beske, F.; Drabinski, T.; Michel, C. (2002): Politische Entscheidungen zu Lasten der gesetzlichen Krankenversicherung, Schriftenreihe des Fritz Beske Instituts für Gesundheits-System-Forschung, Bd. 91, Kiel

Beske, F.; Kern, A.O. (2000): Zum Stand der Fremdleistungen in der gesetzlichen Krankenversicherung, Schriftenreihe des Fritz Beske Instituts für GesundheitsSystem-Forschung, Bd. 81, Würzburg 
Beske, F.; Zalewski, T. (1984): Gesetzliche Krankenversicherung, Systemerhaltung und Finanzierbarkeit, Schriftenreihe des Fritz Beske Instituts für GesundheitsSystem-Forschung, Bd. 10, Kiel

Beske, F. u.a. (2002): Berliner Konzept einer Strukturreform der gesetzlichen Krankenversicherung, Schriftenreihe des Fritz Beske Instituts für Gesundheits-SystemForschung, Bd. 93, Kiel

Bieback, K.-J. (2003): Verfassungsrechtliche Aspekte einer Bürgerversicherung: Der Bund hat die Kompetenz zur Einführung einer umfassenden Versicherung, in: Soziale Sicherheit - Zeitschrift für Arbeit und Soziales, 52. Jg., Nr. 12, S. 416-425

Bieback, K.-J. (2004): Volle GKV-Beitragslast auf Versorgungsbezüge der Rentner seit 2004: Sind die vollen Krankenversicherungsbeiträge auf Betriebsrenten verfassungsgemäß?, in: Soziale Sicherheit - Zeitschrift für Arbeit und Soziales, 53. Jg., Nr. 8/9, S. 289-299

Bieback, K.-J. (2005): Sozial- und verfassungsrechtliche Aspekte der Bürgerversicherung, Schriften der Hans-Böckler-Stiftung, Bd. 61, Baden-Baden

Birg, H. (2000): Perspektiven der Bevölkerungsentwicklung in Deutschland und Europa - Konsequenzen für die sozialen Sicherungssysteme, Bielefeld

Birg, H. (2001): Auswirkungen und Kosten der Zuwanderung nach Deutschland, Gutachten im Auftrag des Bayerischen Staatsministeriums des Innern, Bielefeld

Birg, H. (2004a): Generationenstreß, in: Frankfurter Allgemeine Zeitung, Nr. 79 vom 02.04.2004, S. 39

Birg, H. (2004b): Schrumpfen oder wachsen?, in: Generationengerechtigkeit!, 4. Jg., Nr. 1, S. 12-13

Blanchard, O. (1993): Suggestions for a New Set of Fiscal Indicators, in: Verbon, H.A.A.; Winden, F.A.A.M. van (Hrsg.), The Political Economy of Government Debt, Amsterdam u.a., S. 307-325

Bleckmann, N.; Rodrig, S. (1995): Schadenverhalten in der Krankenversicherung in der Zeit vor dem Tod, Transactions of the International Congress of Actuaries, Brüssel, S. 43-65

BMGS [Bundesministerium für Gesundheit und Soziale Sicherung] (Hrsg.) (2003a): Geringfügige Beschäftigung und Beschäftigung in der Gleitzone, Bonn

BMGS [Bundesministerium für Gesundheit und Soziale Sicherung] (Hrsg.) (2003b): Mitgliederstatistik KM 6, Bonn

BMGS [Bundesministerium für Gesundheit und soziale Sicherung] (Hrsg.) (2004a): Endgültige Rechnungsergebnisse der gesetzlichen Krankenversicherung 2003 nach der Statistik KJ 1, Bonn

BMGS [Bundesministerium für Gesundheit und Soziale Sicherung] (Hrsg.) (2004b): Agenda 2010, Ratgeber zur gesetzlichen Krankenversicherung, Bonn

BMGS [Bundesministerium für Gesundheit und Soziale Sicherung] (Hrsg.) (2004c): Gesundheit in den neuen Ländern, Bonn

BMGS [Bundesministerium für Gesundheit und Soziale Sicherung] (Hrsg.) (2004d): Statistisches Taschenbuch 2004, Bonn 
BMGS [Bundesministerium für Gesundheit und Soziale Sicherung] (Hrsg.) (2004e): Ulla Schmidt: Ausbildungsoffensive im Bereich der Sozialversicherungen schafft Chancen für junge Menschen, Pressemitteilung vom 09.08.2004, Berlin

BMGS [Bundesministerium für Gesundheit und Soziale Sicherung] (Hrsg.) (2004f): Keine Einwanderung in den Sozialstaat - Prof. Sinn stellt erneut falsche Behauptungen auf, Pressemitteilung vom 21.06.2004, Berlin

BMGS [Bundesministerium für Gesundheit und Soziale Sicherung] (Hrsg.) (2005a): Gesetzliche Krankenversicherung, Kennzahlen und Faustformeln, Stand: Juli 2005, Bonn

BMGS [Bundesministerium für Gesundheit und soziale Sicherung] (Hrsg.) (2005b): Gesetzliche Krankenversicherung, Mitglieder, mitversicherte Angehörige und Krankenstand, http://www.bmgs.bund.de/downloads/KM1JD2004.pdf (29.09.2005)

BMGS [Bundesministerium für Gesundheit und soziale Sicherung] (Hrsg.) (2005c): Gesetzliche Krankenversicherung, Mitglieder, mitversicherte Angehörige, Beitragssätze und Krankenstand, http://www.bmgs.bund.de/downloads/ KM1_Juli_Dez_04.pdf (16.09.2005)

Börsch-Supan, A. (2000): Was für die Kapitaldeckung und was für das Umlageverfahren spricht, Beiträge zur angewandten Wirtschaftsforschung, Nr. 587, Mannheim

Börsch-Supan, A. (2004): Kapitaldeckung in der Rentenversicherung, in: Rische, H.; Schmähl, W. (Hrsg.), Gesundheits- und Alterssicherung - gleiche Herausforderungen, gleiche Lösung?, Münster, S. 69-90

Börsch-Supan, A.; Ludwig, A.; Sommer, M. (2003): Demographie und Kapitalmärkte, Die Auswirkungen der Bevölkerungsalterung auf Aktien-, Renten- und Immobilienvermögen, Köln

Boetius, J. (1999): Gesetzliche Krankenversicherung und private Krankenversicherung, Modell eines zukunftssicheren Systems, Münsteraner Reihe, Bd. 59, Karlsruhe

Boetius, J. (2002): Die demographische Herausforderung ist bereits Realität, in: forum für gesundheitspolitik, 8. Jg., Nr. 5, S. 157-161

Boetius, J.; Wiesemann, H.-O. (1998): Die Finanzierungsgrundlagen in der Krankenversicherung, Zur Grenzziehung zwischen GKV und PKV, PKV-Dokumentation, Nr. 22, Köln

Bofinger, P. (2003): Gesetzliche Krankenversicherung, Das falsche Solidarprinzip, in: Handelsblatt, Nr. 51 vom 13.03.2003, S. 10

Bogs, W. u.a. (1966): Soziale Sicherung in der Bundesrepublik Deutschland, Bericht der Sozialenquête-Kommission, Stuttgart u.a.

Boll, S. (1994): Intergenerationale Umverteilungswirkungen der Fiskalpolitik in der Bundesrepublik Deutschland, Finanzwissenschaftliche Schriften, Bd. 66, Frankfurt am Main u.a.

Bontrup, H.-J. (1999): Zu den Irrtümern am Gesundheitsmarkt, in: Sozialer Fortschritt, 48. Jg., Nr. 4, S. 84-92 
Bork, C. (2003): Gutachten zur Quantifizierung der Aufkommens- und Verteilungswirkungen ausgewählter Reformansätze im Gesundheitswesen, Wiesbaden

Bornemann, S.; Daumann, F. (2005): Medical Savings Accounts als Reformoption für das deutsche Gesundheitswesen?, in: Gesundheits- und Sozialpolitik, 59. Jg., Nr. $3 / 4$, S. $42-46$

Braun, B.; Kühn, H.; Reiners, H. (1998): Das Märchen von der Kostenexplosion, Populäre Irrtümer zur Gesundheitspolitik, Frankfurt am Main

Breiholz, H. (2004): Ergebnisse des Mikrozensus 2003, in: Wirtschaft und Statistik, o.Jg., Nr. 6, S. 663-672

Brenner, M.H. (1999): Zum Einfluß der Gesundheitsausgaben auf die Mortalität in der Bundesrepublik Deutschland (1960-1989), in: Walter, U. u.a. (Hrsg.), PublicHealth-Forschung in Deutschland, Bern u.a., S. 370-373

Bress, D. u.a. (2003): Handbuch der Sozialversicherung, Bd. 1, Sechster Teil, Gesetzliche Krankenversicherung, Soziale Pflegeversicherung, 12. Aufl., SanktAugustin

Breyer, F. (1996): Korreferat: Demographische Alterung und Gesundheitskosten: Eine Fehlinterpretation?, in: Oberender, P. (Hrsg.), Alter und Gesundheit, BadenBaden, S. 47-48

Breyer, F. (2000): Kapitaldeckungs- versus Umlageverfahren, in: Perspektiven der Wirtschaftspolitik, 1. Jg., Nr. 4, S. 383-405

Breyer, F.; Schulenburg, J.-M. Graf von der (1987a): Family Structure and Intergenerational Transfers in Social Health Insurance, in: Pethig, R.; Schlieper, U. (Hrsg.), Efficiency, Institutions and Economic Policy, Berlin u.a., S. 63-80

Breyer, F.; Schulenburg, J.-M. Graf von der (1987b): Voting on Social Security, The Family as Decision-Making Unit, in: Kyklos, Bd. 40, S. 529-547

Breyer, F.; Ulrich, V. (2000): Gesundheitsausgaben, Alter und medizinischer Fortschritt: eine Regressionsanalyse, in: Jahrbücher für Nationalökonomie und Statistik, Bd. 220/1, S. 1-17

Breyer, F.; Zweifel, P.; Kifmann, M. (2005): Gesundheitsökonomik, 5. Aufl., Berlin u.a.

Breyer, F. u.a. (2001): Wirtschaftliche Aspekte der Märkte für Gesundheitsleistungen, Ökonomische Chancen unter sich verändernden demographischen und wettbewerblichen Bedingungen in der Europäischen Union, Gutachten des DIW Berlin unter Mitarbeit von IGES Berlin im Auftrag des Bundesministeriums für Wirtschaft und Technologie, Berlin

Breyer, F. u.a. (2004): Reform der sozialen Sicherung, Berlin u.a.

Brody, J.A. (1985): Prospects for an Ageing Population, in: Nature, Vol. 315, S. 463466

Brümmerhoff, D. (1991): Äquivalenzprinzip versus Solidaritätsprinzip in der Gesetzlichen Krankenversicherung, in: Hansmeyer, K.-H. (Hrsg.), Finanzierungsprobleme der sozialen Sicherung II, Schriften des Vereins für Socialpolitik, N. F., Bd. 194/II, Berlin, S. 177-211 
Buchholz, W. u.a. (2001): Wettbewerb aller Krankenversicherungen kann Qualität verbessern und Kosten des Gesundheitswesens senken, DIW-Diskussionspapiere, Nr. 247, Berlin

Buchner, F. (2002): Versteilerung von Ausgabenprofilen in der Krankenversicherung, Gesundheitsökonomische Beiträge, Bd. 37, Baden-Baden

Buchner, F.; Wasem, J. (2000): Versteilerung der alters- und geschlechtsspezifischen Ausgabenprofile von Krankenversicherern, Wirtschaftswissenschaftliche Diskussionspapiere der Ernst-Moritz-Arndt-Universität Greifswald, Nr. 1, Greifswald

Bundesagentur für Arbeit (Hrsg.) (2004): Mini- und Midijobs in Deutschland, Sonderbericht, Dezember 2004, Nürnberg

Bundesknappschaft (Hrsg.) (2004): Geschäftsbericht 2003, Bochum

Bundesministerium der Finanzen (Hrsg.) (2002): Verteilungswirkungen des deutschen Steuersystems, in: Monatsbericht des BMF, o.Jg., Nr. 10, S. 37-43

Bundesministerium der Finanzen (Hrsg.) (2005): Datensammlung zur Steuerpolitik, Ausgabe 2005, Berlin

Bundesversicherungsamt (Hrsg.) (2003): Finanzierung der gesetzlichen Krankenversicherung, Rundschreiben vom 23.12.2003, Geschäftszeichen V1-5500.11764/2002, Bonn

Bundesversicherungsamt (Hrsg.) (2004): 141. Bekanntmachung zum Risikostrukturausgleich, Bonn

Burger, S.; Funk, L.; Jobelius, H.-J. (1994): Die gesetzliche Krankenversicherung unter dem Druck der Bevölkerungsentwicklung, in: Die Ersatzkasse, 74. Jg., Nr. 5, S. 149-154

Busse, R. (1996): Welche Kosten verursacht das letzte Lebensjahr?, in: Walter, U.; Paris, W. (Hrsg.), Public Health - Gesundheit im Mittelpunkt, Meran, S. 89-92

Busse, R. U.a. (1999): Lebensalter, Sterben und Kosten - was wissen wir über den Zusammenhang?, in: Walter, U. u.a. (Hrsg.), Public-Health-Forschung in Deutschland, Bern u.a., S. 393-396

Buttler, G.; Fickel, N.; Lautenschläger, B. (1999): Die Auswirkungen der demographischen Entwicklung auf die Kosten im Gesundheitswesen, in: Allgemeines Statistisches Archiv, Bd. 83, S. 120-136

Cassel, D. (2003): Intergenerative Finanzierungsprobleme der Gesetzlichen Krankenversicherung, in: Cassel, D.; Müller, H.; Thieme, H.J. (Hrsg.), Stabilisierungsprobleme in der Marktwirtschaft, München, S. 235-261

Cassel, D.; Janßen, J. (1999): GKV-Wettbewerb ohne Risikostrukturausgleich? Zur wettbewerbssichernden Funktion des RSA in der Gesetzlichen Krankenversicherung, in: Knappe, E. (Hrsg.), Wettbewerb in der Gesetzlichen Krankenversicherung, Baden-Baden, S. 11-49

Cassel, D.; Oberdieck, V. (2002): Kapitaldeckung in der Gesetzlichen Krankenversicherung, in: Wirtschaftsdienst, 82. Jg., Nr. 1, S. 15-22 
Cassel, D.; Postler, A. (2003): Warten auf Rürup? Zur Dringlichkeit einer Finanzierungsreform der GKV, in: Wirtschaftsdienst, 83. Jg., Nr. 7, S. 437-444

Christlich Demokratische Union Deutschlands; Christlich-Soziale Union in Bayern (Hrsg.) (2004): Reform der gesetzlichen Krankenversicherung - Solidarisches Gesundheitsprämien-Modell, Berlin

Christlich Demokratische Union Deutschlands; Christlich-Soziale Union in Bayern; Sozialdemokratische Partei Deutschlands (Hrsg.) (2005): Gemeinsam für Deutschland - mit Mut und Menschlichkeit, Koalitionsvertrag zwischen CDU, CSU und SPD, http://www.bundesregierung.de/Anlage920135/Koalitionsvertrag.pdf (20.11.2005)

Colvez, A.; Blanchet, M. (1981): Disability Trends in the United States, Population 1966-1976: Analysis of Reported Causes, in: American Journal of Public Health, Vol. 71, Nr. 5, S. 464-471

Crimmins, E.M.; Saito, Y.; Ingegneri, D. (1989): Changes in Life Expectancy and Disability-Free Life Expectancy in the United States, Population and Development Review, Vol. 15, Nr. 2, S. 235-267

Deml, J. (2002): Zur Diskussion um das umlagefinanzierte Rentensystem, Gerecht und sicher, in: Soziale Sicherheit - Zeitschrift für Arbeit und Soziales, 50. Jg., Nr. 12, S. 411-418

Deutsche Bundesbank (Hrsg.) (1999): Möglichkeiten und Grenzen einer verstärkten Kapitaldeckung der gesetzlichen Alterssicherung in Deutschland, in: Monatsbericht der Deutschen Bundesbank, 51. Jg., Nr. 12, S. 15-31

Deutsche Bundesbank (Hrsg.) (2004a): Finanzielle Entwicklung und Perspektiven der gesetzlichen Krankenversicherung, in: Monatsbericht der Deutschen Bundesbank, 56. Jg., Nr. 7, S. 15-32

Deutsche Bundesbank (Hrsg.) (2004b): Zu den Arbeitsmarktentwicklungen von "Hartz IV“, in: Monatsbericht der Deutschen Bundesbank, 56. Jg., Nr. 11, S. 43

Deutsche Bundesbank (Hrsg.) (2005a): Rascher Wandel der Erwerbsarbeit, in: Monatsbericht der Deutschen Bundesbank, 57. Jg., Nr. 7, S. 15-27

Deutsche Bundesbank (Hrsg.) (2005b): Die Wirtschaftslage in Deutschland um die Jahreswende 2004/2005, in: Monatsbericht der Deutschen Bundesbank, 57. Jg., Nr. 2, S. 5-68

Deutsche Bundesbank (Hrsg.) (2005c): Statistischer Teil: 9. Auslandsposition der Deutschen Bundesbank in der Europäischen Währungsunion, Monatsbericht der Deutschen Bundesbank, 57. Jg., Nr. 11, S. 72

Dieterich, T. (1999): Dokumentation "Scheinselbständigkeit“, Zwischenbericht der Kommission, in: Soziale Sicherheit - Zeitschrift für Arbeit und Soziales, 47. Jg., Nr. 9/10, S. 316-321

Dietrich, H. (1999): Empirische Befunde zur selbständigen Erwerbstätigkeit unter besonderer Berücksichtigung scheinselbständiger Erwerbsverhältnisse, in: Mitteilungen aus der Arbeitsmarkt- und Berufsforschung, 32. Jg., Nr. 1, S. 85-101 
Dietrich, H. (2001): Scheinselbständigkeit als neuer Erwerbstyp bzw. neue Unternehmensform? Theoretische und empirische Befunde aus der IAB-Scheinselbständigenstudie, in: Merz, J. (Hrsg.), Existenzgründung 2, Erfolgsfaktoren und Rahmenbedingungen, Baden-Baden, S. 135-153

Dinkel, R.H. (1992): Demographische Alterung: Ein Überblick unter besonderer Berücksichtigung der Mortalitätsentwicklungen, in: Baltes, P.B.; Mittelstraß, J. (Hrsg.), Zukunft des Alterns und gesellschaftliche Entwicklung, Berlin, New York, S. $62-93$

Dinkel, R.H. (1999): Demographische Entwicklung und Gesundheitszustand, Eine empirische Kalkulation der Healthy Life Expectancy für die Bundesrepublik Deutschland auf der Basis von Kohortendaten, in: Häfner, H. (Hrsg.), Gesundheit - unser höchstes Gut, Berlin u.a., S. 61-83

Dixon, A. (2002): Are Medical Savings Accounts a Viable Option for Funding Health Care?, in: Croatian Medical Journal, Vol. 43, Nr. 4, S. 408-416

Doblhammer, G.; Kytir, J. (1999): „Kompression“ oder „Expansion“ der Morbidität?, in: Institut für Demographie der Österreichischen Akademie der Wissenschaften (Hrsg.), Demographische Information, Wien, S. 71-79

Drabinski, T. (2006): ad-hoc-Kurzexpertise: Konsequenzen und gesamtwirtschaftliche Auswirkungen des geplanten BMG-Reformvorschlags zum Gesundheitswesen, Institut für Mikrodaten-Analyse, Kiel

Drabinski, T.; Beske, F. (2003): Der Einfluss der Wiedervereinigung auf die Entwicklung des Beitragssatzes der gesetzlichen Krankenversicherung, Schriftenreihe des Fritz Beske Instituts für Gesundheits-System-Forschung, Bd. 97, Kiel

Dräther, H.; Jacobs, K. (2003): Finanzierungsbasis stabilisieren, GKV-Reformen müssen die Wachstumsschwäche der beitragspflichtigen Einnahmen beenden, in: forum für gesundheitspolitik, 9. Jg., Nr. 4, S. 103-107

Dudey, S. (1993): Vorausschätzung der Kostenentwicklung in der GKV - unter Berücksichtigung des demographischen Wandels für Gesamtdeutschland bis zum Jahre 2030 - aufbauend auf Kranken- und/oder Rentenversicherungsdaten, Bochum

Dudey, S. (1996): Verteilungswirkungen des Sozialversicherungssystems der Bundesrepublik Deutschland und Modellierung seiner zukünftigen Entwicklung, Bochum

Düttmann, R. (1978): Die Finanzierung der gesetzlichen Krankenversicherung, kritische Analyse und Verbesserungsvorschläge, Schriften zur öffentlichen Verwaltung und öffentlichem Recht, Bd. 19, Baden-Baden

Eekhoff, J. (2005): Kein Haushaltszuschuß zur Krankenversicherung, in: Frankfurter Allgemeine Zeitung, Nr. 255 vom 02.11.2005, S. 16

Ehrentraut, O.; Raffelhüschen, B. (2003): Rente mit 67 - ein unvermeidbarer Schritt, in: Wirtschaftsdienst, 83. Jg., Nr. 10, S. 627-630 
Enquete-Kommission Demographischer Wandel (1998): Zweiter Zwischenbericht der Enquete-Kommission „Demographischer Wandel - Herausforderungen unserer älter werdenden Gesellschaft an den Einzelnen und die Politik", BundestagsDrucksache, Nr. 13/11460

Enquete-Kommission Demographischer Wandel (2002): Schlussbericht der EnqueteKommission „Demographischer Wandel - Herausforderungen unserer älter werdenden Gesellschaft an den Einzelnen und die Politik", Bundestags-Drucksache, Nr. $14 / 8800$

Erbsland, M. (1995): Demographische Effekte auf die zukünftigen Behandlungsausgaben und den Beitragssatz der GKV, ZEW-Discussion Paper, Nr. 18, Mannheim

Erbsland, M.; Ried, W.; Ulrich, V. (1999): Die Auswirkungen der Bevölkerungsstruktur auf Ausgaben und Beitragssatz der gesetzlichen Krankenversicherung, in: Wille, E. (Hrsg.), Entwicklung und Perspektiven der Sozialversicherung, BadenBaden, S. 173-197

Erbsland, M.; Wille, E. (1995): Bevölkerungsentwicklung und Finanzierung der gesetzlichen Krankenversicherung, in: Zeitschrift für die gesamte Versicherungswissenschaft, Bd. 84, S. 661-686

Europäische Kommission (Hrsg.) (2003a): Angemessene und nachhaltige Renten, Gemeinsamer Bericht der Kommission und des Rates, http://europa.eu.int/ comm/employment_social/publications/2004/ke5303483_de.pdf (04.11.2005)

Europäische Kommission (Hrsg.) (2003b): Beschäftigung in Europa 2003, Luxemburg

Expertenkommission (1996): Gutachten der Unabhängigen Expertenkommission zur Untersuchung der Problematik steigender Beiträge der privat Krankenversicherten im Alter, Bundestags-Drucksache, Nr. 13/4945

Farhauer, O.; Borchardt, K. (2004): Bürgerversicherung - eine Reformalternative, IFSt-Schrift, Nr. 415, Bonn

Feil, M.; Zika, G. (2005): Wege zu mehr Beschäftigung, Mit niedrigeren Sozialabgaben aus der Arbeitsmarktkrise?, IAB Kurzbericht, Nr. 4, Nürnberg

Feist, K.; Raffelhüschen, B. (2000): Möglichkeiten und Grenzen der Generationenbilanzierung, in: Wirtschaftsdienst, 80. Jg., Nr. 7, S. 440-448

Felder, S. (2003): Kapitaldeckung in der gesetzlichen Krankenversicherung über den Risikostrukturausgleich, Jahrbuch für Wirtschaftswissenschaften, Bd. 54, S. 60-72

Felder, S.; Kifmann, M. (2003): Kurz- und langfristige Folgen einer Bürgerversicherung, Working Paper der Otto von Guericke Universität Magdeburg, Nr. 18, Magdeburg

Felder, S.; Meier, M.; Schmitt, H. (2000): Health Care Expenditure in the Last Months of Life, in: Journal of Health Economics, Vol. 19, Nr. 5, S. 679-695

Felder, S.; Olbrich, A. (2003): Der Entwurf zum Gesundheitssystemmodernisierungsgesetz: zaghaft und widersprüchlich, in: Wirtschaftsdienst, 83. Jg., Nr. 6, S. 359362 
Felderer, B. (1994): Can Immigration Policy Help to Stabilize Social Security Systems?, in: Giersch, H. (Hrsg.), Economic Aspects of International Migration, Berlin u.a., S. 197-226

Fenge, R. (1995): Pareto-Efficiency of the Pay-as-you-go Pension System with Intragenerational Fairness, in: Finanzarchiv, N. F., Bd. 52, S. 357-363

Fetzer, S.; Mevis, D.; Raffelhüschen, B. (2003): Zur Zukunftsfähigkeit des Gesundheitswesens. Eine Nachhaltigkeitsstudie zur marktorientierten Reform des deutschen Gesundheitssystems, Diskussionsbeiträge des Instituts für Finanzwissenschaft der Albert-Ludwigs-Universität Freiburg im Breisgau, Nr. 108, Freiburg

Fetzer, S.; Moog, S.; Raffelhüschen, B. (2001): Zur Nachhaltigkeit der Generationenverträge: Eine Diagnose der Kranken- und Pflegeversicherung, Diskussionsbeiträge des Instituts für Finanzwissenschaft der Albert-Ludwigs-Universität Freiburg im Breisgau, Nr. 99, Freiburg

Fetzer, S.; Raffelhüschen, B. (2002): Zur Wiederbelebung des Generationenvertrags in der gesetzlichen Krankenversicherung, Die Freiburger Agenda, Diskussionsbeiträge des Instituts für Finanzwissenschaft der Albert-Ludwigs-Universität Freiburg im Breisgau, Nr. 103, Freiburg

Fetzer, S. u.a. (2004): Nachhaltige Gesundheitsreformen?, Diskussionsbeiträge des Instituts für Finanzwissenschaft der Albert-Ludwigs-Universität Freiburg im Breisgau, Nr. 124, Freiburg

Finanzministerium des Landes Nordrhein-Westfalen (Hrsg.) (2003): Kostenvergleich Beihilfe-GKV, http://www.pkv.de/downloads/finanzmin.pdf (04.11.2005)

Freie Demokratische Partei (Hrsg.) (2004): Privater Krankenversicherungsschutz mit sozialer Absicherung für alle - die auf Wettbewerb begründete liberale Alternative, Beschluss des 55. ordentlichen Bundesparteitages der FDP am 5.-6. Juni 2004, Dresden

Frerich, J.; Frey, M. (1996): Handbuch der Geschichte der Sozialpolitik in Deutschland, Bd. 1: Von der vorindustriellen Zeit bis zum Ende des Dritten Reiches, 2. Aufl., München

Fries, J.F. (1985): The Compression of Morbidity, in: World Health Forum, Vol. 6, S. 47-51

Fries, J.F. (1989): Erfolgreiches Altern: Medizinische und demographische Perspektiven, in: Baltes, M.M.; Kohli, M. (Hrsg.), Erfolgreiches Altern: Bedingungen und Variationen, Bern, Stuttgart, Toronto, S. 19-26

Friske, C.; Friske, H.-J. (2003): Thema: Transferleistungen zwischen den Generationen (II), Jährliche Leistung der Älteren im Wert von fast $40 \mathrm{Mrd}$. Euro, in: informationsdienst alter \& forschung, 4. Jg., Nr. 9, S. 3-16

Fritzsche, B. (2004): Verteilungspolitische Aspekte einer Umstellung der Beiträge zur Gesetzlichen Krankenversicherung auf Pauschalprämien in Verbindung mit Ausgleichszahlungen, in: RWI-Mitteilungen Quarterly, Vol. 54/55, Nr. 1, S. 51-85

Fuchs, J.; Thon, M. (1999): Nach 2010 sinkt das Angebot an Arbeitskräften, IAB Kurzbericht, Nr. 4, Nürnberg 
Garber, A.M.; MaCurdy, T.E.; McClallen, M.L. (1998): Medical Care at the End of Life: Diseases, Treatment Patterns, and Costs, NBER Working Paper, Nr. 6748, Cambridge

Gasche, M. (2004): Beitragssatzeffekte einer Einbeziehung der Beamten in die GKV, in: Wirtschaftsdienst, 84. Jg., Nr. 5, S. 290-298

Gerber, S. (2003): Die Scheinselbständigkeit im Rahmen des Einzelarbeitsvertrages, Bern, Stuttgart, Wien

Gerken, L.; Raddatz, G. (2003): „Bürgerversicherung“ und „Kopfpauschale“, Im Dickicht der Gesundheitsreform, Argumente zu Marktwirtschaft und Politik, Nr. 79, Berlin

Gerlinger, T. (2003): Das Schweizer Modell der Krankenversicherung, Zu den Auswirkungen der Reform von 1996, Veröffentlichungsreihe der Arbeitsgruppe Public Health, Wissenschaftszentrum Berlin für Sozialforschung (WZB), Nr. 2003-301, Berlin

Glaeske, G. u.a. (1997): Ursachen für den überproportionalen Anstieg der Gesundheitskosten im Alter, Gutachten für den deutschen Bundestag, Enquete-Kommission Demographischer Wandel, o.O.

Göpffarth, D.; Milbrandt, B. (1997): Das Gesundheitswesen als Beschäftigungs- und Wachstumsfaktor, Wirtschaftswissenschaftliche Dokumentation der Technischen Universität Berlin, Nr. 16, Berlin

Grabka, M.M.; Otto, B. (2001): Angleichung der Markteinkommen privater Haushalte zwischen Ost- und Westdeutschland nicht in Sicht, in: DIW-Wochenbericht, 68. Jg., Nr. 4, S. 51-56

Grabka, M.M. U.a. (2002): Kapitaldeckung in der Gesetzlichen Krankenversicherung: Zur Berechnung der finanziellen Auswirkungen eines Umstieg vom Umlage- auf das Kapitaldeckungssystem, DIW-Diskussionspapiere, Nr. 275, Berlin

Greiner, P.A.; Snowdon, D.A.; Greiner, L.H. (1996): The Relationship of Self-Rated Function and Self-Rated Health to Concurrent Functional Ability, Functional Decline, and Mortality: Findings from the Nun Study, in: Journal of Gerontology: Social Sciences, Vol. 51B, Nr. 5, S. 234-241

Greisler, P. (2002): Reden zur Reformperiode der privaten Krankenversicherung, PKV-Dokumentation, Nr. 26, Köln

Greß, S.; Wasem, J. (2004): Integration der Privaten Krankenversicherung (PKV) in den Risikostrukturausgleich der Gesetzlichen Krankenversicherung (GKV) - Eine funktional äquivalente Alternative zur Bürgerversicherung?, in: Recht und Politik im Gesundheitswesen, Bd. 10, Nr. 2, S. 37-44

Greß, S.; Walendzik, A.; Wasem, J. (2005): Nichtversicherte Personen im Krankenversicherungssystem der Bundesrepublik Deutschland - Bestandsaufnahme und Lösungsmöglichkeiten, Expertise für die Hans-Böckler-Stiftung, Essen

Grobe, T.G.; Dörning, H.; Schwartz, F.W. (2003): GEK-Gesundheitsreport 2003, Schriftenreihe zur Gesundheitsanalyse, Bd. 24, Sankt Augustin 
Grömling, M. (2005): Wirtschaftswachstum, in: Institut der deutschen Wirtschaft Köln (Hrsg.), Perspektive 2050, Ökonomik des demographischen Wandels, 2. Aufl., Köln, S. 67-96

Gruenberg, E.M. (1977): The Failures of Success, in: Milbank Memorial Fund Quarterly, Vol. 55, Nr. 1, S. 3-24

Gutzeit, M.; Goger, K. (2001): Die (endlose) Diskussion um die "Scheinselbständigkeit“, in: WiSt - Wirtschaftswissenschaftliches Studium, 29. Jg., Nr. 11, S. 654-656

Hagist, C.; Raffelhüschen, B. (2003): Generationen- vs. Bürgerversicherung: Welches Modell steht für mehr Nachhaltigkeit in der GKV?, Kurzexpertise im Auftrag der Allianz Private Krankenversicherungs-AG, Freiburg

Hagist, C.; Raffelhüschen, B. (2004): Friedens- versus Ausscheidegrenze in der Krankenversicherung: Ein kriegerischer Beitrag für mehr Nachhaltigkeit, in: Zeitschrift für die gesamte Versicherungswissenschaft, Bd. 2, S. 185-206

Hajen, L.; Paetow, H.; Schumacher, H. (2000): Gesundheitsökonomie, Strukturen Methoden - Praxisbeispiele, Stuttgart, Berlin, Köln

Haller, H. (1964): Die Steuern, Tübingen

Hansen, V. (2003): Viel Arbeit für die Rürup-Kommission, in: Arbeitgeber, 55. Jg., Nr. $1 / 2$, S. $10-12$

Hanvoravongchai, P. (2002): Medical Savings Accounts: Lessons Learned From Limited International Experience, World Health Organization, Discussion Paper, Nr. 3-2002, Genf

Hauser, R. (2001): Generationenverträge als Basis des Sozialstaats, Ökonomische Interpretationsmöglichkeiten und fiskalische Konsequenzen, in: Theurl, E. (Hrsg.), Der Sozialstaat an der Jahrtausendwende, Heidelberg, S. 31-51

Heigl, A. (2001): Age Wave - zur Demographieanfälligkeit von Aktienmärkten, Policy Brief der HypoVereinsbank, Nr. 4, München

Heigl, A. (2002): Aktive Lebenserwartung: Konzeptionen und neuer Modellansatz, in: Zeitschrift für Gerontologie und Geriatrie, Bd. 36, Nr. 6, S. 519-527

Heilemann, U.; Löffelholz, H.D. von; Sieveking, K. (2003): Arbeitsmarktgesteuerte Zuwanderung, Szenarien der Zuwanderung sowie rechtliche und institutionelle Aspekte ihrer Steuerung, Schriftenreihe des Rheinisch-Westfälischen Instituts für Wirtschaftsforschung, N. F., Nr. 68, Berlin

Hein, E. u.a. (2004): WSI-Standortbericht 2004: Demographische Entwicklung - Ein Standortproblem?, in: WSI Mitteilungen, 57. Jg., Nr. 6, S. 291-305

Henke, K.-D. (1985): Gesundheitsausgaben in der Bundesrepublik Deutschland: Ein zu hoher Preis für die Gesundheitsversorgung?, in: Ferber, C. von u.a. (Hrsg.), Kosten und Effizienz im Gesundheitswesen, München, S. 477-493

Henke, K.-D. (1991): Alternativen zur Weiterentwicklung der Sicherung im Krankheitsfall, in: Hansmeyer, K.-H. (Hrsg.), Finanzierungsprobleme der sozialen Sicherung II, Schriften des Vereins für Socialpolitik, N. F., Bd. 194/I, Berlin, S. 117-175

Henke, K.-D. (1993a): Beitragssatzstabilität und Allokationswirklichkeit, in: Nagel, E.; Fuchs, C. (Hrsg.), Soziale Gerechtigkeit im Gesundheitswesen, Berlin, S, 51-69 
Henke, K.-D. (1993b): Die Kosten der Gesundheit und ihre Finanzierung, in: Zeitschrift für die gesamte Versicherungswissenschaft, Bd. 82, S. 97-122

Henke, K.-D. (1999): Beschäftigung in der Dienstleistungs- und Informationsgesellschaft unter besonderer Berücksichtigung des Gesundheitswesens, Diskussionspapiere zu Staat und Wirtschaft, Nr. 2, Berlin

Henke, K.-D. (2001): Kapitalbildung, auch im Gesundheitswesen, Auf dem Wege zu einer ordnungspolitischen Erneuerung der Krankenversicherung, Diskussionspapiere zu Staat und Wirtschaft, Nr. 27, Berlin

Henke, K.-D. (2002): Auf dem Wege zu einer ordnungspolitischen Rundumerneuerung des Gesundheitswesens aus der Sicht eines OKonomen, Schriftenreihe des Bundesministeriums für Gesundheit, Bd. 145, Baden-Baden, S. 12-27

Henke, K.-D. (2005): Was ist uns die Gesundheit wert? Probleme der nächsten Gesundheitsreformen und ihre Lösungsansätze, in: Perspektiven der Wirtschaftspolitik, 6. Jg., Nr. 1, S. 95-111

Henke, K.-D. u.a. (2002): Zukunftsmodell für ein effizientes Gesundheitswesen in Deutschland, in: Vereinte Krankenversicherung AG (Hrsg.), Zukunft braucht Visionen, München

Henke, K.-D. u.a. (2004): Eine Systematisierung der Reformvorschläge zur Finanzierung der Krankenversorgung in Deutschland, in: Journal of Public Health, Vol. 12, Nr. 1, S. 10-19

Herzog-Kommission [Kommission "Soziale Sicherheit"] (2003): Bericht der Kommission „Soziale Sicherheit" zur Reform der sozialen Sicherungssysteme, Berlin

Hilbert, J.; Fretschner, R.; Dülberg, A. (2002): Rahmenbedingungen und Herausforderungen der Gesundheitswirtschaft, Gelsenkirchen

Hof, B. (1997): Gesetzliche Rentenversicherung in der demographischen Klemme Alternative Modellrechnungen für Deutschland bis 2040, in: Institut der deutschen Wirtschaft (Hrsg.), Reform des Sozialstaats, Vorschläge, Argumente, Modellrechnungen zur Alterssicherung, Köln, S. 135-202

Hof, B. (2001): Auswirkungen und Konsequenzen der demographischen Entwicklung für die gesetzliche Kranken- und Pflegeversicherung, Gutachten im Auftrag des Gesamtverbandes der Deutschen Versicherungswirtschaft e.V. und des Verbandes der Privaten Krankenversicherung e.V., PKV-Dokumentation, Nr. 24, Köln

Hof, B.; Schlömer, C. (2005): Zur Zukunftsfähigkeit von Kopfprämienmodellen für die GKV im anstehenden demographischen Wandel, in: Sozialer Fortschritt, 54. Jg., Nr. 8, S. 194-205

Hofmann, J.; Hühne, P. (1988): GKV - Solidarprinzip, Wettbewerb und Finanzierungsverfahren, in: Arbeit und Sozialpolitik, 42. Jg., Nr. 8, S. 238-246

Hollederer, A. (2003): Arbeitslosenuntersuchung, Arbeitslos - Gesundheit los chancenlos?, IAB Kurzbericht, Nr. 4, Nürnberg

Homburg, S. (1988): Theorie der Alterssicherung, Berlin u.a.

Horn, G.-A. (2005): Soziale Sicherung ohne Arbeitgeber, in: Handelsblatt, Nr. 101 vom 30.05 .2005 , S. 7 
IG Metall (Hrsg.) (2001): Ein Plädoyer für mehr Qualität und Solidarität, in: Soziale Sicherheit - Zeitschrift für Arbeit und Soziales, 50. Jg., Nr. 11, S. 371-376

Reschke, P. u.a. (2004): Klassifikationsmodelle für Versicherte im Risikostrukturausgleich, Untersuchung zur Auswahl geeigneter Gruppenbildungen, Gewichtungsfaktoren und Klassifikationsmerkmale für einen direkt morbiditätsorientierten Risikostrukturausgleich in der gesetzlichen Krankenversicherung, Gutachten im Auftrag des Bundesministeriums für Gesundheit und Soziale Sicherung, Berlin

Initiative mehr Gesundheit (Hrsg.) (2004): Das Stuttgarter Gesundheitsreform-Modell 2004, Stuttgart

Institut der deutschen Wirtschaft (Hrsg.) (2002): Krankenversicherung, Nur die marktwirtschaftliche Therapie hilft, in: iwd - Informationsdienst des Instituts der deutschen Wirtschaft, 28. Jg., Nr. 12, S. 4-5

Institut der deutschen Wirtschaft (Hrsg.) (2004a): Rentenversicherung, Der Eckrentner hat längst ausgedient, in: iwd - Informationsdienst des Instituts der deutschen Wirtschaft, 30. Jg., Nr. 12, S. 6-7

Institut der deutschen Wirtschaft (Hrsg.) (2004b): Älter werden ohne alt auszusehen, in: iwd - Informationsdienst des Instituts der deutschen Wirtschaft, 30. Jg., Nr. 10, S. 4-5

Institut der deutschen Wirtschaft (Hrsg.) (2004c): EU-Ostenweiterung, Kein Jungbrunnen, in: iwd - Informationsdienst des Instituts der deutschen Wirtschaft, 30. Jg., Nr. 6, S. 7

Institut der deutschen Wirtschaft (Hrsg.) (2005a): Krankenversicherung, Zu früh gefreut, in: iwd - Informationsdienst des Instituts der deutschen Wirtschaft, 31. Jg., Nr. 12, S. 2

Institut der deutschen Wirtschaft (Hrsg.) (2005b): Deutschland in Zahlen 2005, Köln

Institut für Arbeitsmarkt- und Berufsforschung der Bundesanstalt für Arbeit (Hrsg.) (2002): Zukunftssektor Gesundheitswesen - Motor für Beschäftigung, in: IAB Materialien, o.Jg., Nr. 1, S. 1-2

Institut für Arbeitsmarkt- und Berufsforschung der Bundesanstalt für Arbeit (Hrsg.) (2005a): Tabelle 2.4.2 Voll- und Teilzeitbeschäftigte 1991-2004 (unveröffentlichtes Datenmaterial)

Institut für Arbeitsmarkt- und Berufsforschung der Bundesanstalt für Arbeit (Hrsg.) (2005b): Die gesamtfiskalischen Kosten der Arbeitslosigkeit in Deutschland, http://doku.iab.de/presse/2005/info_KostenALO2004.xls (28.11.2005)

Jacobs, K.; Schellschmidt, H. (2002): Äquivalenz, Leistungsfähigkeit und Solidarität Konturen einer GKV-Finanzierungsreform, in: Gesundheit und Gesellschaft Wissenschaft, 2. Jg., Nr. 3, S. 15-22

Jessen, J. (1982): Programmierter Kollaps der GKV? in: Becker, K. (Hrsg.), 100 Jahre gesetzliche Krankenversicherung, Entwicklung, Krise, Lösungsansätze in der Krankenversicherung der Rentner, Mainz, S. 51-61

Kane, R.L. (1988): Beyond Caring: The Challenge to Geriatrics, in: Journal of the American Geriatrics Society, Vol. 36, S. 467-472 
Kane, R.L.; Radosevich, D.M.; Vaupel, J.W. (1990): Compression of Morbidity: Issues and Irrelevancies, in: Kane, R.L.; Evans, J.G.; Macfadyen, D. (Hrsg.), Improving the Health of Older People: A World View, Oxford, New York, Tokyo, S. $30-49$

Kifmann, M. (2003): Die Vorschläge der Kommission zur Finanzierung der Gesetzlichen Krankenkassen: Bürgerversicherung oder Kopfprämien, in: ifo Schnelldienst, 56. Jg., Nr. 10, S. 3-6

Kirchhof, F. (2004): Verfassungsrechtliche Probleme einer umfassenden Krankenund Renten-„Bürgerversicherung“, in: Neue Zeitschrift für Sozialrecht, o.Jg., Nr. 1, S. 1-7

Klein, R. (2004): Ansparen von Selbstbeteiligung in der Krankenversicherung?, in: Vierteljahreshefte zur Wirtschaftsforschung, 73. Jg., Nr. 4, S. 510-521

Kleinhenz, G.D. (2004): Bevölkerung und Wachstum, in: Jahrbücher für Nationalökonomie und Statistik, Bd. 224, S. 74-90

Klose, J.; Schellschmidt, H. (2001): Finanzierung und Leistungen der gesetzlichen Krankenversicherung, Einnahmen- und ausgabenbezogene Gestaltungsvorschläge im Überblick, WIdO Materialien, Nr. 45, Bonn

Knappe, E. (1995): Auswirkungen des demographischen Wandels auf den Gesundheitssektor, in: Oberender, P. (Hrsg.), Transplantationsmedizin, ökonomische, ethische, rechtliche und medizinische Aspekte, Baden-Baden, S. 11-41

Knappe, E.; Arnold, R. (2002): Pauschalprämie in der Krankenversicherung, Ein Weg zu mehr Effizienz und mehr Gerechtigkeit, Gutachten im Auftrag des Verbands der Bayerischen Wirtschaft, München

Knappe, E.; Optendrenk, S. (1999): Der Einfluss des demographischen Wandels auf die Kranken- und Pflegeversicherung, in: Grünheid, E.; Höhn, C. (Hrsg.), Demographische Alterung und Wirtschaftswachstum, Schriftenreihe des Bundesinstituts für Bevölkerungsforschung, Bd. 29, Opladen, S. 157-178

Knappe, E.; Rachold, U. (1997): Demographischer Wandel und Gesetzliche Krankenversicherung, in: Knappe, E.; Winkler, A. (Hrsg.), Sozialstaat im Umbruch, Herausforderungen an die deutsche Sozialpolitik, Frankfurt am Main, S. 91-118

Kohli, M. u.a. (2000a): Generationenbeziehungen, in: Kohli, M.; Kühnemund, H. (Hrsg.), Die zweite Lebenshälfte, Gesellschaftliche Lage und Partizipation im Spiegel des Alters-Survey, Opladen, S. 176-211

Kohli, M. u.a. (2000b): Grunddaten zur Lebenssituation der 40-85jährigen deutschen Bevölkerung, Ergebnisse des Alters-Survey, Berlin

Kommission für Zukunftsfragen der Freistaaten Bayern und Sachsen (1996): Enwerbstätigkeit und Arbeitslosigkeit in Deutschland, Entwicklung, Ursachen und Maßnahmen, Bonn

Kommission zur Reform des Versicherungsvertragsrechts (2004): Abschlussbericht der Kommission zur Reform des Versicherungsvertragsrechts vom 19. April 2004, o.O. 
Kopetsch, T. (1997): Herausforderungen an die Gesetzliche Krankenversicherung, Thünen-Reihe Angewandter Volkswirtschaftstheorie, Working Paper, Nr. 11, Rostock

Kopetsch, T. (2000): Der medizinische Fortschritt und die Grenzen seiner Finanzierbarkeit, in: List Forum für Wirtschafts- und Finanzpolitik, Bd. 26, Nr. 1, S. 33-50

Kopetsch, T. (2001): Zur Rationierung medizinischer Leistungen: Ein Modell für die Gesetzliche Krankenversicherung, in: Sozialer Fortschritt, 50. Jg., Nr. 1, S. 20-29

Kostorz, P. (1998): Versicherungsfremde Leistungen in der Gesetzlichen Krankenversicherung, Eine sozialpolitische Analyse unter besonderer Berücksichtigung der historischen Entwicklung des Leistungskatalogs der GKV, Frankfurt am Main u.a.

Krämer, R. (2003): Bürgerversicherung: Möglichkeiten zur Senkung des Beitragssatzes bei verschiedenen Gestaltungsvarianten, in: Soziale Sicherheit - Zeitschrift für Arbeit und Soziales, 52. Jg., Nr. 12, S. 408-416

Krämer, W. (1992): Altern und Gesundheitswesen: Probleme und Lösungen aus Sicht der Gesundheitsökonomie, in: Baltes P.B.; Mittelstraß, J. (Hrsg.), Zukunft des Alterns und gesellschaftliche Entwicklung, Berlin, New York, S. 563-580

Krämer, W. (1997): Hippokrates und Sisyphus - die moderne Medizin als das Opfer ihres eigenen Erfolges, in: Kirch, W.; Kliemt, H. (Hrsg.), Rationierung im Gesundheitswesen, Regensburg, S. 7-19

Kramer, M. (1980): The Rising Pandemic of Mental Disorders and Associated Chronic Diseases and Disabilities, in: Strömgren, E.; Dupont, A.; Nielsen, J.A. (Hrsg.), Epidemiological Research as Basis for the Organization of Extramural Psychiatry, Acta Psychiatrica Scandinavia, Koppenhagen, S. 382-397

Krey, K.; Meier, B. (2005): Innovationsfähigkeit, in: Institut der deutschen Wirtschaft Köln (Hrsg.), Perspektive 2050, Ökonomik des demographischen Wandels, 2. Aufl., Köln, S. 145-172

Kroker, R.; Pimpertz, J. (2005): Mehrwertsteuererhöhung zur Finanzierung versicherungsfremder Sozialabgaben, in: Wirtschaftsdienst, 85. Jg., Nr. 5, S. 287-290

Kronberger Kreis (2002): Mehr Eigenverantwortung und Wettbewerb im Gesundheitswesen, Stiftung Marktwirtschaft, Frankfurter Institut, Bd. 39, Berlin

Kruse, A. u.a. (2003): Kostenentwicklung im Gesundheitswesen, Verursachen ältere Menschen höhere Gesundheitskosten?, Expertise im Auftrag der AOK BadenWürttemberg, Heidelberg

Kruse, U.; Kruse, S. (2001): Muss die einkommensabhängige Beitragsfinanzierung der gesetzlichen Krankenversicherung überdacht werden?, in: Sozialer Fortschritt, 50. Jg., Nr. 4, S. 90-97

Kühn, H. (2000): Beitragssatzsteigerung der Gesetzlichen Krankenversicherung durch die Erosion der Einnahmeseite - Anmerkungen zu einer verfehlten Widerlegung, in: Gerlinger, T. u.a. (Hrsg.), Jahrbuch für Kritische Medizin, Bd. 33, Hamburg, S. 110-119 
Kühn, H. (2001): Finanzierbarkeit der gesetzlichen Krankenversicherung und das Instrument der Budgetierung, Diskussionspapier P01-204, Wissenschaftszentrum Berlin für Sozialforschung, http://skylla.wz-berlin.de/pdf/2001/p01-204.pdf (24.11.2005)

Laaser, U. (2000): Das Gesundheitswesen in Deutschland: Von der Kosten- zur Nutzenorientierung, in: Laaser, U.; Schwalber, A. (Hrsg.), Das Gesundheitswesen in Deutschland, von der Kosten- zur Nutzenorientierung, Lage, S. 9-17

Lampert, H.; Althammer, J. (2004): Lehrbuch der Sozialpolitik, 7. Aufl., Berlin u.a.

Lamping, W. (1994): Finanzierungsstrukturen, Verteilungskonflikte und politische Gestaltung der GKV, in: Blanke, B. (Hrsg.), Krankheit und Gemeinwohl, Gesundheitspolitik zwischen Staat, Sozialversicherung und Medizin, Opladen, S. 245-289

Lamping, W.; Tamm, I. (1994): Die Grundlegung der Krankenversicherung in Deutschland und England, Analyse und Genese, Funktion und politische Ausgestaltung, in: Blanke, B. (Hrsg.), Krankheit und Gemeinwohl, Gesundheitspolitik zwischen Staat, Sozialversicherung und Medizin, Opladen, S. 111-148

Lauterbach, K.W. (2004): Das Prinzip der Bürgerversicherung, in: Engelen-Kefer, U. (Hrsg.), Reformoption Bürgerversicherung, Wie das Gesundheitssystem solidarisch finanziert werden kann, Hamburg, S. 48-63

Lauterbach, K.W. u.a. (2004a): Bürgerversicherung, Zukunftsfest und sozial ausgewogen, in: Gesundheit und Gesellschaft, 7. Jg., Nr. 7/8, S. 26-27

Lauterbach, K.W. u.a. (2004b): Brennpunkt Gesundheitswesen: Die Bürgerversicherung, in: Gewerkschaftliche Monatshefte, 55. Jg., Nr. 10, S. 594-604

Lauterbach, K.W. u.a. (2005): Bürgerversicherung und Gesundheit, in: StrengmannKuhn, W. (Hrsg.), Das Prinzip Bürgerversicherung, Wiesbaden, S. 67-82

Leu, R.E. (1988): Technologischer Wandel im Gesundheitswesen - Determinanten und Auswirkungen, in: Gäfgen, G.; Oberender, P. (Hrsg.), Technologischer Wandel im Gesundheitswesen, Baden-Baden, S. 9-33

Link, F.J. (2000): Gesetzliche Krankenversicherung, Das Wichtigste auf wenigen Seiten, Karlsruhe

Lipinski, H.; Stutzer, E. (2004): Wollen die Deutschen keine Kinder? Sechs Gründe für die anhaltend niedrigen Geburtenraten, in: Statistisches Monatsheft BadenWürttemberg, 52. Jg., Nr. 6, S. 3-8

Longman, P. (1987): Born to pay, The New Politics of Aging in America, Boston

Lubitz, J.; Riley, G.F. (1993): Trends in Medicare Payments in the Last Year of Life, in: The New England Journal of Medicine, Vol. 328, S. 1092-1096

Lueg, T.; Ruprecht, W.; Wolgast, M. (2003): Altersvorsorge und demographischer Wandel: Kein Vorteil für das Kapitaldeckungsverfahren?, GDV Volkswirtschaft, Nr. 1, Berlin

Lüngen, M. u.a. (2005): Unterschiede in der Inanspruchnahme von Gesundheitsleistungen und der Morbidität zwischen Versicherten in der Gesetzlichen Krankenversicherung und Privaten Krankenversicherung, in: Gesundheits- und Sozialpolitik, 59. Jg., Nr. 3/4, S. 25-30 
Lutz, W.; Scherbov, S. (2003): Can Immigration Compensate for Europe's Low Fertility?, European Demographic Research Papers, Nr. 1, Vienna

Mackenroth, G. (1952): Die Reform der Sozialpolitik durch einen deutschen Sozialplan, in: Albrecht, G. (Hrsg.), Schriften des Vereins für Socialpolitik, N. F., Bd. 4, Berlin, S. 39-76

Matisonn, S. (2000): Medical Savings Accounts in South Africa, National Center for Policy Analysis, http://www.ncpa.org/studies/s234/s234.html (16.11.2005)

Matthes, J.; Römer, C. (2005): Kapitalmärkte, in: Institut der deutschen Wirtschaft Köln (Hrsg.), Perspektive 2050, Ökonomik des demographischen Wandels, 2. Aufl., Köln, S. 293-319

Mayer-Ahuja, N. (2003): Wieder dienen lernen? Vom westdeutschen „Normalarbeitsverhältnis“ zu prekärer Beschäftigung seit 1973, Berlin

Meier, V. u.a. (2004): Modelle zur Übertragung individueller Altersrückstellungen beim Wechsel privater Krankenversicherer, ifo Beiträge zur Wirtschaftsforschung, Bd. 14, München

Meinhardt, V.; Schulz, E. (2003): Kostenexplosion im Gesundheitswesen?, in: DIWWochenbericht, 70. Jg., Nr. 7, S. 105-109

Meyer, U. (1999): Die Vorschläge der Expertenkommission PKV, in: Basedow, J.; Schwark, E.; Schwintowski, H.-P. (Hrsg.), Anleger- und objektgerechte Beratung, Private Krankenversicherung, Ein Ombudsmann für Versicherungen, Beiträge der siebenten Wissenschaftstagung des Bundes der Versicherten, Baden-Baden, S. $105-127$

Meyer, U. (2001): Mehr Wettbewerb in der privaten Krankenversicherung durch Übertragbarkeit der Alterungsrückstellungen, http://web.uni-bamberg.de/sowi/ economics/meyer/forschung/Me-Wb.pdf (28.11.2005)

Milbrodt, H. (2005): Eine unendliche Geschichte? Zur Mitgabe der Alterungsrückstellungen in der PKV, in: PKV publik, o.Jg., Nr. 3, S. 33-35

Ministry of Health Singapore (Hrsg.) (2005): A Guide to Medisave, http://www.cpf.gov.sg/cpf_info/Publication/medisave.asp (13.10.2005)

Musgrave, R.A. (1959): The Theory of Public Finance, New York, Toronto, London

Neumark, F. (1970): Grundsätze gerechter und ökonomisch rationaler Steuerpolitik, Tübingen

Niehaus, F.; Weber, C. (2005): Der überproportionale Finanzierungsbeitrag privat versicherter Patienten zum Gesundheitswesen, Wissenschaftliches Institut der PKV, Köln

Nocera, S. (1996): Alterung und Gesundheit, in: Zweifel, P.; Felder, S. (Hrsg.), Eine ökonomische Analyse des Alterungsprozesses, Bern, Stuttgart, Wien, S. 61-99

Nolting, H.-D.; Wasem, J. (2002): Der Patient vor der Wahl, Durch mehr Wissen zu mehr Verantwortung, Ergebnisse der Janssen-Cilag Bevölkerungsbefragung 2002, Neuss 
Nürnberger, I.; Stapf-Finé, H. (2004): Renten-Nachhaltigkeitsgesetz: Drastische Einschnitte stellen Versicherungssystem in Frage, in: Soziale Sicherheit - Zeitschrift für Arbeit und Soziales, 53. Jg., Nr. 2, S. 38-43

Nullmeier, F. (2005): Leistungsfähigkeitsprinzip und Generationengerechtigkeit als Legitimation der Bürgerversicherung, in: Strengmann-Kuhn, W. (Hrsg.), Das Prinzip Bürgerversicherung, Wiesbaden, S. 51-65

o.V. (2003): Konjunktur und die Hartz-Gesetze verschärfen Lage der Kassenfinanzen, in: Ärzte Zeitung, Nr. 73 vom 17.04.2003, S. 6

o.V. (2004a): Sollten auch Privat-Versicherer beim RSA ins Boot?, in: Ärzte Zeitung, Nr. 139 vom 27.07.2004, S. 7

o.V. (2004b): Wohin die rot-grünen Pläne beim Rentenniveau führen, in: Frankfurter Allgemeine Zeitung, Nr. 60 vom 11.03.2004, S. 17

o.V. (2004c): Wirtschaftsweise watschen die Union für ihr Kompromißmodell ab, in: Ärzte Zeitung, Nr. 210 vom 18.11.2004, S. 6

o.V. (2004d): PKV-Mitgliederversammlung: Die privaten Krankenversicherungen stellen ihr eigenes Zukunftskonzept für die Krankenversicherung vor, in: PKV publik, o.Jg., Nr. 5, S. 49-52

Oberdieck, V. (1998): Beitragssatzexplosion in der gesetzlichen Krankenversicherung? Demographische und medizintechnische Determinanten der Beitragssatzdynamik und ihre reformpolitischen Implikationen, Duisburger volkswirtschaftliche Schriften, Bd. 26, Hamburg

Oberender, P. (2002): Gesundheitspolitik in der Sozialen Marktwirtschaft, Analyse der Schwachstellen und Perspektiven einer Reform, Stuttgart

Oberender, P.; Hebborn, A.; Zerth, J. (2002): Wachstumsmarkt Gesundheit, Stuttgart

OECD (Hrsg.) (2004): OECD Employment Outlook, Paris

Osterkamp, R. (2003): Reform des deutschen Gesundheitswesens: Bürgerversicherung oder Pauschalbeiträge, in: ifo Schnelldienst, 56. Jg., Nr. 10, S. 11-14

Ott, G. (1981): Einkommensumverteilungen in der gesetzlichen Krankenversicherung: Eine quantitative Analyse, Finanzwissenschaftliche Schriften, Bd. 16, Frankfurt am Main, Bern

Peffekoven, R. (2002): Anforderungen an die Steuer- und Finanzpolitik, in: Institut „Finanzen und Steuern“ e.V. (Hrsg.), IFSt-Schrift, Nr. 397, Bonn, S. 13-34

Peffekoven, R. (2004a): Bürgerversicherung stellt die Steuerpolitik auf den Kopf, in: Börsen-Zeitung, Nr. 172 vom 07.09.2004, S. 6

Peffekoven, R. (2004b): Pro \& Contra, Bürgerversicherung: Fortschritt für das Sozialsystem?, in: Die Bank, o.Jg., Nr. 12, S. 34-35

Peffekoven, R. (2004c): Finger Weg, in: Die Welt, Nr. 168 vom 21.07.2004, S. 12

Peffekoven, R. (2005): Umfinanzierung der Sozialsysteme aus Steuermitteln? Kopfpauschalen mit Sozialausgleich weisen den Weg, in: Wirtschaftsdienst, 85. Jg., Nr. 5, S. 279-283 
Pfaff, A.B. (1999): Veränderte Erwerbsbiographien und ihre Auswirkungen auf die Sozialpolitik, in: Schmähl, W.; Rische, H. (Hrsg.), Wandel der Arbeitswelt Folgerungen für die Sozialpolitik, Baden-Baden, S. 31-60

Pfaff, A.B. (2002): Exkurs: Auswirkungen des demographischen Wandels auf die Beitragssatzentwicklung, in: Schlussbericht der Enquete-Kommission „Demographischer Wandel - Herausforderungen unserer älter werdenden Gesellschaft an den Einzelnen und die Politik“, Bundestags-Drucksache, Nr. 14/8800, S. 193-195

Pfaff, A.B. U.a. (2005): Auswirkungen des Kopfprämienmodells der Unionsparteien auf die Finanzierung der Gesetzlichen Krankenversicherung, in: Gesundheits- und Sozialpolitik, 59. Jg., Nr. 7/8, S. 39-49

Pfaff, M.; Stapf-Finé, H. (Hrsg.) (2004): Bürgerversicherung - solidarisch und sicher!, Die Rolle von GKV und PKV, Beitragsgrundlagen, Leistungskatalog, rechtliche Umsetzung, Hamburg

Pimpertz, J. (2001): Marktwirtschaftliche Ordnung der sozialen Krankenversicherung, Untersuchungen zur Wirtschaftspolitik, Bd. 121, Köln

Pimpertz, J. (2002): Leitlinien zur Reform der gesetzlichen Krankenversicherung, Von der fiskalischen Reaktion zur Ordnungspolitik des Gesundheitswesens, Beiträge zur Wirtschafts- und Sozialpolitik, Bd. 271, Köln

Pimpertz, J. (2003): Ausgabenexplosion statt Einnahmenerosion in der gesetzlichen Krankenversicherung, iw-trends, Nr. 1, Köln

Plünnecke, A.; Seyda, S. (2005): Bildung, in: Institut der deutschen Wirtschaft Köln (Hrsg.), Perspektive 2050, Ökonomik des demographischen Wandels, 2. Aufl., Köln, S. 121-143

Postler, A. (2003): Modellrechnungen zur Beitragssatzentwicklung in der Gesetzlichen Krankenversicherung, Auswirkungen von demographischem Wandel und medizinisch-technischem Fortschritt, Diskussionsbeiträge der Fakultät für Wirtschaftswissenschaft der Universität Duisburg-Essen, Nr. 298, Duisburg

Presse- und Informationsamt der Bundesregierung (Hrsg.) (2002): Härten für Rentner werden vermieden, in: Sozialpolitische Umschau, Ausgabe 9, Nr. 104, S. $12-16$

Prognos (Hrsg.) (1998): Auswirkungen veränderter ökonomischer und rechtlicher Rahmenbedingungen auf die gesetzliche Rentenversicherung in Deutschland, DRV-Schriften, Bd. 9, Frankfurt am Main

Projektgruppe Bürgerversicherung des SPD-Parteivorstandes (2004): Modell einer solidarischen Bürgerversicherung, Berlin

Pütz, C. (2004): Krankensparkonten aus Sicht der gesetzlichen Krankenkassen und ihrer Versicherten, in: Vierteljahreshefte zur Wirtschaftsforschung, 73. Jg., Nr. 4, S. 522-527

Raffelhüschen, B. (2001): Der Sozialstaat in der Generationenbilanz - Mitgift oder Hypothek, in: Der überalterte Sozialstaat - Besitzstandswahrung oder Aufbruch?, Veröffentlichungen der Walter-Raymond-Stiftung, Bd. 40, Stuttgart, S. 51-82

Raffelhüschen, B. (2002a): Blüht das Ende des Generationenvertrags?, in: WISU Das Wirtschaftsstudium, 31. Jg., Nr. 2, S. 149-150 
Raffelhüschen, B. (2002b): Ein Plädoyer für ein flexibles Instrument zur Analyse nachhaltiger Finanzpolitik, in: Wirtschaftsdienst, 82. Jg., Nr. 2, S. 73-76

Raffelhüschen, B. (2004): Die Bürgerversicherung in der Diskussion, in: Frankfurter Allgemeine Zeitung, Nr. 201 vom 30.08.2004, S. 17

Raffelhüschen, B.; Hagist, C.; Fetzer, S. (2004): Was bringen Bürgenversicherung und Gesundheitsprämie wirklich?, in: ifo Schnelldienst, 57. Jg., Nr. 15, S. 3-7

Raspe, H. (1999): Stand und Entwicklung ausgesuchter Gesundheitsindikatoren, in: Häfner, H. (Hrsg.), Gesundheit - unser höchstes Gut, Berlin u.a., S. 85-98

Rat der Europäischen Union (2005): Schlussfolgerungen des Vorsitzes zur Tagung des Europäischen Rates am 22./23. März 2005, Brüssel

Rawls, J. (1972): A Theory of Justice, Oxford

Reichert, R. (2004): Festbeträge und Europäisches Kartellrecht, Berlin

Reuter, N. (1997): Finanzierungsprobleme des Sozialstaats, in: Sozialer Fortschritt, 46. Jg., Nr. 6/7, S. 133-137

Richard, S. (1993): Qualitätssicherung und technologischer Wandel im Gesundheitswesen, Eine institutionenökonomische Analyse, Gesundheitsökonomische Beiträge, Bd. 19, Baden-Baden

Richter, W.F. (2005): Gesundheitsprämie oder Bürgerversicherung? Ein Kompromissvorschlag, in: Wirtschaftsdienst, 85. Jg., Nr. 11, S. 693-697

Ritter, U.P.; Hohmeier, J. (1999): Alterspolitik, Eine sozio-ökonomische Perspektive, München, Wien

Robine, J.M.; Mathers, C.D. (1993): Measuring the Compression or Expansion of Morbidity Through Changes in Health Expectancy, in: Robine, J.M. u.a. (Hrsg.), Calculation of Health Expectancies: Harmonization, Consensus Achieved and Future Perspectives, Paris, London, S. 269-286

Rodrig, S.; Wiesemann, H.-O. (2004): Der Einfluss des demographischen Wandels auf die Ausgaben der Krankenversicherung, in: Zeitschrift für die gesamte Versicherungswissenschaft, Bd. 93, S. 17-46

Rosenbrock, R.; Gerlinger, T. (2004): Gesundheitspolitik, Eine systematische Einführung, Bern u.a.

Rosenschon, A. (2001): Familienförderung in Deutschland - eine Bestandsaufnahme, Kieler Arbeitspapier, Nr. 1071, Kiel

Rothschild, K.W. (1998): Korreferat zum Referat B. Raffelhüschen und J. Walliser, Was hinterlassen wir zukünftigen Generationen, in: Gahlen, B.; Hesse, H.; Ramser, H.J. (Hrsg.), Verteilungsprobleme der Gegenwart, Diagnose und Therapie, Tübingen, S. 321-324

Rudolph, H. (2003): Mini- und Midi-Jobs, Geringfügige Beschäftigung im neuen Outfit, IAB Kurzbericht, Nr. 6, Nürnberg

Rühl, A. (1990): Gesundheitssicherung und demographische Entwicklung, Europäische Hochschulschriften, Reihe 5, Bd. 1079, Frankfurt am Main u.a. 
Rürup, B. (2000): Alterndes Deutschland, Herausforderung des demographischen Wandels, in: Deutsche Rentenversicherung, 55. Jg., Nr. 1/2, S. 72-81

Rürup, B. (2002): Kapitaldeckung (k)ein Königsweg, in: Alternde Gesellschaft, Lösungsansätze für die Probleme der Kranken- und Pflegeversicherung, Berliner Reihe, Heft 21, Karlsruhe, S. 15-23

Rürup, B. (2003): Nachhaltige Sozialpolitik im alternden Deutschland, WZB-Vorlesungen, Nr. 6, Berlin

Rürup, B. (2004): „Von der Sache her richtig“, Interview mit Bert Rürup, in: Die Welt, Nr. 9 vom 12.01.2004, S. 3

Rürup, B.; Klopfleisch, R. (1999): Bevölkerungsalterung und Wirtschaftswachstum: Hypothesen und empirische Befunde, in: Grünheid, E.; Höhn, C. (Hrsg.), Demographische Alterung und Wirtschaftswachstum, Schriftenreihe des Bundesinstituts für Bevölkerungsforschung, Bd. 29, Opladen, S. 40-52

Rürup, B.; Wille, E. (2004): Finanzierungsreform in der Krankenversicherung, Gutachten vom 15.07.2004 (Manuskript)

Rürup-Kommission [Kommission für die Nachhaltigkeit in der Finanzierung der Sozialen Sicherungssysteme] (2003): Bericht der Kommission Nachhaltigkeit in der Finanzierung der sozialen Sicherungssysteme, Berlin

Ruland, F. (2001): Das BVerfG und der Familienlastenausgleich in der Pflegeversicherung, in: Neue Juristische Woche, 54. Jg., Nr. 23, S. 1673-1678

Rumm, U. (2000): Kapitaldeckung im Gesundheitswesen, in: Vereinte Krankenversicherung AG (Hrsg.), Gesund ins neue Jahrtausend, München

Schäfer, H. (2001): Ende des Normalarbeitsverhältnisses? Zu Theorie und Empirie der atypischen Beschäftigung in Deutschland, Beiträge zur Wirtschafts- und Sozialpolitik, Bd. 262, Köln

Schäfer, H.; Seyda, S. (2005): Arbeitsmärkte, in: Institut der deutschen Wirtschaft Köln (Hrsg.), Perspektive 2050, Ökonomik des demographischen Wandels, 2. Aufl., Köln, S. 97-120

Schätzerkreis der Gesetzlichen Krankenversicherung (2005): Schätztableau aus der Schätzerkreissitzung vom 07.06.2005, http://www.bundesversicherungs amt.de/ Fachinformationen/Risikostrukturausgleich/Schaetzerkreis/Schaetztableau.pdf (30.06.2005)

Schmähl, W. (1983a): Auswirkungen von Veränderungen der Altersstruktur der Bevölkerung auf die Finanzsituation der gesetzlichen Krankenversicherung im Vergleich zur gesetzlichen Rentenversicherung, Eine modelltheoretische Analyse, in: Konjunkturpolitik, 29. Jg., Nr. 2, S. 100-120

Schmähl, W. (1983b): Lebenseinkommensanalysen - Einige methodische und empirische Fragen im Überblick, in: Schmähl, W. (Hrsg.), Ansätze der Lebenseinkommensanalyse, Tübingen, S. 1-55

Schmähl, W. (1986): Bevölkerungsentwicklung und soziale Sicherung, Auswirkungen demographischer Veränderungen auf die soziale Sicherung im Alter, bei Krankheit und Pflegebedürftigkeit, in: Felderer, B. (Hrsg.), Beiträge zur Bevölkerungsökonomie, Schriften des Vereins für Socialpolitik, Na. F. Bd. Bd 153, Berlin S 5 169-238 
Schmähl, W. (1989): Demographischer Wandel und Finanzierung der Gesetzlichen Krankenversicherung - Auswirkungen und Finanzierungsalternativen, in: Ferber, C. von; Radebold, H.; Schulenburg, J.-M. Graf von der (Hrsg.), Die demographische Herausforderung, Das Gesundheitssystem angesichts einer veränderten Bevölkerungsstruktur, Beiträge zur Gesundheitsökonomie, Bd. 23, Gerlingen, S. 281-333

Schmähl, W. (2001): Umlagefinanzierte soziale Sicherung: Konzeptionen und Finanzierung, in: Theurl, E. (Hrsg.), Der Sozialstaat an der Jahrtausendwende, Heidelberg, S. 171-206

Schmähl, W. (2002a): Alterssicherungspolitik in Deutschland, Anmerkungen zur Situation in Deutschland, in: Politische Studien, 53. Jg., Nr. 2, S. 106-127

Schmähl, W. (2002b): Begrenzung und Verstärkung des Anstiegs von Sozialbeiträgen, in: Wirtschaftsdienst, 82. Jg., Nr. 11, S. 661-666

Schneider, S.; Johnson, P. (2003): Deutsches Wachstumspotenzial: Vor demografischer Herausforderung, in: Deutsche Bank Research (Hrsg.), Aktuelle Themen, Demografie Spezial, Nr. 277, Frankfurt am Main

Schneider, W. (2003): Kopfprämien zur Kassenfinanzierung, Ein Rückschritt für Familien, in: Gesundheit und Gesellschaft, 6. Jg., Nr. 2, S. 42-48

Schönfels, R. von (2002): Kompletter Unsinn, in: Wirtschaftswoche, Nr. 46 vom 7.11.2002, S. 130-133

Schräder, W.F.; Sehlen, S.; Hofmann, J. (2004): Übergangsprobleme zur Bürgerversicherung: Integration von privat Krankenversicherten, in: Soziale Sicherheit Zeitschrift für Arbeit und Soziales, 53. Jg., Nr. 1, S. 6-12

Schreyögg, J. (2002): Finanzierung des Gesundheitssystems durch ,Medical Savings Accounts', in: List Forum für Wirtschafts- und Finanzpolitik, Bd. 28, Nr. 2, S. 157173

Schreyögg, J. (2003a): Medical Savings Accounts, Eine ökonomische Analyse von Gesundheitssparkonten unter besonderer Berücksichtigung des Gesundheitssystems in Singapur, Baden-Baden

Schreyögg, J. (2003b): „Medical Savings Accounts“ - Eine internationale Bestandsaufnahme des Konzeptes der Gesundheitssparkonten und seine Implikationen für Deutschland, in: Zeitschrift für die gesamte Versicherungswissenschaft, Bd. 92, S. 507-532

Schröder, G. (2003): Regierungserklärung von Bundeskanzler Schröder am 14. März 2003 vor dem Deutschen Bundestag, Berlin

Schulenburg, J.-M. Graf von der (1987): Selbstbeteiligung, Theoretische und empirische Konzepte für die Analyse ihrer Allokations- und Verteilungswirkungen, Tübingen

Schulenburg, J.-M. Graf von der (1988): Solidaritätsprinzip und Verteilungsgerechtigkeit, Probleme einer wettbewerbsorientierten Reform der Gesetzlichen Krankenversicherung, in: Hauser, H.; Schulenburg, J.-M. Graf von der (Hrsg.), Health Maintenance Organizations, Beiträge zur Gesundheitsökonomie, Bd. 19, Berlin, S. $195-245$ 
Schulenburg, J.-M. Graf von der (1989a): Verteilungswirkungen demographischer Verschiebungen, in: Ferber, C. von; Radebold, H.; Schulenburg, J.-M. Graf von der (Hrsg.), Die demographische Herausforderung, Das Gesundheitssystem angesichts einer veränderten Bevölkerungsstruktur, Beiträge zur Gesundheitsökonomie, Bd. 23, Gerlingen, S. 341-369

Schulenburg, J.-M. Graf von der (1989b): Gesundheitswesen (Krankenversicherung) und demographische Evolution, in: Recktenwald, H.C. (Hrsg.), Der Rückgang der Geburten - Folgen auf längere Sicht, Mainz, S. 279-297

Schulenburg, J.-M. Graf von der; Kleindorfer, P.R. (1986): Wie stabil ist der Generationenvertrag in der sozialen Krankenversicherung? Zum Problem der Gerechtigkeit und Akzeptanz intergenerativer Umverteilung, in: Gäfgen, G. (Hrsg.), Ökonomie des Gesundheitswesens, Berlin, S. 413-434

Schulte, R. (2004): Rede des Verbandsvorsitzenden Reinhold Schulte anlässlich der Mitgliederversammlung am 3. Juni 2004, Berlin

Schwar, W. (2002): Reformbedarf im Gesundheitswesen, GKV krankt an schwachen Einnahmen, in: Soziale Sicherheit - Zeitschrift für Arbeit und Soziales, 50. Jg., Nr. 2, S. 49-57

Sehlen, S. u.a. (2004): Bürgerversicherung Gesundheit - Grünes Modell -, Simulationsrechnungen zu Ausgestaltungsmöglichkeiten, IGES-Papier, Nr. 04-06, Berlin

Seidler, A.; Busse, R.; Schwartz, F.W. (1996): Auswirkungen einer weiteren Steigerung der Lebenserwartung auf den medizinischen Versorgungsbedarf, in: Die Ersatzkasse, 76. Jg., Nr. 9, S. 317-322

Shiller, R. (2003): Wir brauchen grundsätzliche Veränderungen, in: Handelsblatt, Nr. 183 vom 23.09.2003, S. 9

Siebert, H. (2001): Wirtschaftliche Perspektiven für alternde Gesellschaften, http://www.uni-kiel.de/lfW/pub/siebert/altern.pdf (27.10.2005)

Simon, S. (2001): Umverteilung in der Sozialversicherung, Europäische Hochschulschriften, Reihe 5, Bd. 2714, Frankfurt am Main u.a.

Sinn, H.-W. (2004): Freizügigkeitsrichtlinie: Freifahrt in den Sozialstaat, ifo Standpunkt, Nr. 53, München

Sinn, H.-W. u.a. (2001): EU-Erweiterung und Arbeitskräftemigration, Wege zu einer schrittweisen Annäherung der Arbeitsmärkte, ifo-Beiträge zur Wirtschaftsforschung, Nr. 2, München

Sodan, H. (2003): Zur Steuerfinanzierung versicherungsfremder Leistungen der gesetzlichen Krankenversicherung, Rechtsgutachten erstattet im Auftrag des Verbandes der privaten Krankenversicherung e.V., Berlin

Spitzenverbände der am RSA beteiligten Krankenkassen (Hrsg.) (2003): Vereinbarung nach $\S 267$ Abs. 7 Nr. 1 und 2 SGB V in der Fassung vom 29. April 2003, o.O.

Spreemann, B. (2004): Das „Persönliche Gesundheitskonto“ (GeKo) - ein neues Finanzierungsmodell zur Absicherung von Krankheitskosten in Deutschland, in:

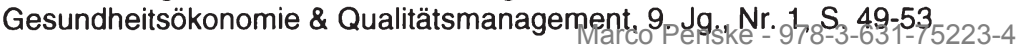


Statistisches Bundesamt (Hrsg.) (1998): Gesundheitsbericht für Deutschland, Gesundheitsberichterstattung des Bundes, Ergebnis eines Forschungsvorhabens, Stuttgart

Statistisches Bundesamt (Hrsg.) (2001): Jobs auf Zeit - abhängig Beschäftigte arbeiten immer häufiger mit befristetem Vertrag, Pressemitteilung vom 30.04.2001, Wiesbaden

Statistisches Bundesamt (Hrsg.) (2002): Gesundheit, Ausgaben 1992-2000, Wiesbaden

Statistisches Bundesamt (Hrsg.) (2003): Bevölkerung Deutschlands bis 2050, 10. koordinierte Bevölkerungsvorausberechnung, Wiesbaden

Statistisches Bundesamt (Hrsg.) (2004a): Leben und Arbeiten in Deutschland, Ergebnisse des Mikrozensus 2003, Wiesbaden

Statistisches Bundesamt (Hrsg.) (2004b): Finanzen und Steuern, Personal des öffentlichen Dienstes, Fachserie 14, Reihe 6, Wiesbaden

Statistisches Bundesamt (Hrsg.) (2004c): Finanzen und Steuern, Versorgungsempfänger des öffentlichen Dienstes, Fachserie 14, Reihe 6.1, Wiesbaden

Steffen, A. (1997): Sozialstaat in der Krise, in: Institut der Deutschen Wirtschaft (Hrsg.), Reform des Sozialstaats, Vorschläge, Argumente, Modellrechnungen zur Alterssicherung, Köln, S. 17-69

Steiner, V.; Wrohlich, K. (2005): Minijob-Reform: Keine durchschlagende Wirkung, in: DIW-Wochenbericht, 72. Jg., Nr. 8, S. 141-146

Steinmann, G.; Fuchs, O.; Tagge, S. (2002): Mögliche Effekte des demographischen Wandels - ein Überblick, in: Wirtschaft im Wandel, 8. Jg., Nr. 15, S. 470-480

Straubhaar, T. (1997): Zuwanderung und Sozialstaat: Bedrohung oder Chance, in: Knappe, E.; Winkler, A. (Hrsg.), Sozialstaat im Umbruch, Herausforderungen an die deutsche Sozialpolitik, Frankfurt am Main, S. 47-64

SVR [Sachverständigenrat zur Begutachtung der gesamtwirtschaftlichen Entwicklung] (1996): Reformen voranbringen, Jahresgutachten 1996/97, Stuttgart

SVR [Sachverständigenrat zur Begutachtung der gesamtwirtschaftlichen Entwicklung] (1998): Vor weitreichenden Entscheidungen, Jahresgutachten 1998/99, Stuttgart

SVR [Sachverständigenrat zur Begutachtung der gesamtwirtschaftlichen Entwicklung] (2000): Chancen auf einen höheren Wachstumspfad, Jahresgutachten 2000/01, Stuttgart

SVR [Sachverständigenrat zur Begutachtung der gesamtwirtschaftlichen Entwicklung] (2001): Für Stetigkeit - gegen Aktionismus, Jahresgutachten 2001/02, Stuttgart

SVR [Sachverständigenrat zur Begutachtung der gesamtwirtschaftlichen Entwicklung] (2002): Zwanzig Punkte für Beschäftigung und Wachstum, Jahresgutachten 2002/03, Stuttgart 
SVR [Sachverständigenrat zur Begutachtung der gesamtwirtschaftlichen Entwicklung] (2003): Staatsfinanzen konsolidieren - Steuersystem reformieren, Jahresgutachten 2003/04, Wiesbaden

SVR [Sachverständigenrat zur Begutachtung der gesamtwirtschaftlichen Entwicklung] (2004): Erfolge im Ausland - Herausforderungen im Inland, Jahresgutachten 2004/05, Wiesbaden

SVR [Sachverständigenrat zur Begutachtung der gesamtwirtschaftlichen Entwicklung] (2005): Die Chance nutzen - Reformen mutig voranbringen, Jahresgutachten 2005/06, Wiesbaden

SVR KAiG (Sachverständigenrat für die Konzertierte Aktion im Gesundheitswesen) (1987): Medizinische und ökonomische Orientierung, Vorschläge für die Konzertierte Aktion im Gesundheitswesen, Jahresgutachten 1987, Baden-Baden

SVR KAiG (Sachverständigenrat für die Konzertierte Aktion im Gesundheitswesen) (1989): Qualität, Wirtschaftlichkeit und Perspektiven der Gesundheitsversorgung, Vorschläge für die Konzertierte Aktion im Gesundheitswesen, Jahresgutachten 1989, Baden-Baden

SVR KAiG (Sachverständigenrat für die Konzertierte Aktion im Gesundheitswesen) (1994): Gesundheitsversorgung und Krankenversicherung 2000, Eigenverantwortung, Subsidiarität und Solidarität bei sich ändernden Rahmenbedingungen, Sachstandsbericht 1994, Baden-Baden

SVR KAiG (Sachverständigenrat für die Konzertierte Aktion im Gesundheitswesen) (1995): Gesundheitsversorgung und Krankenversicherung 2000, Mehr Ergebnisorientierung, mehr Qualität und mehr Wirtschaftlichkeit, Sondergutachten 1995, Baden-Baden

SVR KAiG (Sachverständigenrat für die Konzertierte Aktion im Gesundheitswesen) (1996): Gesundheitswesen in Deutschland, Kostenfaktor und Zukunftsbranche, Bd. I: Demographie, Morbidität, Wirtschaftlichkeitsreserven und Beschäftigung, Sondergutachten 1996, Baden-Baden

SVR KAiG (Sachverständigenrat für die Konzertierte Aktion im Gesundheitswesen) (1998): Gesundheitswesen in Deutschland, Kostenfaktor und Zukunftsbranche, Bd. II: Fortschritt und Wachstumsmärkte, Finanzierung und Vergütung, Sondergutachten 1997, Baden-Baden

SVR KAiG (Sachverständigenrat für die Konzertierte Aktion im Gesundheitswesen) (2003): Finanzierung, Nutzerorientierung und Qualität, Bd. I: Finanzierung und Nutzerorientierung, Gutachten 2003, Baden-Baden

Temkin-Greener, H. u.a. (1992): The Use and Cost of Health Services Prior to Death: A Comparison of the Medicare-Only and the Medicare-Medicaid Elderly Populations, in: Milbank Memorial Fund Quarterly, Vol. 70, Nr. 4, S. 679-701

Ulrich, V. (1995): Alterung und Gesundheit, Korreferat zu Eckhard Knappe: Auswirkungen des demographischen Wandels auf den Gesundheitssektor, in: Oberender, P. (Hrsg.), Transplantationsmedizin, ökonomische, ethische, rechtliche und medizinische Aspekte, Baden-Baden, S. 43-51 
Ulrich, V. (1998): Das Gesundheitswesen an der Schwelle zum Jahr 2000, Wirtschaftswissenschaftliche Diskussionspapiere der Ernst-Moritz-Arndt-Universität Greifswald, Nr. 1, Greifswald

Ulrich, V. (2000): Medizinisch-technischer Fortschritt, demographische Alterung und Wachstum der Gesundheitsausgaben: Was sind die treibenden Faktoren?, in: Gesundheitsökonomie \& Qualitätsmanagement, 5. Jg., Nr. 6, S. 163-172

Ulrich, V. (2003): Demographische Effekte auf Ausgaben und Beitragssatz der GKV, in: Albring, M.; Wille, E. (Hrsg.), Die GKV zwischen Ausgabendynamik, Einnahmenschwäche und Koordinierungsproblemen, Frankfurt am Main u.a., S. 59-83

Ulrich, V.; Schneider, U. (2004): Ausgestaltung und Finanzierung des sozialen Ausgleichs im Rahmen des Steuersystems - Baustein für einen wettbewerblichen Systemwechsel in der Krankenversicherung, Kurzgutachten im Auftrag des Verbandes Forschender Arzneimittelhersteller e.V., Bayreuth

Unabhängige Kommission Zuwanderung (2001): Zuwanderung gestalten, Integration fördern, Bericht der Unabhängigen Kommission „Zuwanderung“, Berlin

United Nations (Hrsg.) (2000): Replacement Migration: Is it a Solution to Declining and Ageing Populations?, New York

United Nations (Hrsg.) (2004): World Population to 2300, New York

Vaupel, J.W.; Manton, K.G.; Stallard, E. (1979): The Impact of Heterogeneity in Individual Frailty on the Dynamics of Mortality, in: Demography, Vol. 16, Nr. 3, S. $439-454$

Verband der privaten Krankenversicherung e.V. (Hrsg.) (1997): Herausforderungen, Entwicklungslinien eines Versicherungszweiges von den Anfängen bis zur Gegenwart, Festschrift zum 50jährigen Bestehen des Verbandes der privaten Krankenversicherung e.V., PKV-Dokumentation, Nr. 20, Köln

Verband der privaten Krankenversicherung e.V. (Hrsg.) (2005): Die private Krankenversicherung, Zahlenbericht 2004/2005, Köln

Verband Deutscher Rentenversicherungsträger (Hrsg.) (2004a): Rentenversicherung in Zahlen 2004, Frankfurt am Main

Verband Deutscher Rentenversicherungsträger (Hrsg.) (2004b): Durchschnittlich erzielte beitragspflichtige Jahresentgelte 2003 (unveröffentlichtes Datenmaterial)

Verband Deutscher Rentenversicherungsträger (Hrsg.) (2004c): Anzahl der Renten und durchschnittlicher Rentenzahlbetrag nach Rentenarten sowie nach Alter des Rentenberechtigten zum Erhebungsstichtag 2003 (unveröffentlichtes Datenmaterial)

Verband Deutscher Rentenversicherungsträger (Hrsg.) (2004d): Stellungnahme anlässlich der öffentlichen Anhörung vor dem Ausschuss für Gesundheit und Soziale Sicherung des Deutsches Bundestages am 11. Februar 2004 zum Entwurf eines "Gesetzes zur Sicherung der nachhaltigen Finanzierungsgrundlagen der gesetzlichen Rentenversicherung (RV-Nachhaltigkeitsgesetz)", Berlin

Verbrugge, L.M. (1984): Longer Life but Worsening Health? Trends in Health and Mortality of Middle-aged and Older Persons, in: Milbank Memorial Fund Quarterly, Vol. 62, Nr. 3, S. 475-519 
Vereinte Dienstleistungsgewerkschaft e.V. (Hrsg.) (2001): Gesundheit solidarisch finanzieren, in: Soziale Sicherheit - Zeitschrift für Arbeit und Soziales, 51. Jg., Nr. 1, S. 6-13

Vliet, R.C.J.A. van; Lamers, L.M. (1998): The High Costs of Death: Should Health Plans get Higher Payments When Members die?, in: Medical Care, Vol. 36, Nr. 10, S. 1451-1460

Wälde, K. (1998): Korreferat zum Referat B. Raffelhüschen und J. Walliser, Was hinterlassen wir zukünftigen Generationen?, in: Gahlen, B.; Hesse, H.; Ramser, H.J. (Hrsg.), Verteilungsprobleme der Gegenwart, Diagnose und Therapie, Tübingen, S. 325-330

Wagner, G.G. (2005): Verlässlichkeit einer höheren Steuerfinanzierung der sozialen Sicherung ist die zentrale Frage, in: Wirtschaftsdienst, 85. Jg., Nr. 5, S. 283-287

Wallau, D. (2004): Effizienzfördernde Reformen im Gesundheitswesen, Studien zur Wirtschaftspolitik, Bd. 78, Frankfurt am Main

Wambach, A. (2004): Gentechnologie und Versicherbarkeit sozialer Risiken, in: Rische, H.; Schmähl, W. (Hrsg.), Gesundheits- und Alterssicherung - gleiche Herausforderungen, gleiche Lösung?, Münster, S. 164-177

Wambach, A.; Wigger, B.U. (2003): Kopfpauschale oder Bürgerversicherung, in: ifo Schnelldienst, 56. Jg., Nr. 10, S. 7-10

Wasem, J. (1996): Private Krankenversicherung und ältere Versicherte, in: Oberender, P. (Hrsg.), Alter und Gesundheit, Baden-Baden, S. 129-165

Weeber, J. (2004): Ökonomische Effekte einer Anhebung der Mehrwertsteuer zur Finanzierung von Sozialleistungen, in: Gesundheits- und Sozialpolitik, 58. Jg., Nr. 3/4, S. $19-23$

Weinmann, J.; Zifonun, N. (2004): Gesundheitsausgaben und Gesundheitspersonal 2002, in: Wirtschaft und Statistik, o.Jg., Nr. 4, S. 449-461

Wenzel, D. (1999): Finanzierung des Gesundheitswesens und interpersonelle Umverteilung: Mikrosimulationsuntersuchung der Einkommenswirkung von Reformvorschlägen zur GKV, Sozialökonomische Schriften, Bd. 17, Frankfurt am Main u.a.

Werding, M.; Kaltschütz, A. (2005): Modellrechnungen zur langfristigen Tragfähigkeit der öffentlichen Finanzen, ifo Beiträge zur Wirtschaftsforschung, Bd. 17, München

Wiesemann, H.-O. (2001): Bedroht Arbeitslosigkeit die Finanzlage der Sozialversicherung? Theoretische und empirische Untersuchung einer zentralen These der Sozialpolitik, in: Henke, K.-D.; Schmähl, W. (Hrsg.), Finanzierungsverflechtung in der Sozialen Sicherung, Europäische Schriften zu Staat und Wirtschaft, Bd. 9, Baden-Baden, S. 110-144

Wigger, B.U. (2004): Grundzüge der Finanzwissenschaft, Berlin, Heidelberg, New York

Wigger, B.U. (2005): Wer profitiert von der weiteren Erhöhung der Tabaksteuer, in: Wirtschaftsdienst, 85. Jg., Nr. 8, S. 518-521 
Wilkins, R.; Adams, O.B. (1987): Changes in the Healthfulness of Life of the Elderly Population: An Empirical Approach, in: Revue Epidémiologique et Santé Publique, Vol. 35, S. 225-235

Wille, E. (1998): Zukünftige finanzielle Absicherung des Krankheitsrisikos, in: Arbeit und Sozialpolitik, 52. Jg., Nr. 1/2, S. 16-27

Wille, E. (1999): Einführung: Die Sozialabgaben als wirtschaftspolitisches Problem, in: Wille, E. (Hrsg.), Entwicklung und Perspektiven der Sozialversicherung, BadenBaden, S. 7-19

Wille, E. (2001): Basis- und Zusatzversorgung in der gesetzlichen Krankenversicherung, Arbeitsbericht der TA-Akademie, Nr. 199, Mannheim

Wille, E. (2002a): Zur Bemessungsgrundlage von Socialfisci - allokative und distributive Überlegungen angestellt am Beispiel der sozialen Krankenversicherung, in: Theurl, E.; Thöni, E. (Hrsg.), Zukunftsperspektiven der Finanzierung öffentlicher Aufgaben, Wien, Köln, Weimar, S. 249-266

Wille, E. (2002b): Reformoptionen der Beitragsgestaltung in der gesetzlichen Krankenversicherung, in: Gesundheit und Gesellschaft Wissenschaft, 2. Jg., Nr. 3, S. 7-14

Wille, E. (2003a): Anmerkung zum Gesetzentwurf der Bundesregierung „zur Modernisierung des Gesundheitssystems“, in: Wirtschaftsdienst, 83. Jg., Nr. 6, S. 355358

Wille, E. (2003b): Finanzierungsoptionen in der Gesetzlichen Krankenversicherung Reformüberlegungen aus der Sicht des Sachverständigenrates, in: Die Krankenversicherung, 55. Jg., Nr. 4, S. 107-112

Wille, E.; Ulrich, V. (1991): Bestimmungsfaktoren der Ausgabenentwicklung in der gesetzlichen Krankenversicherung (GKV), in: Hansmeyer, K.-H. (Hrsg.), Finanzierungsprobleme der sozialen Sicherung II, Schriften des Vereins für Socialpolitik, N. F., Bd. 194/II, Berlin, S. 9-115

Wissenschaftlicher Beirat beim Bundesministerium der Finanzen (2001): Nachhaltigkeit in der Finanzpolitik, Konzepte für eine langfristige Orientierung öffentlicher Haushalte, Schriftenreihe des Bundesministeriums der Finanzen, Heft 71, Berlin

Wissenschaftlicher Beirat beim Bundesministerium der Finanzen (2004): Nachhaltige Finanzierung der Renten- und Krankenversicherung, Schriftenreihe des Bundesministeriums der Finanzen, Heft 77, Berlin

Wissenschaftlicher Beirat beim Bundesministerium der Finanzen (2005): Zur Reform der Gesetzlichen Krankenversicherung: Ein Konsensmodell, http://www.Bundes finanzministerium.de/lang_de/DE/Service/Downloads/Abt_1/0510171a3001,templ ateld=raw,property=publicationFile.pdf (28.10.2005)

Wissenschaftlicher Beirat beim Bundesministerium für Wirtschaft (1998): Grundlegende Reform der gesetzlichen Rentenversicherung, Bonn

Zipperer, M. (2003a): Gutachten im Auftrag des Verbands der privaten Krankenversicherung e.V. zu den Implikationen verfassungsrechtlicher, ordnungspolitischer und finanzieller Art, die mit der Einführung einer Bürgerversicherung verbunden sein könnten, Sankt-Augustin 
Zipperer, M. (2003b): Gutachten im Auftrag des Verbands der privaten Krankenversicherung e.V. zu den administrativen Problemen bei der Einführung einer Bürgerversicherung, Sankt-Augustin

Zweifel, P. (1989): Zu den Folgen des Geburtenrückgangs für das Gesundheitswesen, in: Recktenwald, H.C. (Hrsg.), Der Rückgang der Geburten - Folgen auf längere Sicht, Mainz, S. 298-304

Zweifel, P. (1990): Bevölkerung und Gesundheitswesen: Ein Sisyphus-Syndrom?, in: Felderer, B. (Hrsg.), Bevölkerung und Wirtschaft, Schriften des Vereins für Socialpolitik, N. F., Bd. 202, Berlin, S. 373-386

Zweifel, P.; Breuer, M. (2002): Weiterentwicklung des deutschen Gesundheitssystems, Gutachten im Auftrag des Verbands forschender Arzneimittelhersteller e.V., Zürich

Zweifel, P.; Felder, S.; Meier, M. (1996): Demographische Alterung und Gesundheitskosten: Eine Fehlinterpretation?, in: Oberender, P. (Hrsg.), Alter und Gesundheit, Baden-Baden, S. 29-46

Zweifel, P.; Felder, S.; Meier, M. (1999): Ageing of Population and Health Care Expenditure: A Red Herring?, in: Health Economics, Vol. 8, S. 485-496 


\section{FINANZWISSENSCHAFTLICHE SCHRIFTEN}

Band 1 Werner Steden: Finanzpolitik und Einkommensverteilung. Ein Wachstums- und Konjunkturmodell der Bundesrepublik Deutschland. 1979.

Band 2 Rainer Hagemann: Kommunale Finanzplanung im föderativen Staat. 1976.

Band 3 Klaus Scherer: Maßstäbe zur Beurteilung von konjunkturellen Wirkungen des öffentlichen Haushalts. 1977.

Band 4 Brita Steinbach: "Formula Flexibility" - Kritische Analyse und Vergleich mit diskretionărer Konjunkturpolitik. 1977.

Band 5 Hans-Georg Petersen: Personelle Einkommensbesteuerung und Inflation. Eine theoretisch-empirische Analyse der Lohn- und veranlagten Einkommensteuer in der Bundesrepublik Deutschland. 1977.

Band 6 Friedemann Tetsch: Raumwirkungen des Finanzsystems der Bundesrepublik Deutschland. Eine Untersuchung der Auswirkungen der Finanzreform von 1969 auf die Einnahmenposition der untergeordneten Gebietskörperschaften und ihrer regionalpolitischen Zieladăquanz. 1978.

Band 7 Wilhelm Pfähler: Normative Theorie der fiskalischen Besteuerung. Ein methodologischer und theoretischer Beitrag zur Integration der normativen Besteuerungstheorie in der Wohlfahrtstheorie. 1978.

Band 8 Wolfgang Wiegard: Optimale Schattenpreise und Produktionsprogramme für öffentliche Unternehmen. Second-Best Modelle im finanzwirtschaftlichen Staatsbereich. 1978.

Band 9 Hans P. Fischer: Die Finanzierung des Umweltschutzes im Rahmen einer rationalen Umweltpolitik. 1978.

Band 10 Rainer Paulenz: Der Einsatz finanzpolitischer Instrumente in der Forschungs- und Entwicklungspolitik. 1978.

Band 11 Hans-Joachim Hauser: Verteilungswirkungen der Staatsverschuldung. Eine kreislauftheoretische Inzidenzbetrachtung. 1979.

Band 12 Gunnar Schwarting: Kommunale Investitionen. Theoretische und empirische Untersuchungen der Bestimmungsgründe kommunaler Investitionstätigkeit in NordiheinWesttalen 1965-1972. 1979.

Band 13 Hans-Joachim Conrad: Stadt-Umland-Wanderung und Finanzwirtschaft der Kemstădte. Amerikanische Erfahrungen, grundsätzliche Zusammenhänge und eine Fallstudie für das Ballungsgebiet Frankfurt am Main. 1980.

Band 14 Cay Folkers: Vermögensverteilung und staatliche Aktivität. Zur Theorie distributiver Prozesse im Interventionsstaat. 1981.

Band 15 Helmut Fischer: US-amerikanische Exportförderung durch die DISC-Gesetzgebung. 1981.

Band 16 Günter Ott: Einkommensumverteilungen in der gesetzlichen Krankenversicherung. Eine quantitative Analyse. 1981.

Band 17 Johann Hermann von Oehsen: Optimale Besteuerung. (Optimal Taxation). 1982.

Band 18 Richard Kőssler: Sozialversicherungsprinzip und Staatszuschüsse in der gesetzlichen Rentenversicherung. 1982.

Band 19 Hinrich Steffen: Zum Handlungs- und Entscheidungsspielraum der kommunalen Investitionspolitik in der Bundesrepublik Deutschland. 1983.

Band 20 Manfred Scheuer: Wirkungen einer Auslandsverschuldung des Staates bei flexiblen Wechselkursen. 1983. 
Band 21 Christian Schiller: Staatsausgaben und crowding-out-Effekte. Zur Effizienz einer Finanzpolitik keynesianischer Provenienz. 1983.

Band 22 Hannelore Weck: Schattenwirtschaft: Eine Möglichkeit zur Einschränkung der öffentlichen Verwaltung? Eine ökonomische Analyse. 1983.

Band 23 Wolfgang Schmitt: Steuern als Mittel der Einkommenspolitik. Eine Ergänzung der Stabilitätspolitik? 1984.

Band 24 Wolfgang Laux: Erhöhung staatswirtschaftlicher Effizienz durch budgetäre Selbstbeschränkung? Zur Idee einer verfassungsmäßig verankerten Ausgabengrenze. 1984.

Band 25 Brita Steinbach-van der Veen: Steuerinzidenz. Methodologische Grundlagen und empirisch-statistische Probleme von Länderstudien. 1985.

Band 26 Albert Peters: Ökonomische Kriterien für eine Aufgabenverteilung in der Marktwirtschaft. Eine deskriptive und normative Betrachtung für den Allokationsbereich. 1985.

Band 27 Achim Zeidler: Möglichkeiten zur Fortsetzung der Gemeindefinanzreform. Eine theoretische und empirische Analyse. 1985.

Band 28 Peter Bartsch: Zur Theorie der längerfristigen Wirkungen 'expansiver' Fiskalpolitik. Eine dynamische Analyse unter besonderer Berücksichtigung der staatlichen Budgetbeschränkung und ausgewählter Möglichkeiten der öffentlichen Defizitfinanzierung. 1986.

Band 29 Konrad Beiwinkel: Wehrgerechtigkeit als finanzpolitisches Verteilungsproblem. Möglichkeiten einer Kompensation von Wehrungerechtigkeit durch monetäre Transfers. 1986.

Band 30 Wolfgang Kitterer: Effizienz- und Verteilungswirkungen des Steuersystems. 1986.

Band 31 Heinz Dieter Hessler: Theorie und Politik der Personalsteuern. Eine Kritik ihrer Einkommens- und Vermögensbegriffe mit Blick auf die Leistungsfăhigkeitstheorie. 1994.

Band 32 Wolfgang Scherf: Die beschäftigungspolitische und fiskalische Problematik der Arbeitgeberbeitrăge zur Rentenversicherung. Eine Auseinandersetzung mit der Kritik an der lohnbezogenen Beitragsbemessung. 1987.

Band 33 Andreas Mästle: Die Steuerunion. Probleme der Harmonisierung spezifischer Gütersteuern. 1987.

Band 34 Günter Ott: Internationale Verteilungswirkungen im Finanzausgleich der Europäischen Gemeinschaften. 1987.

Band 35 Heinz Haller: Zur Frage der zweckmäßigen Gestalt gemeindlicher Steuem. Ein Diskussionsbeitrag zur Gemeindesteuerreform. 1987.

Band 36 Thomas Kuhn: Schlüsselzuweisungen und fiskalische Ungleichheit. Eine theoretische Analyse der Verteilung von Schlüsselzuweisungen an Kommunen. 1988.

Band 37 Walter Hahn: Steuerpolitische Willensbildungsprozesse in der Europäischen Gemeinschaft. Das Beispiel der Umsatzssteuer-Harmonisierung. 1988.

Band 38 Ulrike Hardt: Kommunale Finanzkraft. Die Problematik einer objektiven Bestimmung kommunaler Einnahmemöglichkeiten in der gemeindlichen Haushaltsplanung und im kommunalen Finanzausgleich. 1988.

Band 39 Jochen Michaelis: Optimale Finanzpolitik im Modell überlappender Generationen. 1989.

Band 40 Bernd Raffelhüschen: Anreizwirkungen der sozialen Alterssicherung. Eine dynamische Simulationsanalyse. 1989.

Band 41 Berend Diekmann: Die Anleihe- und Darlehenstransaktionen der Europäischen Gemeinschaften. 1990.

Band 42 Helmut Kaiser: Konsumnachfrage, Arbeitsangebot und optimale Haushaltsbesteuerung. Theoretische Ergebnisse und mikroökonometrische Simulation für die Bundesrepublik Deutschland. 1990. 
Band 43 Rüdiger von Kleist: Das Gramm-Rudman-Hollings-Gesetz. Ein gescheiterter Versuch der Haushaltskonsolidierung. 1991.

Band 44 Rolf Hagedorn: Steuerhinterziehung und Finanzpolitik. Ein theoretischer Beitrag unter besonderer Berücksichtigung der Hinterziehung von Zinsertrãgen. 1991.

Band 45 Cornelia S. Behrens: Intertemporale Verteilungswirkungen in der gesetzlichen Krankenversicherung der Bundesrepublik Deutschland. 1991.

Band 46 Peter Saile: Ein ökonomischer Ansatz der Theorie der intermediären Finanzgewalten Die Kirchen als Parafisci. 1992.

Band 47 Peter Gottfried: Die verdeckten Effizienzwirkungen der Umsatzsteuer. Eine empirische allgemeine Gleichgewichtsanalyse. 1992.

Band 48 Andreas Burger: Umweltorientierte Beschäftigungsprogramme. Eine Effizienzanalyse am Beispiel des "Sondervermőgens Arbeit und Umwelt". 1992.

Band 49 Jeanette Malchow: Die Zuordnung verteilungspolitischer Kompetenzen in der Europäischen Gemeinschaft. Eine Untersuchung aufgrund einer Fortentwicklung der ökonomischen Theorie des Föderalismus. 1992.

Band 50 Barbara Seidel: Die Einbindung der Bundesrepublik Deutschland in die Europãischen Gemeinschaften als Problem des Finanzausgleichs. 1992.

Band 51 Ralph Wiechers: Markt und Macht im Rundfunk. Zur Stellung der öffentlich-rechtlichen Rundfunkanstalten im dualen Rundfunksystem der Bundesrepublik Deutschland. 1992.

Band 52 Klaus Eckhardt: Probleme einer Umweltpolitik mit Abgaben. 1993.

Band 53 Oliver Schwarzkopf: Die Problematik unterschiedlicher Körperschaftsteuersysteme innerhalb der EG. 1993.

Band 54 Thorsten Giersch: Bergson-Wohlfahrtsfunktion und normative Ökonomie. 1993.

Band 55 Li-Fang Chou: Selbstbeteiligung bei Arzneimitteln aus ordnungspolitischer Sicht. Das Beispiel der Bundesrepublik Deutschland. 1993.

Band 56 Harald Schlee: Einkommensteuerliche Behandlung von Transferzahlungen. Zur Neuordnung der Familienbesteuerung sowie der Besteuerung von Versicherungsleistungen und Sozialtransfers. 1994.

Band 57 Alexander Spermann: Kommunales Krisenmanagement. Reaktionen baden-württembergischer Stadtkreise auf steigende Sozialhilfekosten und Einnahmenausfälle (198092). 1993.

Band 58 Otto Roloff / Sibylle Brander / Ingo Barens / Claudia Wesselbaum: Direktinvestitionen und internationale Steuerkonkurrenz. 1994.

Band 59 Claudia Wesselbaum-Neugebauer: Internationale Steuerbelastungsvergleiche. 1994.

Band 60 Stephanie Miera: Kommunales Finanzsystem und Bevölkerungsentwicklung. Eine Analyse des kommunalen Finanzsystems vor dem Hintergrund der sich abzeichnenden Bevőlkerungsentwicklung am Beispiel Niedersachsens unter besonderer Berūcksichtigung des Landkreises Wolfenbüttel und seiner Gemeinden. 1994.

Band 61 Wolfgang Scherf: Die Bedeutung des kaldorianischen Verteilungsmechanismus für die gesamtwirtschaftlichen Wirkungen der staattichen Neuverschuldung. 1994.

Band 62 Rainer Volk: Vergleich der Vergünstigungseffekte der verschiedenen investitionsfördernden Maßnahmen. 1994.

Band 63 Hans-Georg Napp: Kommunale Finanzautonomie und ihre Bedeutung für eine effiziente lokale Finanzwirtschaft. 1994. 2., unverănderte Auflage 1994.

Band 64 Bernd Rahmann / Uwe Steinbom / Günter Vornholz: Empirische Analyse der Autonomie lokaler Finanzwirtschaften in der Europäischen Gemeinschaft. 1994. 
Band 65 Carsten Kühl: Strategien zur Finanzierung der Altlastensanierung. 1994.

Band 66 Stephan Boll: Intergenerationale Umverteilungswirkungen der Fiskalpolitik in der Bundesrepublik Deutschland. Ein Ansatz mit Hilfe des Generational Accounting. 1994.

Band 67 Karl Justus Bernhard Neumärker: Finanzverfassung und Staatsgewalt in der Demokratie. Ein Beitrag zur konstitutionellen Finanztheorie. 1995.

Band 68 Christian Haslbeck: Zentrale versus dezentrale Internalisierung externer Effekte bei unvollstăndiger Information. 1995.

Band 69 Regina Müller: Horizontale oder vertikale Transfers zur Durchsetzung eines horizontalen Finanzausgleichs. 1995.

Band 70 Christian Hockenjos: Öffentliche Sportförderung in der Bundesrepublik Deutschland. Darstellung und finanztheoretische Analyse. 1995.

Band 71 Manfred Rosenstock: Die Kontrolle und Harmonisierung nationaler Beihilfen durch die Kommission der Europäischen Gemeinschaften. 1995.

Band 72 Christian Rüsch: Wohnungsbau- und Wohneigentumspolitik im Rahmen der Einkommensteuer. Eine Analyse unter steuersystematischen, verteilungspolitischen und fiskalischen Aspekten. 1996.

Band 73 Stephan Winters: Die kollektive Vorsorge für den Pflegefall im Alter. Eine Untersuchung am Beispiel der gesetzlichen Pflegeversicherung in den Niederlanden. 1996.

Band 74 Knut Blind: Allokationsineffizienzen auf Sicherheitsmärkten: Ursachen und Lösungsmöglichkeiten. Fallstudie: Informationssicherheit in Kommunikationssystemen. 1996.

Band 75 Barbara Petrick-Rump: Ökonomische Wirkungen von Steueramnestien. Untersuchung konkreter Erfahrungen ausgewählter Länder mit dem Einsatz von Steueramnestien anhand eines effizienten Steueramnestieprogramms. 1996.

Band 76 Georg Hirte: Effizienzwirkungen von Finanzausgleichsregelungen. Eine Empirische Allgemeine Gleichgewichtsanalyse für die Bundesrepublik Deutschland. 1996.

Band 77 Ulrike Kirchhoff: Die meinland-pfälzischen Gemeinden im System des Finanzausgleichs. 1996.

Band 78 Kerstin Keil: Der soziale Mietwohnungsbau: Măngel und Alternativen. 1996.

Band 79 Bernhard Manzke: Kinderlastenausgleich versus verstărkte Einwanderung. Alternative Ansätze zur langfristigen Sicherung der Gesetzlichen Rentenversicherung. 1997.

Band 80 Hariolf M. Wenzler: Institutionenökonomik und öffentliche Finanzkontrolle. Eine Analyse am Beispiel der Europăischen Union. 1997.

Band 81 Joachim Nagel: Supply-Side Policy in den USA. Eine theoretische und empirische Analyse der angebotsorientierten Wirtschaftspolitik Reagans unter besonderer Berücksichtigung steuerlicher Aspekte. 1997.

Band 82 Heinz Lampert: Krise und Reform des Sozialstaates. 1997.

Band 83 Monika Hanswillemenke / Bernd Rahmann: Zwischen Reformen und Verantwortung für Vollbeschäftigung. Die Finanz- und Haushaltspolitik der sozial-liberalen Koalition von 1969 bis 1982. 1997.

Band 84 Berthold Fürst: Die Maastrichter Budgetkriterien im Konflikt mit der Verschuldungsautonomie der deutschen Gebietskörperschaften. 1997.

Band 85 Burkhard Pahnke: Einkommensorientierte Förderung des sozialen Mietwohnungsbaues. Bestandsaufnahme und Kritik. 1998.

Band 86 Judith Safford: Staatsverschuldung im Vereinigten Königreich. Die öffentliche Verschuldung unter der Konservativen Regierung von 1979-1994. Ursachen und Auswirkungen. 1998. 
Band 87 Ralf Oberheide: Die Bekämpfung der Steuerumgehung. 1998.

Band 88 Achim Truger: Die neue Finanzwissenschaft zwischen Realitătsferne und Irrelevanz der Annahmen. Eine methodologische Analyse potentieller Verteidigungsstrategien der neuen Finanzwissenschaft gegen den Vorwurt der Realitătsferne ihres entscheidungstheoretischen Fundamentes. 1998.

Band 89 Karin Bickel: Familienbezogene Elemente im System der gesetzlichen Rentenversicherung. Unter besonderer Berūcksichtigung von Ein-Eltern-Familien. 1999.

Band 90 Wolfgang Scherf: Schlüsselzuweisungen und Kreisumlage. Die Problematik der Finanzierung der Landkreise am Beispiel des kommunalen Finanzausgleichs von RheinlandPfalz. 1998.

Band 91 Sandra Ehmann: Familienpolitik in Frankreich und Deutschland - ein Vergleich. 1999.

Band 92 Hendrik Suermann: Einkommensteuerliche Behandlung von Wăhrungsgewinnen und -verlusten. Eine finanzwissenschaftiche Analyse des Steuerrechts in den USA und in Deutschland. 1999.

Band 93 Rolf Bősinger: Die Neuordnung des bundesstaatlichen Finanzausgleichs 1995. Eine theoretische und empirische Analyse unter Berücksichtigung von allokationstheoretischen und polit-ס̋konomischen Gesichtspunkten. 1999.

Band 94 Ulrich Ermschel: Finanzwirtschaftliche Konsequenzen beim Übergang auf das Ursprungslandprinzip im Europăischen Binnenmarkt. Eine Untersuchung am Beispiel des unvollkommenen oligopolistischen Neufahrzeugmarktes. 1999.

Band 95 Ute Hansen: Überwälzte Leistungen der Administration. Eine empirische und theoretische Analyse. 2000.

Band 96 Hans-Werner Seiler: Zur Durchsetzung der Einmalbesteuenung deutscher Körperschaftsgewinne. Strategien zur Vermeidung der im deutschen Körperschaftsteuersystem angelegten Benachteiligung auslăndischer Anteilseigner. Eine finanzwissenschaftiche Analyse. 2000.

Band 97 Steffen Meyer: Zwischenstaattiche Finanzzuweisungen im zusammenwachsenden Europa. Zur Gestaltung eines Finanzausgleichs fūr die Europāische Union. 2000.

Band 98 Marion Hübner: Ökodumping? Umweltpolitik in internationalen Oligopolmärkten. 2000.

Band 99 Christhart Bork: Steuern, Transfers und private Haushalte. Eine mikroanalytische Simulationsstudie der Aufkommens- und Verteilungswirkungen. 2000.

Band 100 Norbert Eichler: Die Probleme des Gemeindefinanzausgleichs im Kooperativen Föderalismus. Eine ökonomische Analyse am Beispiel des Bundeslandes Nordhein-Westfalen. 2000.

Band 101 Wolfgang Scherf: Der Lănderfinanzausgleich in Deutschland. Ungelöste Probleme und Ansatzpunkte einer Reform. 2000.

Band 102 Stefan Dietrich Josten: Staatsverschuldung, intertemporale Allokation und Wirtschaftswachstum. Eine theoretische Analyse staatticher Verschuldungspolitik in Modellen exogenen und endogenen Wachstums. 2000.

Band 103 Axel Breitbach: Steuerhinterziehung und Schattenwirtschaft aus gesamtwirtschaftlicher Sicht. 2000.

Band 104 Alexander Spermann: Negative Einkommensteuer, Lohnsubventionen und Langzeitarbeitslosigkeit. 2001.

Band 105 Michael Broer: Der kommunale Finanzausgleich in Hessen. Historische Darstellung und ökonomische Analyse unter besonderer Berūcksichtigung der Schlüsselzuweisungen. 2001.

Band 106 Jan-Paul Ritscher: Der Einsatz von Finanzderivaten unter einer modemisierten Schuldenstrukturpolitik des Bundes. 2002. 
Band 107 Martin Gasche: Dynamische Fiskalpolitik. Makroökonomische Wirkungen der Fiskalpolitik in einem Real Business Cycle-Modell. 2003.

Band 108 Felix Brosius: Internationaler Steuerwettbewerb und Koordination der Steuersysteme. 2003.

Band 109 Claudia Hensberg: Eigennützige Regierungen im fiskalischen Wettbewerb um Kapital. 2003.

Band 110 Hans-Martin Grambeck: Konsumsteuerreformen und Konsumbesteuerung. Eine vergleichende Analyse und Bewertung verschiedener Konsumsteuermodelle unter besonderer Berücksichtigung der Probleme in offenen Volkswirtschaften. 2003.

Band 111 Antje Draheim: Probleme der finanzpolitischen Willensbildung in Europa. Eine kritische Analyse der europäischen Haushalts- und Finanzverfassung. 2004.

Band 112 Robert Nuscheler: On Competition and Regulation in Health Care Systems. 2005.

Band 113 Guido K. Raddatz: Das Eigenmittelsystem der Europäischen Union. 2005.

Band 114 Markus Euler: Ansatzpunkte für eine Reform des Finanzierungssystems der Europäischen Union. 2005.

Band 115 Marco Penske: Finanzierung der Gesetzlichen Krankenversicherung - Probleme und Reformoptionen. 2006.

www.peterlang.de 


\section{Versorgungsstrukturen und Finanzierungsoptionen auf dem Prüfstand}

\section{Bad Orber Gespräche}

\section{1.-13. November 2004}

Frankfurt am Main, Berlin, Bern, Bruxelles, New York, Oxford, Wien, 2005.

264 S., zahlr. Abb. und Tab.

Allokation im marktwirtschaftlichen System. Herausgegeben von

Hans-Heinrich Nachtkamp, Ulrich Schlieper und Eberhard Wille. Bd. 53

ISBN 3-631-54904-0 • br. € 34.80*

In diesem Band der Bad Orber Gespräche 2004 diskutieren prominente Vertreter der gesetzlichen und privaten Krankenversicherung, der Krankenhausträger und der Politik, wie sie mit wettbewerblichen Mitteln die effiziente Versorgung durch Strukturverbesserungen erreichen und gleichzeitig die eigentliche Ursache der mangelnden Effizienz des Gesundheitswesens, nämlich die nicht angemessene Indikationsstellung ärztlichen Handelns, in den Griff bekommen können. Der Sammelband enthält die erweiterten Referate eines interdisziplinären Workshops zu Versorgungsstrukturen und Finanzierungsoptionen auf dem Prüfstand. Behandelt wurden die beiden Themenkreise integrierte Versorgung und Disease-Management-Programme sowie Finanzierungsoptionen.

Aus dem Inhalt: Reform der Beitragssatzgestaltung unter verfassungsrechtlichen Gesichtspunkten? · Integrierte Versorgung und DiseaseManagement-Programme · Veränderte Rahmenbedingungen für die integrierte Versorgung - ein neues Konzept? · Chancen der integrierten Versorgung für die Krankenhäuser - Die Rolle der Kassenärztlichen Vereinigung bei zukünftigen Versorgungsformen - Möglichkeiten einer wettbewerblichen Differenzierung zwischen den Krankenkassen - Finanzierungsoptionen · uvm.

Frankfurt am Main - Berlin - Bern - Bruxelles - New York - Oxford - Wien

Auslieferung: Verlag Peter Lang AG

Moosstr. 1, $\mathrm{CH}-2542$ Pieterlen

Telefax 0041 (0) $32 / 3761727$

*inklusive der in Deutschland gültigen Mehrwertsteuer

Preisänderungen vorbehalten

Homepage http://www.peterlang.de 
Marco Penske - 978-3-631-75223-4

Downloaded from PubFactory at 01/11/2019 06:54:52AM

via free access 